Guadalupe Sánchez Crespo

\title{
SENSIBILIDAD DE LAS ESCALAS \\ E INDICADORES DE VALIDEZ EN EL PERFIL DE PERSONALIDAD DEL MMPI-2
}

EDICIONES UNIVERSIDAD DE SALAMANCA 


\section{COLECCIÓN VITOR}

90

c

Ediciones Universidad de Salamanca

y $\mathrm{M}^{\mathrm{a}}$ Guadalupe Sánchez Crespo

$1^{a}$ edición: Julio, 2002

I.S.B.N.: 84-7800-783-0

Depósito Legal: S. 875-2002

Ediciones Universidad de Salamanca

Plaza de San Benito, s/n

37002 Salamanca (España)

Página en internet: http://webeus.usal.es

Correo-e: eus@usal.es

Realización:

Nemática, S.L.

Impreso en España - Printed in Spain

Todos los derechos reservados.

Ni la totalidad ni parte de este libro

puede reproducirse ni transmitirse

sin permiso escrito de

Ediciones Universidad de Salamanca

CEP. Servicio de Bibliotecas

SÁNCHEZ CRESPO, Guadalupe

Sensibilidad de las escalas e indicadores de validez en el perfil de personalidad del MMPI-2 [Archivo de ordenador] / Guadalupe

Sánchez Crespo. --Salamanca: Ediciones Universidad de Salamanca, 2002

1 disco compacto. (Colección Vítor; 90)

Tesis-Universidad de Salamanca, 2002

1. Universidad de Salamanca (España)-Tesis y disertaciones académicas.

2. Minnesota, Inventario Multifásico de la Personalidad-Evaluación.

$159.923 .072(043.2)$ 


\section{RESUMEN}

\section{TITULO: Sensibilidad de las escalas e indicadores de validez en el perfil de personalidad del MMPI-2.}

El objetivo de esta investigación se ha centrado en evaluar la sensibilidad en las Escalas de Validez del MMPI-2 (L, F, Fb, K, TRIN, VRIN) y una serie de índices de Validez (F-K, S, Fp, I.R., Ds-r, FBS, Odecp, Wsd) a la distorsión del perfil de personalidad como resultado de las diferentes formas de responder al cuestionario.

La muestra total está compuesta por 3.079 sujetos de los cuales un grupo de población normal $(\mathrm{N}=1.723)$ y otra clínica ( $\mathrm{N}=561)$ contesta de forma sincera y honesta a la prueba; otros grupos de sujetos, igualmente considerados de población normal, intentan mostrar su buena imagen $(\mathrm{N}=284)$, su mala imagen $(\mathrm{N}=272)$ y sujetos que responden sin tener en cuenta la información contenida en el ítem $(\mathrm{N}=200)$, siendo diferenciados cada grupo respectivo por su género.

Los resultados aportan la precisión y sensibilidad de las diferentes escalas para identificar la consistencia/inconsistencia, el fingimiento positivo, fingimiento negativo de las respuestas en los perfiles de personalidad de la adaptación española del MMPI2."

Descriptores: Escalas de Validez, MMPI-2, Evaluación, falsificación, fingimiento positivo, fingimiento negativo. 



\section{ABSTRACT \\ TITLE: Sensibility of the scales and indicators of validity in the profile of personality of the MMPI-2.}

The aim of this study has been to focus on evaluating sensitivity to personality profile distortion in MMPI-2 Validity Scales (L, F, Fb, K, TRIN, VRIN) and a series of Validity Subscales (F-K. S. Fp, I.R., Ds-r, FBS, Odecp, Wsd) resulting from the different ways of answering the questionnaires.

The total sample comprised 3,079 subjects, of whom one group of normal population $(\mathrm{N}=1,723)$ and another group of clinical population $(\mathrm{N}=561)$ answered the test questions honestly and sincerely; three other groups of normal population either attempted to 'fake good' (over report) $\mathrm{N}=284$ ), 'fake bad' (under report) $(\mathrm{N}=272)$ or to respond without taking into consideration the information contained in the item $(\mathrm{N}=200)$. Each group was differentiated according to gender.

Results pointed to the accuracy and sensitivity of the different scales in identifying consistence/inconsistence, over reporting (fake good), under reporting (fake bad), malingering in responses in the personality profiles of the Spanish adaptation of the MMPI-2.

Key word: Validity Scales, MMPI-2, Evaluation, Malingering, overreporting, underreporting. 



\section{I $\mathcal{N}$ I CE GEDERAL}

PARTE I: ESTUDIO TEÓ RICO .19

CAPITULO I. - LA DISTORSIÓN DEL PERFIL........................................................................................20

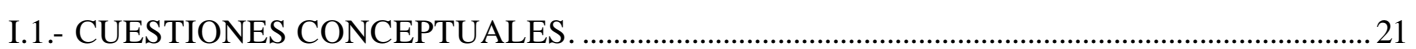

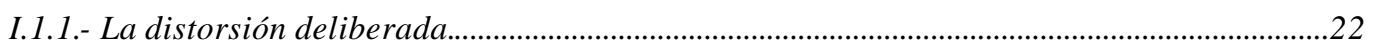

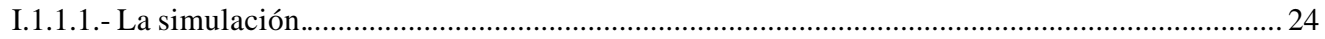

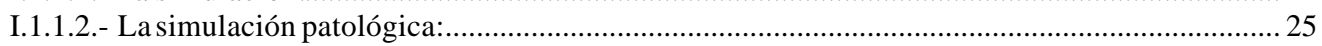

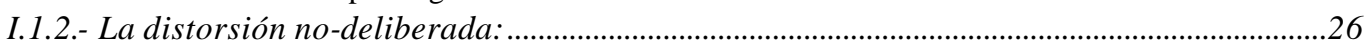

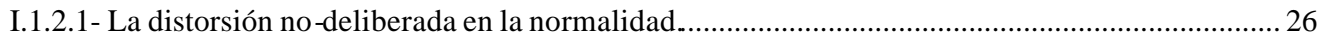

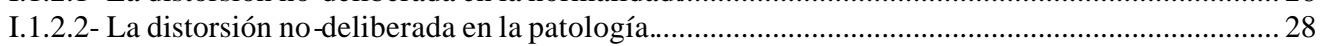

I.2.- LA EVALUACIÓN DE LA SIMULACIÓN: ............................................................................. 28

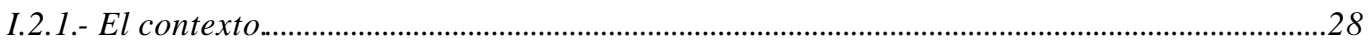

I.2.2.- Los sujetos y su sintomatología.......................................................................................29

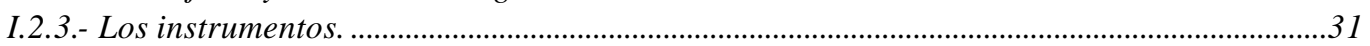

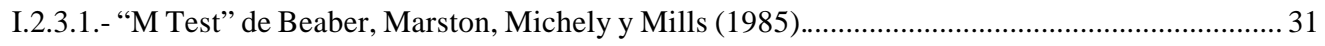

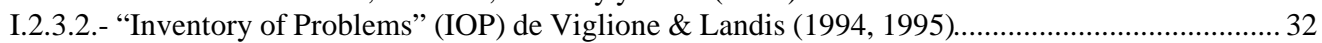

I.2.3.3.- "Structured Inventory of Malingered Symptomatology" (SIMS) de Smith $(1992,1998) \ldots \ldots \ldots . .33$

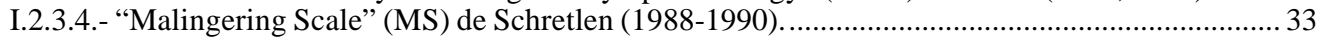

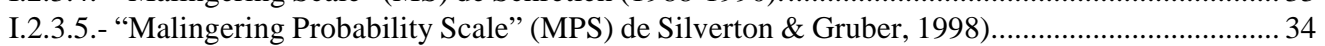

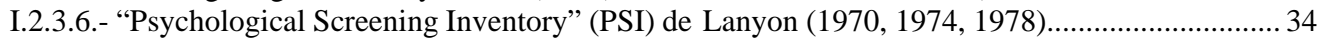

I.2.3.7.- Cuestionario de reacciones personales (D.S.) de Avila y Tomé (1989) ....................................35

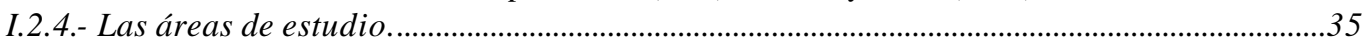

I.2.4.1.- La evaluación de la inteligencia y de las capacidades cognitivas......................................35

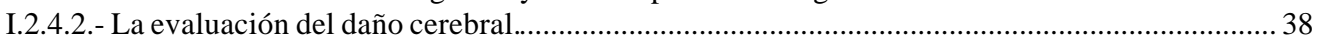

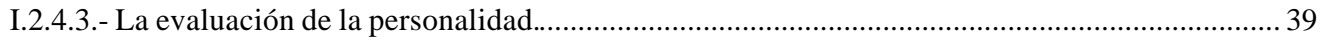

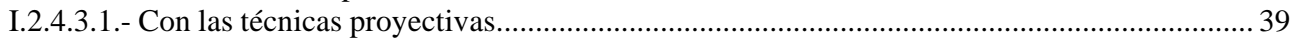

I.2.4.3.2.- Con las técnicas psicométricas....................................................................... 41

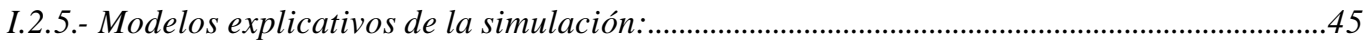

\section{CAPITULO II.- EL MINNESOTA MULTIPHASIC PERSONALITY INVENTORY-2}

(M.M.P.I. -2).............................................................................................................................................................4

II.1.- EL M.M.P.I. ORIGINAL. .................................................................................................... 47

II.2.- EL M.M.P.I.-2: LA NECESIDAD DE UNA NUEVA REESTANDARIZACIÓN, 50 AÑOS

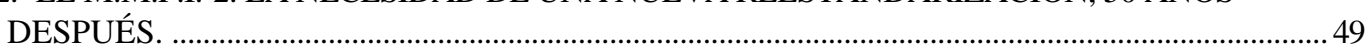

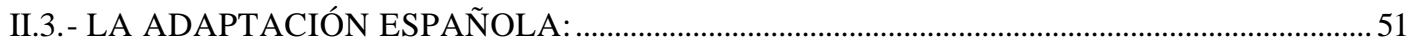

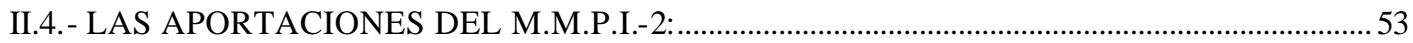

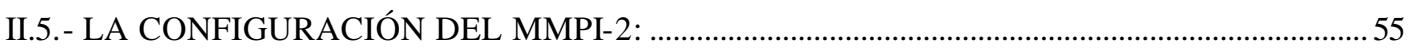

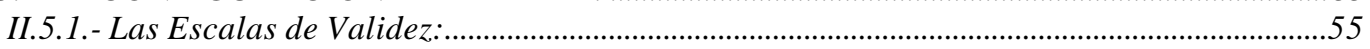

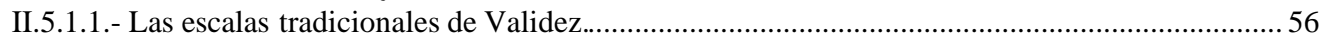

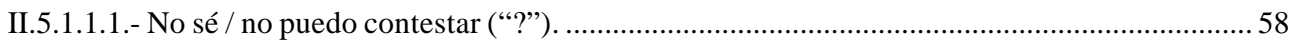

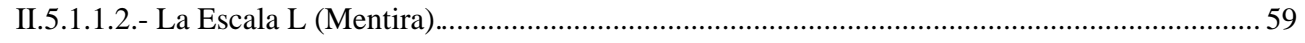

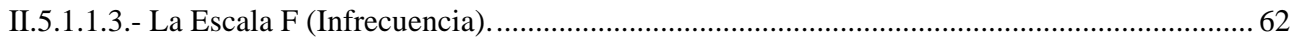

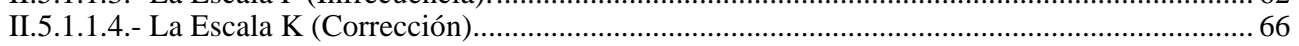

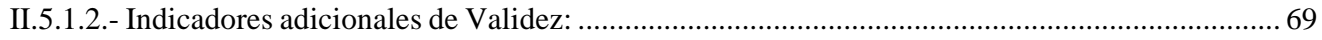

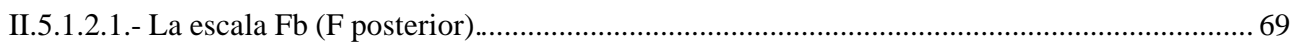

II.5.1.2.2.- Escala VRIN (Inconsistencia de Respuestas Variables)............................................... 70

II.5.1.2.3.- Escala TRIN (Inconsistencia de las Respuestas Verdadero)................................................. 73

II.5.1.2.4.- El porcentaje de Verdadero (V\% ) y Falso (F\%) ........................................................... 74

II.5.2.- Otras Escalas del MMPI-2 …...............................................................................................74

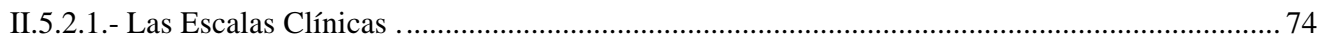

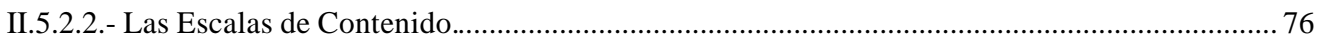

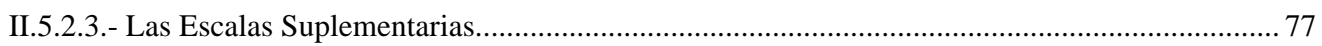




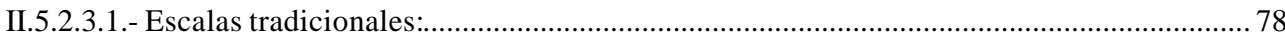

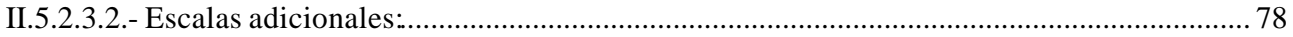

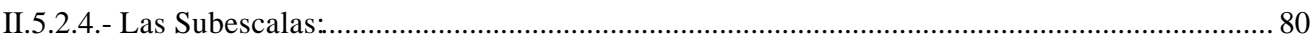

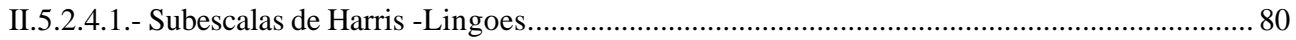

II.5.2.4.2.- Subescalas de Wiener-Harmon. Los ítems Obvio-sutiles................................................ 81

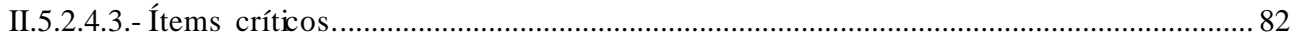

II.5.3.- La configuración e interpretación de los perfiles en el MMPI-2 ….....................................83

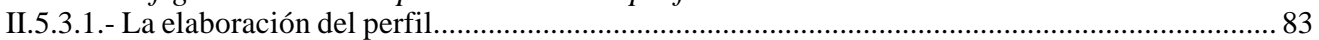

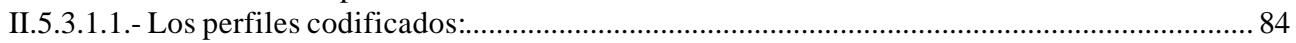

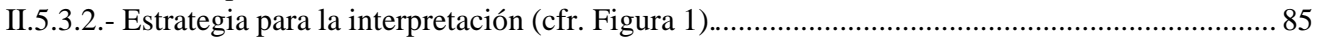

\section{CAPÍTULO III. - INVESTIGACIÓN DE LA VALIDEZ DE PERFILES EN EL MMPI2.......91}

III.1.- REVISIÓN ACTUAL DE LOS ESTUDIOS: ............................................................................... 91

III.1.1.- Las escalas principales de Validez: L, F y K ........................................................................94

III.1.2.- Gough: el Índice (F-K) y la Escala de Disimulación (Ds)....................................................98

III.1.2.1.- El Índice de Gough F-K ................................................................................................. 98

III.1.2.2.- La escalas de Disimulación (Ds y Ds -r) de Gough................................................................ 100

III.1.3.- Perfiles de respuestas al azar (random response)............................................................... 101

III.1.4.- Perfiles de respuestas "todo verdad" / "todo falso". ........................................................... 103

III.1.5.- Perfiles con fingimiento de buena / mala imagen (fake good / fake bad)...................... 104

III.1.6.- Perfiles defensivos. .......................................................................................................... 107

III.1.7.- Perfiles con exageración/minimización de síntomas (overreporting/underreporting)..108

III.1.8.- Perfiles de hacerse el enfermo (malingering)................................................................ 111

III.1.9.- Escalas de Deseabilidad social.......................................................................................... 114

III.1.10.- Escala Superlativa (S) de Butcher y Han (1995).............................................................. 115

III.1.11.- Escala de Fingimiento Positivo (Mp; ODecp) de Cofer, Chance, \& Judson, (1949). 115

III.1.12.- Escala Psiquiátrica F(p) de Arbisi \& Ben-Porath $(1995,1998)$.................................... 116

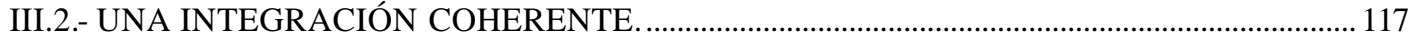

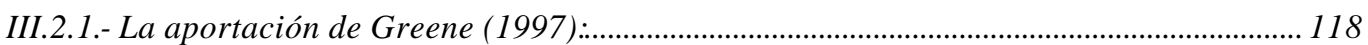

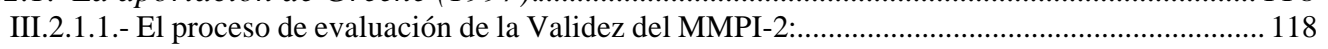

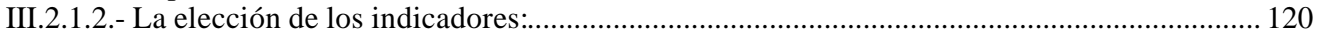

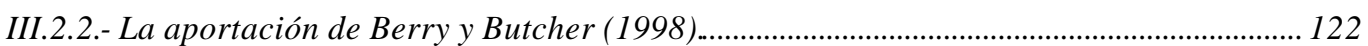

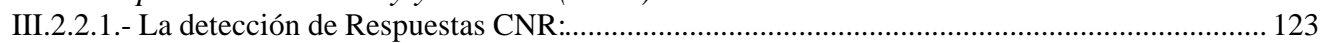

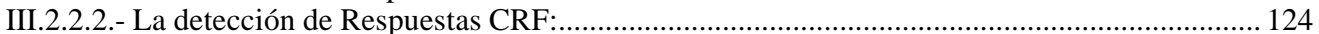

III.2.2.3.- Resumen de la aportación: …...................................................................................... 125

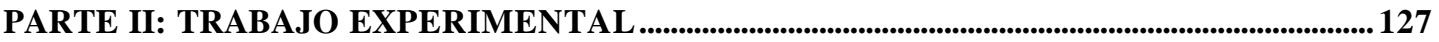

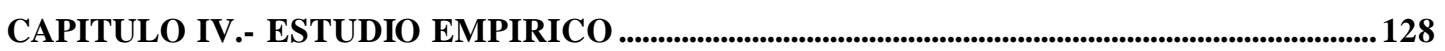

IV.1.- JUSTIFICACIÓN Y PLANTEAMIENTO DEL PROBLEMA. ............................................... 128

IV.2.- DISEÑO METODOLÓGICO .................................................................................................. 130

IV.2.1.- Formulación de los objetivos e hipótesis de investigación: ................................................ 130

IV.2.1.1.- Hipótesis de investigación $1^{\mathrm{a}}$ : Inconsistencia/Consistencia............................................... 130

IV.2.1.2.- Hipótesis de investigación $2^{\mathrm{a}}$ : Fingimiento negativo......................................................... 131

IV.2.1.3.- Hipótesis de investigación $3^{\mathrm{a}}$ : Fingimiento positivo............................................................... 132

IV.2.2.- Instrumentos de aplicación ........................................................................................... 133

IV.2.2.1.- El Cuestionario de Personalidad MMPI-2:......................................................................... 134

IV.2.2.2.- Otras escalas e indicadores de Validez del MMPI-2:........................................................ 134

IV.2.2.2.1.- La escala de Inconsistencia de Respuestas (IR) de Sewell \& Rogers (1994):................. 134

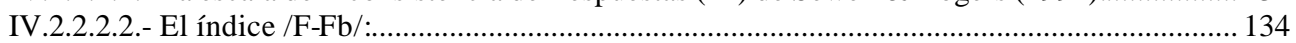

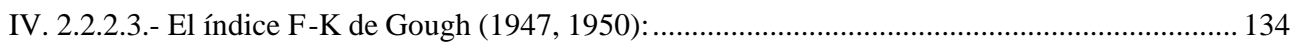

IV.2.2.2.4.- La escala de "Fake-Bad” (FBS) de Lees -Haley, Englis \& Glenn (1991):.............................. 135

IV.2.2.2.5.- La escala revisada de Disimulación (Ds -r) de Gough (1957)........................................ 135

IV. 2.2.2.6.- La Escala de Fingimiento Positivo o de Otro Engaño (ODecp) de Nichols \&

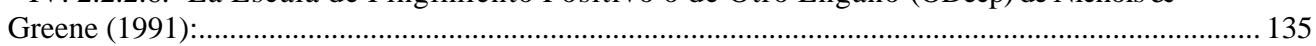

IV. 2.2.2.7.- La escala Superlativa (S) de Butcher \& Han (1995): ................................................... 135

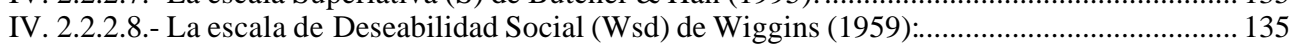

IV. 2.2.2.9.- La escala Psiquiátrica F(p) de Arbisi \& Ben-Porath (1995):.......................................... 136

IV.2.3.- Análisis de la muestra ..................................................................................................... 136

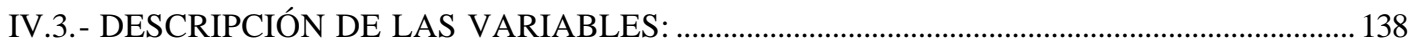

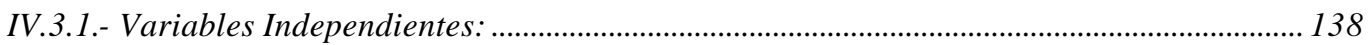


IV.3.2.- Variables dependientes: ....................................................................................................... 139

IV.4.- CORRECCION Y TRATAMIENTO ESTADISTICO DE LOS DATOS: .............................. 140

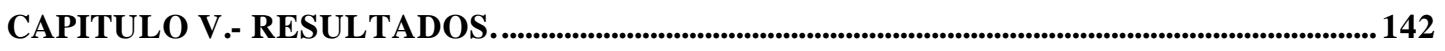

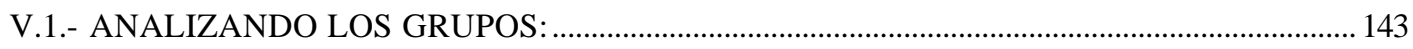

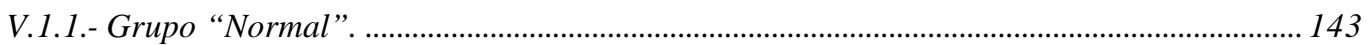

V.1.2.- Grupo "Clínico”, .................................................................................................................. 150

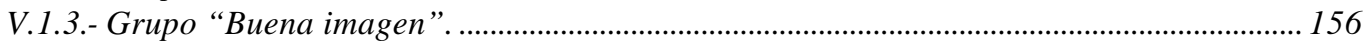

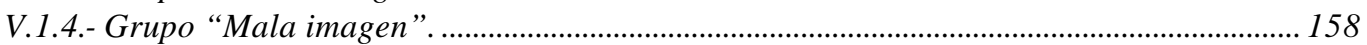

V.1.5.- Grupo de "Respuestas inconsistentes (Rta. Inc.) ". ............................................................ 161

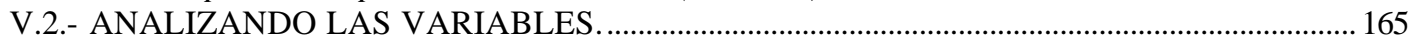

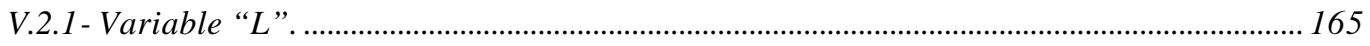

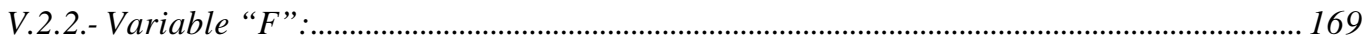

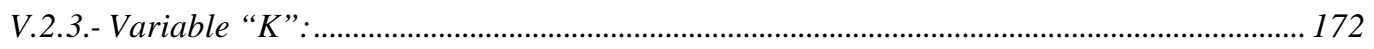

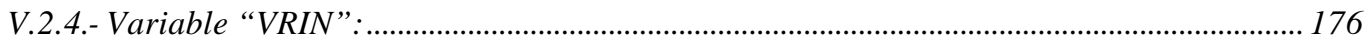

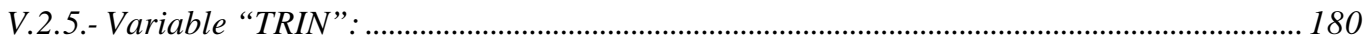

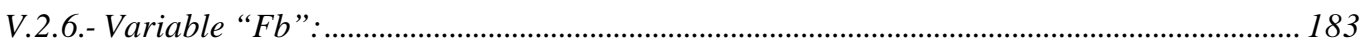

V.2.7.- Variable "F-K” (Índice de Simulación de Gough, 1947, 1950):........................................ 186

V.2.8.- Variable “ $F(p)$ ” (Escala Psiquiátrica de Arbisi \& Ben-Porath, 1995, 1998)................. 190

V.2.9.- Variable "S" (Escala Superlativa de Butcher y Han, 1995).............................................. 193

V.2.10.- Variable "Ds-r" (Escala revisada de Disimulación de Gough, 1957)............................ 197

V.2.11.- Variable "FBS". Escala de "Hacerse el enfermo" de Lees-Haley, English \& Glenn,

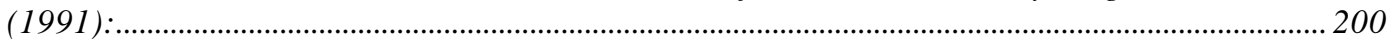

V.2.12.- Variable “ODecp” (Escala de Fingimiento Positivo o de Otro Engaño, de Nichols \&

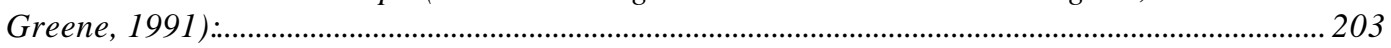

V.2.13.- Variable “IR”. Escala de Inconsistencia de Respuestas de Sewell \& Rogers, (1994): 206

V.2.14.- Variable "Wsd” (Escala de Desabilidad Social de Wiggings, 1959):.............................. 209

V.2.15.- Variable "/F-Fb/": ...................................................................................................... 212

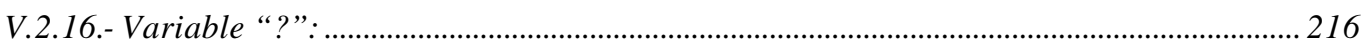

V.3.- DISEÑO DE LA HOJA DE PERFIL SEGÚN LA ESTRATEGIA DEL MMPI-2..................219

V.3.1.- El diseño tradicional del MMPI..................................................................................... 219

V.3.2.- Nuestra propuesta de diseño, en la Hoja de Perfil, para algunas de las Escalas e

Índices de Validez.............................................................................................................................. 220

V.3.2.1.- Cambio de sentido de las variables tradicionales del MMPI: L y K............................ 221

V.3.2.2.- Respecto a otras variables investigadas: "ODecp", "S" y "Wsd"........................................... 222

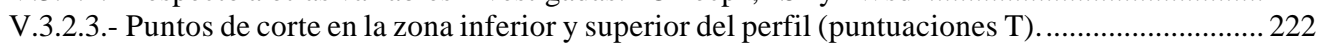

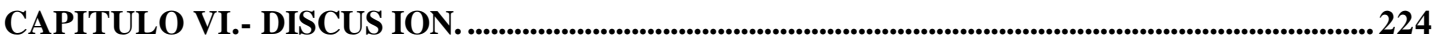

VI.1.- ESCALAS E ÍNDICES DE VALIDEZ QUE PERMITEN DIFERENCIAR SUJETOS QUE RESPONDEN DE FORMA INCONSISTENTE/CONSISTENTE (HIPÓTESIS 1 ${ }^{\mathrm{a}}$ )..................................................................... 224

VI.2.- ESCALAS E ÍNDICES DE VALIDEZ QUE SE MUESTRAN SENSIBLES A LA IDENTIFICACIÓN

“FINGIMIENTO NEGATIVO” EN EL PERFIL DEL MMPI-2 (HIPÓTESIS 2º)........................................... 232

VI.3.- ESCALAS E ÍNDICES DE VALIDEZ QUE SE MUESTRAN SENSIBLES A LA IDENTIFICACIÓN DE

“FINGIMIENTO POSITIVO” EN EL PERFIL DEL MMPI-2 (HIPÓT ESIS 3 $3^{\mathrm{a}}$ )................................................ 238

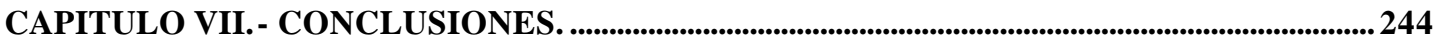

VII.1.- CONCLUSIÓN GENERAL $1^{\mathrm{a}}$ :......................................................................................... 244

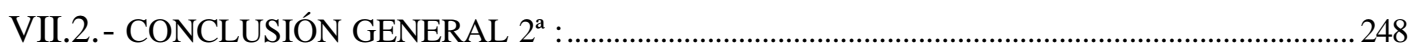

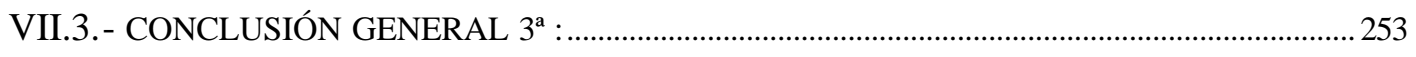

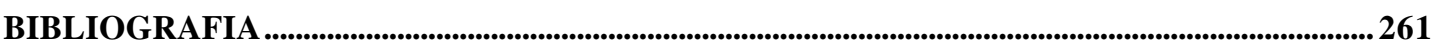

ANEXO: ÍTEMS CORRESPONDIENTES A LAS ESCALAS E INDICES DE VALIDEZ ..... 284

ANEXO 1: ÍTEMS CORRESPONDIENTES A LA ESCALA L (15 ÍTEMS ).......................................................2 285

ANEXO 2: ÍTEMS CORRESPONDIENTES A LA ESCALA F (60 ÍTEMS ) .......................................................286

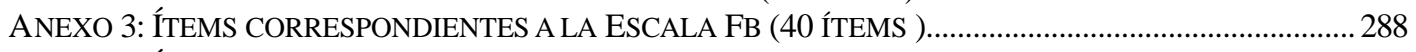

ANEXO 4: ÍTEMS CORRESPONDIENTES A LA ESCALA K (30 ÍTEMS ) .......................................................289

ANEXO 5: ÍTEMS CORRESPONDIENTES A LA ESCALA VRIN (49 PARES) .............................................. 290 
ANEXO 6: ÍTEMS CORRESPONDIENTES A LA ESCALA TRIN (23 PARES).... 292

ANEXO 7: ESCALA DE DESEABILIDAD SOCIAL (WSD) DE WIGGINS (1959)

ANEXO 8: INCONSISTENCIA DE RESPUESTAS(IR) DE SEWELL \& ROGERS (1994).

ANEXO 9: ESCALA DE FINFIMIENTO POSITIVO O DE OTRO ENGAÑO (ODECP) DE NICHOLS \&

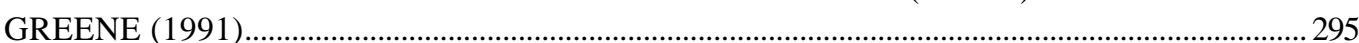

ANEXO 10: ESCALA DE “FAKE-BAD” (FBS) DE LEES-HALEY, ENGLIS \& GLENN (1991)................... 296

ANEXO 11: ESCALA DE DISIMULACIÓN (DS) DE GOUGH (1954) …………….......................................... 297

ANEXO 12: ESCALA REVISADA DE DISIMULACIÓN (DS-R) DE GOUGH (1957) .......................................299

ANEXO 13: ESCALA SUPERLATIVA (S) DE BUTCHER \& HAN (1995) ........................................................ 300

ANEXO 14: ESCALA PSIQUIÁTRICA F(P) DE ARBISI \& BEN-PORATH (1995) ............................................ 302

\section{$I \mathcal{N} \mathcal{D} I \mathcal{C E} \mathcal{D E} \mathcal{T} \mathcal{A} \mathcal{B} \mathcal{L A S}$}

Tabla 1: Anulaciones y cambios de ítems y su efecto sobre las Escalas Básicas

Tabla 2: Análisis comparativo de los principales pasos seguidos en el proceso de la adaptación española

Tabla 3: Aportes diferenciativos entre el MMPI original, el MMPI-2 y el MMPI-A

Tabla 4: Implicaciones de las puntuaciones en la Puntuación “?” (Interrogante)

Tabla 5: Implicaciones de las puntuaciones en la Escala L (Mentira)

Tabla 6: Implicaciones de las puntuaciones en la Escala F (Infrecuencia)

Tabla 7: Implicaciones de las puntuaciones en la Escala K (Corrección)

Tabla 8: Implicaciones de las puntuaciones en la Escala $\mathrm{Fb}$ (F posterior)

Tabla 9: Implicaciones de las puntuaciones en la Escala VRIN

Tabla 10: Implicaciones de las puntuaciones en la Escala TRIN

Tabla 11: Subescalas de Obvio-Sutil de Wiener-Harmon

Tabla 12.- Principales tipos de códigos de dos y tres variables en el MMPI-2

Tabla 13: Características de los grupos de la muestra

Tabla 14: Grupo de "normales". ANOVA por sexos

Tabla 15: Estadísticos principales de tendencia central. Grupo Normal

Tabla 16: Percentiles. Grupo "Normal

Tabla 17: Matriz de correlaciones. Grupo "Normal

Tabla 18: Grupo clínico. ANOVA por sexos

Tabla 19: Estadísticos principales de tendencia central. Grupo Clínico

Tabla 20: Percentiles. Grupo "Clínico

Tabla 21: Matriz de correlaciones. Grupo "Clínico"

Tabla 22: Estadísticos principales de tendencia central. Grupo "Buena imagen

Tabla 23: Grupo "Buena imagen". ANOVA por sexos

Tabla 24: Percentiles. Grupo "Buena imagen"

Tabla 25: Matriz de correlaciones. Grupo "Buena imagen"

Tabla 26: Grupo "Mala imagen". ANOVA por sexos

Tabla 27: Estadísticos principales de tendencia central. Grupo "Mala imagen"

Tabla 28: Percentiles. Grupo "Mala imagen"

Tabla 29: Matriz de correlaciones. Grupo "Mala imagen"

160

160

Tabla 30: Estadísticos principales de tendencia central. Grupo "Respuestas inconsistentes" 161

Tabla 31: Percentiles. Grupo "Respuestas inconsistentes"

Tabla 32: Matriz de correlaciones. Grupo "Respuestas inconsistentes"

Tabla 32.1: Puntuaciones Típicas (T) de las Escalas e Indices de Validez según los diferentes tipos de Respuestas Inconsistentes

Tabla 33: Variable "L”. Percentiles. Análisis comparativo entre grupos 166

Tabla 34: Variable "L". Correlaciones

Tabla 35: Variable "L”. Puntuaciones Medias y St.D. Análisis por grupos 167

Tabla 36: Variable "L". ANOVA. Diferencias significativas entre grupos 167

Tabla 37: Variable "L". Diferencias intergrupos e intersexos 168

Tabla 38: Variable "F”. Percentiles. Análisis entre grupos 169

Tabla 39: Variable "F". Correlaciones

170

Tabla 40: Variable "F”: Puntuaciones Medias y St.D. Análisis comparativo entre grupos 
Tabla 41: Variable "F". ANOVA. Diferencias significativas entre grupos 171

Tabla 42: Variable "F". Diferencias intergrupos e intersexos 172

Tabla 43: Variable "K": Percentiles. Análisis comparativo entre grupos 173

Tabla 44: Variable "K”. Correlaciones $\quad 174$

Tabla 45; Variable "K”. Puntuaciones Medias y St.D. Análisis comparativo entre grupos 174

Tabla 46: Variable "K”. ANOVA. Diferencias significativas entre grupos 174

Tabla 47: Variable "K". Diferencias intergrupos e intersexos 175

Tabla 48: Variable "VRIN". Percentiles. Análisis comparativo entre grupos 176

Tabla 49: Variable "VRIN". Correlaciones 177

Tabla 50: Variable "VRIN". Puntuaciones Medias y St.D. Análisis comparativo entre grupos 177

Tabla 51: Variable "VRIN". ANOVA. Diferencias significativas entre grupos 178

Tabla 52: Variable "VRIN". Diferencias intergrupos e intersexos 179

Tabla 53: Variable "TRIN”. Percentiles. Análisis por grupos 181

Tabla 54: Variable "TRIN". Correlaciones 181

Tabla 55: Variable "TRIN”. Puntuaciones Medias y St.D. Análisis comparativo entre grupos 182

Tabla 56: Variable "TRIN”. ANOVA. Diferencias significativas entre grupos 182

Tabla 57: Variable "TRIN”. Diferencias intergrupos e intersexos 183

Tabla 58: Variable "Fb". Percentiles. Análisis por grupos 184

Tabla 59: Variable "Fb". Correlaciones 184

Tabla 60: Variable "Fb": Puntuaciones Medias y St.D. Análisis comparativo entre grupos 185

Tabla 61: Variable "Fb". ANOVA. Diferencia significativas entre grupos 185

Tabla 62: Variable "Fb". Diferencias intergrupos e intersexos 186

Tabla 63: Variable "F-K". Percentiles. Análisis por grupos 187

Tabla 64: Variable "F-K". Correlaciones 187

Tabla 65: Variable "F-K": Puntuaciones Medias y St.D. Análisis comparativo entre grupos 188

Tabla 66: Variable "F-K". ANOVA. Diferencia significativas entre grupos 188

Tabla 67: Variable "F-K". Diferencias intergrupos e intersexos 189

Tabla 68: Variable "F(p)”. Percentiles. Análisis por grupos 190

Tabla 69: Variable "F(p)". Correlaciones 191

Tabla 70: Variable "F(p)": Puntuaciones Medias y St.D. Análisis comparativo entre grupos 191

Tabla 71: Variable "F(p)". ANOVA. Diferencias significativas entre grupos 192

Tabla 72: Variable "F(p)". Diferencias intergrupos e intersexos 193

Tabla 73: Variable "S”. Percentiles. Análisis por grupos 194

Tabla 74: Variable "S". Correlaciones 194

Tabla 75: Variable "S": Puntuaciones Medias y St.D. Análisis comparativo entre grupos 195

Tabla 76: Variable "S". ANOVA. Diferencias significativas entre grupos 195

Tabla 77: Variable "S". Diferencias intergrupos/intersexos 196

Tabla 78: Variable "Ds-r”. Percentiles. Análisis por grupos 197

Tabla 79: Variable "Ds-r". Correlaciones 198

Tabla 80: Variable "Ds-r": Puntuaciones Medias y St.D. Análisis comparativo entre grupos 198

Tabla 81: Variable "Ds-r". ANOVA. Diferencias significativas entre grupos 198

Tabla 82: Variable "Ds-r". Diferencias intergrupos e intersexos 199

Tabla 83: Variable "FBS". Percentiles. Análisis por grupos 200

Tabla 84: Variable "FBS". Correlaciones 201

Tabla 85: Variable "FBS": Puntuaciones Medias y St.D. Análisis comparativo entre grupos 201

Tabla 86: Variable "FBS". ANOVA. Diferencias significativas entre grupos 201

Tabla 87: Variable "FBS". Diferencias intergrupos e intersexos 202

Tabla 88: Variable "ODecp”. Percentiles. Análisis por grupos 203

Tabla 89. Variable "ODecp”. Correlaciones 204

Tabla 90: Variable "ODecp”: Puntuaciones Medias y St.D. Análisis comparativo entre grupos 204

Tabla 91: Variable "ODecp”. ANOVA. Diferencias significativas entre grupos 204

Tabla 92: Variable "ODecp”. Diferencias intergrupos/intersexos 205

Tabla 93: Variable "IR". Percentiles. Análisis por grupos 206

Tabla 94: Variable "IR". Correlaciones 207

Tabla 95: Variable "IR": Puntuaciones Medias y St.D. Análisis comparativo entre grupos 207

Tabla 96: Variable "IR". ANOVA. Diferencias significativas entre grupos 208

Tabla 97: Variable "IR”. Diferencias intergrupos/intersexos 209 
Tabla 98: Variable "Wsd”. Percentiles. Análisis por grupos 209

Tabla 99. Variable "Wsd". Correlaciones 210

Tabla 100: Variable "Wsd": Puntuaciones Medias y St.D. Análisis comparativo entre grupos 211

Tabla 101: Variable "Wsd". ANOVA. Diferencias significativas entre grupos 211

Tabla 102: Variable "Wsd". Diferencias intergrupos/intersexos 212

Tabla 103 Variable “/F-Fb/”. Percentiles. Análisis por grupos 213

Tabla 104: Variable “/F-Fb/”. Correlaciones 214

Tabla 105: Variable “/F-Fb/”: Puntuaciones Medias y St.D. Análisis comparativo entre grupos 214

Tabla 106: Variable “/F-Fb/". ANOVA. Diferencias significativas entre grupos 215

Tabla 107: Variable “/F-Fb/”. Diferencias intergrupos/intersexos 216

Tabla 108 Variable “?”. Percentiles. Análisis por grupos 216

Tabla 109: Variable “?”: Puntuaciones Medias y St.D. Análisis comparativo entre grupos 217

Tabla 110: Variable “?”. ANOVA. Diferencias significativas entre grupos 217

Tabla 111: Variable “?”. Correlaciones 218

Tabla 112: Variable “?”. Diferencias intergrupos/intersexos 219

Tabla 113: Equivalencias de las puntuaciones típicas de las Escalas L y K al cambiar el sentido de sus puntuaciones directas $\quad 221$

Tabla 114: Puntos de corte de las Escalas e Indices de Validez. Varones 223

Tabla 115: Puntos de corte de las Escalas e Indices de Validez. Mujeres 223

Tabla 116: Variables que detectan inconsistencia en las respuestas $\quad 257$

Tabla 117: Variables que detectan el "fingimiento negativo 258

Tabla 118: Variables que detectan el "fingimiento positivo 259

\section{I $\mathcal{N D I C E}$ DE FIGURAS}

Figura 1: Estrategia para la interpretación del MMPI-2 (adaptado de Butcher y Williams [1992]) 90

Figura 2: Proceso de la evaluación de la Validez del MMPI-2 (Greene, $1997 \quad 119$

Figura 3: Evaluación de la Validez del MMPI-2 (Berry \& Butcher, 1998

\section{I $\mathcal{N}$ I CES $\mathcal{D E}$ PERF I LES}

Perfil 1: Escalas e índices de Validez y Básicas del perfil medio clínico de mujer 155

Perfil 2: Escalas e índices de Validez y Básicas del perfil medio clínico de varón 155

Perfil 3: Varón que ha contestado siendo sincero y honesto y posteriormente intentando dar una buena imagen de sí mismo

Perfil 4: Perfil comparativo del grupo de población normal y de buena imagen

Perfil 5: perfil comparativo del grupo de población normal y de mala imagen 159

Perfil 6: Comportamiento del perfil del MMPI-2 cuando se contesta a todos los ítems del cuestionario como "falso"

Perfil 7: Comportamiento del perfil del MMPI-2 cuando se contesta a todos los ítems del cuestionario como "verdadero"

Perfil 8: Comportamiento del perfil del MMPI-2 cuando se contesta a todos los ítems del cuestionario de forma alternativa y secuencial como "verdadero/falso"

Perfil 9: Comportamiento del perfil del MMPI-2 cuando se contesta a todos los ítems del cuestionario de forma alternativa y secuencial como "falso/verdadero"

Perfil 10: Comportamiento del perfil del MMPI-2 cuando un varón contesta de forma aleatoria ( $s i n$ tener en cuenta el contenido de la información de los ítems)

Perfil 11: Perfil medio de 100 formas diversas de contestar al cuestionario sin tener en cuenta el contenido de la información de los ítems(Rtas. Inconsistentes) 
I $\mathcal{N}$ I CE $\mathcal{D E}$ GRA FICAS

Gráfica 1: Grupo normales. Variable "Odecp”. Análisis por sexos 144

Gráfica 2: Grupo normales. Variable "FBS". Análisis por sexos 145

Gráfica 3: Grupo normales. Variable "F". Análisis por sexos 145

Gráfica 4: Grupo normales. Variable "Wsd". Análisis por sexos 146

Gráfica 5: Grupo normales. Variable "/F-Fb/". Análisis por sexos 146

Gráfica 6: Grupo normales. Variable Ds-r. Análisis por sexos 146

Gráfica 7: Grupo normales. Variable "IR". Análisis por sexos 147

Gráfica 8: Grupo normales. Variable "TRIN". Análisis por sexos 147

Gráfica 9: Grupo normales. Variable "?”. Análisis por sexos 148

Gráfica 10: Grupo normales. Variable "F(p)". Análisis por sexos 148

Gráfica 11: Grupo normales. Variable "F-K". Análisis por sexos 148

Gráfica 12: Grupo normales. Variable "K". Análisis por sexos 149

Gráfica 13: Grupo clínico. Variable "FBS". Análisis por sexos 151

Gráfica 14: Grupo clínico. Variable "Ds-r". Análisis por sexos 152

Gráfica 15: Grupo clínico. Variable "ODecp". Análisis por sexos 152

Gráfica 16: Grupo clínico. Variable "IR". Análisis por sexos 152

Gráfica 17: Grupo clínico. Variable "Ds". Análisis por sexos 153

Gráfica 18: Grupo clínico. Variable "Wsd". Análisis por sexos 153

Gráfica 19: Grupo Mala imagen. Variable "L". Análisis por sexos 160

Gráfica 20: Variable "L". ANOVA 167

Gráfica 21: Variable "L". Análisis intersexos/intergrupos $\quad 168$

Gráfica 22: Variable "F". ANOVA 171

Gráfica 23: Variable "F". Análisis intersexos/intergrupos 171

$\begin{array}{ll}\text { Gráfica 24: Variable "K". ANOVA } & 175\end{array}$

Gráfica 25: Variable "K". Análisis intersexos/intergrupos $\quad 175$

Gráfica 26: Variable "VRIN". ANOVA 179

Gráfica 27: Variable "VRIN". Análisis intersexos/intergrupos $\quad 179$

Gráfica 28: Variable "TRIN". ANOVA 182

Gráfica 29: Variable "TRIN". Análisis intersexos/intergrupos 183

Gráfica 30: Variable "Fb". ANOVA 185

Gráfica 31: Variable "Fb". Análisis intersexos/intergrupos 186

Gráfica 32: Variable. "F-K". ANOVA 189

Gráfica 33: Variable "F-K". Análisis intersexos/intergrupos 189

Gráfica 34: Variable "F(p)". ANOVA 192

Gráfica 35: Variable " $\mathrm{F}(\mathrm{p})$ ". Análisis intersexos/intergrupos 192

Gráfica 36: Variable "S". ANOVA 196

Gráfica 37: Variable "S". Análisis intersexos/intergrupos 196

Gráfica 38: Variable "Ds-r". ANOVA 199

Gráfica 39: Variable "Ds-r". Análisis intersexos/intergrupos 199

Gráfica 40: Variable "FBS". ANOVA 201

Gráfica 41: Variable "FBS". Análisis intersexos/intergrupos 201

Gráfica 42: Variable"ODecp". ANOVA 205

Gráfica 43: Variable "ODecp". Análisis intersexos/intergrupos 205

Gráfica 44: Variable "IR". ANOVA 208

Gráfica 45: Variable "IR". Análisis intersexos/intergrupos 208

Gráfica 46: Variable "Wsd". ANOVA 211

Gráfica 47: Variable "Wsd". Análisis intersexos/intergrupos 211

Gráfica 48: Variable "/F-Fb/". ANOVA 215

Gráfica 49: Variable "/F-Fb/". Análisis intersexos/intergrupos 215

Gráfica 50: Variable "?". ANOVA 218

Gráfica 51: Variable "?". Análisis intersexos/intergrupos 218 
Introducción

La fiabilidad y validez de los Cuestionarios de personalidad o el problema de la aceptabilidad de un protocolo.

Cuando preguntamos a una persona sobre un acontecimiento determinado puede contestarnos de diversas formas, incluso con el silencio, pero siempre, esa respuesta, tendrá la peculiaridad de estar condicionada por una carga subjetiva y personal. Cuando, a través de un Cuestionario, realizamos una serie de preguntas sobre determinados acontecimientos o actividades psicológicas (cognitivas, motoras, psicofisiológicas) que hacen referencia a momentos de la propia vida del sujeto, este Cuestionario se convierte en un "autoinforme" ya que el sujeto nos ha ofrecido una visión personal de sus propios acontecimientos.

Los Autoinformes, como técnica de evaluación de rasgos psicológicos, factores o dimensiones de la personalidad, han sido fuertemente criticados desde distintos puntos de vista $\mathrm{y}$ por diversos autores y corrientes psicológicas (Mischel, 1968.; El behaviorismo de Watson y Skinner) Quizás la principal crítica radica en que este tipo de técnicas no presentan las garantías científicas adecuadas ya que el sujeto informa, subjetivamente, de diferentes hechos o actividades psicológicas que tienen relación con diversos eventos o situaciones de la vida del sujeto.

Los Autoinformes, en su diversidad de formatos, han sido siempre una de las técnicas más utilizadas en la evaluación tradicional de los rasgos y, en la actualidad, siguen utilizándose ampliamente para la evaluación de los factores integrantes de la personalidad del sujeto. Fernández-Ballesteros (1992) admite y muestra como características esenciales de los autoinformes: la "estructuración" tanto por lo que se refiere a la formulación de la pregunta como a la respuesta exigida; evalúan conductas o clases de conductas ya especificadas de antemano; solicitan información sobre eventos que ocurren habitualmente; y las respuestas se registran de forma estructurada (T.I, pg.241). 
El MMPI es un autoinforme cuyos ítems, para construir el Cuestionario, han sido seleccionados a través de una estrategia empírica. En base a esta estrategia, los ítems son seleccionados por el hecho de discriminar entre distintos grupos criterio. El MMPI fue construido en base a los autoinformes que diferenciaban entre sujetos normales y psicopatológicos, en función de la nosología psiquiátrica. Lo importante, señala Fernández-Ballesteros (1992), "no es el contenido verbal de cada ítem. Ni que cada ítem permita predecir la conducta que cuestiona en la vida real al sujeto. Lo importante es que cada puntuación de cada escala, test o subtest, es una medida del atributo del que da cuenta" (T.I, pg.225).

En la actualidad, y las innumerables investigaciones existentes así lo avalan, la técnica de evaluación del Minnesota Multiphasic Personality Inventory (MMPI) goza de toda la credibilidad, fiabilidad y validez científica en la comunidad tanto psiquiátrica como psicológica.

Y es en esta misma línea de investigación cuando nos adentramos para poder intentar apreciar la sensibilidad de determinadas Escalas e Índices de Validez para detectar si un perfil es plenamente fiable y puede ser interpretado con todas las garantías diagnósticas. Un determinado perfil, expresado por las puntuaciones reflejadas en una gráfica, está representando, de forma esquemática, todas las dimensiones de la prueba que se ha aplicado, ofreciendo, de este modo, un dibujo esquemático de las implicaciones de cada uno de los factores que intervienen en la formación de la personalidad del sujeto. Pero no siempre aquello que aparece en la gráfica, representativa del perfil, puede tener la validez adecuada. A veces encontramos que el perfil se encuentra, de alguna manera, "distorsionado", no parece corresponder con la personalidad, con las dimensiones que previamente hemos intentado analizar.

Actualmente, la determinación de la aceptabilidad de un protocolo es un importante reto para todos los investigadores que tienen como objetivo la validez y fiabilidad en la evaluación de las variables de personalidad y su correspondiente perfil clínico. Mediante diversas estrategias de confrontación podemos verificar la distorsión de la prueba. Ello hace que los investigadores que han abordado la aceptabilidad de la técnicas de evaluación de la personalidad con una estrategia psicométrica, hayan ido desarrollando diferentes pruebas suplementarias de validez y fiabilidad para su propia técnica (Cassisi, \& Workman, 1992; Crowne \& Marlowe, 1960; Gough, 1950; Krug, 1979; Millon, 1992). Cada protocolo del test debe examinarse para determinar su aceptabilidad como base para realizar inferencias personológicas o generar hipótesis diagnósticas. Sólo si se asume que el individuo cumplimenta el test marcando los ítems consistentemente de forma que seguramente refleja sus autopercepciones, puede el clínico proceder con el proceso interpretativo. Los tradicionales indicadores de validez, solos o en combinación, nos van a permitir evaluar la aceptabilidad de una determinada administración de la técnica.

El realizar un control de validez y fiabilidad sobre la evaluación de la prueba se convierte en una obligación necesaria. En determinadas situaciones de evaluación, como en los casos de elaboración de informes periciales de tipo psico(pato)lógico, es necesario tener en cuenta el motivo de la pericia y poder apreciar aquello que las personas, objeto de la pericia, tienen "en juego". El clima de sinceridad y mutua confianza que debe existir entre paciente y evaluador en cualquier situación normal de entrevista y análisis clínico, no se puede mantener con la misma seguridad en la 
sinceridad y confianza cuando el ambiente se especifica en el peritaje forense, ya que los intereses del evaluado pueden ser muy distintos.

Las técnicas psicológicas que evalúan dimensiones de la personalidad, mediante una estrategia psicométrica en la que los sujetos deben autoevaluarse, sobreentendiéndose que deben ser "sinceros" consigo mismo, se encuentran especialmente expuestas a correr el riesgo de ser contestadas de una forma muy peculiar según la voluntariedad, motivación e interés del sujeto, el cansancio, el nivel de lectura tanto en su velocidad como en su comprensión, un vocabulario exiguo, un nivel de edad no apropiado, dar buena o mala imagen de sí mismo, contestar de forma inconsistente, aparecer como trastornado mental, disimular una enfermedad, etc., etc. Todo ello hace que tengamos que tomar un interés específico para que el protocolo que hemos recogido pueda gozar de la validez apropiada. Estamos hablando, como bien se puede entender de la fiabilidad $\mathrm{y}$ validez de un determinado protocolo y en ningún caso estamos haciendo referencia a ningún índice de fiabilidad o validez psicométrica de una determinada técnica, más propio de los análisis psicométricos y estadísticos.

El Minnesota Multiphasic Personality Inventory (MMPI) ha sido, tradicionalmente, una de las técnicas de evaluación más utilizadas por psiquiatras y peritos para el diagnóstico de los trastornos de la personalidad e incluso poder apreciar y diferenciar "psicópatas" de "psicóticos", "enfermos" de no-enfermos" (Roman, Tuley, Villanueva, y Mitchell, 1990) en los diferentes dictámenes psiquiátricos de las salas de justicia, ayudando con ello a jueces y jurados a delimitar la responsabilidad criminal.

Para el presunto culpable de un acto delictivo, probablemente le interesa "aparecer" en su perfil de personalidad como "trastornado" para, con este diagnóstico, intentar obtener algún tipo de exención, total o parcial, en la responsabilidad penal del hecho delictivo (Kurlychek \& Jordan, 1980; Roman, Tuley, Villanueva, \& Mitchell, 1990). No es menos importante para el evaluador saber apreciar la sinceridad con que contestan unos padres interesados en conseguir la guarda y custodia de su hijo, o el individuo que intenta falsear una prueba de personalidad para aparecer con un diagnóstico falso y conseguir, de esta manera, las indemnizaciones o pensiones correspondientes (Graham, Watts \& Timbrook, 1991; Welzler \& Marlowe, 1990; Lees-Haley, 1991).

Para la persona que aspira a ocupar un puesto de trabajo y se le cita para un análisis psicológico (entrevista o examen psicotécnico), probablemente le interesa "aparecer" en el perfil psicológico de su prueba como una personalidad con las dotes apropiadas y ajustadas al puesto de trabajo e incluso causar una buena impresión. Esta persona intenta, posiblemente, ocultar sus defectos para realzar excesivamente sus virtudes.

A otras personas no les interesa realizar la prueba pero se ven obligadas, por diversos motivos, a realizarla. El desinterés, la ausencia de colaboración y la falta de motivación hace que la distracción se apodere de la persona y se refleje en la prueba. Juegan con el test a responder de forma incoherente, sin tener en cuenta el sentido de los ítems, respondiendo de una forma anómala y caprichosa (Berry, Wetter, Baer, Larsen et al., 1992; Wetter, Baer, Berry, Smith et al., 1992).

Pero no siempre el individuo intenta falsear conscientemente la prueba. A veces la distorsión de un perfil viene causado porque el sujeto comete el simple error de alterar la correspondencia exacta entre el número de la pregunta y el de la respuesta; otras veces existe en la persona una cierta tendencia a contestar todo lo que se le pregunta como "verdadero", o también como "falso"; y otras veces, un inadecuado nivel de 
lectura o comprensión, o la misma influencia de sustancias (Fals, 1995) en el individuo, pueden estar provocando una alteración en la contestaciones a la prueba y por consiguiente una distorsión del perfil de personalidad.

No es extraño, pues, que en la reestandarización del MMPI (resultando MMPI-2 para adultos y MMPI-A para jóvenes adolescentes) llevada a cabo por el equipo de investigadores de la Universidad de Minnesota (Butcher, J.N., Dahlstrom, W.G.; Graham, J.R.; Tellegen, A. y Kaemer, B. 1989), cincuenta años después, tuvieran en cuenta la intensificación de su estudio y ampliación de algunas variables específicas para detectar la validez de los perfiles.

Una adaptación no quiere decir, simplemente, traducir una determinada prueba y, sin más, aplicarla a una población. En la adaptación que hemos realizado al castellano hemos tenido que seguir, escrupulosamente, las directrices señaladas por la Universidad de Minnesota en cuanto a su traducción, selección estratificada de las muestras por regiones y edades, comparación con otras poblaciones de habla española (versión chilena, argentina y mexicana), giros gramaticales para su mejor comprensión, validación interjueces, baremación, etc. etc.

\section{$\mathcal{E l}$ objetivo de nuestra investigación.}

Nuestro propósito en esta investigación es poder apreciar, en la reciente adaptación castellana del MMPI-2, las diversas aportaciones de fiabilidad y validez que nos muestran las Escalas principales de Validez: L, F, K,; las Escalas adicionales aportadas por la reestructuración del MMPI-2: Fb, VRIN y TRIN.

Son muchos los interrogantes que se nos plantean cuando abordamos este tema específico de la validez de un perfil. Tradicionalmente, con el MMPI original, nos hemos encontrado con las variables "?" (interrogante), "L" (escala de mentira), "F" (escala de infrecuencia) y " $K$ " (factor corrector o de defensividad). Con la nueva reestandarización y adaptación al castellano del MMPI-2 nos hemos encontrado con tres nuevas escalas dentro del grupo denominado de "Validez", con las "Fb" (F posterior), con la "VRIN" (Inconsistencia de respuestas variables) y "TRIN" (Inconsistencia de respuestas verdadero). La necesidad de un soporte mayor de investigación con las VRIN y TRIN (Butcher et al., 1989) nos motivaron este trabajo con la finalidad de presentar nuevas aportaciones con estas variables.

Esta aportación se han visto ampliada por la investigación de otras escalas e índices de validez realizadas con los ítems del MMPI y/o MMPI-2. La Escala de Deseabilidad social (Wsd) de Wiggins (1959), la Escala de Inconsistencia de Respuestas (I.R.) de Sewell \& Rogers (1994), la escala de Fingimiento Positivo o de Otro Engaño (ODecp) de Nichols \& Glenn (1991), la Escala de "Fake-bad" (FBS) de Lees-Haley, Englis \& Glenn (1991), el Índice de Disimulación (Ds) de Gough (1954), el Índice Revisado de Disimulación (Ds-r) de Gough (1957), la Escala Superlativa (S) de Butcher \& Han (1995) y la Escala Psiquiátrica $\mathrm{F}(\mathrm{p})$ de Arbisi \& Ben-Porath (1995), y su comportamiento a través del MMPI-2, son las contribuciones que intentamos llevar a cabo en este trabajo.

Para poder dar respuesta a estos interrogantes, nos hemos servido de las respuestas ofrecidas al Cuestionario de Personalidad de Minnesota (MMPI-2) por sujetos que han contestado de una forma coherente y sincera, sujetos que intentan ofrecer una "buena 
imagen" de sí mismo, sujetos que intentan dar una "mala imagen" de sí mismos, individuos que contestan de forma inconsistente al cuestionario y pacientes ambulatorios que, contestando de forma honesta y sincera, requieren los servicios del psicólogo acudiendo a un Centro de Salud Mental, con una sintomatología psicopatológica diagnosticada.

Para llevar a cabo este estudio hemos planteado nuestra investigación comentando las diferentes variables que pueden estar subyaciendo en la distorsión de un perfil de la personalidad y, por consiguiente, poder apreciar la fiabilidad y validez de los datos aportados por el sujeto a la hora de la interpretación y evaluación diagnóstica. Después de ofrecer un pequeño panorama de diversos instrumentos que nos pueden aportar criterios para evaluar la distorsión de un perfil, nos hemos centrado en la técnica del MMPI-2, exponiendo las principales variables que componen las Escalas de Validez denotadoras de protocolos no fiables para su interpretación.

El estado actual de las investigaciones en las diferentes variables distorsionadoras de la fiabilidad del perfil de personalidad en el MMPI, es el apartado siguiente que hemos abordado antes de entrar en el estudio empírico.

El planteamiento del problema, las hipótesis planteadas, la metodología de la investigación y la descripción y análisis de las variables intervinientes en este estudio empírico, se corresponde con el apartado IV de este trabajo.

El análisis de los resultados, las gráficas correspondientes y la interpretación de los diferentes análisis comparativos entre los diferentes grupos muestrales, sus conclusiones, la confrontación y discusión con otras investigaciones llevadas a cabo, van a conformar el penúltimo apartado de este estudio antes de exponer la bibliografía referida en nuestro estudio. 
PARTE I: $\mathcal{E S} \mathcal{T} \mathcal{T}$ DI O $\mathcal{T}$ EÓ RICO 
CAPITULO I. - LA DIS TORS IÓN $\mathcal{N}$ DEL PERFIL.

Introducción.

Desde el punto de vista de nuestro trabajo, el término de "validez" puede tener distintos tipos de acepciones. Ya Dahlstrom y Welsh (1972) advierten de las dificultades de comprensión que puede tener este término. Por una parte el significado de la teoría psicométrica clásica denota que el término puede significar la propiedad de una determinada escala o factor que puede contribuir a legitimar las inferencias que sobre la escala se puedan realizar. Por otra parte, el término de "validez" se puede entender, como lo hace Núñez (1979), cuando nos habla de las "Escalas de validez" del MMPI para señalar el grado de confianza que se puede obtener para poder realizar, a través del perfil de la prueba, inferencias sobre las dimensiones de la personalidad. A esta segunda acepción nos estamos refiriendo en este trabajo cuando hablamos de "validez" o "fiabilidad" de un determinado perfil. De igual manera el término "fiabilidad" es sinónimo de "validez" y tampoco queremos significar con ello la "fiabilidad" psicométrica de una determinada prueba. 


\section{I.1. - CUES TIONES CONCEPT UIALES .}

La fiabilidad o validez de un perfil y, por consiguiente, la seguridad en la veracidad de sus datos y la subsiguiente interpretación de los factores y diagnóstico, va a venir condicionado por el grado de distorsión que se ha detectado en el perfil.

\section{La respuesta distorsionada}

Cuando hablamos de "distorsión " nos estamos refiriendo a una serie de factores que están interviniendo en la elaboración de un determinado evento que lo hace deformado o sospechoso de su validez. El Diccionario de la Lengua Española de la Real Academia Española (1992) define el término de distorsión (referido por el latín "distorsio-nis") como "deformación, de imágenes, sonidos, señales, etc., producida por su transmisión o reproducción".

Furnham (1986, pg. 269) con el término de "distorsión" alude específicamente a aquellas ocasiones en que la persona da deliberadamente respuestas falsas para crear la impresión concreta de que se pondría enferma si no consigue el puesto de trabajo"(citado por Seisdedos, pg. 54), pero el mismo autor diferencia entre "distorsión" como una protección poco honesta de una "deseabilidad social" en la que se intenta presentar, ante los demás, una posición más favorable.

Con el término de "distorsión" queremos especificar una generalidad de variables que no tienen por qué estar referidas, ni expresa ni específicamente, por el termino de "simulación" aunque lo implique y suponga. Es decir, cuando un sujeto contesta a los ítems del cuestionario de una manera inconsistente, no está intentando "simular" nada, simplemente podemos apreciar la falta de motivación por parte del sujeto para colaborar con nosotros en la tarea propuesta. Otro tanto podemos observar cuando en el sujeto apreciamos la tendencia a contestar sus ítems como "verdadero" o como "falso", dando como resultado un porcentaje elevado de respuestas "verdadero" o falso respectivamente, o simplemente encontramos ciertas incoherencias porque el sujeto no domina el significado de las palabras, o la inadecuación del nivel de lectura, o simplemente se ha producido una falta de concordancia entre los números de las preguntas y los números de las respuestas, etc. De todas estas formas de contestar al cuestionario podemos apreciar que el perfil obtenido se encuentra "distorsionado".

Es evidente que, cuando un individuo trata de ofrecer una "buena o mala imagen", exagerando o minusvalorando, la sintomatología que conscientemente sabe que le afecta, también podemos apreciar que el perfil está, no solamente "falseado", sino también "distorsionado". Es decir, estamos haciendo referencia a una "intencionalidad" para poder obtener un beneficio secundario.

Con ello queremos significar que el término "distorsión" es mucho más amplio que el, simplemente, de "falsificación" o "simulación".

Nos identificamos plenamente con la concepción de Rogers $\left(1984,1990^{a}\right.$, 1990, 1991, 1992, 1993, 1997,) acerca de la "distorsión". Rogers (1997) considera que la "disimulación" hace referencia a los intentos conscientes, por parte del individuo, de distorsionar sus respuestas. "Disimular", para Rogers, es ofrecer cualquier tipo de respuesta que no sea, precisamente, la honesta. Rogers, pues, en este caso emplea los 
términos "disimular" y "distorsión" como sinónimos aunque diferencia la distorsión "positiva" (ofrecer buena imagen) de la "negativa" (ofrecer mala imagen).

El 16 PF de Cattell (1970) nos ofrece una escala denominada "Escala de distorsión motivacional" tratando de detectar aquellos sujetos que intentan dar una buena imagen de sí mismo en su contestación a esta prueba psicométrica de la personalidad. Esta escala fue elaborada a partir de un grupo de 45 sujetos que contestaron al 16PF de tal manera que nos presentaran la imagen más favorable de ellos mismos. Sus resultados fueron analizados comparativamente con una muestra de sujetos que contestaban honestamente. De forma similar, en el mismo 16PF, se elaboró la escala de "Mala imagen" haciendo que los sujetos contestaran a los ítems de la prueba intentando ofrecer una imagen negativa de sí mismos.

A través del análisis de las Escalas de Validez del MMPI-2, vamos a intentar apreciar los diferentes perfiles que se encuentran "distorsionados", aunque no todos ellos sean, necesariamente, falseados intencionadamente para obtener un posible beneficio posterior.

Un perfil puede resultar distorsionado de múltiples maneras, tanto como la imaginación o idiosincrasia del propio sujeto pueda llegar a hacerlo. Desde el punto de vista de la intencionalidad y consciencia del sujeto en alterar su propia respuesta, vamos a hacer nuestra exposición para poder apreciar de forma más nítida los tipos de distorsión y las denominaciones dadas por los autores en sus estudios acerca de este problema.

Hablamos de "distorsión negativa" cuando el sujeto, deliberadamente intenta alterar los resultados de una prueba con objeto de ofrecer una imagen negativa o "mala imagen" en las capacidades o características de personalidad a través de la evaluación de un instrumento. El concepto de "mala imagen" cambia en función del tipo de prueba. Así, un instrumento de evaluación que apreciase la dimensión "inteligencia" o "aptitudes", la imagen negativa resultante sería un nivel intelectual bajo o de una inadecuada aptitud para determinadas tareas. En una prueba de personalidad, la imagen negativa o "mala imagen", consistiría en mostrar las dimensiones que, particularmente, considero como negativas o de una personalidad desequilibrada.

La "distorsión positiva" se centraría más en las características de la personalidad, intentando aparecer como más equilibrados de lo que en realidad sabemos que estamos. Mucho más difícil resulta dar una imagen positiva en las pruebas de aptitudes o inteligencia .

Exponemos, pues, diversas formas por las cuales un determinado perfil se puede apreciar como distorsionado:

\section{I.1.1. - La distorsión de libe rada.}

Evidentemente esta distorsión apreciada en el perfil la presenta el sujeto, intencionadamente, con el objetivo específico de obtener un beneficio. El sujeto sabe, conoce y quiere conseguirlo.

- "Defensividad": Este término propuesto por Rogers (1984) sería el término opuesto al de simulación. La "defensividad" consistiría en la negación de síntomas físicos y psíquicos con el objetivo de ofrecer una imagen positiva al evaluador. 
Hemos de apreciar que el término presenta una notable semejanza con la teoría psicoanalítica, pero, en nuestro caso, nada tiene que ver con los mecanismos de defensa. El significado de nuestra terminología de "defensividad" parte de la base de la existencia de un deseo, consciente, de ofrecer una imagen positiva al evaluador, sin llegar a analizar la motivación que pueda estar subyaciendo. Pero a nuestro entender, este término de "defensividad" según lo expresa Rogers (1984), nos parece restrictivo ya que uno no solamente se "defiende" presentando el lado más favorable de su personalidad (que Rogers supone la "buena imagen"), también puede interesar, a veces, (un presunto culpable de un homicidio, por ejemplo) una imagen negativa de sí mismo (intentando aparecer como trastornado) $\mathrm{y}$, evidentemente, se está "defendiendo" ante lo que le espera en el dictamen judicial. A través de la bibliografía existente sobre este tema hemos encontrado diversos términos para expresar este concepto: Para Rogers (1984) se identificaría con "underreporting", "faking good", "buena imagen" o "fingimiento positivo". Para nuestro entender, la "defensividad" es mucho más amplia y variada según ambientes e intereses. En este trabajo vamos a respetar el término de defensividad expresado por los diversos investigadores, teniendo en cuenta que, de forma más precisa vamos a diferenciarlos como "fingimiento positivo" o fingimiento negativo".

- "Overreporting": Exagerar deliberadamente los síntomas de una enfermedad, incapacidad o incompetencia. Otros términos asociados: "Fake bad", "Faking bad", "Fingimiento negativo". Para algunos autores (Greene, 1997, 2000) este término se encuentra especialmente indicado para sujetos clínicos con diferentes tipos y severidad de sintomatología psicopatológica. Es más, incluso este autor Greene (2000, pg.97) va a identificar como "overreporting" al fingimiento positivo y "underreportin" al fingimiento negativo.

- "Underreporting" Cuando se intenta minimizar, de forma deliberada, los síntomas de una enfermedad, incapacidad o incompetencia. Otros términos asociados: "Fake good", "faking good", "Fingimiento positivo". Como en el caso anterior (Greene, 1997, 2000) este término se encuentra especialmente indicado para sujetos clínicos con diferentes tipos y severidad de sintomatología psicopatológica.

- "Faking good": Cuando el individuo, de forma deliberada e intencionada, quiere dar una buena imagen de sí mismo. Se convierte en una forma de defensividad ante "algo" que le molesta, no le interesa en este momento, o no admite en sí mismo. Algunos autores lo identifican con "Fake good". Otros términos asociados: "buena imagen", "hacerse el bueno", "fingimiento positivo", "underreporting".

- "Faking bad". Cuando, por el contrario, el sujeto intenta dar una mala imagen de sí mismo. Por algún motivo personal al sujeto le interesa aparecer, intencionadamente, como enfermo, incapacitado, incompetente. También denominado en la literatura científica como "Fake bad". Algunos autores lo identifican con el término "malingering".

- "Malingering". Es un fingimiento deliberado de enfermedad, incapacidad o incompetencia. Otros autores lo identifican con "hacerse el enfermo". Otros términos asociados: "faking bad", "fake bad", "fingimiento negativo".

- "Fingimiento positivo": Cuando el sujeto intenta mostrarse como más ajustado y equilibrado psicológicamente, minimizando su sintomatología, o mostrándose con 
una personalidad perfecta y equilibrada. Algunos autores (Rogers, 1984) lo denominan "defensividad". Otros términos asociados: "buena imagen", "faking good", "fake good".

- "Fingimiento negativo": El sujeto se encuentra especialmente motivado para mostrase desequilibrado o desajustado psicológicamente, exagerando su sintomatología o mostrando una imagen desfavorable de sí mismo. Otros términos asociados: "malingering", "mala imagen", "Faking bad","fake bad".

- "Responder al azar" ("random response"). El sujeto, deliberadamente y por distintas motivaciones personales, responde de una forma aleatoria con el resultado evidente de un perfil distorsionado.

- "Deseabilidad social" ("social desirability". Crowne \& Marlowe, 1960): fingir, de forma deliberada, una buena imagen de sí mismo o también dar la imagen que creo que los demás esperan de mi. Una definición más específica de la "deseabilidad social" la encontramos en Nederhof (1985) como la "tendencia a negar rasgos indeseables y a arrogarse los socialmente deseables, así como la tendencia a decir aquello que, al interlocutor, le coloca en una posición favorable" (citado por Seisdedos, 1995, pg.54). No nos encontramos totalmente seguros de que esta "deseabilidad social" se encuentre enmarcada dentro del apartado de la distorsión deliberada porque, en nuestra opinión, podemos encontrar elementos no siempre conscientes y deliberados cuando una persona trata de aparentar lo que no es. Otros términos asociados: "Defensividad", "buena imagen", "Fingimiento positivo".

\section{I.1.1.1. - La simulación.}

El fingimiento o simulación consiste en aparentar, producir, intensificar o disminuir signos, síndromes de enfermedad o síntomas patológicos con una intención claramente beneficiosa para el simulador. La capacidad de simulación es una importante variable de la personalidad del sujeto existiendo personalidades que son netamente simuladores perfectos y los cuales pueden resultar difícilmente detectables.

Podemos considerar, de forma general, que la simulación tiene dos elementos esenciales a considerar, por una parte la producción intencionada de los signos patológicos, y por otra la obtención de un beneficio. Estos beneficios están cargados, a veces, de una gran subjetividad, experimentándose de forma múltiple y diversa, ya que cada ocasión y persona puede interpretar de forma personal la calidad y magnitud del beneficio.

En el caso práctico, por ejemplo, de la evaluación psicológica en la que se nos solicita un informe psicológico pericial podemos encontrar los intereses o motivaciones más diversas: el interno en una Institución Penitenciaria que busca ser trasladado a dependencias hospitalarias o psiquiátricas, el de evitar o retrasar una vista judicial, lograr algún tipo de exención de pena, obtener cualquier tipo de indemnización por un presunto daño psicológico, el de evitar ser internado en un centro psiquiátrico (disimulando su trastorno) o intentar dar buena imagen para conseguir la guarda $\mathrm{y}$ custodia de los hijos.

No podemos decir que todas las formas de simulación que resultan, en definitiva engañosas, sean intencionadas. Desde el punto de vista de la intencionalidad, podemos apreciar diferentes formas de engaño. 
Marco Ribé, Martí Tusquets y Pons Bartran (1990), denominan "simulación total o verdadera" cuando el sujeto finge, de forma plenamente consciente y deliberada, el padecimiento de una enfermedad de acuerdo con los conocimientos intuitivos o concretos que posee acerca de la enfermedad simulada. Para estos autores existen otros tipos de simulación (pg. 491).

- Disimulación (o simulación invertida): Consiste en el intento, por parte de la persona afectada de cualquier discapacidad física, psíquica o sensorial, de ocultar su sintomatología. Se manifiesta en los delirantes querulantes, paranoico con delirio de persecución, hipocondríacos y los delirantes celotípicos.

- Sobresimulación: Es una forma de simulación que realiza un enfermo mental o un anormal, pero que padece un cuadro clínico diferente del que exhibe. Esta sobresimulación la realizan enfermos que cursan con normalidad de conciencia; sobre todo los afectados de Depresión Mayor, los delirantes de contenidos celotípicos o similar, algunos epilépticos y también en los que desarrollan estados paranoides.

- Perseveración o metasimulación. Consiste en la prolongación, consciente, de los síntomas de un trastorno mental verdadero que recientemente curó pero que le interesa (beneficio) mantener el trastorno (por ejemplo, seguir cobrando la pensión de invalidez) .

- Hipersimulación: Es el hecho de exagerar su engaño en determinados momentos (observación médica pericial, vigilancia, presentación ante el juez, etc.).

- Presimulación: La realizada por un individuo, con anterioridad a la comisión del delito, en forma muy llamativa y ante testigos cualificados, con la intención de posteriormente poder invocar el padecimiento previo de trastorno mental. (p.e. hacer ver durante un tiempo que no está cuerdo, para después poder cometer su delito. Posteriormente aducirá trastorno mental previo al delito cometido).

- Retrosimulación. Implica la presentación de síntomas de cuadros psiquiátricos que ya han remitido. Consideramos que la diferencia básica con la denominada Metasimulación es que en el caso de la retrosimulación transcurre un tiempo entre la remisión de la enfermedad y el inicio de la conducta simuladora. En el espacio de tiempo transcurrido entre el verdadero problema psiquiátrico y la aparición de la retrosimulación el paciente no presenta sintomatología, ni real ni ficticia.

\section{I.1.1.2. - La simulación patológica:}

El Manual de diagnóstico y estadístico de los trastornos mentales (DSM-IV), en su traducción castellana (1995) define la simulación como la "producción intencionada de síntomas físicos o psicológicos desproporcionados o falsos, motivados por incentivos externos, como..." (pg. 698) exponiendo a continuación algunos ejemplos para poder evaluar la "sospecha" de la existencia de simulación. En el sistema del DSM-IV, el fingimiento o simulación debe ser diferenciado del Trastorno Facticio, que se caracteriza como "aquel en el que los síntomas, físico o psicológicos, son fingidos o producidos intencionadamente, con el fin de asumir el papel de enfermo" (pg. 483). La diferencia esencial entre Simulación y Trastornos Facticio se centra en el hecho de que la producción de síntomas, en el Trastorno Facticio, no persigue obtener una ganancia o 
beneficio si no la necesidad patológica de "estar enfermo" (aquí radica la patología, precisamente). El diagnóstico de Trastorno Facticio implica siempre un grado de patología.

La presencia de un Trastorno Facticio no excluye, necesariamente, la coexistencia de éste con verdaderos síntomas, tanto físicos como psíquicos. Estos pacientes son proclives a presentar cualquier patología psiquiátrica, considerándose habitualmente las que presentan características de personalidad límite. Ford (1983) considera que el perfil general del paciente con Trastorno Facticio apunta hacia una mujer soltera, menor de cuarenta años, con conflictos de relación y mecanismos represivos respecto a la hostilidad y las vivencias sexuales.

En el Trastorno Facticio podemos encontrar un predominio de síntomas psicológicos, físicos o una combinación de ambos. Los pacientes con estos trastornos pueden llegar a estructurar su vida alrededor de los Centros de Salud, comprometiendo a todo el equipo médico o psiquiátrico.

El DSM-IV nos proporciona los criterios para descubrir y distinguir este tipo de trastorno de la enfermedad física verdadera y del trastorno mental verdadero. "Las sospechas deben despertarse cuando se produzcan cualquier combinación de los siguientes síntomas en una persona hospitalizada:

- Un cuadro clínico dramático o atípico que no pertenece a una enfermedad física o mental identificable.

- Síntomas o comportamientos que aparecen cuando el individuo es observado.

- Seudología fantástica,

- Comportamiento antisocial en la sala de hospitalización (p.e. falta de cumplimiento de las reglas y normas hospitalarias, discusiones excesivas con las enfermeras y médicos).

- Conocimiento excesivo de la terminología médica y rutinas hospitalarias.

- Consumo encubierto de fármacos.

- Múltiples intervenciones terapéuticas (p.e. cirugía, electroshock).

- Historia intensa de viajes.

- Pocos o ningún visitante durante la hospitalización.

- Curso clínico fluctuante con producción rápida de "complicaciones" de nueva "patología" una vez que las exploraciones iniciales resultan negativas". (pg, 485)

\section{I.1.2. - La distorsión no-deliberada:}

No siempre se busca una intencionalidad desde la cual obtener un beneficio, a veces nos podemos encontrar con protocolos cuyos perfiles se evidencian claramente distorsionados y por lo tanto invalidados para la interpretación adecuada. Existen, pues otras formas de distorsión en las que la intencionalidad no se encuentra claramente expresada o abiertamente expuesta.

\section{I.1.2.1- La distorsión no-deliberada en la normalidad.}

Queremos referir las formas esenciales de responder, de forma no intencionada, a los ítems planteados en el Cuestionario. 
- "La tendencia a responder". Los ítems formulados en los diferentes cuestionarios pueden ser contestados según diversos tipos de formatos. Los más comunes se corresponden con los modelos de respuesta "SI /NO", o ¡SI / i / NO" o "Verdadero / Falso", o los formatos escalares, tipo Licker "-3,-2,-1,0,+1,+2,3" ó " $0,1,2,3,4,5$ " que nos pueden proporcionar ejemplos en donde los sujetos pueden presentar una cierta "inclinación" a contestar, independientemente del contenido de los ítems, de una manera determinada o sentir preferencia por cierto tipo de respuestas o contestaciones. Esta "inclinación" a contestar se puede apreciar que el sujeto la lleva a cabo de forma no consciente ni intencionada.

- Queremos referir la "aquiescencia o asentimiento" como la tendencia que muestra un sujeto a responder afirmativamente "Si" o "Verdadero" a las preguntas formuladas, con independencia del contenido de las mismas. El MMPI-2 permite esta forma de contestar por medio de dos índices: el porcentaje de respuestas correspondiente a Verdadero (V\%) y a Falso (F\%) y la variable TRIN.

- Sin embargo, cuando los ítems del cuestionario se encuentran formulados en forma escalar, podemos encontrar, por una parte, la tendencia del sujeto a elegir los lugares centrales o medios de la escala ("restricción de rangos"). Así en una escala de $-3-2-10+1+2+3$ el sujeto se "inclina" sistemáticamente a contestar en los puntos centrales (entre $-1,0,+1$ ). De otra parte podemos encontrarnos con la tendencia del sujeto a contestar los valores extremos de las escalas $(-3,-2$ ó $+3,+2)$ denominados como "errores escalares".

- Edad inapropiada. El sujeto no se adecua a la edad establecida para la que se ha elaborado la prueba.

- Inadecuada motivación para realizar la prueba. No todos los sujetos tienen la misma motivación para realizar las pruebas que nosotros le exigimos. A veces, la no voluntariedad del sujeto puede estar subyaciendo en una falta de colaboración y, por consiguiente, de motivación. Esto potencia la distracción.

- Déficit del nivel de lectura o de comprensión. Podemos encontrarnos con sujetos cuyo bagaje cultural y escolar sea deficitario y no pueda comprender el significado de algunas palabras. Este mismo aspecto puede suceder con personas extranjeras que no dominen adecuadamente nuestro idioma, incluso personas de países latinoamericanos.

- Un "salto" entre la lectura del número del ítem y su no correspondencia con el mismo número de la casilla de la respuesta,

- Distracciones y falta de atención. Falta de mantenimiento de la atención continuada, como es el caso de aquellas técnicas que contemplan un número importante de ítems y que fácilmente pueden conllevar a la monotonía (CPI de California, MMPI-2-A).

Estas variables, y posiblemente otras que en este momento se nos "escapan" pueden ser las causantes de la existencia de un perfil distorsionado. 


\section{I.1.2.2- La distorsión no-deliberada en la patología.}

$\mathrm{Si}$ consideramos las distorsiones involuntarias en sujetos afectados psicopatológicamente, el DSM-IV nos habla de dos tipos de trastornos, los Somatomorfos y los disociativos.

Los primeros tienen como característica común "la presencia de síntomas físicos que sugieren una enfermedad médica y que no pueden explicarse completamente por la presencia de una enfermedad, por los efectos directos de una sustancia o por otro trastorno mental (p.e. trastorno de angustia)" (pg. 457). A diferencia de lo que ocurre en los Trastornos Facticios y en la Simulación, los síntomas físicos no son intencionados ni simulados. Se encuentran referidos por la Hipocondría (referido en el MMPI-2 por la sigla "Hy"), la Somatización (anteriormente Histeria y referido por el MMPI-2 por la sigla "Hs"), el Trastorno de conversión, por el dolor y dismórfico corporal.

Los segundos, referidos por los Trastornos Disociativos (DSM-IV, pg.489 y ss.) presentan como característica general una alteración de las funciones integradoras de la conciencia, de la identidad, la memoria y la percepción del entorno. Los principales tipos de trastornos se expresan a través de la Amnesia disociativa (antes denominado como Amnesia psicógena), la Fuga disociativa (antes denominado como Fuga psicógena), y el Trastorno de Identidad Disociativo (antes denominado como Personalidad múltiple).

\section{I.2 - LA EVALUACIÓN $\mathcal{N} \mathcal{D E}$ LA S IMULACIÓN:}

Cuando nos planteamos llevar a cabo la evaluación de la simulación, debemos tener en cuenta los elementos que intervienen e interactúan en ella, como son: el contexto en el que se encuentra inmerso el sujeto, las personas objeto de la evaluación y el tipo de simulación y sintomatología manifiesta, los instrumentos que podemos utilizar para detectar la simulación y, finalmente, el áera o variable psicológica que el sujeto intente simular. A continuación exponemos estos cuatro elementos.

\section{I.2.1. - El contexto.}

El contexto en el que se realiza la evaluación puede determinar, en gran medida, los resultados. En el contexto clínico, cuando el paciente solicita ayuda de un profesional de la psicología, damos por supuesto la confianza, sinceridad y la colaboración mutua entre paciente y evaluador clínico. Ello nos ayudará a realizar un acertado diagnóstico y contribuirá a una pronta recuperación del paciente. Sin embargo, en otros contextos, como los jurídicos, e incluso laborales, en donde estén en juego, y dependan mayormente de un informe psicológico pericial, patrimonios importantes, grandes indemnizaciones, guarda y custodia de los hijos, adopción de niños, años de reclusión en una institución psiquiátrica, penas privativas de libertad, etc., debemos ponernos en guardia ante los supuestos de confianza, sinceridad y colaboración mutua. El profesional puede ser considerado como un obstáculo, como un burócrata "a sueldo" de la Administración, instrumento del sistema, o mera extensión de la organización que contrata sus servicios. Con estas consideraciones podemos entender las dificultades con las que puede pasar el profesional para obtener una información veraz. 
No es extraño que en los contextos laborales se presenten con mayor frecuencia la hipersimulación, metasimulación o perseveración, mientras que en el contexto penitenciario son las simulaciones verdaderas y las sobresimulaciones las que se dan con mayor asiduidad.

\section{I.2.2.- Los sujetos y su sintomatología.}

A la hora de la evaluación de la simulación, desde el punto de vista del sujeto, debemos hacer referencia a varios aspectos, desde nuestro punto, esenciales.

Ser un buen simulador requiere unas dotes especiales para poder llevarlo a cabo con éxito. Habitualmente se simulan síntomas aislados y de corta duración, como la falta de memoria, alucinaciones, ideas delirantes, apatía, falta de control de los impulsos, hipocondrías, etc., siendo raro encontrarse con simuladores que intentan simular un síndrome completo (entre otras cosas porque desconocen la coherencia del síndrome) y lo que suele suceder es encontrarse con una mezcla incoherente e inconsistente de síntomas referidos por varias enfermedades. Es, precisamente, esta falta de coherencia en la sintomatología, la base principal para llegar al descubrimiento de la simulación.

El simulador puede adoptar una actitud pasiva y de inhibición comportamental, negándose a realizar cualquier actividad alegando enfermedad. Llevando al extremo esta pasividad, podemos encontrarnos con el simulador "catatónico" que adopta una postura de "mimo paralizado" para simular su enfermedad. El simulador activo puede manifestar cualquier tipo de actividad desproporcionada, desordenada e incoherente a través de gritos, gestos bruscos, agresiones o con comportamientos ridículos, gesticulaciones extravagantes, contestando de forma absurda e ilógica para dar la apariencia o sensación de que están locos (o al menos de la idea que ellos poseen de la "locura" que no siempre coincide con la coherencia expresada por los diferentes manuales de nosología psiquiátrica, DSM-IV ó CIE-10).

La semiología médica es la ciencia encargada del estudio de los síntomas de las enfermedades. Tradicionalmente, en las Ciencias de la Salud, el síntoma es considerado como un indicador de la existencia de un proceso patológico o de una enfermedad. En el caso de la simulación no se puede mantener esta relación directa de síntomaenfermedad.

La sintomatología que refiere el simulador puede ser no solo incoherente, sino también diversa. Castilla del Pino (1980) hace referencia a dos tipos fundamentales de síntomas, cuya distinción se centra en función del origen biológico o funcional de los mismos. De forma general considera que todos los síntomas son somáticos, puesto que es el mismo cuerpo el único vehículo de expresión de todos ellos. Algunos de estos síntomas se corresponden, con mayor propiedad, con la esfera estrictamente biológica siendo denominados por Castilla del Pino (1980) como "aconductuales" (p.e. la dilatación pupilar o la elevación de la temperatura) porque no son reflejo de aspectos psicológicos. De la misma manera, cuando los síntomas tienen su origen en lo psíquico o mental, lo denomina sintomatología "conductual" (p.e. el llanto, las expresiones faciales).

Esta clasificación de la sintomatología establecida por Castilla del Pino (1980) tiene su primera manifestación en la psiquiatría más clásica de Bleuler (1967) cuando llevó a 
cabo una distinción entre síntomas "físicos" y "psicógenos", siendo estos últimos referidos por el malestar psicológico del sujeto.

Para el evaluador los síntomas "físicos" (Bleuler, 1967) o "aconductuales" (Castilla del Pino, 1980) conllevan una base fisiológica que, en su mayoría, se encuentra bien establecida y puede ser evaluado, con la ayuda de los avances tecnológicos, de un modo más preciso y objetivo que los "conductuales", aunque, a veces, no exentas de dificultades. Sin embargo, para el evaluador de síntomas "psicógenos" (Bleuler, 1967) o "conductuales" (Castilla del Pino, 1980) la situación puede complicarse cuando se encuentra con un sujeto simulador de una "indeterminada" patología ya que puede recurrir, voluntariamente, a todo un elenco de variables cognitivas, motoras o psicofisiológicas para poder engañar. Entonces es cuando obliga al Psicólogo Clínico a echar mano de su experiencia e intuición personal, para poder detectar al simulador.

Pero además, la producción de síntomas puede verse reforzada por otras variables del sujeto: las que hacen referencia a los conocimientos de la sintomatología psiquiátrica del sujeto y aquellas variables referentes al tipo de beneficio esperado. Cuando el simulador posee conocimientos de la sintomatología psiquiátrica e intenta expresarlos, el evaluador puede encontrarse con más dificultades para detectarlo. Este conocimiento puede haberlo experimentado y extenderlo de forma artificial en el tiempo (metasimulación, perseveración), aumentarlo en su intensidad (sobresimulación), manifestarlo en mayor medida (hipersimulación) o recrearlo artificialmente cuando la sintomatología ya ha remitido (retrosimulación). Ya hemos comentado anteriormente que el beneficio esperado de los efectos de la simulación pueden referirse a diverso ámbitos, ya sean carcelarios, jurisdiccionales o laborales.

Por todo ello, los clínicos debemos estar atentos ante tal sospecha. De forma escueta y resumida exponemos algunas de las particularidades que suscitan esta sospecha:

Falta de colaboración durante la evaluación diagnóstica. Debemos centrar nuestra atención en las incongruencias, contestar de forma vaga o general, dificultades en la precisión, no centrarse en el tema, etc., ante determinadas preguntas.

Incoherencia, invalidez o falta de fiabilidad/Validez en los resultados de las diversas pruebas de personalidad que se administran.

Confución en los síntomas de la enfermedad que presenta el sujeto. Simulan síntomas aislados de una enfermedad porque desconocen el síndrome completo. No es extraño que mezclen la sintomatología de diversos trastornos. Esta incoherencia puede apreciarse, en algunas de las técnicas psicométricas de la personalidad (MMPI, por ejemplo) por la distorsión e incoherencia del perfil.

A un sujeto diagnosticado de Trastorno antisocial de la personalidad (DSM-IV) no parece importarle mentir o falsear sobre cualquier aspecto que pueda perjudicarle o si sabe que puede obtener un beneficio.

En el ámbito de los Centros Penitenciarios: cualquier estrategia es posible si de su resultado exitoso se pueden obtener beneficios carcelarios (permisos fines de semana, ser internado en un hospital general, etc.).

En el ámbito de la jurisdicción:

- Petición, por parte del fiscal, de una pena o sanción grave ante un delito cometido. 
- Petición, por parte de la defensa, de una indemnización que represente una cantidad importante de dinero alegando cualquier incapacidad o minusvalía a causa de un accidente laboral o de tráfico.

- Si en el fondo del tema/delito existen fuertes sumas o patrimonios importantes en juego.

- En los Juzgados de Familia, cuando se lucha por la guardia y custodia del/os hijo/s (también la casa y la pensión alimenticia).

\section{I.2.3. - Los instrumentos.}

Nuestro objetivo, en este apartado, es intentar ofrecer una visión general y actualizada de las estrategias e instrumentos utilizados para evaluar las diversas formas de simulación, engaño, fingimiento o falsificación empleados por los sujetos.

Podemos preguntarnos por el tipo de estrategia que subyacen en las diferentes pruebas psicológicas para detectar la distorsión empleadas por los simuladores. Lanyon (1970) elaboró dos tipos de estrategias que son utilizadas cuando responden a una prueba: exagerando el síntoma o seleccionando el síntoma para distorsionarlo.

En el primero de los casos la estrategia del sujeto consiste en exagerar los síntomas e intenta responder en la dirección en la que puntúa una determinada escala (en todos aquellos ítems en los que supone que se cuestiona la presencia de un sintomatología psiquiátrica). El sujeto no presta demasiada atención a la congruencia de los síntomas, sino que se limita a contestar de forma "aquiescente" a todos ellos, de tal manera que no elige a los ítems, sino que va contestando a todos ellos. Esta estrategia, también esta contemplada en la elaboración de los ítems correspondiente a la Escala F del MMPI en donde se puede apreciar que el sujeto puede estar "exagerando" la sintomatología.

La segunda estrategia elaborada por los simuladores, y puesta de manifiesto por Lanyon (1970), se encuentra referida por la selección de los ítems que denotan o representan, "a priori" (según el simulador) un determinado trastorno o enfermedad que pretende simular. La diferencia con la estrategia anterior es que, en ésta, el sujeto tiene en cuenta determinados ítems . Un ejemplo característico de esta estrategia es la Escala Ds (Gough, 1954) en la que el autor considera que la escala Ds se encuentra formada por un conjunto de ítems que los sujetos tienden a contestar erróneamente cuando pretenden simular determinados cuadros patológicos.

A continuación vamos a describir algunos de los instrumentos más importantes utilizados para la evaluación de las diferentes formas en las que un perfil pueda aparecer distorsionado.

\section{I.2.3.1. " "M Test" de Beaber, Marston, Michely y Mills (1985).}

Esta técnica diseñada por Beaber, Marston, Michely \& Mills (1985) tiene como objetivo esencial poder evaluar la simulación de un trastorno específico clínico como es la Esquizofrenia. Los 33 ítems de que consta la prueba intentan evaluar la confusión (escala $\mathrm{C}$ ), la esquizofrenia (escala $\mathrm{S}$ ) y la simulación (Escala $\mathrm{M}$ ):

- - Escala de Confusión (Escala C): formada por los 8 primeros ítems de la prueba que no hacen referencia a sintomatología alguna ya que se encuentran 
referidos por pensamientos y actitudes de los pacientes y que tienen como único objetivo evaluar la capacidad de comprensión del sujeto para comprender el significado de las cuestiones planteadas en las demás escalas.

- - Escala de Esquizofrenia (Escala S): siguiendo las directrices del DSM-III$\mathrm{R}$, esta escala recoge en un total de 10 ítems la sintomatología esencial de la Esquizofrenia.

- - Escala de Simulación (Escala M): compuesta por 15 ítems que parecen denotar la presencia de síntomas de esquizofrenia, pero que realmente no se presentan en ningún cuadro clínico de la sintomatología psicótica (alucinaciones atípicas o cuadros demasiado severos).

La prueba se fundamenta en el supuesto de que el simulador no va a lograr distinguir adecuadamente entre la verdadera sintomatología esquizofrénica, en la Escala $\mathrm{S}$, y la sintomatología falseada mostrada en la escala $M$. Los verdaderos esquizofrénicos no van a contestar de forma afirmativa a los ítems planteados en la Escala M. Esta estrategia en la construcción de la prueba, planteada por los autores, presenta cierta similitud con la utilizada en Escala F del MMPI, compuesta por 64 ítems que raramente van a ser contestados, en la dirección puntuable, por personas normales.

En este sentido, el "M Test" se encuentra más próximo a la escala de Disimulación de Gough $(1950,1954)$ que fue elaborada partiendo de ítems que discriminaban adecuadamente entre sujetos normales simuladores de verdaderos pacientes afectos de neuroticismo.

La capacidad discriminativa de la prueba para poder detectar simuladores de verdaderos enfermos es elevada. Los estudios llevados a cabo por Beaber, Marston, Michely \& Mills (1985) mostraron que utilizando solamente las escalas M y C consiguieron detectar correctamente al $78 \%$ de los estudiantes simuladores y al $87 \%$ de los verdaderos pacientes psiquiátricos.

\section{I.2.3.2. " "Inventory of Problems" (IOP) de Viglione \& Landis (1994, 1995)}

Viglione y Landis (1994, 1995) elaboraron una prueba compuesta por 162 ítems , repartidos en 19 escalas y agrupadas éstas en cuatro categorías, como "Symtom Endorsement", "Symptom attributes", "Test Behavior" y "Empirical Scales", y cuyo objetivo es la evaluación, en diversos contextos de la simulación de síntomas psiquiátricos.

La modalidad de respuesta para contestar a los diferentes ítems se encuentra expresada por "verdadero", "falso" y "no parece tener sentido", se corrige en forma computerizada y el tiempo empleado para completarlo es, aproximadamente, entre $45 \mathrm{y}$ 90 minutos. Con el "no parece tener sentido" los autores consideran que esta opción sería sensible a la resistencia de los simuladores a dar respuestas que pueden ser demasiado evidentes.

Existen pocos trabajos de investigación realizados con esta prueba. Los mismos autores llevaron a cabo un estudio (Viglione y Landis, 1995) con una muestra de sujetos simuladores de sintomatología psiquiátrica $(n=49)$ y honestos $(n=89)$, encontrando en sus resultados diferencias estadísticamente significativas entre uno y otro grupo para todas las escalas. Desconocemos otros trabajos que puedan corroborar o no estas conclusiones y la bondad de esta técnica de evaluación de los simuladores. 


\section{I.2.3.3. - "Structured Inventory of Malingered Symptomatology" (S IMS) de S mith (1992, 1998).}

Para elaborar este Cuestionario Estructurado de Sintomatología Fingida (SIMS) los autores (Smith, 1992; Smith \& Burger, 1998) reunieron un total de 75 ítems provenientes de diversas técnicas (MMPI, WAIS, Structured Interview of Reported Symptoms de Rogers, Bagby \& Dickens, 1992), debidamente modificados y estructurados con el objetivo de discriminar respuestas falseadas y organizados a través de cinco escalas de 15 reactivos cada una: Baja inteligencia (LI), Trastorno afectivo (AF), Alteración neurológica (N), Psicosis (P) y Amnesia (AM).

Para validar la prueba llevaron a cabo una investigación (Smith, 1992; Smith \& Burger, 1998) con una muestra de 476 estudiantes, de los cuales a un grupo de ellos se les adiestró para simular trastornos específicos que coincidieran con cada una de las escalas que intentaban evaluarlos. También se les administró las Escalas $\mathrm{F}$ y K del MMPI, la de "Mala Imagen" del 16 PF de Cattell y una parte de la Malingering Scale. El otro grupo de la muestra contestaba honestamente. Se estableció el correspondiente "punto de corte" para cada una de las escalas e incluso para el "total de la escala", intentando con ello detectar adecuadamente a los sujetos simuladores y diferenciarlos de los no simuladores. Los resultados obtenidos con la puntuación total de la escala pudieron clasificar correctamente al $95,6 \%$ de los simuladores y a los $87,9 \%$ de los sujetos no simuladores.

Esta misma escala SIMS ha sido empleada con un grupo de 53 adolescentes (Rogers, Hin \& Sewell, 1995) con algún qué otro problema con la justicia. Los resultados mostraron a la escala AF (trastorno afectivo) como la que mejor discriminaba a los adolescentes honestos de los simuladores.

\section{I.2.3.4. "Malingering Scale" (MSS) de Schretlen (1988-1990).}

Según explica el administrador de la prueba a los sujetos, esta técnica tiene como objetivo evaluar los aspectos relacionados con la inteligencia. A través de sus 90 ítems y durante 20 minutos, los sujetos tienen que elegir, entre las dos posibles respuestas (elección forzada), la que ellos crean que es la correcta. La primera alternativa es correcta el mismo número de veces que la segunda posibilidad, permitiendo de esta forma evitar los efectos relacionados con la aquiescencia y, si acaso se produjese, se podría detectar con una simple inspección visual.

Los ítems tienen diversas procedencia siendo, algunos de ellos, extraídos de pruebas de inteligencia ya clásicas, y otros fueron configurados según la pericia del propio autor

Los ítems de la "Malingering Scale" se encuentran referidos por las cuatro escalas siguientes:

- Vocabulario. Compuesta por 26 ítems de elección forzada entre dos alternativas que intentan apreciar el conocimiento de los significados de las palabras.

- Información. A través de 24 ítems semejantes algunos a la escala de Wechsler (WAIS), pero con un grado de dificultad menor.

- Abstracción. Compuesta por 20 ítems, igualmente, de elección forzada. 
- Aritmética. Los 20 ítems, extraídos de otras diferentes pruebas, son de respuesta semiabierta.

En el estudio realizado por Schretlen, Stacy Schant, Wilfred \& Hoida (1992) con una muestra de internos en Centros Penitenciarios (simuladores adiestrados y sinceros) y pacientes ingresados en unidades de Psiquiatría (verdaderos pacientes) encontraron, que las mayores diferencias fueron las obtenidas por el grupo de simuladores al comparar su puntuaciones con los sujetos honestos, tanto prisioneros como verdaderos pacientes psiquiátricos.

\section{I.2.3.5. "Malingering Probability Scale" (MPS) de Silverton er Gruber, 1998).}

Los autores (Silverton \& Gruber, 1988) han elaborado una prueba compuesta por 140 ítems dicotómicos, a responder "verdadero" o "falso" agrupados en las siguientes cuatro escalas: Depresión (DEP), Trastorno Disociativo (DIS), Estrés postraumático. A través de ellas exponen toda una estrategia para detectar la presencia de los simuladores, semejante a las ya descritas en el "M Test" exponiendo una serie de ítems, obtenidos a través del DSM-III-R, que el verdadero paciente no contestaría.

En el estudio llevado a cabo por Smith (1997) con un grupo de estudiantes, pacientes psiquiátricos y sujetos sometidos a peritación forense a los que también se les administraron la prueba del MMPI, los resultados mostraron que la mayor correlación se daba entre las escalas de Depresión de la Malingering Probability Scale y del MMPI respectivamente $(\mathrm{r}=.77)$, y algo mas baja al correlacionar el Estrés postraumático (PTS) de la Malingering Probability Scale y la Ansiedad (A) del MMPI $(\mathrm{r}=.66)$. La escala de Esquizofrenia (SCH) de la Malingering Probability Scale y la Esquizofrenia del MMPI (Sc) obtuvieron una correlación de 0,56.

\section{I.2.3.6. - "Psychological Screening Inventory" (PS I) de Lanyon (1970, 1974, $1978)$.}

Esta prueba elaborada y desarrollada por Lanyon $(1970,1974,1978)$ se compone de 130 ítems de respuesta dicotómica ("verdadero"-"falso") con el objetivo de evaluar la presencia de psicopatología en pacientes y ambientes clínicos a través de las siguientes 5 escalas:

- Escala de Alienación. Intenta apreciar la similitud entre perfiles de personas normales y de enfermos con patología psiquiátrica.

- Escala de Disconformidad Social (Sr). Lleva a cabo la comparación de perfiles de sujetos normales con sujetos con Trastorno Antisocial de la Personalidad referido pos sujetos encarcelados.

- Escala de Malestar (Di). La escala es muy similar a las escalas de Neuroticismo de otras escalas.

- Escala de Expresión (Ex). La escala es muy similar a la extraversión-introversión de otras pruebas (p.e. los 16 factores de Personalidad de Cattell, 16PF o el Eysenck Personality Questionnaire-Revised, EPQ-R).

- Escala de Defensividad (De). Intenta apreciar la tendencia de los sujetos a presentar una imagen positiva de sí mismo rechazando lo que ellos mismos creen ser negativo de su persona. 
- Escala de Respuestas Aleatoria (Ra). Con esta escala se pretende detectar las respuestas al azar, la falta de atención o motivación al contestar.

Posteriormente (Lanyon, 1970) introduce dos tipos de estrategias que, a su juicio, subyacen en la conducta de los simuladores. Una de ellas es la "Exageración generalizada de síntomas" (SOE) en la que se intentaría apreciar la conducta del simulador intentando exagerar su sintomatología. La otra sería la "Escala de Estereotipo Psiquiátrico Erróneo" (EPS) a través de la simulación selectiva de determinados ítems $\mathrm{y}$ en la que se pretende identificar personas sin patología que pretendan pasar como enfermos con trastornos mentales.

\section{I.2.3.7.- Cuestionario de reacciones personales (D.S.) de Avila y Tomé (1989)}

Esta es la Escala de Deseabilidad Social de Crowne y Marlowe (1960) adaptada al castellano por Avila y Tomé (1989) y denominada como "Cuestionario de reacciones personales" por los adaptadores para evitar la reactividad del sujeto al detectar su nombre original. Su objetivo es evaluar la deseabilidad social de los individuos sin implicaciones psicopatológicas por medio de la autoatribución de comportamientos y rasgos socialmente deseables y la negación de comportamientos y aspectos indeseables de sí mismo.

Compuesta por 33 ítems a contestar dicotómicamente con "Verdadero" (V) o "Falso" (F). Los estudios realizados con población española logran alcanzar un índice de fiabilidad de Cronbach de 0,8 y la distribución de las puntuaciones obtenidas se ajustaron a la curva normal.

\section{I.2.4. - Las áreas de estudio.}

No pretendemos exponer de forma exhaustiva un elenco de las diversas investigaciones que se han realizado estudiando la simulación en las diferentes áreas de la psicología, ya que entendemos que éste es un elemento colateral que no se centra en el objetivo de nuestra investigación. Simplemente queremos exponer, dejar constancia que la deteccion de los perfiles distorsionados se han contemplado en otras áreas y con diferentes pruebas de evaluación.

\section{I.2.4.1. La evaluación de la inteligencia y de las capacidades cognitivas.}

Hunt y Older (1943) fueron pioneros en describir un tipo de estrategia para la detección de la simulación a través de los tests de inteligencia. Su estrategia se fundamentaba en el supuesto de que los simuladores no se encuentran debidamente familiarizados con el síndrome del trastorno mental que tratan de aparentar, aunque sí de algunos de los síntomas. Estos autores compararon las puntuaciones de 45 reclutas considerados como "normales", que debían de contestar a un test de inteligencia simulando retraso mental, y por otra parte otros 45 que presentaban un retraso mental verdadero. Los resultados mostraron que los sujetos retrasados contestaban correctamente en mayor proporción a los ítems fáciles, de una prueba de inteligencia, que los sujetos simuladores. Justamente resultaba lo contrario cuando se analizaban los resultados de los ítems difíciles, había mayor proporción de simuladores que contestaban correctamente estos ítems . 
En la misma dirección los investigadores Warschspress, Berenberg \& Jacobson (1953) llegaron a igual conclusión, afirmando que los reclutas simuladores distorsionaban su puntuación en Cociente Intelectual al contestar de forma extremadamente errónea preguntas de respuesta fácil para cualquier sujeto. Schretlen (1988) comenta que los resultados más prometedores sobre detección de simulación en tests de inteligencia se obtienen cuando el análisis se centra en los aspectos cualitativos del WAIS. Por ello, el autor cita los trabajos de Warschspress, Berenberg \& Jacobson (1953) en donde se señalan algunas de las características de los simuladores: responder a los ítems grotescamente absurdos (p.e. "la nieve siempre cae en verano"), a los ítems cuya respuesta correcta es aproximada (p.e. $5+2=8$ ) y ofrecer una marcada incoherencia en toda la prueba.

El procedimiento empleado por Hunt y Older (1943) se basa en seleccionar, según grado de dificultad, un determinado conjunto de ítems que discriminen simuladores y no simuladores. Estos ítems seleccionados suelen estar distribuidos a lo largo de la prueba para dificultar su detección por parte del sujeto. De esta manera se forma un conjunto de ítems que, de forma habitual son contestados correctamente por los sujetos con verdadero déficit, pero erróneamente por aquellos sujetos que han sido adiestrados para efectuar la simulación.

Por ello, las pruebas como WAIS que disponen de "orden de dificultad creciente" no parece discriminar adecuadamente. Esto lo describe Schretlen (1988) al comentar el diseño del WAIS-R (Wechsler, 1987) por su dificultad creciente de las pruebas y por disponer de muy pocos ítems que pueden considerarse como fáciles de resolver para un sujeto con déficit intelectual. Por ello la capacidad de esta prueba para discriminar entre sujetos simuladores y aquellos que presentan realmente un verdadero déficit intelectual, se ve seriamente mermada.

Basándose en las características anotadas por Warschspress, Berenberg \& Jacobson (1953), especificadas en líneas anteriores, Basch y Alper (1980) llevaron a cabo una investigación para operacionalizar y cuantificar los aspectos cualitativos del WAIS desarrollando un sistema de categorización de respuestas a varios de los subtest (Aritmética, Dígitos, Cubos, Información, Figuras incompletas y Rompecabezas) asignando un punto por cada respuesta aproximada. El estudio se realizó con tres grupos: pacientes psiquiátricos sin síntomas psicóticos; pacientes psiquiátricos con sospecha de simular una esquizofrenia y pacientes verdaderamente esquizofrénicos. Los resultados mostraron que los pacientes sospechosos de simular una esquizofrenia ofrecían un mayor número de respuestas aproximadas (ofrecían mayor puntuación) que los componentes de los otros grupos experimentales.

Si hacemos un resumen sobre la capacidad discriminativa de las pruebas de inteligencia (especialmente el WAIS) para detectar el fingimiento podemos decir lo siguiente:

$1^{\circ}$.- No resulta adecuado exponer los ítems en orden de dificultad.

$2^{\circ}$.- El análisis cualitativo de los ítems puede aportar alguna significación.

$3^{\circ}$.- El WAIS-R no se muestra como herramienta útil para discriminar simuladores de lesión cerebral de los verdaderos pacientes.

$4^{\mathrm{o}}$.- En los ítems considerados con un índice bajo de dificultad, los sujetos simuladores ofrecen peores resultados que los sujetos realmente retrasados mentales. 
El test Guestáltico Visomotor de la psiquiatra Lauretta Bender (1938) goza del prestigio de ser una de las técnicas más eficientes en los diversos campos de la evaluación clínica. Larson (1932) contemporáneo de Lauretta Bender pudo apreciar la capacidad discriminatoria de esta técnica para detectar simuladores. Para llevar a cabo este estudio tomó a un grupo de profesionales de la salud (médicos) para que simularan deficiencia mental y otro grupo, experimental, referido por prisioneros que estaban siendo juzgados por diversos delitos y que parecían simular una psicosis de la cual, si obtenían éxito, podrían obtener un beneficio (atenuar o eximir la pena). Los resultados obtenidos mostraron que ambos grupos mostraban los dibujos distorsionados pero cada cual los hacía de forma distinta, tendiendo a disminuir (disminución de la figura) el tamaño medio de los elementos y a simplificarlos (simplificación de la figura), pero ninguno mostró características propias de las figuras que significasen algún tipo de trastornos, ya sean orgánicos o funcionales.

Cuando se ha tratado de evidenciar falsos recuerdos, o fallos en la memoria, una de las escalas principales que se ha utilizado ha sido la "Escala de Memoria de Wechsler (WMS)", desarrollada por el propio Wechsler, en 1943, y revisada en 1987 (WMS-R). Los estudios realizados por Bernard (1990) y por Bernard, Houston \& Natoli (1993) con este instrumento para discriminar sujetos simuladores de sinceros, con un diseño experimental de "control parcial", llegaron a conclusiones algo diferentes en sus dos experimentos ya que, en el primero de ellos (1990) pudo clasificar correctamente al $74 \%$ de la muestra y en el segundo (1993) al 88\%. El hecho de que en 12 de los 13 subtests que conforman el WMS-R se observen diferencias significativas entre las medias del grupo control y el grupo de simuladores, es un indicador de que la polarización de las puntuaciones es excesiva.

La prueba de Reconocimientos de dígitos de Portland (Portland Digit Recognition Test), compuesta por 30 ítems dicotomizados, cuyo objetivo principal es evaluar la memoria de reconocimiento, se ha manifestado como una prueba discriminativa para la detección de los simuladores. Binder (1993), administrando esta prueba a dos grupos de pacientes que solicitaban una compensación económica por déficits de memoria $\mathrm{y}$ disfunciones cerebrales y a otro grupo que no solicitaban ningún tipo de indemnización, puedo apreciar que el primer grupo de pacientes obtuvo puntuaciones significativamente menores a las obtenidas por los sujetos que no solicitaban indemnización alguna. Prácticamente, a los mismos resultados llegaron Rose, Hall y Allen (1995) con su investigación utilizando diferentes grupos como muestras: 30 estudiantes entrenados para simular como verdaderos pacientes; 30 sujetos no entrenados pero aparentando; 30 pacientes con verdaderos déficits de memoria y 30 sujetos totalmente sanos que contestaron honestamente.

También desde la evaluación de la memoria se elaboró la "Prueba de Dígitos Recurrentes" (HRD) de Hebb`s desarrollada por Lezak (1983). La prueba está compuesta por 24 series de números que recuerda en su estructura a los subtests de las pruebas de Wechsler (WAIS, Escala de Memoria de Wechsler -WMS) pero con la diferencia de que cada tres secuencias se repite una ya presentada con anterioridad.

Los trabajos realizados por Milner (1970) denotan una importante contribución a las implicaciones neuropsicológicas de esta prueba. Pudo mostrar cómo sujetos sanos que contestan a la prueba de forma honesta, tienden a ir aumentando su tasa de aprendizaje hasta niveles más altos que los pacientes con lesión temporal izquierda que 
manifestaban dificultades de aprendizaje (sobre todo cuando la lesión también afectaba al hipocampo).

El estudio de Bernard, Houston \& Natoli (1993), intentó apreciar los indicadores de simulación en tests neuropsicológicos, utilizó a dos grupos de sujetos para su investigación a los que administró la Prueba de Dígitos Recurrentes (HRD). El grupo control estaba formado por sujetos sin ningún tipo de lesión cerebral que debían de seguir honestamente las indicaciones del examinador. El grupo experimental se encontraba formado por sujetos adiestrados para simular. Los resultados apuntaron que no existían diferencias estadísticamente significativas entre ambos grupos cuando se trataba de recordar la amplitud de toda la secuencia pero sí existían diferencias estadísticas cuando se comparaban las ejecuciones en aquellas series en las que aparece una secuencia recurrente (aquella en la que se repite una secuencia de números), mostrando a los sujetos simuladores con resultados significativamente más bajos que los sujetos control.

\section{I.2.4.2. - La evaluación del daño cerebral.}

Psicólogos y neurólogos son requeridos en numerosas ocasiones para verificar la existencia o no de una lesión cerebral. A diferencia del experto en Psiquiatría y psicopatología, el neuropsicólogo, además de las técnicas psicológicas de evaluación puede disponer de otro tipo de técnicas denominadas de "neuroimagen" (electroencefalogramas, tomografías computerizadas, angiografías, etc.) que de una forma, algunas veces más objetiva, puede apreciar el daño cerebral producido.

El neuropsicólogo también cuenta con importantes pruebas neuropsicológicas que, a veces, pueden detectar antes, e incluso con mayor precisión, algunos trastornos incipientes que a través de las técnicas de neuroimagen no llegan a apreciarse más que cuando se encuentra en un estado avanzado. Algunas de las técnicas más utilizadas son el Test de Luria y la batería de Hasltead-Reitan.

El test de Luria, publicado por vez primera por Christensen (1975) está basado en los trabajos realizados por el equipo de Alexander Luria en la Unión Soviética relacionando la actividad cerebral con los comportamientos de conducta. Sin embargo, la batería de Hasltead-Reitan se fundamenta más en la denominada por los autores como "inteligencia biológica".

Heaton, Smith, Lehman \& Vogt (1978) realizaron una investigación sobre la evaluación de la simulación a través de la Batería de Hasltead-Reitan. Para llevar a cabo este estudio seleccionaron a un grupo de 16 sujetos, simuladores de lesión cerebral, y a otro grupo de sujetos que padecía realmente diversas lesiones cerebrales. A todos ellos se les solicitó que realizasen las tareas indicadas en la prueba. Los resultados mostraron que, sobre las 37 medidas neuropsicológicas que tomaron de cada uno de los grupos, 30 eran capaces de clasificar correctamente al $100 \%$ de la muestra. Estos resultados fueron criticados por Goebel (1983) considerando que las conclusiones obtenidas por Heaton, Smith, Lehman \& Vogt (1978) difícilmente podrían ser aplicadas en la clínica ya que el diseño no fue el adecuado (faltaba el grupo control) y por incluir en el análisis discriminante un número mayor de variables que el total de sujetos que formaban los grupos (37 variables vs. 32 sujetos).

Goebel (1983) llevó a cabo una investigación sobre la capacidad discriminativa de las Escalas Manipulativas del WAIS-R a través de un grupo de sujetos considerados 
como "normales" para que simulasen algún tipo de lesión cerebral. Los resultados fueron comparados con otro grupo de sujetos que efectivamente mostraban diversos tipos de lesiones cerebrales, dando como resultado la existencia de diferencias ligeramente significativas de ejecución entre ambos grupos de sujetos pero no con la suficiente claridad y convencimiento como para poder generalizar los resultados a la clínica aplicada.

A semejantes resultados había llegado ya Heaton (1978) acerca de la capacidad discriminativa del WAIS en la evaluación de la simulación con sujetos simuladores de lesión cerebral.

Berry y Butcher (1998), utilizando el MMPI-2 llevaron a cabo un gran trabajo con aquellas personas que intentaban fingir, prolongar, algún tipo de daño cerebral para poder conseguir alguna indemnización o beneficio a través de los litigios con las empresas planteados ante la justicia. Más adelante exponemos un resumen de la literatura científica acerca del fingimiento de estas personas y la diferente sensibilidad de las escalas.

\section{I.2.4.3.- La evaluación de la personalidad.}

Quizás el recurso más fácil para el simulador, y posiblemente el más común, sea adoptar alguna característica de la personalidad distinta a las que posee. La posibilidad de atribuirse la sintomatología propia de la locura (la que el sujeto considera como tal), hacerse pasar por enfermo o presentarse con algún trastorno de personalidad, nos lleva a analizar con más detenimiento este tipo de simulación.

Intentando hacer una clara presentación de nuestro trabajo, vamos a ver en primer lugar las técnicas de tipo proyectivo y posteriormente nos centraremos en las técnicas psicométricas donde podremos apreciar otras pruebas de evaluación de la personalidad que presentan alguna forma de control de la validez o fiabilidad de un perfil. Esto nos servirá para enlazar con la técnica fundamental de nuestra investigación, el MMPI.

\section{I.2.4.3.1.- Con las técnicas proyectivas.}

No pretendemos hacer una presentación exhaustiva de las investigaciones que se han realizado con las técnicas proyectivas para evaluar la simulación y los diversos tipos de simuladores. Nos interesa, simplemente, exponer los matices esenciales de estas técnicas y poder apreciar la evaluación de la simulación a través de la técnica esencial, y más utilizada por los clínicos, como es el test de Rorschach.

Si atendemos al término de proyección, podemos decir, en su concepto más esencial, y literal, que es la expresión de algo interior y propio que se muestra al exterior, de tal manera que si no existe esa imagen en el interior de la persona difícilmente se podrá expresar. En el supuesto caso que la película "ET" de Spielberg nunca se hubiera filmado, ningún niño podría ver "la mano de ET" en el test de Rorschach (detalle de la parte superior, en posición normal, de la lámina IX), ni nadie podría contar una historia acerca de este simpático personaje (técnicas temáticas) simplemente, porque no existió nunca y, por consiguiente, ahora tampoco existiría en la mente del niño.

Todos sabemos que el mismo concepto de proyección tiene también una carga psicoanalítica y desde este punto de vista las cosas que se dicen (historias, imágenes, personajes) no aparecen "por casualidad" o "al azar", sino que si se dice es porque 
existe previamente en la mente del sujeto. El mismo Hermann Rorschach, al enseñarle sus manchas de tinta a sus propios pacientes, pudo darse cuenta que lo que ellos decían tenía que ver con su propia enfermedad mental. El depresivo no "veía" lo mismo que el esquizofrénico, ni que el paranoico, cada uno respondía según el trastorno que padecía.

En un principio (Forsberg, 1941) se pensó que la técnica del Rorschach no podría ser falseada, después de llevar a cabo un estudio comparando las respuestas de un grupo de personas que eran sometidas al test en cuatro ocasiones distintas, una de las cuales la persona tenía que simular las interpretaciones. No se encontraron diferencias estadísticamente significativas entre las puntuaciones dadas por estas personas. Posteriormente otros investigadores (Kahn, Fox, \& Rhode, 1988; Bash \& Alpert, 1980; Schretlen, 1986) han podido determinar que la técnica del Rorschach puede llegar a ser falseada.

Los primeros estudios sobre la falsificación del test de Rorschach fueron llevados a cabo por Carp y Shavzin (1950) al analizar a una muestra de 20 personas, sin evidencia de patología, para que respondiesen a cada una de las láminas de dos formas diferentes: ofreciendo una buena imagen de sí mismo, y otra, ofreciendo mala imagen. Los resultados mostraron que los sujetos al intentar ofrecer una mala imagen presentaban siempre los mismos elementos: escaso número de respuestas, respuestas menos elaboradas y los contenidos más comunes eran referidos por interpretaciones sexuales y agresivas. Esto no sucedió cuando intentaron ofrecer la buena imagen de sí mismos.

Albert, Fox y Kahn (1980) administraron el Rorschach a distintos grupos de sujetos. Un primer grupo estaba compuesto por esquizofrénicos; otro por estudiantes que simulaban una esquizofrenia paranoide, de los cuales a la mitad de ellos se les instruyó de cómo tenían que simular los verdaderos síntomas paranoides, y otro grupo de estudiantes normales. Los protocolos fueron enviados a diferentes jueces, expertos en Rorschach. Los resultados demuestran que estos jueces no supieron discriminar qué protocolos pertenecían a los verdaderos paranoicos, a los esquizofrénicos y diferenciarlos de los normales. Un $72 \%$ del total de los estudiantes que simulaban una esquizofrenia paranoide, y habían sido informados previamente de la sintomatología, fueron clasificados como verdaderos esquizofrénicos, mientras que los verdaderos psicóticos solamente fueron clasificados como tales en un $42 \%$.

En el trabajo de investigación llevado a cabo por Frueh y Kinder (1994) sobre la posibilidad de detectar la simulación de Estrés Postraumático a través del test de Rorschach, se hicieron tres grupos: el primero, formado por 40 sujetos normales asignados aleatoriamente a dos subgrupos de 20 sujetos. A uno de estos subgrupos se les instruyó para simular el trastorno por Estrés Postraumático; al otro se les administró la prueba en formato estándar. El tercer grupo formado por 20 sujetos eran veteranos de guerra que habían participado en la contienda del Vietnam. Los resultados mostraron que los sujetos que simulaban estrés postraumático obtenían, en algunas variables del Test de Rorschach, puntuaciones equivalentes a los sujetos con verdadero estrés postraumático, pero analizando las interpretaciones desde un punto de vista cualitativo, se pudo apreciar que el grupo de sujetos adiestrados para simular presentaba unas respuestas de duro contenido emocional en las que se ponía de manifiesto la mayor gravedad del trastorno. Los resultados, globalmente considerados son coincidentes con los de Carp y Shavzin (1950) en cuanto a la elaboración y número de las respuestas. 
En la investigación realizada por Netter y Viglione (1994) intentando descubrir a los simuladores de esquizofrenia a través del Rorschach, analizaron los protocolos de 40 sujetos normales dividiendo la muestra en dos grupos: 20 contestaban de forma honesta y otros 20 simulaban esquizofrenia. Los resultados mostraron la posibilidad de poder simular la enfermedad mental, ya que los mismos simuladores podían ser capaces de engañar al evaluador.

Ante este cúmulo de investigaciones presentadas, hemos de tener cierta cautela ya que aún se sigue investigando con esta técnica en diversos campos, sobre todo el equipo de Exner (1994) que continuamente nos muestra los últimos avances en sus investigaciones.

\section{I.2.4.3.2.- Con las técnicas psicométricas.}

Posiblemente una de las ventajas que poseen las técnicas de tipo proyectivas sobre las de tipo psicométrico referente a la evaluación de la simulación, es que en aquellas el sujeto no sabe muy bien qué es lo que implica, desde el punto de vista de la evaluación psicológica, su respuesta, mientras que en los cuestionarios de tipo psicométrico puede conocer, bajo su óptica particular, las posibles repercusiones de su forma de contestar a los ítems formulados. Por ello los autores que han elaborado este tipo de técnicas han tenido un especial cuidado en la incorporación de variables de control que denoten la posibilidad de falsificación o de simulación de la prueba. La mayor parte de los cuestionarios multifactoriales de evaluación de la personalidad proporcionan alguna medida de evaluación del fingimiento.

Los ítems omitidos, que no fueron contestados, o que se contestaron al mismo tiempo como "verdadero" y "falso" (caso del MMPI: "?") no presentan una referencia específica en la mayor parte de los cuestionarios si exceptuamos el M.M.P.I.-2, MCMIII/III y el P.A.I. (Personality Assessment Inventory). Para Morey (1991) el perfil del P.A.I. no debería interpretarse si llegan a omitirse más de 17 ítems, mientras que para el MCMI-II/III se recomienda que las dobles marcas y/o ítems omitidos no superene el mínimo de 11. Podemos afirmar, de forma general que un gran número de ítems omitidos pueden afectar a la validez de un perfil. Sin embargo, ni el CPI-R (California Personality Inventory-Revised), ni el 16 PF (Sixteen Personality Factor Questionnaire) explican qué, o cuántos, ítems omitidos o no contestados deberían revisarse $\mathrm{o}$ proporcionan un criterio indicativo de que la validez del cuestionario esté afectada de forma negativa. El clínico debería revisar la hoja de respuesta de algunos de los cuestionarios de personalidad para poder apreciar qué y cuántos ítems dejan sin contestarse. En la mayoría de los casos, simplemente con solicitar a la persona que revise esos ítems y marque la respuesta más adecuada (incluso ante la duda), sería suficiente para solucionar este problema.

La consistencia o coherencia de las respuestas también es evaluada por algunos cuestionarios de personalidad. Estas escalas son, generalmente, similares a las escalas de Infrecuencia (F del MMPI-2) en que están formadas de ítems con baja frecuencia de respuestas para personas consideradas como normales. 


\section{I.2.4.3.2.1. - Millon Multiaxial Clinical Inventory (M.C.M.I.):}

Para el MCMI (Millon Clinical Multiaxial Inventory) en sus distintas versiones I, II y III, el Indice de Validez (Escala $V$ ) es la más sencilla de las distorsiones a evaluar ya que se requiere solamente la identificación de las tendencias extremas de respuesta, aquellas que suponen bien una notable confusión mental o un comportamiento negativista extremo. Debido a la disposición del formato de respuesta del MCMI-II no es probable que el sujeto pierda erróneamente una línea o efectúe una doble marca. Sin embargo los problemas de incomprensión o de respuesta al azar ocurren si los pacientes se encuentran desorientados sobre lo que expresan los ítems o tienen un determinado deseo de tratar de mostrarse sí mismos como consecuencia de los resultados que pueda ofrecer el test. Para identificar a tales pacientes fueron incluidos ítems de contenido inverosímil, aunque no absurdos, comprensibles, en una escala de "respuesta al azar" del MCMI-I. La continua investigación ha reducido la escala a sólo cuatro ítems . Estos cuatro ítems ya incluidos en el MCMI-I constituyen el Indice de Validez. Una investigación de los resultados sobre respuesta al Rta. Inc. indica que cerca del $100 \%$ de los sujetos que puntuaron al azar al contestar el MCMI-I fueron correctamente detectados por este índice. (Avila y Jiménez, 1998)

- El Índice de Sinceridad (Escala X) para el MCMI, es el indicador de Nivel de Sinceridad diseñado para poder apreciar hasta qué punto los pacientes se encuentran inclinados a ser francos y sinceros (auto-revelarse). Al contrario que con las medidas de "Deseabilidad" y "Alteración", que son descritas brevemente como el esfuerzo de los pacientes para presentar cualquier rasgo psicológico como "bueno" o "malo", la Escala de "Sinceridad" pretende ser neutral con respecto a la simulación psicopatológica. El foco se centra en la sinceridad y franqueza, reflejando en un extremo, una tendencia a no ser reservado, y expresarse libremente, y en el otro extremo, a ser reticente, ambiguo o reservado. (Ávila y Jiménez, 1998)

- El Índice de Deseabilidad (Escala Y) del MCMI, este indicador de "Deseabilidad" comprende una combinación de factores tales como: hacer lo posible por causar una buena impresión, aparecer mentalmente saludable y socialmente virtuoso, negando ser poco atractivo, con alguna problemática peculiar, o cosas semejantes.

- El Índice de Alteración (Escala Z), al igual que la Deseabilidad, el indicador de Alteración, está formado por una combinación de elementos que contribuyen, por parte de algunos pacientes, a la tendencia a degradarse o denigrarse a sí mismos, a acentuar su angustia psicológica y a exhibir su vulnerabilidad emocional. (Ávila y Jiménez, 1998). Esta escala fue diseñada para evaluar fingimiento y es esencialmente la misma en las tres versiones del MCMI. Bagby, Gillis, Toner, \& Goldberg (1991) informaron que esta escala era efectiva identificando estudiantes instruidos para fingir en el MCMI-II. Wierzbicki \& Daleiden (1993), Wierzbicki \& Howard (1992), han analizado la efectividad de las escalas Obvio y Sutil del MCMI para evaluar el fingimiento en estudiantes y prisioneros varones, encontrando que pueden ser útiles para identificar los protocolos fingidos.

\section{I.2.4.3.2.2. - Personality Assessment Inventory (P.A.I.)}

La Escala de Impresión Negativa (NIM; Morey, 1991) del PAI (Personality Assessment Inventory) se utiliza para evaluar fingimiento. La NIM, una escala de infrecuencia, está compuesta por 9 ítems con un contenido altamente improbable, 
atípico, psicótico, disfórico y orgánico. Una elevación moderada en NIM (73T - 91T) sugiere algún grado de exageración de quejas de problemas, mientras que una puntuación $>91 \mathrm{~T}$ en NIM indica que la persona está fingiendo y que el test debería ser considerado como no válido. Morey (1993) también ha elaborado otros índices que pueden utilizarse para identificar fingimiento en el PAI.

Rogers, Ornduff, \& Sewell (1993) encontraron que NIM podía identificar estudiantes que fueron fingidores de esquizofrenia, pero tenían más dificultades identificando estudiantes que fingían decepción y ansiedad generalizada.

La Escala de Impresión Positiva (PIM; Morey, 1991) está compuesta por 9 ítems , diseñada para evaluar a las personas que se presentan a sí mismas relativamente libres de pequellos fallos (puntuaciones moderadas 57T - 67T), o aquellas que niegan exageradamente las faltas más comunes (puntuaciones superioes a 67T).

Cashel, Rogers y Sewell (1995) encontraron que PIM tiene una función discriminante relativamente efectiva.

\subsection{3. - Cuestionario Factorial de Personalidad, 16PF.}

El Cuestionario Factorial de personalidad del Dr. Raymond B. Cattell comprende 16 factores de primer orden para identificar los rasgos esenciales de personalidad del individuo llevándose a cabo mediante un análisis factorial de distintas variables que intentan describir la conducta humana.

La nueva forma 5 (16 PF-5) es una adaptación y revisión de las mismas 16 escalas primarias de personalidad identificadas por Cattell hace casi 50 años. Existen cambios de denominaciones (los antiguos factores denominados de "segundo orden" ahora se identifican como "dimensiones globales") (Russell y Karol, 1995) aunque siguen sustentándose en una estructura factorial similar. Uno de los aportes interesantes que presenta este 16PF-5 ha sido el diseño de nuevos índices para evaluar los diferentes sesgos que pueden ofrecer los sujetos a la hora de responder. Son los denominados "estilos de respuestas: "Manipulación de la Imagen" (MI), "Índice de Infrecuencia" (IN) y “Aquiescencia" (AQ).

La Manipulación de la Imagen (MI) viene a sustituir a las escalas de "distorsión" o "buena/mala imagen" de las ediciones anteriores y cuyo contenido intenta apreciar las conductas, sentimientos y actitudes de tipo más o menos socialmente deseable. Esta manipulación de la imagen ("impression Management") alude a la manipulación que el sujeto pueda hacer de su imagen tanto de forma consciente e intencionada como inconsciente o no deliberada. Esta escala se compone de 12 elementos cuyos valores más altos están indicando una mayor tendencia a responder de una forma socialmente deseable, mientras que un valor bajo de esta escalas nos sugiere atribuirse de aspectos socialmente menos deseables o una exageración de estas cualidades.

La Escala de Infrecuencia (IN) en el 16 PF se encuentra referida por las respuestas sin contestar (ítems omitidos o interrogantes para otros cuestionarios) compuesta por un total de 38 elementos (alternativa B), siendo una puntuación elevada indicativa de diferentes motivaciones que el evaluador debe apreciar adecuadamente teniendo en cuenta variables contextuales, de contenido de los ítems y personales del sujeto.

La Escala de Aquiescencia (AQ) en el 16 PF-5 nos muestra la tendencia del sujeto a responder "SI", o "Verdadero" a los ítems , independientemente del contenido de los 
mismos. Integrada por la totalidad de los 95 elementos que el 16 PF-5 tiene para responder "verdadero", su alto porcentaje y su utilidad vendría dada por el descubrimiento de la incoherencia o inconsistencia en las contestaciones del sujeto. Este tipo de respuestas podría reflejar también una mala imagen de sí mismo, incomprensión de los contenidos de los ítems, distracción, falta de motivación, respuestas dadas al azar o dificultad para evaluarse o describirse.

I.2.4.3.2.4.- Inventario Psicológico de California (C.P.I.).

La relación del MMPI con el CPI es claramente evidente. En la versión actual de 462 ítems , 194 proceden del Minnesota Multiphasic Personality Inventory (MMPI, Hathaway \&Mckinley, 1940) y el Indice de Gough (F-K) es utilizado también por el MMPI-2 en su interpretación de la validez de un protocolo. En la edición de 1957 (Gough, 1957), el Inventario Psicológico de California (C.P.I.) estaba compuesto por 480 ítems, y se pasó de las 15 escalas de la versión de 1951 a las 18 en la versión de 1957 con la elaboración de "Presencia Social", "Autoaceptación" y "Autocontrol". En la versión actual (1987) nos encontramos con 20 escalas ya que se han añadido las nuevas escalas denominadas "Potencial directivo" y "Orientación Laboral".

La escala de "Buena Impresión"(GI) del CPI fue elaborada siguiendo la estrategia de Ruch (1942) pasándose la prueba a un grupo de personas consideradas como normales para repetírselas, posteriormente, a los mismos sujetos pero con la intención de ofrecer una imagen favorable de sí mismos ya que se trataba de conseguir un puesto de trabajo, o bien de crear en el jefe una imagen como personas admirables. El trabajo se centró en un conjunto de ítems experimentales que fueron identificados previamente por Ruch como los mejores y que, basándose en su intuición y experiencia, podrían valorar lo que las personas intentan presentar para crear una impresión favorable de sí misma.

La escala "Sentirse bien"(Well-Being; Wb) del CPI-R (Revisado), está constituida por 38 ítems que enfatizan los aspectos mentales positivos de la salud del sujeto y de un "sentirse bien". Esta escala puede ofrecernos información sobre el fingimiento. Es virtualmente idéntica a la escala Revisada de Disimulación de Gough (Ds-r; Gough, 1957). Las respuestas desviadas en esta escala se interpretan de diversa forma: las puntuaciones bajas reflejan fingimiento y las elevadas reflejan una descripción de bienestar. Poca investigación existe sobre la validez de $\mathrm{Wb}$ como índice de fingimiento (Megargeee, 1972).

El CPI (California Personality Inventory) tiene una escala de infrecuencia que fue elaborada por los ítems que fueron contestados por no más del $5 \%$ de la muestra normativa. Mientras que altas puntuaciones en el CPI fueron designadas para evaluar rasgos positivos, la respuesta desviada fue invertida para cada ítem y la escala fue renombrada como escala de "Comunalidad" $(\mathrm{Cm})$. Las puntuaciones $\mathrm{T} \leq 29$ (en varones) y $\mathrm{T} \leq 24$ (en mujeres) en la $\mathrm{Cm}$, generalmente son vistos en las respuestas aleatorias, pero también se pueden observar en el fingimiento.

La "Comunalidad en lo personal" $(\mathrm{Cm})$ se basa en la misma estrategia que utilizaron Hathaway y Mckinley para la Escala F del MMPI. Esta escala viene constituida por un conjunto de ítems a los cuales la mayoría de las personas responde como "verdadero", y se añadió además otro conjunto de ítems, a los cuales en la mayoría de las ocasiones se responde como "verdadero" a la opción negativa; es decir, además de los verdaderos se añadieron otros a los que debe contestar como "falso". Las altas puntuaciones de Cm 
sugieren que la persona evaluada ha reaccionado ante el cuestionario de una manera típica, normal, mientras que las bajas puntuaciones nos pueden estar indicando una forma atípica de responder.

Estas tres escalas (Wb, Gi y $\mathrm{Cm}$ ) del Inventario Psicológico de California (CPI) tienen importantes implicaciones interpretativas cuando se trata de descubrir protocolos invalidados. En la primera edición del CPI fueron propuestas tres ecuaciones para detectar las falsificaciones positivas y los protocolos respondidos al azar presentadas en la Guía para la interpretación del CPI de McAllister (1986).

Como hemos podido comprobar, en esta breve exposición de las principales variables contenidas en los Cuestionarios de personalidad para detectar la fiabilidad y validez de los datos expresados, las técnicas elaboradas mediante una estrategia psicométrica, presentan formas y variables muy semejantes para detectar un protocolo invalidado.

\section{I.2.5. - Modelos explicativos de la simulación:}

Los estudios realizados por uno de los principales investigadores sobre la temática de la simulación, Rogers $(1990,1996,1997)$ sugieren tres modelos explicativos de la conducta simuladora que subyacen en las diversas motivaciones personales: desde la patología, desde el contexto criminalizador o desde el modelo adaptacional.

1.- El modelo patogénico: Este modelo considera que el simulador es, ciertamente, un enfermo. La simulación permite al sujeto percibir un cierto control sobre una sintomatología emergente con objeto de desarrollarla y mantenerla. De alguna manera se identifica con la "necesidad de estar enfermo" que habíamos comentado con los Trastornos Facticios.

2.- El modelo criminalizador: Más acorde con los ambientes médico-legales y los criterios expresados en el DSM-IV (APA, 1994), parece que este modelo de simulación se configura como un cuadro en el que la persona con un Trastorno Antisocial de la Personalidad, en situación de evaluación pericial o forense, decide no colaborar con el evaluador y fingirse enfermo, denotándose comportamientos, actitudes e incoherencias psicopatológicas evidentes para un experto. El modelo propuesto por la American Psychiatric Association (APA, DSM) acerca de la simulación o fingimiento fue criticado por Rogers (1990) como excesivamente moralista unida a un temor de "maldad" y no apoyada por la investigación. Este modelo no parece clarificar muchos de los aspectos del falsificador que son interesantes descubrir para el evaluador.

3.- El modelo adaptacional: Este modelo explica la simulación como una decisión que toma el sujeto ante la amenaza de ruina de sus intereses y/o de la posibilidad de obtener un beneficio. Así, aquellas personas evaluadas en un contexto que, a priori, se percibe como adverso (carcelario, judicial, policial, etc.) simularán, en mayor medida que aquellas otras personas evaluadas en ámbitos que se pueden percibir como menos amenazantes (consulta clínica, centros de orientación, educativos, etc.). Este modelo es el que, con carácter menos peyorativo explica la simulación. Dicho modelo "adaptacional" de Rogers (1990), asume que el sujeto percibe la evaluación como un reto en que el mismo sujeto tiene algo que ganar o perder dependiendo de los resultados de la evaluación. El fingimiento o simulación se convierte en una conducta de refuerzo y que puede resultar potencialmente útil. En este contexto, Berry y Butcher (1998), 
comentan cómo los pacientes lesionados cerebrales que se han visto involucrados en un accidente y experimentan pasajeras secuelas físicas o emocionales, pueden sentir como "de justicia", y quizás también por "venganza", perseguir la compensación para su sufrimiento y que las personas $\mathrm{u}$ organizaciones (empresas) sean percibidas como "maltratadores" o culpables. Desde esta perspectiva del modelo adaptacional, las quejas post-traumáticas pueden ser mantenidas como auténticos refuerzos. Es el caso de un litigio prolongado con una leve lesión cerebral en donde la posibilidad de una compensación económica se convierte en un poderoso refuerzo para sus quejas físicas.

Más recientemente se ha propuesto otro modelo, no diferente al adaptacional, que acentúa el rol de los factores psicosociales en el desarrollo y mantenimiento de quejas crónicas en una lesión cerebral. Putnam \& Millis (1994) se dieron cuenta que las quejas físicas eran comunes en la lesión cerebral y que la etiología fundamental de estos síntomas pueden encubrir una combinación de factores neuropsicológicos, sociales y psíquicos. La mayor parte de los pacientes informaron de tales problemas sólo pasajeramente, pero una pequeña minoría continuaba quejándose de ellos durante meses $\mathrm{y}$, a veces, años. La determinación de la intencionalidad o inconsciencia de las quejas puede convertirse en un trabajo interminable y quizás, hasta un reto insoluble, para el clínico. Las últimas investigaciones de Rogers (1997) van en este sentido. 
CAPITULO I I. - EL MI NNES OTA $\mathcal{M U L T} I$ PHAS IC PERS O N $\mathcal{A} L I \mathcal{T} \mathcal{Y} I \mathcal{N} \mathcal{V E \mathcal { N }} O$ RV - 2 (M. M.P. I . 2).

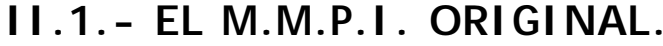

El Minnesota Multiphasic Personality Inventory (M.M.P.I.) es una de las técnicas más ampliamente utilizadas en la evaluación diagnóstica, diseñado para evaluar un gran número de dimensiones de la personalidad y trastornos emocionales, que se gesta y se desarrolla hacia los años 30, en el hospital de la Universidad de Minnesota con un grupo de no pacientes que acompañan, en las salas de espera del hospital, a que los amigos o parientes pasen la consulta con el psicoterapeuta. De esta forma la espera se hace menos pesada al mismo tiempo que se aprovecha para poder apreciar los diversos aspectos de la personalidad. Estos sujetos no pacientes eran casados, vivían en pequeñas ciudades o áreas rurales y sus edades estaban comprendidas entre los 16 y 65 años, convirtiéndose en una muestra representativa de la población americana de los años 30 .

Stark R. Hathaway, psicólogo clínico y J. Charnley Mckinley, neuropsiquiatra comenzaron sus trabajos a finales de los años 30 con una ayuda de la Universidad de Minnesota. Esperaban que el MMPI fuera un instrumento útil para una evaluación diagnóstica rutinaria. Durante 1930 y 1940 la principal función de los psicólogos y psiquiatras era asignar una etiqueta psicodiagnóstica apropiada a los casos individuales 
examinados. Para atribuir a cada paciente un diagnóstico previo utilizaron la técnica de la entrevista individual a la que acompañaban con un Examen del Estado Mental del sujeto y otras pruebas psicológicas. Con ello pretendían que la aplicación de un Cuestionario de Personalidad proporcionara una forma más eficaz de establecer un diagnóstico.

Todo este trabajo les llevó a 1940 cuando publican su primer artículo (Hathaway y Mckinley, 1940) presentando, de forma breve, los pasos que habían efectuado para escribir y redactar los ítems del Minnesota Personality Schedule. Más de 1.000 ítems fueron desarrollados basándose en la experiencia personal, creencias o actitudes de los pacientes para, posteriormente, ser reducidos a 504. Fueron muchas las variables que se tuvieron en cuenta a la hora de redactar las diversas frases que componían los ítems. Se tuvo especial cuidado que las frases empleadas no dieran la impresión de ser un examen formal ni un interrogatorio acerca de su forma de pensar; algunas frases fueron redactadas en forma negativa para no "caer" en la "tendencia de respuesta" a "verdadero" (aspecto que, posteriormente, se ha convertido en polémica de comprensión adecuada de los ítems, al menos en la población española); era obligado que los diferentes ítems reflejasen un amplio rango de trastornos psicológicos, psiquiátricos, somáticos y neurológicos en los que los investigadores se mostraban interesados, dándose cuenta, posteriormente, que la feminidad y masculinidad era una variable a especificar y constatar de alguna forma por lo que el "rol del género" habría que introducirlo. Todas estas variables a controlar y especificar convirtieron la inicial lista de ítems en un total de 550 ítems . Posteriormente, algunas ediciones del MMPI, (entre ellas la castellana) incluyeron la duplicación de 16 ítems para poder controlar la corrección mecánica de aquella época, convirtiendo en 566 la totalidad de los ítems .

Las diferentes investigaciones planteadas comenzaron por discriminar primeramente a los pacientes neuróticos para, posteriormente, continuar con los que presentaban un trastorno psicótico y finalizar con el conjunto básico de las escalas clínicas.

Uno de los primeros trabajos desarrollados por Hathaway y Mckinley se encuentran referidos por un estudio contrastado entre las respuestas dadas al test por un grupo de pacientes hipocondríacos y las respuestas dadas por otro grupo (control) de no pacientes que visitaban el hospital. De su análisis estadístico se obtuvo la escala de Hipocondría (Mckinley y Hathaway, 1940) que serviría posteriormente para discriminar a los sujetos neuróticos de los no neuróticos. Seguidamente se llevaron a cabo otros trabajos semejantes con diferentes variables neuróticas: Psicastenia (Mckinley y Hathaway, 1942), reacción depresiva (Mckinley y Hathaway, 1942) y la Histeria de conversión (Mckinley y Hathaway, 1944).

A continuación estudiaron y desarrollaron otras tres escalas del ámbito de la psicosis: la Psicosis Maníaco-Depresiva, en su fase maníaca, (Mckinley y Hathaway, 1944), Paranoia y Esquizofrenia (Hathaway, 1956). Con la Desviación Psicopática (Mckinley y Hathaway, 1944), la Masculinidad-Feminidad (Hathaway, 1956) y la Introversión Social desarrolladas posteriormente en la Universidad de Wisconsin por L.E. Drake (1946) y Thiede (Drake y Thiede, 1948) terminaron de componer las 10 Escalas Clínicas que aparecen en el MMPI.

A los autores Hathaway y Mckinley no les pasó desapercibido que cualquier técnica psicológica que pretenda evaluar y precisar un diagnóstico fiable, debe de poseer ciertos componentes o variables que controlen la veracidad y exactitud de los datos aportados. 
En los diversos cuestionarios psicológicos que evalúan el ámbito de la personalidad estos mecanismos controladores se convierten en indispensables ya que estas técnicas de evaluación psicológicas pueden ser fácilmente vulnerables a lafalta de sinceridad solicitada en las respuestas. Se veía, pues, la necesidad de disponer de una serie de variables que aportan la fiabilidad, validez y seguridad de que los datos recogidos fueran sinceros. Dando respuesta a estas cuestiones, los autores presentan tres indicadores de validez de las respuestas: los ítems dejados sin contestar (definida por una interrogante), una medida de falseamiento (Escala "L") y un indicador de respuestas exageradamente desviadas o dadas al azar (Escala " $F$ "). Posteriormente fue añadido un cuarto indicador de validez: la variable "K" (escala de corrección) (Meehl y Hathaway, 1946; Mckinley, Hathaway y Meehl, 1948) para poder apreciar adecuadamente la posibilidad de que los sujetos pudiesen exagerar sus respuestas encubriendo, de esta forma, sus problemas y dificultades. Más tarde esta misma escala va a ser utilizada también como un factor de corrección efectuando la ponderación de cinco escalas clínicas de la prueba.

Es hacia 1950 cuando el MMPI se plasma definitivamente y, a partir de entonces, su aceptación crece de forma rápida en los Estados Unidos traduciéndose a otros idiomas y adaptándose en numerosos países.

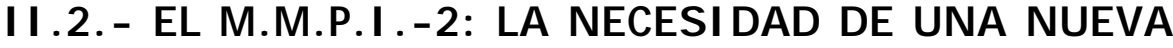 REES TANDARIZACIÓN 50 AÑNOS DES PUIÉS.}

Fue en 1989 cuando decidieron llevar a cabo una revisión profunda del MMPI denominando a esta nueva versión revisada como el MMPI-2. Aunque el original MMPI viene a ser el test de personalidad más extensamente utilizado en los EE. UU., y quizás en el mundo, han sido también expresadas críticas sobre algunos aspectos de esta técnica. Hasta la publicación del MMPI-2, en 1989, el MMPI no había sido revisado desde que fue publicado en el año 1943. Se veía necesario llevar a cabo una revisión en profundidad no solamente sobre los baremos sino también sobre los mismos ítems componentes del Cuestionario.

Después de 1950 se estableció el formato del MMPI. Su aceptación por las distintas culturas ha obligado a la adaptación y traducción a los diversos idiomas (Butcher, 1996), lo que ha hecho que surjan cuestiones acerca de algunos de los ítems que tratan del ajuste sexual, funciones corporales, temas religiosos y cuestiones étnicas. Dado los cambios producidos en la cultura americana, casi cinco décadas después de que los ítems fueran originariamente escritos por los autores de la técnica, surgieron cuestiones acerca de expresiones idiomáticas anticuadas y referencias a material literario y actividades de recreo cada vez más desconocidas. El extendido uso de la técnica y los diversos cambios culturales hicieron necesario reeditar los ítems del MMPI. Pero aún más importante era la creciente evidencia de que la población estaba ahora respondiendo a algunos de estos ítems de forma sustancialmente distinta (Colligan y otros, 1983; Dahlstrom, Lachar y Dahlstrom, 1986) creando, por ello, la necesidad de una reestandarización con baremos nacionales y actuales.

Se comenzó por adaptar el Cuestionario preparándose una forma especial de investigación del MMPI (denominada "cuaderno AX"), manteniéndose 550 ítems originales (82 de ellos modificados por las razones señaladas y anulados los 16 
duplicados), añadiéndose 154 ítems provisionales, formando un total de 704 ítems para la forma "AX". La mayoría de las adiciones fueron diseñadas para proporcionar una mejor cobertura de temas y áreas de interés que no habían recibido atención adecuada en el originario conjunto de ítems (Schofield, 1966). Estos ítems se destinaron a reemplazar a otros que eran culturalmente inadecuados o psicométricamente no fiables, así como a servir de medidas suplementarias en las áreas de funcionamiento familiar, trastornos alimentarios, abuso de sustancias, disposición para el tratamiento $\mathrm{o}$ rehabilitación e interferencias en el trabajo.

Inicialmente se pasó el test a 2.900 sujetos para incluirlos en la muestra de reestandarización, reduciéndose, finalmente, a 2.600 sujetos. Las razones más frecuentes para eliminar a un sujeto de la muestra fue la de un protocolo MMPI inaceptable: excesivas omisiones ( $>40$ de los 704 ítems ); una puntuación excesivamente alta $(>20)$ en cualquiera de las escalas de Validez. Fuentes adicionales de protocolos problemáticos para su aceptación fueron el tener incompleto o ausentes los datos biográficos o los referentes a sucesos recientes de su vida y omitir la identificación de fecha o de sexo.

La obtención de la muestra americana tuvo en cuenta la distribución geográfica (California, Minnesota, Carolina del Norte, Ohio, Pensilvania, Virginia, y reserva india), distintas etnias (Asiáticos, Negros, Hispanos, Indios americanos, Blancos y otros), el estado civil (Casado, Viudo, Divorciado, Separado y Soltero), profesiones de los sujetos (Especialistas, Directivos, Cualificados, Clérigos, Trabajadores y otras profesiones), distribución de los ingresos (distribuidos desde los 0 \$ hasta los $60.000 \$$ ) tanto varones como mujeres.

La gran tarea que suponía la revisión y reestructuración, así como la inviabilidad de adquirir fondos hicieron retrasar los planes por algún tiempo. En 1982 la Universidad de Minnesota nombró un Comité de Reestructuración compuesto por James N. Butcher, W. Grant Dahlstrom y John R. Graham para que llevaran a cabo la revisión en profundidad del MMPI, aportando el los fondos necesarios para dicha tarea. El distribuidor del test es la National Computer System que suministra los diferentes materiales de la técnica, formas, puntuaciones y correcciones de los datos.

La versión final revisada contiene 567 ítems . La Tabla 1 presenta una visión general de los elementos que fueron suprimidos, cambiados y los mantenidos, siguiendo los diversos criterios esbozados para su reestructuración (lenguaje sexista, actualización al idioma y uso, clarificación gramatical y simplificación) en los diferentes estudios e investigaciones.

Las mejoras en el MMPI-2 incluye, además de algunas escalas nuevas, una baremación más representativa y contemporánea, actualizada y perfeccionada con la supresión de los elementos que presentaban algún tipo de objeción. La estandarización ha sido efectuada de nuevo en todas las escalas, mediante un nuevo tipo de puntuaciones $\mathrm{T}$ ("Puntuaciones T Uniformes") de manera que su distribución sea similar, evitando así los sesgos típicos del perfil en el MMPI original. Esta nueva estandarización se logra identificando la distribución compuesta (media) de las 8 escalas, y ajustando cada escala a la distribución promedio. Las nuevas normas se elaboran mediante una muestra aleatoria del censo de 2.600 varones y mujeres. La valoración de los resultados ha incorporado que sea la puntuación T 65 el punto de corte para la interpretación clínica. 
Tabla 1: Anulaciones y cambios de items y su efecto sobre las Escalas Básicas

\begin{tabular}{|c|c|c|c|c|c|c|c|}
\hline \multicolumn{4}{|c|}{ Numero de ítems } & \multicolumn{4}{|c|}{ Tipos de cambio } \\
\hline Escala & Anulados & Permanecen & Cambiados & A & $\mathrm{B}$ & $\mathrm{C}$ & $\mathrm{D}$ \\
\hline $\mathrm{L}$ & - & 15 & 2 & 1 & 1 & - & - \\
\hline $\mathrm{F}$ & 4 & 60 & 12 & 1 & 5 & 6 & - \\
\hline $\mathrm{K}$ & - & 30 & 1 & - & 1 & - & - \\
\hline Hs & 1 & 32 & 5 & - & 1 & 3 & 1 \\
\hline $\mathrm{D}$ & 3 & 57 & 2 & 1 & 1 & - & - \\
\hline Hy & - & 60 & 9 & - & 4 & 2 & 3 \\
\hline $\mathrm{Pd}$ & - & 50 & 4 & - & 2 & 1 & 1 \\
\hline Mf & 4 & 56 & 6 & 1 & 2 & 1 & 2 \\
\hline $\mathrm{Pa}$ & - & 40 & 2 & 1 & - & - & 1 \\
\hline $\mathrm{Pt}$ & - & 48 & 2 & - & - & 1 & 1 \\
\hline $\mathrm{Sc}$ & - & 78 & 13 & - & 1 & 7 & 5 \\
\hline $\mathrm{Ma}$ & - & 46 & 7 & 4 & 2 & 1 & - \\
\hline $\mathrm{Si}$ & 1 & 69 & 6 & - & 3 & 2 & 1 \\
\hline \multicolumn{4}{|c|}{ No pertenecen a ninguna Escala Básica: 16} & 3 & 7 & 3 & 3 \\
\hline
\end{tabular}

* No pertenecen a ninguna Escala : 16 ítems

A: Eliminación por posible terminología sexista.- B: Modernización en su idioma y uso..- C: Clarificación gramatical (tiempo, voz, adición menor o supresión)..- D: Simplificación. (Tomado del Manual del Inventario Multifásico de Personalidad de Minnesota -2, pg. 21)

La estabilidad psicométrica de los 68 ítems nuevos fue demostrada por Ben-Porath y Butcher (1989a). Igualmente la comparación de las escalas antiguas y nuevas y los perfiles resultantes ha sido satisfactoria (Ben-Porath, 1990, 1991 y Butcher, 1989b y 1990).

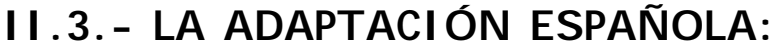

La traducción castellana de la primera versión del MMPI contenía un número apreciable de ítems con sentido ambiguo, extraño o desfasados cultural o socialmente, que implicaban, además, sesgos inaceptables de corte ideológico.

La adaptación española realizada con el MMPI original (1975 y reeditado en 1986) mostraba un relativo desajuste entre los baremos oficiales autorizados por la Universidad de Minnesota para su utilización con la población española a lo que se añadieron las "normas 1979", preparada por Seisdedos a partir de una variedad de muestras españolas. La muestra de tipificación española carecía de la estratificación por edades y zonas geográficas de procedencia, estando más frecuentemente integrada por sujetos adolescentes, estudiantes universitarios o sujetos cumpliendo el Servicio Militar, convirtiéndose más en muestras incidentales y asistemáticas.

Todo ello hizo que la revisión del MMPI original en España se hiciera deseable, intentando con ello los objetivos siguientes:

a.- Corrección de los defectos formales y contenidos inaceptables legalmente.

b.- Actualización del instrumento, incluyendo nuevos ítems y nuevas escalas que tengan interés en los actuales criterios clínicos y psicopatológicos.

c.- Ofrecer contrapartidas valiosas para el clínico y mejora de las escalas específicas, ya que de las 18 escalas que eran utilizadas en España con el MMPI original, se ha pasado a un número tres veces superior de escalas con el MMPI-2.

d.- Extremar más aún los controles de validez y fiabilidad.

Todos estos argumentos subrayan el interés por poner a punto en España una nueva versión del MMPI. 
En la preparación de la versión castellana se ha seguido las indicaciones para el proceso de traducción elaboradas por James N. Butcher y la University of Minnesota Press (véase Tabla 2). Se contrastaron las diferentes versiones del Cuestionario realizadas en lengua española, para sus propios países, de México, Argentina y Chile. De estos análisis se obtuvieron las resoluciones adecuadas para dejar, de una forma experimental aún, la nueva versión del Cuestionario adaptado al castellano.

El primer estudio experimental (Avila-Espada y Jiménez-Gómez, 1996) fue realizado con una muestra de 426 sujetos considerados como "normales" (193 varones y 233 mujeres). Los resultados obtenidos fueron analizados comparativamente con la muestra norteamericana encontrando, en general, una notable semejanza entre ambas muestras.

Tabla 2: Análisis comparativo de los principales pasos seguidos en el proceso de la adaptación e spañola.

\begin{tabular}{|c|c|}
\hline MODELO EXPERIMENTAL AMERICANO & MODELO EXPERIMENTAL ESPAÑOL \\
\hline \multicolumn{2}{|c|}{ Se parte de una forma experimental } \\
\hline * 550 ítems originales & * Se respeta básicamente la estructura americana \\
\hline * 82 se modificaron & * Se contrastan las versiones Mexicana, Chilena, y Argentina \\
\hline \multicolumn{2}{|l|}{ * 154 se añadieron para evaluar otras áreas } \\
\hline * Total ítems del Cuadernillo AX: 704 & * Se revisan las diferentes traducciones del inglés. \\
\hline * Diversas razas & * Solamente una raza (blanca) \\
\hline * Varios Estados (7) & * De todas las regiones (17) \\
\hline * Edades: $18-95$ años & * Edades: $19-65$ \\
\hline * Hombres: 1.138 & * Hombres: Normales (734) y clínica (232) \\
\hline * Mujeres: 1.462 & * Mujeres: Normales (1.172) y clínica (293) \\
\hline * Estratificación de las edades & * Estratificación por sexos, edades y regiones. \\
\hline * Excesivas omisiones ( $>40$ sobre 704 ítems ) & * Excesivas omisiones (> 30 sobre 567 ítems ) \\
\hline $\begin{array}{l}\text { * Puntuación excesivamente alta ( }>20 \text { en cualquiera de las } \\
\text { escalas } \mathrm{F} \text { ó } \mathrm{Fb})\end{array}$ & \\
\hline * Datos de identificación incompletos & * Datos de identificación incompletos \\
\hline
\end{tabular}

Posteriormente, en este proyecto de adaptación, se ampliaron las muestras, tanto de población normal como clínica, agrupadas según el género en tres cuotas de edad: 19-29 años; 30-44 años y 45-65 años. Con respecto a la distribución geográfica, la muestra fue obtenida de todas las regiones españolas, completando así un número de 1.906 sujetos normales (734 varones -38,51\%-, y 1.172 mujeres $-61,49 \%$ ) y 525 sujetos clínicos (232 varones $-44,19 \%$ - y 293 mujeres $-55,81 \%$ ), siendo la muestra bruta obtenida muy superior pero los diferentes controles de validez de la misma prueba (sobre todo las respuestas dejadas en blanco y las dobles marcas) para la aceptación del protocolo con fines de investigación, la han dejado, finalmente en los sujetos reseñados.

Se realizaron los diferentes análisis estadísticos para contrastar las estimaciones de equivalencia entre la versión castellana y la norteamericana volviendo a encontrarnos notables semejanzas, tanto en las diversas intercorrelaciones entre las escalas como en los principales componentes del análisis factorial, mostrando una evidencia, esencialmente coincidente, con la estructura inferida en la población norteamericana en donde la solución a cuatro factores (ANOVA) domina sobre las tres o cinco y reapareciendo las tradicionales diferencias entre la estructura factorial observada en las muestras masculinas y femeninas. 


\section{I.4. - LAS APORTACIONES DEL M.M.P. I. - 2:}

Hemos señalado anteriormente que el MMPI original, aplicable a la población adolescente y adulta, dió origen, con su actualización y revisión, a dos formatos distintos: MMPI-A para adolescentes y MMPI-2 adultos. Veamos, de forma resumida en la Tabla 3 los aportes diferenciativos que supuso la reestructuración del MMPI original.

Tabla 3: Aportes diferenciativos entre el $\mathcal{M M P I}$ original, el $\mathcal{M M P I}-2$ y el $\mathcal{M M} \mathscr{M} I-\mathcal{A}$

\begin{tabular}{|c|c|c|}
\hline MMPI & MMPI-2 & MMPI-A \\
\hline $\mathbf{N}^{0}$. ítems $=567$ & $\mathbf{N}^{0}$. ítems $=567$ & $\mathrm{~N}^{0}$. ítems $=478$ \\
\hline \multicolumn{3}{|l|}{ Escalas de Valide $z$} \\
\hline "?". Interrogante & "??": Interrogante & "“?": Interrogante \\
\hline L: Mentira & L: Mentira & L: Mentira \\
\hline F:Incoherencia & F: Incoherencia & F: Incoherencia \\
\hline \multirow{5}{*}{ K: Corrección } & K: Corrección & K: Corrección \\
\hline & Fb: F posterior & F1: Infrecuencia $1^{\text {a }}$ parte \\
\hline & & F2: Infrecuencia $2^{\mathrm{a}}$ parte \\
\hline & $\begin{array}{l}\text { VRIN: Inconsistencia de respuestas } \\
\text { variables }\end{array}$ & $\begin{array}{l}\text { VRIN: Inconsistencia de respuestas } \\
\text { variables }\end{array}$ \\
\hline & $\begin{array}{l}\text { TRIN: Inconsistencia de respuestas } \\
\text { Verdadero }\end{array}$ & $\begin{array}{l}\text { TRIN: Inconsistencia de respuestas } \\
\text { Verdadero }\end{array}$ \\
\hline \multicolumn{3}{|l|}{ Escalas Básicas } \\
\hline Hs: Hipocondría & Hs: Hipocondría & Hs: Hipocondría \\
\hline D: Depresión & D: Depresión & D: Depresión \\
\hline Hy: Histeria & Hy: Histeria & Hy: Histeria \\
\hline Pd: Desviación psicopática & Pd: Desviación psicopática & Pd: Desviación psicopática \\
\hline Mf: Masculinidad-Feminidad & Mf Masculinidad-Feminidad & Mf Masculinidad-Feminidad \\
\hline Pa: Paranoia & Pa: Paranoia & Pa: Paranoia \\
\hline Pt: Psicastenia & Pt: Psicastenia & Pt: Psicastenia \\
\hline Sc: Esquizofrenia & Sc: Esquizofrenia & Sc: Esquizofrenia \\
\hline Ma: Hipomanía & Ma: Hipomanía & Ma: Hipomanía \\
\hline Si: Introversión social & Si: Introversión social & Si: Introversión social \\
\hline \multicolumn{3}{|l|}{ Escalas de Contenido } \\
\hline & ANX: Ansiedad & A-anx: Ansiedad \\
\hline & FRS: Miedos & \\
\hline & OBS: Obsesión & A-obs: Obsesión \\
\hline & DEP: Depresión & A-dep: Depresión \\
\hline & HEA: Preocupaciones por la salud & A-hea: Preocupación por la salud \\
\hline & BIZ: Pensamiento extravagante. & A-biz: Pensamiento extravagante. \\
\hline & ANG: Hostilidad & A-ang: Hostilidad \\
\hline & CYN: Cinismo & A-cyn: Cinismo \\
\hline & ASP: Conductas antisociales & A-con: Conductas antisociales \\
\hline & TPA: Comportamiento tipo A. & \\
\hline & LSE: Baja autoestima & A-lse: Baja autoestima \\
\hline & SOD: Malestar social & A-sod: Malestar social \\
\hline & FAM: Problemas familiares & A-fam: Problemas familiares \\
\hline & WRK: Interferencia laboral & A-sch: problemas escolares \\
\hline & $\begin{array}{lll}\text { TRT: } & \text { Indicadores } & \text { negativos } \\
\text { tratamiento. }\end{array}$ & $\begin{array}{lll}\begin{array}{c}\text { A-trt: } \\
\text { tratamiento. }\end{array} & \text { negativos } & \mathrm{de} \\
\end{array}$ \\
\hline & & A-las: Bajas aspiraciones \\
\hline & & A-aln: Alienación \\
\hline \multicolumn{3}{|c|}{ Escalas S uplementarias } \\
\hline & A: Ansiedad & A: ansiedad \\
\hline & R: Represión & R: Represión \\
\hline \multirow[t]{3}{*}{ Es: Fuerza del Yo } & Es: Fuerza del yo & \\
\hline & $\begin{array}{lccc}\text { MAC-R: } & \text { Escala } & \text { revisada } & \text { de } \\
\text { Alcoholismo de McAndrew } & \\
\end{array}$ & $\begin{array}{c}\text { MAC-R: } \begin{array}{c}\text { Escala } \\
\text { Alcoholismo de McAndrew }\end{array} \\
\end{array}$ \\
\hline & $\begin{array}{l}\text { O-H: Hostilidad } \\
\text { controlada. }\end{array}$ & \\
\hline
\end{tabular}




\begin{tabular}{|c|c|c|}
\hline Do: Dominancia & Do: Dominancia & \\
\hline \multirow[t]{10}{*}{ Re: Responsabilidad social } & Re: Responsabilidad social. & \\
\hline & Mt: Inadaptación universitaria & \\
\hline & GM: Rol de género masculino & \\
\hline & GF: Rol de género femenino & \\
\hline & $\begin{array}{l}\text { PK: Trastorno por estrés postraumático } \\
\text { (Keane) }\end{array}$ & \\
\hline & $\begin{array}{l}\text { PS: Trastorno por estrés postraumático } \\
\text { (Schlenger) }\end{array}$ & \\
\hline & MDS: Malestar matrimonial & \\
\hline & APS: Potencial de adicción & PRO: Potencial de adicción \\
\hline & AAS: Reconocimiento de adicción. & ACK: Reconocimiento de adicción. \\
\hline & & IMM: Inmadurez \\
\hline \multicolumn{3}{|l|}{ Dy: Dependencia } \\
\hline \multicolumn{3}{|l|}{ Cn: control } \\
\hline \multicolumn{3}{|l|}{ Subescalas } \\
\hline & D1: Depresión subjetiva & D1: Depresión subjetiva \\
\hline & D2: Retardo psicomotor & D2: Retardo psicomotor \\
\hline & D3: Disfunción física & D3: Disfunción física \\
\hline & D4: Enlentecimiento mental & D4: Enlentecimiento mental \\
\hline & D5: Rumiación & D5: Rumiación \\
\hline & Hy1: Negación de ansiedad social & Hy1: Negación de ansiedad social \\
\hline & Hy2: Necesidad de afecto & Hy2: Necesidad de afecto \\
\hline & Hy3: Lasitud-malestar & Hy3: Lasitud-malestar \\
\hline & Hy4: Quejas somáticas & Hy4: Quejas somáticas \\
\hline & Hy5: Inhibición a la agresión & Hy5: Inhibición a la agresión \\
\hline & Pd1: Discordia familiar & Pd1: Discordia familiar \\
\hline & Pd2: Problemas con la autoridad & Pd2: Problemas con la autoridad \\
\hline & Pd3: Frialdad social & Pd3: Frialdad social \\
\hline & Pd4: Alienación social & Pd4: Alienación social \\
\hline & Pd5: Autoalienación & Pd5: Autoalienación \\
\hline & Pa1: Ideas persecutorias & Pa1: Ideas persecutorias \\
\hline & Pa2: Hipersensibilidad & Pa2: Hipersensibilidad \\
\hline & Pa3: Ingenuidad & Pa3: Ingenuidad \\
\hline & Sc1:Alienación social & Sc1:Alienación social \\
\hline & Sc2: Alienación emocional & Sc2: Alienación emocional \\
\hline & $\begin{array}{l}\text { Sc3: Ausencia del control de yo, } \\
\text { cognitivo. }\end{array}$ & $\begin{array}{l}\text { Sc3: Ausencia del control de yo, } \\
\text { cognitivo. }\end{array}$ \\
\hline & $\begin{array}{l}\text { Sc4: Ausencia del control de yo, } \\
\text { conativo. }\end{array}$ & $\begin{array}{l}\text { Sc4: Ausencia del control de yo, } \\
\text { conativo. }\end{array}$ \\
\hline & $\begin{array}{l}\text { Sc5: : Ausencia del control de yo, } \\
\text { inhibición defectuosa. }\end{array}$ & $\begin{array}{l}\text { Sc5: : Ausencia del control de yo, } \\
\text { inhibición defectuosa. }\end{array}$ \\
\hline & Sc6: Experiencias sensoriales extrañas & Sc6: Experiencias sensoriales extrañas \\
\hline & Ma1: Amoralidad & Ma1: Amoralidad \\
\hline & Ma2: Aceleración psicomotriz & Ma2: Aceleración psicomotriz \\
\hline & Ma3: Imperturbabilidad & Ma3: Imperturbabilidad \\
\hline & Ma4: Autoenvanecimiento. & Ma4: Autoenvanecimiento \\
\hline & Si1: Timidez/auto-cohibición & Si1: Timidez/auto-cohibición \\
\hline & Si2: Evitación social & Si2: Evitación social \\
\hline & $\begin{array}{l}\text { Si3: Alienación respecto a sí mismo y a } \\
\text { otros. }\end{array}$ & $\begin{array}{l}\text { Si3: Alienación respecto a sí mismo y a } \\
\text { otros }\end{array}$ \\
\hline
\end{tabular}

Entre los cambios aportados por la nueva versión (MMPI-2) son las Escalas de Validez (?, L, F, K, Fb, VRIN y TRIN), de las cuales los tres últimos constituyen una novedad, las que nos interesan especialmente en relación con nuestro trabajo. Estas Escalas de Validez constituyen la clave más importante de interpretación de los datos aportados por el paciente: su consideración y adecuada evaluación nos indica la fiabilidad de las demás Escalas (Básicas, de Contenido, Suplementarias) y por consiguiente la Validez y fiabilidad de la información dada por el paciente.

Nuestro estudio se centra en el análisis empírico de las Escalas de Validez para el que disponemos de tres tipos de muestra: "clínica" (sujetos con patología diagnosticada), "normal" (sujetos ausente de síntomas patológicos), una muestra de 
"Respuestas inconsistentes" (sujetos que responden al sin tener en cuenta el sentido de los ítems ) y sujetos que van a expresar una autoimagen positiva o negativa.

\section{I.5 - LA CONFIGURACIÓN $\mathcal{N}$ DEL $\mathcal{M M P I}$ - 2 :}

\section{II.5.1. - Las Escalas de Valide z:}

Para evaluar un protocolo del MMPI-2 como aceptable el sujeto debe leer y considerar el contenido de cada ítem y responder a ello según considere aplicado a sí mismo, como "verdadero" o "falso". Ocasionalmente el individuo puede responder de una forma idiosincrásica a los ítems sin tener en cuenta el contenido del mismo. Tal comportamiento ocurre generalmente entre personas que carecen de las adecuadas destrezas de lectura y comprensión, pueden encontrarse confusos ante tal tarea o pueden presentar una actitud negativa hacia los procedimientos de evaluación o los profesionales de la Psicología. Otras veces los sujetos se pueden encontrar altamente motivados para ofrecer un ajuste psicológico más o menos aceptable ante las preguntas del MMPI-2, intentando ofrecer una mejor imagen de sí mismos.

En circunstancias ideales, el examinador debería poder valorar la tendencia a responder por parte del sujeto intentando asegurar que los sujetos completen la prueba con la honestidad y sinceridad que señalan las instrucciones del test. Por ello es importante poder apreciar la disposición y motivación del sujeto y saber, por parte del profesional administrador, cómo detectar los protocolos sospechosos de validez. Así, ante la sospecha de un protocolo no válido, podría ser útil, por parte del administrador, poder observar la conducta del individuo al realizar la prueba. La falta de congruencia entre el perfil y la conducta observada puede aportarnos alguna idea del tipo, clase o estilo de respuesta que da el sujeto.

Si un protocolo del MMPI-2 se juzga nulo, el examinador debería estar dispuesto a hablar de la situación con el sujeto y volverle a administrar la prueba. Frecuentemente, una segunda vez produce un protocolo válido. Si esto no fuera posible o siguiera dando un protocolo no válido, la interpretación no debería intentarse.

Según Graham (1990), sería tentador poder interpretar que una persona que presenta un protocolo con una buena imagen, en que un número de síntomas y problemas se niegan o rechazan, es realmente una persona inadaptada o desajustada que intenta ocultar ese desajuste. Tal conclusión, sigue comentando Graham (1990) no está justificada. La persona puede estar bien ajustada pero por circunstancias diversas, siente la necesidad de presentarse a sí misma como mejor adaptada. Este tipo de casos no es extraño encontrarlo en ambientes jurídicos y sobre todo en progenitores que intentan conseguir la guardia y custodia de sus hijos.

Algunos usuarios del MMPI-2 consideran un protocolo nulo, y por consiguiente no interpretable, cuando tiene más de 30 ítems sin contestar u omitidos o la puntuación $\mathrm{T}$ es mayor de 70 en una o más de las escalas estándar de validez. Aunque esta es una práctica muy prudente no deja de ser una visión muy simplista de resolver el problema. Así, por ejemplo, en el manual del MMPI-2 (Butcher, Dahlstrom, Graham, Tellegen y Kaemmer, 1989) se presentan casos en que la puntuación de la escala $\mathrm{F}$, encontrándose en un rango de puntuación entre 71 a 90, puede estar indicando una psicosis. 
Gynther, Altman y Warbin (1973) demostraron que perfiles con puntuaciones $\mathrm{T} \geq$ 100 en la Escala $\mathrm{F}$ pueden estar plenamente correlacionados con algunos comportamientos y tipos de personalidad clínicos (desorientaciones, alucinaciones, ilusiones, escasa atención). Igualmente decir, la experiencia clínica nos demuestra que encontrar una escala $\mathrm{K}$ con puntuaciones $\mathrm{T}>70$ entre las personas con buen nivel educativo no es algo excepcional.

Algunos sujetos se enfrentan al MMPI-2 con un comportamiento claramente intencionado y sus protocolos deben ser totalmente invalidados. Es el caso de los sujetos que responde sin tener en cuenta el sentido de los ítems o intentan fingir deliberadamente una determinada patología. Otros sujetos no siguen adecuadamente las instrucciones del test y su forma de responder no parece estar totalmente ajustada a la sinceridad que se necesita, pueden ser pacientes que al exagerar su sintomatología y problemática particular están realizando una llamada de atención acerca de la ayuda que necesitan.

Estas formas de responder deben ser tenidas en cuenta cuando se interpreta el resultado del protocolo ya que no tienen por qué invalidar, necesariamente, la prueba. Las pistas de interpretación para la validez del test nos la van a proporcionar las escalas de Validez

\section{II.5.1.1. - Las escalas tradicionales de Validez.}

La Escalas de Validez del MMPI-2 tienen como objetivo determinar si el protocolo es aceptable para su correcta interpretación y poder inferir dimensiones esenciales de la personalidad del sujeto o realizar hipótesis diagnósticas. Con anterioridad hemos podido ver las diversas formas en que puede quedar distorsionado un perfil bien de forma deliberada o no. Los indicadores de validez del perfil del MMPI-2 fueron diseñados para ayudar a detectar estas fuentes de distorsión y poder determinar la fiabilidad de los datos aparecidos en el perfil.

Greene (1977) hace una revisión de las diferentes estrategias adoptadas para evaluar el fingimiento y la defensividad a través de los diversos cuestionarios existentes en la evaluación de la personalidad. Cuando Meehl y Hathaway (1946) elaboraron el MMPI estaban convencidos de la posibilidad de falseamiento de la prueba, de que alguien podría obtener beneficios personales a través de esta falsificación. Para ello elaboraron dos tipos de categorías generales en las que estaban incluídos los falsificadores: la considerada por ellos como "fingimiento" (fingirse mal) y la de "defensividad" ("fingirse bien"). Estos autores consideraron tres estrategias posibles para evaluar el fingimiento y la defensividad:

$1^{\text {a }}$.- La inconsistencia (o "incoherencia") de respuestas para los ítems de contenido semejante.

$2^{\mathrm{a}}$.- Los ítems sumamente convenientes pero infrecuentemente atribuidos.

$3^{\mathrm{a}}$.- Ítems empíricamente identificados.

Con la primera estrategia, el clínico propone al sujeto una serie de ítems con la oportunidad y posibilidad de poder distorsionar fácilmente su respuesta y observar, posteriormente, los resultados de sus respuestas para los ítems redactados de idéntica forma, tanto en sentido positivo como en negativo. El Cuestionario del MMPI presenta 16 ítems repetidos. Los resultados aportaron un gran número de respuestas 
incoherentes, sugiriendo a los autores, que las personas se mostraron incapaces o poco dispuestas a responder de forma coherente. Por ello, los mismos autores no estaban muy convencidos de que este tipo de estrategia "funcionara" adecuadamente. En la reestandarización del MMPI estos 16 ítems de redacción idéntica, fueron eliminados y se elaboraron dos nuevas escalas denominadas "Insonsistencia de Respuestas Variable (VRIN) e "Inconsistencia de Respuestas Verdadero" (TRIN) que veremos detenidamente en apartados posteriores.

La segunda estrategia adoptada por Meehl y Hathaway (1946) era la de elaborar una serie de ítems que fueran extremadamente deseables de contestar en una dirección determinada pero que, justamente en esta misma dirección de la respuesta, fuese muy probablemente falso. Estos ítems atentan contra las cualidades humanas de educación, responsabilidad, honestidad, etc., de las cuales, en todos presuponemos una tendencia socialmente deseable y natural. Si una persona se atribuye un gran número de estos ítems, la probabilidad de que las respuestas no sean sinceras es muy alta. La Escala L (Mentira) fue elaborada con este objetivo, indicando con ello un grado de "defensividad" de la persona.

La Escala F (infrecuencia) se elaboró con arreglo a una variante de esta misma segunda estrategia con la finalidad de valorar actitudes de respuestas al test. Los ítems para esta Escala $\mathrm{F}$ fueron inicialmente seleccionados porque eran contestados con una relativa baja frecuencia por la mayor parte del grupo de población normal evaluado con el MMPI. Es decir, si una persona se atribuye un gran número de ítems de esta Escala $\mathrm{F}$, esta persona responde de forma atípica con referencia a su grupo normativo. Esta misma estrategia fue adoptada por el MMPI-2 y ampliada con la elaboración de la escala $\mathrm{Fb}$ ( $\mathrm{F}$ posterior) que hace referencia a la segunda parte de la prueba.

Una última estrategia para detectar el fingimiento y la defensividad evaluada por el MMPI fue la aportada por estos mismos autores, Meehl y Hathaway (1946), elaborando un procedimiento empírico para identificar los ítems de los que se obtienen diferentes respuestas con dos grupos seleccionados de personas: aquellos que contestan de forma sincera y aquellos otros que son instruidos para falsear la prueba. La Escala de Disimulación de Gough (Ds, 1954), que se describirá posteriormente, se encuentra basada en esta estrategia. Meehl y Hathaway (1946), adoptaron una variante de esta tercera estrategia desarrollando la Escala K (correctora), elaborada para diferenciar pacientes internados con perfiles normales de individuos, supuestamente normales, con perfiles anormales. Posteriormente determinaron las diferentes proporciones de $\mathrm{K}$ que deben ser añadidas a determinadas escalas Clínicas para maximizar la discriminación entre el grupo criterio y el grupo normativo.

Los indicadores de la validez que disponemos en el MMPI-2 deben ser analizados de forma combinada, determinando la peculiaridad de cada variable y las implicaciones posibles cuando se conjugan con los resultados de las demás. Los principales indicadores que vamos a exponer de forma más detallada, en este apartado y en el siguiente, son: la escala "no sé / no puedo contestar", la Escala "L" (mentira); la Escala "F" (Incoherencia); la Escala "Fb" (F posterior); la Escala "K" (corrección); la Escala TRIN (Inconsistencia de las respuestas verdadero) y la Escala VRIN (Inconsistencia de respuestas variables). 
II.5.1.1.1. - No sé / no puedo contestar ("?").

Esta "variable" no se considera propiamente una "escala", es, sencillamente, el número de ítems que no se han contestado o que, por motivos diferentes, han sido omitidos por el sujeto o que son marcados, al mismo tiempo, como "verdadero" y "falso". Obviamente la omisión de un gran número de ítems puede afectar de forma diferente al perfil de la prueba, ya que puede darse el caso de que una mayor parte de las omisiones afecten a una misma variable o a un conjunto importante de variables de la prueba, dando como resultado unas puntuaciones bajas y cuestionando la interpretación del perfil. Su cantidad se lleva a cabo realizando un recuento visual de los ítems no contestados y de las dobles marcas.

Las razones que puede tener un individuo para omitir un determinado ítem son numerosas y peculiares. Individuos no cooperativos o defensivos, con problemas depresivos o de lectura pueden dejar sin contestar los ítems. Si el sujeto ha omitido más de 30 preguntas dentro de los 370 primeras, el protocolo se debe considerar nulo (Meehl, 1946). No debemos de olvidar que las Escalas de Validez y Clínicas pueden ser puntuadas hasta el ítem 370. Por ello, si las omisiones ocurren después del ítem 370 (el sujeto puede no contestar todo el MMPI-2) las Escalas Clínicas pueden interpretarse pero las puntuaciones de algunas escalas Suplementarias y de Contenido se encontrarán, probablemente, atenuadas y no deberían interpretarse.

Greene (1997) presenta los datos obtenidos por Butcher et al. (1989) con una muestra de 2.600 sujetos pertenecientes a la población normal y los compara con los obtenidos por Greene (1995) con 3.475 pacientes con trastornos mentales, obteniendo que el 75\% de los sujetos normales y de pacientes psiquiátricos contestaron a todos los ítems de la prueba; sin embargo solamente el $90 \%$ omitió 2 o menos ítems y sólo el $1 \%$ de los sujetos, tanto de la muestra normal como clínica, dejaron de contestar a 15 (muestra normal) o 20 ítems (muestra clínica).

Las pautas de interpretación de la variable “?” las resume Butcher \& Williams, (1992), de la siguiente forma:

- - "P.D. $\geq 30$ indica que el sujeto ha producido un protocolo nulo y que no debería interpretarse excepto si se dan las circunstancias anotadas anteriormente. Otras escalas del MMPI-2 no deben interpretarse.

- - Si la mayoría de los ítems (“?”) se encuentran al final del cuestionario (después del 370) podrían interpretarse las escalas de Validez y las Clínicas. Sin embargo, las Escalas Suplementarias y las de Contenido, que contienen ítems de la segunda parte del Cuestionario, no deben interpretarse.

Las posibles razones de la omisión de los ítems pueden ser atribuidas a:

- Actitud defensiva

- Indecisión

- Fatiga, cansancio

- Mal humor

- Falta de motivación

- Distracción

- Bajo nivel de lectura y de comprensión

- Percibir los ítems como irrelevantes" (pg. 43). 
Greene (2000, Tabla 3.6, pg.49) muestra las diferentes puntuaciones directas y pautas de interpretación de esta variable(?):

- $\mathrm{PD}=0-2$. Considerado como una puntuación "normal. El sujeto ha omitido un par de ítems sin ninguna consecuencia para la interpretación global del perfil.

- $\mathrm{PD}=3-5$. Considerado como una puntuación "leve". El sujeto ha omitido algunos ítems más, pero sin mayor importancia,

- $\mathrm{PD}=6-25$. Considerado como una puntuación "moderada". Indica que el sujeto ha omitido más ítems que lo normal. Si la puntuación se encuentra próxima a 25 , el perfil debería cuestionarse.

- PD $\geq 26$ : Considerado como "dudoso". Los sujetos no se encuentran cómodos ejecutando la prueba. Se debe tener especial precaución para emitir un perfil significativo acerca de sí mismo. Para que pueda tener validez la prueba, este amplio números de ítems sin contestar deberían ser contrastados.

La Tabla 4 (Ávila y Jiménez, 1990, pg.37), así como las siguientes que hacen referencia a las implicaciones interpretativas de las puntuaciones obtenidas en las diversas escalas, han sido tomadas esencialmente de los trabajos realizados en el Workshop internacional celebrado en la ciudad belga de Brujas en 1992 a cargo del equipo de investigación de James N. Butcher. El lector debería reconocer que los descriptores expuestos en estos resúmenes no aparecen en todos los sujetos afectados de estas puntuaciones. Estos descriptores deben ser apreciados como hipótesis o pautas de interpretación y que deben contrastarse adecuadamente con la obtención de otras informaciones obtenidas por otros medios o técnicas diagnósticas.

Tabla 4: Implicaciones de las puntuaciones en la Puntuación "?" (Interrogante)

\begin{tabular}{|c|c|c|c|}
\hline Puntuación directa & Utilidad del perfil & Origen de la elevación & Hipótesis interpretativas \\
\hline P.D. $\geq 30$ & Probablemente inválido & $\begin{array}{l}\text { Serios problemas de lectura o } \\
\quad \text { dislexia. } \\
\text { Retardo psicomotor. } \\
\text { Confusión } \\
\text { Desafío } \\
\text { Indecisión } \\
\end{array}$ & $\begin{array}{l}\text { Depresión grave } \\
\text { Estado obsesivo }\end{array}$ \\
\hline P.D. $=11-29$ & Validez cuestionable & $\begin{array}{l}\text { Problemas leves de lectura } \\
\text { Ausencia de experiencia } \\
\text { Supercauteloso o legalístico }\end{array}$ & $\begin{array}{l}\text { No familiaridad con el idioma } \\
\text { Ideación paranoide. }\end{array}$ \\
\hline P.D. $=2-10$ & $\begin{array}{ccc}\begin{array}{l}\text { Probablemente } \\
\text { contenido } \\
\text { selectivas) }\end{array} & \text { por } & \begin{array}{c}\text { (probar el } \\
\text { omisiones }\end{array} \\
\end{array}$ & Interpretación idiosincrásica & \\
\hline P.D. $=0-1$ & Válido & & \\
\hline
\end{tabular}

\section{II.5.1.1.2. - La Escala L (Mentira).}

Esta escala, denominada originalmente escala de "mentira" (del inglés "Lie". mentira), fue diseñada para detectar, de forma sencilla, los intentos, por parte de los sujetos, de presentarse a sí mismos de forma favorable. La escala se basa en la idea de que los individuos que intentan reclamar un excelente ajuste psicológico se atribuirán ítems que indican elevadas características morales, éticas y de responsabilidad. Aunque la Escala L puede reflejar algún tipo de engaño en la situación del test, no podemos inferir que el sujeto en su vida personal sea un "mentiroso" o presente una tendencia general a mentir, más bien nos sirve para detectar cómo las faltas menores y los defectos de carácter, que en la mayoría de los sujetos son admisibles, en estos sujetos son difícilmente aceptables. 
Los 15 ítems que componen esta escala (ver Anexo 1) son evidentes en su contenido y se centran sobre la afirmación de gran virtud (por ejemplo: "a veces tengo ganas de maldecir" [falso] o "no siempre digo la verdad" [falso]). Las puntuaciones por encima de 65 sugieren que el individuo se presenta de una forma positiva intentando crear una idea favorable y no realista de sus características morales y ajuste psicológico.

Esta escala es un buen indicador de respuesta distorsionada o inválida, encontrándose asociada también con características de personalidad que sugieren ingenuidad, pensamiento rígido y una imagen no realista. No es aconsejable la interpretación asilada de esta escala (ni ninguna del MMPI-2), ya que, justamente con la puntuación K (corrección) puede aportarnos matizaciones o clarificaciones de su hipótesis interpretativa.

Aunque la mayoría de los ítems de L no se contestan en la dirección de las puntuaciones (falso) por la mayor parte de la gente, muchos de los sujetos de la población normal atribuyen varios (3) de los ítems en dicha dirección.

Para Graham (1990) las puntuaciones en la Escala L se encuentran relacionadas con el nivel de educación, estatus socieconómico y sofisticación psicológica. Cuanto mayor nivel educativo y las personas se encuentren dentro de una categoría social más alta, menor es la puntuación en la escala L. Es decir, si una puntuación bruta de 3 ó 4 en la Escala L debería ser el promedio para una clase media-baja, laboral o por debajo del promedio de inteligencia, semejante puntuación debería ser considerada "moderadamente alta" para una persona con nivel universitario y procedente de una clase social elevada.

Para Butcher (1990), las puntuaciones elevadas en L generalmente tienden a afectar también las respuestas de los ítems de las escalas Clínicas, dando perfiles que infravaloran el número y la gravedad de los problemas que un sujeto puede tener. Entre las personas que presentan estas puntuaciones altas, podemos encontrar los siguientes tipos (Butcher, 1990):

- Personas que intentan presentarse de forma favorable (situación de selección de personal o casos de custodia) para impresionar al evaluador.

- Personas con baja inteligencia o carencia de ajuste psicológico.

- Algunos grupos subculturales o grupos étnicos minoritarios.

- Sujetos con desórdenes neuróticos o con problemática de somatización.

Las puntuaciones bajas generalmente son indicativas de respuesta franca y sincera a los diferentes ítems, bastante seguros de sí mismos, conocedores de sus limitaciones y conscientes de la aceptación de sus defectos. Estos sujetos con puntuaciones bajas han sido descritos como perceptivos, socialmente responsables e independientes. También parecen ser personalidades fuertes, naturales, tranquilas y pudiendo funcionar con un rol de líder aunque en ocasiones pueda dar la impresión, sobre todo para los demás, de ser algo cínicos y sarcásticos.

A veces las puntuaciones inferiores al promedio en la Escala L pueden sugerir una actitud desviada en las respuestas e interpretarse como una exageración de los problemas y de sus características negativas, pero esta interpretación es más propia de la escala K como más adelante veremos.

Graham (1990), nos resume las interpretaciones según las puntuaciones obtenidas. 
- "Las puntuaciones elevadas en la Escala L son indicativas de personas que:

- Están intentando dar una buena impresión de sí mismos por no estar respondiendo de forma sincera a los ítems .

- Pueden estar a la defensiva, negando y reprimiendo ciertos aspectos de sí mismos.

- Pueden estar confusos

- Pueden manifestar poca o ninguna relación de sus propias motivaciones.

- Muestran poca conciencia de las consecuencias de su comportamiento para otras personas.

- Sobrevaloran su propia capacidad.

- Tienden a ser convencional y socialmente conformistas

- Son poco originales en pensamientos e inflexibles en la resolución de los problemas.

- Son rígidos y moralistas

- Tienen baja tolerancia al estrés.

- Las puntuaciones bajas en la escala L, son indicativas de personas que:

- Probablemente responde de forma franca y sincera a los ítems .

- Confían en sí mismos y pueden admitir sus pequeñas faltas y fallos.

- En algunos casos, pueden estar exagerando características negativas.

- Son perceptivos y socialmente confiados

- Aparecen como fuertes, naturales y relajados

- Son confiados e independientes

- Funcionan como líderes

- Son buenos comunicadores

- Pueden ser descritos por los demás como cínicos y sarcásticos". (pgs. 2425).

Butcher y Williams (1992) nos indican las pautas interpretativas de esta escala L:

- " $\mathrm{T} \geq 65$ indican un posible perfil inválido debido a una presentación demasiado virtuosa de sí mismo.

- $\mathrm{T}=60-64$ sugiere que se utilizó una serie de respuestas para dar buena impresión.

Las puntuaciones elevadas en la Escala L pueden encontrarse asociadas con otras escalas del MMPI-2. Así la escala TRIN (Inconsistencia de las respuestas verdadero) pueden ayudar al clínico a determinar si una puntuación elevada L puede ser debida al conjunto de respuestas de "falso" o "diciendo no" o al conjunto de respuestas de "verdadero" o "diciendo sí". Otros descriptores asociados con las puntuaciones elevadas sería los siguientes:

- Falta de buena voluntad para admitir pequeños defectos.

- Proclamación irrealista de virtud

- Denotación de un alto respeto por la moral

- Visión ingenua de sí mismo

- Esfuerzo notable por engañar a otros sobre los motivos o ajustes

- Problemas de ajuste de la personalidad" (pg.44). 
Tabla 5: Implicaciones de las puntuaciones en la Escala L (Mentira)

\begin{tabular}{|l|l|l|l|}
\hline Puntuaciones T & Utilidad del perfil & Origen de la elevación & Hipótesis interpretativas \\
\hline $\mathbf{T} \geq \mathbf{8 0}$ & Probablemente inválido & Fingir un buen ajuste & Prueba de resistencia o ingenuidad \\
\hline $\mathbf{T}=\mathbf{7 0 - 7 9}$ & Validez cuestionable & $\begin{array}{l}\text { Respuestas al azar } \\
\text { Rechazo de faltas }\end{array}$ & $\begin{array}{l}\text { Estado confusional } \\
\text { Estilo depresivo } \\
\text { Falta de comprensión }\end{array}$ \\
\hline $\mathbf{T}=\mathbf{6 0 - 6 9}$ & Probablemente válido & Cuadro defensivo & $\begin{array}{l}\text { Superconvencional y conformista } \\
\text { Moralista } \\
\text { Rígidamente virtuoso }\end{array}$ \\
\hline $\mathbf{T}=\mathbf{5 0 - 5 9}$ & Válido & $\begin{array}{l}\text { Típica aproximación al test. Puntuaciones } \\
\text { dentro de la media. }\end{array}$ & Conforme con su propia imagen \\
\hline $\mathbf{T} \leq \mathbf{4 9}$ & $\begin{array}{l}\text { Cuadro de "buscar conseguir algo más". } \\
\text { Todas las respuestas son "verdadero" }\end{array}$ & $\begin{array}{l}\text { Auto-confiado e independiente. } \\
\text { Crítico, sarcástico }\end{array}$ \\
\hline
\end{tabular}

La Tabla 5 nos presenta una síntesis de los principales indicadores interpretativos referidos por sus puntuaciones T. (Avila y Jiménez, 1999, pg.38)

\section{II.5.1.1.3. - La Escala F (Infrecuencia).}

Esta escala, originariamente, fue elaborada para detectar las formas anormales o atípicas de responder (Meehl \& Hathaway, 1946; Mckinley, Hathaway, \& Meehl, 1948), como una medida de la tendencia a reconocer o admitir una extensa gama de problemas psicológicos o también para "fingirse malo" o crear una mala imagen. Un individuo que presenta puntuaciones altas en $\mathrm{F}$ está reconociendo un amplio rango de quejas o dolencias que son infrecuentes para la población general reflejando con ello una tendencia a la exageración de los problemas o una presencia real de patología.

Los 64 ítems de la escala original (véase Anexo 2) fueron contestados en la dirección de puntuación por menos del $10 \%$ de los sujetos adultos de la población normalizada. Muchos de los ítems de la Escala $\mathrm{F}$ fueron suprimidos del MMPI-2 porque su contenido podría ser molesto, dejando a la escala con 60 ítems (véase Tabla 1).

Un análisis factorial de la Escala F original (Comrey, 1958) identificó 19 dimensiones de contenidos evaluando diversas características, como el pensamiento paranoico, actitudes o conductas antisociales, hostilidad y pobre salud física. Una persona puede obtener una puntuación alta en $\mathrm{F}$ por atribuirse algunos de los ítems pero no necesariamente todos de estas 19 áreas de contenido.

Al estar las escalas del MMPI-2 intercorrelacionadas, las puntuaciones elevadas en F, generalmente se encuentran asociadas con puntuaciones altas en las escalas Clínicas, especialmente las escalas $6(\mathrm{~Pa})$ y $8(\mathrm{Sc})$. Puntuaciones en $\mathrm{F}$ también se han encontrado correlacionadas con la edad y la raza en adolescentes negros, obtienen, aproximadamente, $10 \mathrm{~T}$ puntuaciones más en esta escala que otros grupos.

Para Graham (1990, pg. 25) la utilización de la Escala F en la práctica clínica puede servirnos para tres funciones importantes:

- Siendo un índice de la actitud al responder, es útil para detectar respuestas desviadas.

- En caso de poder descubrir un perfil invalidado, la Escala F sería un buen indicador de la psicopatología y cuanto mayor puntuación mayor índice de psicopatología.

- Generar inferencias sobre otras características adicionales y conductas. 
Los investigadores (Butcher, 1990; Graham, 1990; Butcher \& Williams, 1992) coinciden en considerar que una puntuación alta en $\mathrm{F}$ refleja una tendencia a exagerar los problemas. Excesivas confirmaciones a los ítems de esta escala están sugiriendo que una persona está intentando presentar una imagen desfavorable de sí mismo. Cuando nos preguntamos por las razones que pueden tener las personas al contestar de esta forma hemos de decir que, en general reflejan confusión, desorganización o exageración de los síntomas. Según estos investigadores dichas razones pueden obedecer a diferentes aspectos:

- Responder al azar a los ítems de la técnica. Al concretarse en los contenidos específicos de esta escala, hace que la incoherencia sea grande.

- Posible fingimiento de una enfermedad. Las personas que tienen este propósito no saben qué ítems contestar $\mathrm{y}$ en qué dirección hacerlo, terminando por atribuirse en sus respuestas un número exagerado de cuestiones correspondientes a esta escala. Los pacientes reales son más selectivos en su patrón de respuestas.

- El bajo nivel de lectura y de comprensión de los ítems puede ser otra de las causas de elevación en esta escala.

- Pueden tener distinto nivel cultural. Individuos con notables y diferentes bagajes culturales pueden ofrecer este tipo de puntuaciones elevadas (Butcher \& Williams, 1992)

- Los adolescentes, en general, suelen tener más altas estas puntuaciones que los adultos. Esto resulta, en parte, porque los adolescentes se identifican más miméticamente con los problemas.

- Personalidades psicóticas u orgánicamente dañadas que se encuentran confusas o desorganizadas. A menudo esta escala está asociada con problemas severos y crónicos de pacientes psiquiátricos. Consecuentemente se sugiere que el punto de corte para sugerir la invalidez de $\mathrm{F}$ alcance el valor de $>100$ (Graham, Wats \& Timbrook, 1991).

- Pueden estar contestando a todos los ítems como "verdadero" o como "falso" (Graham, 1990).

- Las personas con alto índice de estrés pueden encontrarse también con puntuaciones elevadas en esta escala.

- Pueden estar intentando conseguir la atención del clínico solicitando ayuda.

Después de todo ello es inevitable la pregunta para el evaluador: ¿cuál es el intervalo de puntuaciones $\mathrm{F}$ para poder considerar como inválido un perfil del MMPI-2?. Para Butcher (1990), si bien una puntuación de $\mathrm{T}=70$ es tomada como criterio sugerente de invalidez de la prueba, este no sería el caso de la escala F. Los clínicos no comienzan a considerar la invalidez del perfil hasta que $\mathrm{F}$ no llega al nivel de $\mathrm{T}=90$. En algunos casos, como es el de la admisión de un paciente psiquiátrico o del encarcelamiento en una institución correctora, es apropiado interpretar perfiles con puntuaciones comprendidas para esta escala entre 90 y 109 puntuaciones T.

A pesar de todas las investigaciones, podemos observar que no todos los autores de los trabajos realizados se ponen de acuerdo para delimitar claramente los intervalos de puntuaciones altas y sus implicaciones diagnósticas. Así, para Butcher y Williams (1992, pg.47): 
- Un perfil con puntuaciones $\mathrm{T} \geq 110$ debe ser invalidado porque se atribuye demasiados ítems .

- El intervalo comprendido entre $\mathrm{T}=90-109$ es sintomático de un perfil no válido y que puede ser obtenido por pacientes psiquiátricos con una extrema gravedad (Graham, 1990, utiliza el intervalo 80-99 para este diagnóstico). Las puntuaciones VRIN $\geq 79$ pueden ayudarnos a delimitar si el perfil es consistente.

- El intervalo de $\mathrm{T}=80-89$ nos está indicando el intento de exageración de síntomas (Graham, 1990, lo especifica en el intervalo 80-99). Igualmente podemos consultar si la escala VRIN presenta una puntuación $\mathrm{T} \geq 79$ para poder descartar respuestas inconsistentes.

- El intervalo de puntuaciones comprendidas entre $\mathrm{T}=60-79$ (65-79 para Graham, 1990) nos puede estar indicando un problema orientado hacia los ítems .

Para Graham (1990) las puntuaciones T en un rango de 80-99 son indicativas de:

- "Estar fingiéndose enfermos.

- Exageración de síntomas y problemas como, petición de ayuda

- Pueden estar mostrando una alta resistencia a realizar la prueba adecuadamente.

- Pueden ser claramente psicóticos para el criterio usual.

- Cuando las puntuaciones varían entre el rango $\mathrm{T}=65-79$, pueden ser indicio de:

- Presencia de atípicas concepciones políticas, sociales y religiosas

- Manifestación de severos desórdenes clínicos de tipo neurótico y psicótico.

Si se encuentra relativamente libre de índices psicopatológicos, los sujetos con estas puntuaciones pueden ser descritos como: variables, inquietos, insatisfechos, cambiantes, inestables, Curiosos, complejos, tercos, dogmáticos, oportunistas.

Cuando el rango de puntuaciones se encuentra comprendido entre $\mathrm{T}=50-64$, puede ser señal de:

- Haberse atribuido ítems relacionados con alguna área problemática particular.

- Un funcionamiento suficiente en la mayoría de los aspectos y de las situaciones de su vida.

- Las puntuaciones bajas son indicativas de personas que:

- Contestan a los ítems como la mayoría de las personas normales.

- Se encuentran, probablemente, libre de problemas psicopatológicos.

- Son socialmente conformistas.

- Pueden dar una buena imagen en las respuestas a los ítems del MMPI-2" (pgs.26 y 27).

Dos años después (Graham, 1992 y Butcher \& Williams, 1992) a tenor de las recientes investigaciones se ajustaron los intervalos de las puntuaciones. Por ejemplo, ya no encontramos el intervalo 80-99 sino el 80-100 y el 50-64 se encuentra dividido en dos intervalos referidos por el 50-59 y 60-64, todos, naturalmente, en puntuaciones $\mathrm{T}$. Estos ajustes podemos verlos en la Tabla 6 donde se presenta una síntesis de los 
principales pautas de interpretación posibles o hipotéticas referidos por sus puntuaciones T. (Avila y Jiménez, 1999, pg.39).

Greene (2000, Tabla 3.22, pg. 70) muestra los siguientes niveles y consideraciones hipotéticas, tanto para $\mathrm{F}$ como para $\mathrm{Fb}$ en puntuaciones $\mathrm{T}$ :

- $\leq 45$. Considerado como "bajo".

- 46-58. Normal

- 59-80. Moderada.

- 81-110. Dudosa.

- $\geq 111$. Extrema

Greene $(1997,2000)$ alude tres razones cuando las puntuaciones de la Escala $\mathrm{F}$ y/o Fb son elevadas:

- Inconsistencia de respuestas.

- Presencia de psicopatología.

- Fingimiento.

Y cuando las puntuaciones son bajas, pueden obedecer a las siguientes razones:

- Ausencia de psicopatología.

- Defensividad.

De esta forma, las razones que pueda tener una persona para expresar una puntuación alta o baja en la Escala F, a veces resulta difícil de determinar sin considerar otros indicadores de la consistencia y precisión de las respuestas a los ítems del cuestionario del MMPI-2.

Tabla 6: Implicaciones de las puntuaciones en la Escala F (Infrecuencia)

\begin{tabular}{|c|c|c|c|}
\hline Puntuaciones T & Utilidad del perfil & Origen de la elevación & Hipótesis interpretativas \\
\hline$T>100$ & Perfil inválido & $\begin{array}{l}\text { Respuestas al azar } \\
\text { Errores de corrección } \\
\text { Grave dislexia } \\
\text { Contestar a todo como "verdadero" }\end{array}$ & $\begin{array}{l}\text { Actitud no cooperativa } \\
\text { Fingir mala imagen de sí mismo } \\
\text { Paciente psiquiátrico que puede } \\
\text { estar desorientado, confuso, con } \\
\text { un comportamiento claramente } \\
\text { psicótico. }\end{array}$ \\
\hline$T=80-100$ & $\begin{array}{l}\text { Perfil invalidado } \\
\mathrm{Si} \text { válido, considerar serios } \\
\text { problemas psicopatológicos }\end{array}$ & $\begin{array}{l}\text { Fingir enfermedad } \\
\text { Procesos psicóticos } \\
\text { Responder "Falso" a todos los } \\
\text { items. } \\
\text { Exageración de problemas }\end{array}$ & $\begin{array}{l}\text { Reafirmación } \\
\text { Deseabilidad social } \\
\text { Estado confusional. }\end{array}$ \\
\hline$T=65-79$ & Probablemente válido & $\begin{array}{l}\text { Fingir enfermedad } \\
\text { Procesos psicóticos }\end{array}$ & $\begin{array}{l}\text { Psicótico } \\
\text { Neurótico severo } \\
\text { Problemática de sociabilidad } \\
\text { Propenso al cambio de humor, } \\
\quad \text { desasosiego, } \\
\text { insatisfecho } \\
\text { Cambiante, impredecible. }\end{array}$ \\
\hline$T=60-64$ & Probablemente válido & & $\begin{array}{l}\text { Problemas en un área particular } \\
\text { (trabajo, salud, sexo, etc.) }\end{array}$ \\
\hline$T=\mathbf{5 0 - 5 9}$ & Registro aceptable & Puntuaciones dentro de la media & $\begin{array}{l}\text { Buen funcionamiento } \\
\text { Respuestas normales }\end{array}$ \\
\hline $\mathbf{T}<\mathbf{5 0}$ & Registro aceptable & $\begin{array}{l}\text { Conformidad } \\
\text { Posible falsa imagen }\end{array}$ & $\begin{array}{l}\text { Convencionalidad } \\
\text { Sinceridad } \\
\text { Conformidad social. }\end{array}$ \\
\hline
\end{tabular}

Los clínicos, probablemente, legarían a la conclusión que una PD > 26 (110T) en la Escala $\mathrm{F}$ no refleja psicopatología, pero sí podría reflejar un patrón de incoherencia de respuestas o de fingimiento. De forma parecida, una $\mathrm{PD}=0$ (40T) podría reflejar la ausencia de psicopatología o defensividad. 
Ya que muchas decisiones clínicas se toman fundamentadas en función de la puntuación obtenida en la Escala $\mathrm{F}$, sería recomendable para los profesionañes la utilización de otros indicadores de validez en el MMPI-2 que ayuden a discriminar adecuadamente el por qué del valor conseguido por un sujeto en esta escala.

\section{II.5.1.1.4.- La Escala K(Corrección).}

La experiencia con la Escala L del MMPI pronto indicó que parecía ser totalmente insensible a la distorsión de algunos perfiles. La escala $\mathrm{K}$ fue elaborada como algo más sutil y efectiva ante los intentos del sujeto de negar o simular síntomas psicopatológicos deseando con ello presentarse de forma más favorable e incluso poder, en un sentido opuesto, exagerar su patología para evidenciar una mala imagen de sí mismo (Meehl y Hathaway, 1946; Mckinley \& Hathaway, 1948). De esta manera las puntuaciones elevadas dadas en la escala $\mathrm{K}$ fueron consideradas como una forma de defensividad ante el abordaje del test, considerando que las puntuaciones bajas fueron pensadas para poder apreciar una inusual franqueza y autocrítica.

La escala $\mathrm{K}$ originariamente estaba compuesta por 30 ítems que fueron empíricamente identificados contrastando las respuestas a los ítems de sujetos patológicos que producían perfiles normales (falsos negativos) con las respuestas dadas por sujetos normales. La versión del MMPI-2 sigue manteniendo el mismo número de ítems aunque uno de ellos fue cambiado.

Los 30 ítems, componentes de esta escala, cubren una amplia área de contenidos diversos en los que una persona puede llevar a cabo una negación de sus problemas (hostilidad, recelo, discordias familiares, ausencia de confianza, excesiva preocupación).

Investigaciones posteriores con el MMPI aportaron nueva información sobre esta escala K. Además de esta actitud defensiva, la escala muestra una relación con el nivel educativo y el estatus socioeconómico, de tal modo que los sujetos con mejor educación y mayor nivel socioeconómico presentaban puntuaciones elevadas (Dahlstrom, Welsh \& Dahlstrom, 1975; Dahlstrom, Lachar \& Dahlstrom, 1986). Los sujetos con estatus o reputación social considerable pueden dudar sobre hacer revelaciones que podrían suponer una pérdida de ese estatus o reputación al admitir francamente problemas emocionales, personales, matrimoniales, dudas, todo tipo de inseguridades o tener problemas con la familia. Moderadas elevaciones en la escala $\mathrm{K}$ a veces, reflejan un yo fuerte y personas con buenos ajustes psicológicos que no les importa evidenciar, y hasta expresar de forma sincera, los desajustes personales.

Resulta difícil, pues, poder diferenciar si un sujeto actúa de forma defensiva o por el contrario se trata de un sujeto psicológicamente sano con un buen ajuste y equilibrio psicológico. De todas formas los ítems de esta escala son más sutiles que los de la Escala L y, por consiguiente, menos probable que una persona defensiva reconozca el propósito de los ítems y tratará de evitar que le descubran.

Por ello es importante poder interpretar estas puntuaciones dentro de un contexto de otras informaciones sobre el sujeto. Los datos biográficos, experiencias, formación, nivel cultural pueden darnos luz sobre esta dificultad. También puede ser que se realice la comparación de los perfiles clínicos sin la corrección de las K (Graham, 1987; Greene, 1989). El uso de las ponderaciones de la escala K, al corregir algunas de las 
escalas Clínicas del perfil, se diseñó, precisamente, para tener en cuenta el impacto de estas orientaciones al contestar a los ítems del cuestionario.

Para Graham (1990), las puntuaciones elevadas en K denotan el intento, por parte del sujeto, de mantener una apariencia se suficiencia, control y eficacia. Los sujetos inhibidos, tímidos e indecisos que no se complican emocionalmente con otras personas, también presentan puntuaciones elevadas en esta escala. La delincuencia es improbable entre la gente con puntuaciones altas en esta escala K. Cuando estas puntuaciones elevadas se encuentran acompañadas con puntuaciones elevadas de las escalas Clínicas, es probable que la persona presente serios trastornos psicopatológicos y no tenga conciencia de ello. Cuando las puntuaciones son moderadamente altas podemos hipotetizar que no padecen estos trastornos psicológicos y que parecen presentar un buen ajuste psicológico, un yo fuerte $u$ otro tipo de características positivas para su personalidad.

Siguiendo las pautas del mismo autor, las puntuaciones medias en la escala $\mathrm{K}$ sugieren un saludable equilibrio entre la autoevaluación positiva del sujeto y su propia autocrítica. Tales personas tienden a estar bien ajustadas psicológicamente y manifiestan pocos síntomas propios de desequilibrio emocional. Se manifiestan como independientes, seguros de sí mismos y capaces de tratar los problemas de la vida diaria de forma equilibrada. Parecen mostrar un buen nivel de habilidades intelectuales y amplios intereses, se manifiestan algo ingenuos, emprendedores, versátiles y ocurrentes. Son personas que manifiestan un pensamiento claro y abordan los problemas de forma razonable y sistemática. En situaciones sociales, se relacionan bien con las demás personas, son entusiastas, verbalmente elocuentes e influyentes ante los demás.

Finalmente, las puntuaciones bajas en esta escala $\mathrm{K}$ pueden indicar que estas personas han podido contestar al cuestionario de varias formas distorsionadas, bien intentando presentar una imagen desfavorable, bien contestando a todo como "verdadero", bien experimentando cierta confusión en su mente, tanto funcional o de naturaleza orgánica, o bien exagerando sus propios problemas como indicativo de una petición de ayuda. Este tipo de puntuaciones bajas pueden revelar también que estamos tratando con personas muy críticas consigo mismos y con los demás encontrándose, de alguna forma, insatisfechos. Pueden ser personas ineficaces a la hora del tratamiento de los problemas de la vida diaria dudando sobre sus propias motivaciones y comportamientos. Se presentan como socialmente conformistas y tienden a ser demasiado sumisos con la autoridad. Son inhibidos, reservados y superficiales manteniendo una actitud ante la vida cargada de cinismo, escepticismo, crítica y desconfiada, tendiendo a ser suspicaces sobre las motivaciones de los demás.

Graham (1990) resume de la siguiente manera las implicaciones de las puntuaciones $\mathrm{K}$.

- "Puntuaciones elevadas son indicativas de las personas que:

- Pueden haber contestado como "Falso" a la mayor parte de los ítems (F\% alto).

- Pueden haber intentado dar una buena imagen en sus respuestas.

- Pueden estar intentando dar una sensación de suficiencia, control y eficacia.

- Son tímidos e inhibidos.

- Se muestran indecisos en su compromiso emocional con las personas. 
- Son intolerantes y no aceptan las actitudes y creencias poco convencionales de otras personas.

- Falta de perspicacia (intuición) y autocomprensión.

- No presentan abiertamente una conducta delincuente.

- Si las escalas Clínicas son elevadas, puede estar seriamente perturbado psicológicamente pero tiene poca conciencia de ello.

- Si no está perturbado psicológicamente puede tener un Yo fuerte, superior a la media, y otras características positivas.

- Puntuaciones medias en la escala K son indicativas de las personas que:

- Mantienen un equilibrio saludable entre la autoevaluación positiva y la autocrítica en las respuestas a los ítems del MMPI-2.

- Se encuentran bien equilibrados desde el punto de vista psicológico.

- Muestran pocos signos evidentes de trastornos emocionales.

- Son independientes y seguros de sí mismos.

- Son capaces de tratar adecuadamente los problemas de la vida diaria.

- Muestran amplios intereses.

- Son ingeniosos, emprendedores, versátiles e inventivos.

- Muestran un pensamiento claro abordando los problemas de forma razonable y sistemática.

- Tienen don de gentes.

- Se muestran entusiastas y verbalmente elocuentes.

- Toman un rol predominante en las relaciones con los demás.

- Puntuaciones bajas en la escala K son indicativas de las personas que:

- Pueden haber respondido "Verdadero" a la mayor parte de los ítems (V\% alto).

- Pueden haber fingido mala imagen en sus respuestas.

- Pueden estar exagerando sus problemas como una llamada de atención y solicitud de ayuda.

- Pueden manifestar una psicosis aguda o confusión orgánica.

- Son personas insatisfechas, críticas consigo mismas y con los demás.

- Son incapaces de tratar los problemas de la vida diaria de forma adecuada.

- Muestran poca percepción de sus propias motivaciones y de las de los demás.

- Son socialmente conformistas.

- Son demasiado complacientes con la autoridad.

- Presentan un lento ritmo personal.

- Se muestran inhibidas, retraídas y superficiales.

- Son socialmente difíciles.

- Son directas, francas y duras en las diversas situaciones sociales.

- Son cínicas, escépticas, caústicas y desconfiadas.

- Se muestran suspicaces ante las motivaciones de los demás." (pgs. 29-30) 
Tabla 7: Implicaciones de las puntuaciones en la Escala K(Corrección)

\begin{tabular}{|l|l|l|l|}
\hline Puntuaciones T & Utilidad del perfil & Origen de la elevación & Hipótesis interpretativas \\
\hline $\mathrm{T}>70$ & Perfil invalidado & $\begin{array}{l}\text { Fingir buena imagen. } \\
\text { Marcada defensividad } \\
\text { Contestar a todo como "Falso" (F\% alto) }\end{array}$ & $\begin{array}{l}\text { Implicación emocional acusada } \\
\text { Inhibición, timidez } \\
\text { Desconfianza } \\
\text { Ausencia de comprensión. }\end{array}$ \\
\hline $\mathrm{T}=60-70$ & Validez cuestionada & $\begin{array}{l}\text { Defensividad moderada } \\
\text { No reconocimiento del problema }\end{array}$ & $\begin{array}{l}\text { Clínicamente defensivo. Todo lo niega } \\
\text { Intolerante } \\
\text { Sin capacidad para la intuición. }\end{array}$ \\
\hline $\mathrm{T}=50-59$ & Perfil válido & Autoevaluación equilibrada & $\begin{array}{l}\text { Muy ajustado. } \\
\text { Independiente } \\
\text { Inteligente } \\
\text { Entusiasta } \\
\text { Intereses amplios }\end{array}$ \\
\hline $\mathrm{T}<50$ & Perfil invalidado & $\begin{array}{l}\text { Fingir "hacerse el enfermo". } \\
\text { Exageración de sus propios desajustes } \\
\text { Contestar a todo como "Verdadero" (V\% alto) }\end{array}$ & $\begin{array}{l}\text { Confuso } \\
\text { Autocrítico } \\
\text { Conformista } \\
\text { Introvertido } \\
\text { Cínico, suspicaz. }\end{array}$ \\
& & &
\end{tabular}

La Tabla 7 nos presenta una síntesis de las principales pautas de interpretación referidas por sus puntuaciones T. (Avila y Jiménez, 1999, pg.41).

II.5.1.2.- Indicadores adicionales de Validez:

Los trabajos de reestructuración y reestandarización del MMPI realizadas por el equipo de la Universidad de Minnesota (Butcher, Dahlstrom, Graham, Tellegen y Kaemmer, 1989) aportaron tres nuevas escalas de validez en el MMPI-2 para ayudar en la evaluación de actitudes invalidantes: Fb, VRIN y TRIN.

Ante una técnica tan extensa en números de ítems, y administradas a sujetos con diversos tipo de gravedad patológica, el cansancio y la falta de motivación para terminarla podría ser un handicap para su corrección. La escala $\mathrm{Fb}(\mathrm{F}$ posterior o " $\mathrm{F}$ back") nos puede ayudar a detectar estos aspectos ya que se encuentra evaluando la última parte de la técnica con las mismas características e implicaciones interpretativas que dispone la Escala $\mathrm{F}$ que se encarga de valorar la primera parte de la prueba.

La incoherencia en las respuestas, propuesta a través de "pares de ítems " con semejante $u$ opuesto sentido, son otras dos variables (VRIN y TRIN) que fueron añadidas en esta misma reestructuración del MMPI original. Son dos nuevos tipos de escalas (Tellegen, 1982, 1988a) diseñadas para completar las indicaciones de validez tradicionales pero con la salvedad que no intentan detectar un determinado contenido o información del ítem. Las puntuaciones obtenidas a través de estas dos escalas nos proporcionan un índice de la tendencia del sujeto a responder a los ítems de forma inconsistente, incoherente o contradictoria. Tiene un cierto parecido a la escala de Descuido de Greene (1978) que igualmente fue desarrollada para identificar el tipo de incoherencia en las respuestas al MMPI.

De esta manera el definitivo MMPI-2 se nos muestra con un total de 7 escalas ("?", $\mathrm{L}, \mathrm{F}, \mathrm{K}, \mathrm{Fb}$, VRIN y TRIN) que nos pueden aportar información suficiente para detectar la distorsión del perfil.

\section{II.5.1.2.1. L La escala $\mathcal{F} 6$ (F posterior).}

$\mathrm{La}$ escala $\mathrm{Fb}$ ("F Back scale") es un índice adicional de validez del test $\mathrm{y}$ originariamente fue desarrollada en la versión revisada del MMPI para detectar la 
posible desviación de las respuestas motivadas por la extensión de la prueba a través del cuadernillo experimental utilizado en la recogida de datos normativos del MMPI-2 (Butcher, Dahlstrom, Graham, Tellegen \& Kaemer, 1989). Este procedimiento utilizado para desarrollar la escala $\mathrm{Fb}$ fue similar al usado con la elaboración de la Escala $\mathrm{F}$ estándar. La escala Fb incluía originalmente 64 ítems, apareciendo posteriormente en la edición experimental del cuadernillo con un $10 \%$ de respuestas en la dirección de la puntuación cuando fue contestada por la población normal. La versión definitiva para el MMPI-2 de esta escala se quedó en 40 de los 64 ítems originales.

En la versión definitiva del MMPI-2, el último ítem de la Escala $\mathrm{F}$ es el 361, sin embargo el primer ítem de la escala $\mathrm{Fb}$ es el 281. Por lo tanto podemos decir que es fundamentalmente la segunda parte de la prueba la que detecta esta escala Fb. No podemos afirmar, como algunos manuales indican, que es a partir del ítem 370

Una puntuación elevada, y distinta de la F, puede sugerir que el sujeto dejó de prestar atención a los ítems del test, por cansancio o fatigabilidad (no olvidemos que esta prueba puede ser aplicada a pacientes con diversas patologías tanto en su sintomatología como en su intensidad). Caso de que la Fb presente una puntuación semejante hemos de referirnos a la interpretaciones de la Escala F.

No hemos de perder de vista que las puntuaciones de esta escala afectan a las Escalas Suplementarias y de Contenido. Una puntuación de $\mathrm{Fb} \mathrm{T} \geq 120$ invalidaría totalmente el protocolo, sin embargo cuando las puntuaciones son $\mathrm{T} \geq 80$ sugieren alguna clase de respuesta desviada de los ítems y sería necsaria una cuidadosa interpretación de las escalas Suplementarias y de Contenido en los cuales se basan estos ítems, precisamente.

Los sujetos que contestan "verdadero" a la mayoría de los ítems del MMPI-2, o que intenten dar una mala imagen, también producirían puntuaciones elevadas en la escala $\mathrm{Fb}$.

La Tabla 8 nos presenta una síntesis de las principales pautas de interpretación posibles o hipotéticas referidos por sus puntuaciones T. (Avila y Jiménez, 1999, pg.42).

Tabla 8: Implicaciones de las puntuaciones en la Escala $\mathcal{F} b$ (F posterior)

\begin{tabular}{|c|c|c|c|}
\hline Puntuaciones T & Utilidad del perfil & Origen de la elevación & Hipótesis interpretativas \\
\hline $\mathrm{T}>\mathbf{1 0 0}$ & Perfil inválido & $\begin{array}{l}\text { Responder al azar } \\
\text { Responder a todo como "Falso } \\
\text { Ofrecer una mala imagen de sí } \\
\text { mismo." }\end{array}$ & $\begin{array}{l}\text { Paciente psiquiátrico que puede } \\
\text { estar desorientado, confuso o que } \\
\text { puede mostrar claramente su } \\
\text { conducta psicótica. }\end{array}$ \\
\hline $\mathbf{T}=\mathbf{8 0 - 1 0 0}$ & $\begin{array}{l}\text { Perfil invalidado. } \mathrm{Si} \text { válido, } \\
\text { considerar serios } \\
\text { psicopatológicos. }\end{array}$ & $\begin{array}{l}\text { Responder a todo como "Falso". } \\
\text { Hacerse el enfermo } \\
\text { Exagerar sus desajustes }\end{array}$ & $\begin{array}{l}\text { Posibles } \\
\text { psicopatológicos. } \\
\text { Confuso } \\
\text { Fatiga, cansancio }\end{array}$ \\
\hline$T=65-69$ & Validez cuestionable & $\begin{array}{l}\text { Responder a todo como "Falso" } \\
\text { Hacerse el enfermo } \\
\text { Exagerar sus desajustes }\end{array}$ & $\begin{array}{l}\text { Considerar serios } \\
\text { psicopatológicos } \\
\text { Fatiga, cansancio. }\end{array}$ \\
\hline$T=50-64$ & Puntuación dentro de la media & Puntuaciones aceptables & \\
\hline $\mathbf{T}<\mathbf{5 0}$ & Validez cuestionable & $\begin{array}{l}\text { Considerar que ha podido expresar } \\
\text { una "buena imagen" de sí } \\
\text { mismo. }\end{array}$ & \\
\hline
\end{tabular}

II.5.1.2.2. - Escala VRIN (Inconsistencia de Respuestas Variables)

Esta escala se elaboró para el MMPI-2 como un indicador adicional de validez (Butcher, Dahlstrom, Graham, Tellegen y Kaemer, 1989) con el objetivo de detectar la 
tendencia de los sujetos a responder de una forma inconsistente o incoherente a los ítems . Esta escala VRIN se encuentra compuesta por 49 pares de ítems (cfr. Anexo 5) con contenido similar u opuesto. Cada vez que un sujeto responde a los ítems en un par de forma incoherente o inconsistente se anotará un punto para la escala VRIN. Se produce incoherencia o inconsistencia si el sujeto contesta a los ítems en la dirección propuesta.

Aunque las indicaciones de los autores (Butcher, Dahlstrom, Graham, Tellegen y Kaemmer, 1989) que llevaron a cabo la elaboración de esta escala nos advierten de su experimentalidad hasta encontrar datos empíricos más consistentes, no obstante, en sus investigaciones, sugieren que una puntuación directa igual o mayor a 13 ( $>14$ para la adaptación española; Avila y Jiménez, 1999) nos puede estar indicando incoherencia o inconsistencia en sus respuestas y posiblemente puede estar invalidando los resultados de la prueba.

Las respuestas de forma inconsistente pueden producir una puntuación $\mathrm{T}$ muy elevada en VRIN (>100). En protocolos que se han respondido a todos los ítems como "todo verdadero" (V\% alto) o como "todo falso" (F\% alto) las puntuaciones VRIN se encuentran dentro de las puntuaciones medias (50T). Igualmente, sujetos que de forma deliberada intentan ofrecer una mala o buena imagen en el MMPI-2 producen puntuaciones T medias en VRIN.

Para Graham (1990), esta escala VRIN se muestra mas eficaz cuando es utilizada conjuntamente con la puntuación obtenida en la escala $\mathrm{F}$. Una puntuación alta en $\mathrm{F} y$ una puntuación elevada en VRIN debería sugerir la idea de que el sujeto ha respondido aleatoriamente a los ítems del MMPI-2. Sin embargo, una puntuación alta en F unida a una puntuación baja o moderada en VRIN debería sugerir la no existencia de aleatoriedad o confusión. Por otro lado, uno debería sospechar del protocolo que procede de una persona severamente perturbada que responde válidamente a los ítems , así como de la persona que intenta aparecer más trastornado de lo que realmente está.

En el trabajo llevado a cabo por Greene (1997) comparando una muestra de población normal de 2.600 sujetos (Butcher et al., 1989) con 3.475 pacientes con trastornos mentales graves y 2.500 sujetos que contestan aleatoriamente a los ítems (Greene, 1995), se pudo apreciar que con una $\mathrm{PD}=13$ (equivalente a $80 \mathrm{~T}$ ) en la escala VRIN era contestado por $0,2 \%$ de los sujetos de la población normativa, por el $2,4 \%$ de los pacientes con trastornos y por el $84,4 \%$ de los sujetos que contestaban de forma inconsistente. Esto nos puede dar idea de la sensibilidad de esta escala.

Las investigaciones más actuales no se ponen de acuerdo para determinar cuál es el punto de corte que significa la inconsistencia de las respuestas dadas. Se han sugerido, como punto de corte, la puntuación de 10 (Greene, 1991), 13 (Butcher et al., 1989) y 14 (Berry, Baer y Harris, 1991). Greene (1997, pg. 177) propone la siguiente guía general para determinar la significatividad de las respuestas en la escala VRIN:

$1^{\circ}$.- Con una $\mathrm{PD} \leq 7$, existe una alta probabilidad de que el paciente se atribuya los ítems de una forma consistente.

$2^{\circ}$.- Con una $\mathrm{PD}=8-15$, no parece estar claro si el paciente está contestando a los ítems de una forma consistente o inconsistente. En este caso se recomienda al clínico que examine los restantes índices de validez. Estos mismos índices pueden resultar válidos, igualmente, cuando la puntuación de VRIN $\leq 7$ para podernos asegurar de que 
los ítems han sido contestados de forma coherente, especialmente en la segunda parte del MMPI-2.

$3^{\circ}$.- Con una $\mathrm{PD} \geq 16$, existe una alta probabilidad de que el sujeto haya contestado a los ítems de forma inconsistente.

No obstante en la última revisión Greene $(2000$, pg. 64, Tabla 3,18) reestructura los diferentes puntos de corte de sus puntuaciones directas: 0-2 (bajo); 3-7 (normal); 8-10 (dudoso) $\mathrm{y} \geq 11$ (acusado).

Una de las ventajas, sumamente interesantes, de VRIN sobre las escalas de infrecuencia $(\mathrm{F}$ y $\mathrm{Fb}$ ), en esta evaluación de la coherencia de respuestas, es que VRIN no se ve afectada por la presencia, el tipo o la severidad de la sintomatología psicopatológica, como se aprecia en el trabajo de Greene (1997, pg.176 y 2000, pg. 57) al comparar las puntuaciones medias y las desviaciones estándar similares en el MMPI2 para el grupo normativo y los pacientes con trastornos mentales. Estas puntuaciones son notablemente similares a las obtenidas por nuestro grupo de población normal (véanse tablas 45,46 y 47 ).

Igualmente, para este autor (Greene 1997, 2000), VRIN tampoco parece afectado por el fingimiento o la defensividad ya que la persona ha de atribuirse los ítems de forma coherente para poder cambiar sus respuestas. Al mostrarse bastante más coherente de lo que debía esperarse, la escala VRIN se convierte en un potencial indicador de fingimiento y defensividad del MMPI-2; consecuentemente esta escala nos puede proporcionar una buena estimación de la consistencia de las respuestas a los ítems .

Es así como VRIN podría convertirse en un detector de perfiles, considerados aparentemente coherentes por las escalas de infrecuencia, pero que muestra sus respuestas incoherentes. Igualmente también puede ayudar a demostrar que la persona ha respondido a los ítems de forma coherente a pesar de las puntuaciones elevadas en $\mathrm{F}$ y Fb (Evans \& Dinning, 1983; Gallucci, 1985; Maloney, Duvall, \& Friesen, 1980; Wetter, Baer, Berry, Smith, \& Larsen, 1992). Estos descubrimientos indican que VRIN y las Escalas de infrecuencia no evalúan idénticos procesos en la prueba de actitudes (Fekken \&Holden, 1987) y, consecuentemente, no pueden ser sustituidas por otras escalas.

Aunque VRIN es útil para identificar patrones inconsistentes de respuestas, hemos de tener en cuenta que una puntuación aceptable solamente indica que la persona ha respondido de forma coherente, pero no necesariamente con precisión o exactitud (honestidad) ya que un sujeto puede, de una forma coherente, mostrar su fingimiento o su defensividad. Además, VRIN evalúa solamente la consistencia de las respuestas de las personas, no detectará (como aprecia Greene, 1997, 2000) patrones de respuesta "todo verdadero" (VRIN =5) o "todo falso" (VRIN =5), que son consistentes pero no es la realidad del patrón de realización de la prueba.

Estos mismos patrones son fácilmente detectables por TRIN en los que se pueden obtener puntuaciones excesivamente altas o baja (23 ó 0, respectivamente). Las razones que tiene una persona para contestar de esta forma incoherente, pueden ser múltiples y variadas y, si deseamos profundizar en sus causas, tendremos que realizar un estudio más profundo de la persona a través de otras técnicas de evaluación. 
Tabla 9: Implicaciones de las puntuaciones en la Escala VRIN.

\begin{tabular}{|l|l|l|}
\hline Puntuación directa & Utilidad del perfil & Hipótesis interpretativa \\
\hline PD $>14$ & Perfil invalidado & Responder al azar \\
\hline PD $\leq \mathbf{1 4}$ & Perfil válido & \\
\hline
\end{tabular}

La Tabla 9 nos presenta una síntesis de las principales pautas de interpretación posibles o hipotéticas referidos por sus puntuaciones T. (Avila y Jiménez, 1999, pg.44).

\section{II.5.1.2.3.- Escala TRIN (Inconsistencia de las Respuestas Verdadero)}

La escala de Inconsistencia de respuestas Verdadero (TRIN) fue desarrollada en el MMPI-2 con el propósito de poder identificar a los sujetos que responden de forma incoherente o inconsistente a los ítems dando respuestas de "verdadero" de forma indiscriminada (aquiescencia, conformidad, consentimiento) o dando respuestas "falso", igualmente de forma discriminada, (no aquiescencia, disconformidad) (Butcher, Dahlstrom, Graham, Tellegen y Kaemmer, 1989). En estos casos el resultado de los perfiles deben ser invalidados y no interpretados.

Esta escala TRIN se compone de 20 pares de ítems (cfr. Anexo 6) que son opuestos de contenidos. Dos respuestas "verdadero" para algún par de ítems o dos respuestas "falso" para otro par de ítems indican inconsistencia o incoherencia en las respuestas.

Las puntuaciones de TRIN pueden estar en un rango de 0 a 23. Puntuaciones elevadas nos están indicando una tendencia a dar respuestas "verdadero" de forma indiscriminada, y puntuaciones directas bajas nos muestran una tendencia a responder a los ítems como "falso", igualmente, de forma indiscriminada. Cuando las puntuaciones directas son convertidas a las puntuaciones baremadas $\mathrm{T}$, las puntuaciones directas superior e inferior al promedio, se convierten en puntuaciones $\mathrm{T}$ altas, que van seguidas por una " $\mathrm{V}$ " o una "F" para indicar la dirección de la inconsistencia de respuesta.

Tabla 10: Implicaciones de las puntuaciones en la Escala TRIN.

\begin{tabular}{|l|l|l|}
\hline Puntuaciones directas & Utilidad del perfil & Hipótesis interpretativas \\
\hline$>\mathbf{1 4}$ & Perfil invalidado & Tendencia a la aquiescencia de respuestas \\
\hline $\mathbf{9 - 1 3}$ & Perfil válido & \\
\hline$<\mathbf{9}$ & Perfil válido & Tendencia a la no-aquiescencia de las respuestas (más bien, no sabe o no contesta) \\
\hline
\end{tabular}

Como sucede con la escala VRIN, la TRIN es también considerada como una escala experimental (Butcher, Dahlstrom, Graham, Tellegen y Kaemmer, 1989) y su interpretación debería hacerse cuidadosamente hasta encontrar un mayor número de investigaciones empíricas. En ello estamos con este trabajo de tesis que presentamos e intentaremos aportar datos empíricos a través de nuestra investigación. No obstante, el manual original del MMPI-2 (Butcher, Dahlstrom, Graham, Tellegen y Kaemmer, 1989) sugiere que una puntuación directa de $13+$ ó -5 deben ser indicio de respuesta indiscriminada que debería anular el protocolo. Para la adaptación castellana (Avila y Jiménez, 1999) esta puntuación directa que invalida el protocolo debe ser superior a 14 (cfr. Tabla 10).

La Tabla 10 nos presenta una síntesis de las principales pautas de interpretación posibles o hipotéticas referidos por sus puntuaciones T. (Avila y Jiménez, 1999, pg.43).

1 “verdadero" en castellano; "T" (true) en inglés. 
II.5.1.2.4. - El porcentaje de Verdadero (V\%) y Falso (F\%).

Una forma de apreciar la tendencia de respuesta por parte de un sujeto es analizar el porcentaje de respuestas que el mismo individuo ha dado a las distintas opciones de "Verdadero" (V\%) o de "Falso" (F\%) por medio de sus porcentajes. El Manual para la administración y corrección de Butcher, Dahlstrom, Graham, Tellegen \& Kaemmer (1989) y la adaptación castellana realizada por Avila y Jiménez (1999) no presentan datos referentes a los porcentajes dados a las respuestas. Butcher y Williams (1992) nos indican que un porcentaje de respuestas $\mathrm{V} \%$ o $\mathrm{F} \%$ extremadamente bajo, inferior al $20 \%$ o superior al $80 \%$ reflejarían un patrón de respuestas altamente distorsionado, tal como una manipulación consciente o de respuestas descuidadas a lo que preguntan los ítems .

\section{II.5.2.- Otras Escalas del MMPPI-2:}

Las Escalas fundamentales del MMPI-2 son las denominadas tradicionalmente Clínicas de las cuales se van a obtener todas las demás. En este apartado no vamos a dedicar de forma minuciosa y detallada a la descripción del conjunto de escalas y de sus componentes, simplemente haremos una descripción somera de las mismas, ya que no es el tema central de nuestra tesis.

Por "otras Escalas" hemos denominado en este capítulo a un grupo de Escalas y Subescalas, que se agrupan de la siguiente manera:

Escalas principales:

- Clínicas

- De Contenido

- Suplementarias

Subescalas:

- De Harris-Lingoes

- Wiener-Harmon.

- Ítems críticos

A continuación, vamos a describir de forma sencilla cada conjunto de escalas y sus componentes.

\section{II.5.2.1. Las Escalas Clínicas.}

Las Escalas Clínicas se componen de 9 dimensiones de la Personalidad que intentan apreciar los principales componentes de la psicopatología de la persona. La mayor parte de las Escalas del MMPI fueron derivadas a través del método empírico de grupos contrastados. Hathaway y Mckinley seleccionaron muestras homogéneas de sujetos normales y de pacientes psiquiátricos. A ambos grupos de la muestra se les administraron los diferentes ítems representativos de un determinada patología seleccionando aquellos ítems que resultaron ser significativamente diferentes en sus puntuaciones en cada una de las dos muestras.

Como veremos a continuación, estas escalas Clínicas vienen representadas por una sigla y también por un número, de tal forma que podemos hacer referencia a ellas indistintamente a través del dígito, de la sigla o del nombre. Más adelante podremos observar la generación de códigos diagnósticos en los que se hacen referencia, expresamente, a los dígitos representativos de cada factor. 
- 1 Hs.- Hipocondría: Las altas puntuaciones indican la presencia de numerosos problemas físicos de origen ambiguo. Estos problemas tienden a ser crónicos y no suelen responder a los tratamientos psicológicos. La presencia de enfermedades orgánicas no suele incidir en la elevación de las puntuaciones de esta escala. Esta escala es una versión mejorada de la inicial $\mathrm{H}-\mathrm{Ch}$.

- 2 D.- Depresión: Evalúa los síndromes clínicos de la Depresión, sin que permita distinguir entre las distintas formas clínicas del trastorno. Para efectuar una valoración más precisa hay que utilizar las formas abreviadas de la Escala.

- 3 Hy.- Histeria: Evalúa la similitud de las respuestas de los sujetos con las características de los pacientes con sintomatología de Trastorno Histérico de Conversión. No permite distinguir entre la Neurosis Histérica de Conversión y la Personalidad Histriónica grave.

- 4 Pd.- Desviación psicopática: Evalúa características relacionadas con el Trastorno de Personalidad Antisocial, con incapacidad de presentar una respuesta emocional profunda, elusión de las normas sociales, y abundancia de complicaciones en las relaciones interpersonales, con numerosos comportamientos desviados (mentira, abuso de drogas o alcohol, perversiones sexuales, actos delictivos).

- 5 Mf.- Masculinidad / Feminidad: Esta escala evalúa el ajuste a los estereotipos de rol sexual, y la eventual desviación hacia los intereses del otro sexo. Parte de los ítems fueron extraídos de la obra de Terman y Miles (1936) reflejando los valores tópicos de la época. Los elementos que se seleccionaron primaban la indicación de tendencia hacia la feminidad en los varones. En las mujeres la escala no tiene una significación clara.

- 6 Pa.- Paranoia: Esta escala recoge características de pacientes con delirios de persecución o referencia, de susceptibilidad, sospecha, e hipersensibilidad general. Aunque la escala no discrimina con absoluta seguridad los estados paranoides, es claramente indicativa de Esquizofrenia Paranoide, Paranoia, y en todo caso de la necesidad de tratamiento.

- 7 Pt.- Psicastenia: Esta escala recoge características de los pacientes que presentan fobias, obsesiones o compulsiones, aunque éstas no sean incapacitantes. Está relacionada con otras escalas, principalmente con la D, siendo frecuente la asociación entre puntuaciones elevadas en ambas escalas.

- 8 Sc.- Esquizofrenia: Evalúa la semejanza con los pacientes con alteraciones del pensamiento, conductas desorganizadas o bizarras, como los típicos en la esquizofrenia simple, hebefrénica o paranoide, aunque esta escala no recoge la ideación paranoide.

- 9 Ma.- Hipomanía: Evalúa las características de personalidad definidas como hiperproductividad del pensamiento e hiperactividad maníaca. La escala evalúa principalmente comportamiento hipomaníaco, con frecuente asociación con comportamientos psicopáticos.

- O Si.- Introversión social: No es propiamente una escala clínica. Las puntuaciones altas indican tendencia a aislarse del contacto social interpersonal, relacionado con el concepto de introversión. Personas apáticas, tímidas, inseguras, con dificultad para 
tomar decisiones, faltas de confianza en sus capacidades, que no encuentran satisfacción en el contacto social.

II.5.2.2. - Las Escalas de Contenido.

Las Escalas de Contenido del MMPI-2 se desarrollan utilizando una combinación de métodos racionales y estadísticos, dando como resultado un grupo de 15 escalas que se consideran consistentes internamente, relativamente independientes y clínicamente representativas de dimensiones de contenido importantes. Por lo tanto las Escalas de Contenido del MMPI-2 proporcionan al clínico una validez psicométrica comparativamente semejante al resto de las escalas de la prueba. El papel de las escalas de Contenido, para discriminar el diagnóstico, ha sido evaluado en diferentes investigaciones. El estudio realizado con pacientes psiquiátricos (Ben-Porath, Butcher y Graham, 1991) mostraron que las escalas BIZ (Pensamiento bizarro) y DEP (Depresión) resultaban más efectivas en el diagnóstico que las escalas Clínicas D (Depresión) y Sc (Esquizofrenia).

Las escalas de personalidad, basadas en el contenido, tienen la ventaja de ser más fáciles de interpretar gracias a la homogeneidad de sus propios contenidos (Burisch, 1984), demostrando con ello ser tan válidas para describir y predecir variables de personalidad como otras escalas desarrolladas mediante otros métodos (Hase \& Goldberg, 1967). La interpretación del contenido del MMPI-2 se ha convertido en un anexo, ampliamente aceptado, a la interpretación de las escalas empíricas tradicionales (Graham, 1987).

Las Escalas de Contenido pueden ofrecer ayuda a los clínicos para comprender las puntuaciones elevadas de las Escalas Clínicas que permitan la confirmación o eliminación de ciertos rasgos comportamentales representados en la escala.

Las 15 Escalas de Contenido son las siguientes:

- ANX - Ansiedad: Se pretende evaluar los síntomas generales de ansiedad, incluyendo tensión, problemas somáticos, problemas de insomnio, preocupaciones y escasa concentración.

- FRS - Temores: Su objetivo evaluativo pretende detectar a las personalidades temerosas, con diversos miedos: a los lugares altos, ver sangre, relacionados con el dinero, a los animales, espacios abiertos-cerrados, a salir de casa, etc.

- OBS - Obsesividad: Muestra la tendencia de los sujetos a manifestar grandes dificultades para tomar decisiones y que son propensos a rumiar excesivamente sus preocupaciones y problemas, impacientando con ello a los que les rodean.

- DEP - Depresión: Detecta a los sujetos caracterizados por pensamientos significativamente depresivos, melancólicos, tristes, sin interés por sus vidas ni por su futuro.

- HEA - Preocupaciones por la salud: Esta escala fue desarrollada específicamente para evaluar a las personas que se preocupan excesivamente de su salud informando reiteradamente de sus múltiples problemas en los distintos sistemas orgánicos.

- BIZ - Pensamiento bizarro: Detectan a las personalidades que presentan un proceso de pensamiento psicótico, informando de alucinaciones auditivas, visuales, 
olfativas, aún reconociendo que esos mismos pensamientos son extraños y peculiares.

- $\boldsymbol{A N G}$ - Ira: Describe a las personalidades con problemas de control en su conducta, manifestándose irritables, exaltados, impacientes y gruñones, sintiéndose, a veces, con ganas de "romper todo lo que encuentran a mano".

- CYN - Cinismo: Caracterizan a los pacientes por creencias misántropas, esperando ocultas motivaciones negativas tras los actuaciones de los demás (p.e. creen que la mayoría de la gente es honesta sólo porque temen encontrarse con la justicia e ir a la cárcel).

- ASP - Conducta antisocial: Esta escala nos detecta a las personalidades con problemas de conducta y problemas con la ley.

- TPA - Tipo A: Escala desarrollada para evaluar a las personalidades exigentes, trabajadoras, que se impacientan frecuentemente, irritables, directos y autoritarios con los demás. Describen a la personalidad "Tipo A".

- LSE - Baja autoestima: Referida por las puntuaciones que detectan a las personalidades caracterizadas por bajas opiniones y actitudes negativas sobre sí mismo.

- SOD - Malestar social: Escala referida para evaluar a los sujetos que se sienten intranquilos cuando están rodeados de gente, huyendo de las fiestas y de los acontecimientos sociales, prefiriendo la soledad.

- FAM - Problemática familiar: Escala desarrollada para evaluar las relaciones problemáticas entre los miembros de la familia.

- WRK - Interferencia en el trabajo: La escala es indicativa de conductas o actitudes que, probablemente, contribuyen a un desajuste y deficiente ejecución en el trabajo habitual.

- TRT - Indicadores negativos de tratamiento: Las puntuaciones elevadas denotan a los sujetos con dificultades y actitudes negativas hacia el tratamiento médico o psicológico, no creyendo en los cambios posibles y que nadie puede ayudarles o atenderles.

\section{II.5.2.3.- Las Escalas Suplementarias.}

El MMPI-2 dispone de un número de escalas, denominadas "Suplementarias", utilizadas para ayudar a interpretar las escalas Clínicas y aumentar la cobertura de problemas y trastornos clínicos. Al interpretar estas escalas no pueden especificarse los valores absolutos de las puntuaciones altas y bajas. En general, como ya ocurría con las escalas Clínicas, las puntuaciones $\mathrm{T}$ mayores de 65 podrían considerarse como puntuaciones altas y las puntuaciones $\mathrm{T}$ menores de 40 podrían ser consideradas como puntuaciones bajas. Para algunas escalas, como la escala Revisada de Alcoholismo de McAndrew, suelen hacerse mayores recomendaciones específicas concernientes a los niveles de puntuación.

La mayor parte de las escalas Suplementarias o especiales del MMPI se desarrollaron con un objetivo específico, como podría ser el control de la hostilidad, los problemas de 
abuso de alcohol o el desajuste escolar. Su aplicación es, generalmente, más pequeña y limitada que las escalas Clínicas y las de Contenido del MMPI-2.

II.5.2.3.1. - Escalas tradicionales:

El material interpretativo para estas cuatro escalas es, generalmente, más completo que el de algunas medidas más recientes que actualmente se están ofreciendo en el MMPI-2:

- A - Ansiedad: Desarrollada por Welsh (1956), a través de 39 ítems en el MMPI-2 (igualmente en el MMPI original), para evaluar la primera dimensión que emerge cuando las escalas de Validez y Clínicas son sometidas a análisis factorial. Las puntuaciones altas reflejan malestar, ansiedad y trastornos emocionales generales. Por el contrario, los sujetos que puntúan bajo tienden a ser enérgicos, competitivos y socialmente abiertos.

- $\boldsymbol{R}$ - Represión: Igualmente fue desarrollada por Welsh (1956) con el mismo tratamiento estadístico del análisis factorial. Esta escala se compone de 37 ítems en el MMPI-2 (40 en el MMPI original). Sus puntuaciones altas denotan un cierto convencionalismo y sumisión, personas que se esfuerzan por evitar situaciones desagradables o no placenteras. Las puntuaciones bajas refieren personalidades acomodaticias, adaptables, expresivos, desinhibidos e informales, tendiendo a ser emocionalmente excitables, agresivos, astutos e incluso dominantes.

- ES - Fuerza del Yo: Desarrollada por Baron (1953) específicamente para evaluar la capacidad de un individuo para sacar provecho de una psicoterapia individual o de grupo. Esta escala está compuesta, en la versión del MMPI-2, por 52 ítems (68 en el MMPI original). Es una medida de adaptabilidad, resistencia, recursos personales y funcionamiento efectivo, considerándose también como un buen indicador de salud mental. Las puntuaciones elevadas denotan un buen contacto con la realidad, sentimientos de adecuación personal y buen funcionamiento físico. Las puntuaciones bajas denotan, probablemente, sentimientos de incapacidad para afrontamiento ante el estrés con pobre concepto de sí mismo y con dificultades para adaptarse a las situaciones problemáticas.

- MAC-R - Escala Revisada de Alcoholismo de McAndrew: Esta escala fue desarrollada por McAndrew (1965) utilizando 49 ítems para la versión final del MMPI-2. Las puntuaciones elevadas $(>28)$ hacen referencia a la propensión a la adicción general, más que con tendencias alcohólicas únicamente, sujetos socialmente extrovertidos, exhibicionistas y amantes de correr riesgos. Las puntuaciones por debajo de 24 indicarían ausencia de un problema de abuso de sustancias .

\section{II.5.2.3.2.- Escalas adicionales:}

- $\boldsymbol{O}-\boldsymbol{H}$ - Hostilidad controlada: Las investigaciones de Megargee, Coock y Mendelson (1967) sobre una muestra de presos considerados como violentos y no violentos, hicieron desarrollar esta escala a través de 28 ítems en la versión del MMPI-2 (31 en el MMPI original). Esta escala proporciona una medida de la capacidad del individuo para tolerar las frustraciones sin tomar represalias. 
- Do - Dominancia: Desarrollada por Gough, Mclosky y Meehl (1951) con sujetos que muestran una alta o baja dominancia en sus relaciones interpersonales. La escala se compone de 25 ítems en su versión final del MMPI-2 (28 en el MMPI original). Es una medida de las tendencias del sujeto a dominar y liderar el grupo en sus relaciones interpersonales.

- Re - Responsabilidad: Esta escala fue desarrollada igualmente por Gough, Mclosky y Meehl (1952) a través de 30 ítems en la versión definitiva del MMPI-2 (32 en el MMPI original). Es una medida tendente a evaluar la capacidad de responsabilidad ante sí y ante el grupo de las personas (visto por sí mismo o referido por los demás).

- Mt - Ajuste inadecuado: Kleinmuntz (1961) fue quien desarrolló esta escala para discriminar entre escolares con buen y mal ajuste emocional. La versión final del MMPI-2 está compuesta por 41 ítems (43 en el MMPI original). Las investigaciones posteriores han demostrado que la escala $\mathrm{Mt}$ es útil para identificar los problemas emocionales, pero no tanto para predecir futuras dificultades de ajuste. Las puntuaciones elevadas denotan personalidades propensas, en general, a ser pesimistas, ansiosos y estar pobremente ajustados. Puntuaciones bajas denotan sujetos bien ajustados y optimistas.

- GM y GF - Rol sobre el género: Ambas escalas se han desarrollado de forma separada (Dahlstrom, 1988; Peterson, 1989): GM (rol del género masculino) y GF (rol del género femenino) con 47 y 46 ítems respectivamente en la versión final del MMPI-2. Presentan referencias con la escala 5-Masculinidad/Feminidad de este mismo test así como la Masculinidad/feminidad del Inventario Psicológico de California (CPI, de Gough, 1957, 1987). Sus interpretaciones se encuentran relacionadas con la autopercepción de su propio papel referido a su sexo masculino o femenino.

- PK y PS: Trastorno por estrés postraumático: Escala desarrollada por Keane, Malloy y Fairbank (1984) basándose en el contraste de pacientes psiquiátricos de la Administración de Veteranos que manifestaban bien un trastorno de estrés postraumático o bien estaban libres de esta aplicación condicional. La escala PS, resultado del trabajo de Schlenger y Kulka (1987, fue desarrollada contrastando el estado emocional de los Veteranos del Vietnan con el de los que fueron identificados como sujetos que mostraban un trastorno de estrés postraumático sin más implicaciones psiquiátricas.

- MDS.- Escala de Malestar Matrimonial: La escala de Malestar Matrimonial (MDS) está diseñada para identificar malestar o discordia en las relaciones íntimas. Los catorce ítems de la escala, empíricamente construida, fueron diseñados para identificar malestar matrimonial. El contenido de los ítems se reparte en: calidad de vida en el hogar, peleas familiares, sexo, amor e intimidad. Nueve de los ítems también aparecen en cualquiera de las dos escalas, 4 (Pd) o FAM, y como consecuencia la correlación de MDS con estas dos escalas es alta. La correlación con la Escala de Ajuste Diádico de Spainer (DAS; Spainer, 1976) en la muestra normativa completa fue de $-0,55$ en oposición a $-0,41$ para ambas escalas 4 y FAM con la DAS. 
- APS.- Escala de Potencial de Adicción: La escala de Potencial de Adicción (APS) está compuesta por 39 ítems del MMPI-2, caracteriza individuos con potencial para desarrollar problemas de abuso de sustancias. Ninguno de los ítems contiene referencias obvias de abuso de alcohol o drogas. Los ítems se relacionan con dimensiones de la personalidad y situaciones vitales asociadas con abuso de sustancias.

- ASS.- Escala de Reconocimiento de Adicción: Como complemento de la escala APS, la cual no contiene ítems obvios de abuso de sustancias, la Escala de Reconocimiento de Adicción (AAS) contiene ítems totalmente relacionados al abuso de sustancias. La construcción de la escala AAS (Butcher, en prensa) comenzó con una búsqueda racional a través de los ítems del MMPI-2, agrupando los reactivos con contenido que indicaran problemas de abuso de sustancias.

\section{II.5.2.4.- Las Subescalas:}

Fundamentalmente consideramos las de Harris-Lingoes y las de Wiener-Harmon.

\section{II.5.2.4.1.-Subescalas de Harris-Lingoes.}

Harris y Lingoes (1955) construyeron subescalas para las escalas Clínicas 2, 3, 4, 6, 8,9 y 0 , examinando el contenido de los ítems dentro de cada una y agrupando intuitivamente los ítems que parecían similares en contenido, o que ellos juzgaban que reflejaban una única actitud y un único rasgo. La información que ofrecen estas escalas es especialmente útil en la comprensión de una puntuación elevada ( $T$ entre 65 y 75) de una determinada escala clínica cuando, sobre todo, no se esperaba, a la vista del historial del sujeto o de la misma información obtenida. Las escalas son las siguientes:

- 2 - D: Depresión:

- D1.- Depresión subjetiva.

- D2.- Retardo psicomotor.

- D3.- Disfunción física.

- D4.- Entorpecimiento mental.

- D5.- Rumiación.

- 3 - Hy - Histeria:

- Hy1.- Negación de ansiedad social.

- Hy2.- Necesidad de afecto.

- Hy3.- Relax-malestar.

- Hy4.- Quejas somáticas.

- Hy5.- Inhibición de la agresión.

- 4 - Pd - Desviación psicopática:

- Pd1.- Discordia familiar.

- Pd2.- Problemas con la autoridad.

- Pd3.- Imperturbabilidad social.

- Pd4.- Alienación social.

- Pd5.- Autoalienación.

- 6 - Pa - Paranoia: 
- Pa1.- Ideas persecutorias.

- Pa2.- Mordacidad.

- Pa3.- Sencillez.

- 8 - Sc - Esquizofrenia:

- Sc1.- Alienación social.

- Sc2.- Alienación emocional.

- Sc3.- Ausencia de control cognitivo.

- Sc4.- Ausencia de control conativo.

- Sc5.- Ausencia de autocontrol.

- Sc6.- Experiencias sensoriales extrañas.

- 9 - Ma - Hipomanía:

- Ma1.- Amoralidad.

- Ma2.- Aceleración psicomotriz.

- Ma3.- Imperturbabilidad.

- Ma4.- Autoenvanecimiento.

- 0 - Si - Introversión Social: Subescalas Si (Hosteler y otros, 1989)

- Sil.- Timidez/Autoconocimiento

- Si2.- Evitación social

- Si3.- Alienación respecto a sí mismo y respecto a los demás.

II.5.2.4.2. - Subescalas de Wiener-Harmon. Los items Obvio-sutiles.

Wiener y Harmon (1946) denominaron "obvios" a aquellos ítems que fácilmente se detectaban como indicadores de perturbación emocional. Contrariamente a estos se encontraban los ítems "sutiles" que eran más difíciles de detectar, por parte de los sujetos, los diferentes tipos de perturbaciones. Existía la presunción, por parte de la mayor parte de los clínicos, de que las escalas contenían algunos ítems que, de forma sutil y no obvia, permitían evaluar a un sujeto, sin que fuese consciente de que estaba transmitiendo información importante sobre sí mismo. Intentando identificar cuales son los ítems que presentaban esta peculiaridad, encontraron que 110 ítems eran considerados como "sutiles" y 146 como "obvios. Aunque Wiener y Harmon (1946) intentaron desarrollar subescalas obvio y sutil para todas y cada una de las escalas clínicas, sólo tuvieron éxito en las cinco siguientes: Depresión (D), Histeria (Hy), Desviaciones psicopáticas (Pd), Paranoia (Pa) e Hipomanía (Ma).

Wiener y Harmon (1946) encontraron que sus escalas podrían utilizarse para evaluar la validez del protocolo en el registro del test, informando que la defensividad encontrada en las puntuaciones altas de la escala "L" se relacionaba con las puntuaciones sutiles más que con las puntuaciones obvias.

Las investigaciones disponibles sobre las subescalas Obvio y Sutil de Wiener y Harmon (1946) no sugieren un criterio explícito para definir el fingimiento y la defensividad.

Un nuevo debate ha surgido durante la última década sobre la utilidad de las subescalas Obvio y Sutil como una medida del fingimiento y la defensividad con partidarios (Brems \& Johnson, 1991; Dannembaum \& Lanyon, 1993; Dush, Simons, 
Platt, Nation, \& Ayres, 1994, Greene, 1988b; Lees-Haley \& Fox, 1990) y detractores (Schretlen, 1990; Timbrook, Graham, Keiller, \& Watts, 1993; Weed et al., 1990).

La investigación llevada a cabo por Timbrook, Graham, Keiller, \& Watts, (1993); Weed et al., (1990) concluyeron que la diferencia total de puntuaciones entre las subescalas Obvio y Sutil no proporcionaba una información adicional más allá de la que suministra las escalas tradicionales de validez. El trabajo de Dush y col. (1994) parece sugerir, sin embargo, que la diferencia total de puntuaciones $\mathrm{T}$ en las subescalas Obvio y Sutil proporcionan información adicional en pacientes con dolor en que la dirección "verdadero" (V) de los ítems Obvios es opuesta de la respuesta desviada (F) para la mayor parte de los ítems somáticos del MMPI-2.

Las puntuaciones óptimas de corte en el total de la diferencia de $\mathrm{T}$ entre las subescalas Obvio y Sutil, han sido extremadamente variadas. Van desde un rango de +106 (Rogers, Bagby, \& Chakraborty, 1993), +160 (Sivec et al., 1994), +169 (Bagby, Rogers, \& Buis, 1994), +179 (Bagby, Rogers, Buis, \& Kalemba, 1994) hasta 200 (Fox, Gerson, \&Lees-Haley, 1995).

Las subescalas de Obvio-Sutil, con su número de ítems, se presentan en la Tabla 11:

Tabla 11: Subescalas de Obvio-Sutil de Wiener-Harmon

\begin{tabular}{|l|l|l|}
\hline Denominación & Obvio. $\mathbf{N}^{0}$. Ítems & Sutil. $\mathbf{N}^{0}$. Ítems \\
\hline D- Depresión & D-O: 39 ítems & D-S: 18 ítems \\
\hline Hy- Histeria & Hy-O: 32 ítems & Hy-S: 28 ítems \\
\hline Pd- Desviación psicopática & Pd-O: 28 ítems & Pd-S: 22 ítems \\
\hline Pa- Paranoia & Pa-O: 23 ítems & Pa-S: 17 ítems \\
\hline Ma- Hipomanía & Ma-O: 23 ítems & Ma-S: 23 ítems \\
\hline
\end{tabular}

II.5.2.4.3.- Ítems críticos.

Los autores del MMPI original se interesaron por los aspectos médicos, neurológicos y psiquiátricos, fundamentalmente en los estados precoces. Este interés supuso la introducción de algunos ítems que detectaran algún trastorno incipiente o un síndrome prodómico. El ítem crítico implica la utilización individual del ítem del MMPI como un signo o indicador patognómico sintomático de patología.

Para el MMPI, las primeras investigaciones con los ítems críticos, tales como los de Grayson (1951) fueron ampliamente desarrollados a través de unas medidas puramente racionales, por simple selección de aquellos ítems que pudieran reflejar adecuadamente un problema particular o un interés del clínico. El primer esfuerzo por desarrollar una validez empírica con los ítems del MMPI fueron los trabajos conducidos por Koss y Butcher (1973), Koss, Butcher y Hoffman (1976) y Koss (1979). Se desarrolló y validó un conjunto de ítems críticos diferenciando pacientes hospitalizados que han experimentado un momento de crisis de aquellos otros pacientes que no habían experimentado ningún episodio crítico. Los resultados mostraron la existencia de una considerable utilidad clínica de los grupos de ítems críticos para ser utilizados con problemas especiales. Con la revisión del MMPI-2, han tenido que efectuarse algunas modificaciones con respecto a algunos problemas, tales como los de alcohol-drogas y de depresión-suicidio.

Otro grupo de ítems críticos fueron publicados por Lachar y Wrobel (1979) para tratar diferentes problemas. Aproximadamente dos terceras partes de los ítems de KossButcher (1973) fueron replicados en el estudio de Lachar-Wrobel (1979). Sin embargo, 
aunque algunos grupos de ítems fueron añadidos en diferentes áreas, no obstante podemos apreciar que ambos grupos, los de Koss-Butcher y Lachar-Wrobel, no son redundantes.

- Los grupos de ítems críticos de Koss-Butcher (1973) son los siguientes:

- Estado agudo de ansiedad

- Ideación depresiva suicida

- Sentimiento de ser amenazado

- Estrés situacional debido al alcoholismo.

- Confusión mental

- Ideas persecutorias.

- Los grupos de ítems críticos de Lachar-Wrobel (1979) son los siguientes:

- Desajuste caracterológico (actitud antisocial)

- Conflicto familiar

- Síntomas somáticos

- Preocupación sexual y Desviación.

Precisamente porque los ítems críticos poseen un contenido obvio nos pueden proporcionar otro medio de evaluar la precisión o exactitud de la respuesta dada por el sujeto a los ítems. Un gran número de ítems críticos son respondidos por personas que están fingiendo o experimentan una extensa y severa psicopatología. Consecuentemente, muy pocos ítems críticos son respondidos por personas que son defensivas o no experimentan psicopatología alguna.

El número de ítems críticos que la persona responde puede ser otro índice de la precisión o exactitud de las respuestas dadas por el sujeto, según sea un número grande (fingimiento) o pequeño (defensividad).

\section{II.5.3. - La configuración e interpretación de los perfiles en el $\mathcal{M M P I}-2$ \\ II.5.3.1. - La elaboración del perfil.}

La realización del perfil se lleva a cabo situando las puntuaciones obtenidas por el sujeto a la Hoja de Perfil adecuada a cada sexo y grupo de Escalas. Para ello existe un único perfil de la personalidad que viene determinado por:

- Perfil referido por las puntuaciones correspondientes de las Escalas de Validez y las Clínicas (denominado "perfil básico").

- Perfil referido por las Escalas Suplementarias.

- Perfil referido por las Escalas de Contenido.

En relación con la elaboración del Perfil Básico, referido por las Escalas de Validez y las Clínicas, es necesario añadir el factor corrector "K", o una fracción de éste, a las puntuaciones directas (antes de trasladarlas al interior de la Hoja de Perfil) de las siguientes escalas: Hs (Hipocondría: Hs+0,50K), Pd (Desviación psicopática. Pd + 0,40K), Pt (Psicastenia: Pt. + 1,00K), Sc (Esquizofrenia: Sc + 1,00 K) y Ma (hipomanía: Ma. + 0,20K). Para facilitar este cómputo se utiliza la Tabla de Fracciones K que se incluyen en la Hoja de Perfil. 
- Perfil referido por las Escalas de Contenido.

En relación con la elaboración del Perfil Básico, referido por las Escalas de Validez y las Clínicas, es necesario añadir el factor corrector "K", o una fracción de éste, a las puntuaciones directas (antes de trasladarlas al interior de la Hoja de Perfil) de las siguientes escalas: Hs (Hipocondría: Hs+0,50K), Pd (Desviación psicopática. Pd + 0,40K), Pt (Psicastenia: Pt. + 1,00K), Sc (Esquizofrenia: Sc + 1,00 K) y Ma (hipomanía: Ma. + 0,20K). Para facilitar este cómputo se utiliza la Tabla de Fracciones K que se incluyen en la Hoja de Perfil.

La formulación de hipótesis interpretativas a partir de los datos reflejados en el perfil clínico del MMPI-2 va a depender de tres aspectos esenciales e interrelacionados de las puntuaciones:

- La aceptabilidad de las puntuaciones del perfil, determinadas por las escalas de Validez.

- La elevación absoluta de las escalas componentes en contrastación con la baremación de las puntuaciones $\mathrm{T}$.

- Las configuraciones relativas de estas puntuaciones dentro del perfil individual.

- Complementar dichas puntuaciones con las obtenidas a través de diversas escalas auxiliares, como las Suplementarias, de Contenido, ítems críticos y subescalas.

II.5.3.1.1. - Los perfiles codificados:

Para resumir los patrones del test obtenidos por el MMPI-2, se utiliza un sistema de codificación que intenta reducir el amplio rango de perfiles posibles a un número más manejable. La codificación se realiza únicamente con las Escalas de Validez y las Clínicas. Para dicha codificación hemos de tener en cuenta el número asignado a cada escala Clínica, ya expresado con anterioridad en la descripción de este mismo grupo de escalas. En el pasado se utilizaron dos sistemas diferentes con el MMPI: el método de codificación, original de Hathaway (1947) y el procedimiento de codificación ampliado, o total, de Welsh $(1948,1951)$, siendo éste último el que se ha mantenido en MMPI-2.

Un código viene definido por las puntuaciones más elevadas de una o más escalas Clínicas en el perfil estándar, siguiendo un orden de mayor a menor. La interpretación a través de los códigos fue desarrollada primeramente en el MMPI original cuando se pudo comprobar que, en algunos casos, se encontraban con puntuaciones elevadas en más de una escala. A lo largo de la literatura se han descrito numerosos tipos de códigos:

- El tipo "punto alto" o "perfil punta" que se manifiesta cuando una puntuación de una escala se eleva sobre todas las demás superando el punto de corte ( $\mathrm{T}$ $65)$.

- El código formado por dos escalas ("punto dos"), uno de los más frecuentemente investigados, ocurre cuando dos escalas Clínicas, (por ejemplo: la 2 y la 7) se elevan sobre las demás por encima del punto de corte (T 65). Este tipo de código es definido como código de dos escalas (27/72). 
- El código de "punto tres" se forma cuando son tres escalas Clínicas las que se elevan en el perfil sobre el punto de corte (T 65). Así, por ejemplo, las elevaciones de las escalas 2, 4, y 7 produce el código 2-4-7, un tipo de perfil encontrado a menudo en los programas de intervención con pacientes adictos al alcohol y las drogas.

- El tipo de código "punto cuatro", aunque un tanto extraño e infrecuente, puede encontrarse en algunos casos (p.e. 1-2-3-4 en la clínica médica). Sobre los tipos de códigos superiores a cuatro escalas Clínicas no se han encontrado investigaciones relevantes.

En cuanto a la similitud entre los códigos del MMPI original y el MMPI-2, las puntuaciones estándar de las escalas son totalmente consistentes entre uno y otro. Graham, Timbrook, Ben-Porath y Butcher (1991), han demostrado que los tipos de códigos del MMPI-2 fueron totalmente congruentes con los tipos de código del MMPI original cuando se mantuvo la misma definición del tipo de código. En este aspecto, en una evaluación sobre el MMPI-2, Vicent (1990), concluye que "podemos confiar razonablemente que esta comparación (del MMPI-2) con el original (MMPI) es aceptable" (pg.82).

La Tabla 12 nos muestra los diferentes tipos de códigos que con mayor frecuencia se han estudiado con el MMPI-2.

Tabla 12.- Principales tipos de códigos de dos y tres variables en el $\mathcal{M M P I - 2}$

\begin{tabular}{|l|l|l|l|l|l|}
\hline \multicolumn{7}{|c|}{ Códigos de dos variables } \\
\hline $1-2 / 2-1$ & $1-3 / 3-1$ & $1-4 / 4-1$ & $1-8 / 8-1$ & $1-9 / 9-1$ & $2-3 / 3-2$ \\
\hline $2-4 / 4-2$ & $2-6 / 6-2$ & $2-7 / 7-2$ & $2-8 / 8-2$ & $2-9 / 9-2$ & $3-4 / 4-3$ \\
\hline $3-6 / 6-3$ & $3-8 / 8-3$ & $3-9 / 9-3$ & $4-5 / 5-4$ & $4-6 / 6-4$ & $4-7 / 7-4$ \\
\hline $4-8 / 8-4$ & $4-9 / 9-4$ & $6-8 / 8-6$ & $6-9 / 9-6$ & $7-8 / 8-7$ & $8-9 / 9-8$ \\
\hline \multicolumn{7}{|l|}{ Códigos de tres variables } \\
\hline $1-2-3$ & \multicolumn{7}{l}{} \\
\hline
\end{tabular}

II.5.3.2. - Estrategia para la interpretación (cfr. Figura 1).

Una vez que disponemos de todos los datos sobre nuestra mesa hemos de abordar uno de los momentos más delicados de la evaluación: la interpretación. Pero, ¿qué estrategia adoptamos?. Vamos a seguir, esencialmente, la estrategia basada en nuestra experiencia con la técnica consultando, al mismo tiempo, el proceso adoptado por los profesores Butcher y Williams (1992).

Fase I. - Analizando el contexto:

Uno de los aspectos esenciales en la comprensión e interpretación de los datos aportados por el MMPI-2, es tener en cuenta, de modo prioritario, el contexto en el que nos encontramos y el motivo de la solicitud de la prueba. No es lo mismo realizar el MMPI-2 en un contexto clínico, laboral, de selección de personal o jurídico.

Siempre es importante considerar el contexto de aplicación de la prueba para una correcta interpretación, pero lo es aún más cuando intentamos detectar un posible fingimiento o simulación de los datos que pueda aportar la prueba, con el fin de obtener un beneficio, fundamentalmente económico. 
Cuando nos encontramos en un contexto clínico, tanto en el paciente como en el administrador de la prueba, podemos presuponer un clima de mutua confianza y sinceridad. El paciente tiene plena confianza en el evaluador a sabiendas de que todo lo que diga será en beneficio de su salud. De la misma manera, el evaluador, no tiene por qué sospechar cualquier tipo de fingimiento de un sujeto que voluntariamente se acerca para solicitar ayuda de un profesional y solucionar sus problemas psicológicos.

Pero este clima de mutua confianza, puede cambiar radicalmente cuando el contexto es judicial o de selección de personal. Tanto en uno como en otro, el sujeto se está "jugando" algo muy serio para sí mismo (y para su familia, posiblemente). Es una compensación económica, es una custodia de los hijos, pueden ser años de cárcel, patrimonios considerables o un puesto de trabajo largamente perseguido. Evidentemente, en estos casos, de poco sirve que le advirtamos al sujeto que la prueba que le vamos a presentar requiere una dosis esencial y fundamental de honestidad y sinceridad consigo mismo para poder obtener un reflejo fiel de los rasgos esenciales de su "forma de ser".

Por todo ello es importante tener en cuenta en el proceso de evaluación el contexto en el que se desarrolla dicha labor.

Fase II. - Analizando los objetivos:

Pero, tan importante como el contexto, es saber apreciar los diversos objetivos de nuestra intervención. ¿Para qué queremos administrar esta prueba, y exactamente "ésta": el MMPI-2?.

Evidentemente sabemos que es una prueba que evalúa la personalidad del sujeto, pero la personalidad de la que se "sospecha" fingimiento o engaño, minusvaloración de los síntomas psicopatológicos o pretendemos diferenciar grados en los diferentes trastornos mentales. Tres cuestiones a tener muy claras:

- ¿Qué variables de la personalidad pretendemos evaluar?,

- ¿Con qué finalidad?

- ¿Es esta la técnica más idónea para evaluar lo que pretendemos?

El MMPI-2 se compone de 567 ítems . Esto no es nuevo a estas alturas de este trabajo, pero...¿ipor qué no se podría administrar otra prueba con menos ítems ? Por ejemplo, ¿no se podría aplicar el test de Millon, en cualquiera de sus dos últimos niveles (MCMI-II ó III: Millon Clinical Multiaxial Inventory) que tiene solamente 175 ítems ?. Lo que se puede hacer en 30-35 minutos con el MCMI (175 ítems ), ¿por qué cansar al sujeto con 60-90 minutos (567 ítems )?.

Todo va a depender de los objetivos planteados. Así, por ejemplo, las ventajas que tiene el MMPI-2 sobre el test de Millon (MCMI-II ó III) son la fiabilidad de las Escalas de Validez, su aportación para detectar el fingimiento o la defensividad del sujeto y, por otra parte, el considerable número de variables con que cuenta el profesional para obtener información. La adaptación castellana realizada por Avila y Jiménez (1999) presenta más de 70 variables de las que el evaluador puede tomar nota en un contexto clínico-forense. El test de Millon, aunque presenta variables que pueden detectar la validez de la prueba $(\mathrm{X}, \mathrm{Y}, \mathrm{Z})$, no presenta tanta información como lo hace el mismo MMPI-2. 
Un historial clínico-biográfico adecuado del que obtener información relevante, puede abarcar las siguientes áreas:

- Área de la genética: antecedentes familiares.

- Área del desarrollo: gestación, parto y desarrollo infantil.

- Área educativa: centros y nivel educativo alcanzado, problemática.

- Área clínica de enfermedades: operaciones, enfermedades importantes físicas y psíquicas, internamientos. Problemas de adicción: juego, alcohol, drogas.

- Área laboral: tipo de trabajo y puesto que ocupa, responsabilidad, bajas laborales.

- Área social: relaciones con los amigos, compañeros de trabajo, reuniones.

- Área familiar: relación con su cónyuge, hijos, parientes próximos y lejanos.

- Área de los sucesos extraordinarios: traumas físicos o psíquicos, accidentes, suceso extraordinario.

Es necesario obtener la información adecuada y relevante en cada una de estas áreas para poder disponer de las bases fundamentales en las que pueden sustentarse una posible sintomatología.

Fase IV. - Analizando su actitud de colaboración:

Una vez que hemos decidido administrar el MMPI-2, conviene tener en cuenta aspectos como la disposición y forma de responder a los ítems que presenta el sujeto ante el cuestionario. Es importante analizar:

\section{IV.A. - Antes de corregir la prue ba:}

Si el sujeto de presenta ante nosotros de forma voluntaria (necesita ayuda psicológica y voluntariamente busca a un profesional) o es obligada (se trata de un peritaje para un caso judicial)

- Si es adecuada su colaboración y contribución con la tarea propuesta.

- Si se cansa, falta de motivación y debemos animarle a que termine.

- Si lo hace de una vez o es necesario llevar a cabo la prueba en más de una sesión.

- Si es lento o se advierte cierta rapidez, casi impulsiva, en contestar

- Si observamos falta de concentración o distracción.

- Si deja ítems sin contestar. Le cuesta comprender (¿por su nivel inadecuado de lectura o por su gravedad sintomatológica?).

- Si observamos que contesta de forma inconsistente a los ítems de la prueba.

IV.B. - Corregida la prue ba:

- Evaluar las Escalas principales de Validez: L, F y K

- Evaluar las escalas adicionales de Validez: Fb, VRIN, TRIN

- Evaluar las interrelaciones de algunas escalas tradicionales de Validez con las adicionales: F y VRIN; F y Fb; L y TRIN; K y TRIN.

- Evaluar el índice de validez de Gough: F-K 
- En caso de dudas, poder apreciar, dentro de lo posible, otros índices o escalas que nos ayuden a apreciar la validez: Escala de Disimulación de Gough, Escala Psiquiátrica $\mathrm{F}(\mathrm{p})$ de Arbisi y Ben-Porath, Escala de deseabilidad Social de Wiggins, u otras que se explican a lo largo de esta exposición.

Es importante este capítulo de interpretación para poder determinar la validez o no de la prueba y poder pasar, o no, a la fase siguiente de evaluación de síntomas y comportamientos.

Fase V. - Evaluación de sintomas y comportamientos:

Cuando observamos el perfil de las escalas Clínicas, hemos de fijarnos detalladamente cuáles son las variables que sobrepasan la puntuación de corte establecida para el MMPI-2 (65T), y poder estimar la elevación de la escala correspondiente.

Tanto Butcher y Williams (1992) como Casullo (1999), aluden a los descriptores y patrones sintomáticos característicos de las Escalas Clínicas que definen las diferentes variables del MMPI-2. La interpretación de las variables, por parte del clínico, no puede llevarse a cabo de una forma simple y "matemática": "esta puntuación es alta, por consiguiente indica que". Si bien el MMPI fue originariamente diseñado con la idea de que el aumento de determinadas escalas clínicas deberían corresponderse con ciertos grupos diagnósticos, no fue un objetivo primordial establecer, a partir de su sola administración e interpretación, la inferencia de un diagnóstico clínico. El MMPI más bien ha sido usado para informar acerca de características de personalidad y comportamiento que pueden ayudar a realizar un diagnóstico descriptivo. Las fuentes de información más importantes para ello, según Casullo (1999), son la consideración de los siguientes aspectos:

- Elevación de las escalas Clínicas .

- Inclinación del perfil

- Información de la combinación de los códigos

- Puntuación de las Escalas de Contenido.

La labor del clínico requiere de todos sus conocimientos y experiencia psicológica. Es necesario, en la tarea diagnóstica, poder componer el "puzzle" con todas las variables en juego, armonizando adecuadamente tanto la información obtenida a través del MMPI-2 como la obtenida por otros canales de detección (entrevistas, historial clínico-biográfico, informes, etc.). En esta fase el trabajo se centra en tareas como:

V.A.- Análisis de las puntuaciones de las Escalas:

- Qué forma tiene el perfil: ¿forma de "sierra", plano, por debajo o por encima de la "franja de normalidad", con "picos", con "valles"...?

- Las variables que presentan una puntuación elevada en las Escalas Clínicas .

- Comprobar si se ajustan a algún tipo de código especificado en el MMPI-2.

- Qué tipo de relación existe con las variables que presentan una puntuación elevada en las Escalas Suplementarias. 
- Ver si tienen alguna relación con las variables que presentan una puntuación elevada en las Escalas de Contenido.

\section{V.B. - Especificar la evaluación y gravedad de la sintomatología.}

A medida que aumentan las puntuaciones en las escalas Clínicas del MMPI-2, por encima del punto de corte (65T), aumenta la probabilidad de presencia de desorden y de un cuadro sintomático significativo. Si se observan elevaciones mayores de $80 \mathrm{~T}$ en las Escalas Clínicas y una validez del perfil aceptable, puede inferirse la presencia de un desorden de naturaleza severa. Nos interesa poder apreciar adecuadamente:

- La existencia de patología y su gravedad: ansiedad, estado depresivo, psicosis, confusión, paranoia, estado de crisis.

- Evaluación del autocontrol/acting out: inhibición, impulsividad, sobrecontrol (represión).

V.C. - Evaluación del estilo de relaciones interpersonales:

La interpretación del MMPI-2 provee hipótesis acerca de cómo el sujeto interactúa con los demás y cuáles son sus factores sociales o de contexto que pueden influir en el ajuste psicológico de una persona. El MMPI-2 aporta información acerca de las habilidades sociales y los posibles problemas interpersonales a través de varias fuentes. Nos interesa centrarnos en las siguientes variables:

- La Escala Si y las subescalas Si1, Si2 y Si3 que nos pueden suministrar datos sobre la disposición, comodidad y competencia sociales de los sujetos.

- Otras variables que nos ofrecen información acerca de este aspecto: Hipocondría (Hs), Desviaciones psicopáticas (Pd), Dominancia (Do), Paranoia (Pa), Esquizofrenia (Sc), Malestar matrimonial (MDS), y Malestar Social (SOD).

Fase VI.- Hipótesis para el tratamiento:

Un uso importante del MMPI-2 es el correspondiente a la evaluación de las características personales en función de su disposición eventual a un tratamiento psicológico. Para ello, pueden ser de utilidad las Escalas Suplementarias y las de Contenido, ya que disponen de indicadores para ello y sobre todo la variable "Indicadores negativos de tratamiento" (TRT) cuyas puntuaciones elevadas pueden denotar ciertas actitudes negativas hacia los médicos y personal de salud mental, no queriendo cambiar ninguna actitud pensando que sus males no tienen ya remedio. Otros indicadores se encuentran centrados en los problemas personales, las actitudes, el autoconcepto, los comportamiento de interferencia, etc.

Por último, reproducimos las preguntas que se hacen Butcher y Williams (1992) ante la necesidad del tratamiento:

- “¿Necesita el sujeto tratamiento psicoterapéutico y/o psiquiátrico?

- ¿Es consciente el sujeto de sus problemas?

- ¿Se puede confiar en su autodescripción?

- ¿Está dispuesto a ofrecer información personal al clínico?

- ¿Se encuentra motivado para el tratamiento? 
- ¿Revela su capacidad de insight acerca de sus problemas?

- ¿Se encuentra dispuesto a cambiar su comportamiento o actitudes?

- ¿Revela indicios de responsabilidad para el tratamiento?

- ¿Existe algún hecho negativo que pueda interferir en la relación terapéutica?"' (pg. 185).

Figura 1: Estrategia para la interpretación del $\mathcal{M M} \mathscr{M}$ - 2 (adaptado de Butcher y Williams [1992])

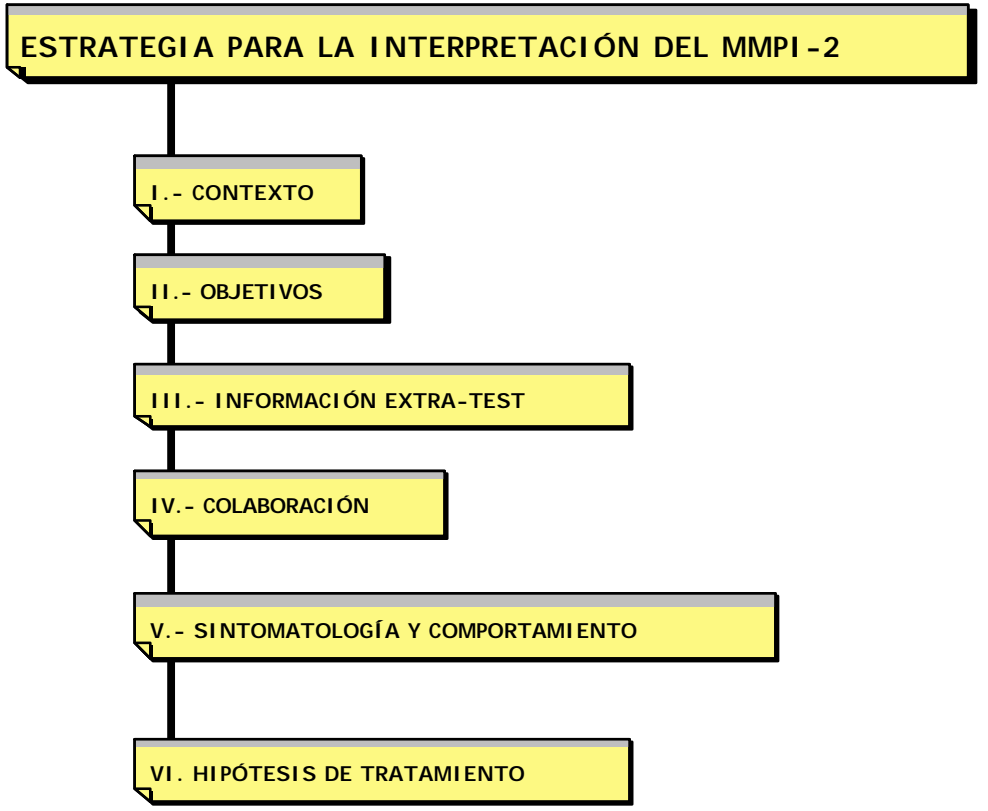




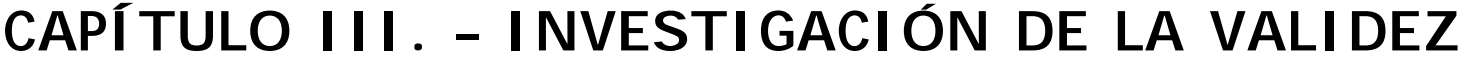 DE LOS PERFILES EN EL MMPI - 2 .}

III.1. - REVIS IÓN ACTUAL DE LOS ES TUDIOS :

A la hora de analizar los diferentes estudios llevados a cabo acerca de la Validez de los perfiles del MMPI y MMPI-2, esencialmente encontramos dos grandes tipos de estudios. Por una parte los centrados en la metodología del diseño realizado (Schretlen 1988, 1990 y 1992) y por otra, los estudios centrados en el tipo de muestra y de instrucción ofrecida para la realización de la prueba con el MMPI (Berry, Baer \& Harris, 1991) o con el MMPI-2 (Rogers, Sewell \& Salekin, 1994). A estos dos grandes grupos de investigación vamos a hacer referencia.

Estudios centrados en el diseño experimental:

Al analizar los diferentes trabajos llevados a cabo sobre la simulación por medio de diferentes técnicas de evaluación, Schretlen (1988, 1990 y 1992), agrupó las investigaciones existentes a través de una variable denominada "nivel de control" 
referido por la complejidad y rigor metodológico llevado a cabo en el diseño experimental realizado.

- Denominó estudios de "bajo control" aquellos que están realizados con una escasa muestra, incluso de casos individuales y único, de sujetos que realizan una simulación de padecimiento psiquiátrico. Los resultados obtenidos de estos estudios se muestran como escasamente fiables y con poca capacidad de generalización.

- Los denominados como estudios de "control parcial" serían aquellos en los que se comparan los resultados de los sujetos instruidos para simular un trastorno mental, o sospechoso de simularlo, con los obtenidos por otros grupos de sujetos. Cualquiera de estos grupos, con los que se van a comparar sus puntuaciones, bien pueden ser sujetos "normales" que responden a la prueba con sinceridad, o sujetos que presentan un verdadero trastorno y que responden según su propia enfermedad. Los resultados de comparar solamente dos grupos presenta limitaciones importantes ya que no puede concluir hasta qué punto la diferencia de puntuaciones se debe a factores como la presencia de simulación o de psicopatología verdadera entre los evaluados.

- Los denominados por Schretlen (1988, 1990 y 1992) como grupo de "control completo" son aquellos diseños experimentales en los que se muestran tres grupos de sujetos: aquellos que son adiestrados para simular o sospechoso de hacerlo (denominado como "grupo experimental"), sujetos que son pacientes psiquiátricos y que, por tanto, presentan un verdadero trastorno (denominado como "grupo control") y sujetos considerados como "normales", sin evidencia de patología, y que van a contestar a la prueba de una forma sincera y honesta (denominados como "grupo criterio"). Este tipo de diseño presenta la ventaja del análisis de las variables en los tres grupos diferentes (control, experimental y de criterio). Ello nos permite la comparación entre sujetos adiestrados para simular y verdaderos enfermos y, a su vez, con los sujetos sanos. De esta manera si observásemos que entre los sujetos sanos y los sujetos simuladores, por ejemplo, no resultasen diferencias significativas en sus análisis estadísticos, el investigador debería replantearse la misma investigación. Los simuladores, posiblemente, no supieron simular adecuadamente.

Estudios centrados en el muestreo e instrucciones:

Las primeras investigaciones sobre la simulación se llevaron a cabo con diferentes muestras, proporcionando a los sujetos participantes las instrucciones generales para fingir:

- Con población normal:

- Con estudiantes (Austin, 1992; Bagby, Rogers \& Buis, 1994; Graham, Watts \& Timbrook, 1991; Wetter y otros, 1992; Worthington \& Schlottmann, 1986; Woychyshyn, McElheran \& Romey, 1992, 1992),

- Con profesionales (Gough, 1954; Lachar \& Wrobel, 1979).

- Con muestras comunes (Wetter, Baer, Berry, Robinson \& Sumpter, 1993).

- Con muestra clínica:

- Pacientes con trastornos mentales (Bagby, Rogers, Buis \& Kalemba, 1994); Graham y otros, 1991; Rogers, Sewell \& Ustad, 1995). 
- Pacientes con problemas con la justicia (Bagby, Rogers \& Buis, 1994; Iverson, Franzen \& Hammond, 1995; Walters, 1998; Walters, White \& Greene, 1988)

Estos estudios mostraron que el grupo de fingimiento podía diferenciarse del grupo que realizaba la prueba honestamente, aunque la escala o índice específico empleado y la puntuación óptima de corte tuviera que variar generalmente de un estudio a otro. Como se esperaba, las investigaciones han demostrado más dificultades en distinguir entre el grupo instruido para fingir y pacientes que entre los grupos simuladores y sujetos normales. Esta línea de investigación ha tenido sus críticas ya que las personas no sabían qué patología simular. Ante estos resultados los investigadores vieron la necesidad de instruir a los sujetos proporcionándoles información sobre los síntomas concretos que presenta el trastorno a simular.

Justamente, teniendo en cuenta la crítica de los primeros estudios, se realizaron trabajos instruyendo adecuadamente a los sujetos experimentadores con la sintomatología específica de las siguientes patologías:

- Trastorno de personalidad borderline (Sivec, Hilsenroth \& Lynn, 1995) Wetter y otros, 1993; Wetter y otros, 1994).

- Lesión cerebral (Lamb, Berry, Qetter \& Baer, 1994)

- Paranoia (Sivec y otros, 1994)

- Trastornos de estrés postraumático (Fairbank, McCaffrey \& Keane, 1985; Wetter y otros, 1993).

- Esquizofrenia (Rogers, Bagby \& Chakraborty, 1993; Wetter y otros, 1993)

- Trastorno somatoforme (Sivec y otros, 1994).

De estos estudios se obtuvieron dos conclusiones (Greene, 1997):

$1^{\text {a }}$.- Las Escalas de Validez generalmente son útiles para detectar estos trastornos, tal como esquizofrenia y trastornos de la personalidad borderline que se caracterizan por una extensa y severa psicopatología. Nuevamente, la escala e índice específico más útil varía según los estudios así como las puntuaciones de corte consideradas como óptimas.

$2^{\mathrm{a}}$.- Las personas que son instruidas para fingir un trastorno específico que se caracteriza por una psicopatología limitada y menos severa son más difíciles de detectar (Lamb y otros, 1994; Wetter y otros, 1993).

En la última serie de estudios se investigaron los efectos que proporcionan los sujetos participantes con información sobre las escalas de Validez que son utilizadas para detectar el fingimiento o defensividad (Lamb y otros, 1994; Rogers, Bagby \& Chakraborty, 1993), en ocasiones en combinación con información sobre criterios específicos de diagnóstico. La información proporcionada a los sujetos sobre las escalas de validez es considerada como la mejor forma de fingir sin ser detectados (Baer, Wetter \& Berry, 1995; Rogers, Bagby \& Chakraborty, 1993). La información sobre las escalas de validez es más valiosa para evitar la detección del fingimiento que el mismo criterio específico del diagnóstico (Rogers, Bagby \& Chakraborty, 1993).

En resumen, los mejores resultados ofrecidos con el MMPI los proporcionaban la escala F, la Escala de disimulación de Gough (Ds) y el Índice de simulación de Gough (F-K). Cuando se llevó a cabo la reestructuración del MMPI, los mejores resultados para evidenciar el fingimiento con el MMPI-2 fueron ofrecidos por la escala F, el Índice 
de simulación de Gough (F-K) y la diferencia, en puntuaciones T, entre las Subescalas Obvio y Sutil (Wiener, 1948).

A continuación exponemos, de forma más específica, algunas de las investigaciones realizadas con las diferentes variables e índices llevados a cabo tanto con el MMPI como con el MMPI-2.

\section{III.1.1. - Las escalas principales de Valide $z: \mathcal{L}, \mathcal{F} y \mathcal{K}$}

Hathaway y Mckinley desarrollaron estas tres escalas con el objetivo de analizar la presencia de actitudes invalidantes y suministrar al clínico no solamente las pautas de interpretación para la validez del test sino también aspectos esenciales sobre la accesibilidad y franqueza del examinando. Las investigaciones con el MMPI original mostraron, en general, que los indicadores de validez también proporcionaban información sobre la personalidad del sujeto.

El trabajo llevado a cabo en 1985 por los investigadores de la Universidad del Estado de Luisiana, McAnulty, Rappaport, y McAnulty con las variables de Validez del MMPI en una muestra de 156 estudiantes universitarios no licenciados, a los que se le pidió que fingieran una buena imagen de sí mismos, concluyen que las escalas de Validez (L, F y K) y, en concreto el índice F-K no discrimina a los sujetos que fingen una buena imagen de los que no lo hacen.

Un caso específico de que las Escalas de Validez pueden suministrar información acerca de aspectos diversos de la personalidad y, más concretamente de la utilidad para la planificación del tratamiento psicoterapéutico, nos lo muestra la investigación llevada a cabo en el Centro Médico de la Universidad de Colorado, en Denver, por los investigadores Post, y Gasparitova-Krasnec (1979), con una muestra de 60 pacientes internos, con media de edad de 30-34 años y que fueron asignados a 3 grupos diferentes, en base a las puntuaciones obtenidas en las escalas F y K del MMPI original. El primer grupo lo formaron los perfiles de los sujetos que habían tenido algún incidente de "acting out" y que reclamaban "ayuda"; el segundo grupo estaba formado por sujetos con un perfil hiperdefensivo y el último por sujetos con un perfil medio. Los sujetos que formaron el primer grupo de "perfil de ayuda" fueron percibidos como "acting out" y engendraron más sentimientos de frustración que los sujetos componentes de los otros dos grupos. Los resultados sugieren que, aunque los sujetos integrados en el grupo primero de "perfil de ayuda" en algunos sistemas es considerado como invalidados, estos perfiles de validez pueden ser utilizados para la planificación del tratamiento terapéutico.

Para poder apreciar si las escalas F y F-K podrían discriminar el fingimiento de un trastorno mental, Johnson, Klingler y Williams (1977) investigadores del Hospital VA de la ciudad de Salt Lake, llevaron a cabo una investigación con un grupo de 228 veteranos que requerían tratamiento psicoterapéutico, y a los que se les aplicaron el MMPI, el Examen del estado Mental y una entrevista estructurada. Los resultados obtenidos manifestaron una relación, estadísticamente significativa, entre $\mathrm{F}$ y F-K conjuntamente con los clasificados como "hacerse el enfermo" ("fake bad").

Woychyshym, McElheran y Romney (1992) llegan a la conclusión de que las escalas del MMPI original (L, F, K y F-K) confrontados con nuevos índices de validez (TR, Ca, Ds, Mp y Ws-Wo) fueron igual de fiables para detectar sujetos con buena imagen. Los 
nuevos índices parecen tener utilidad clínica cuando se sospecha buena imagen en el MMPI. Para estos autores, las nuevas escalas del MMPI-2 poco pueden aportar a los índices de validez tradicionales.

Burish \& Houston (1976) llevaron a cabo un estudio con 66 sujetos varones normales utilizando la Escala L como una medida de defensividad ante el enfrentamiento a situaciones estresantes. Los resultados sugieren que los sujetos con altas puntuaciones en $\mathrm{L}$ utilizaron diversas maniobras defensivas para enfrentarse a las distintas situaciones estresantes, y solamente obtuvieron de forma parcial resultados exitosos. Los autores concluyen que la Escala L correlaciona de forma significativa con otra medida de defensividad y no correlaciona con las escalas de Sc (Esquizofrenia) y Hs (Hipocondría). Estos datos, según sus autores apoyan la validez de la Escala L como una medida de defensividad.

Con el objetivo de demostrar que la Escala F del MMPI era contestada de forma atributiva por menos del 10\% de los sujetos de la población normal, Gravitz (1987) analiza una amplia muestra de 6.686 varones y de 4.717 mujeres a los que se les administró el MMPI y del que se investigó la forma de responder a la Escala $\mathrm{F}$ para determinar si, tal como requiere la muestra normativa, los sujetos se atribuyen menos de un $10 \%$ de los ítems de esta escala $\mathrm{F}$. Los resultados demostraron que más del $10 \%$ de los hombres se atribuyeron 5 ítems en la dirección opuesta a la establecida, mientras un porcentaje similar de mujeres solamente se atribuyeron 4 ítems . Los autores aconsejan que, como reflejo de la nueva tendencia del comportamiento americano $\mathrm{y}$, dado que el MMPI es ampliamente utilizado, debería ser de nuevo baremado.

En el trabajo realizado por Greene (1997) tomando diferentes tipos de muestra (normales, con trastornos mentales graves y sujetos que responden aleatoriamente) y analizando diferentes tipos de Escalas (F, Ds, Obvio-Sutil, F-K...) pudo apreciar que los pacientes con desórdenes mentales respondían aproximadamente 3 veces más a los ítems de la escala $\mathrm{F}$ que los sujetos normales. Resulta interesante apreciar cómo el 50\% de los pacientes con trastornos mentales responden 8 o menos ítems de la Escala F. Este relativo y pequeño número de respuestas en la Escala $\mathrm{F}$, podría reflejar que estos ítems actualmente son infrecuentes en una cierta situación clínica y/o que un porcentaje bastante alto de pacientes psiquiátricos son defensivos.

Según la revisión de distintas investigaciones realizada por Greene (1997) la puntuación óptima de corte para la Escala $\mathrm{F}$ con las que se pueden identificar a personas que son fingidores, dentro de los ejemplos clínicos, tienen un rango variable que va desde 17 (Bagby, Rogers, Buis, \& Kalemba, 1994), 23 (Graham et al., 1991) y 28 (Rogers, Bagby, \& Chakraborty, 1993). En los resultados obtenido por Greene (1997), una puntuación de corte de 17 podría clasificar a cerca del $20 \%$ de los pacientes como fingidores, mientras que una puntuación de 28 clasificaría apenas al 5\%.

Existen varias escalas de infrecuencia disponibles en el MPPI-2 que también pueden ser utilizadas para evaluar la consistencia de las respuestas. Como pudimos ver anteriormente, las escalas $\mathrm{F} \mathrm{y} \mathrm{Fb}$ se componen de ítems que fueron atribuidos por menos del $10 \%$ de la población normal tanto en el MMPI como en el MMPI-2. Tres nuevas escalas adicionales de infrecuencia han sido desarrolladas recientemente para el MMPI-2. Se tratan de la escala de "Fake-Bad" (FBS, de Lees-Haley, English \& Glenn, 1991), la Escala Psiquiátrica F (F(p), de Arbisi \& Ben-Porath, 1995) y la Escala de Respuesta Inconsistente (IR, de Sewell \& Rogers, 1994). 
- La escala de Fake-Bad (FBS, de Lees-Haley, English \& Glenn, 1991) consiste en 43 ítems (ver Anexo 10) que se atribuyen infrecuentemente los fingidores de lesiones de tipo psicosomáticas

- La Escala Psiquiátrica F(p), de Arbisi \& Ben-Porath, 1995) está compuesta por 27 ítems (ver Anexo 14) y que una muestra de pacientes con distintos trastornos raramente se los atribuyen.

- La Escala de Respuesta Inconsistente (IR, de Sewell \& Rogers, 1994) se compone de 16 ítems (ver Anexo 8), de los cuales la mitad de ellos son propios de la Escala F(p) (Arbisi \& Ben-Porath, 1995) y que son contestados de forma infrecuentes por una muestra clínica.

Según el trabajo de Greene (1997), las intercorrelaciones entre estas escalas de infrecuencia es alta, excepto para el promedio de FBS. Por el contrario las intercorrelaciones de estas escalas de infrecuencia con las escalas de inconsistencia tienden a ser fuertemente bajas $(<.30)$, lo que sugiere que están evaluando diferentes aspectos de la coherencia de las respuestas.

Los clínicos asumimos habitualmente que los sujetos que van a realizar la prueba del MMPI-2 van a seguir el mismo patrón de respuestas para los 567 ítems de los que se compone la prueba. Esta suposición no siempre es apropiada, ya que la motivación, y la habilidad de los sujetos, pacientes y normales, para mantener la atención y concentración puede cambiar a lo largo de la prueba. No es extraño que la escasa motivación y el cansancio merme la capacidad de atención del sujeto para completar la prueba adecuadamente. Por ello, la primera parte de la prueba y la segunda pueden quedar afectadas cuando se evalúan las Escalas $\mathrm{F}$ y Fb.

¿Qué diferencia entre las puntuaciones de $\mathrm{F}$ y Fb puede convertirse en un indicador de consistencia o coherencia en las respuestas dadas por el sujeto?. Este es el planteamiento que se hizo Greene (1997) cuando realizó un análisis comparativo de las puntuaciones obtenidas en $\mathrm{F}$ y $\mathrm{Fb}$ por tres tipos de muestras (normales, pacientes con trastornos psiquiátricos y personas que responden aleatoriamente). Sus resultados muestran que el $70 \%$ de los perfiles realizados por los sujetos que contestaron al azar obtienen una puntuación de $\mathrm{F}-\mathrm{Fb} \geq 7$ y que menos del $26 \%$ de los mismos que han obtenido en la escala VRIN entre 8 y 15, mostraban en $\mathrm{F}-\mathrm{Fb}$ una puntuación de 6 . Este último dato aporta soluciones a las puntuaciones directas de VRIN (PD $=8-15)$ en las que no estaba claro si las respuestas del sujeto eran consistentes o no.

Berry y su equipo de investigación (Berry et al., 1991; Berry, Wetter, Baer, Larsen, Clark, \& Monroe, 1992) ha examinado la utilidad de las medidas de consistencia de los ítems respondidos para detectar a las personas que fueron instruidas para responder aleatoriamente después de completar 100, 200, 300, 400 ó 500 ítems de forma coherente. Sus resultados muestran que F, Fb y VRIN fueron efectivas al detectar este tipo de personas que respondieron de forma inconsistente y que fueron más efectivas tanto en cuanto los ítems respondidos aleatoriamente se aumentaban.

Los clínicos deberíamos tener en cuenta que los ítems para las escalas tradicionales de Validez (L, F y K) y para las Clínicas, se encuentran en los primeros 370 ítems. Si la inconsistencia de las respuestas se observa con posterioridad al ítem 370, los clínicos aún podríamos evaluar e interpretar las escalas principales de Validez. La ventaja de la corrección manual de la Escala VRIN, es poder apreciar si la incoherencia de respuestas 
se encuentra distribuida por todo el protocolo o simplemente afecta a una determinada zona o parte del MMPI-2.

En el trabajo realizado por Hopkins (1999) sobre el papel de la escala K como medida de validez en el ámbito jurídico y, específicamente, en los casos de guarda y custodia, presenta un doble objetivo en su investigación: por una parte explorar la defensividad o el self favorable en las respuestas cuando se trata de evaluar la guarda y custodia $\mathrm{y}$, por otra parte, valorar la consciente o inconsciente distorsión de las respuestas emitidas por los padres en conflicto. Sus resultados muestran la existencia de diferencias significativas entre los patrones de respuestas dadas por padres implicados en la asignación de la guarda y custodia de sus hijos y la forma estándar (contestar honesta y sinceramente) de responder al MMPI/MMPI-2. Es decir, la existencia de un sesgo de respuesta en los padres que licitan la guarda y custodia de sus hijos. Por otra parte, el diseccionar las respuestas de los padres litigantes entre "conscientes" e "inconscientes" como categorías aparte, esta autora mostró en este trabajo una contribución a la predicción y comprensión de las respuestas defensivas en los padres litigantes.

En el mismo ámbito de la litigación jurídica de los padres acerca de la guarda y custodia de sus hijos, el trabajo de Medoff (1999) cuestiona la validez clínica y/o estadística de los datos aportados por el MMPI-2. A pesar de los resultados empíricos que identifica los patrones de elevación en las Escalas de Validez L y K y que se muestran estadísticamente significativos, no por ello siempre se corresponden con la validez clínica en los casos de guarda y custodia. En este estudio son identificados y discutidos las falsas atribuciones causales que contribuyen a las dificultades de caracterización o pérdida de datos importantes relacionados con el funcionamiento de la personalidad y que deben ser revisados los peligros potenciales asociados a tales falsas atribuciones.

El trabajo de Siegel y Langford (1998) pretende demostrar la aportación de las Escalas de Validez en el MMPI-2 con dos grupos de padres inmersos en el proceso jurídico de guarda y custodia de sus hijos. La muestra está compuesta exclusivamente por mujeres entre 27 y 45 años distribuida en dos grupos según presentasen el "Síndrome de Alienación Parental" (P.A.S. "Parental Alienation Syndrome") o no. Estos investigadores parten de la hipótesis de que los padres con Síndrome de Alienación Parental deberían ofrecer puntuaciones significativamente más elevadas en $\mathrm{K}$ y L, y más bajas en $\mathrm{F}$, que los padres que no presentan este comportamiento. Sus resultados demuestran que la hipótesis fue confirmada en las Escalas $\mathrm{K}$ y $\mathrm{F}$, indicando que los padres con PAS tienen mayor facilidad para completar las cuestiones del MMPI-2 de una forma defensiva. Se discute las implicaciones de los resultados en los posibles trastornos de personalidad de los padres con un comportamiento de Síndrome de Alienación Parental. Igualmente llegaron a concluir que los padres con PAS tienen mayor facilidad que los padres que no presentan este comportamiento, para utilizar las defensas psicológicas de negación y proyección que se encuentran asociadas con los patrones de las Escalas de Validez. 
III.1.2.- Gough: el Índice (F-K) y la Escala de Disimulación (Ds).

\section{III.1.2.1. - El Índice de Gough F. K}

A veces, podemos encontrar que no existe una clara diferencia entre perfiles atípicos $\mathrm{y}$ aquellos que presentan alteraciones psiquiátricas importantes. El método tradicional consiste en descartar los protocolos con puntuaciones $\mathrm{T}>65$ en $\mathrm{L}, \mathrm{F}$ o $\mathrm{K}$, o inferiores a 30 .

Para solucionar este problema, el Índice F-K (Gough, 1947, 1950) fue desarrollado combinando dos de las tres escalas tradicionales de validez del MMPI.

Debemos tener buen cuidado de no confundir el Índice (F-K) de la Escala de Simulación (Ds) y su revisión (Ds-r). Ésta última se compone de un grupo de ítems diseñados para evaluar solamente fingimiento, mientras que el Índice F-K utiliza las relaciones entre las escalas tradicionales de Validez $\mathrm{F}$ y $\mathrm{K}$ para evaluar tanto el fingimiento como la defensividad.

El interés de Gough por determinar la fiabilidad de un perfil y, consecuentemente, de los datos vertidos y diagnóstico de la personalidad del sujeto, le llevó a realizar su primer trabajo (Gough, 1947, 1950) examinando las configuraciones del MMPI asociadas con el disimulo, proponiendo un índice F-K para poder detectar y desechar los protocolos que no son válidos, siendo utilizado algunas veces como una medida de respuesta o de exageración de síntomas en el MMPI-2. Gough propuso utilizar la diferencia entre las puntuaciones directas $\mathrm{F}$ y K $(\mathrm{F}-\mathrm{K})$ de forma que, si el resultado es positivo y mayor de nueve $(+9)$ indicaría fingimiento en el sentido de ofrecer una "mala imagen", mientras que si es negativo y menor de nueve (-9), indicaría la tendencia a ofrecer una "buena imagen" de sí mismo como estrategia de la defensividad del sujeto. Si la puntuación se encontraba entre los valores 0 a 9, el perfil era considerado como válido.

Las puntuaciones F-K muy elevadas indicarían también casos psicóticos graves, y las muy bajas (negativas) podrían indicar tendencias acusadamente rígidas y defensivas en los sujetos. Igualmente sobre la interpretación del mismo podemos hacer ciertas discriminaciones. En la tendencia a ofrecer una "buena imagen", destacan las elevaciones L y K, con bajo F, y las bajas puntuaciones en todas las Escalas Clínicas. En cambio, cuando se intenta ofrecer una "mala imagen", destacan el alto F y los bajos $\mathrm{L}$ y K, con elevaciones típicas en Sc y $\mathrm{Pa}$. En el perfil de simulación, las puntuaciones son más moderadas, y aparecen picos en las escalas Depresión, Desviación psicopática, Paranoia y Esquizofrenia. Es importante acompañarnos, para la interpretación, de las nuevas escalas del MMPI-2 referidas por VRIN y TRIN.

En un trabajo posterior (1950) pudo determinar que una diferencia de 10 puntos marcaba el punto de corte significativo del intento de ofrecer una "mala imagen", y una puntuación menor de 10 era significativa de presentar una "buena imagen".

Posteriormente Carson (1969) ha modificado esta puntuación a once (11), mientras que Butcher y Williams (1992), para el MMPI-2 concretan la puntuación en quince (15). El trabajo de Wetzler \& Marlowe (1990) va en esta misma dirección intentando detectar la exageración de los síntomas. 
Cuando se trata del fingimiento de lesiones físicas, parece ser que este índice y la escala de Wiener-Harmon, sutil-obvio, presentan mayor sensibilidad a este tipo de fingimiento, según el estudio realizado por Beal (1989) con una muestra clínica.

Este problema de los puntos de corte siempre ha sido un tema candente en las investigaciones que se llevan a cabo con el Índice de Gough (F-K). El estudio realizado por Osborne, Colligan. \& Offord (1986) con una población normal, establece dos puntuaciones medias diferentes según sexos. Para los hombres: $\mathrm{F}-\mathrm{K}=-9,77$ y para las mujeres: F-K $=-11,22$.

Greene (1997, pgs. 188-189) presenta un resumen sobre la distribución de las puntuaciones F-K en sujetos normales y pacientes con diversos síntomas psicopatológicos. Sus resultados muestran que los sujetos normales consiguen puntuaciones medias cercanas a -12 , mientras que los pacientes psiquiátricos consiguen puntuaciones medias de -4 .

Ya que la escala $\mathrm{F}$, por sí misma, también puede reflejar la presencia de psicopatología, actualmente el uso de estas puntuaciones produciría una proporción inaceptablemente alta de falsos positivos (personas que están diciendo ser fingidores pero que experimentan actualmente una psicopatología significativa). Roger y Graham (1997) son partidarios de una puntuación bastante superior a +9 en F-K para discriminar el número de falsos positivos.

De igual manera, tomando como referencia las puntuaciones de corte de Greene (1988) y comprobando que se producían una alta proporción de "falsos positivos", los resultados del estudio realizado por Gillis, Rogers, \& Dickens (1990) con muestra de población normal y clínica y con el objetivo de detectar a los simuladores que pretenden mostrarse de forma negativa, mostraron que F y F-K fueron indicadores relativamente eficaces para distinguir a las personas que se fingen enfermas. Los autores sugieren que se tomen otro parámetros de puntos de corte.

El estudio de Gallucci (1984) trató de evaluar la efectividad de los índices F y F-K del MMPI para detectar disimulación a través de una muestra clínica de pacientes psiquiátricos compuesta por 40 mujeres y 80 hombres (que reclaman un subsidio por incapacidad). Se formaron cuatro grupos diferentes según los niveles de motivación y exageración de su patología con el fin de alcanzar el grado deseado para conseguir el subsidio. Cuando se controla el nivel de patología y la edad, los incrementos de los índices en F y F-K coinciden sistemáticamente con el aumento de la motivación para disimular (exagerar su patología).

Fortova (1979) analiza los indicadores de simulación y disimulación a través del MMPI con una muestra de 33 mujeres y 18 varones pacientes en terapia y 14 mujeres y 9 varones como sujetos control, la autora del instituto de Psiquiatría de Praga, utilizó las Escalas F, K, L, F-K y L+K al mismo tiempo que fueron observados los cambios en las Escalas Obvio-Sutil de D.N. Wiener (1956). Se utilizaron tres tipos de instrucciones: las estándar (contestar al cuestionario de forma sincera), instrucciones para simular e instrucciones para disimular. La Escala $\mathrm{F}$ fue el mejor indicador de simulación. Sin embargo, los resultados para la disimulación fueron variados, pero parecía que el $\mathrm{L}+\mathrm{K}$ fue el que mejor reflejaba la disimulación. Las puntuaciones correspondientes a los ítems "Obvio" de Wiener aumentaron con las instrucciones de simular; sin embargo, disminuyeron bajo las instrucciones de disimular. Las puntuaciones correspondientes a 
los ítems "sutil" de Wiener, se mostraron opuestas excepto para los pacientes masculinos en los que se incrementaron ligeramente. Como conclusión final los ítems de la Escala Obvio-Sutil pueden ayudar a tomar decisiones en sujetos con perfiles límites en el MMPI.

Un problema con el índice F-K, comentado por Greene (1997), en la identificación de la defensividad es que alguien pueda:

- Estar reconociendo la capacidad para manejar sus propios problemas.

- Estar bien ajustado o adaptado (alta PD en K).

- No estar experimentando estrés o conflicto (baja PD en F).

Por este índice, probablemente, sería más bien definido como defensivo que como normal. De este modo personas normales que contestan el MMPI-2 a menudo serían clasificados inapropiadamente como defensivos en el índice F-K.

Según los resultados de Greene (1997) en la investigación llevada a cabo con muestras de sujetos normales y sujetos con trastornos mentales, si las puntuaciones en el índice F-K de $\leq-12$ se utilizan como un criterio de defensividad (se corresponde con el percentil 50), entonces, el $25 \%$ de los pacientes deberían ser también clasificados como defensivos. De nuevo, un considerable \% de pacientes evaluados en una situación clínica están siendo defensivos.

En resumen, el índice de Gough (F-K) parece mostrarse con cierta efectividad para detectar a los simuladores, especialmente a los que intentan exagerar la sintomatología psicopatológica. La mayor parte de los estudios sobre el MMPI y el MMPI-2 con este índice han utilizado como muestra a personas normales que han sido instruidas para fingir síntomas patológicos. Muchas investigaciones (Austin, 1992; Graham et al. 1991; Woychyshyn et al., 1992) han confirmado la utilidad de F-K para identificar estudiantes instruidos para fingir. Otras investigaciones (Graham et al., 1991; Woychyshyn et al., 1992) también han demostrado que la Escala F, por sí sola, identificó fingidores de forma igual, o mejor, que el Índice F-K. Los puntos de corte óptimos en estos estudios presentan un rango de 6 (Sivec et al., 1994) a 17 (Graham et al., 1991). Las investigaciones no parecen ponerse de acuerdo en el punto de corte que varía según el ambiente en el que se administra, las indicaciones suministradas y el diferente tipo de muestra elegida.

\section{III.1.2.2.- La escalas de Disimulación (Ds y Ds-r) de Gough.}

La escala de Disimulación de Gough (Ds), inicialmente compuesta por 74 ítems se elaboró para diferenciar a un grupo de personas neuróticas, de grupos de estudiantes y profesionales psicólogos instruidos para simular neurosis contestando al MMPI. Dada que la escala, y que algunos ítems podrían ser significativos de extrema patología, posteriormente fue reducida (Gough, 1954) a 58 ítems (ver Anexo 11) y revisada (Ds-r) y reducida (Gough, 1957) a un total de 32 ítems (ver Anexo 12).

Las diferentes investigaciones con esta escala de Disimulación (Ds) ha sido limitada por el hecho de que no es reconocible como una de las escalas estándar para ser utilizada de forma usual. No parece haber consenso si se debe utilizar la versión original o la revisada de la escala Ds (Bagby, Rogers, \& Buis, 1994; Bagby, Rogers, \& Kalemba, 1994; Bagby, Rogers, \& Chakraborty, 1993) o si es necesario llevar a cabo más investigaciones sobre esta escala (Berry, Baer \& Harris, 1991). 
Los datos presentados por Greene (1997, pgs. 188-189) resumen el rango de puntuaciones en Ds para sujetos normales y pacientes con trastornos mentales. Una PD $\geq 26$ ocurre en el $1 \%$ de los sujetos normales y un $25 \%$ en los pacientes psiquiátricos. Con una $\mathrm{PD} \geq 38$ en Ds, indicativa de fingimiento, obtendríamos que el $5 \%$ de los pacientes deberían ser clasificados como personas que han respondido de forma imprecisa, mientras que ninguno de los adultos normales serían clasificados de esta manera.

\section{III.1.3. - Perfiles de respuestas al azar (random response).}

Este tipo de perfil distorsionado se produce cuando el sujeto contesta a los ítems de forma inconsistente o aleatoria sin tener en cuenta el contenido de los mismos. Una persona puede utilizar un determinado patrón de respuestas de forma idiosincrásica: cinco ítems seguidos se señalan como "verdadero", los cinco siguientes como "falsos", los cinco siguientes como "verdaderos", los siguientes como "falsos"; una columna de la hoja de respuesta es contestada como "falsos", la siguiente como "verdaderos", etc. En nuestra investigación nos hemos preocupado de hacer una extensa variación de patrones de respuestas producidas inconsistentemente. Es evidente que las configuraciones de los perfiles resultantes deben ser claramente invalidados.

Una rápida mirada a la hoja de respuestas nos puede advertir, o suscitar la sospecha, de que el sujeto ha contestado de esta forma inconsistente que podemos confirmar posteriormente examinando los diferentes indicios de validez. En general el gran número de ítems en las escalas e índices de validez utilizados será el mejor modo de determinar un tipo de respuesta al azar. La Escala F contiene un total de 60 ítems y contestando al azar toda la prueba, es probable que, al menos la mitad de ellos no se responden en la dirección correcta del ítem. Para una puntuación directa de $\mathrm{F}=30$ supone una puntuación de $120 \mathrm{~T}$, lo que resulta anormalmente elevada. Es así como podemos disponer de la Escala $\mathrm{F}$ como una de los indicadores más fiables para detectar un tipo de respuesta aleatorio (Carlin \& Hewitt, 1990; Dahlstrom et al., 1972; Rogers, Dolmetsch, \& Cavanaugh, 1983; Sewell \& Rogers, 1994). De forma similar ocurre con los 40 ítems que conforman la escala $\mathrm{Fb}$, de los cuales una puntuación de $\mathrm{Fb}=20$ en puntuaciones directas es equivalente a 120T.

Para Graham (1990), este tipo de perfil de respuestas al azar presenta como características:

- Una elevada puntuación T en la Escala F (generalmente mayor de 100),

- La Escala L se encuentra moderadamente elevada $(\mathrm{T}=60-70)$,

- La Fb también se encuentra elevada, generalmente sobre el mismo nivel de las puntuaciones $\mathrm{T}$ que presenta la escala $\mathrm{F}$.

- La puntuación de VRIN también aparece anormalmente elevada muy próxima a los niveles de $\mathrm{F}$ y $\mathrm{Fb}$.

- La puntuación TRIN se presenta algo elevada pero bastante menos que VRIN.

- Las escalas clínicas se caracterizan generalmente por puntuaciones elevadas, con la puntuación más alta en la escala Sc (Esquizofrenia) y segida de la escala Pa (Paranoia).

- Las escalas Mf (Masculinidad-Feminidad y Si (Introversión Social), probablemente se encuentran por debajo de la puntuación $70 \mathrm{~T}$. 
Estas características señaladas por Graham (1990) hemos de entenderla siempre y cuando el sujeto conteste en su totalidad a la prueba siguiendo un patrón de respuesta inconsistente y/o al azar, lo cual no es una conducta frecuente. Lo más normal es que el sujeto comience contestando adecuadamente y posteriormente cambie respondiendo de forma inconsistente. De esta forma, muchos perfiles nulos se aproximarán a alguna de las características presentadas, pero, debido a lo que hemos comentado, no lo harán con la misma exactitud. Un perfil sospechoso y resultante de haber sido contestado de forma inconsistente (todo o parte) debe ser anulado y no ser objeto de interpretación.

Para evaluar la sensibilidad de las Escalas de validez del MMPI-2, Wetter, Baer, Berry, Smith, y otros (1992) utilizaron cuatro grupos de estudiantes en su investigación de los efectos de la respuesta aleatoria (random response) y las respuestas de fingimiento intencionado (malingering) con el MMPI-2: un grupo contestó el test al azar; al segundo se le instruyó para que fingiera un trastorno psicológico moderado; al tercero para que simulara un trastorno severo; y al cuarto se le pidió que contestara de forma sincera. Los resultados mostraron que las Escalas de validez del MMPI-2 fueron sensibles a estas formas de responder: respuesta aleatoria y fingimiento de patología. En ambos casos se producen puntuaciones elevadas en $\mathrm{F}$ y $\mathrm{Fb}$, aunque solamente la respuesta aleatoria produce puntuaciones elevadas en VRIN.

Estos resultados indican que una puntuación elevada en la Escala $F$ puede ser clarificada al relacionarla con VRIN en el caso del grupo con respuesta aleatoria. Así, una puntuación elevada en F, combinada con una puntuación elevada en VRIN sugiere claramente la posibilidad de un patrón de respuesta inconsistente.

Para identificar los protocolos del MMPI de aquellos sujetos que dan respuestas aleatorias, los autores Rogers, Dolmesch, \& Cavanaugh (1983), compararon las muestras de 40 perfiles de pacientes con otros 40 generados aleatoriamente por ordenador, analizándose las Escalas de Validez, las Clínicas y escalas diseñadas para detectar aleatoriedad (índice de Test-Retest y Escala de Descuido). Los resultados denotan que la Escala $F>80$ y el índice Test-Retest $>4$ son de mayor utilidad clínica para identificar correctamente a los que responden aleatoriamente. Los autores concluyen que es necesario identificar adecuadamente a los fingidores (malingeres) de los severamente trastornados y de aquellos que responden de una forma inconsistente.

En el trabajo llevado a cabo por Greene (1997) comparando una muestra de población normal de 2.600 sujetos (Butcher et al., 1989) con 3.475 pacientes con trastornos mentales graves y 2.500 sujetos que contestan aleatoriamente a los ítems (Greene, 1995), se pudo apreciar que con una $\mathrm{PD}=13$ (equivalente a $80 \mathrm{~T}$ ) en la escala VRIN era contestado por $0,2 \%$ de los sujetos de la población normativa, por el $2,4 \%$ de los pacientes con trastornos y por el $84,4 \%$ de los sujetos que contestaban de forma inconsistente.

En la investigación realizada por Berry, Wetter, Baer, Widiger, et als (1991) para poder detectar la sensibilidad de algunas escalas de validez a la forma de responder aleatoriamente al MMPI-2, utilizaron una muestra de 180 estudiantes universitarios a los que se les pidió que contestaran un número de respuestas del Cuestionario del MMPI-2 de forma correcta y el resto de forma aleatoria. Los resultados mostraron que los tres índices (F, Fb y VRIN) fueron sensibles a las respuestas dadas al azar.

Un año después, Barry, Wetter, Baer, Larse,. et al. (1992) vuelven a corroborar los resultados con una muestra de sujetos normales. Los autores investigaron la validez de 
las variables F, Fb y VRIN, en diferentes muestras de sujetos (estudiantes, voluntarios y trabajadores) para detectar a los que responden de forma inconsistente al cuestionario del MMPI-2. Los autores concluyeron que los índices de F, Fb y VRIN son buenos indicadores para detectar las respuestas aleatorias. Los resultados sugieren que las respuestas aleatorias son más frecuentes en la parte final del test aunque un número significativo de sujetos distribuye sus respuestas aleatorias a lo largo de toda la prueba.

Paolo y Ryan (1992) insisten en el grupo de escalas sensibles a la detección de las respuestas aleatorias propuestas por Barry, Wetter, Baer, Larse,. et al. (1992). Para ello analizaron, con una muestra de 200 hombres pacientes, la utilidad de las escalas F, Fb y VRIN del MMPI-2, y dos escalas más acerca de la sensibilidad para detectar los patrones de contenido de no-respuestas (CNR de R.L. Greene, 1991) o de responder sin tener en cuenta el contenido, para investigar acerca de cuales de las escalas detectan con mayor sensibilidad la respuesta inconsistente en la muestra clínica. Los protocolos cumplimentados por el grupo de pacientes que contestaron de forma sincera se contrastaron los protocolos generados, de forma totalmente aleatoria, por un programa de ordenador. Los resultados indican que las Escalas VRIN, F y Fb eran las que mejor diferenciaban significativamente a los dos grupos. Las dos escalas nuevas de responder sin tener en cuenta el contenido de los ítems (CNR) no aportaban información adicional aprovechable acerca de las Escalas de Validez del MMPI-2.

\section{III.1.4. - Perfiles de respuestas "todo verdad" / "todo falso".}

La facilidad con que se detecta un protocolo marcado en sus respuestas como "todo es verdadero" o "todo es falso", hace que, a simple vista esa hoja de respuestas sea enviada de forma inmediata a la papelera y se proceda seguidamente a hacerle entender al sujeto que lo que estamos haciendo es algo más serio y que su actitud supone una pérdida de tiempo.

Pero es distinto cuando nuestro propósito en el test es poder determinar, con el objetivo de la investigación, las variaciones de un perfil cuando, una vez corregido, son detectables algunos factores indicativos de validez. El perfil resultante va a obedecer, expresa y exclusivamente, a la forma como se elaboraron los ítems y la dirección de la respuesta desarrollada por los autores del MMPI-2. En ningún caso, pues, va a obedecer a un pensamiento del sujeto que contesta.

En los estudios de Graham (1990, pgs.38-39) presenta la gráfica característica de "todo verdadero" en la que se puede apreciar una puntuación extremadamente elevada en la Escala F (generalmente > que 100T), las escalas L y K suelen estar por debajo de 70T y una exagerada elevación de las puntuaciones en las Escalas Clínicas, sobre todo en las $\mathrm{Pa}$ (paranoia) y Sc (esquizofrenia). La escala $\mathrm{Fb}$ se encontrará igualmente muy elevada, muy próxima a los niveles de la escala F. Las escalas TRIN igualmente elevada $(>120 \mathrm{~T})$, aunque la escala VRIN se puede encontrar cerca de las 50T. Evidentemente, este perfil no debe ser objeto de interpretación en ninguno de los casos.

En el caso de responder "todo falso" como indica la gráfica de Graham, (1990, pgs 40-41). aparecen elevaciones exageradas en las escalas L, F y K y puntuaciones muy elevadas en las escalas Clínicas. Las puntuaciones $\mathrm{T}$ de $\mathrm{Fb}$ y VRIN se encuentran cerca de la puntuación 50T, mientras que la puntuación T de TRIN se muestra excesivamente 
elevada ( $>110)$. Estas puntuaciones son coincidentes, de forma general, con las aportadas Graham (1990).

\section{III.1.5.- Perfiles con fingimiento de 6uena / mala imagen (fake good / fake $6 a d)$.}

La existencia de perfiles en el MMPI-2 de individuos que, deliberadamente, intentan ofrecer una buena o mala imagen de sí mismo es otro de los aspectos a tener en cuenta para detectar a los simuladores e invalidar el perfil.

El tratar de presentarse a sí mismo de un modo favorable, se convierte en una forma de defensividad ante "algo" que molesta, no interesa en este momento, o no se admite. Algunos autores lo denominan "Faking good", (también "Fake good"). Incluso algunos pacientes, no ya personas normales, completan el MMPI-2 con la motivación de negar los problemas y aparecer mucho mejor psicológicamnte de lo que realmente están.

Debido a que es bastante obvia la naturaleza de los ítems de la escala L, individuos brillantes intelectualmente, bien educados y psicológicamente ajustados, pueden detectar la intención de los ítems y obtener, de esta manera, una baja puntuación en L. Sin embargo, como los ítems de la escala K, no son tan obvios como los de la escala L, el mismo tipo de personas podrían producir puntuaciones muy elevadas en la escala $\mathrm{K}$, si adoptan hacia el test una actitud de "buena imagen". De todas formas, antes de concluir que una puntuación alta en $\mathrm{K}$ indica una estrategia de buena imagen, sería necesario tener en cuenta las características apuntadas por Graham (1990) ya que personas con un alto nivel socioeconómico tienden a puntuar más alto en $\mathrm{K}$ que los sujetos con un nivel más bajo.

Algunos clínicos tienden a utilizar el índice F-K para identificar tanto los perfiles de "buena imagen" como los de "mala imagen". Si la puntuación directa de F-K es negativa y elevada, es posible que haya intentado ofrecer una actitud de buena imagen. Sin embargo, esta diferencia de puntuaciones no puede ser utilizada apropiadamente como diagnóstico en personas con alto estatus socioeconómico por su tendencia a dar puntuaciones elevadas en $\mathrm{K}$.

Cuando, por el contrario, el sujeto intenta ofrecer una mala imagen de sí mismo, podemos apreciar la existencia de una motivación personal por la que le interesa aparecer, intencionadamente, como enfermo, incapacitado, incompetente. También denominado en la literatura científica como "Faking bad", (también "Fake bad"). Algunos autores lo identifican también por el término "malingering".

Graham (1990), analizó los perfiles típicos de las personas que intentan ofrecer una imagen negativa, para ello contó con adolescentes a los que se les dió instrucciones de presentarse a sí mismos como si tuvieran serios problemas psicológicos y emocionales. Los datos de este estudio de Graham y Watts, no publicados (citado por Graham, 1990) caracterizan el perfil de "fake bad" por una elevación de las puntuaciones $\mathrm{T}$ en la variable $\mathrm{F}$ (generalmente $\mathrm{F}>100 \mathrm{~T}$ ) y de la variable $\mathrm{Fb}$. Las puntuaciones de las escalas VRIN y TRIN no son significativamente elevadas ya que los sujetos que están fingiendo una mala imagen están respondiendo al contenido de los ítems . Para Graham (1990) las puntuaciones de las escalas Clínicas siguen siendo muy elevadas, sobre todo $\mathrm{Pa}$ (Paranoia) y Sc (Esquizofrenia). Sin embargo las escalas Mf (Masculinidad/Feminidad) y Si (Introversión) son, generalmente, las menos elevadas en este tipo de perfil. 
Graham (1990) afirma, de forma general que, siempre que la puntuación directa de la Escala $\mathrm{F}$ es mayor que la puntuación directa de la escala $\mathrm{K}$, debe considerarse la posibilidad de "hacerse el enfermo" y cuanta mayor es la diferencia tanta mayor es la probabilidad de fingir una mala imagen. A primera vista el perfil "fake bad" podría parecer similar al perfil que uno debería esperar al obtenido por una persona que está realmente trastornado psicológicamente, pero, sin embargo existen, a juicio del autor una diferencia sumamente importante: la puntuación de la escala F, generalmente es más elevada para el perfil "fake bad". El rango, comúnmente aceptado, de la puntuación $\mathrm{T}$ de la Escala $\mathrm{F}$ para personas diagnosticadas como psicóticos se encuentra entre $71 \mathrm{y}$ 90, mientras que el perfil "fake bad" para la Escala F se encuentra por encima de 100T. Es decir, en un perfil "fake bad" las puntuaciones de las escalas Clínicas tienden a ser mucho más extremadamente altas que en un perfil válido para una persona con un trastorno grave.

Los perfiles típicos de la actitud de "fingirse bueno" ("faking good") los muestra Graham (1990, pgs. 47 y 48) como una forma de "uve" en la configuración del perfil de las escalas de validez, con elevaciones en las escalas L y K y una puntuación, en la escala F, en el rango entre 40 y 50T. Mirando las escalas Clínicas subsiguientes a este perfil, podemos apreciar que éstas se encuentran en un rango de puntuaciones por bajo de la "franja de normalidad" o puntos de corte; es decir con una puntuación entre $30 \mathrm{y}$ $50 \mathrm{~T}$, pero con las escalas Hy (Histeria), Mf (Masculinidad-feminidad) y Ma (hipomanía) algo más elevadas.

Posteriormente los trabajos de Graham, Watts, y Timbrook (1991) para detectar los perfiles "fake bad" y "fake good" en sujetos normales y clínicos mostraron que los resultados indican que la media de los perfiles y la puntuación óptima de corte se parecen a las establecidas previamente en el MMPI original. Se logró una identificación precisa de las personas que fingían buena (fake good) o mala imagen (fake bad). Fue posible diferenciar entre pacientes y sujetos normales que se fingían enfermos. Pero fue necesario utilizar diferentes puntuaciones de corte para distinguir entre sujetos normales que hicieron el test siguiendo las instrucciones de honestidad y aquellos que fueron instruidos para fingir una mala imagen (fake bad).

El mismo Gough (1950) pudo detectar que las personas que intentan crear la impresión de una psicopatología severa puntúan considerablemente más alto en la Escala $\mathrm{F}$ que en la escala K. Sugirió que la diferencia entre la puntuación directa de la Escala $\mathrm{F}$ y la directa de la $\mathrm{K}$ podría servir como un índice útil para detectar los perfiles "faking bad". Gough (1950) y Meehl (1951) indican que cuando dicho índice sea un número positivo y mayor que $9(\mathrm{~F}-\mathrm{K}>9)$ debería considerarse como un perfil de "fingirse malo". En una posterior investigación Carson (1969) sugirió elevar la puntuación de corte a 11 para poder precisar con mayor exactitud el perfil de "fingirse enfermo".

La investigación de Grow, McVaugh y Eno (1980) llevada a cabo con diferentes muestras de población, clínica y normal, para detectar el fingimiento, pudo determinar que del 10 al $81 \%$ de la Varianza asociada al fingimiento puede ser explicada por varias estrategias: $\mathrm{F}-\mathrm{K} \geq 7$ detecta un fingimiento de mala imagen (hacerse el enfermo). F-K $\leq$ - 11 para fingir buena imagen.

Sobre este mismo tema de encontrar las puntuaciones de corte Gillis, Rogers y Dickens (1990) intentan detectar, con el MMPI los estilos de respuestas en población 
normal y clínica para hacerse el enfermo. Tomadas las puntuaciones de corte de Greene (1988) para estos indicadores de Validez, producían una alta proporción de "falsos positivos". En esta investigación los resultados mostraron que F y F-K fueron indicadores relativamente eficaces para distinguir a las personas que se fingen enfermas. Los autores sugieren que se tomen otros parámetros de puntos de corte.

Wetzler y Marlowe (1990) también utilizaron el índice de Gough para detectar la exageración de sus síntomas que presentan los sujetos de una muestra clínica cuando se les han administrado el MMPI, MMPI-2 y el Millon Multiaxial Clinical Inventory en su versión II.

Los trabajos realizados por Wetter, Baer, Berry, Robison, y otros (1993) con sujetos clínicos y normales pudieron determinar que los sujetos falsificadores obtuvieron puntuaciones inferiores en $\mathrm{K}$ y elevadas en F, Fb F-K, Ds, así como sobre las 10 Escalas Clínicas, igual que la muestra clínica.

Cuando se trata de evidenciar si la información de la sintomatología puede ayudar a llevar a cabo una mejor simulación en sujetos clínicos y normales, las investigaciones realizadas por Wetter, Baer, Berry y Reynolds (1994) concluyeron que la información específica de síntomas fue de poca ayuda en la simulación convincente del trastorno en el MMPI-2.

Lim y Butcher (1996), en una investigación llevada a cabo con muestras clínicas y de población normal llegaron a concluir que el MMPI-2 suministra una aceptable identificación de los perfiles fingidos y la escala $\mathrm{S}$ y sus subescalas serían útiles para detectar los perfiles de negación o de reclamación de una imagen perfecta, aunque los intentos para diferenciar las dos estrategias de análisis no llegaron a tener éxito.

Con una muestra de estudiantes, considerados como normales, Austin (1992) realizó un trabajo para detectar la buena y mala imagen a través de un análisis multivariado (MANOVA), llegando a la conclusión de que se producía una diferencia estadísticamente significativa para las puntuaciones de todas las escalas de Validez en tres formas de responder: las subescalas de Validez, Supresora y la Subescala ValidezSupresora fueron las más útiles en la detección de sujetos que fingen mala imagen (fake bad). La Escala L era la mejor para determinar la buena imagen (fake good).

Cramer (1995) trata de diferenciar los psicóticos de los neuróticos administrando el MMPI-2 en una población normal. Para este autor los resultados indican que conjuntamente todas las Escalas de Validez podrían discriminar los perfiles neuróticos de psicóticos y perfiles auténticos de los simulados.

Rogers, Sewell y Ustad (1995) llevaron a cabo una investigación con el MMPI-2 tratando de descubrir de forma sistemática los indicadores de "fake bad" en pacientes crónicos. Los resultados indicaron que pacientes que han respondido con sinceridad presentaron puntuaciones elevadas en $\mathrm{F}, \mathrm{Fb}$ y otras Escalas de Validez. Los pacientes crónicos modificaban sus puntuaciones en la dirección de mostrar una psicopatología más severa. Un resultado inesperado fué las bajas puntuaciones obtenidas por una minoría de pacientes.

En 1997, Cloak, Kirklen, Strozie y Reed realizaron un trabajo para poder detectar los estilos de respuestas de los "faking bad" con el MMPI-2 en una muestra clínica. Se investigó la habilidad de las personas para fingir el Trastorno por Estrés Postraumático o una lesión cerebral a través de la consistencia temporal de sus respuestas. Los 
resultados mostraron que los sujetos que fueron preparados para fingir un trastorno por estrés postraumático obtuvieron en una administración test-retest (al cabo de dos semanas) puntuaciones que no mostraron diferencia significativa con las conseguidas por los sujetos a los que se les administró el MMPI-2 de forma estándar. Sin embargo se obtuvo un coeficiente de fiabilidad, significativamente más bajo, cuando los sujetos fingían una enfermedad de lesión cerebral. El Análisis de la varianza indicó que los individuos que fingían un trastorno obtuvieron puntuaciones significativamente más elevadas en las Escalas de validez sensibles a la exageración (overreporting)de los síntomas, y, sin embargo, no se encontró diferencias significativas en los diferentes tiempos de aplicación. Por ello los autores concluyen que es necesario diferenciar el tipo de trastorno para poder apreciar la consistencia temporal de las respuestas.

Investigar qué Escalas de Validez del MMPI-2 se muestran más sensibles para detectar el fingimiento positivo (fake-good) fue el objetivo marcado por Maloney (1998) con una muestra de 114 estudiantes a los que instruyó para contestar de una forma determinada. Un grupo de estudiantes deberá contestar de forma honesta y sincera (forma estándar) y otro grupo estaba instruido para fingir de manera positiva y presentar la mejor imagen de sí mismo. Sus resultados mostraron que las variables K y L fueron las escalas de validez más sensibles para detectar el fingimiento positivo.

El equipo de investigación, formado por Scafidi, Field, Prodromidis \& Abrams (1999), tenía como objetivo poder determinar si las bajas puntuaciones en la escala de Depresión de Beck (BDI) eran signo de una simulación de la depresión (faking-good) o por el contrario era cierto que no presentaban dicho trastorno. Para realizar este trabajo empleó a 79 madres adolescentes, con una media de edad de 18,1 años, a las que administró las pruebas del MMPI-2 y el Cuestionario de Depresión de Beck (BDI). Dividió la muestra en tres grupos: no-depresivo, depresivo y con puntuaciones bajas. Sus resultados mostraron que el grupo depresivo mostró mayores puntuaciones que el no-depresivo; que el grupo de puntuaciones bajas en el BDI dio más perfiles fake-good que los otros dos grupos; y que el Análisis discriminante indicó que el $90 \%$ de los perfiles de fake-good podían ser clasificados correctamente basándose en las puntuaciones del BDI y en las escalas de defensividad (fake-good).

\section{III.1.6.- Perfiles defensivos.}

Ya hemos comentado anteriormente que el concepto de "defensividad" se encuentra delimitado por la intención de presentarse de una forma ajustada y equilibrada psicológicamente. En nuestro estudio los hemos identificado como "fingimiento positivo".

Pero hemos de concretar aún más el término "defensividad". En la literatura científica correspondiente a la evaluación de los distintos modos de falsificación, se ha identificado como "defensividad" todo aquello que "molesta", es "inaceptable" o "no interesa" decir o mostrar. La "defensividad", en nuestra opinión, no siempre se encuentra referido, necesaria ni obligadamente, a presentarse" mejor de lo que es uno"; a veces, puede ser posible presentarse "peor de lo que uno es" para "defenderse" de algo que se puede apreciar como hiriente, negativo, agresivo o me puede traer malas consecuencias. Así por ejemplo, podemos entender que una persona se "defiende" presentándose de una forma negativa, presentando una mala imagen de sí mismo 
mostrándose con una sintomatología patológica con la finalidad de evitar una responsabilidad penal o criminal.

Por ello, en nuestra investigación hemos optado por prescindir del término "defensividad" ya que nos parece ambiguo y dependiente de variables no claramente especificadas. Hemos optado por diferenciar entre "fingimiento positivo" para aquellas personas que se presentan de una forma positiva, mostrándose "mejor de lo que uno es", y "fingimiento negativo" para aquellas personas que se muestran de forma negativa, exagerando sus síntomas, o mostrando una mala imagen de sí mismos, porque, de alguna manera, obtienen algún beneficio.

A veces también nos encontramos con personas que, por alguna razón, se sienten motivadas a presentar una impresión favorable, pero no realista, de sí mismos, intentando no hacerlo de forma descarada y sí de una manera más sutil. Por ejemplo aquellas personas que pretenden ser seleccionadas para un puesto de trabajo o aquellas otras que quieren conseguir la custodia de sus hijos en un proceso de separación. Estas personas, de forma sutil, van a enfatizar su características positivas y minimizar las negativas.

Para Graham (1990, pg.50), en este tipo de perfiles defensivos, las puntuaciones de L y K son típicamente más elevadas que la $\mathrm{F}$. Sin embargo, las puntuaciones en estas dos escalas no se presentarán tan extremadamente altas como el tipo de respuestas de "buena imagen". Para personas bien dotadas intelectualmente y con un alto grado educativo, la Escala L puede no ser significativamente elevada en un perfil defensivo, aunque encontremos elevada la escala K. En un perfil defensivo, las puntuaciones en las escalas Clínicas, no se encontrarán tan bajas como en un tipo de respuesta de buena imagen.

Butcher $\left(1985^{\mathrm{a}}\right)$ sugirió algunos procedimientos para la interpretación de perfiles en los que la configuración de las escalas de Validez estén sugiriendo defensividad. Si existe alguna escala Clínica elevada superior a una puntuación de 65T, estas puntuaciones deben interpretarse como tradicionalmente se ha hecho, pero cuando se está intentando presentar una imagen demasiado favorable las puntuaciones $\mathrm{T}$ de las escalas Clínicas que se sitúan en el rango 60-65, deben considerarse como significativas. Si todas las puntuaciones en un perfil defensivo se encuentran por debajo de $60 \mathrm{~T}$, el perfil no proporciona información clínica útil sobre el sujeto.

En realidad, resulta difícil detectar este tipo de casos, ya que con las puntuaciones de tales perfiles uno no puede decir si es indicativo de un buen ajuste personal, que está motivado para aparecer aún más ajustado o es un perfil de una persona pobremente ajustada que está intentando aparecer más equilibrada.

\section{III.1.7.- Perfiles con exageración / minimización de sintomas (overreporting / underreporting).}

Quizás uno de los perfiles más difíciles de detectar como simulado es el de una persona que realmente tiene sintomatología y problemas psicopatológicos y los exagera o minimiza en sus respuestas a los ítems del MMPI-2. El perfil resultante dependerá en gran parte de la naturaleza de los trastornos presentes, no existiendo un prototipo determinado para esta clase de respuesta. 
Para Graham (1990), el mejor indicio que tal tipo de respuesta puede estar presente es que el nivel de elevaciones o disminuciones en la Escala $\mathrm{F}$ y las escalas Clínicas parecen ser mayores o menores que lo que se podría esperar teniendo en cuenta la historia personal y las observaciones realizadas durante la entrevista y/o las diversas pruebas psicológicas. Hemos de tener en cuenta que la exageración o la minimización de la sintomatología no debe invalidar, de forma completa, un perfil, pero es necesario modificar las declaraciones interpretativas teniendo en cuenta la probabilidad de exagerar o minimizar los problemas y sintomatología.

En la literatura científica encontramos dos términos para describir aquellas personas que exageran o minimizan sus problemas y síntomas:

- "Overreporting": exagerar los síntomas de una enfermedad, incapacidad o incompetencia de forma deliberada o no. Algunos autores lo identifican también con "Fake bad".

- "Underreporting": minimizar los síntomas de una enfermedad, incapacidad o incompetencia de forma deliberada o no. Algunos autores lo identifican también con "Fake good".

Uno de los trabajos de investigación esenciales acerca de esta temática es el análisis que realizan Baer, Wetter \& Berry (1992) sobre 25 estudios. Los autores revisan las investigaciones existentes acerca de la detección de los sujetos que minimizan sus síntomas patológicos. Para ello compararon los sujetos que responden de forma honesta al Cuestionario de aquellos que minusvaloran sus síntomas. Se analizaron varios índices, como las escalas L y K, la escala de Deseabilidad Social y la Escala de Fingimiento Positivo (Positive Malingering). De la investigación realizada, los autores sugieren que los sujetos que minimizan sus síntomas patológicos de aquellos que responden honestamente, difirieron, aproximadamente una desviación estándar sobre la media en estas escalas. La escala de Fingimiento Positivo (Positive Malingering) y una de las escalas de la Deseabilidad Social mostraron un resultado prometedor de, aproximadamente, 1,5 desviación estándar. Para las escalas L y K los resultados mostraron justamente $-1,0$ desviación estándar.

En la investigación llevada a cabo por Cloak, Kirklen, Strozier y Reed (1997) con una muestra de población normal encontraron cuatro factores en su análisis de las escalas de Validez del MMPI-2. Denominando esos cuatro factores como: "minimizar los síntomas", "exagerar los síntomas", "cinismo" y "trastorno psicológicos". El "minimizar" y la "exageración" de los síntomas parecen confirmar la utilidad de las escalas que evalúan deseabilidad social/defensividad y fingimiento respectivamente. El factor "exageración" parece reflejar el aumento de síntomas psicológicos o físicos. El de "cinismo" se muestra contrario al factor "minimizar"; y el cuarto factor, los "trastornos psicológicos", no presenta una relación para responder sesgadamente. Los autores sugieren una mayor definición y consistencia interna.

En el estudio realizado por Baer \& Sekirnaj (1997) se investigó, tanto en una muestra clínica como normal, los efectos de la información sobre las Escalas de Validez del MMPI-2 que detectan la minusvaloración de los síntomas cuando se completa el test, advirtiéndoselo a un grupo si y a otro no. Los resultados mostraron que las Escalas tradicionales de detección de la sintomatología minimizada fueron efectivas al discriminar sujetos no informados de los informados en cualquiera de las dos muestras 
analizadas. Estas escalas fueron algo menos efectivas para discriminar a los sujetos informados tanto de la muestra clínica como de la normalizada. Los autores concluyen que sus resultados son consistentes con las investigaciones anteriores, sugiriendo que el entrenamiento en la información sobre las Escalas de Validez puede interferir con la habilidad del test para detectar a los sujetos que minimizan los síntomas.

Cuando se trata de exagerar la sintomatología por lesiones cerebrales los autores Berry, Wetter, Baer, Youngjohn, et als. (1995) trabajaron con una muestra dividida en cuatro grupos diferentes: sujetos normales que contestan sinceramente; sujetos normales que simulan una lesión cerebral; pacientes lesionados cerebralmente que no buscan una indemnización y pacientes igualmente lesionados pero que sí buscan una indemnización compensatoria. Los resultados sugieren que las escalas de MMPI-2 que evalúan la exageración de patología (overreporting) son sensibles a la generación de quejas somáticas y posiblemente a la exageración de la sintomatología. Finalmente los autores sugieren que, a pesar de esta investigación, sería necesario confrontar estos resultados con nuevas aportaciones.

Baer, Wetter, Nichols, Greene,. et als. (1995) intentan evaluar la sensibilidad de las escalas de Validez del MMPI-2 para detectar a los simuladores que exageran o minimizan sus problemas. Los autores definen dos grupos en su muestra: 50 sujetos completan el protocolo del MMPI-2 bajo las instrucciones estándares, mientras que otros 50 sujetos lo realizan intentando ofrecer una buena imagen de sí mismos (fake good). Los resultados mostraron que los sujetos que intentaron ofrecer una buena imagen (fake good) obtuvieron una puntuación significativamente más alta que en el resto de las escalas overreporting y que las dos escalas suplementarias Deseabilidad Social (J.S. Wiggins, 1959) y la Escala Superlativa J.N. Butcher \& K. Han, 1993) tienen una validez significativa sobre las escalas tradicionales L y K en discriminar perfiles de underreporting.

El objetivo del estudio llevado a cabo por Greene (1988) es investigar acerca de la fiabilidad del Índice de Disimulación de Gough, la Escala de Disimulación de H.G. Gough (1954) y la Escala de Obvio-Sutil de D.N. Wiener (1948). De un total de 851 perfiles del MMPI, se eligieron 106 que fueron clasificados en tres grupos de pacientes según los códigos del mismo MMPI: 28 sujetos con puntuaciones elevadas en el código 2-7 / 7-2 (D-Pt); 43 sujetos, igualmente con puntuaciones elevadas en el código 7-8 / 87 (Pt-Sc) y 35 pertenecientes a otros perfiles. La Escala Obvio-Sutil es discutida como medio para identificar sujetos que intentan exagerar o minimizar la patología.

Otro trabajo de Greene (2000), acerca de los pacientes que exageran su sintomatología, nos aporta las variables que pueden estar relacionadas con el "overreporting":

- Escalas de infrecuencia: F, y Fb,

- Escala psiquiátrica F(p) de Arbisi \& Ben-Porath, $(1995,1998)$

- Índice de simulación (F-K) de Gough, $(1947,1950)$

- Índice de Disimulación(Ds) de Gough, (1954)

- Items críticos de Koss \& Butcher, (1973)

- Ítems críticos de Lachar \& Wrobel, (1979)

- Subescalas de Wiener-Harmon, (1948).

Todas estas escalas, sigue afirmando Greene, (2000, pg.65), excepto la Escala Psiquiátrica F(p) de Arbisi y Ben-Porath (1995, 1998), son esencialmente idénticas, 
como lo demuestran las elevadas correlaciones existentes entre ellas superiores a ,80 en los estudios de la muestra psiquiátrica investigadas por Caldwell $\left(1997^{\mathrm{a}}\right)$.

\section{III.1.8.- Perfiles de hacerse el enfermo (malingering).}

En la práctica clínica nos encontramos también con dificultades para diferenciar el perfil de una persona equilibrada que responde a los ítems del MMPI-2 sin exagerar la sintomatlogía, del perfil resultante para un sujeto realmente perturbado.

La literatura científica ha empleado el término de "malingering" para identificar el fingimiento deliberado de una enfermedad, incapacidad o incompetencia. Algunos autores lo asocian o identifican también con "faking bad".

Como en ocasiones hemos comentado, resulta difícil ponerse de acuerdo para aunar los diferentes matices que los distintos términos vienen a expresar las diversas formas de simulación. En el apartado final de este capítulo expondremos las soluciones aportadas por Greene (1997) y las de Berry y Butcher (1998) para integrar, de forma coherente, este "maremagnum" terminológico.

Así, Graham (1990), diferencia en su obra los términos de "malingering" y "faking bad" como dos formas diferentes de simulación, y encuentra que los sujetos que responden a la forma de "malingering" presentan el perfil típico en las escalas de validez siguiente:

- La Escala F no se encuentra con valores extremadamente altos como ocurre con el perfil de los "fake bad",

- Las escalas L y K generalmente se encuentran con un valor cercano a los 50T.

- El rasgo más distintivo del perfil de "malingering" es la apariencia de un perfil en forma de "sierra" (figura 3.5, pg.46).

Esta apariencia de "sierra" en el perfil "malingering", Graham (1990) lo justifica porque la persona que está fingiendo tiende a atribuirse una amplia gama de síntomas patológicos que son reflejados fundamentalmente en las escalas D (Depresión, Pd (Desviación psicopática), Pa (Paranoia) y Sc (Esquizofrenia) pero evita atribuirse aquellos ítems que pueden evidenciar una patología extrema. Sin embargo, en la tercera edición de la misma publicación (Graham, 2000) ya no hace la discriminación entre ambas palabras asimilándose los dos conceptos bajo el término "faking bad".

El trabajo realizado por Bagby, Rogers, Buis. y colaboradores (1997) para poder detectar a los fingidores de esquizofrenia y depresión a través del MMPI-2 demostraron que las Escalas de Validez e indicadores del MMPI-2 detectaban mejor a los sujetos fingidores de Esquizofrenia que a los que fingían Depresión. Las escalas que mejor distinguían a los sujetos de la muestra clínica con Esquizofrenia de la muestra normal, fingidores de Esquizofrenia, fueron las Escalas de Validez F, Fb y F(p), mientras que las Escalas $\mathrm{F}$ y $\mathrm{Fb}$ fueron las que mejor distinguían a sujetos de la muestra clínica con diagnóstico de Depresión de los sujetos normales fingidores del mismo trastorno.

Beal (1989) utilizó las escalas de disimulación de Gough en el MMPI para tratar de detectar a los simuladores de lesiones físicas, a través de una muestra clínica, encontrando que la escala de disimulación de Gough (F-K) y la escala de Wiener 
Harmon Sutil-Obvio son más sensibles a los tipos de fingimiento en sujetos con lesiones físicas.

También con el MMPI Lees-Haley (1989) distinguía diferentes contextos y patologías para que las escalas $\mathrm{F}$ y F-K pudieran ser aceptadas para detectar a los simuladores en una muestra clínica. Llegó a la conclusión de que las escalas F y F-K son cuestionables como índices de fingimiento porque se aplican a sujetos que difieren en la patologías que fingen, así como en los contextos. El autor concluye que no es posible generalizar la aplicación de estas escalas a las diferentes patologías y por ello sugiere distintos "puntos de corte" según la patología mostrada.

El estudio realizado por Berry, Baer y Harris (1991) sobre 28 investigaciones para detectar a los simuladores con el MMPI analizando las puntuaciones directas y $\mathrm{T}$ de las escalas F, F-K, índice original y Revisado y las Escalas de Sutil-Obvio, los resultados sugieren que estos índices son buenos para detectar fingimiento intencionado (malingering) y que las mejores escalas para su detección son las puntuaciones directas y $\mathrm{T}$ de $\mathrm{F}$, la escala de Disimulación original y el índice F-K y debiendo adoptar la precaución correspondiente con las escalas de Indice de Disimulación revisado y las Escalas de Sutil-Obvio. Fueron revisadas las puntuaciones de corte para la predicción del fingimiento (malingering) sugiriendo los autores la necesidad de investigar apropiadamente las puntuaciones de corte para su uso en poblaciones específicas.

Si nos adentramos en el ámbito forense y la aplicación del MMPI para detectar a los fingidores encontramos el estudio llevado a cabo por Hawk y Cornell (1989) en el que compararon los perfiles del MMPI realizados por 18 sujetos criminalmente acusados y que intentaban fingir (malingering) (MAL), con 17 sujetos psicóticos (PSY) acusados de crímenes y 36 sujetos normales y que no presentan intención de engañar (nonmalingering) tomados como sujetos control (CONTRS)). Tanto los sujetos MAL como los PSY no pudieron ser testados en, aproximadamente, el 50\% de los casos bien por una producción incompleta o por contestar al azar en la prueba. En el resto aparecen diferencias entre los sujetos que fingían y los otros grupos en varias escalas del MMPI y en el Índice F-K. Un análisis discriminante clasificó fielmente los sujetos MAL y los PSY en base a las variables del MMPI. Los autores concluyen que el MMPI puede tener una utilidad considerable para detectar el fingimiento intencionado (malingering) cuando los sujetos cooperan con la prueba.

En el mismo ámbito de la jurisdicción y al tiempo de reclamar indemnizaciones por lesiones y/o secuelas psíquicas, el MMPI-2 puede ayudarnos para detectar a los fingidores. Este es el estudio realizado por Lees-Haley (1991) que analizó las puntuaciones obtenidas en la escalas F y F-K (índice de Gough, 1950) de grupos de sujetos (fingidores y no-fingidores) que reclaman judicialmente una indemnización por lesiones físicas Los resultados contemplan que tanto la Escala F como el Índice F-K parecen diferenciar correctamente a los fingidores (malingerers) de los no-fingidores (non-malingeres). Los autores sugieren que deberían utilizarse puntuaciones de corte más bajas para los fingidores de lesiones físicas que para aquellos criminales que fingen locura o incapacidad.

Cassisi y Workman (1992) utilizaron una forma abreviada del MMPI-2, con una muestra de sujetos normales, para poder detectar a los fingidores basándose fundamentalmente en las escalas tradicionales de Validez. Se llevaron a cabo dos estudios con las variables L, F y K del MMPI-2, uno en su versión normal y otro en una 
versión breve. En esta última versión a los sujetos se les dio instrucciones diferentes a la hora de completar el Cuestionario: sea sincero, intente dar una buena imagen (fake good) e intente dar una mala imagen (fake bad). Los resultados sugieren que esta forma abreviada del MMPI-2 puede ser útil sola o combinada con otros cuestionarios para identificar potenciales problemas de autoinformación.

El objetivo de la investigación de Iverson, Franzen y Hammond (1995), fue analizar las diferencias entre pacientes que fingen una enfermedad mental y pacientes psiquiátricos que han respondido de forma honesta y sincera al MMPI-2. Los resultados muestran que las escalas de Validez del MMPI-2 pueden diferenciar, con un alto grado de precisión, enfermos instruidos para fingir enfermedad mental de aquellos pacientes psiquiátricos reales. Este estudio es uno de los pocos en el que se analizó la nueva escala $\mathrm{Fb}$ y resultó que fue menos precisa clasificando a los fingidores experimentales que la escala $\mathrm{F}$.

Con una muestra de sujetos normales y clínicos el estudio de Bagby, Rogers, Buis y Kalemba (1994), comparan dos grupos de sujetos: por una parte aquellos que simularon una enfermedad psiquiátrica bajo las instrucciones de buena imagen (fake good) y de mala imagen (fake bad), y por otra parte pacientes psiquiátricos que contestaron normalmente al MMPI-2. Los resultados muestran que para perfiles que reflejan buena imagen el índice F-K $<-12$; y para perfiles que reflejan mala imagen la Escala $\mathrm{F}>89$ y el Índice F-K > 7. Estos fueron los puntos de corte óptimos para dichos perfiles. Fake bad (hacerse el enfermo o fingir mala imagen) es tomada, por estos autores, como "malingered " y "Fake good" (fingir buena imagen) es considerada como una respuesta defensiva.

La utilidad de las escalas de Validez del MMPI-2, con una muestra de sujetos normales y clínicos es el objetivo de los autores Bagby, Rogers y Buis (1994). Analizan la efectividad de varias escalas de validez e índices del MMPI-2 para detectar a los fingidores (malingered $=$ Fake bad) y los sujetos que responden de una forma defensiva (Fake good). La muestra de 215 sujetos, considerados como normales, completaron el cuestionario bajo las condiciones de "fake bad", "fake good" y responder sinceramente. Los 173 sujetos de la muestra clínica contestaron de forma normal. Los resultados mostraron cuatro indicadores de validez que indicaron ser moderadamente efectivos para detectar los perfiles de "fake bad": F, F-K, la versión revisada de la escala de Disimulación del MMPI-2 y el índice Obvio-Sutil. Sin embargo, los indicadores del perfil de "fake good" fueron mucho menos efectivos; solamente F-K y Obvio-Sutil parecen tener una moderada utilidad.

El objetivo planteado por Moran (2000) en su trabajo es estudiar el comportamiento de las variables F y F-K y su contribución para diferenciar sujetos que se hacen los enfermos (malingering). En su investigación toma una muestra de 153 estudiantes que divide en un total de 9 grupos diferentes de los que, a algunos de ellos, se les instruye para que simulen síntomas psiquiátricos de tipo depresivo, maníaco y una sintomatología aleatoria. Sus resultados concluyen que es posible detectar bien la simulación de la Depresión, pero no la manía y la sintomatología psiquiátrica fue detectada acertadamente en la mitad de los casos.

En su trabajo, Gallagher (1998), basándose en las Escalas de Validez del MMPI-2, intenta detectar "malingering" con una muestra total de 182 sujetos internados en un correccional. Estableció tres grupos: el primero de ellos con 49 sujetos, sin patología 
evidente, a los que se les instruye para que den "mala imagen" (fake-bad); el segundo grupo está formado por 75 sujetos que deben contestar al cuestionario de forma estándar (honesta y sinceramente); y el tercer grupo formado por internos con psicopatologías específicas que, igualmente, deben contestar de forma estándar. Los resultados demuestran que la Escala $\mathrm{F}(\mathrm{p})$ demostró su validez con respecto a las Escalas K y F. Otro resultado obtenido fue que $\mathrm{F}(\mathrm{p})$ discriminó entre los grupos de instrucción fakebad $\mathrm{y}$ el que presentaba síntomas psiquiátricos específicos, pero no lo hizo adecuadamente entre el grupo Fake-bad y los sujetos considerados como normales que no presentaban psicopatología evidente. También pudo demostrar Gallagher que la escala $\mathrm{Fb}$ no contribuyó al incremento de la validez más que las otras.

La investigación llevada a cabo por Larrabee (1998) se centró en detectar a las personas que exageran y/o prolongan su malestar corporal cuando se encuentran inmersas en procesos de reclamación jurídica. El objetivo era evaluar la sensibilidad del MMPI/MMPI-2 para exagerar su sintomatología en sujetos con sospecha de "hacerse el enfermo". Para ello, a cada uno de los 12 sujetos con daño cerebral que reclamaban una indemnización por encontrarse enfermos, además del MMPI-2, se les administró una entrevista clínica, una batería neuropsicológica y unas pruebas que detectaban los síntomas de validez. Los resultados demuestran que 3 de los 12 sujetos presentaron puntuaciones elevadas en las escalas de Validez F y en las Escalas Clínicas Hs y Hy. Igualmente, pudo mostrar que 11 de los 12 sujetos presentaron elevaciones en la Escala FBS de Lees-Haley. La conclusión a que llega Larrabee es que debe ser diagnosticado como "Fake-bad" cuando existan, en las Escalas Clínicas, puntuaciones Hs y Hy >80T y la Escala de Validez FBS se encuentre significativamente elevada.

Con una muestra de 40 sujetos con ideas suicidas o intentos de suicidio, de un total de 58 hospitalizados, el grupo de investigadores Rissmiller, Wayslow, Madison, Hogate, Rissmiller \& Steer (1998), intentan determinar la prevalencia de "hacerse el enfermo" ("malingering") en personas con intentos y/o ideas de suicidio que son sistemáticamente hospitalizados. Los resultados muestran que el $10 \%$ de los sujetos mostraron "malingering" e indicaron incentivos externos que motivaron el engaño de ideación o intento suicida. También pudieron verificar que ninguna de las Escalas de Validez del MMPI-2 correlacionaron con el auto-informe de malingering. Algunos pacientes pudieron fingir, sin ser detectados, sus intenciones suicidas. Los datos demuestran la dificultad inherente en detectar malingering a través de la entrevista clínica y los tests psicológicos.

\section{III.1.9. - Escalas de Deseabilidad social.}

Wiggins (1959) desarrolló su Escala de Deseabilidad social, compuesta por 33 ítems (ver Anexo 7), para discriminar estudiantes que contestaban al MMPI de una manera socialmente deseable de aquellos otros que contestaban al test de forma honesta y sincera. La Escala de Wiggins tiene uno de los efectos mayores en la identificación de estudiantes orientados para ser defensivos (Baer, et als., 1992). La distribución de puntuaciones de los sujetos normales y de la muestra clínica son muy similares en todo el rango completo (citado por Greene, 1997, pg.199 y 200).

Edwards (1957) define la deseabilidad social como la tendencia de los sujetos, cuando describen su propia personalidad, a "atribuirse afirmaciones con valoraciones 
socialmente apetecibles y a rechazar las que poseen valores socialmente peyorativos" (pg. VI, citado por Seisdedos, 1985).

Ramanaiah, Schill, \& Lock-Sing-Leung. (1977) presentan los resultados concernientes a dos estudios acerca de la estructura interna de la escala de Deseabilidad Social de Marlowe-Crowne (MCSD). En el primer estudio se confrontó que la atribución y la negación son dos de los principales componentes de la Escala factorizando las intercorrelaciones entre los ítems de la MCSD, ofreciendo la confirmación de la hipótesis planteada a través de la muestra de 189 sujetos. En el segundo estudio, con 180 sujetos, se investigó la validez diferencial de estos componentes (atribución y negación) para predecir puntuaciones en la Escala L, Escala $\mathrm{K}$ y la escala Represión-Sensibilización, todas ellas derivadas del MMPI. Los componentes de atribución y negación servirían para predecir puntuaciones en la Escala $\mathrm{K}$ y en la Escala de Represión-Sensibilización pero no en la escala L. De esta forma los resultados corroboran parcialmente las hipótesis planteadas.

Sobre la validez de la Escala de Marlowe-Crowne y las escalas de Validez del MMPI, Robinette (1991) investigó el constructo de validez de la forma abreviada compuesta por 13 ítems de la escala de Deseabilidad Social iniciada por Reynolds (1982), utilizando las Escalas de validez del MMPI. Con una muestra de 481 militares, la forma abreviada de Marlowe-Crowne replicó las correlaciones entre la escala estándar de Marlowe-Crowne y las escalas de Validez del MMPI inicialmente propuestas por Crowne y Marlowe (1960). Los resultados demuestran que la forma abreviada de la escala de Deseabilidad Social de Marlowe-Crowne es una medida económica de la deseabilidad social.

\section{III.1.10. - Escala Superlativa (S) de Butcher y Han (1995).}

Butcher y Han (1995) elaboraron la escala Superlativa (S) para evaluar personas que se presentan a sí mismos de una manera exageradamente ajustados y que se encuentran frecuentemente en individuos ante situaciones de selección de personal. En la investigación llevada a cabo por Greene (1997) con distintos tipos de muestras (normales y patológicos) pudo determinar que correlaciona significativamente con la escala K ( .82 y .88). Como era de esperar, los individuos de población normal obtienen puntuaciones más altas en la escala $\mathrm{S}$ que las obtenidas por los pacientes, pero las distribuciones se hacen similares para las puntuaciones elevadas $(\mathrm{PD}>38)$.

\section{III.1.11. - Escala de Fingimiento Positivo (MMp; ODecp) de Cofer, Chance, fogudson, (1949).}

Esta Escala de Fingimiento Positivo (Mp) fue desarrollada para identificar defensividad. Cofer, Chance, \& Judson, (1949) solicitaron a grupos de estudiantes que respondieran al MMPI como una persona emocionalmente trastornada (fingimiento) o dando la mejor impresión (defensividad). Identificaron 34 ítems que fueron insensibles al fingimiento pero sí lo fueron para la defensividad (fingimiento positivo). Encontraron que una puntuación $\geq 20$ identificaba correctamente al $96 \%$ de los que contestaron adecuadamente y el 86\% de los defensivos en el MMPI. También pudieron apreciar que las puntuaciones en la Escala Mp tendían a correlacionar positivamente con las puntuaciones de las subescalas Sutil de Wiener. 
Baer, Wetter \& Berry (1992) encontraron en su meta-análisis que Mp tenía un alto grado de sensibilidad en discriminar estudiantes instruidos para ser defensivos. Las puntuaciones óptimas de corte con muestras de estudiantes, varían con un rango que va desde +9 (Bagby, Rogers, Buis, \& Kalemba, 1994) a +13 (Baer et al., 1995) y +14 (Bagby, Rogers, \& Buis, 1994).

Nichols \& Greene (1991) han adaptado la Escala Mp para el MMPI-2 y renombrado como Otro Engaño (ODecp ), reduciéndola a 33 ítems . Las investigaciones realizadas por Greene (1997) con diferentes tipos de muestra (normal y con trastornos psiquiátricos) le permitió obtener puntuaciones en la escala ODecp de tal manera que $\mathrm{PD} \geq 19$ se encontraron en, aproximadamente, el 5\% de los sujetos tanto normales como de los pacientes con trastornos y las distribuciones de las puntuaciones tienden a ser semejantes en los dos grupos.

El trabajo realizado por Leavenworth (1998) tiene como objetivo predecir la correlación entre disimulación y psicopatía con una muestra de 100 presos internados en un centro penitenciario, partiendo de la hipótesis de que las puntuaciones de las Escalas de Validez del MMPI-2 que detectan tanto Fake-good como Fake-bad, deberían correlacionar con las puntuaciones de la escala Psychopathy Checklist-Revised (PCLR). Para llevar a cabo este estudio administra la prueba del MMPI-2, un Autoinforme de evolución de síntomas psicológicos, una entrevista semiestructurada para evaluar psicopatía y el PCL-R. Sus resultados concluyen que su hipótesis no llegó a cumplirse. Además encontró que las medias de las puntuaciones de Mp (fingimiento positivo) y las escalas de Validez de Fake-good fueron elevadas para todos los internos; los afroamericanos correlacionaron significativamente más alto en la variable ODecp que los caucasianos.

\section{III.1.12.- Escala Psiquiátrica $\mathcal{F}(p)$ de Arbisi ơ Ben-Porath (1995, 1998).}

Arbisi, y Ben-Porath $(1995,1998)$ en su estudio con una muestra clínica proponen una nueva escala en el MMPI-2 para poder detectar a los simuladores. Los resultados aportan una nueva escala de validez, la Escala Psiquiátrica $F(p)$, que ayuda a distinguir, entre los pacientes psiquiátricos, aquellos que responden honestamente de los que intentan exagerar sus síntomas de forma intencionada.

Compuesta por 27 ítems (ver Anexo 14) que raramente fueron contestados por pacientes psiquiátricos así como por la muestra normativa. Las puntuaciones elevadas en esta escala no deberían encontrarse dentro de una psicopatología severa. $F(p)$, puede funcionar como una escala adicional para clarificar el origen de una $\mathrm{F}$ elevada, aunque debería emplearse, por ahora, de forma cautelosa hasta que se encuentren nuevas evidencias que avalen esta posibilidad.

Las correlaciones entre $\mathrm{F}(\mathrm{p})$, la Escala $\mathrm{F}$ y las puntuaciones de otras escalas del MMPI-2 indican que la Escala $\mathrm{F}(\mathrm{p})$ es menos indicativa de un desajuste psicológico y una severa patología que la Escala F (Arbisi \& Ben-Porath, 1998; Ladd, 1998). Utilizando los datos recogidos por Graham, Watts \& Timbrook (1991), Arbisi \& BenPorath (1995) demostraron que las puntuaciones de la Escala $F(p)$ unida a las puntuaciones de la escala $\mathrm{F}$ puede ayudar a discriminar entre personas que intentan presentar una mala imagen y pacientes psiquiátricos. 
Aunque Arbisi \& Ben-Porath no han establecido el punto de corte óptimo para la Escala $\mathrm{F}(\mathrm{p})$ para poder así diferenciar entre los simuladores que intentan ofrecer una mala imagen y los pacientes psiquiátricos, no obstante, se sugiere que las puntuaciones típicas (T) superiores a 100 en la Escala $F(p)$ probablemente son indicativas de fingimiento de mala imagen (faking-bad) .

Rogers, Sewell \& Ustad (1995) realizaron un trabajo con pacientes psiquiátricos que contestaron al MMPI-2 de forma estándar (honesta y sinceramente) y con otro grupo que fue instrído para que respondieran al cuestionario de forma que exageraran sus síntomas. Encontraron que las puntuaciones superiores a 106T (para varones) y $113 \mathrm{~T}$ (para mujeres) en la escala $\mathrm{F}(\mathrm{p})$ fueron identificativas de exageración de síntomas. También pudieron apreciar que la Escala $F$ fue igualmente efectiva en esta misma discriminación y que las $\mathrm{F}$ y $\mathrm{F}(\mathrm{p})$ presentaron puntuaciones altamente correlacionadas. Desafortunadamente estos autores no informaron de datos concernientes al incremento de la validez cuando es utilizada la escala $F(p)$ conjuntamente con la escala $F$. No obstante dos estudios posteriores demostraron que la Escala $F(p)$ incrementa su validez con la Escala $\mathrm{F}$ en la detección de internos encarcelados cuando fueron instruidos para dar mala imagen de sí mismos (Gallagher, 1997) y con estudiantes universitarios que fueron igualmente instruidos para fingir esquizofrenia (Bagby, Rogers, Buis, Nicholson, Cameron, Rector, Schuller \& Seeman, 1997).

Algunos estudios posteriores han indicado que la escala $\mathrm{F}(\mathrm{p})$ puede ser más precisa que la Escala $\mathrm{F}$ para identificar pacientes psiquiátricos, en regímenes de internado y de ambulatorio, que son instruidos para exagerar sus síntomas y problemas (Arbisi \& BenPorath. 1998b; Berry, Adams, Clark, Thacker, Burger, Wetter, Baer \& Borden, 1996).

La investigación llevada a cabo por Echols (1999) tuvo como objetivo poder determinar el efecto de la raza (Afroamericanos y Caucasianos) en la validez del MMPI-2 con la contribución de la Escala $\mathrm{F}(\mathrm{p})$ y su análisis comparativo con las Escalas $\mathrm{F}$ y $\mathrm{Fb}$. La muestra se encuentra referida por pacientes psicóticos, con trastornos afectivos, con trastornos de personalidad, con problemas de adicción (alcohol solamente, alcohol y cocaína y sustancias diversas). Los resultados apoyan las conclusiones previas. Por una parte se demuestra que la Escala $F(p)$ tiende a ser menos sensible a la psicopatología que las $\mathrm{F}$ y $\mathrm{Fb}$, resultando ser más bajas sus puntuaciones que en $\mathrm{F}$ y $\mathrm{Fb}$; por otra, se evidencian menos protocolos nulos a través de $\mathrm{F}$ (p) que sobre la Escala F.; y por otra, la F(p), en pacientes de diversas razas, no se muestra como un factor que contribuya a la detección de un protocolo válido.

El trabajo de Ladd (1998) con una muestra de 180 sujetos adultos en tratamiento ambulatorio con dependencia de sustancias, con y sin diagnóstico psiquiátrico, comparó las puntuaciones medias obtenidas en las Escalas de infrecuencia $F(p)$, F y Fb. Sus resultados demuestran que dichas puntuaciones en $\mathrm{F}(\mathrm{p}), \mathrm{F}$ y Fb evidencian su validez en dichos pacientes con dependencia de sustancias.

\section{I I.2 . - UNA I INTEGRACI ÓN CO HERENTE.}

Después de recorrer los vericuetos científicos nos encontramos inmersos en distintas y diversas controversias que resultan difícilmente conciliables para poder hacer un resumen adecuado y mínimamente clarificador. Al menos una cosa nos ha quedado 
clara ante tantas investigaciones realizadas: la suma importancia dadas a las Escalas de Validez para la interpretación adecuada y fiable de los perfiles del MMPI-2.

A continuación vamos a exponer las dos soluciones aportadas por dos grupos de investigadores: la de Greene (1997) y la de Berry y Butcher (1998).

\section{III.2.1.- La aportación de Greene (1997):}

Greene (1997) nos hace notar que estamos ante uno de los inventarios de personalidad más utilizados como medida de psicopatología y con un mayor número de investigaciones con el MMPI/MMPI-2. Este autor nos recuerda también que ya Mehl y Hathaway (1946), cuando elaboraron el MMPI, estaban convencidos de la necesidad de evaluar dos categorías opuestas en la forma de contestar: "faking bad" y "faking good". Cualquiera de estas dos opciones la precisión o exactitud de las respuestas queda en entredicho.

La minimización de los síntomas, Greene (1997) lo denomina, en términos generales, como "Defensividad" por cuanto la persona intentan "defenderse" para no aparecer como un enfermo con una patología determinada; sus síntomas no parecen ser tan graves y por consiguiente intenta decir que "yo no estoy tan enfermo como la gente supone". Esta defensividad es demostrada por diversos autores en la literatura científica con diferentes términos: "Fake/Faking good" (fingirse bien), "Underreporting" (minimizar la sintomatología) o "Disimulation" (disimulación).

Exagerar la sintomatología psicopatológica, Greene (1997) lo denomina, en términos generales, como "Fingimiento" por cuanto el enfermo intenta aparecer como más enfermo, o sus síntomas son más severos o presentan mayor grado de gravedad, de lo que realmente son. Es decir, se "finge" estar más enfermo de lo que se está ciertamente. En la literatura científica encontramos términos equivalentes: "Fake/Faking bad" (fingirse mal), "Malingering" (fingimiento) u "Overreporting" (exagerar la sintomatología).

\section{III.2.1.1. - El proceso de evaluación de la Validez del $\mathcal{M M P I - 2 :}$}

Por todo ello, cuando intentamos analizar el perfil de una persona al contestar al MMPI-2, la evaluación de la validez será el primer paso, dentro de todo el proceso de evaluación del MMPI-2, para poder determinar la fiabilidad de la prueba. Esta evaluación debe ser realizada de una forma secuencial. Greene (1997, pg. 172) plantea el siguiente proceso para evaluar la validez de un protocolo (ver Figura 2).

- $1^{o}$.- Verificar los ítems que han sido omitidos. Más exactamente se refiere al control del "?" (no sé o no puedo contestar). Cuando hablamos de "ítems omitidos" estamos hablando de forma inapropiada ya que no solamente contamos los ítems que el sujeto ha dejado sin contestar, sino también aquellos que el sujeto ha contestado, en la misma casilla de la respuesta, como "verdadero" y "falso" a la vez. Estos también se contabilizan en el MMPI-2 como "ítems omitidos".

La omisión de un número excesivo de ítems en un Cuestionario de personalidad es un problema poco frecuente en la mayor parte de las evaluaciones clínicas. Cuando esto sucede se detecta fácilmente con una revisión cuidadosa de la hoja de respuestas, o si la corrección esta realizada de forma computarizada, automáticamente nos muestra el número de ítems omitidos. 
Ocasionalmente una persona muy defensiva o con cierta problemática de tipo paranoide podrá tener dificultades para contestar la mayor parte de los ítems del Cuestionario. Estas características de la personalidad van a mostrarse, de forma evidente, en la entrevista clínica. La omisión de los ítems no es un problema típico cuando el fingimiento se encuentra implicado, ya que la persona debe atribuirse los ítems de una forma adecuada a la estrategia de fingimiento adoptada por el sujeto. Pueden darse algunos casos, no frecuentes, en los que el sujeto afirma encontrarse demasiado alterado como para contestar a todos los ítems .

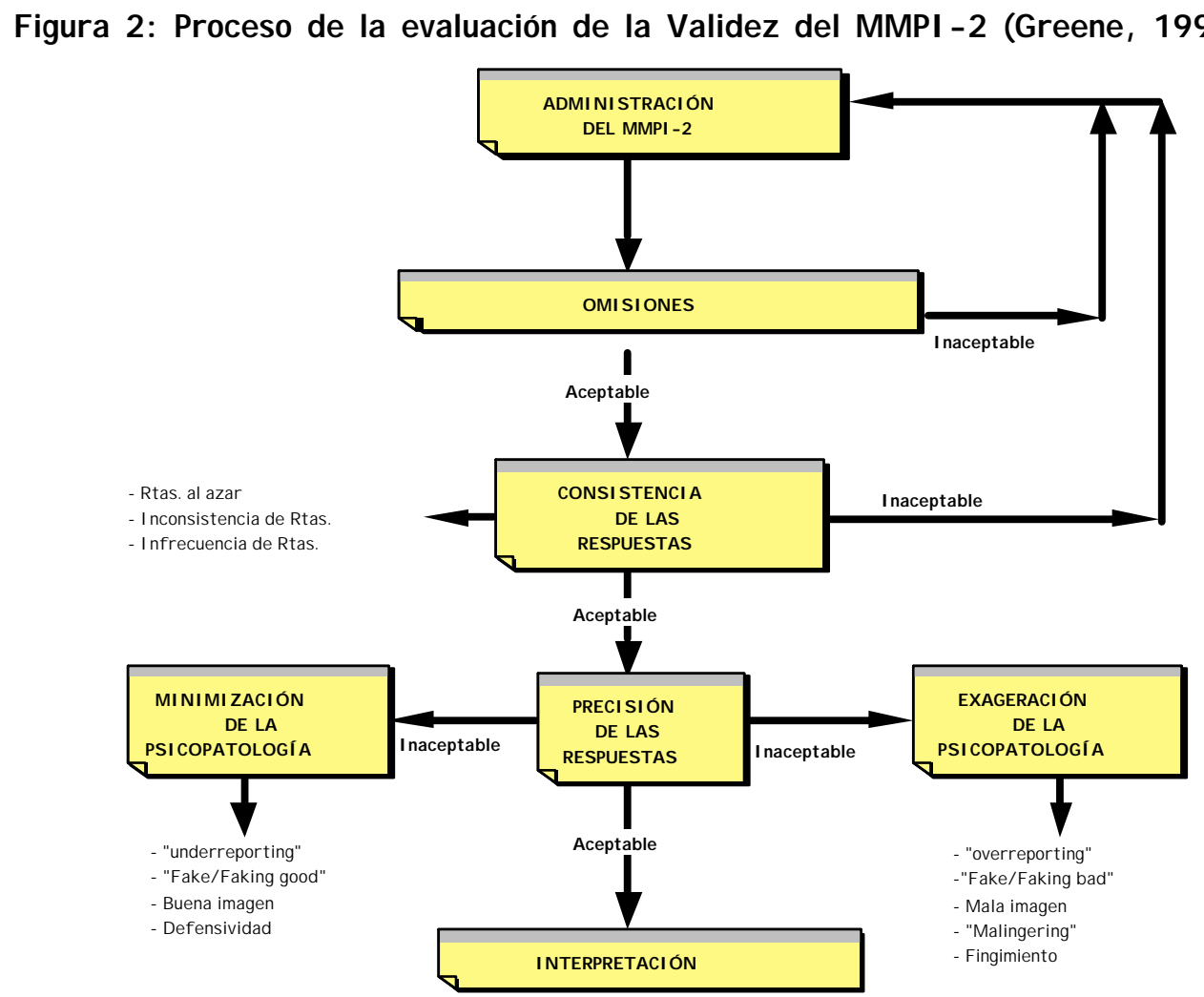

- $2^{o}$.- Confrontar la consistencia o coherencia de las respuestas a los ítems (un sujeto puede falsificar la prueba de una forma coherente). El segundo paso para evaluar la validez de las respuestas dadas por el sujeto se encuentra referido por la coherencia o consistencia de sus respuestas. Dicha coherencia se refiere a que la persona, una vez contrastados los ítems, ha contestado de una forma fiable. Este procedimiento es necesario antes de que se realice cualquier evaluación de la precisión de su respuesta.

Greene (1997) diferencia entre "coherencia de respuesta al ítem" y "exactitud o precisión de la respuesta al ítem" dependiendo si se tiene en cuenta, o no, su contenido en el momento de contestar. Por ello, las medidas de la "coherencia" de los ítems evalúan si el sujeto ha proporcionado un patrón fiable de respuestas para los ítems durante todo el cuestionario, mientras que la medida de la "precisión" del ítem evalúa si el sujeto ha intentado distorsionar sus respuestas a los ítems de una manera determinada (defensividad/fingimiento).

La estrategia adoptada por Greene (1997) para analizar la coherencia de las respuestas está basada en el análisis de: 
- Las respuestas al azar.

- La respuestas inconsistentes o incoherentes. Los sujetos pueden responder de forma inconsistente o incoherente de múltiples y variadas formas. Para evaluar esta forma inconsistente de respuestas el MMPI-2 dispone de las ya mencionadas escalas: Inconsistencia de Respuestas Variable (VRIN) e Inconsistencia de Respuestas verdadero (TRIN).

- Las respuestas Infrecuentes.

- $3^{o}$.- Confrontar la precisión o exactitud en sus respuestas a los ítems (fingimiento o defensividad). El siguiente paso para confrontar la validez de un protocolo es, precisamente, poder evaluar la precisión o exactitud de sus respuestas; es decir, no se trata de si el sujeto ha contestado de forma coherente a los ítems (puede haber falseado la prueba de forma coherente) sino de saber, de forma apropiada, si sus respuestas son sinceras, honestas, correctas, exactas o precisas, según sus propios patrones y rasgos de personalidad.

¿Cómo se puede llegar a esto?. Hemos de echar mano de toda la documentación personal que pueda estar a nuestro alcance, incluyendo historia biográfica y clínica, y analizar adecuadamente los rasgos de personalidad que el sujeto ha plasmado en el MMPI-2.

La estrategia de Greene (1997) para poder determinar la precisión de las respuestas consiste en el aánlisis de las siguientes escalas e índices:

- Escalas de Infrecuencia.

- Ítems Críticos de Lachar-Wrobel.

- Subescalas de Obvio-Sutil de Wiener-Harmon.

- Índice F-K y la Escala de Disimulación de Gough (Ds).

Lo que sí debe tener claro el clínico es que un perfil que ha sido definido como "fingido", no puede, ni debe, ser interpretado como un perfil "válido". Las razones específicas de la persona para fingir, deberían averiguarse con una entrevista clínica y el perfil puede ser calificado como un reflejo de tal proceso; sin embargo, ni el código del MMPI-2 ni las escalas individuales deben interpretarse.

Cuando las respuestas de una persona han sido identificadas como respuestas inexactas por la extrema defensividad o fingimiento, el perfil estándar no es interpretable bajo ningún concepto, ya que es reflejo de un estilo de respuestas no válido, dando por finalizado el proceso de interpretación del correspondiente MMPI-2. La persona debería repetir la prueba, aunque es posible que resulte el mismo perfil de invalidez. Cuando la persona se encuentre motivada para fingir, puede tener dificultades para responder adecuadamente a los ítems en las siguientes administraciones. Los investigadores no han establecido, aún, si el fingimiento posiblemente se mantiene a lo largo de la situación de tratamiento para una persona determinada aunque Audubon \& Kirvin (1982) encontraron, al menos, alguna influencia situacional en el estilo de respuesta.

\section{III.2.1.2.- La elección de los indicadores:}

La exactitud o precisión de la respuesta verificará si la persona ha adoptado un patrón de respuesta para fingir o para ser defensivo. Es importante poder determinar que la extensión y gravedad de la psicopatología de la que el sujeto informa sea un fiel 
reflejo de su historia y antecedentes. Consecuentemente, los clínicos no debemos extrañarnos que las actitudes de fingimiento se relaten como sintomatología patológica, y a la inversa, que las actitudes de defensividad sean relatadas como ausencia de síntomas patológicos.

Greene (1997, pgs. 184-185) considera algunos aspectos básicos sobre el fingimiento $\mathrm{y}$ la defensividad que deben explicitarse $\mathrm{y}$ tenerse en cuenta para evaluar adecuadamente la precisión o exactitud de las respuestas:

1.- Los investigadores asumen que el fingimiento y la defensividad representan un "continuum" que se caracteriza porque el fingimiento está en un extremo y la defensividad en el otro. Por consiguiente, la precisión del patrón de respuestas, se transformará gradualmente en fingimiento o defensividad como un movimiento de un lado a otro de este "continuum". No existe un punto concreto en el que el ejercicio de la persona refleje, de un vistazo, fingimiento o defensividad. En cambio, sí podemos predecir la "probabilidad" de que en el protocolo realizado por esta persona refleje fingimiento o defensividad.

2.- Dado que los diferentes matices de graduación del fingimiento y la defensividad existen dentro de este continuo, son numerosas las escalas que pueden utilizarse para valorar ambos tipos de respuesta reflejando fingimiento en sus puntuaciones altas y defensividad en las bajas. Existen escalas que valoran ambos aspectos y otras que, fundamentalmente, se centran en la valoración del fingimiento o de la defensividad.

3.- Muchas personas, cuando deciden fingir, lo hacen de una forma tan burda y extrema que es fácilmente detectable en la mayor parte de los casos a través de las variables de validez del MMPI-2.

4.- La presencia de fingimiento o defensividad no excluye psicopatología. Una persona que, actualmente, tiene un trastorno determinado también puede fingir o ser defensivo sobre la presencia de psicopatología. Las escalas e índices para evaluar la exactitud de las respuestas no puede determinar si la persona, actualmente, tiene psicopatología, solamente si la persona ha proporcionado una precisa descripción de sí mismo.

El MMPI-2, nos aporta una serie de indicadores a través de los cuales podemos apreciar una mayor sensibilidad para estos dos matices del fingimiento y defensividad:

- Escalas que, fundamentalmente, presentan una mayor sensibilidad para evaluar el fingimiento y defensividad:

- Escala de Infrecuencia (F)

- Ítems críticos

- Índice de Gough (F-K)

- Subescalas de Obvio y sutil de Wiener (1948).

- Escalas que, fundamentalmente, presentan una mayor sensibilidad para evaluar sólo Fingimiento:

- Escala de Disimulación de Gough (Ds y Ds-r).

- Escalas que, fundamentalmente, presentan una mayor sensibilidad para evaluar sólo Defensividad:

- Escala L (mentira) 
- Escala K (correctora)

- Escala de Fingimiento Positivo (Mp; ODecp; Cofer, Chance, \& Judson, 1949)

- Escala Superlativa (S) de Butcher y Han, (1995)

- Escala de Deseabilidad Social de Wiggins (Wsd, 1959).

La respuesta desviada, para la mayoría de estas escalas que solamente evalúan la defensividad, es contestada como "falso". El análisis realizado por Greene (1997) concluye que $\mathrm{L}, \mathrm{K}$ y $\mathrm{S}$ son virtualmente escalas de respuestas de Falso. Las intercorrelaciones entre estas medidas son mucho más variables que las que se pudieron determinar en las escalas de fingimiento.

Hemos podido apreciar una serie de escalas e índices diferentes para evaluar el fingimiento o la defensividad de una persona. El clínico debería seleccionar la estrategia más adecuada para detectar este evento teniendo en cuenta el tipo de población, los ámbitos específicos y las situaciones de tratamiento. La elección de una de estas escalas o índices para evaluar la defensividad parece ser más difícil que para evaluar el fingimiento porque se consideranmedidas de diferentes aspectos de la defensividad. La investigación necesita examinar cuáles de estas escalas o índices de defensividad o fingimiento es la más apropiada en una situación clínica particular.

\section{III.2.2. - La aportación de Berry y Butcher (1998).}

El trabajo de Berry y Butcher (1998) se encuentra centrado esencialmente en el modelo adaptacional propuesto por Putnam y Millis (1994) del "rol de los factores psicosociales", cuando se trata de detectar el fingimiento de los síntomas de daño cerebral a través del MMPI-2.

Uno de los mayores atractivos que posee el MMPI-2 para los psicólogos forenses ha sido la disponibilidad de las Escalas de Validez para la detección de las distintas tipos de respuestas. Nichols, Greene \& Schmolck (1989) dividieron las clases de respuestas en el MMPI en dos categorías (cfr. Figura 3):

- Responder sin tener en cuenta el contenido del ítem (CNR, "Content Nonresponsiveness")

- Responder al ítem de forma fingida (CRF; "Content Responsive Faking").

CNR está presente cuando las respuestas no tienen una relación significativa con las preguntas. Las respuestas omitidas y las dobles marcas, así como las respuestas dadas aleatoriamente, se encontrarían dentro de esta categoría. La falta de colaboración, bajo nivel de comprensión lectora o psicosis, pueden dar como resultado una respuesta CNR. La característica que lo define es que las respuestas no pueden ser interpretadas porque no se encuentran referidas, de forma significativa, con el contenido del ítem.

Las respuestas CRF ocurren cuando el sujeto distorsiona las respuestas basándose en el contenido de las preguntas. Existen dos grandes categorías de CRF:

- Respuestas que minimizan la psicopatología (“underreporting”).

- Respuestas que exageran la psicopatología (“overreporting”). 
En el primero de estos dos tipos, el sujeto contesta a las preguntas de tal manera que los problemas psicológicos son negados o minusvalorados. Estos casos no se presentan en los litigios jurídicos que afectan a los pacientes con lesiones cerebrales por lo que son contemplados en el esquema desarrollado para la evaluación de la validez del MMPI-2 por estos autores.

En el segundo tipo, el sujeto trata de exagerar los síntomas o inventa problemas psicológicos. Esta clase de respuesta sí resulta interesante detectarla para poder evaluarla adecuadamente en los casos de lesiones cerebrales que se presentan para informes forenses.

\section{III.2.2.1. - La detección de Respuestas CNR:}

La mayor parte de las escalas de Validez tradicionales del MMPI-2 son sensibles para detectar las respuestas CNR. Las tres escalas que, fundamentalmente, parecen ser más sensible a la detección de este tipo de respuestas, y según las investigaciones más recientes, son: "?", F, Fb, VRIN y TRIN. En las líneas siguientes, vamos a ir comentando, brevemente, alguno de estos aspectos.

La escala "no sé / no puedo contestar (“?”), al igual que para el MMPI, implica, simplemente la suma del número de respuestas omitidas y dobles marcas. El examinador, revisando la hoja de respuestas con el paciente presente, puede preguntar por los ítems no respondidos o marcados doblemente, de esta manera se puede paliar y aprovechar el protocolo. Aunque se han publicado pocos trabajos empíricos con datos sobre el impacto de los diferentes niveles de respuestas omitidas o de dobles marcas en el MMPI-2, Graham (1993) apuntó que el manual del MMPI-2 sugiere que los protocolos con 30 o más ítems omitidos deben ser considerados altamente sospechosos, si no completamente inválidos. La recomendación que hizo fue que, protocolos con más de 10 ítems omitidos deben ser interpretados con sumo cuidado y que no lo fueran aquellos que tuvieran 30 ó más ítems sin contestar.

Un cierto número de investigaciones han examinado la respuesta aleatoria en el MMPI-2. Berry, Wetter y Cols. (1991) encontraron que F, Fb y VRIN fueron todas sensibles a la presencia de respuestas aleatorias y en un estudio análogo posterior (Berry, Wetter, Baer, Larsen, Clark, \& Monroe, 1992) investigaron la detección de varios niveles parciales de respuestas al azar. Paolo y Ryan (1992) confirmaron estos resultados con muestras clínicas.

Berry y cols. (1992) encontraron que estas mismas escalas de validez estaban correlacionadas significativamente con la autoestima en el número de respuestas aleatorias dadas en el MMPI-2 administrado bajo las instrucciones generales.

Wetter, Baer, Berry, Smith, \& Larsen (1992) encontraron que, aunque F, Fb y VRIN fueron sensibles a las respuestas aleatorias, VRIN fue más sensible que las demás a la exageración de la sintomatología, sugiriendo que VRIN funcionaría con el MMPI-2 como TR y CLS lo hacían con el MMPI original.

Gallen y Berry (1996) examinaron los poderes de predicción, positivo y negativo, para $\mathrm{F}, \mathrm{Fb}$ y VRIN en diferentes proporciones de respuestas aleatorias. Concluyeron que, con un $5 \%$ de respuestas aleatorias, una VRIN con PD $\geq 13$ tenía un poder de predicción del 100\% para detectar una forma de responder al azar. 
Dada la sensibilidad de $\mathrm{F}$ y $\mathrm{Fb}$ para detectar la exageración de síntomas, tanto como la sensibilidad de VRIN para las respuestas inconsistentes, se recomienda la utilización, dentro del ámbito forense, de la escala VRIN para clarificar el origen de una puntuación elevada.

Figura 3: Evaluación de la Valide $z$ del $\mathcal{M M P I}$ - 2 (Berry of Butcher, 1998)

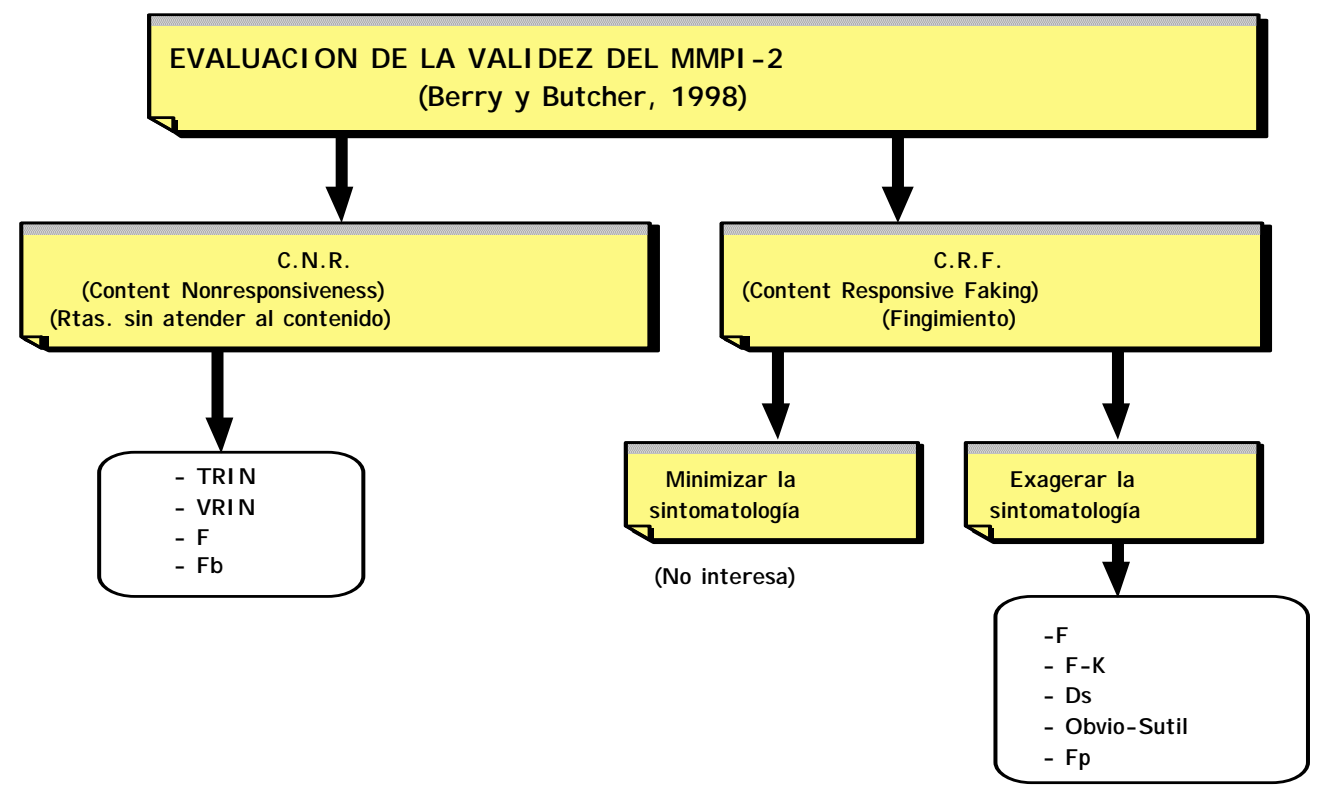

Aunque son pocas las investigaciones realizadas con TRIN, no obstante podemos apreciar una aceptable sensibilidad hacia las respuestas contestadas de forma inconsistente. Wetter y Tharpe (en prensa) investigaron el impacto de diferentes niveles de respuestas al azar para Verdadero o para Falso en las escalas clínicas y de validez del MMPI-2. Sus resultados demostraron una gran sensibilidad para detectar los modelos de respuestas al azar, tanto contestando en forma de "verdadero" como "falso", y recomendaron la utilización de la puntuaciones de corte publicados en el manual para el rechazo y consideración de protocolos como no válidos $(\mathrm{PD} \leq 5 \geq 13$ ).

\section{I I.2.2.2. - La detección de Respuestas CRF:}

Los dos tipos de respuestas que hacen referencia a las CRF se especifican en aquellas que minimizan o exageran la sintomatología psicopatológica. Una y otra forma de responder conllevan implícitamente, como hemos visto a lo largo de toda la literatura e investigaciones científicas, un intento de falsificación, bien a través de la "defensividad" (minimizando los síntomas) o bien del "fingimiento" (exagerando los síntomas).

Nos encontramos, pues, ante el mismo tipo de respuestas propuesto por Greene (1997) y que contemplamos en el apartado anterior. Pero Berry y Butcher (1998), basándose, fundamentalmente, en el contexto jurisdiccional de solicitud de indemnizaciones económicas por secuelas psíquicas tras un accidente postraumático, solamente le interesa poder determinar, a través del MMPI-2, la "exageración" de la sintomatología o "fingimiento". Berry y Butcher (1998) en este trabajo no hacer referencia a la "defensividad" o minimización de la sintomatología psicopatológica, ya que como dijimos anteriormente es raro que se produzca esta circunstancia en el medio jurídico para pacientes con lesiones cerebrales. 
¿Cuáles son los indicadores del MMPI-2 para detectar este tipo de respuesta que exagera sus sintomatología?. Lo hemos podido ver a través de todo lo dicho anteriormente cuando hemos hablado del "fingimiento" o falsificación. Solamente recordar que en el MMPI-2 se manifiesta a través de las escalas F, Fb, el Índice de F-K de Gough, la escala de Disimulación (Ds) de Gough, las subescalas Obvio-Sutil de Wiener y Harmon y últimamente por la Escala Psiquiátrica $\mathrm{F}(\mathrm{p})$ de Arbisi y Ben-Porath $(1995,1998)$. De todas estas escalas hemos realizado los comentarios anteriormente.

Si bien los resultados de estas escalas pueden proporcionar un buena efectividad, los clínicos deben ajustar las decisiones, de forma adecuada, según los individuos. Berry, Baer, \& Harris (1991) revisaron las puntuaciones de corte publicadas en diferentes estudios para la identificación de la exageración de la sintomatología en el MMPI. Aunque era posible identificar grupos de puntuaciones de corte óptimas, sin embargo eran incapaces de encontrar puntos de corte específicos que estuvieran confirmados de forma consistente en la literatura científica. De este modo, aunque un incremento de la elevación de las escalas de exageración debería conducir a un crecimiento de la posibilidad de su presencia, no existen puntuaciones claras que, concluyentemente, indiquen la presencia de una clase de respuestas en todos los tipos de población. De esta manera, un clínico que se encuentra con una escala $\mathrm{F}$ elevada en un paciente con daño cerebral, debería estar preocupado por la posibilidad de una clase de respuesta exagerada, pero no debería concluir, automáticamente, que se encuentra ante un caso de fingimiento.

De forma semejante, los consistentes resultados aportados por las subescalas ObvioSutil, deben ser utilizados con moderación, como ya comentamos anteriormente en la crítica realizada por Timbrook, Graham, Keiller y Watts (1993).

Rogers et al. (1994) también examinaron el problema de las puntuaciones de corte para la identificación del fingimiento en casos individuales. Revisaron 15 estudios concluyendo que las puntuaciones de corte óptimas variaban extensamente. El utilizar una puntuación media, sugerida por algunos autores, fracasó para todos los informes. Obviamente ni el enfoque de agrupamiento ni el enfoque de término medio es una solución ideal para este problema.

Nos identificamos plenamente con la sugerencia de Berry y Butcher (1998) sobre la necesidad de nuevas investigaciones para identificar factores moderadores como el género (Graham, Watts, \& Trimbook, 1991) o los ambientes (Berry, 1995) que podrían estar contribuyendo a la heterogeneidad de las puntuaciones de varias poblaciones. Con optimismo, tales investigaciones podrán permitir la identificación de puntuaciones de corte para poblaciones particulares que, de forma consistente y precisa, podrán llegar a identificar el fingimiento de forma adecuada. Hasta que tales investigaciones estén disponibles y respaldadas por un trabajo independiente, las escalas que detectan la exageración de síntomas en el MMPI-2 pueden ser el mejor criterio como advertencia de la posibilidad de fingimiento.

\section{II.2.2.3.- Resumen de la aportación:}

Los autores (Berry y Butcher, 1998, pg. 227) nos ofrecen un resumen de la literatura científica sobre el fingimiento de síntomas de lesión cerebral en el MMPI/MMPI-2. La literatura científica, hasta el momento (1998), nos sugiere las siguientes conclusiones: 
$1^{\mathrm{a}}$.- El MMPI/MMPI-2 contiene un número de escalas con demostrada sensibilidad a la exageración de los síntomas psicológicos. En general, las escalas que presentan la mayor consistencia para el éxito en esta tarea es la escala F. Una menor consistencia presentan: el Índice de Gough: F-K, la Escala de Disimulación de Gough (Ds/Ds-r) y la Fb. Con menos soporte en la actualidad están las Escalas Psiquiátrica de Arbisi y BenPorath (1995) y la escala "Fake-Bad" (FBS) de Lees-Haley, Englis \& Glenn (1991). Berry y Butcher (1998) recomiendan, para estas dos últimas una cierta precaución en su uso hasta que no aparezcan nuevos aportes empíricos.

2a.- Estudios análogos sugieren que los sujetos que fabrican, y posiblemente exageran, síntomas psicopatológicos de lesión cerebral, tienden a mostrar elevadas las escalas de exageración en el MMPI-2. Aunque varias escalas del MMPI/MMPI-2 tienen buen apoyo para la sensibilidad de exageración de síntomas, las puntuaciones de corte no se encuentran disponibles. Por lo tanto, estas escalas no pueden ser utilizadas, solo de forma concluyente, para identificar el fingimiento de síntomas psicopatológicos. Sin embargo, la elevación creciente de las puntuaciones en estas escalas aumentaría más y más la posibilidad en cuanto a la exageración de síntomas.

Como regla general, después de descartar la inconsistencia de las respuestas con las escalas VRIN y TRIN, la escala $\mathrm{F}$, con puntuaciones $\geq 80 \mathrm{~T}$ nos plantearíamos la posibilidad de una exageración para el MMPI-2. Puntuaciones $\geq 90 \mathrm{~T}$ son una señal clara de la necesidad de una atención especial por la posibilidad de disimulación de síntomas. Sin embargo, dada la ausencia de puntuaciones específicas, el diagnóstico de fingimiento de síntomas psicopatológicos requerirá la confrontación de otros datos procedentes de campos diferentes (entrevistas, datos clínicos-biográficos, observaciones de la conducta, etc.).

$3^{\mathrm{a}}$.- Estudios de pacientes con lesiones cerebrales leves, con fuerte evidencia de fingimiento de déficit cognitivo, sugieren que solamente exageran una parte de la sintomatología psicopatológica. El fingimiento de déficit cognitivos y elaboración de síntomas psicopatológicos pueden ser dimensiones independientes en individuos que fingen una lesión o daño cerebral. Esta simulación de déficits cognitivos no pueden ser deducidos del fingimiento de síntomas psicopatológicos. De igual forma la elaboración de síntomas psicopatológicos no pueden deducirse del fingimiento de déficits cognitivos. De este modo, las dos clases de fingimiento deberían evaluarse de manera independiente en pacientes con daño cerebral con importantes resultados dependiendo del resultado de sus evaluaciones neuropsicológicas.

4. Hay evidencia de que algunos pacientes con lesión cerebral pueden llegar, por sus evaluaciones neuropsicológicas, a prever los procedimientos específicos para evaluar la integridad de su síntomas. Desafortunadamente, no disponemos de una metodología empírica para la detección de este tipo de falsificación. 
PARTE I I : TRABAI O EXPERI MEX $\mathcal{T} \mathcal{A} \mathcal{L}$ 
CAPITULO IV . - ESTUDIO EMPIRICO

\section{Introducción}

Hasta el momento hemos realizado una exposición teórica del problema sobre la sensibilidad de Escalas e indicadores que pueden ayudar a precisar la validez de los datos manifestados en un perfil del MMPI-2. Hemos presentado las formas de distorsión de un perfil, sus métodos para evaluarlo, sus áreas de estudio y la descripción de las investigaciones más actuales con escalas e indicadores de la fiabilidad de un perfil cuando administramos la técnica del Minnesota Multiphasic Personality Inventory-2 de Hathaway y Mckinley en su adaptación al castellano.

Nuestro paso siguiente será formular nuestros objetivos e hipótesis de trabajo y desarrollar todo un estudio empírico para poder contrastar nuestras formulaciones hipotéticas a través de los resultados obtenidos.

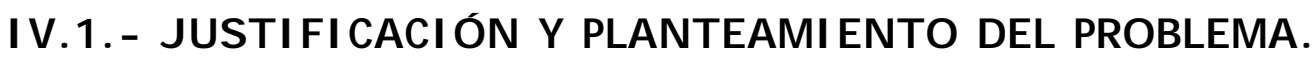

Toda técnica que intente evaluar rasgos de personalidad debe tener en cuenta la seguridad de que los datos aportados son fiables y válidos. Debe saber apreciar que el perfil expresado por el paciente es totalmente adecuado y coherente con su realidad.

Detectar a un simulador y poder determinar si intenta engañar al perito o al administrador de la prueba (a pesar de que sabe que tiene que responder de forma 
totalmente sincera), siempre aporta un grado de fiabilidad de los datos expresados en el perfil de la prueba.

Todo esto cobra especial relevancia cuando nos centramos en el ámbito de la jurisdicción. Las secuelas psíquicas de los accidentes de tráfico o laborales acompañadas de la solicitud de sus respectivas indemnizaciones, o los padres que desean presentarse como idóneos para la guarda y custodia de los hijos, o para la adopción de un hijo, o la evaluación psiquiátrica adecuada en cualquier peritaje delimitando la responsabilidad criminal... son algunos de los casos obligadamente esenciales que nos llevan a justificar el estudio de estos indicadores de validez.

La técnica del MMPI de evaluación de los rasgos de personalidad, ha sido tradicionalmente utilizada por psiquiatras y psicólogos para detectar y evaluar problemas de personalidad cuando se ha intentado realizar un peritaje psicopatológico. A partir de ahora, los jueces, peritos psiquiatras y psicólogos, pueden disponer de una constatación real, técnica y científica, de la evaluación de la personalidad del sujeto implicado a través de la expresión de un perfil de su personalidad, para que puedan realizar un dictamen más ajustado a derecho. Para ello se le aportan elementos esenciales para preguntarse por la fiabilidad de los datos aportados, como:

- ¿Qué grado de coherencia o consistencia presentan sus respuestas en el MMPI-2?

- ¿Qué grado de exageración, simulación o fingimiento de síntomas presenta sus respuestas en el MMPI-2?

- ¿Qué grado de minusvaloración, simulación o defensividad de sus síntomas presenta sus respuestas en el MMPI-2?.

Es por ello que en todos los casos de evaluación de la personalidad, tanto normal como patológica, en los que se necesite la elaboración de un peritaje de tipo psicológico, este estudio tiene todo su fundamento para ser investigado. A estos tres interrogantes quisieramos dar alguna respuesta.

Una técnica de tipo psicométrico que intenta evaluar los rasgos de personalidad, tal como es el MMPI-2, necesita disponer de una serie de escalas o índices que nos indiquen la fiabilidad de los datos aportados. Conocemos las Escalas de Validez tradicionales como la F, L y $\mathrm{K}$ más aquellos que se encuentran en la categoría de indicadores adicionales, tales como VRIN, TRIN y Fb.

En nuestro país, tras la reestandarización del MMPI (dando lugar al MMPI-2) y su adaptación castellana, no se ha investigado con estas Escalas e indicadores de Validez utilizando estudios empíricos adecuados. Sí, se ha hecho la adaptación de la prueba, pero no se ha realizado ningún estudio serio con grupos experimentales.

Por ello nuestra investigación, no solamente aporta la contrastación de estas Escalas e Indicadores adicionales de Validez de la prueba (L, F, K, Fb, VRIN, TRIN), sino que además presenta la investigación y adaptación castellana de otras Escalas más actuales que pueden aportar mayor grado de fiabilidad de la técnica del MMPI-2 tales como la Escala Psiquiátrica F(p) de Arbisi \& Ben-Porath (1995), la Escala Superlativa (S) de Butcher \& Han (1995), la Escala Revisada de Disimulación (Ds-r) de Gough (1957), la escala "Fake-Bad"(FBS) de Lees-Haley, Englis \& Glen (1991), la Escala de Inconsistencia de Respuestas (IR) de Sewell \& Rogers, (1994), la Escala de 
Deseabilidad Social (Wsd) de Wiggins (1959) y la Escala de Fingimiento positivo o de Otro Engaño (ODecp) de Nichols \& Greene (1991).

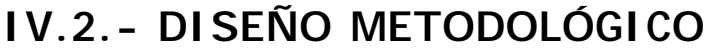

Pasando del nivel conceptual teórico hasta el más específico metodológico, intentamos describir el proceso seguido en nuestro estudio: los objetivos y planteamientos de las hipótesis de trabajo, los instrumentos utilizados para llevar a cabo estas hipótesis, las características de la muestra, la estrategia en la recogida de los datos y el análisis estadístico empleado.

\section{IV.2.1.- Formulación de los objetivos e fipótesis de investigación:}

Nuestro objetivo general es poder analizar la sensibilidad de distintas escalas e indicadores de Validez del MMPI-2 para discriminar, dentro de la población española, entre protocolos contestados de forma honesta y aquellos en los que se ha realizado algún tipo de distorsión en las respuestas de los sujetos.

- Objetivo general: apreciar la distorsión de los perfiles.

- Objetivos específicos: poder detectar el tipo de distorsión realizada. Este tipo de distorsión viene especificada de tres formas:

- Poder identificar perfiles denotadores de la incoherencia o inconsistencia en sus respuestas.

- Poder identificar perfiles que expresen buena imagen o fingimiento positivo.

- Poder detectar aquellos perfiles en los que el sujeto intenta exponer una mala imagen de sí mismo.

Estas tres formas de distorsión se van a concretar en los objetivos más precisos y específicos que conforman nuestras hipótesis de investigación y que, a continuación, se exponen:

IV.2.1.1. - Hipótesis de investigación $1^{a}$ : Inconsistencia/Consistencia.

Nuestro objetivo en esta primera hipótesis es poder encontrar las Escalas o Indicadores que nos permitan detectar si el sujeto contesta de forma inconsistente a los ítems propuestos en el test, es decir, sin prestar la adecuada atención o desinteresarse totalmente, del contenido de los ítems . No es fácil, en un protocolo tan extenso como el MMPI-2, ser adecuadamente coherente en las respuestas. Las personas que prestan atención, procuran no distraerse, se encuentran suficientemente motivados, comprenden e interpretan correctamente los ítems, tienen especial cuidado en no "saltarse" ninguna línea (que la pregunta del ítem 125 coincida con el mismo número de ítem en su respuesta), o contestan de forma honesta y sincera, ofreciendo un perfil "coherente" o "consistente". De lo contrario podremos apreciar su inconsistencia en el perfil del MMPI-2.

Pero también una persona puede intentar falsificar la prueba de una forma adecuadamente coherente o consistente. De tal manera que el sujeto que intenta dar una "buena o mala imagen" de sí mismo puede presentar un perfil coherente en sus respuestas si ha tenido en cuenta este aspecto, pero no por ello debe ser considerado el 
perfil del MMPI-2 como válido. Los buenos falsificadores intentan, precisamente cuidar este aspecto. Los sujetos que afrontan esta forma de responder al cuestionario, teniendo en cuenta el contenido de los ítems, los denominaremos como "consistentes".

El poder detectar la coherencia o incoherencia de los datos aportados en un protocolo se convierte en un elemento poderoso para poder evaluar la fiabilidad de los datos.

Nuestro primer problema planteado obedece a la siguiente pregunta: ¿A través de qué tipos de Escalas o Indicadores de Validez podemos identificar un perfil MMPI-2 de Inconsistencia o Consistencia en las respuestas del sujeto?.Ello nos ha llevado a plantear las siguientes hipótesis y subhipótesis:

HIPÓTES IS GENERAL 1: "En la adaptación castellana del MMPI-2, determinadas escalas e indices de valide $z$ permiten diferenciar sujetos que responden de forma inconsistente de aquellos que lo hacen de manera consistente.

- Subhipótesis 1.1: "Los sujetos que contestan a los ítems MMPI-2 de forma inconsistente obtendrán valores significativos más altos en la escala de Inconsistencia de Respuestas Variables (VRIN) que los que responden de manera consistentes".

- Subhipótesis 1.2: "Los sujetos que contestan a los ítems MMPI-2 de forma inconsistente obtendrán valores significativos más altos en la escala de Inconsistencia de Respuestas Verdadero (TRIN) que los sujetos que responden de manera consistentes".

- Subhipótesis 1.3: "Los sujetos que contestan a los ítems MMPI-2 de forma inconsistentes obtendrán valores significativos más altos en las escalas de Infrecuencia (F) y (Fb) que aquellos que responden de manera consistente".

- Subhipótesis 1.4: Los sujetos que contestan a los ítems MMPI-2 de forma inconsistente obtendrán valores significativos más altos en Indice de Infrecuencia $/ \mathbf{F}-\mathbf{F b} /$ que los que responden de manera consistente".

- Subhipótesis 1.5: Los sujetos que contestan a los ítems MMPI-2 de forma inconsistente obtendrán valores significativos más altos en la escala de Inconsistencia de Respuestas (IR) que los que responden de manera consistente".

\section{IV.2.1.2. - Hipótesis de investigación $2^{a}$ : Fingimiento negativo.}

Dando un paso más adelante, nuestro segundo objetivo se centra en encontrar qué Escalas o indicadores de Validez nos van a permitir identificar a los simuladores que, pretendiendo ser adecuadamente coherentes en sus respuestas, sin embargo, presentan un protocolo fingido, falso. Es el caso de los sujetos que, intencionada e interesadamente y de forma totalmente coherente, presentan una "mala imagen" $\mathrm{o}$ exageración de su propia sintomatología para poder conseguir algún beneficio posterior (indemnizaciones, pensiones, reducir pena, retrasar vistas judiciales, argucias diversas, etc). 
El sujeto se finge enfermo, exagerando sus síntomas, dando mala imagen o presentando una imagen desfavorable de sí mismo. A este tipo de fingimiento lo denominamos como "negativo".

El poder detectar e identificar este tipo de falsificación cobra una gran importancia en determinados ambientes de la Jurisprudencia.

Nuestro segundo planteamiento queda especificado en la siguiente pregunta: ¿A través de qué tipos de Escalas o Indicadores de Validez podemos identificar un perfil MMPI-2 de Fingimiento negativo en las respuestas del sujeto?. Ello nos lleva a plantearnos nuestra segunda hipótesis general y sus subhipótesis específicas:

\section{HIPOTESIS GEXERAL 2: "En la adaptación castellana del $\mathcal{M} M P I-2$, determinadas Escalas e Indices de Valide $z$ permiten diferenciar sujetos que fingen una imagen negativa o desfavorable de símismos de aquellos otros que no lo hacen".}

- Subhipótesis 2.1: "Los sujetos que contestan a los ítems MMPI-2 fingiéndose negativamente obtendrán valores significativos más altos en las escalas de Infrecuencia $\mathbf{F}$ y $\mathbf{F b}$ de aquellos otros que no lo hacen.

- Subhipótesis 2.2: "Los sujetos que contestan a los ítems MMPI-2 fingiéndose negativamente obtendrán valores significativos más altos en el Indice de Infrecuencia $/ \mathbf{F - F b / ~ d e ~ a q u e l l o s ~ o t r o s ~ q u e ~ n o ~ l o ~ h a c e n . ~}$

- Subhipótesis 2.3: "Los sujetos que contestan a los ítems MMPI-2 fingiéndose negativamente obtendrán valores significativos más altos en el Indice de Simulación de Gough (F-K) de aquellos otros que no lo hacen.

- Subhipótesis 2.4: "Los sujetos que contestan a los ítems MMPI-2 fingiéndose negativamente obtendrán valores significativos más altos en la escala de Disimulación de Gough (Ds) y/o la "revisada" (Ds-r) de aquellos otros que no lo hacen.

- Subhipótesis 2.5: "Los sujetos que contestan a los ítems MMPI-2 fingiéndose negativamente obtendrán valores significativos más altos en la Escala de hacerse el enfermo FBS de aquellos otros que no lo hacen.

- Subhipótesis 2.6: "Los sujetos que contestan a los ítems MMPI-2 fingiéndose negativamente obtendrán valores significativos más altos en la Escala Psiquiátrica $\mathbf{F}(\mathbf{p})$ de aquellos otros que no lo hacen.

\section{IV.2.1.3.- Hipótesis de investigación $3^{a}:$ Fingimiento positivo.}

Nuestro tercer objetivo queda plasmado en poder determinar qué tipo de Escalas o indicadores nos pueden aportar información relevante acerca de la minusvaloración de la sintomatología o mejores ajustes de personalidad. Son aquellas personas que sabiéndose con algún problema psicológico (o psicopatológico) intentan aparecer como "perfectamente" normales y ajustados en su perfil de personalidad. Es el polo opuesto de la hipótesis general anterior.

Nos referimos a las personas que desean aparecer ante los demás, y ante el evaluador como personas equilibradas psicológicamente, minusvalorando su sintomatología, 
ofreciendo e intentando presentar siempre su "buena imagen". A este tipo de falsificación lo denominamos "fingimiento positivo".

Se aprecia especialmente este tipo de sujetos en situaciones de "selección de personal" para ocupar una plaza o puesto de trabajo. Igualmente que en la hipótesis anterior, la evaluación realizada con esta técnica dentro del ámbito de la Jurisprudencia, cobra una especial relevancia, especialmente en los casos de guarda y custodia, acogimiento o adopción de los hijos en donde los padres siempre van a presentar su mejor imagen.

Esto nos lleva a plantearnos la siguiente pregunta: ¿A través de qué tipos de Escalas o Indicadores de Validez, en la técnica del MMPI-2, podemos identificar un perfil MMPI-2 indicativo del Fingimiento positivo en las respuestas del sujeto?.

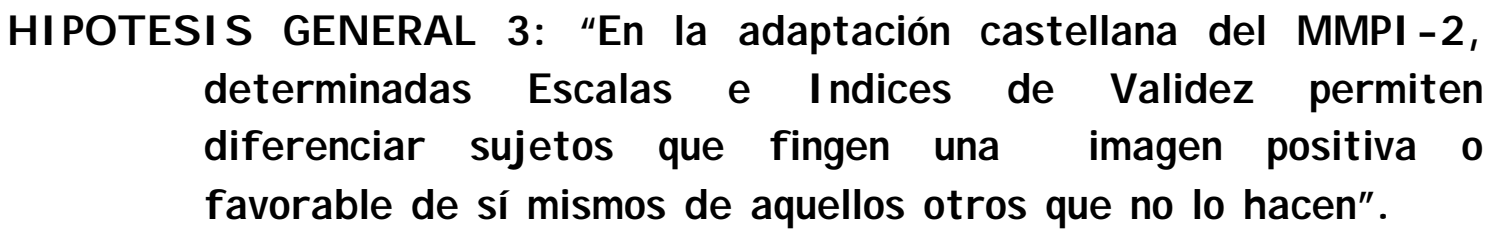

- Subhipótesis 3.1: "Los sujetos que responden a los ítems MMPI-2 fingiéndose positivamente obtendrán valores significativos más altos en la escala de Mentira (L) de aquellos otros que no lo hacen.

- Subhipótesis 3.2: "Los sujetos que responden a los ítems MMPI-2 fingiéndose positivamente obtendrán valores significativos más altos en la escala $\mathbf{K}$ de aquellos otros que no lo hacen.

- Subhipótesis 3.3: "Los sujetos que responden a los ítems MMPI-2 fingiéndose positivamente obtendrán valores significativos más altos en la escala de Fingimiento Positivo (ODecp) de aquellos otros que no lo hacen.

- Subhipótesis 3.4: "Los sujetos que responden a los ítems MMPI-2 fingiéndose positivamente obtendrán valores significativos más altos en la escala de Deseabilidad Social (Wsd) de aquellos otros que no lo hacen.

- Subhipótesis 3.5: "Los sujetos que responden a los ítems MMPI-2 fingiéndose positivamente obtendrán valores significativos más altos en la escala Superlativa

(S) de aquellos otros que no lo hacen.

Para poder llevar a cabo estas hipótesis hemos contado con una muestra variada de sujetos que contestaron de distinta manera a los ítems del cuestionario: sincera y honesta, clínicos, mostrando buena imagen, mostrando mala imagen y los que contestaron de forma inconsistentes. Sus diferentes respuestas han sido analizadas adecuadamente.

\section{IV.2.2.- Instrumentos de aplicación.}

El instrumento esencial es el Cuestionario de Personalidad MMPI-2, y de los 567 ítems que componen dicha prueba, se han obtenido diferentes subescalas e índices para demostrar la validez de la misma prueba. 
IV.2.2.1.- El Cuestionario de Personalidad MMPI - 2:

El Cuestionario de Personalidad M.M.MP.I.-2 (Minnesota Multiphasic Personality Inventory-2), con sus 567 ítems y con más de 80 factores integrados en sus diferentes Escalas (Validez, Básicas, Contenido y Suplementarias). De todas estos factores solamente nos interesaban, para nuestro estudio, las siguientes escalas ya descritas suficientemente con anterioridad:

- Las escalas tradicionales de Validez del MMPI-2: L, F y K

- Los indicadores adicionales de Validez del MMPI-2: No sé / no puedo contestar (“?”), Fb, VRIN y TRIN.

IV.2.2.2.- Otras escalas e indicadores de Validez del MMPI-2:

Para poder llevar a cabo nuestro estudio nos servimos, además, de una serie de escalas e indicadores, obtenidos del MMPI y/o de su respectiva reestandarización (MMPI-2), que se encuentran en la literatura e investigación científica para poder aportar soluciones a los planteamientos hipotéticos realizados en nuestra prueba de personalidad del MMPI-2. Las escalas e indicadores de validez son los mostrados en las líneas siguientes y que vamos a tratar de evaluar para poder aclarar su aportación a la fiabilidad del perfil del MMPI-2.

IV.2.2.2.1. - La escala de Inconsistencia de Respuestas (IR) de Sewell o Rogers (1994):

Es una escala (ver Anexo 8), que fue elaborada para identificar la incoherencia de las respuestas dadas por los sujetos. Cuando las puntuaciones son elevadas nos están indicando que el individuo ha respondido de una forma incoherente y su perfil adolece de consistencia en sus respuestas.

IV.2.2.2.2. - El indice $/ \mathcal{F} \cdot \mathcal{F} b /$ :

Es un índice de infrecuencia para poder apreciar las diferentes respuestas dadas a las dos partes de la prueba del MMPI-2. Las puntuaciones, según Greene (1997), deben tomarse en valores absolutos.

IV. 2.2.2.3. - El indice F. K de Gough (1947, 1950):

En nuestra investigación nos interesaba saber y constatar qué nos podía aportar este índice. El índice F-K es utilizado para detectar y desechar los protocolos que no son válidos, algunas veces tambien sirve como una medida de respuesta disimulada o de exageración de síntomas en el MMPI-2. Gough propuso utilizar la diferencia entre las puntuaciones directas $\mathrm{F}$ y $\mathrm{K}(\mathrm{F}-\mathrm{K})$ de forma que, si el resultado es positivo y mayor de nueve $(+9)$ indicaría fingimiento en el sentido de ofrecer una "mala imagen", mientras que si es negativo y menor de nueve (-9), indicaría la tendencia a ofrecer una "buena imagen" de sí mismo como estrategia defensiva del sujeto. Si la puntuación se encontraba entre los valores 0 a 9 , el perfil era considerado como válido.

Investigaciones posteriores, como ya vimos anteriormente, han propuesto otros "puntos de corte" según la muestra y el ámbito de referencia. 
IV.2.2.2.4. - La escala de "Fake-Bad" (FBS) de Lees-Haley, Englis of Glenn (1991):

La escala de Fake-Bad (FBS, de Lees-Haley, English \& Glenn, 1991) consiste en 43 ítems (ver Anexo 10) que son atribuidos infrecuentemente por fingidores de lesiones personales.

IV.2.2.2.5. - La escala revisada de Disimulación (Ds - r) de Gough (1957).

La escala de Disimulación de Gough (Ds), inicialmente compuesta por 74 ítems se elaboró para diferenciar a un grupo de personas neuróticas de grupos de estudiantes y profesionales psicólogos instruidos para simular neurosis contestando al MMPI. Dado que la escala, y que algunos ítems podrían ser significativos de extrema patología, posteriormente fue reducida (Gough, 1954) a 58 ítems (ver Anexo 11) y revisada (Ds-r) y reducida (Gough, 1957) a un total de 32 ítems (ver Anexo 12).

Ya que las dos escalas eran muy semejantes y que su mismo análisis estadístico de la correlación es altísima (.98) en cualquiera de los grupos muestrales aplicados, hemos decidido trabajar en nuestra investigación solamente con una de ellas, ya que nos parecía una forma de redundancia en los datos y resultados. Por ello hemos seleccionado la "revisada".

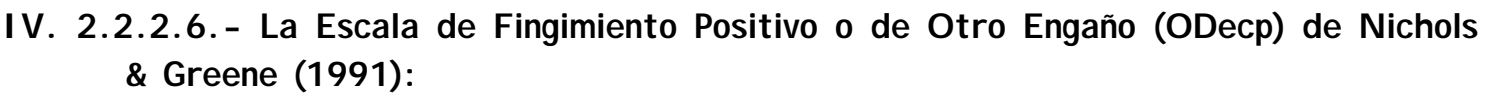

Esta escala (ver Anexo 9) fue desarrollada para identificar defensividad. Las investigaciones realizadas por Greene (1997) con diferentes tipos de muestra (normal y con trastornos psiquiátricos) resumen el rango de puntuaciones que se obtuvieron en la escala "ODecp" con sujetos normales y con trastornos mentales. Las PD $\geq 19$ se encontraron en, aproximadamente, el 5\% de los sujetos tanto normales como de los pacientes con trastornos y las distribuciones de las puntuaciones tienden a ser semejantes en los dos grupos.

\section{2.2.2.7. - La escala Superlativa (S) de Butcher of Han (1995):}

Butcher y Han (1995) elaboraron la escala Superlativa (S) para evaluar personas que se presentan a sí mismos de una manera exageradamente ajustados y que se encuentran frecuentemente en individuos ante situaciones de selección de personal para ocupar un puesto de trabajo. En la investigación llevada a cabo por Greene (1997) con distintos tipos de muestras (normales y patológicos) se pudo apreciar una altísima correlación, y significativa con la escala K (.82 y .88). Como se esperaría, los individuos de población normal obtienen puntuaciones más altas en la escala $\mathrm{S}$ que las obtenidas por los pacientes, pero las distribuciones se hacen justamente parecidas para las puntuaciones elevadas ( $\mathrm{PD} \geq 38)$.

IV. 2.2.2.8. - La escala de Deseabilidad Social (Wsd) de Wiggins (1959):

Wiggins (1959) desarrolló su Escala de Deseabilidad social (ver Anexo 7), para discriminar estudiantes que contestaban al MMPI de una manera socialmente deseable de aquellos otros que contestaban al test de forma honesta y sincera. La Escala de Wiggins tiene uno de los efectos mayores en identificación de estudiantes orientados 
para ser defensivos (Baer, et als., 1992). La distribución de puntuaciones de los sujetos normales y de la muestra clínica son muy similares en todo el rango completo (citado por Greene, 1997, pg.199 y 200).

IV. 2.2.2.9. - La escala Psiquiátrica $\mathcal{F}(p)$ de Arbisi fo Ben-Porath (1995):

La escala Psiquiátrica $\mathrm{F}(\mathrm{p})$ (ver Anexo 14) ayuda a distinguir, pacientes psiquiátricos que responden honestamente de los que intentan exagerar sus síntomas de forma intencionada.

Las puntuaciones elevadas en esta escala no deberían encontrarse dentro de una psicopatología severa. $\mathrm{F}(\mathrm{p})$, puede funcionar como una escala adicional para clarificar el origen de una $\mathrm{F}$ elevada, aunque debería emplearse, por ahora, de forma cautelosa hasta que se encuentren nuevas investigaciones que avalen lo que comentamos.

\section{IV.2.3. - Análisis de la muestra.}

El equipo de investigación que dirigen los profesores Avila y Jiménez del Departamento de Personalidad, Evaluación y Tratamiento Psicológicos de la Universidad de Salamanca, llevó a cabo la adaptación al castellano del MMPI-2 desde la reunión de Brujas (Bruselas) del año 92 en colaboración con el equipo de investigación de los profesores Butcher y Ben-Porath de la Universidad de Minnesota.

Se utilizó una gran parte de la muestra empleada en la adaptación castellana para nuestro estudio, especialmente la muestra clínica y gran parte de la población normal. Tanto la muestra de "buena imagen" y "mala imagen" como la inconsistente fue específicamente obtenida teniendo muy claro el objetivo de este estudio.

Para conseguir la muestra se tuvo en cuenta las distintas regiones geográficas de la población española así como la estratificación de las diversas edades. Éstas fueron concretadas en los siguientes intervalos: 19-29 años; 30-44 años y 45-64 años. Por razones obvias se rechazaron todos aquellos protocolos que presentaran una edad superior a los 64 años y también aquellos que presentaran una puntuación en "No sé / no puedo contestar (“?") $\geq 30$.

Los administradores de la prueba son profesionales de la Psicología, con más de 10 años de experiencia, conocedores, ampliamente, de la técnica del MMPI.

Las muestras empleadas en esta investigación quedan distribuidas y especificadas de la siguiente manera (cfr. Tabla 13):

Sujetos denominados, en nuestra investigación, como "normales": está compuesta por 1.722 sujetos considerados como normales (sin evidencia de patología) que han contestado a los ítems del MMPI-2 de forma totalmente sincera y honesta. Estos sujetos presentan una media de edad de casi 30 años (29 años y 10 meses) de los cuales 1.037 son mujeres y 685 varones.

Sujetos denominados, en nuestra investigación, como "clínicos". Son verdaderos pacientes en régimen abierto ambulatorio que acuden a un Centro de Salud o Ambulatorio de la Seguridad Social o del cualquier otro organismo oficial, con diferentes problemas de tipo psicológico y psiquiátrico (de gravedad leve o moderada), solicitando ayuda en Salud Mental. Esta muestra no incluye pacientes crónicos 
internados en un centro psiquiátrico. El número de sujetos son de 561 pacientes, de los cuales 309 son mujeres y 252 son varones, teniendo una media de edad de 34 años.

Sujetos denominados, en nuestra investigación, como de "buena imagen". Son sujetos considerados "normales" (sin evidencia de patología) a los que se les instruyó para que realizaran la prueba del MMPI-2 dos veces: una, siendo sinceros (forma normal de administrar la prueba) y otra intentando ofrecer una "buena imagen" de sí mismo. El número de sujetos fue de 284, de los cuales 163 fueron mujeres y 121 varones, teniendo una media de edad de 27 años.

Sujetos denominados, en nuestra investigación, como de "mala imagen". Son sujetos considerados "normales" (sin evidencia de patología) a los que se les instruyó para que contestaran al MMPI-2 dos veces: una, siendo sinceros (forma normal de administrar la prueba) y otra intentando ofrecer una "mala imagen" de sí mismo. El número de sujetos fue de 272, de los cuales 174 fueron mujeres y 98 varones, teniendo una media de edad de casi 27 años (26 años y 11 meses).

Para estos dos últimos grupos, se verificaba posteriormente, que los sujetos habían seguido adecuadamente las normas de la tarea, comparando el perfil de puntuaciones de ambas aplicaciones.

Sujetos denominados, en nuestra investigación, como de "Respuestas inconsistentes". Para ello se han rellenado 200 protocolos sin tener en cuenta el sentido de los ítems, independiente de la edad y sexo. Las respuestas han seguido la siguiente estrategia:

- Todas las respuestas son Verdaderas.

- Todas las respuestas son Falsas.

- Las 5 primeras respuestas son Verdaderas y las 5 siguientes Falsas (alternativamente y comenzando por la respuesta $\mathrm{n}^{\circ} .1$ del Cuestionario).

- Las 5 primeras respuestas son Verdaderas y las 5 siguientes Falsas (alternativamente y comenzando por la respuesta $\mathrm{n}^{\circ} .567$ del Cuestionario).

- Las 10 primeras respuestas son Verdaderas y las 10 siguientes Falsas (alternativamente y comenzando por la respuesta $\mathrm{n}^{\circ} .1$ del Cuestionario).

- Las 10 primeras respuestas son Verdaderas y las 10 siguientes Falsas (alternativamente y comenzando por la respuesta $\mathrm{n}^{\circ} .567$ del Cuestionario).

- Las 50 primeras respuestas son Verdaderas y las 50 siguientes Falsas (alternativamente y comenzando por la respuesta $\mathrm{n}^{\circ} .1$ del Cuestionario).

- Las 50 primeras respuestas son Verdaderas y las 50 siguientes Falsas (alternativamente y comenzando por la respuesta $\mathrm{n}^{\circ} .567$ del Cuestionario).

- Las 100 primeras respuestas son Verdaderas y las 100 siguientes Falsas (alternativamente y comenzando por la respuesta $\mathrm{n}^{\circ} .1$ del Cuestionario).

- Las 100 primeras respuestas son Verdaderas y las 100 siguientes Falsas (alternativamente y comenzando por la respuesta $\mathrm{n}^{\circ} .567$ del Cuestionario). 
- La primera columna de la Hoja de Respuesta son todas Verdaderas, la segunda columna se responde al azar y la tercera columna son marcadas todas como Falsas. Y así sucesivamente.

- La primera columna de la Hoja de Respuesta son todas Falsas, la segunda columna se responde al azar y la tercera columna son marcadas todas como Verdaderas. Y así sucesivamente.

- La primera columna de la Hoja de Respuesta son todas al azar, la segunda columna se responde como "verdadero", la tercera columna son todas marcadas al azar, y la cuarta columna son señaladas como Falsas. Y así sucesivamente.

Tabla 13: Características de los grupos de la muestra.

\begin{tabular}{|c|c|c|c|c|}
\hline $\begin{array}{c}\text { Denominación de los grupos de } \\
\text { la muestra }\end{array}$ & \multicolumn{2}{|c|}{$\mathbf{N}$} & $\begin{array}{c}\text { Total N } \\
\text { Ambos sexos }\end{array}$ & $\begin{array}{c}\text { Media de Edad } \\
\text { (años) }\end{array}$ \\
\hline Normales & 1.038 & 685 & 1.723 & 30 \\
\hline Clínicos & 309 & 252 & 561 & 34 \\
\hline Buena imagen & 163 & 121 & 284 & 27 \\
\hline Mala imagen & 174 & 98 & 272 & - \\
\hline Rta. Inc. & 100 & 100 & 200 & \\
\hline Total & 1.823 & 1.256 & 3.079 & \\
\hline
\end{tabular}

\section{IV.3. - DES CRIPCIÓ $\mathcal{N}$ DE LAS VARI ABLES :}

Las variables son las expresadas por las distintas escalas e indicadores de evaluación de la validez de la prueba a través de los instrumentos, ya reseñados, que hemos empleado para esta investigación. Podemos diferenciar las variables dependientes de las independientes.

\section{IV.3.1.- Variables Independientes:}

Las variables consideradas como independientes las hemos especificado por:

- "Grupo": referido por los distintos grupos de sujetos de la muestra:

- "Normales": sujetos a los que se les ha administrado la prueba de forma estándar y con la normativa correcta. Han contestado al cuestionario de forma honesta y siendo sinceros consigo mismo

- "Clínicos": sujetos que han solicitado ayuda del profesional de la Psicología a través de un Centro oficial (de Salud, Ambulatorio, de la Seguridad Social, etc.). La prueba se les ha administrado igualmente que al grupo anterior de sujetos "normales", siguiendo la normativa estándar. Su contestación al Cuestionario las han realizado de la misma forma.

- "Buena imagen": sujetos a los que se les han instruido para que contesten al cuestionario intentando ofrecer una imagen positiva de sí mismo, no siendo sinceros consigo mismo.

- "Mala imagen": sujetos a los que se les han instruido para que contesten al cuestionario intentando ofrecer una imagen negativa de sí mismo, no siendo sinceros consigo mismo. 
- "Respuestas inconsistentes (Rta. Inc.)": sujetos que han contestado con diferentes estrategias pero siempre sin atender al contenido de los ítems del cuestionario.

- "Sexo": identificando a cada uno de los sujetos de los distintos grupos por su género.

\section{IV.3.2.- Variables dependientes:}

Especificadas por las distintas escalas e indicadores de validez implicadas en la evaluación del Cuestionario de Personalidad del MMPI-2. Estas variables, ya suficientes explicitadas en apartados anteriores, las podemos describir de la siguiente forma:

- "L": Escala denominada en el MMPI-2 como de "Mentira". Actualmente contemplada en el grupo de las Escalas tradicionales de Validez del MMPI-2, (ver Anexo 1).

- "F": Escala denominada en el MMPI-2 como de "Infrecuencia". Actualmente contemplada en el grupo de las Escalas tradicionales de Validez del MMPI-2. Referida sólo por la primera parte de la prueba, (ver Anexo 2).

- “Fb": Escala denominada en el MMPI-2 como de "Infrecuencia posterior". Actualmente contemplada en el grupo de indicadores adicionales de Validez del MMPI-2. Referida solamente por la segunda parte de la prueba, (ver Anexo 3).

- "/F-Fb/": Indice de infrecuencia que analiza las diferencias, en valores absolutos, entre las dos escalas anteriores. No contemplada específicamente en el MMPI-2.

- "K": Escala denominada en el MMPI-2 como de "Corrección" o "Variable correctora". Actualmente contemplada en las escalas tradicionales de Validez de la prueba, (ver Anexo 4).

- "VRIN": Escala denominada en el MMPI-2 como "Inconsistencia de Respuestas Variables". Contemplada en el grupo de los indicadores adicionales de Validez del MMPI-2. Los autores (Butcher, et al, 1989) la consideran como una variable experimental siendo necesaria una investigación más extensa, (ver Anexo $5)$.

- "TRIN": Escala denominada en el MMPI-2 como "Inconsistencia de Respuestas Verdadero". Contemplada en el grupo de los indicadores adicionales de Validez del MMPI-2. Los autores (Butcher, et al, 1989) la consideran como una variable experimental siendo necesaria una investigación más extensa, (ver Anexo $6)$.

- "F-K": Escala denominada en la literatura científica como "Índice de Gough". Analiza las diferencias, en valores reales, entre las escalas tradicionales de validez F y K del MMPI-2. Está considerada, en la literatura e investigaciones científicas, como un indicador de validez del MMPI-2, aunque no contemplada explícitamente en la prueba.

- "FBS": Escala denominada como de "Fingimiento" ("fake-bad") por los autores Lees-Haley, Englis \& Glenn (1991). Está considerada, en la literatura e 
investigaciones científicas, como un indicador de validez del MMPI-2, aunque no contemplada explícitamente en la prueba, (ver Anexo 10).

- "Ds-r": Escala denominada como de "Disimulación" por su autor (Gough, 1957). En nuestro estudio nos hemos inclinado, de las dos existentes en este autor, por la "revisada". Está considerada, en la literatura e investigaciones científicas, como un indicador de validez del MMPI-2, aunque no contemplada explícitamente en la prueba, (ver Anexo 12).

- "ODecp": Escala denominada por el los autores (Nichols \& Greene, 1991) como de "Decepción" o "Engaño". Está considerada, en la literatura e investigaciones científicas, como un indicador de validez del MMPI-2, aunque no contemplada explícitamente en la prueba, (ver Anexo 9).

- "S": Escala denominada por sus autores (Butcher \& Han, 1995) como "Superlativa". Está considerada, en la literatura e investigaciones científicas, como un indicador de validez del MMPI-2, aunque no contemplada explícitamente en la prueba, (ver Anexo 13).

- "Wsd": Escala denominada por su autor (Wiggins, 1959) como de "Deseabilidad social". Está considerada, en la literatura e investigaciones científicas, como un indicador de validez del MMPI-2, aunque no contemplada explícitamente en la prueba, (ver Anexo 7).

- “F(p)": Escala denominada por sus autores (Arbisi \& Ben-Porath, 1995) como "Psiquiátrica". Está considerada, en la literatura e investigaciones científicas, como un indicador de validez del MMPI-2, aunque no contemplada explícitamente en la prueba, (ver Anexo 14).

En nuestra investigación todas estas variables dependientes las hemos agrupado en las tres hipótesis planteadas para determinar los elementos esenciales de evaluación.

En aras a la utilidad de la evaluación de las variables y siguiendo la formulación hipotética, nos hemos planteado estas cuestiones:

$1^{\mathrm{a}}$.- ¿Qué variables son las que detectan la consistencia/inconsistencia de la prueba?

$2^{\mathrm{a}}$.- ¿Qué variables son las que detectan el fingimiento positivo/negativo de la prueba?.

\section{IV.4 . - CORRECCION Y TRATAMI ENTO ES TADIS TICO DE LOS $\mathcal{D A T O S}$ :}

Para garantizar la objetividad y la fiabilidad de los datos, los protocolos han sido leídos a través de lectora óptica de marcas, de la que, tras un posterior proceso informático de corrección de la prueba, se generaron y traspasaron los datos correspondientes a un programa estadístico (Statview, 5.0) del que se obtuvieron los estadísticos adecuados de las distintas variables (medidas de tendencia central, ANOVA, correlaciones, Análisis factorial, etc.).

Un dato esencial y fundamental que hemos aportado con nuestra investigación han sido la adaptación y baremación española de cada una de estas Escalas e Indicadores de validez a través de la conversión de las puntuaciones directas en Típicas "T" (media = 
50; Desv. St.=10) para unificarlas con el baremo tradicional del MMPI-2, de tal manera que estos baremos generados pueden ser utilizados adecuadamente en la adaptación castellana actualizada del MMPI-2. 
CAPITULO V. - RES ULTADOS .

Introducción:

Vamos a ir analizando la contribución de cada una de las variables propuestas para investigar (variables dependientes) entre los diferentes grupos (variables independientes) experimentados y contemplando, al mismo tiempo la contribución según su género. Los resultados son expuestos en diferentes gráficas en sus diversos análisis comparativos.

Para una mejor comprensión de los datos y resultados vamos a seguir el esquema siguiente:

- Exposición y análisis de los resultados estadísticos obtenidos en los diferentes grupos. De cada grupo obtendremos:

- Análisis de las diferencias, estadísticamente significativas, entre sexos (ANOVA)

- Análisis de los porcentajes resultantes (percentiles más significativos).

- Análisis de los estadísticos de tendencia central de las variables implicadas.

- Análisis de las correlaciones de las variables.

- Análisis de las diferencias, estadísticamente significativas, entre las variables (ANOVA).

- Contribución de cada variable analizada al planteamiento de la hipótesis:

- Variables que contribuyen a la consistencia/inconsistencia de la prueba.

- Variables que contribuyen a la detección del fingimiento negativo de la prueba. 
- Variables que contribuyen a la detección del fingimiento positivo de la prueba..

- Diseño de la Hoja de Perfil según la estrategia del MMPI-2.

\section{V.1.- $\mathcal{A} \mathcal{N} \mathcal{A} L I Z \mathcal{A N D O}$ LOS GRUPOS:}

Mediante las Tablas correspondientes vamos a exponer los resultados obtenidos en el tratamiento estadístico fundamental de las variables.

\section{V.1.1. - Grupo "Normal".}

Recordemos que este grupo calificado de "normal" se encuentra referido por sujetos de población normal, sin evidencia de patología alguna, a los que se les ha administrado la prueba de forma estándar (siendo sinceros consigo mismo) según la normativa exigida por la misma administración de la prueba.

La totalidad de la muestra que contestaron adecuadamente al MMPI-2 es de 1.723 sujetos, presentando una media edad muy cercana a los 30 años. Las Tablas correspondientes que a continuación se muestran expresan los estadísticos fundamentales de cada variable.

En la Tabla 14 podemos observar las diferencias estadísticas entre las puntuaciones medias referidas por su sexo. Se constata que de las 17 variables $^{2} 12$ de ellas $(70,59 \%)$ se muestran estadísticamente significativas en los diferentes niveles examinados, incluso siendo sus diferencias mínimas, lo que nos demuestra que el análisis con los sujetos considerados como normales, deben ser realizado teniendo en cuenta su género.Por otra parte no debe extrañarnos encontrar estas diferencias ya que los mismo baremos de los sujetos están diferenciados por sexos. Como veremos más adelante estas escasas diferencias entre las puntuaciones medias apreciadas en la Tabla 14 , posiblemente, se deban básicamente al numero extenso de sujetos $(\mathrm{N})$ más que a las mismas diferencias entre dichas puntuaciones. En los siguientes grupos, al disminuir el número de sujetos, podemos ver que, siendo las diferencias entre las puntuaciones medias mayores, sin embargo, no se refleja significación estadística alguna.

Estas diferencias entre sexos a través de las distintas escalas e indices de validez no se encuentran contemplados en ninguna de nuestra hipótesis y subhipótesis planteadas inicialmente. Por ello mismo nos vemos obligados a exponer y tratar de responder a este nuevo análisis planteado inicialmente por grupos y posteriormente por variables (escalas e índices).

Podemos observar, en esta Tabla 14, que de las 12 variables que presentan una diferencia estadísticamente significativa, en 10 de ellas $(83,33 \%)$ son los varones los que presentan los valores más altos, y solamente en dos de ellas son las mujeres las que muestran sus puntuaciones más elevadas (Ds-r y FBS).

Vamos a ir exponiendo las gráficas correspondientes por orden de mayor a menor diferencia entre las puntuaciones medias intersexos.

\footnotetext{
2 Para nuestro análisis consideraremos como "variable" al "no sé/no puedo contestar" (¿), aunque en sentido estricto, no lo sea.
} 
Tabla 14: Grupo de "normales". $\mathcal{A} \mathcal{N} O \mathcal{V A}$ por sexos.

\begin{tabular}{|c|c|c|c|c|c|c|c|c|}
\hline Variables & Sexo & $\mathbf{N}$ & Media & Dv.St. & Err.St. & Dif.Med. & $p$ & Sign.(5\%) \\
\hline \multirow[t]{2}{*}{ L } & Mujer & 1038 & 4,721 & 2,315 & , 072 &,- 103 &, 3789 & No signif. \\
\hline & Varón & 685 & 4,823 & 2,455 & ,094 & - & - & - \\
\hline \multirow[t]{2}{*}{$\mathbf{F}$} & Mujer & 1038 & 6,598 & 4,566 &, 142 & $-1,326$ & $<<, 0001$ & Signif. \\
\hline & Varón & 685 & 7,924 & 6,067 &, 232 & - & - & - \\
\hline \multirow[t]{2}{*}{$\mathbf{K}$} & Mujer & 1038 & 14,349 & 4,399 &, 137 &,- 445 &, 0459 & Signif. \\
\hline & Varón & 685 & 14,794 & 4,718 &, 180 & - & - & - \\
\hline \multirow[t]{2}{*}{ Fb } & Mujer & 1038 & 3,983 & 3,907 &, 121 & ,037 & ,8650 & No signif. \\
\hline & Varón & 685 & 3,946 & 5,015 &, 192 & - & - & - \\
\hline \multirow[t]{2}{*}{ VRIN } & Mujer & 1038 & 7,913 & 2,979 &, 092 &, 080 & ,5985 & No signif. \\
\hline & Varón & 685 & 7,834 & 3,214 &, 123 & - & - & - \\
\hline \multirow[t]{2}{*}{ TRIN } & Mujer & 1038 & 9,535 & 1,707 & 053 &,- 300 &, 0004 & Signif. \\
\hline & Varón & 685 & 9,835 & 1,754 &, 067 & - & - & - \\
\hline \multirow[t]{2}{*}{ Fp } & Mujer & 1038 & 2,090 & 1,926 & ,060 &,- 328 &, 0032 & Signif. \\
\hline & Varón & 685 & 2,418 & 2,676 &, 102 & - & - & - \\
\hline \multirow[t]{2}{*}{$\mathbf{S}$} & Mujer & 1038 & 23,858 & 7,363 & ,229 &,- 088 &, 8163 & No signif. \\
\hline & Varón & 685 & 23,946 & 8,088 & ,309 & - & - & - \\
\hline \multirow[t]{2}{*}{ DS } & Mujer & 1038 & 13,446 & 6,969 & ,208 & ,531 &, 1174 & No signif. \\
\hline & Varón & 685 & 12,915 & 7,155 &, 273 & - & - & - \\
\hline \multirow[t]{2}{*}{ Ds-r } & Mujer & 1038 & 8,677 & 4,497 &, 140 & ,864 & $<, 0001$ & Signif. \\
\hline & Varón & 685 & 7,813 & 4,497 &, 172 & - & - & - \\
\hline \multirow[t]{2}{*}{ FBS } & Mujer & 1038 & 13,496 & 4,708 &, 146 & 1,362 & $<, 0001$ & Signif. \\
\hline & Varón & 685 & 12,134 & 4,699 &, 180 & - & - & - \\
\hline \multirow[t]{2}{*}{ Odecp } & Mujer & 1038 & 12,680 & 4,015 &, 125 & $-2,019$ & $<, 0001$ & Signif. \\
\hline & Varón & 685 & 14,699 & 4,435 & ,169 & - & - & - \\
\hline \multirow[t]{2}{*}{ IR } & Mujer & 1038 & 1,255 & 1,331 &, 041 &,- 311 & $<, 0001$ & Signif. \\
\hline & Varón & 685 & 1,566 & 1,853 &, 071 & - & - & - \\
\hline \multirow[t]{2}{*}{ Wsd } & Mujer & 1038 & 13,585 & 3,369 &, 105 & $-1,152$ & $<, 0001$ & Signif. \\
\hline & Varón & 685 & 14,737 & 3,578 &, 137 & - & - & - \\
\hline \multirow[t]{2}{*}{ F-K } & Mujer & 1038 & $-7,750$ & 7,771 & ,241 &,- 880 &, 0319 & Signif. \\
\hline & Varón & 685 & $-6,870$ & 9,109 & ,348 & - & - & - \\
\hline \multirow{2}{*}{$/ \mathrm{F}-\mathrm{Fb} /$} & Mujer & 1038 & 3,354 & 2,748 &, 085 & $-1,004$ & $<, 0001$ & Signif. \\
\hline & Varón & 685 & 4,358 & 3,148 &, 120 & - & - & - \\
\hline \multirow[t]{2}{*}{$i$} & Mujer & 1038 & 3,174 & 5,211 &, 162 & ,747 &, 0025 & Signif. \\
\hline & Varón & 685 & 2,428 & 4,710 &, 180 & - & - & - \\
\hline
\end{tabular}

Gráfica 1: Grupo normales. Variable "Odecp". Análisis por sexos

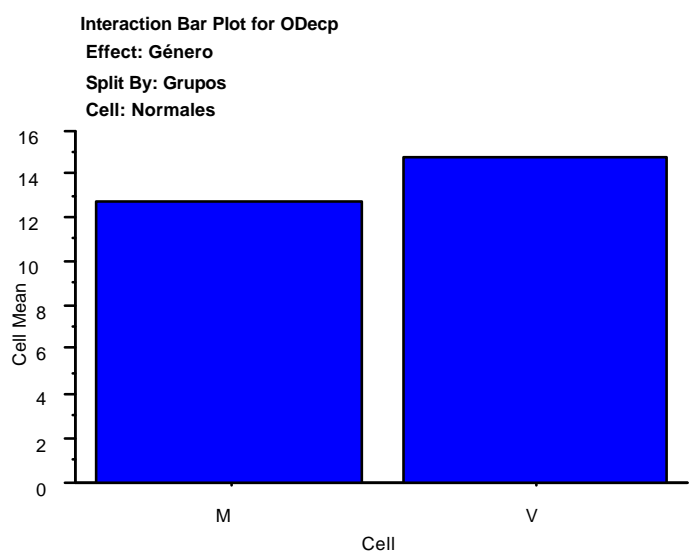

Es la escala de Fingimiento positivo o de Otro engaño (ODecp) la que presenta la diferencia más alta entre ambos sexos (varones: 14,699; mujeres: 12,68) de las variables que hemos analizado, como podemos apreciarlo a través de la Gráfica 1. 
Gráfica 2: Grupo normales. Variable "FBS". Anális is por sexos

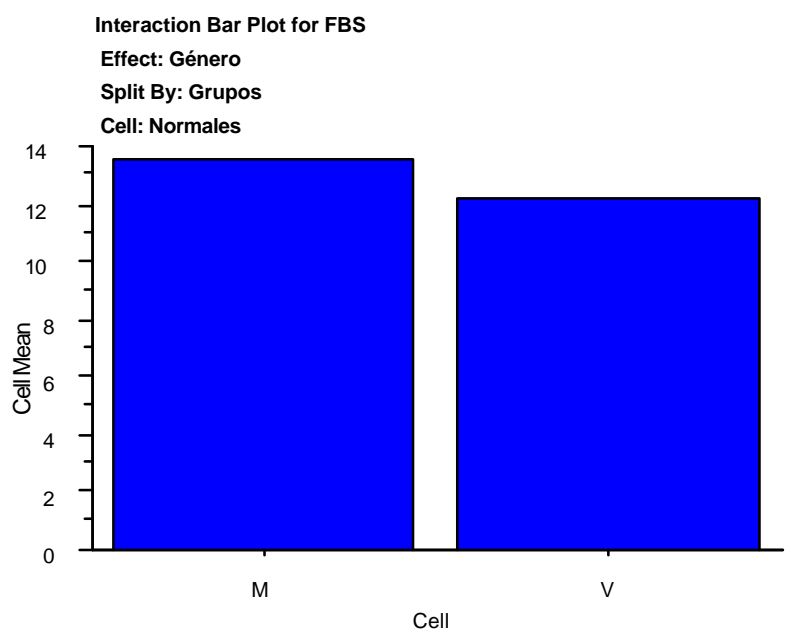

Cuando se trata de mostrar una mala imagen o fingirse negativamente a través de la Escala de "Hacerse el enfermo" (FBS), son las mujeres las que presentan una mayor incidencia sobre los varones (mujeres:13,496; varones:12,134). Esta variable se convierte en la segunda que presenta la mayor incidencia media en su diferencia intersexos.

Gráfica 3: Grupo normales. Variable "F". Análisis por sexos

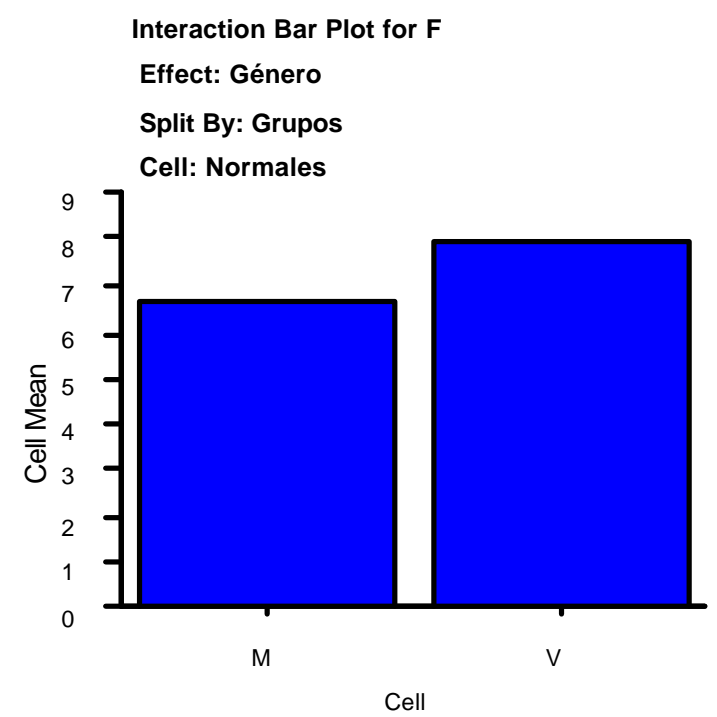

Cuando se trata de reconocer o admitir una extensa gama de problemas psicológicos o incluso poder fingirse mal, a través de la variable $\mathrm{F}$, en la población considerada como normal, son los varones los que presentan una mayor puntuación media (varones: 7,924, mujeres: 6,598) siendo, en nuestro estudio, la tercera diferencia más elevada. 
Gráfica 4: Grupo normales. Variable "Wsd". Análisis por sexos.

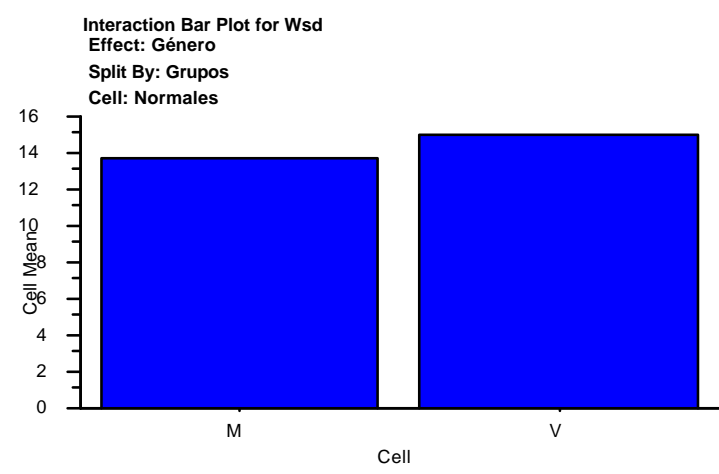

Es la Escala de Deseabilidad social (Wsd) la cuarta variable que muestra la mayor diferencia entre sus puntuaciones medias cuando su análisis se realiza entre los dos sexos (varones: 14,737, mujeres: 13,585). Son los varones los que presentan su mayor incidencia.

Gráfica 5: Grupo normales. Variable "/F्F- Fb/". Análisis por sexos

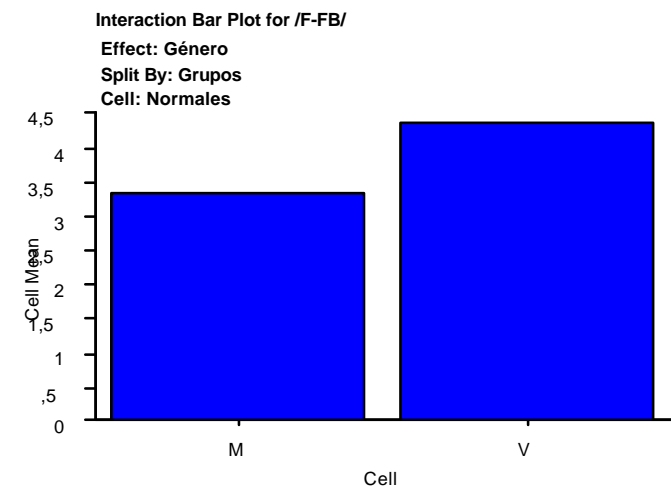

Volvemos a encontrarnos con la escala $\mathrm{F}$ en su aálisis diferencial, en puntuaciones absolutas, entre la primera parte y la segunda de la prueba $(/ \mathrm{F}-\mathrm{Fb} /)$, podemos apreciar la superioridad por parte de los varones en sus puntuaciones medias (varones: 4,358; mujeres: 3,354$)$.

Gráfica 6: Grupo normales. Variable Ds-r. Análisis por sexos.

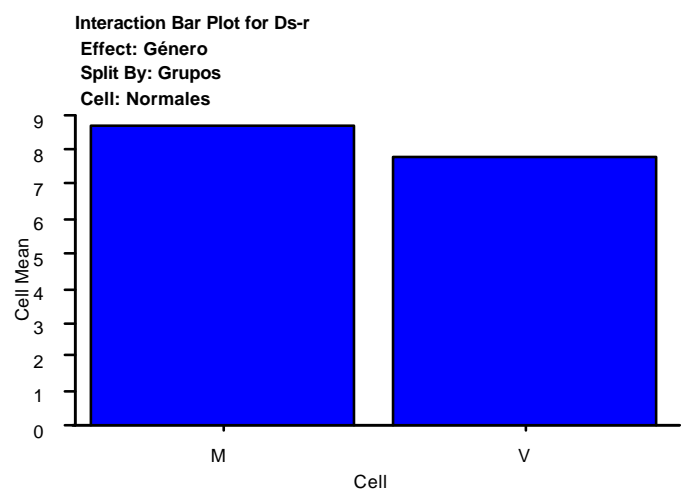


La Escala de Disimulación revisada de Gough (Ds-r) nos muestra una mayor incidencia media por parte de las mujeres (varones: 7,813; mujeres: 8,677). Queremos hacer constar que la misma escala de Disimulación de Gough (Ds) no revisada, en nuestro estudio no ha resultado ser estadísticamente significativa en su diferencia intersexo.

Gráfica 7: Grupo normales. Variable "IR". Análisis por sexos.

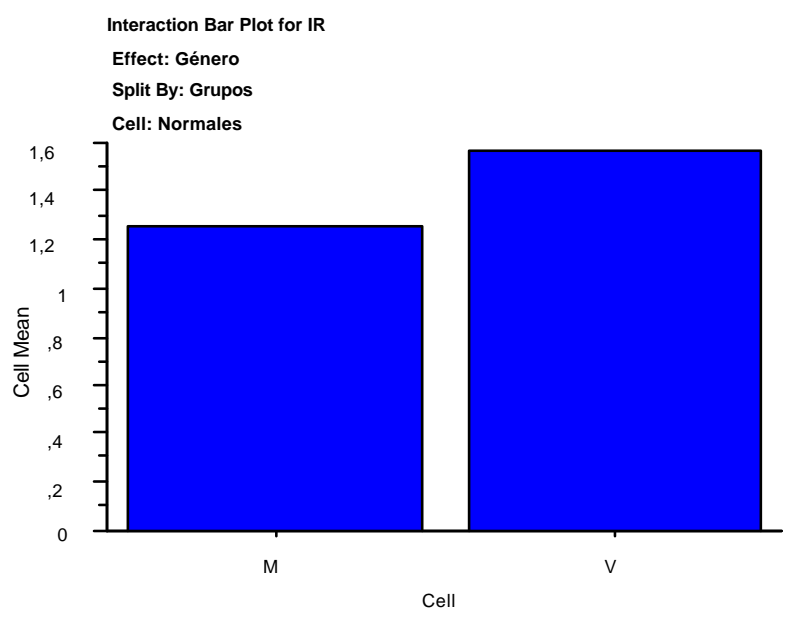

La inconsistencia de respuestas de Sewell y Rogers se muestra con mayor incidencia en los varones (varones: 1,853; mujeres: 1,331) mostrándose como la séptima puntuación más alta de nuestro estudio en su diferencia estadística $(<, 0001)$ intersexos.

A continuación exponemos las siguientes gráficas correspondientes a las diferentes variables, analizadas igualmente por sexos, pero que no lograronn alcanzar una diferencia estadística <,0001. Las variables y por este orden fueron las siguientes:TRIN, ?, F(p), F-K y K.

Gráfica 8: Grupo normales. Variable "TRRIN". Anális is por sexos

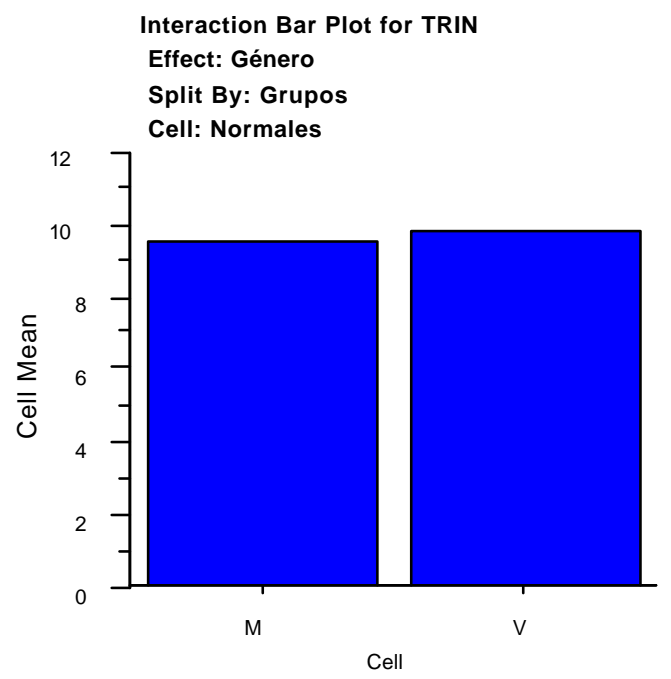


Gráfica 9: Grupo normales. Variable "?". Análisis por sexos

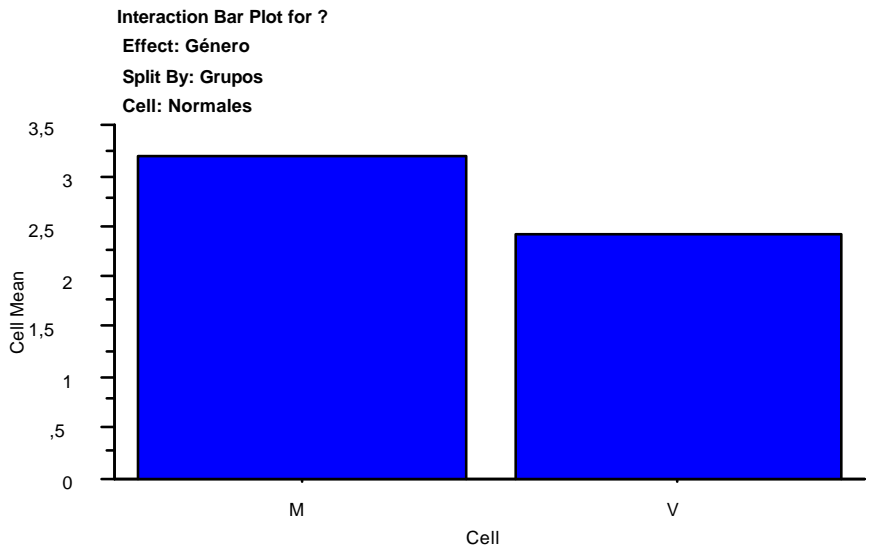

Gráfica 10: Grupo normales. Variable "F(p)". Análisis por sexos

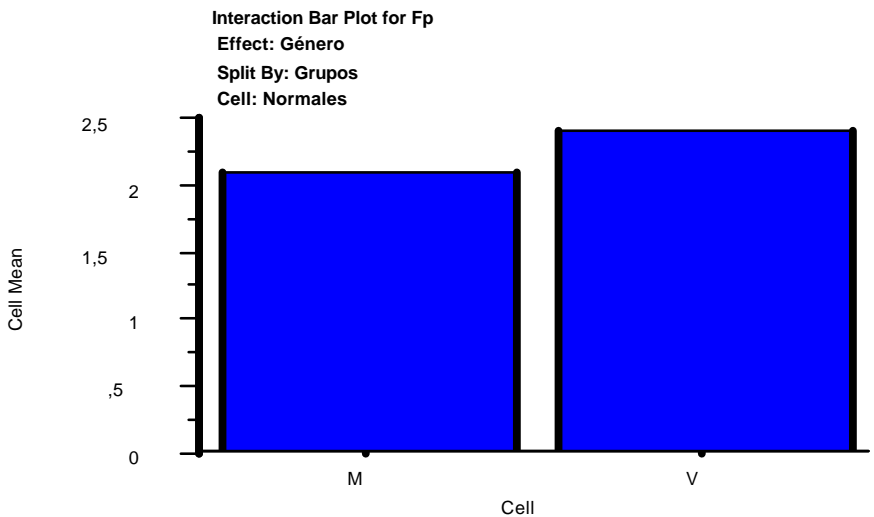

Gráfica 11: Grupo normales. Variable "F- $\mathcal{K}$ ". Anális is por sexos

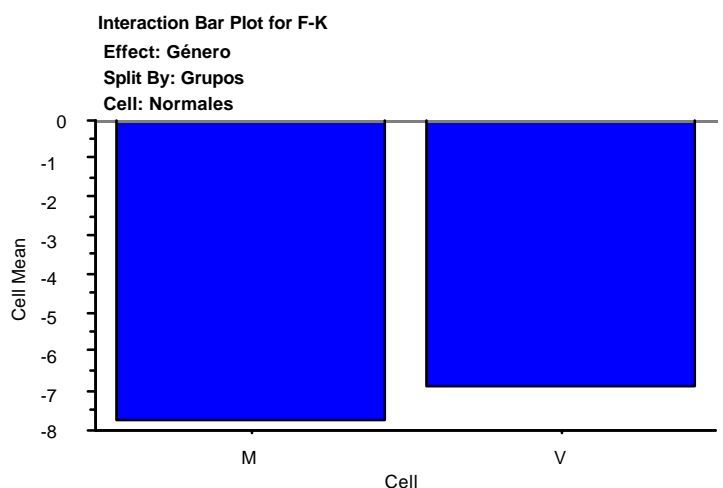

En ambos sexos se muestran las puntuaciones en forma negativa, siendo menor en los varones (varones: -6,87; mujeres: -7,75) lo que nos dice que este valor del Indice de Gough (F-K) se ajusta a las investigaciones más recientes (Osborne, Coligan \& Offord, 1986; Greene, 1997, 2000). 
Gráfica 12: Grupo normales. Variable "K". Análisis por sexos.

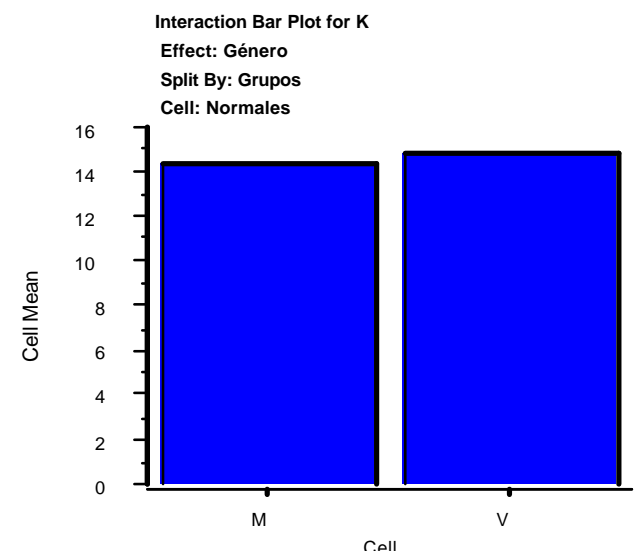

En este análisis intersexos hemos de constatar la existencia de 5 variables que no resultaron ser estadísticamente significativa al nivel de confianza del 5\%: L, Fb, VRIN, S, y Ds.

Tabla 15: Estadísticos principales de tendencia central. Grupo Normal.

\begin{tabular}{|c|c|c|c|c|}
\hline Variables & Media & Desv.St. & Simetría & Kurtosis \\
\hline Edad & 29,885 & 11,084 & 1,365 & .828 \\
\hline L & 4,761 & 2,371 & .426 & .006 \\
\hline F & 7,125 & 5,254 & 1,906 & 5,202 \\
\hline K & 14,526 & 4,532 & .047 & -.618 \\
\hline Fb & 3,968 & 4,380 & 2,117 & 5,677 \\
\hline VRIN & 7,882 & 3,074 & .738 & 1,371 \\
\hline TRIN & 9,654 & 1,732 & .162 & .516 \\
\hline Fp & 2,220 & 2,259 & 2,351 & 9,201 \\
\hline S & 23,893 & 7,657 & .172 & -.295 \\
\hline Ds-r & 8,334 & 4,515 & .660 & .209 \\
\hline FBS & 12,955 & 4,750 & .585 & .429 \\
\hline Odecp & 13,483 & 4,301 & .236 & -.080 \\
\hline IR & 1,379 & 1,566 & 2.242 & 7,429 \\
\hline Wsd & 14,043 & 3,498 & .231 & -.046 \\
\hline F-K & $-7,400$ & 8,337 & .683 & .521 \\
\hline /F-Fb/ & 3,753 & 2,954 & 1,365 & 3,024 \\
\hline $\mathbf{i}$ & 2,878 & 5,029 & 2,533 & 6,677 \\
\hline
\end{tabular}

Tabla 16: Percentiles. Grupo "Normal".

\begin{tabular}{|c|c|c|c|c|c|c|c|c|c|c|c|c|c|c|c|c|}
\hline$\%$ & $\mathbf{L}$ & $\mathbf{F}$ & $\mathbf{K}$ & $\mathbf{F b}$ & VRIN & TRIN & Fp & S & Ds-r & FBS & Odecp & IR & Wsd & F-K & /F-Fb/ & i \\
\hline $\mathbf{1 0}$ & 2 & 2 & 9 & 0 & 4 & 8 & 0 & 14 & 3 & 7 & 8 & 0 & 10 & -17 & 1 & 0 \\
\hline $\mathbf{2 5}$ & 3 & 4 & 11 & 1 & 6 & 9 & 1 & 18 & 5 & 10 & 10 & 0 & 12 & -14 & 2 & 0 \\
\hline $\mathbf{5 0}$ & 5 & 6 & 15 & 3 & 8 & 10 & 2 & 24 & 8 & 12 & 13 & 1 & 14 & -8 & 3 & 1 \\
\hline $\mathbf{7 5}$ & 6 & 9 & 18 & 5 & 10 & 11 & 3 & 39 & 11 & 16 & 16 & 2 & 16 & -3 & 5 & 3 \\
\hline $\mathbf{9 0}$ & 8 & 13 & 21 & 9 & 12 & 12 & 5 & 34 & 15 & 19 & 19 & 3 & 19 & 4 & 8 & 9 \\
\hline
\end{tabular}


Tabla 17: Matriz de correlaciones *. Grupo "Normal".

\begin{tabular}{|c|c|c|c|c|c|c|c|c|c|c|c|c|c|c|c|c|c|}
\hline & $\mathbf{L}$ & $\mathbf{F}$ & $\mathbf{K}$ & Fb & $\begin{array}{c}\text { VRI } \\
\mathbf{N} \\
\end{array}$ & TRIN & Fp & $\mathbf{S}$ & Ds & Ds-r & FBS & Odecp & IR & Wsd & F-K & $\begin{array}{l}\text { /F- } \\
\text { Fb/ }\end{array}$ & i \\
\hline $\mathbf{L}$ & 1,00 & & & & & & & & & & & & & & & & \\
\hline $\mathbf{F}$ &,- 15 & $\overline{1,00}$ & & & & & & & & & & & & & & & \\
\hline $\mathbf{K}$ & ,39 &,- 45 & 1,00 & & & & & & & & & & & & & & \\
\hline Fb &,- 06 & ,74 &,- 46 & $\overline{1,00}$ & & & & & & & & & & & & & \\
\hline VRIN &,- 04 & 37 &,- 21 & ,36 & 1,00 & & & & & & & & & & & & \\
\hline TRIN &,- 02 &, 14 &,- 25 &, 22 &,- 01 & 1,00 & & & & & & & & & & & \\
\hline Fp & ,18 &, 70 &,- 22 & ,71 & ,30 &, 16 & 1,00 & & & & & & & & & & \\
\hline $\mathbf{S}$ &, 45 &,- 48 &, 81 &,- 46 &,- 16 &,- 20 &,- 21 & 1,00 & & & & & & & & & \\
\hline Ds &,- 32 &, 75 &,- 68 & ,76 &, 33 &, 23 &, 51 &,- 72 & 1,00 & & & & & & & & \\
\hline Ds-r &,- 39 &, 67 &,- 68 &, 68 &, 28 &, 19 &, 40 &,- 73 &, 94 & 1,00 & & & & & & & \\
\hline FBS &, 12 & 35 &,- 17 &, 45 &, 22 &, 02 & 30 &,- 11 & ,42 & ,42 & 1,00 & & & & & & \\
\hline Odecp &, 58 &,- 17 &, 37 &,- 11 &,- 13 &, 16 &, 13 &, 43 &,- 33 &,- 38 &,- 16 & 1,00 & & & & & \\
\hline IR &, 20 & ,63 &,- 20 & ,67 &, 27 &, 17 &, 80 &,- 20 &, 46 &, 37 & ,28 &, 16 & 1,00 & & & & \\
\hline Wsd &, 48 &,- 04 & ,09 &, 07 &,- 04 & 28 &, 22 &, 12 &,- 07 &,- 11 &,- 08 &, 80 &, 25 & 1,00 & & & \\
\hline F-K &,- 31 & 87 &,- 83 &, 72 &, 35 &, 22 &, 56 &,- 74 & 84 &, 79 &, 31 &,- 31 &, 50 &,- 07 & 1,00 & & \\
\hline /F-Fb/ &,- 01 &,- 05 &,- 01 &,- 03 &,- 06 &,- 08 &,- 01 &,- 03 &,- 04 &,- 03 & 02 &,- 12 &,- 04 &,- 13 &,- 03 & 1,00 & \\
\hline$i$ &,- 14 & ,61 &,- 17 & ,08 &, 16 &,- 05 & ,28 &,- 21 & ,28 &, 25 &, 05 &,- 13 & ,21 & $\begin{array}{l}-12 \\
\end{array}$ & ,48 &,- 04 & 1,00 \\
\hline
\end{tabular}

A simple vista podemos apreciar que la variable $/ \mathrm{F}-\mathrm{Fb} /$ sólo muestra correlación significativa con las variables TRIN, ODecp y Wsd, todas ellas en sentido negativo.

\section{V.1.2. - Grupo "Clínico".}

Referido por aquellas personas que han solicitado la ayuda del profesional de la psicología acercándose a un Centro de Salud. Fueron considerados como válidos los protocolos de 561 personas a las que se les administró, de forma estándar, la prueba del MMPI-2.

La media de edad se encuentra referida en los 34 años. Los estadísticos esenciales obtenidos por este grupo se muestran en las siguientes tablas.

Podemos apreciar, por esta Tabla 18, que las variables Ds, Ds-r, FBS, ODecp, IR y Wsd fueron las que resultaron estadísticamente significativas (n.c. 5\%) cuando comparamos las puntuaciones medias de los varones frente a las mujeres, mientras que el resto no lo fue.

Al igual que hicimos con el grupo de normales, con este grupo vamos a exponer las gráficas de aquellas variables que resultaron ser estadísticamente diferentes.

Curiosamente las variables coincidentes entre ambos grupos, normales y clínicos, que resultaron ser estadísticamente significativas al <,0001 en este análisis intersexos, fueron: la Escala revisada de Disimulación de Goug (Ds-r) y la Escala de Hacerse el enfermo de Lees-Haley, English \& Gleen (FBS). Las que fueron igualmente diferentes estadísticamente a otro nivel de confianza (5\%) y coincidentes con el grupo de normales, fueron: Wsd, IR y ODcep.

La Escala de Disimulación de Gough (Ds) sí resultó diferente en el grupo clínico pero no así en el grupo de normales. Igualmente loas escalas F, K, TRIN, F(p), F-K, /F$\mathrm{Fb} / \mathrm{e}$ ?, resultaron ser diferentes en el grupo normal pero no en el clínico cuando se efectúa el análisis intersexos.

Las puntuaciones medias de la Escala FBS (Gráfica 13) se muestran sensiblemente más elevadas que en el grupo de normales observando la misma tendencia de 
superioridad por parte de las mujeres en sus puntuaciones medias (varones: 16,909; mujeres: 20,071).

Tabla 18: Grupo clínico. $\mathcal{A} \mathcal{N} O \mathcal{V A}$ por sexos.

\begin{tabular}{|c|c|c|c|c|c|c|c|c|}
\hline Variables & Sexo & $\mathbf{N}$ & Media & Dv.St. & Err.St. & Dif.Med. & $\mathbf{p}$ & Sign.(5\%) \\
\hline \multirow[t]{2}{*}{$\mathbf{L}$} & Mujer & 309 & 5,023 & 2,433 & , 138 & ,296 &, 1502 & No signif. \\
\hline & Varón & 252 & 4,726 & 2,414 &, 152 & - & - & - \\
\hline \multirow[t]{2}{*}{$\mathbf{F}$} & Mujer & 309 & 12,835 & 7,490 &, 426 &,- 609 & ,3408 & No signif. \\
\hline & Varón & 252 & 13,444 & 7,582 & ,478 & - & - & - \\
\hline \multirow[t]{2}{*}{$\mathbf{K}$} & Mujer & 309 & 11,939 & 4,628 &, 263 &,- 236 & ,5443 & No signif. \\
\hline & Varón & 252 & 12,175 & 4,530 & 285 & - & - & - \\
\hline \multirow[t]{2}{*}{ Fb } & Mujer & 309 & 10,392 & 7,228 & ,411 & ,479 & ,4363 & No signif. \\
\hline & Varón & 252 & 9,913 & 7,262 & ,457 & - & - & - \\
\hline \multirow[t]{2}{*}{ VRIN } & Mujer & 309 & 8,427 & 3,034 &, 173 &,- 307 & 2471 & No signif. \\
\hline & Varón & 252 & 8,734 & 3,224 & ,203 & - & - & - \\
\hline \multirow[t]{2}{*}{ TRIN } & Mujer & 309 & 10,142 & 2,093 &, 119 &, 095 & ,6017 & No signif. \\
\hline & Varón & 252 & 10,048 & 2,191 &, 138 & - & - & - \\
\hline \multirow[t]{2}{*}{ Fp } & Mujer & 309 & 3,540 & 2,946 &, 168 &,- 269 & ,3109 & No signif. \\
\hline & Varón & 252 & 3,810 & 3,333 &, 210 & - & - & - \\
\hline \multirow[t]{2}{*}{$\mathbf{S}$} & Mujer & 309 & 19,246 & 7,567 &, 430 &,- 155 & ,8049 & No signif. \\
\hline & Varón & 252 & 19,401 & 7,151 &, 450 & - & - & - \\
\hline \multirow[t]{2}{*}{ DS } & Mujer & 309 & 22,006 & 9,396 &, 535 & 2,014 &, 0105 & Signif. \\
\hline & Varón & 252 & 19,992 & 9,063 &, 571 & - & - & - \\
\hline \multirow[t]{2}{*}{ Ds-r } & Mujer & 309 & 13,887 & 5,983 & ,340 & 2,057 & $<, 0001$ & Signif. \\
\hline & Varón & 252 & 11,829 & 5,519 & ,348 & - & - & - \\
\hline \multirow[t]{2}{*}{ FBS } & Mujer & 309 & 20,071 & 6,366 &, 362 & 3,162 & $<, 0001$ & Signif. \\
\hline & Varón & 252 & 16,909 & 5,496 &, 346 & - & - & - \\
\hline \multirow[t]{2}{*}{ Odecp } & Mujer & 309 & 11,725 & 4,047 &, 230 & $-1,148$ & ,0017 & Signif. \\
\hline & Varón & 252 & 12,873 & 4,559 & ,287 & - & - & - \\
\hline \multirow[t]{2}{*}{ IR } & Mujer & 309 & 2,553 & 2,268 &, 129 &,- 526 & ,0091 & Signif. \\
\hline & Varón & 252 & 3,079 & 2,482 &, 156 & - & - & - \\
\hline \multirow[t]{2}{*}{ Wsd } & Mujer & 309 & 13,903 & 3,581 & ,204 &,- 744 &, 0206 & Signif. \\
\hline & Varón & 252 & 14,647 & 3,999 &, 252 & - & - & - \\
\hline \multirow[t]{2}{*}{ F-K } & Mujer & 309 & ,896 & 10,727 & ,610 &,- 373 & ,6779 & No signif. \\
\hline & Varón & 252 & 1,270 & 10,414 & ,656 & - & - & - \\
\hline \multirow[t]{2}{*}{ /F-Fb/ } & Mujer & 309 & 4,262 & 3,189 &, 181 &,- 476 &, 0949 & No signif. \\
\hline & Varón & 252 & 4,738 & 3,542 & 223 & - & - & - \\
\hline \multirow[t]{2}{*}{ d } & Mujer & 309 & 3,731 & 5,621 &, 320 &, 426 & ,3634 & No signif. \\
\hline & Varón & 252 & 3,306 & 5,382 & ,339 & - & - & - \\
\hline
\end{tabular}

Gráfica 13: Grupo clínico. Variable "FुBS". Análisis por sexos.

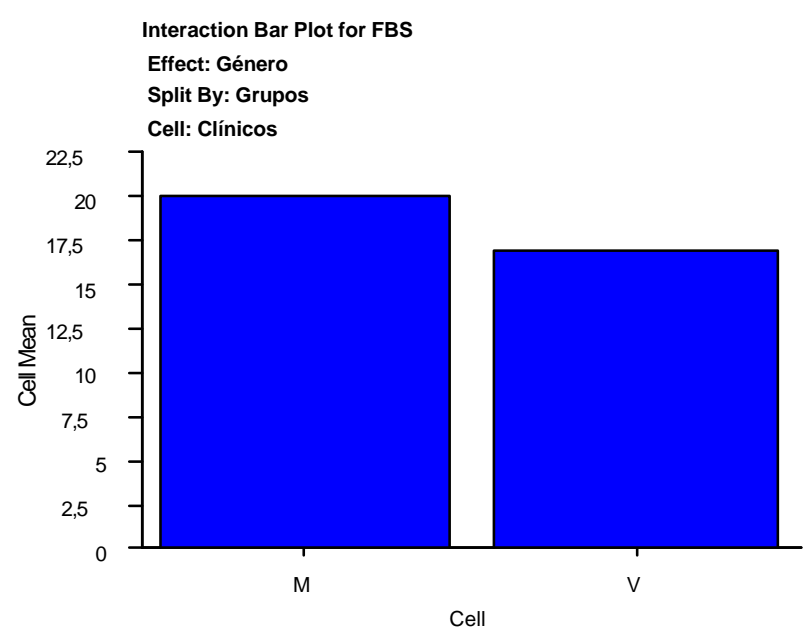


Gráfica 14: Grupo clínico. Variable "Ds-r". Análisis por sexos.

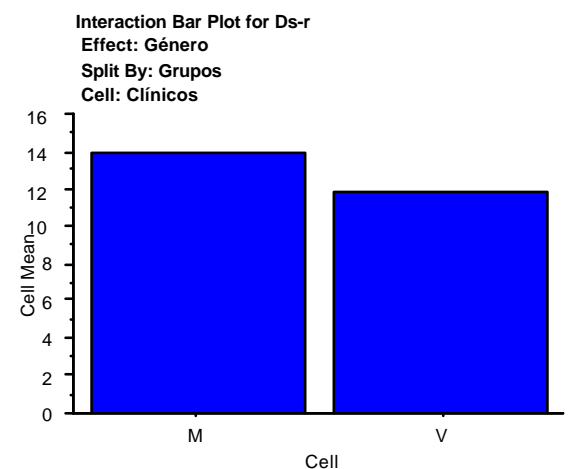

Gráfica 15: Grupo clínico. Variable "ODecp". Análisis por sexos.

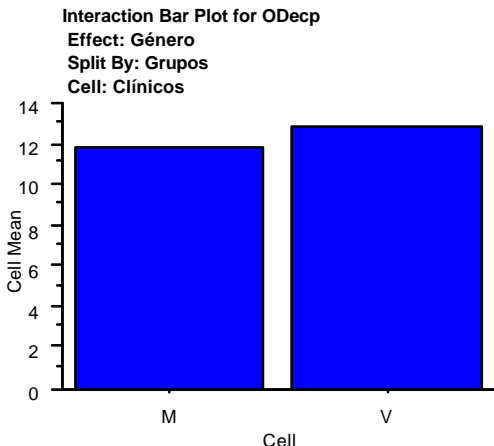

La Escala revisada de Disimulación de Gough (Ds-r), expuesta en la Gráfica 14, se muestra igualmente diferente que en el grupo clínico, con puntuaciones sensiblemente más elevadas en el grupo clínico pero mostrando la misma tendencia de superioridad por parte de las mujeres (varones: 11,829; mujeres:13,887).

Esta Escala de Fingimiento Positivo (ODecp) se muestra coincidente con el grupo normal en su análisis diferencial, aunque en distinto nivel de confianza. Los dos grupos, normal y clínico, muestran sus puntuaciones más elevadas por parte de los varones (varones: 12,873; mujeres:11,725).

Gráfica 16: Grupo clínico. Variable "IR". Análisis por sexos.

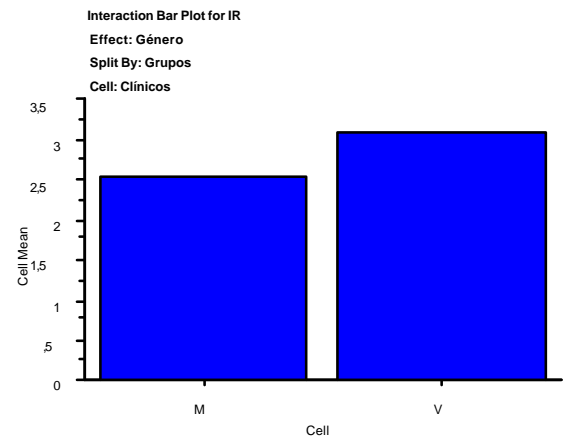


Como podemos apreciar por las gráficas 7 y 16, esta variable de Inconsistencia de Respuestas (IR) igualmente se muestra estadísticamente significativa, en su análisis intersexos, tanto en el grupo de normales como en el de clínicos, aunque a niveles de confianza diferentes. Son coincidentes, igualmente, la superioridad por parte de los varones en sus puntuaciones medias (varones:3,079; mujeres: 2,553).

Las puntuaciones obtenidas en Escala de Disimulación de Gough (Ds) por parte del grupo de normales y clínicos se han mostrado estadísticamente diferentes (Gráfica 17) al realizar el análisis intersexual, ya que no se ha mostrado diferente en el grupo de normales. Es coincidente, en ambos grupos, la superioridad de las puntuaciones por parte de las mujeres. La media de puntuaciones en el grupo clínico es, por parte de los varones, 19,992; y por parte de las mujeres 22,006.

La escala de Deseabilidad Social (Wsd), al igual que aconteció con el grupo clínico, se ha manifestado estadísticamente diferente, aunque a diferentes niveles de confianza, en su análisis intersexos, coincidiendo en su puntuación más elevada por parte de los varones (varones: 14,647; mujeres: 13,903). Las puntuaciones medias del grupo clínico $\mathrm{y}$ el de normales presentan una notable semejanza incluso si lo apreciamos por sexos.

Gráfica 17: Grupo clínico. Variable "Ds". Análisis por sexos.

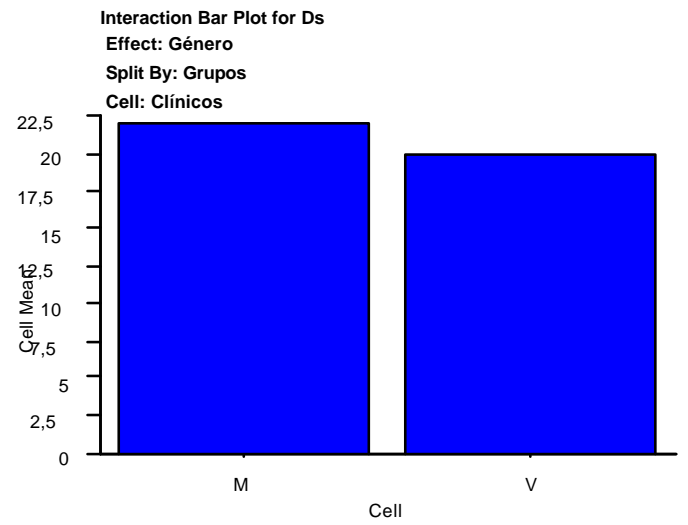

Gráfica 18: Grupo clínico. Variable "Wsd". Análisis por sexos.

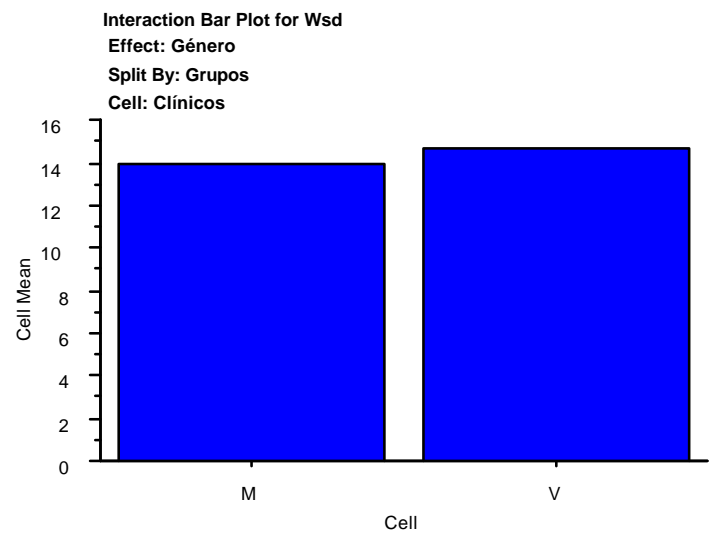


Tabla 19: Estadísticos principales de tendencia central. Grupo Clínico.

\begin{tabular}{|c|c|c|c|c|}
\hline Variables & Media & Desv.St. & Simetría & Kurtosis \\
\hline Edad & 34,289 & 11,750 &, 684 &,- 407 \\
\hline L & 4,889 & 2,426 &, 411 &,- 235 \\
\hline F & 13,109 & 7,531 &, 866 &, 686 \\
\hline K & 12,045 & 4,582 &, 450 &,- 267 \\
\hline Fb & 10,176 & 7,240 &, 628 &,- 312 \\
\hline VRIN & 8,565 & 3,122 &, 425 &, 014 \\
\hline TRIN & 10,100 & 2,137 &, 555 &, 654 \\
\hline Fp & 3,661 & 3,126 & 1,497 & 2,709 \\
\hline S & 19,316 & 7,377 &, 474 &,- 290 \\
\hline Ds-r & 12,963 & 5,865 &, 090 &,- 758 \\
\hline FBS & 18,651 & 6,189 &, 204 &,- 489 \\
\hline Odecp & 12,241 & 4,319 &, 227 &,- 117 \\
\hline IR & 2,790 & 2,379 & 1,064 &, 680 \\
\hline W sd & 14,237 & 3,789 &, 171 &,- 126 \\
\hline F-K & 1,064 & 10,580 &, 180 &,- 276 \\
\hline /F-Fb/ & 4,476 & 3,357 & 1,127 & 1,552 \\
\hline $\mathbf{i}$ & 3,540 & 5,514 & 2,223 & 4,988 \\
\hline
\end{tabular}

Tabla 20: Percentiles. Grupo "Clínico".

\begin{tabular}{|c|c|c|c|c|c|c|c|c|c|c|c|c|c|c|c|c|}
\hline \% & L & F & K & Fb & VRIN & TRIN & Fp & S & Ds-r & FBS & Odecp & IR & W sd & F-K & /F-Fb/ & i \\
\hline $\mathbf{1 0}$ & 2 & 4 & 6 & 2 & 5 & 8 & 1 & 10 & 5 & 11 & 7 & 0 & 10 & -13 & 1 & 0 \\
\hline $\mathbf{2 5}$ & 3 & 7 & 9 & 4 & 6 & 9 & 1 & 14 & 8 & 14 & 9 & 1 & 11 & -7 & 2 & 0 \\
\hline $\mathbf{5 0}$ & 5 & 12 & 12 & 9 & 8 & 10 & 3 & 19 & 13 & 18 & 12 & 2 & 14 & 1 & 4 & 1 \\
\hline $\mathbf{7 5}$ & 6 & 18 & 15 & 15 & 10 & 11 & 5 & 24 & 17 & 23 & 15 & 4 & 17 & 8 & 6 & 5 \\
\hline $\mathbf{9 0}$ & 8 & 23,4 & 19 & 21 & 13 & 13 & 7 & 30 & 21 & 27 & 18 & 6 & 19 & 15 & 9 & 11 \\
\hline
\end{tabular}

Tabla 21: Matriz de correlaciones *. Grupo "Clínico".,

\begin{tabular}{|c|c|c|c|c|c|c|c|c|c|c|c|c|c|c|c|c|c|}
\hline Var. & $\mathbf{L}$ & $\mathbf{F}$ & $\mathbf{K}$ & $\mathbf{F b}$ & VRIN & TRIN & Fp & $\mathbf{S}$ & Ds & Ds-r & FBS & Odecp & IR & $\begin{array}{c}\text { Ws } \\
\text { d }\end{array}$ & F-K & $\begin{array}{l}\mathrm{F}- \\
\mathrm{Fb} /\end{array}$ & i \\
\hline $\mathbf{L}$ & 1,00 & & & & & & & & & & & & & & & & \\
\hline $\mathbf{F}$ &,- 21 & 1,00 & & & & & & & & & & & & & & & \\
\hline $\bar{K}$ & 37 &,- 50 & 1,00 & & & & & & & & & & & & & & \\
\hline Fb &,- 18 & ,79 &,- 54 & 1,00 & & & & & & & & & & & & & \\
\hline VRIN & 01 & 13 &, 05 & ,08 & 1,00 & & & & & & & & & & & & \\
\hline TRIN &,- 05 &, 26 &,- 35 &, 03 &, 06 & 1,00 & & & & & & & & & & & \\
\hline $\mathbf{F p}$ &, 03 & ,77 &,- 28 &, 65 &, 18 &, 25 & 1,00 & & & & & & & & & & \\
\hline $\mathrm{S}$ & 45 &,- 56 &, 81 &,- 57 & 09 &,- 27 &,- 30 & 1,00 & & & & & & & & & \\
\hline Ds &,- 32 &, 81 &,- 67 &, 82 &, 07 &, 31 &, 57 &,- 73 & 1,00 & & & & & & & & \\
\hline Ds-r &,- 32 &, 74 &,- 66 & ,78 &, 05 &, 25 &, 51 &,-- 72 & ,96 & 1,00 & & & & & & & \\
\hline FBS &, 05 &, 44 &,- 32 &, 57 &, 03 &, 12 &, 32 &,- 30 & ,58 & ,64 & $\begin{array}{ll}1,00 \\
\end{array}$ & & & & & & \\
\hline Odecp &, 51 &,- 17 &, 32 &,- 22 & 17 &, 17 &, 09 & 40 &,- 28 &,- 33 &,- 22 & 1,00 & & & & & \\
\hline IR &, 01 & ,77 &,- 33 &, 72 &, 15 &, 29 & ,78 &,- 36 & ,61 &, 54 &, 34 & ,08 & 1,00 & & & & \\
\hline Wsd &, 33 &, 03 &, 02 &, 01 &, 11 &, 33 &, 18 & 07 &, 01 &,- 05 &,- 07 & 81 &, 21 & 1,00 & & & \\
\hline F-K &,- 31 & ,93 &,- 79 &, 80 &, 07 &, 34 & ,67 &,- 75 & ,87 & ,81 & ,45 &,- 26 & ,69 & ,01 & 1,00 & & \\
\hline /F-Fb/ &,- 03 &, 44 &,- 08 &, 02 &, 13 &, 02 &,- 34 &,- 13 & 20 &, 18 & 03 &, 05 &, 27 &, 06 &, 35 & 1,00 & \\
\hline i &, 06 &,- 06 &, 05 &,- 07 &,- 11 &,- 11 &,- 03 &, 02 &,- 08 &,- 08 &, 02 &,- 08 &,- 06 &,- 11 &,- 06 & 01 & 1,00 \\
\hline
\end{tabular}

Destacamos la ausencia de correlación “?” con el resto de las variables y la VRIN que solamente lo hace, con un valor escaso, con F(p) (.18), ODecp (.17) e IR (.15).

Los dos perfiles clínicos, tanto de varón como de mujer, que se han realizado con la toda la población clínica necesitada de asistencia por profesionales clínicos de la Psicología, muestran una adecuada y perfecta consistencia (VRIN y TRIN) y coherencia en sus contestaciones. Igualmente se nos evidencia la fiabilidad y validez de sus respuestas cuando contemplamos los valores de normalidad obtenidos a través de sus escalas e índices de Validez. Sus escalas Básicas o Clínicas se muestran elevadas la mayor parte de ellas pero sin sobrepasar los límites de la normalidad. 


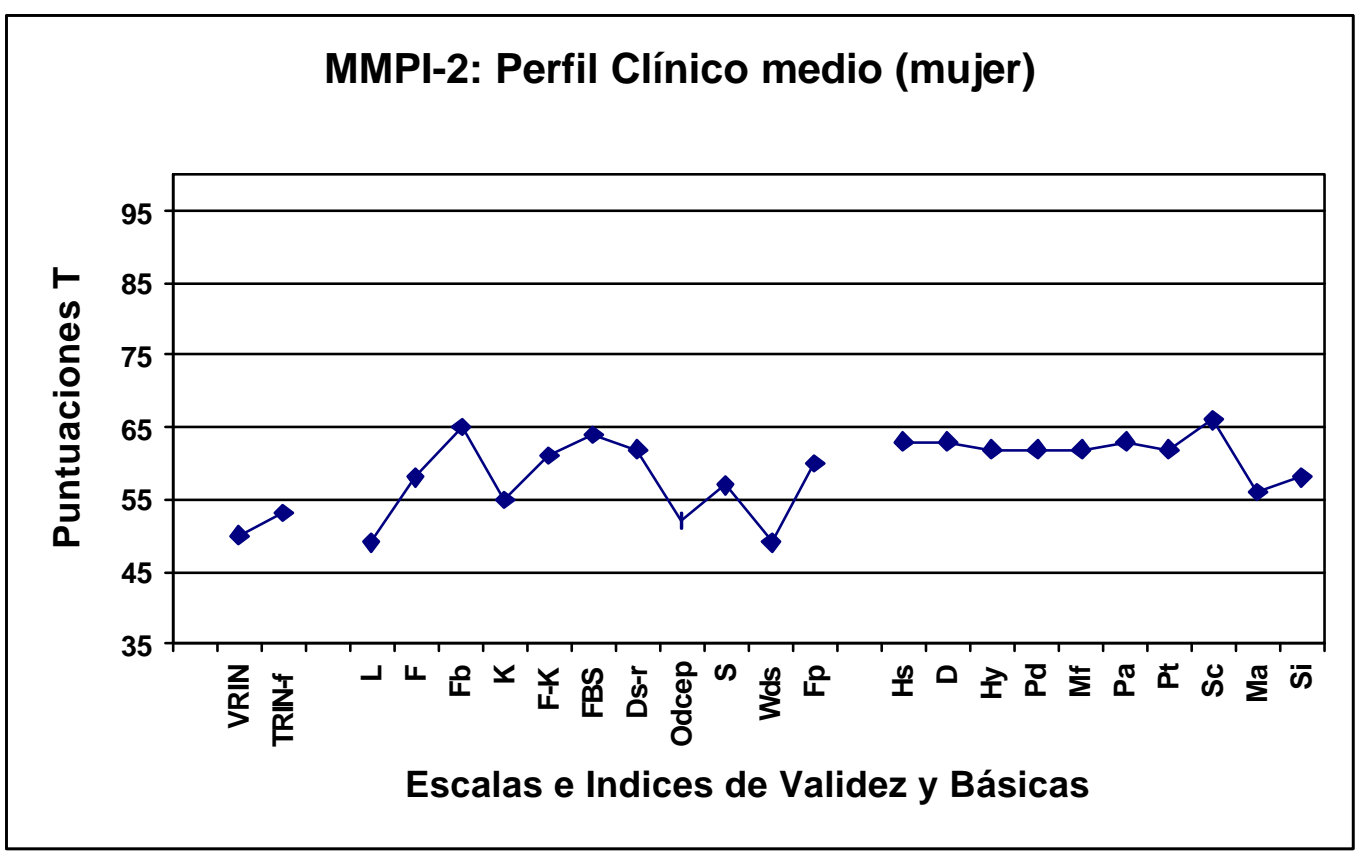

Perfil 1: Escalas e indices de Validez y Básicas del perfil medio clínico de mujer

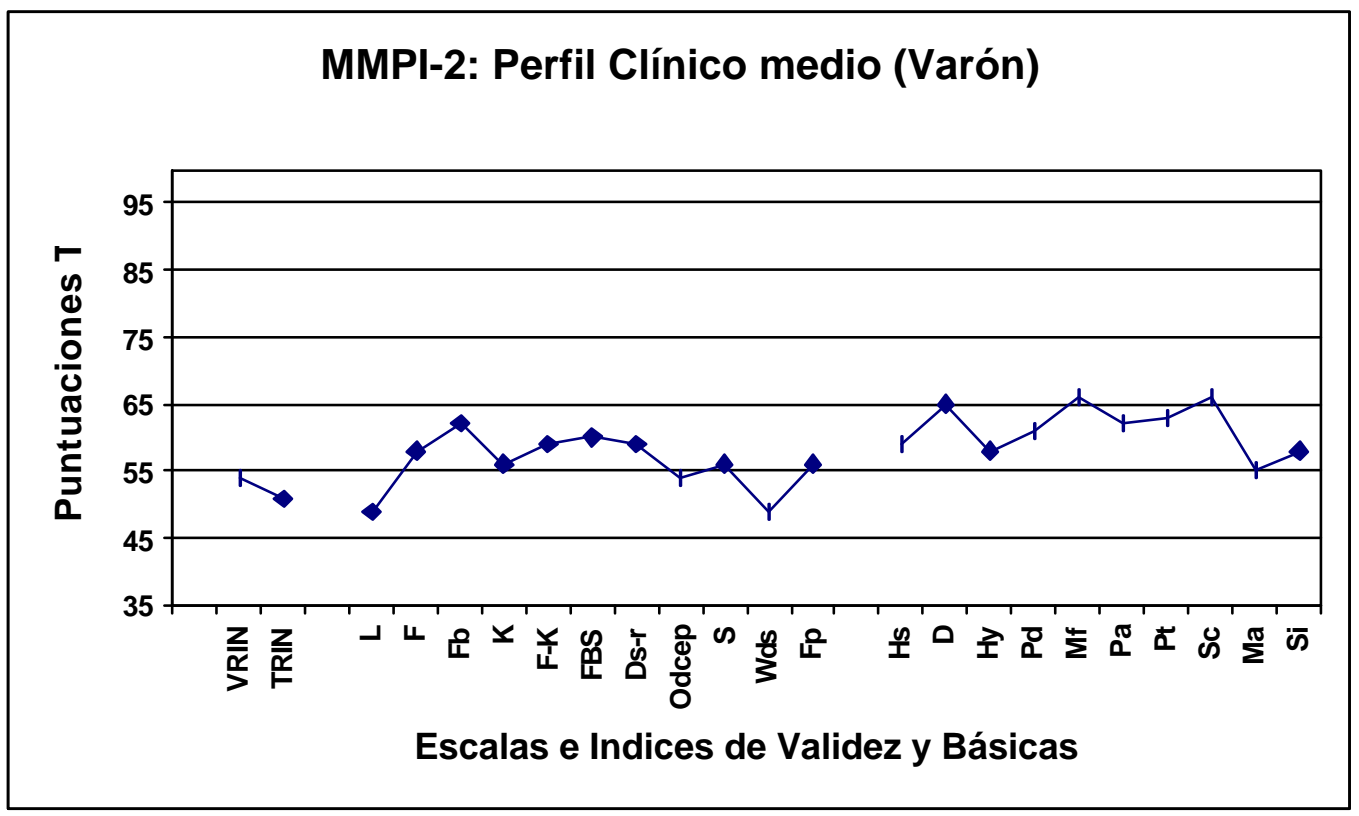

Perfil $2^{3}$ : Escalas e indices de Valide $z$ y Básicas del perfil medio clínico de varón

\footnotetext{
${ }^{3}$ Nuestra propuesta de las puntuaciones directas del perfil para las Escalas de Validez F y K siguen una estrategia distinta a la de Minnesota (ver más adelante). Nuestro diseño ha invertidoel sentido de las puntuaciones directas con respecto a las puntuaciones $\mathrm{T}$ de estas dos escalas (a mayor punt. directa, menor punt. T).
} 


\section{V.1.3.- Grupo "Buena imagen".}

Referido por el grupo de 282 personas a las que se les solicitó que contestaran a la prueba intentando dar una buena imagen de sí mismo, presentando una visión positiva y favorable de su persona.

La media de edad de este grupo se encuentra referida por los 27 años y cuyos estadísticos principales se muestran en las Tablas siguientes.

Tabla 22: Estadísticos principales de tendencia central. Grupo "Buena imagen".

\begin{tabular}{|c|c|c|c|c|}
\hline Variables & Media & Desv.St. & Simetría & Kurtosis \\
\hline Edad & 27,191 & 8,676 & 2,066 & 3,639 \\
\hline $\mathbf{L}$ & 10858 & 2,812 &,- 909 &, 210 \\
\hline F & 4,132 & 5,256 & 3,340 & 13,334 \\
\hline K & 19,677 & 4,141 &,- 861 &, 970 \\
\hline Fb & 2,223 & 4,525 & 3,813 & 15,533 \\
\hline VRIN & 5,723 & 3,317 & 1,284 & 2,678 \\
\hline TRIN & 10,174 & 1,535 &, 286 &, 972 \\
\hline Fp & 4,156 & 2,381 & 2,638 & 10,125 \\
\hline S & 36,333 & 8,250 &,- 947 &, 594 \\
\hline Ds-r & 3,255 & 3,767 & 2,013 & 4,461 \\
\hline FBS & 12,461 & 3,106 &, 506 & 1,953 \\
\hline Odecp & 23,826 & 4,516 &,- 978 &, 515 \\
\hline IR & 3,028 & 1,463 & 1,903 & 7,112 \\
\hline Wsd & 22,826 & 4,395 &,- 655 &, 091 \\
\hline F-K & $-15,365$ & 8,209 & 1,985 & 4,981 \\
\hline F-Fb/ & 2,550 & 2,310 & 1,582 & 2,911 \\
\hline $\mathbf{i}$ & 1,106 & 2,848 & 5,799 & 44,111 \\
\hline
\end{tabular}

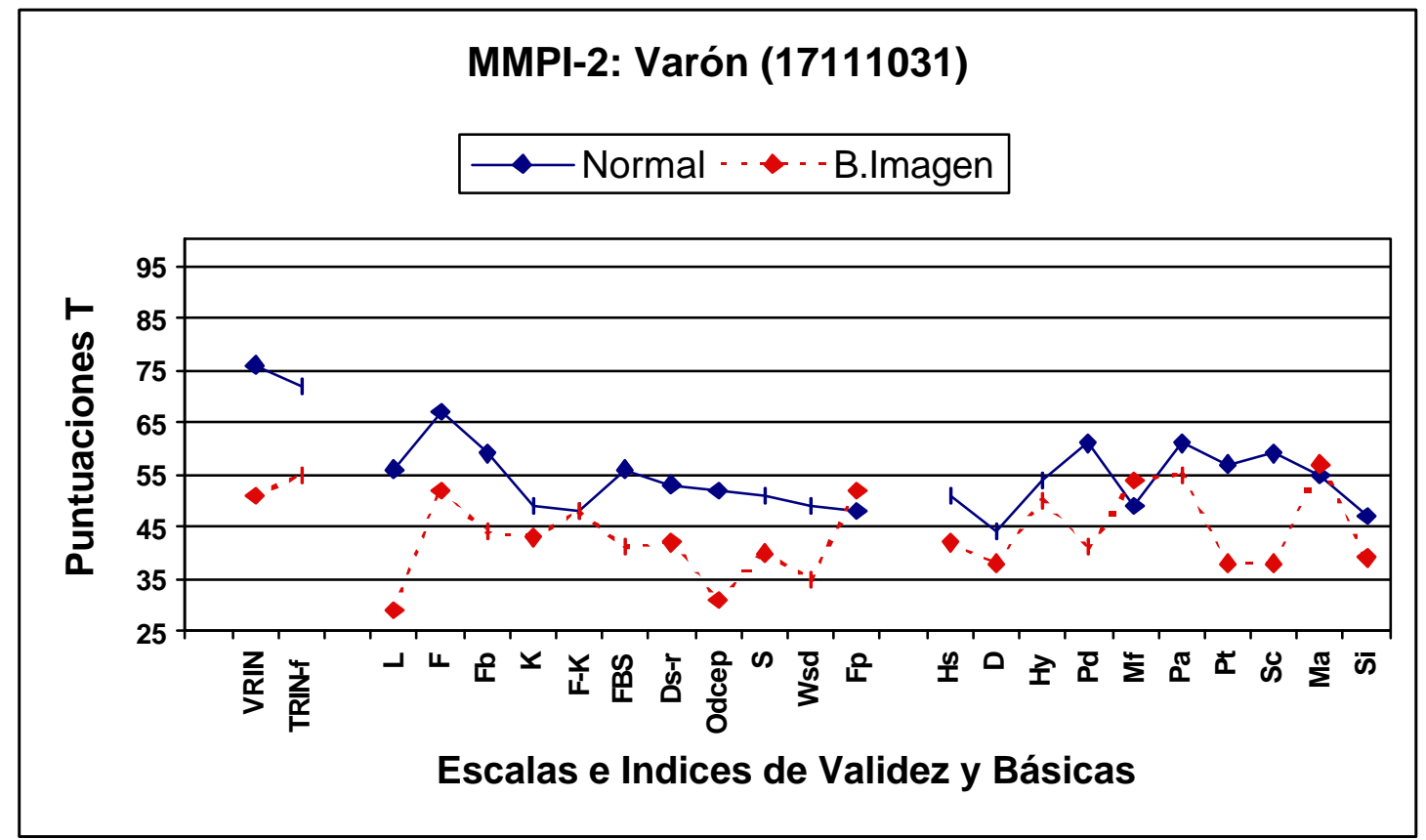

Perfil 3: Varón que ha contestado siendo sincero y honesto y posteriormente intentando dar una buena imagen de sí mismo.

Si contemplamos los perfiles correspondientes a los grupos de población normal podemos ver que sus valores se encuentran alrededor de la puntuación media, mientras que la población que ha respondido expresando lo mejor de sí mismo a través de sus respuestas al cuestionario, sus puntuaciones se muestran generalmente por debajo de la 
franja de normalidad, tanto en las escalas e índices de Validez como en las Básicas o Clínicas.

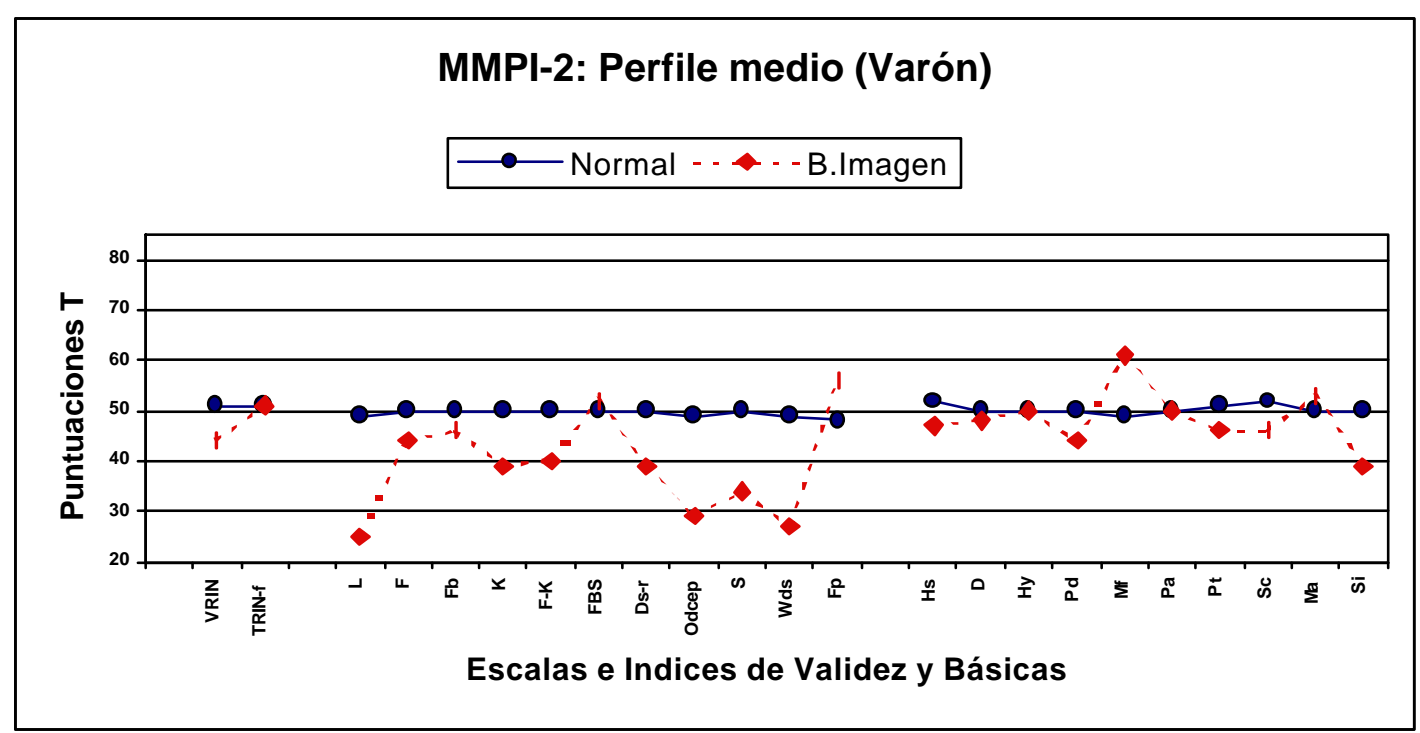

Perfil 4: Perfil comparativo del grupo de población normal y de Guena imagen.

Tabla 23: Grupo "Buena imagen". ANoVA por sexos.

\begin{tabular}{|c|c|c|c|c|c|c|c|c|}
\hline Variables & Sexo & $\mathbf{N}$ & Media & Dv.St. & Err.St. & Dif.Med. & $\mathbf{p}$ & Sign.(5\%) \\
\hline \multirow[t]{2}{*}{ L } & Mujer & 163 & 11,031 & 2,818 & ,221 & ,409 &, 2286 & No signif. \\
\hline & Varón & 119 & 10,622 & 2,798 &, 257 & - & - & \\
\hline \multirow[t]{2}{*}{$\mathbf{F}$} & Mujer & 163 & 4,294 & 5,419 &, 424 &,- 042 & ,9477 & No signif. \\
\hline & Varón & 119 & 4,336 & 5,046 &, 463 & - & - & - \\
\hline \multirow[t]{2}{*}{$\mathbf{K}$} & Mujer & 163 & 19,699 & 4,264 & 334 &,- 020 & ,9676 & No signif. \\
\hline & Varón & 119 & 19,689 & 3,982 & 365 & - & - & - \\
\hline \multirow[t]{2}{*}{$\mathbf{F b}$} & Mujer & 163 & 2,294 & 4,450 & 349 &, 168 & ,7581 & No signif. \\
\hline & Varón & 119 & 2,126 & 4,642 &, 426 & - & - & - \\
\hline \multirow[t]{2}{*}{ VRIN } & Mujer & 163 & 5,632 & 3,315 &, 260 &,- 217 & .5886 & No signif. \\
\hline & Varón & 119 & 5,849 & 3,331 & ,305 & - & - & - \\
\hline \multirow[t]{2}{*}{ TRIN } & Mujer & 163 & 10,092 & 1,527 &, 120 &,- 194 & ,2963 & No signif. \\
\hline & Varón & 119 & 10,286 & 1,547 &, 142 & & - & \\
\hline \multirow[t]{2}{*}{ Fp } & Mujer & 163 & 4,184 & 2,234 &, 175 & ,066 & 8176 & No signif. \\
\hline & Varón & 119 & 4,118 & 2,578 &, 236 & - & - & - \\
\hline \multirow[t]{2}{*}{$\mathbf{S}$} & Mujer & 163 & 36,706 & 8,221 & ,644 &, 882 & 3762 & No signif. \\
\hline & Varón & 119 & 35,824 & 8,296 &, 760 & - & - & - \\
\hline \multirow[t]{2}{*}{ DS } & Mujer & 163 & 6,840 & 6,087 & 477 &,- 294 & 6976 & No signif. \\
\hline & Varón & 119 & 7,134 & 6,508 &, 597 & - & - & - \\
\hline \multirow[t]{2}{*}{ Ds-r } & Mujer & 163 & 3,196 & 3,624 & 284 &,- 140 & .7588 & No signif. \\
\hline & Varón & 119 & 3,336 & 3,969 & 364 & & - & \\
\hline \multirow[t]{2}{*}{ FBS } & Mujer & 163 & 12,736 & 3,103 & 243 &, 652 & 0816 & No signif. \\
\hline & Varón & 119 & 12,084 & 3,082 &, 283 & - & - & - \\
\hline \multirow[t]{2}{*}{ Odecp } & Mujer & 163 & 23,693 & 4,731 & 371 &,- 315 & ,5637 & No signif. \\
\hline & Varón & 119 & 24,008 & 4,216 & 386 & & & \\
\hline \multirow[t]{2}{*}{ IR } & Mujer & 163 & 3,043 & 1,389 & 109 &, 035 & 8452 & No signif. \\
\hline & Varón & 119 & 3,008 & 1,565 & ,143 & - & - & - \\
\hline \multirow[t]{2}{*}{ Wsd } & Mujer & 163 & 22,748 & 4,482 & 351 &,- 184 & ,7287 & No signif. \\
\hline & Varón & 119 & 22,933 & 4,290 & 393 & - & - & - \\
\hline \multirow[t]{2}{*}{ F-K } & Mujer & 163 & $-15,374$ & 8,479 & ,664 &,- 021 & ,9829 & No signif. \\
\hline & Varón & 119 & $-15,353$ & 7,860 &, 720 & & & \\
\hline \multirow[t]{2}{*}{$/ F-F b /$} & Mujer & 163 & 2,429 & 2,169 &, 170 &,- 285 & 3074 & No signif. \\
\hline & Varón & 119 & 2,714 & 2,491 &, 228 & 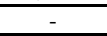 & - & \\
\hline \multirow[t]{2}{*}{$i$} & Mujer & 163 & 1,110 & 2,893 & 227 & ,010 & ,9778 & No signif. \\
\hline & Varón & 119 & 1,101 & 2,796 &, 256 & - & - & - \\
\hline
\end{tabular}

Como podemos apreciar por esta Tabla 23 no hemos encontrado ninguna variable estadísticamente significativa al nivel de confianza mínimo analizado (5\%). 
Tabla 24: Percentiles. Grupo "Buena imagen".

\begin{tabular}{|c|c|c|c|c|c|c|c|c|c|c|c|c|c|c|c|c|}
\hline $\mathbf{\%}$ & L & F & K & Fb & VRIN & TRIN & Fp & S & Ds-r & FBS & Odecp & IR & Wsd & F-K & /F-Fb/ & i \\
\hline $\mathbf{1 0}$ & 7 & 1 & 14 & 0 & 2 & 8 & 2 & 25 & 0 & 8 & 17 & 1 & 16 & -23 & 0 & 0 \\
\hline $\mathbf{2 5}$ & 9 & 2 & 18 & 0 & 4 & 9 & 3 & 32 & 1 & 11 & 22 & 2 & 20 & -20 & 1 & 0 \\
\hline $\mathbf{5 0}$ & 11 & 3 & 20 & 1 & 5 & 10 & 4 & 38 & 2 & 13 & 25 & 3 & 23 & -17 & 2 & 0 \\
\hline $\mathbf{7 5}$ & 13 & 5 & 22 & 2 & 7 & 11 & 5 & 42 & 4 & 14 & 27 & 3 & 26 & -13 & 4 & 1 \\
\hline $\mathbf{9 0}$ & 14 & 8 & 25 & 5 & 10 & 12 & 6 & 45 & 8 & 15 & 29 & 4 & 28 & -6 & 5,3 & 3 \\
\hline
\end{tabular}

Tabla 25: Matriz de correlaciones*. Grupo "Buena imagen".

\begin{tabular}{|c|c|c|c|c|c|c|c|c|c|c|c|c|c|c|c|c|c|}
\hline Var. & $\mathbf{L}$ & F & $\mathbf{K}$ & Fb & VRIN & TRIN & Fp & $\mathbf{S}$ & Ds & Ds-r & FBS & Odecp & IR & $\begin{array}{c}\text { Ws } \\
\text { d }\end{array}$ & F-K & $\begin{array}{l}/ \mathrm{F}- \\
\mathrm{Fb} /\end{array}$ & i \\
\hline $\mathbf{L}$ & 1,00 & & & & & & & & & & & & & & & & \\
\hline $\mathbf{F}$ &,- 43 & 1,00 & & & & & & & & & & & & & & & \\
\hline $\mathbf{K}$ &, 65 &,- 52 & 1,00 & & & & & & & & & & & & & & \\
\hline $\mathbf{F b}$ &,- 39 & ,85 &,- 47 & 1,00 & & & & & & & & & & & & & \\
\hline VRIN &,- 38 &, 67 &,- 49 &, 63 & 1,00 & & & & & & & & & & & & \\
\hline TRIN &,- 06 &, 01 &,- 17 &, 07 &,- 01 & 1,00 & & & & & & & & & & & \\
\hline Fp &, 01 &, 74 &,- 19 &, 76 & , 47 &, 06 & 1,00 & & & & & & & & & & \\
\hline $\mathbf{S}$ & ,73 &,- 06 & ,84 &,- 51 &,- 59 &,- 12 &,- 20 & 1,00 & & & & & & & & & \\
\hline Ds &,- 54 &, 88 &,- 63 & ,83 & ,66 &, 11 & ,61 &,- 70 & 1,00 & & & & & & & & \\
\hline Ds-r &,- 61 & 81 &,- 67 &, 77 &, 65 &, 04 & , 48 &,- 75 &, 95 & 1,00 & & & & & & & \\
\hline FBS &, 02 &, 35 &, 11 &, 40 &, 15 &,- 08 &, 35 &, 13 &, 29 & ,21 & 1,00 & & & & & & \\
\hline Odecp & ,77 &,- 46 &, 54 &,- 41 &,- 37 &, 07 &,- 08 & ,70 &,- 54 &,- 63 &,- 13 & 1,00 & & & & & \\
\hline IR &, 12 &, 57 &,- 12 & ,69 &, 34 &, 06 & ,83 &,- 11 & ,49 &, 34 &, 31 &, 02 & 1,00 & & & & \\
\hline Wsd & ,67 &,- 60 &, 35 &,- 29 &,- 27 & ,24 &, 01 &, 52 &,- 39 &,- 49 &,- 09 & ,90 &, 10 & 1,00 & & & \\
\hline F-K &,- 61 & ,90 &,- 08 &, 78 & ,68 &, 09 &, 57 &,- 78 &, 88 &, 86 &, 17 &,- 57 &, 42 &,- 41 & 1,00 & & \\
\hline /F-Fb/ &,- 35 & ,70 &,- 45 &, 35 &, 45 & ,04 & ,33 & ,46 &, 58 &, 54 & ,09 &,- 35 &, 15 &,- 28 & ,68 & 1,00 & \\
\hline$i$ &,- 02 &, 00 &,- 03 &,- 01 &,- 01 &,- 08 &,- 03 &, 08 &, 02 &, 04 &,- 03 &,- 10 &, 00 &,- 14 &, 02 & ,02 & 1,00 \\
\hline
\end{tabular}

Destacamos la variable "?" que no presenta correlación significativa con ninguna de las demás, aspecto que se ha repetido con otros grupos. También hemos de apreciar que la única variable que correlacionan con TRIN es la Wsd (.24).

\section{V.1.4.- Grupo "Mala imagen".}

A los 269 sujetos que conforman la muestra se les solicitó que contestaran a la prueba del MMPI-2 intentando dar una imagen desfavorable y negativa de sí mismos. Estos sujetos presentan una media de edad de casi 27 años y los diferentes resultados estadísticos más esenciales se presentan en las Tablas expuestas a continuación.

Por la Tabla 26 hemos podido apreciar que solamente la Escala L es la que ha resultado ser estadísticamente significativa cuando hemos analizado sus puntuaciones medias a través de sus sexos. Los varones, al igual que en los sujetos normales y de buena imagen, han resultado ser superiores en sus puntuaciones, pero no así con el grupo clínico en donde las puntuaciones de las mujeres fueron más elevadas.

Podemos apreciar que bs perfiles de mala imagen se muestran sobre la parte superior de la franja de normalidad consignada por el MMPI-2, tanto en las escalas e índices de Validez como en las escalas Básicas o Clínicas.

No debemos olvidar que las puntuaciones directas de las escalas de Validez F y K, en nuestro diseño particular, la hemos invertido con el objetivo único que todos los valores de mala imagen de sí mismo se encuentren plasmados en la parte superior de la hoja de respuesta del perfil, y los valores de buena imagen se encuentren referidos en la parte inferior de la misma hoja del perfil. 


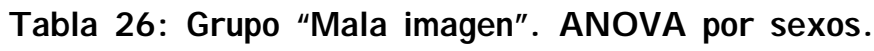

\begin{tabular}{|c|c|c|c|c|c|c|c|c|}
\hline Variables & Sexo & $\mathbf{N}$ & Media & Dv.St. & Err.St. & Dif.Med. & $\mathbf{p}$ & Sign.(5\%) \\
\hline \multirow[t]{2}{*}{ L } & Mujer & 172 & 2,302 & 2,634 & 201 &,- 883 &, 0151 & Signif. \\
\hline & Varón & 97 & 3,186 & 3,186 &, 324 & - & - & - \\
\hline \multirow[t]{2}{*}{$\mathbf{F}$} & Mujer & 172 & 47,302 & 11,570 & $\begin{array}{l}, 882 \\
\end{array}$ & .715 & ,6402 & No signif. \\
\hline & Varón & 97 & 46,588 & 12,802 & 1,300 & - & - & - \\
\hline \multirow[t]{2}{*}{$\mathbf{K}$} & Mujer & 172 & 10,326 & 3,968 & .303 &,- 056 & ,9146 & No signif. \\
\hline & Varón & 97 & 10,381 & 4,326 & ,439 & - & - & \\
\hline \multirow[t]{2}{*}{$\mathbf{F b}$} & Mujer & 172 & 31,837 & 8,641 & .659 &, 662 & .5673 & No signif. \\
\hline & Varón & 97 & 31,175 & 9,869 & 1,002 & - & - & - \\
\hline \multirow[t]{2}{*}{ VRIN } & Mujer & 172 & 8,244 & 3,808 & 290 &,- 282 & .5761 & No signif. \\
\hline & Varón & 97 & 8,526 & 4,221 &, 429 & - & - & - \\
\hline \multirow[t]{2}{*}{ TRIN } & Mujer & 172 & 8,971 & 1,995 &, 152 &,- 246 & 3125 & No signif. \\
\hline & Varón & 97 & 9,216 & 1,751 &, 178 & & - & \\
\hline \multirow[t]{2}{*}{ Fp } & Mujer & 172 & 18,610 & 4,964 & 378 &, 167 & 8025 & No signif. \\
\hline & Varón & 97 & 18,443 & 5,745 &, 583 & & - & \\
\hline \multirow[t]{2}{*}{$\mathbf{S}$} & Mujer & 172 & 12,227 & 7,223 & .551 & $-1,072$ &, 2501 & No signif. \\
\hline & Varón & 97 & 13,299 & 7,506 &, 762 & - & - & - \\
\hline \multirow[t]{2}{*}{ DS } & Mujer & 172 & 44,209 & 10,119 &, 772 & ,415 & ,7496 & No signif. \\
\hline & Varón & 97 & 43,794 & 10,455 & 1,062 & & & \\
\hline \multirow[t]{2}{*}{ Ds-r } & Mujer & 172 & 24,820 & 6,025 & ,459 &,- 232 & ,7615 & No signif. \\
\hline & Varón & 97 & 25,052 & 5,978 & ,607 & - & - & \\
\hline \multirow[t]{2}{*}{ FBS } & Mujer & 172 & 23,570 & 6,816 &, 520 & $-1,008$ & ,2489 & No signif. \\
\hline & Varón & 97 & 24,577 & 6,955 &, 706 & - & - & - \\
\hline \multirow[t]{2}{*}{ Odecp } & Mujer & 172 & 9,192 & 4,899 & .374 &,- 313 & ,6157 & No signif. \\
\hline & Varón & 97 & 9,505 & 4,927 &, 500 & & - & \\
\hline \multirow[t]{2}{*}{ IR } & Mujer & 172 & 10,640 & 3,080 &, 235 &,- 092 & 8197 & No signif. \\
\hline & Varón & 97 & 10,732 & 3,377 &, 343 & 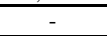 & - & \\
\hline \multirow[t]{2}{*}{ Wsd } & Mujer & 172 & 9,041 & 4,505 &, 344 &,- 382 & .5117 & No signif. \\
\hline & Varón & 97 & 9,423 & 4,706 &, 478 & & - & \\
\hline \multirow[t]{2}{*}{ F-K } & Mujer & 172 & 39,977 & 12,817 & ,977 & ,771 & ,6525 & No signif. \\
\hline & Varón & 97 & 36,206 & 14,542 & 1,476 & & & \\
\hline \multirow[t]{2}{*}{$/ \mathbf{F}-\mathrm{Fb} /$} & Mujer & 172 & 15,523 & 5,071 & 387 & , 111 & 8654 & No signif. \\
\hline & Varón & 97 & 15,412 & 5,279 & .536 & & & \\
\hline \multirow[t]{2}{*}{$i$} & Mujer & 172 & 1,349 & 3,484 &, 266 & 328 & ,4737 & No signif. \\
\hline & Varón & 97 & 1,021 & 3,805 &, 386 & & 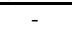 & \\
\hline
\end{tabular}

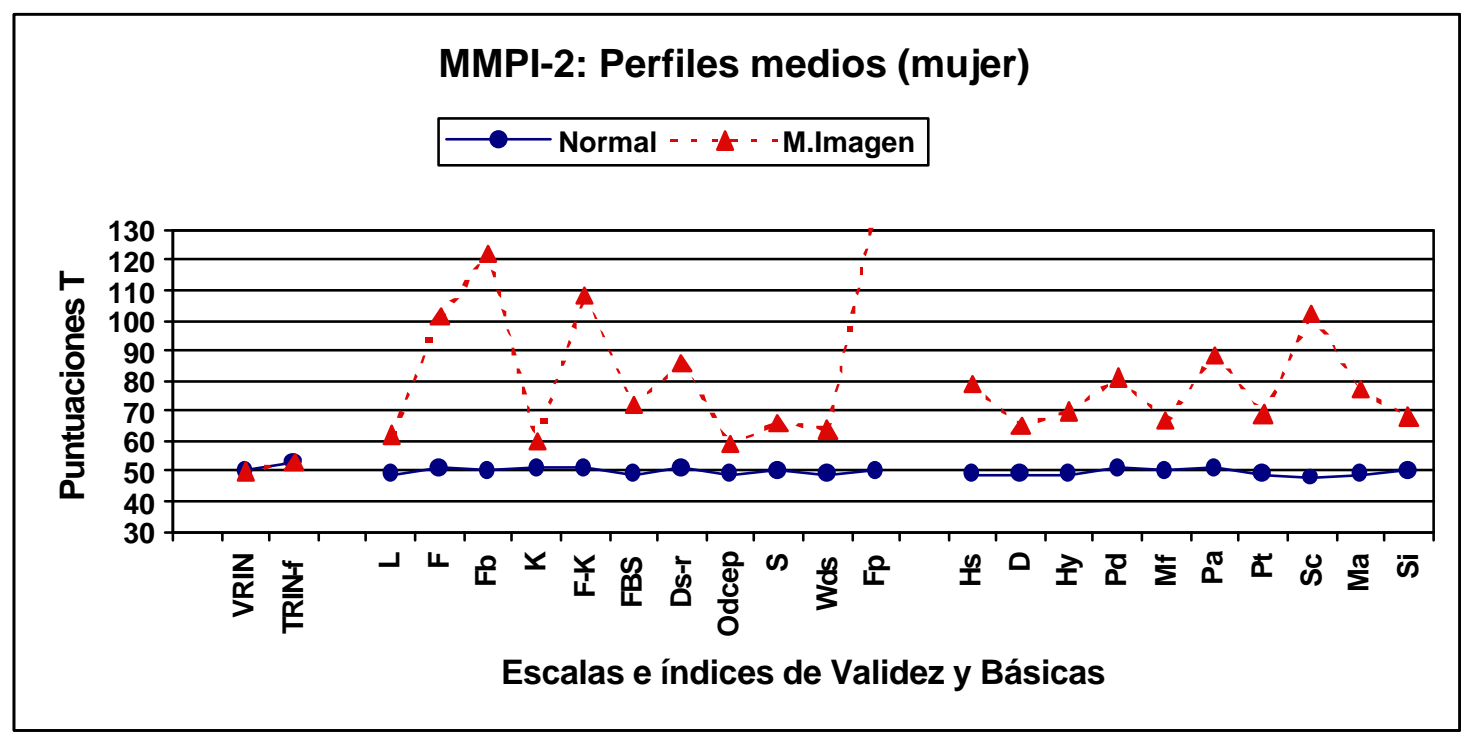

Perfil 5: perfil comparativo del grupo de población normal y de mala imagen.

Podemos observar el comportamiento de las variables VRIN y TRIN en donde se constata que el sujeto, al contestar de forma coherente y consistente al cuestionario, tanto si lo hace de forma sincera y honesta como si lo hace falsificado, sus puntuaciones se encuentran inmersos en la normalidad. 
Gráfica 19: Grupo Mala imagen. Variable "L". Anális is por sexos.

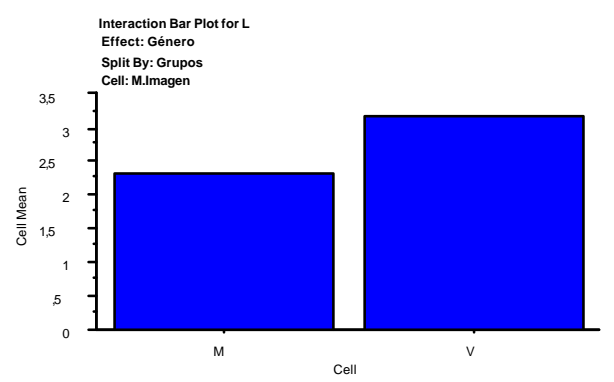

Tabla 27: Estadísticos principales de tendencia central. Grupo "Mala imagen".

\begin{tabular}{|c|c|c|c|c|}
\hline Variables & Media & Desv.St. & Simetría & Kurtosis \\
\hline Edad & 26,866 & 8,382 & 2,346 & 5,671 \\
\hline L & 2,621 & 2,871 & 1,370 & 1,283 \\
\hline F & 47,045 & 12,010 & $-1,436$ & 1,565 \\
\hline K & 10,346 & 4,093 &, 971 &, 949 \\
\hline Fb & 31,599 & 9,090 & $-1,359$ & 1,137 \\
\hline VRIN & 8,346 & 3,956 &, 850 & 1,231 \\
\hline TRIN & 9,059 & 1,911 &, 522 & 1,646 \\
\hline Fp & 18,550 & 5,249 & $-1,422$ & 1,677 \\
\hline S & 12,613 & 7,330 & 1,177 & 1,283 \\
\hline Ds-r & 24,903 & 5,998 &,- 798 &,- 185 \\
\hline FBS & 23,933 & 6,871 &,- 911 &,- 057 \\
\hline Odecp & 9,305 & 4,902 &, 836 &, 624 \\
\hline IR & 10,673 & 3,184 & $-1,498$ & 1,694 \\
\hline W sd & 9,178 & 4,573 &, 681 &, 102 \\
\hline F-K & 36,699 & 8,209 & $-1,119$ &, 749 \\
\hline /F-Fb/ & 15,483 & 2,310 &,- 839 &, 703 \\
\hline $\mathbf{Z}$ & 1,230 & 2,848 & 4,694 & 25,318 \\
\hline
\end{tabular}

Tabla 28: Percentiles. Grupo "Mala imagen".

\begin{tabular}{|c|c|c|c|c|c|c|c|c|c|c|c|c|c|c|c|c|}
\hline \% & L & F & K & Fb & VRIN & TRIN & Fp & S & Ds-r & FBS & Odecp & IR & Wsd & F-K & /F-Fb/ & i \\
\hline $\mathbf{1 0}$ & 0 & 30 & 6 & 18 & 4 & 7 & 11 & 5 & 16 & 13 & 4 & 6 & 4 & 16,4 & 7,4 & 0 \\
\hline $\mathbf{2 5}$ & 1 & 42 & 8 & 27 & 6 & 8 & 16 & 8 & 21 & 19 & 6 & 10 & 6 & 30 & 13 & 0 \\
\hline $\mathbf{5 0}$ & 1 & 52 & 10 & 35 & 8 & 9 & 21 & 11 & 27 & 27 & 9 & 12 & 8 & 41 & 17 & 0 \\
\hline $\mathbf{7 5}$ & 4 & 56 & 12 & 38 & 10,3 & 10 & 22 & 16 & 30 & 29 & 12 & 13 & 12 & 47 & 19 & 1 \\
\hline $\mathbf{9 0}$ & 7 & 58 & 16 & 40 & 13 & 12 & 23 & 23 & 31 & 31 & 16 & 13 & 16 & 50 & 21 & 2 \\
\hline
\end{tabular}

Tabla 29: Matriz de correlaciones *. Grupo "Mala imagen".

\begin{tabular}{|c|c|c|c|c|c|c|c|c|c|c|c|c|c|c|c|c|c|}
\hline Var. & $\mathbf{L}$ & $\mathbf{F}$ & K & $\mathbf{F b}$ & VRIN & TRIN & Fp & $\mathbf{S}$ & Ds & Ds-r & FBS & Odecp & IR & $\begin{array}{c}\text { Ws } \\
\text { d }\end{array}$ & F-K & $\begin{array}{l}\text { /F- } \\
\text { Fb/ }\end{array}$ & $i$ \\
\hline $\mathbf{L}$ & 1,00 & & & & & & & & & & & & & & & & \\
\hline $\mathbf{F}$ &,- 15 & 1,00 & & & & & & & & & & & & & & & \\
\hline $\bar{K}$ &, 68 &,- 20 & $\overline{1,00}$ & & & & & & & & & & & & & & \\
\hline Fb &,- 19 & ,91 &,- 25 & 1,00 & & & & & & & & & & & & & \\
\hline VRIN &, 52 &,- 27 &, 51 &,- 27 & 1,00 & & & & & & & & & & & & \\
\hline TRIN &,- 09 &,- 10 &,- 18 &,- 04 & ,08 & 1,00 & & & & & & & & & & & \\
\hline $\mathrm{Fp}$ &, 04 &,- 93 &,- 06 & ,89 &,- 17 &,- 06 & 1,00 & & & & & & & & & & \\
\hline $\mathbf{S}$ & ,74 &,- 37 &, 84 &,- 41 & ,59 & $\begin{array}{l}-, 10 \\
\end{array}$ &,- 20 & 1,00 & & & & & & & & & \\
\hline Ds &,- 34 & ,88 &,- 41 & ,88 &,- 41 & ,02 & ,79 &,- 58 & 1,00 & & & & & & & & \\
\hline Ds-r &,- 39 &, 83 &,- 43 &, 83 &,- 42 & ,00 &, 72 &,- 59 & ,97 & 1,00 & & & & & & & \\
\hline FBS &,- 05 & 80 &,- 12 &, 76 &,- 23 &,- 05 &, 76 &,- 25 & 83 & ,83 & 1,00 & & & & & & \\
\hline Odecp &, 65 &,- 44 &, 48 &,- 47 & ,56 &, 16 &,- 27 & ,67 &,- 56 &,- 62 &,-- 41 & 1,00 & & & & & \\
\hline IR &, 05 &, 87 &,- 06 &, 88 &,- 13 &,- 03 & ,91 &,- 19 &, 74 &, 68 & ,71 &,- 25 & 1,00 & & & & \\
\hline Wsd & ,56 &,- 43 & ,31 &,- 42 &, 50 & ,29 &,- 27 &, 52 &,- 47 & $\begin{array}{l}-, 53 \\
\end{array}$ &,- 36 & ,90 &,- 23 & 1,00 & & & \\
\hline F-K &,- 35 & ,95 &,- 48 &, 89 &,- 40 &,- 03 &, 85 &,- 60 & ,91 &, 88 & ,76 &,- 54 &, 80 &,- 48 & 1,00 & & \\
\hline$/ \mathbf{F - F b /}$ &,- 02 &, 70 &,- 04 &, 35 &,- 15 &,- 17 &, 58 &,- 14 &, 50 & ,47 &, 52 &,- 20 &, 45 &,- 26 & ,64 & 1,00 & \\
\hline i &, 17 &, 02 &, 09 &, 01 &, 02 &, 06 &, 06 &, 11 &,- 03 &,- 02 &, 05 & ,06 &, 07 &, 08 &,- 01 & , 03 & 1,00 \\
\hline
\end{tabular}

* Resultaron ser estadísticamente significativas al $\mathrm{p}<.001(\geq, 21)$ 
Al igual que con el grupo de buena imagen, se repite el mismo fenómeno estadístico con las variables “?” y TRIN en donde no se muestra correlación alguna con la primera y solamente la Wsd con la segunda (.29).

\section{V.1.5. - Grupo de "Respuestas inconsistentes (Rta. Inc.)".}

Los 200 protocolos del MMPI-2 contestados sin atender el contenido de los ítems son independientes de la edad y el sexo, ya que, para nuestro trabajo, estas variables mo presentan ninguna incidencia importante cuando se trata de contestar de esta forma.

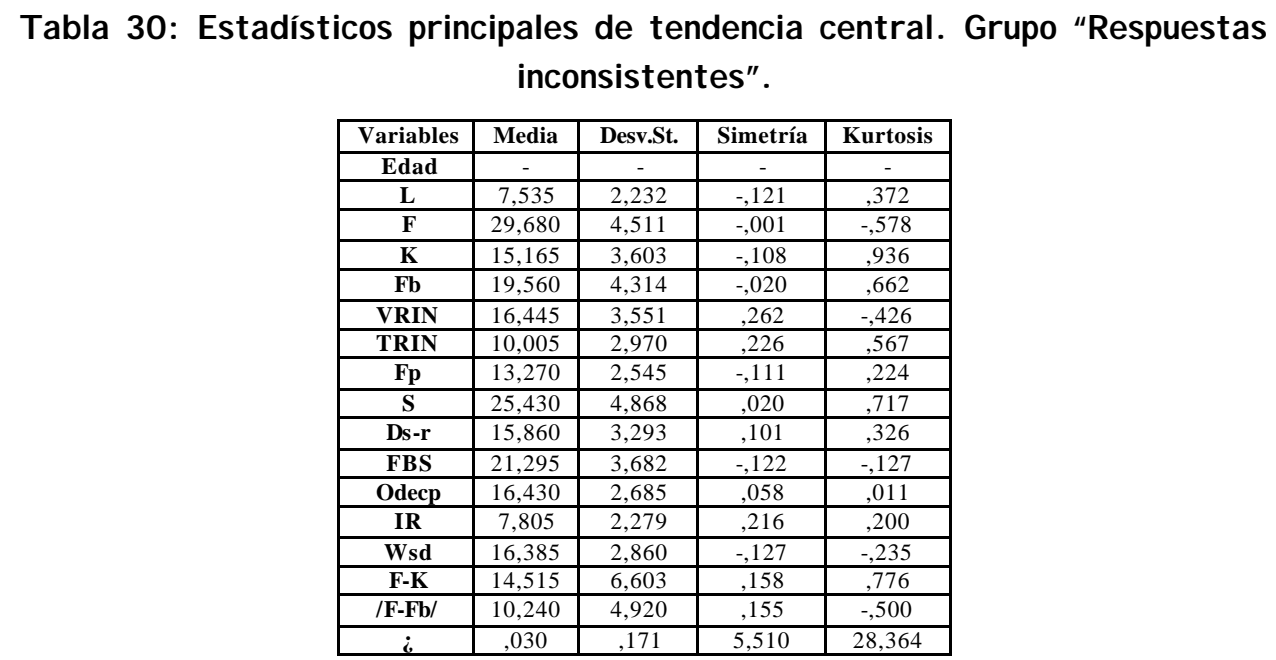

Tabla 31: Percentiles. Grupo "Respuestas inconsistentes".

\begin{tabular}{|c|c|c|c|c|c|c|c|c|c|c|c|c|c|c|c|c|}
\hline \% & L & F & K & Fb & VRIN & TRIN & Fp & S & Ds-r & FBS & Odecp & IR & Wsd & F-K & $/$ F-Fb/ & : \\
\hline $\mathbf{1 0}$ & 4,5 & 24 & 11 & 14 & 12 & 6 & 10 & 20 & 12 & 16,5 & 13 & 5 & 13 & 6,5 & 4 & 0 \\
\hline $\mathbf{2 5}$ & 6 & 26 & 13 & 17 & 14 & 8 & 12 & 22 & 14 & 19 & 15 & 6 & 15 & 10,5 & 6 & 0 \\
\hline $\mathbf{5 0}$ & 8 & 30 & 15 & 20 & 16 & 10 & 13 & 26 & 16 & 21 & 16 & 8 & 16 & 14,5 & 10 & 0 \\
\hline $\mathbf{7 5}$ & 9 & 33 & 17 & 22 & 19 & 12 & 15 & 28 & 18 & 24 & 18 & 9 & 18 & 18 & 13,5 & 0 \\
\hline $\mathbf{9 0}$ & 10 & 36 & 19 & 24 & 21 & 14 & 16 & 31 & 20 & 26 & 20 & 11 & 20 & 23 & 16,5 & 0 \\
\hline
\end{tabular}

Tabla 32: Matriz de correlaciones *. Grupo "Respuestas inconsistentes".

\begin{tabular}{|c|c|c|c|c|c|c|c|c|c|c|c|c|c|c|c|c|c|}
\hline Var. & $\mathbf{L}$ & $\mathbf{F}$ & $\mathbf{K}$ & Fb & VRIN & TRIN & Fp & $\mathbf{S}$ & Ds & Ds-r & FBS & Odecp & IR & $\begin{array}{c}\text { Ws } \\
\text { d }\end{array}$ & F-K & $\begin{array}{l}\text { /F- } \\
\mathrm{Fb} /\end{array}$ & i \\
\hline $\mathbf{L}$ & 1,00 & & & & & & & & & & & & & & & & \\
\hline $\mathbf{F}$ &,- 33 & 1,00 & & & & & & & & & & & & & & & \\
\hline $\mathbf{K}$ & ,41 &,- 31 & 1,00 & & & & & & & & & & & & & & \\
\hline $\mathbf{F b}$ &,- 47 & ,31 &,- 51 & 1,00 & & & & & & & & & & & & & \\
\hline VRIN &,- 03 &, 02 &, 03 &, 01 & 1,00 & & & & & & & & & & & & \\
\hline TRIN &,-- 40 & ,31 &,- 40 & ,40 & $\begin{array}{l}-, 20 \\
\end{array}$ & 1,00 & & & & & & & & & & & \\
\hline $\mathbf{F p}$ &,- 03 & ,45 &,- 16 & ,42 & \begin{tabular}{l|l|}
,- 01 \\
\end{tabular} & ,21 & 1,00 & & & & & & & & & & \\
\hline $\mathbf{S}$ & ,44 &,- 33 &, 55 &,- 45 & ,13 &,- 45 &,- 19 & 1,00 & & & & & & & & & \\
\hline Ds &,- 39 &, 42 &,- 44 & 41 &, 00 & ,38 & 28 &,- 44 & 1,00 & & & & & & & & \\
\hline Ds-r &,- 30 & ,29 &,- 40 &, 36 &,- 01 &, 27 &, 17 &,- 34 & ,84 & 1,00 & & & & & & & \\
\hline FBS &, 18 &,- 04 &, 07 &,- 04 & ,08 &,- 14 &, 09 &, 17 &, 08 &, 15 & $\begin{array}{ll}1,00 \\
\end{array}$ & & & & & & \\
\hline Odecp &, 21 &, 02 &,- 01 &,- 05 &,- 05 &, 14 &, 04 &, 05 &, 04 &, 02 & ,04 & 1,00 & & & & & \\
\hline IR &,- 14 &, 33 &,- 43 &, 46 & 02 &, 27 & ,46 &,- 34 & ,34 &, 34 &, 04 & ,11 & 1,00 & & & & \\
\hline Wsd &,- 00 &, 10 &,- 22 &, 13 & $\begin{array}{l}-, 09 \\
\end{array}$ & ,31 &, 13 &,- 24 &, 18 & ,07 &,- 14 & ,68 & ,25 & 1,00 & & & \\
\hline F-K &,- 45 &, 85 &,-- 76 & ,49 &,- 00 &, 43 & ,40 &,- 53 & ,53 & ,41 &,- 07 &, 03 &, 46 & ,19 & 1,00 & & \\
\hline /F-Fb/ & 11 &, 60 &, 11 &,- 54 &,- 02 &,- 05 & 06 &, 07 &, 04 &,- 03 &,- 02 &, 07 &,- 07 &,- 02 &, 35 & 1,00 & \\
\hline i &,- 02 &, 04 &, 00 &, 01 &, 04 &, 05 &, 03 &, 04 &, 03 &, 04 & ,07 &, 05 &, 03 &,- 02 &, 03 & ,02 & 1,00 \\
\hline
\end{tabular}

* Resultaron ser estadísticamente significativas al $\mathrm{p}<.001(\geq, 23)$ 
Ya expresamos anteriormente las diversas formas de contestar de manera inconsistente cuando nos referimos a la descripción de la muestra.

En este grupo destacamos la inexistencia de correlación significativa con tres variables: "?", FBS y VRIN. Y solamente la ODecp correlaciona de forma significativa con Wsd.

Tabla 32.1: Puntuaciones Típicas $(\mathcal{T})$ de las Escalas e Indices de Validez según los diferentes tipos de Respuestas Inconsistentes*.

\begin{tabular}{|c|c|c|c|c|c|c|c|c|c|c|}
\hline Esc/tipo & \multicolumn{2}{|c|}{ V/F } & \multicolumn{2}{c|}{ F/V } & \multicolumn{2}{c|}{ T.F } & \multicolumn{2}{c|}{ T.V } & \multicolumn{2}{c|}{ Rta. Inc. } \\
\hline Sexo & Varón & Mujer & Varón & Mujer & Varón & Mujer & Varón & Mujer & Varón & Mujer \\
\hline VRIN & $69 \mathrm{~T}$ & $69 \mathrm{~T}$ & $85 \mathrm{~T}$ & $87 \mathrm{~T}$ & $41 \mathrm{~T}$ & $40 \mathrm{~T}$ & $41 \mathrm{~T}$ & $40 \mathrm{~T}$ & $72 \mathrm{~T}$ & $84 \mathrm{~T}$ \\
\hline TRIN-F & - & - & $55 \mathrm{~T}$ & $53 \mathrm{~T}$ & $106 \mathrm{~T}$ & $106 \mathrm{~T}$ & - & - & - & $53 \mathrm{~T}$ \\
\hline TRIN-V & $74 \mathrm{~T}$ & $76 \mathrm{~T}$ & - & - & - & - & $120 \mathrm{~T}$ & $120 \mathrm{~T}$ & $68 \mathrm{~T}$ & - \\
\hline $\mathbf{L}$ & $53 \mathrm{~T}$ & $53 \mathrm{~T}$ & $25 \mathrm{~T}$ & $23 \mathrm{~T}$ & $10 \mathrm{~T}$ & $0 \mathrm{~T}$ & $70 \mathrm{~T}$ & $70 \mathrm{~T}$ & $37 \mathrm{~T}$ & $27 \mathrm{~T}$ \\
\hline F & $72 \mathrm{~T}$ & $68 \mathrm{~T}$ & $101 \mathrm{~T}$ & $91 \mathrm{~T}$ & $68 \mathrm{~T}$ & $66 \mathrm{~T}$ & $105 \mathrm{~T}$ & $93 \mathrm{~T}$ & $90 \mathrm{~T}$ & $82 \mathrm{~T}$ \\
\hline Fb & $82 \mathrm{~T}$ & $92 \mathrm{~T}$ & $82 \mathrm{~T}$ & $91 \mathrm{~T}$ & $48 \mathrm{~T}$ & $47 \mathrm{~T}$ & $116 \mathrm{~T}$ & $120 \mathrm{~T}$ & $76 \mathrm{~T}$ & $91 \mathrm{~T}$ \\
\hline K & $43 \mathrm{~T}$ & $42 \mathrm{~T}$ & $56 \mathrm{~T}$ & $55 \mathrm{~T}$ & $20 \mathrm{~T}$ & $17 \mathrm{~T}$ & $79 \mathrm{~T}$ & $80 \mathrm{~T}$ & $58 \mathrm{~T}$ & $49 \mathrm{~T}$ \\
\hline F-K & $62 \mathrm{~T}$ & $64 \mathrm{~T}$ & $88 \mathrm{~T}$ & $96 \mathrm{~T}$ & $47 \mathrm{~T}$ & $47 \mathrm{~T}$ & $101 \mathrm{~T}$ & $112 \mathrm{~T}$ & $81 \mathrm{~T}$ & $82 \mathrm{~T}$ \\
\hline FBS & $73 \mathrm{~T}$ & $70 \mathrm{~T}$ & $68 \mathrm{~T}$ & $64 \mathrm{~T}$ & $77 \mathrm{~T}$ & $74 \mathrm{~T}$ & $62 \mathrm{~T}$ & $60 \mathrm{~T}$ & $78 \mathrm{~T}$ & $60 \mathrm{~T}$ \\
\hline Ds-r & $68 \mathrm{~T}$ & $66 \mathrm{~T}$ & $69 \mathrm{~T}$ & $66 \mathrm{~T}$ & $46 \mathrm{~T}$ & $44 \mathrm{~T}$ & $91 \mathrm{~T}$ & $89 \mathrm{~T}$ & $82 \mathrm{~T}$ & $71 \mathrm{~T}$ \\
\hline ODecp & $47 \mathrm{~T}$ & $42 \mathrm{~T}$ & $45 \mathrm{~T}$ & $39 \mathrm{~T}$ & $50 \mathrm{~T}$ & $44 \mathrm{~T}$ & $43 \mathrm{~T}$ & $44 \mathrm{~T}$ & $52 \mathrm{~T}$ & $49 \mathrm{~T}$ \\
\hline S & $51 \mathrm{~T}$ & $51 \mathrm{~T}$ & $46 \mathrm{~T}$ & $46 \mathrm{~T}$ & $25 \mathrm{~T}$ & $23 \mathrm{~T}$ & $72 \mathrm{~T}$ & $74 \mathrm{~T}$ & $47 \mathrm{~T}$ & $48 \mathrm{~T}$ \\
\hline Wsd & $49 \mathrm{~T}$ & $46 \mathrm{~T}$ & $41 \mathrm{~T}$ & $37 \mathrm{~T}$ & $66 \mathrm{~T}$ & $64 \mathrm{~T}$ & $24 \mathrm{~T}$ & $19 \mathrm{~T}$ & $46 \mathrm{~T}$ & $40 \mathrm{~T}$ \\
\hline Fp & $82 \mathrm{~T}$ & $97 \mathrm{~T}$ & $101 \mathrm{~T}$ & $120 \mathrm{~T}$ & $75 \mathrm{~T}$ & $86 \mathrm{~T}$ & $107 \mathrm{~T}$ & $120 \mathrm{~T}$ & $90 \mathrm{~T}$ & $120 \mathrm{~T}$ \\
\hline
\end{tabular}

* $\mathrm{V} / \mathrm{F}=$ Respuestas "verdadero/falso" contestadas de forma alternativa, ordenada y secuenciada. $\mathrm{F} / \mathrm{V}=$ Respuestas "falso/verdadero" contestadas de forma alternativa, ordenada y secuenciada.

T.F = Respuestas a todos los ítems del Cuestionario como "todo falso".

$\mathrm{T} . \mathrm{V}=$ Respuestas a todos los ítems del Cuestionario como "todo verdadero".

Rta. Inc. = respuestas contestadas sin tener en cuenta la información contenida en los ítems.

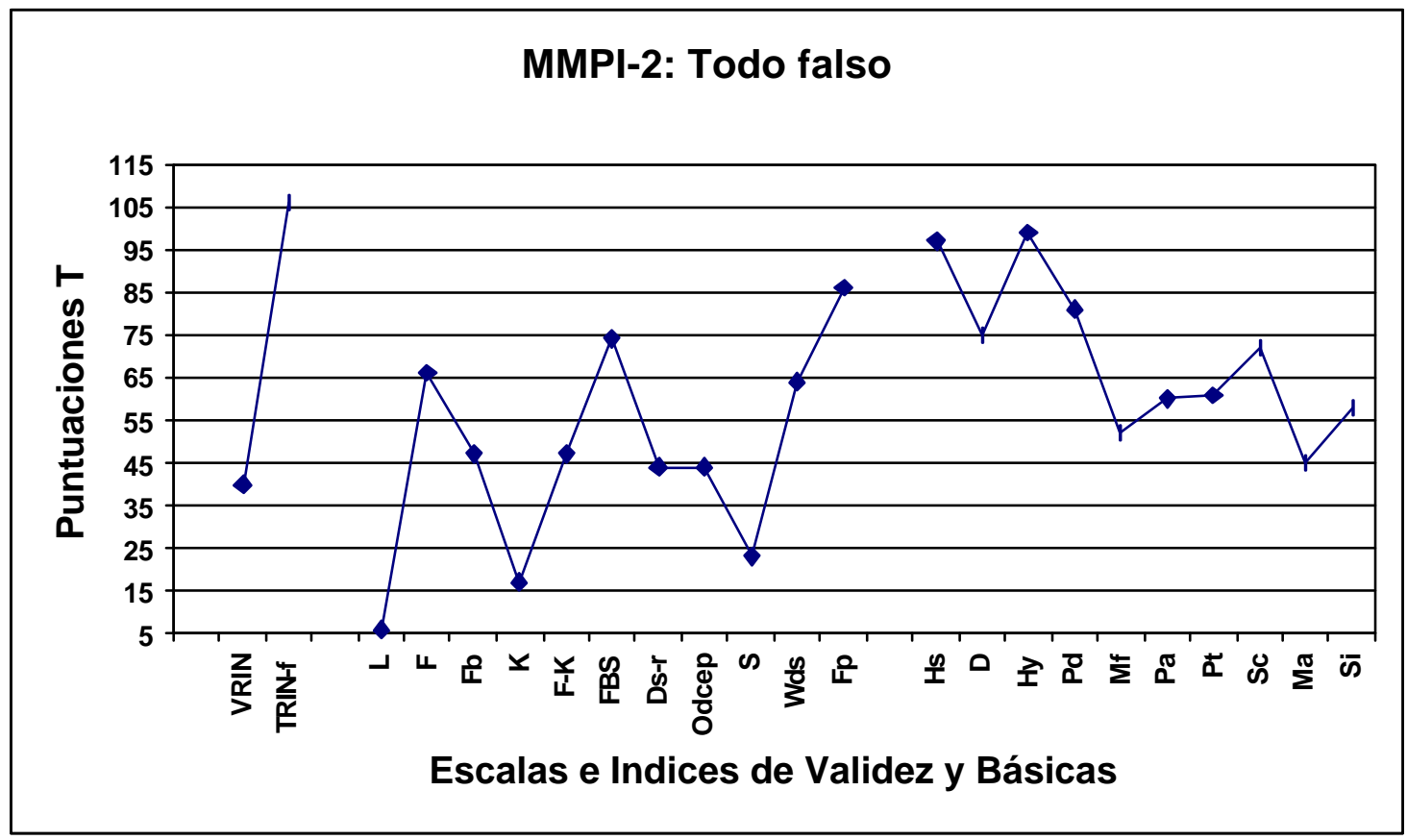

Perfil 6: Comportamiento del perfil del $\mathcal{M M P I - 2}$ cuando se contesta a todos los items del cuestionario como "falso" 


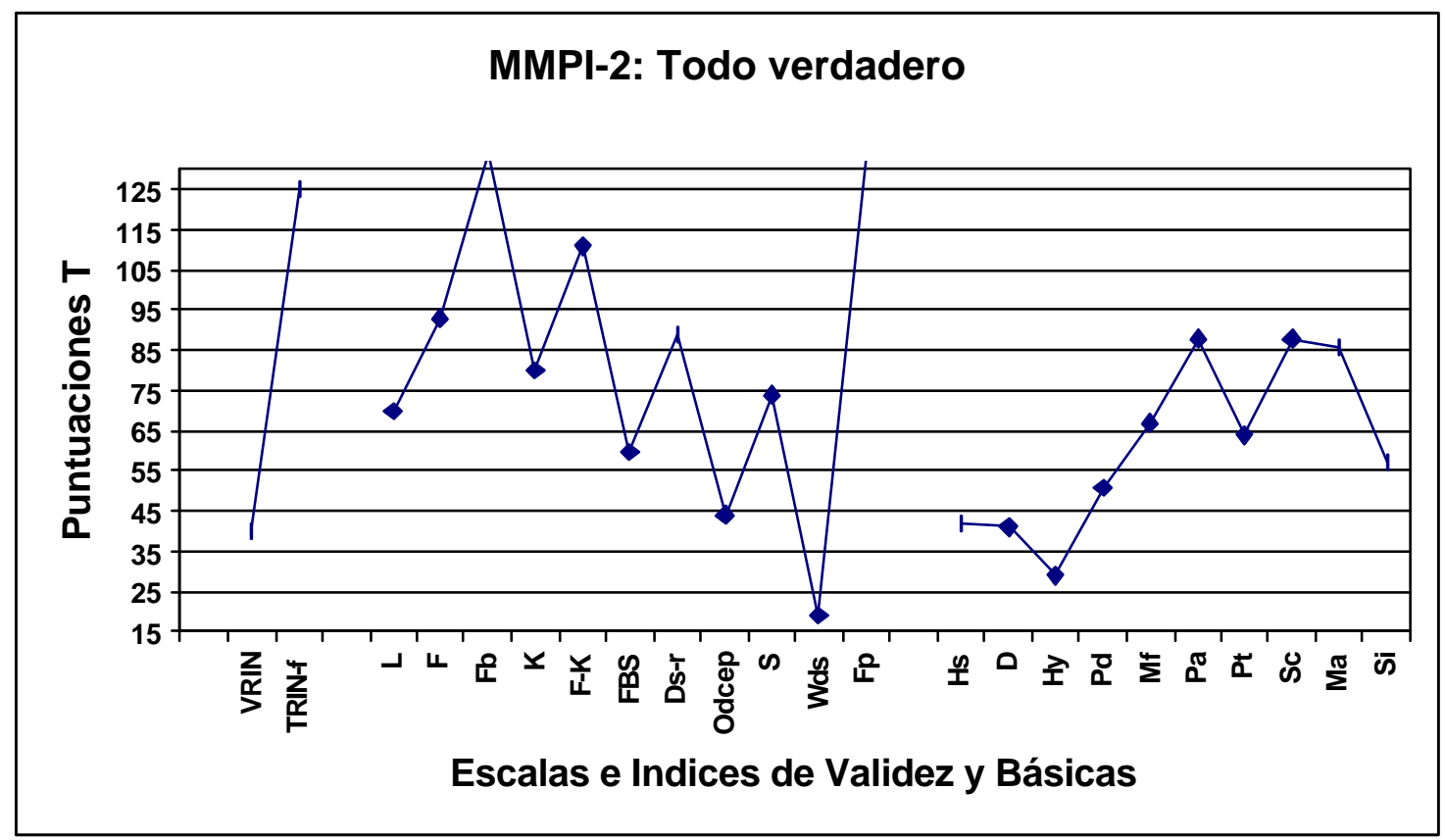

Perfil 7: Comportamiento del perfil del $\mathcal{M M P I}-2$ cuando se contesta a todos los items del cuestionario como "verdadero"

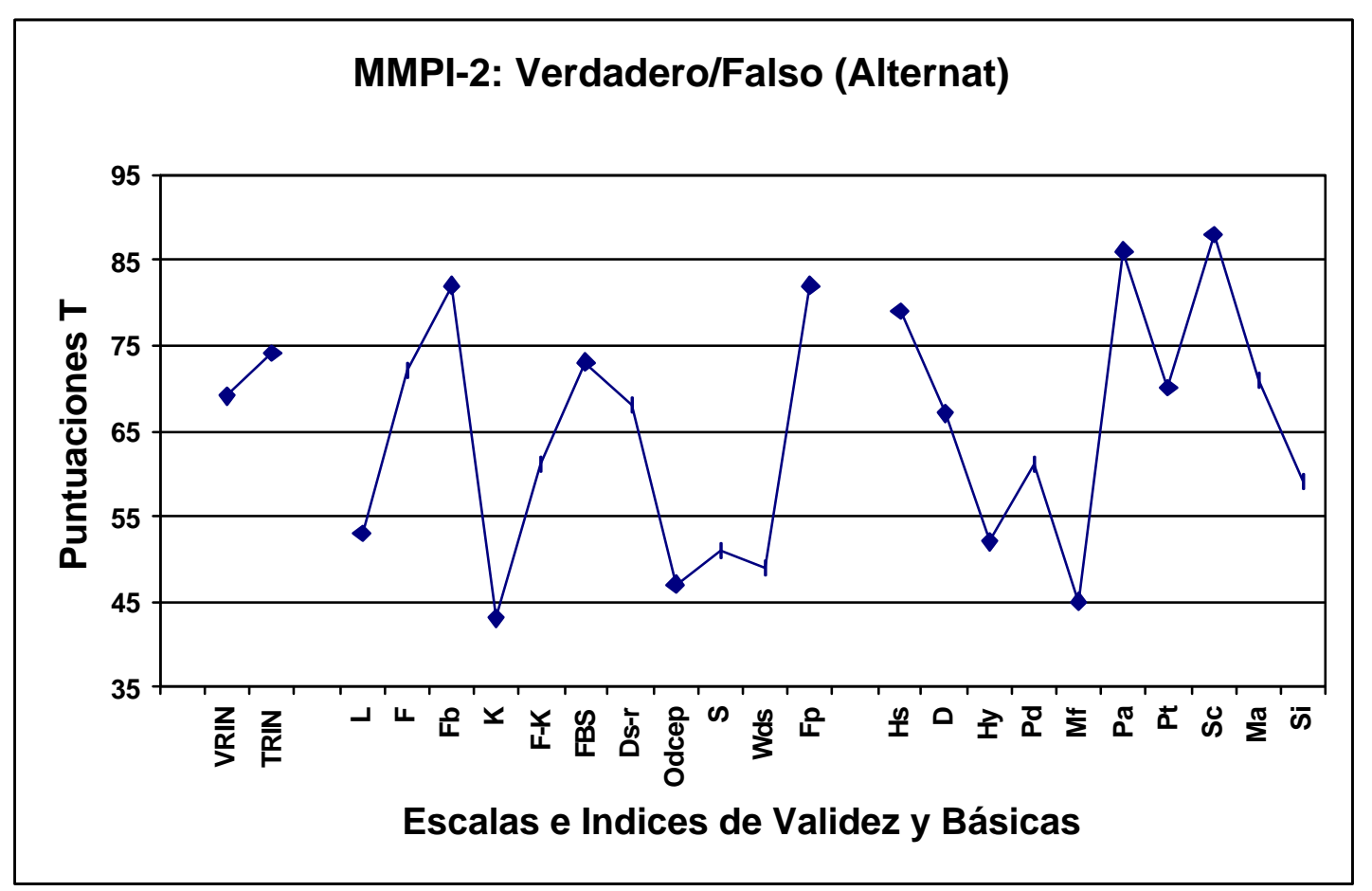

Perfil 8: Comportamiento del perfil del $M$ MPI- 2 cuando se contesta a todos los items del cuestionario de forma alternativa y secuencial como "verdadero/falso". 


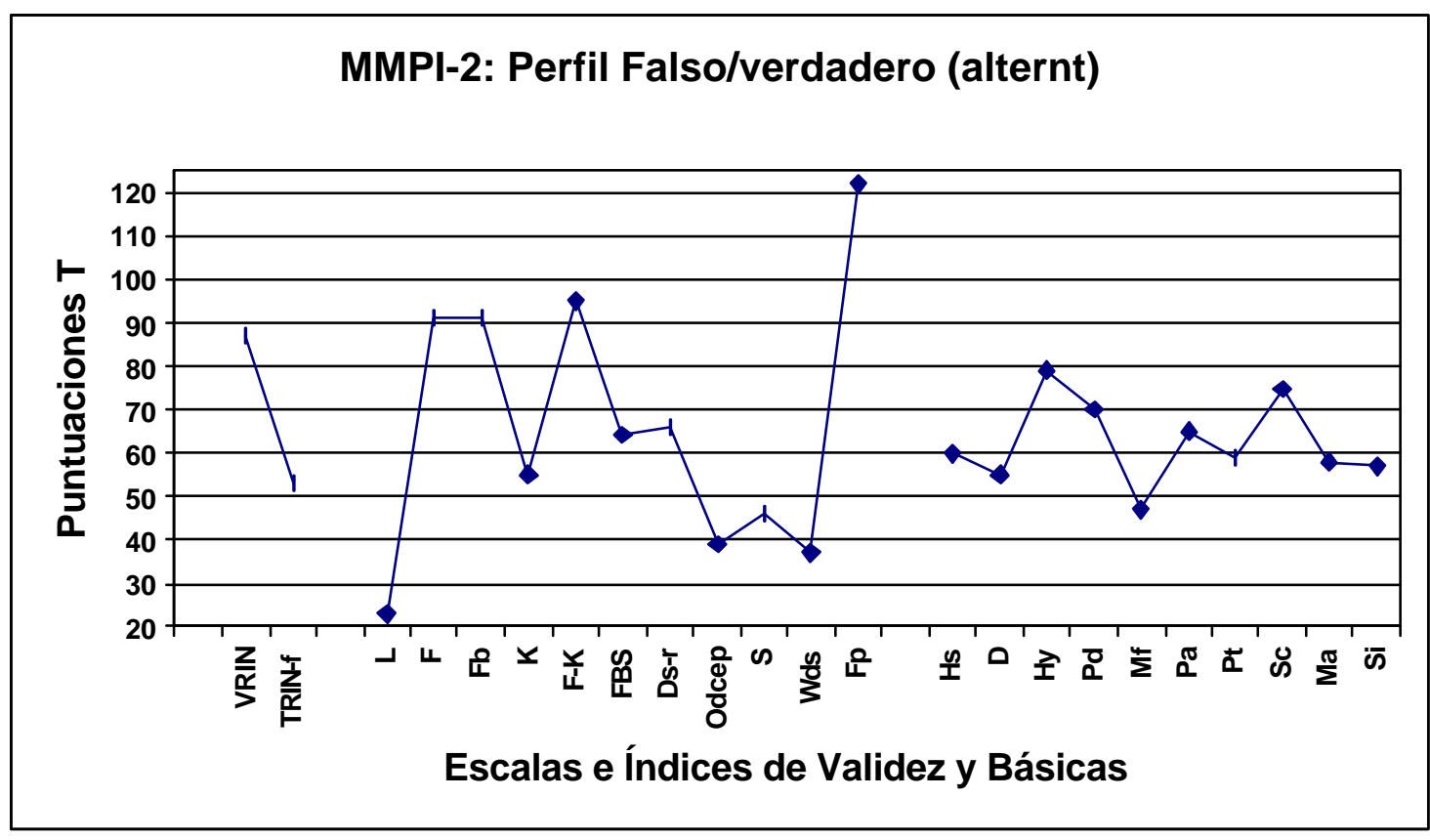

Perfil 9: Comportamiento del perfil del $\mathcal{M M P I}-2$ cuando se contesta a todos los items del cuestionario de forma alternativa y secuencial como "falso/verdadero".

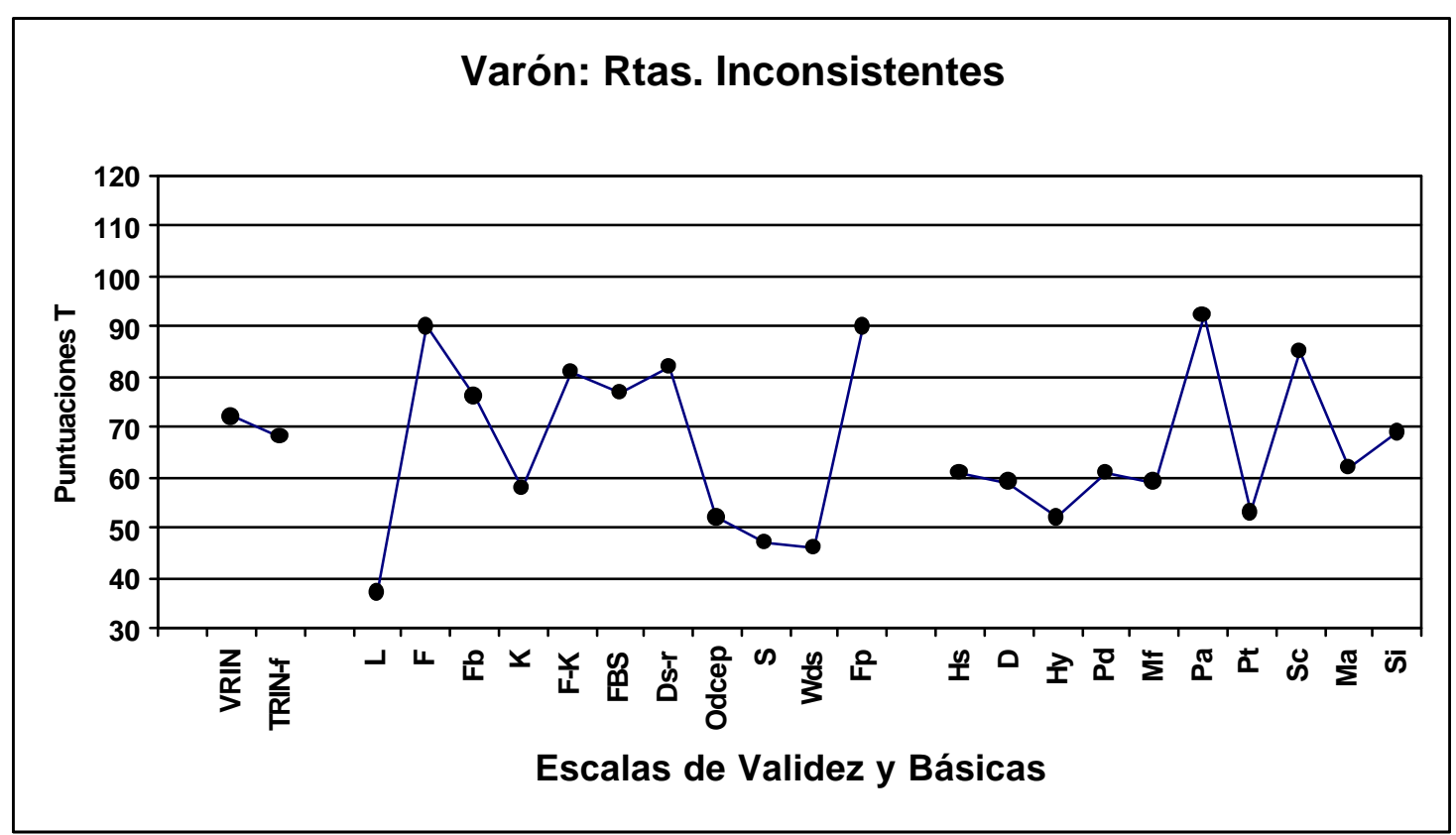

Perfil 10: Comportamiento del perfil del MMPI-2 cuando un varón contesta de forma aleatoria (sin tener en cuenta el contenido de la información de los items). 


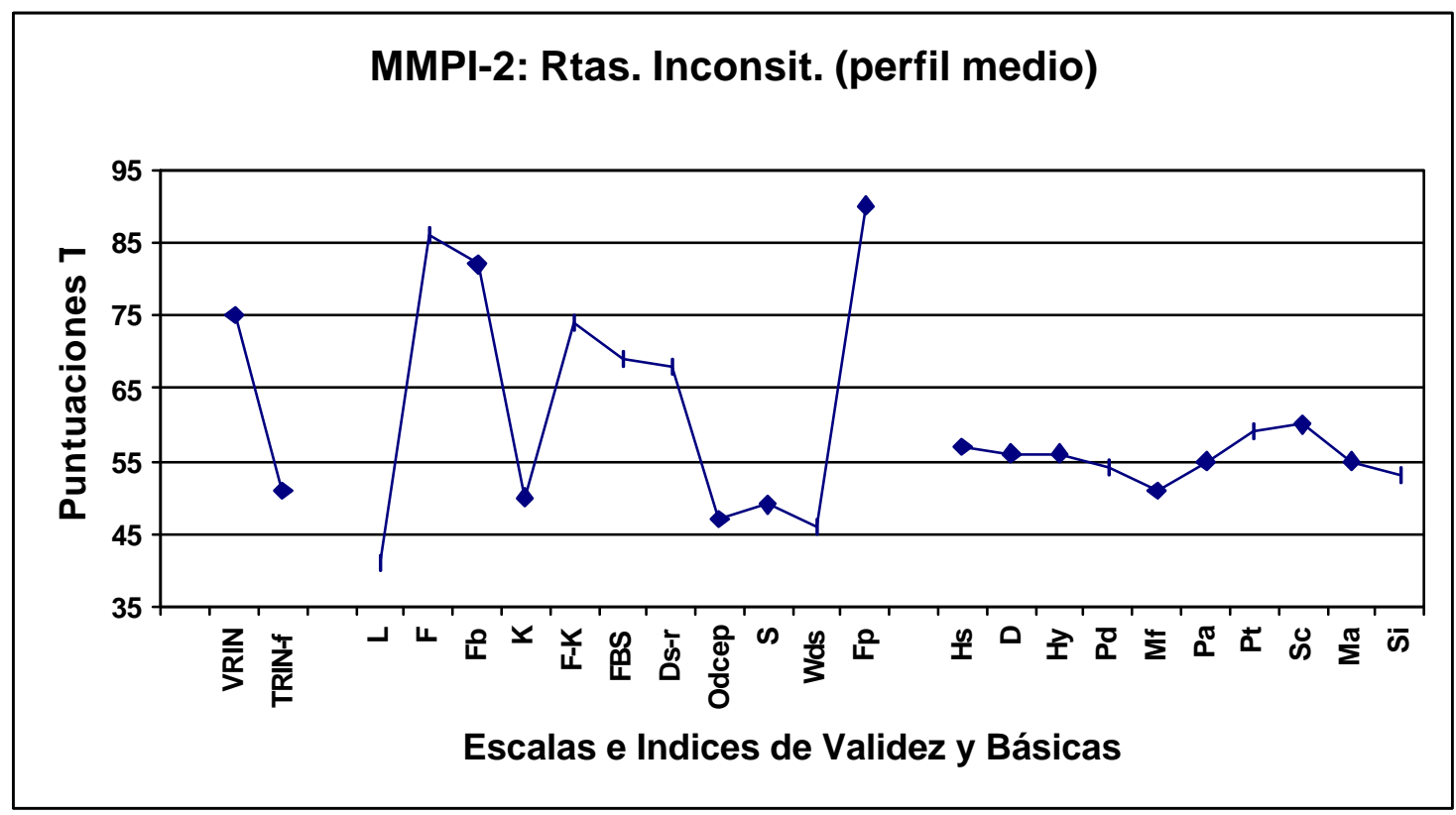

Perfil 11: Perfil medio de 100 formas diversas de contestar al cuestionario sin tener en cuenta el contenido de la información de los items(Rtas. Inconsistentes).

Deseamos destacar la curiosidad, en su perfil medio, al encontrar las Escalas Básicas o Clínicas dentro de la normalidad cuando se contesta de esta forma. Solamente algunas de las escalas e índices de Validez (VRIN, F, Fb, F-K, FBS, Ds-r y Fp) detectarían que este perfil ha sido falseado.

\section{V.2. - $\mathcal{A} \mathcal{N} \mathcal{A} L I Z \mathcal{A} \mathcal{N} D O$ LAS VARIABLES .}

Nos interesa analizar el comportamiento de cada una de las variable y establecer sus resultados mediante un análisis comparativo, esencialmente a través de las puntuaciones medias, percentiles y el Análisis de la Varianza.

Al igual que en el análisis realizado por grupos en el apartado anterior, debido a la diferencia encontrada entre géneros, nos vemos obligados, de la misma manera, a efectuar este mismo análisis por sexos en cada una de las variables. Por ello expondremos las gráficas y tablas correspondientes en donde se reflejen las diferencias encontradas.

\section{V.2.1- Variable "L".}

Recordemos que la escala "L" se compone de 15 ítems que fueron seleccionados para identificar a aquellos sujetos que deliberadamente intentan presentar una buena imagen ante los demás. Es pues, una escala que denota la defensividad del sujeto ante hechos o situaciones en las que desea ocultar lo negativo de sí mismo.

En nuestro estudio hemos encontrado en esta variable la más alta incidencia en los sujetos que intencionadamente tratan de dar buena imagen (Media: 10,858) siendo significativamente alta en su análisis comparativo con todos los demás grupos. 
Tabla 33: Variable "L". Percentiles. Análisis comparativo entre grupos.

\begin{tabular}{|c|c|c|c|c|c|}
\hline Percentiles & Normal & Clínico & Buena Imagen & Mala Imagen & Rta. Inc. \\
\hline $\mathbf{1 0}$ & 2 & 2 & 7 & 0 & 4,5 \\
\hline $\mathbf{2 5}$ & 3 & 3 & 9 & 1 & 6 \\
\hline $\mathbf{5 0}$ & 5 & 5 & 11 & 1 & 8 \\
\hline $\mathbf{7 5}$ & 6 & 6,25 & 13 & 4 & 9 \\
\hline $\mathbf{9 0}$ & 8 & 8 & 14 & 7 & 10 \\
\hline
\end{tabular}

Podemos apreciar igualmente que esta variable "L" no discrimina a los sujetos clínicos de los normales ni tampoco de aquellos que intentan mostrarnos una mala imagen de sí mismos. Estos resultados son plenamente coincidentes con los obtenidos por la mayor parte de los investigadores (Butcher, 1990; Greene, 1997; Butcher \& Williams, 1992; Graham, 1990 y1993; y Greene,1991).

Hemos de concluir, pues que con esta variable podemos detectar a los sujetos que intentan mostrar lo mejor de sí mismos ocultando aquellos aspectos desagradables de su persona. Se muestra, pues, como una variable de defensividad.

También podemos apreciar en esta Tabla 33 de percentiles de la variable "L" cómo los sujetos que intentan ofrecer una buena imagen consiguen las puntuaciones más altas. A través de estos resultados, podemos apreciar también que el $90 \%$ de los sujetos del grupo de buena imagen obtienen una puntuación tan alta como el $10 \%$ del resto de los grupos (normales, clínicos y mala imagen).

Podemos señalar, igualmente, que los grupos de sujetos normales y clínicos no presentan diferencia alguna percentilar en su incidencia (lo que ocurrirá también en la inexistencia de incidencia media), por lo cual es una variable que no permitirá discriminar a los sujetos sanos de aquellos que presenten algún problema clínico.

Estos resultados son coincidentes con los aportados por Butcher et al. (1989) y los de Greene (1997) con muestras de 2.600 sujetos normales y con 3.475 pacientes con trastornos mentales graves, en donde la distribución percentilar de la escala L en ambos grupos de sujetos es similar.

Tabla 34: Variable "L". Correlaciones $*$.

\begin{tabular}{|c|c|c|c|c|c|}
\hline Variables & Normal & Clínico & Buena Imagen. & Mala Imagen. & Rta. Inc \\
\hline $\mathbf{L}$ & 1.00 & 1.00 & 1.00 & 1.00 & 1.00 \\
\hline $\mathbf{F}$ & -.154 & -.212 & -.434 & -.155 & -.329 \\
\hline $\mathbf{K}$ & .395 & .373 & .648 & .683 & .413 \\
\hline $\mathbf{F b}$ & -.059 & -.180 & -.392 & -.190 & -.478 \\
\hline VRIN & -.041 & .010 & -.380 & .521 & -.029 \\
\hline TRIN & -.016 & -.052 & -.066 & -.092 & -.408 \\
\hline Fp & .178 & .033 & .066 & .037 & -.034 \\
\hline $\mathbf{S}$ & .451 & .450 & .732 & .739 & .440 \\
\hline Ds & -.315 & -.324 & -.536 & -.339 & -.394 \\
\hline Ds-r & -.348 & -.318 & -.614 & -.382 & -.304 \\
\hline FBS & .118 & .055 & .016 & -.046 & .179 \\
\hline ODecp & .578 & .506 & .772 & .646 & .211 \\
\hline IR & .196 & .013 & .116 & .048 & -.142 \\
\hline Wsd & .482 & .332 & .683 & .565 & .005 \\
\hline F-K & -.312 & -.312 & -.604 & -.347 & -.450 \\
\hline i & -.006 & .059 & -.020 & .173 & -.016 \\
\hline$/ \mathbf{F - F b} /$ & -.135 & -.030 & -.346 & -.023 & .109 \\
\hline
\end{tabular}

* Los valores en negrita, resultaron ser estadísticamente significativos al $\mathrm{p}<.001$

En los resultados obtenidos con los sujetos que ofrecen buena imagen, hemos podido comprobar que las correlaciones más altamente positivas se muestran con las variables “ODecp" (.772), "S" (.732); "Wsd" (.683) y "K" (.648). De la misma manera las 
correlaciones más altamente negativas se obtuvieron con las variables "Ds-r" (-.614); "F-K" (-.604) y con "Ds" (-.534).

Igualmente podemos apreciar que la variable "?" no correlaciona significativamente en ningún grupo, y solamente la TRIN con las respuestas inconsistentes.

Tabla 35: Variable "L". Puntuaciones Medias y St.D. Anális is por grupos.

\begin{tabular}{|c|c|c|c|c|c|c|c|c|c|}
\hline \multicolumn{2}{|c|}{ Normal } & \multicolumn{2}{c|}{ Clínico } & \multicolumn{2}{c|}{ Buena Imagen } & \multicolumn{2}{c|}{ Mala Imagen } & \multicolumn{2}{c|}{ Rta. Inc. } \\
\hline Media & St.D & Media & St.D & Media & St.D & Media & St.D & Media & St.D \\
\hline 4,761 & 2,371 & 4,889 & 2,426 & 10,858 & 2,812 & 2,621 & 2,871 & 7,535 & 2,232 \\
\hline
\end{tabular}

Con los datos y gráfica aportados, podemos mostrar que no existe diferencia estadística entre los sujetos considerados como normales y los clínicos en su ANOVA, y que sin embargo el grupo de "buena imagen" se destaca notablemente sobre los demás encontrándose diferencias estadísticamente significativas con los demás grupos.

Los sujetos que intentan ofrecer una imagen negativa de sí mismos son los que presentan la incidencia más baja. Este resultado puede convertirse en un indicador significativo para este tipo de sujetos al interpretar la escala "L" de nuestro MMPI-2. Para Graham (1990, pgs. 24-25) las puntuaciones bajas en esta escala L, entre otras posibilidades, comenta que "pueden ser indicativas, en algunos casos, de estar exagerando características negativas". Esta posibilidad queda plenamente confirmada y demostrada en nuestro estudio.

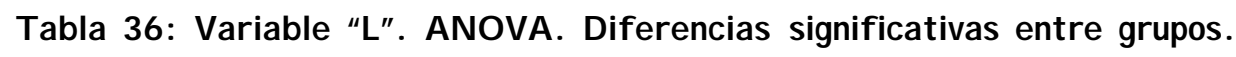

\begin{tabular}{|c|c|c|c|c|}
\hline Grupos & Dif.Med. & Dif. Crit. & $\mathbf{p}$ & Signf. (5\%) \\
\hline Normal vs. Clínico &,- 128 &, 235 &, 2853 & NO \\
\hline Normal vs. B. Imagen & $-6,097$ &, 310 & $<, 0001$ & SI \\
\hline Normal vs. M. Imagen & 2,141 &, 317 & $<, 0001$ & SI \\
\hline Normal vs. Rtas. Inc. & $-2,774$ &, 361 & $<, 0001$ & SI \\
\hline Clínico vs. B. Imagen & $-5,969$ &, 353 & $<, 0001$ & SI \\
\hline Clínico vs. M. Imagen & 2,269 &, 358 & $<, 0001$ & SI \\
\hline Clínico vs. Rtas. Inc. & $-2,646$ &, 398 & $<, 0001$ & SI \\
\hline B. Imagen vs. M. Imagen & 8,237 &, 412 & $<, 0001$ & SI \\
\hline B. Imagen vs. Rtas. Inc. & 3,323 &, 447 & $<, 0001$ & SI \\
\hline M. Imagen vs. Rtas. Inc. & $-4,914$ &, 451 & $<, 0001$ & SI \\
\hline
\end{tabular}

$$
\text { Gráfica 20: Variable "L". } \mathcal{A N} O \mathcal{V A}
$$

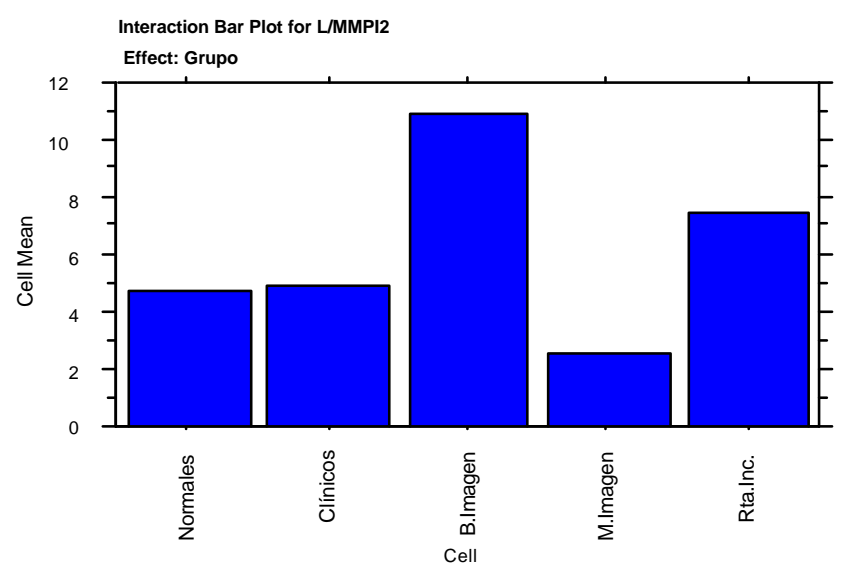


Cuando realizamos el análisis diferenciado por sexos (Gráfica 21; Tabla 37), podemos apreciar que no existen diferencias estadísticamente significativas entre los grupos normales y clínicos, tanto si realizamos el análisis entre varones de ambos grupos como de mujeres. Al realizar el análisis con los demás grupos, podemos ver que todos son significativos (Tabla 37).

\section{Gráfica 21: Variable "L". Análisis intersexos/intergrupos.}

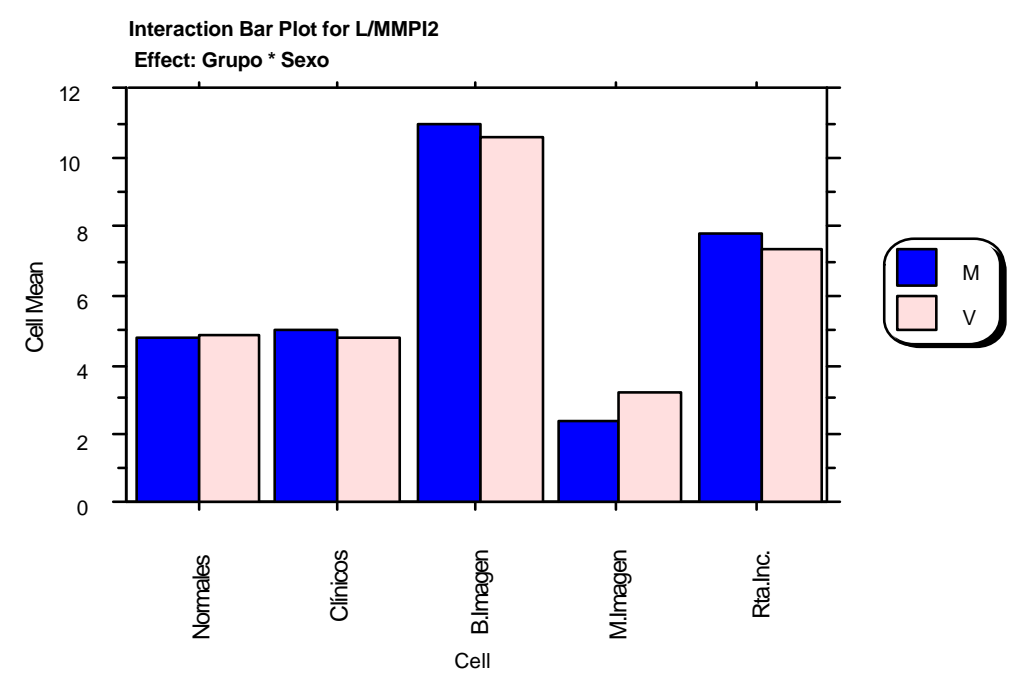

Tabla 37: Variable " $L$ ". Diferencias intergrupos e intersexos *.

Fisher's PLSD for $\mathrm{L}$

Effect: Grupos

Significance Level: $5 \%$

Split By: Género

Cell: $M$

B.Imagen, Clínicos

B.Imagen, M.Imagen

B.Imagen, Normales

B.Imagen, Rta.Inc.

Clínicos, M.Imagen

Clínicos, Normales

Clínicos, Rta.Inc.

M.Imagen, Normales

M.Imagen, Rta.Inc.

Normales, Rta.Inc.

\begin{tabular}{|c|c|c|}
\hline Mean Diff. & Crit. Diff & P-Value \\
\hline 6,008 & ,456 & $<, 0001$ \\
\hline 8,728 & ,514 & $<, 0001$ \\
\hline 6,310 & ,397 & $<, 0001$ \\
\hline 3,281 & ,598 & $<, 0001$ \\
\hline 2,720 & ,448 & $<, 0001$ \\
\hline ,302 & ,305 &, 0523 \\
\hline$-2,727$ & ,541 & $<, 0001$ \\
\hline-2.418 & .387 & $<.0001$ \\
\hline$-5,448$ & ,592 & $<, 0001$ \\
\hline$-3,029$ & 493 & $<, 0001$ \\
\hline
\end{tabular}

Fisher's PLSD for L
Effect: Grupos
Significance Level: $5 \%$
Split By: Género
Cell: V
B.Imagen, Clínicos
B.Imagen, M.Imagen
B.Imagen, Normales
B.Imagen, Rta.Inc.
Clínicos, M.Imagen
Clínicos, Normales
Clínicos, Rta.Inc.
M.Imagen, Normales
M.Imagen, Rta.Inc.
Normales, Rta.Inc.

\begin{tabular}{|c|c|c|}
\hline Mean Diff. & Crit. Diff & P-Value \\
\hline 5,896 & ,555 & $<, 0001$ \\
\hline 7,436 & 683 & $<, 0001$ \\
\hline 5,798 & ,496 & $<, 0001$ \\
\hline 3,302 & ,677 & $<, 0001$ \\
\hline 1,541 & ,597 & $<, 0001$ \\
\hline -,097 & , 368 & ,6045 \\
\hline$-2,594$ &, 590 & $<, 0001$ \\
\hline$-1,638$ & ,542 & $<, 0001$ \\
\hline$-4,134$ & ,712 & $<, 0001$ \\
\hline$-2,497$ & ,535 & $<, 0001$ \\
\hline
\end{tabular}

* $\mathrm{M}=$ mujeres; $\mathrm{V}=$ Varones. $\mathrm{S}=$ significativo.

Resumiendo, teniendo en cuenta nuestros resultados, esta variable nos puede ser útil para:

- - detectar a los sujetos que intentan dar una buena imagen de sí mismo.

- - apreciar la defensividad del sujeto ante la prueba. 
- - tenerla en cuenta cuando se trata de dar mala imagen. Solamente cuando se trata de ofrecer una imagen desfavorable de sí mismo, los varones presentan una mayor incidencia en sus puntuaciones que las mujeres.

- - precisar su interpretación, siempre que lo hagamos valorando las puntuaciones referentes a las escalas: K, ODecp, $\mathrm{S}$ y Wsd.

\section{V.2.2. - Variable "F":}

Recordemos que esta variable fue elaborada, originalmente (Meehl \& Hathaway, 1946; McKinley, Hathaway \& Meehl, 1948), para detectar las formas anormales o atípicas de contestar y como medida de la tendencia a reconocer o admitir una extensa gama de problemas psicológicos o también de "fingirse malo" o crear una mala imagen.

Posteriormente los investigadores (Butcher, 1990; Graham, 1990; Butcher \& Williams, 1992) coinciden en considerar que una puntuación alta en $F$ refleja una tendencia a exagerar los problemas.

Nuestros resultados confirman los obtenidos por los investigadores mencionados, encontrando una altísima puntuación en el grupo de los simuladores que se fingen como con problemas o tratan de ofrecer una imagen negativa de sí mismos. Este grupo se destaca notablemente en su puntuación media $(47,045)$ y en su puntuación percentilada (Tablas 40 y 38 respectivamente).

Esta variable también puede detectar a los sujetos que responden inconsistentemente al cuestionario. Después del grupo de mala imagen son los que presentan las puntuaciones más elevadas (media: 29,680) y sus puntuaciones percentiladas aparecen igualmente como las mas altas y semejantes a las de mala imagen.

Tabla 38: Variable "TF". Percentiles. Análisis entre grupos.

\begin{tabular}{|c|c|c|c|c|c|}
\hline Percentiles & Normal & Clínico & Buena Imagen. & Mala Imagen. & Rta. Inc. \\
\hline $\mathbf{1 0}$ & 2 & 4 & 1 & 30 & 24 \\
\hline $\mathbf{2 5}$ & 4 & 7 & 2 & 42 & 26 \\
\hline $\mathbf{5 0}$ & 6 & 12 & 3 & 52 & 30 \\
\hline $\mathbf{7 5}$ & 9 & 18 & 5 & 26 & 33 \\
\hline $\mathbf{9 0}$ & 13 & 23,4 & 8 & 58 & 36 \\
\hline
\end{tabular}

Según los resultados mostrados en esta Tabla 38 sobre los percentiles de respuestas, podemos ver que el $90 \%$ de los sujetos que intentan ofrecer una imagen negativa de sí mismos dan más de 30 respuestas y el $10 \%$ más de 58 respuestas, y los sujetos que contestan inconsistentemente, el $90 \%$ de ellos ofrecen más de 24 respuestas. Esto se diferencia notablemente del grupo de los normales y de los clínicos.

Por estos resultados, podemos justificar que la variable F nos puede ayudar a detectar a aquellos sujetos que, o bien contestan de forma inconsistente o bien intentan ofrecer una mala imagen de sí mismos.

De la Tabla 39, donde se nos muestran los resultados de las correlaciones de la variable $\mathrm{F}$ con el resto de las variables, podemos detallar, en primer lugar, h elevada y positiva correlación presentada en aquellas variables que se sirven de la escala $\mathrm{F}$ como integrante, por ejemplo la $\mathrm{F}-\mathrm{K}$, la $/ \mathrm{F}-\mathrm{Fb} / \mathrm{y}$ naturalmente la $\mathrm{Fb}$ que es la variable que refleja el mismo concepto y contenido que la $\mathrm{F}$ en la segunda parte de la prueba. 
Tabla 39: Variable "F". Correlaciones.

\begin{tabular}{|c|c|c|c|c|c|}
\hline Variables & Normal & Clínico & Buena Imagen & Mala Imagen & Rta. Inc. \\
\hline $\mathbf{L}$ & -.154 & -.212 & -.434 & $\begin{array}{l}.155 \\
\end{array}$ & $\begin{array}{l}.329 \\
\end{array}$ \\
\hline $\mathbf{F}$ & 1.00 & 1.00 & 1.00 & 1.00 & 1.00 \\
\hline $\mathbf{K}$ & -.449 & -.496 & -.520 & -.213 &.- .316 \\
\hline $\mathbf{F b}$ & .737 & .792 & .854 & .913 & .316 \\
\hline VRIN & .371 & .134 & .673 & -.275 & .025 \\
\hline TRIN & .136 & .263 & .014 & -.100 & .316 \\
\hline $\mathbf{F p}$ & .704 & .769 & .738 & .929 & .454 \\
\hline $\mathbf{S}$ & -.476 & -.565 & -.559 & -.374 & -.334 \\
\hline Ds & .746 & .810 & .884 & .885 & .426 \\
\hline Ds-r & .668 & .739 & .818 & .834 & .290 \\
\hline FBS & .351 & .438 & .351 & .804 & .043 \\
\hline ODecp & -.166 & -.170 & -.462 & -.437 & .027 \\
\hline IR & .628 & .769 & .572 & .873 & .329 \\
\hline Wsd & -.040 & .030 & -.356 & -.431 & .103 \\
\hline F-K & .874 & .927 & .902 & .954 & .856 \\
\hline$i$ & -.046 & -.059 & .004 & .016 & .039 \\
\hline /F-Fb/ & & 444 & 70 & & \\
\hline
\end{tabular}

* Los valores en negrita, resultaron ser estadísticamente significativos al $\mathrm{p}<.001$

Pero debemos destacar también las altísimas correlaciones, de signo positivo, existentes de la escala $\mathrm{F}$ con otras variables como la escala psiquiátrica $\mathrm{F}(\mathrm{p})$ de Arbisi \& Ben-Porath $(1995,1998)$ cuya idea principal era diferenciar a los sujetos que contestan honestamente de aquellos que intentan exagerar sus síntomas psiquiátricos de forma intencionada. Igualmente podemos apreciar las altísimas correlaciones positivas con las escalas de Disimulación de Gough (Ds y Ds-r) y la inconsistencia de respuestas IR de Sewell y als. (1994).

Las variables que correlacionan negativamente con esta variable $\mathrm{F}$, las encontramos con la escala S, Superlativa de Butcher \& Han (1995), y con la ODecp de Nichols \& Greene (1991).

Tabla 40: Variable "F": Puntuaciones Medias y $\mathcal{S}$ t. $\mathcal{D}$. Análisis comparativo entre grupos.

\begin{tabular}{|c|c|c|c|c|c|c|c|c|c|}
\hline \multicolumn{2}{|c|}{ Normal } & \multicolumn{2}{c|}{ Clínico } & \multicolumn{2}{c|}{ Buena Imagen } & \multicolumn{2}{c|}{ Mala Imagen } & \multicolumn{2}{c|}{ Rta. Inc. } \\
\hline Media & St.D & Media & St.D & Media & St.D & Media & St.D & Media & St.D \\
\hline 7,125 & 5,254 & 13,109 & 7,531 & 4,312 & 5,256 & 47,045 & 12,010 & 29,680 & 4,511 \\
\hline
\end{tabular}

Por último destacar las altísimas correlaciones, de signo positivo, que presenta el grupo que intenta ofrecer una mala imagen de sí mismo con la mayor parte de las variables que hemos comentado en los párrafos anteriores $(\mathrm{F}(\mathrm{p})=, 929 ; \mathrm{F}-\mathrm{K}=$,954; Ds = ,885; Ds-r $=, 834 ; \mathrm{FBS}=, 804 ; \mathrm{IR}=, 873 ; / \mathrm{F}-\mathrm{Fb} /=, 701)$. Las correlaciones negativas de este grupo pueden apreciarse en la Tabla 38 que igualmente son muy ilustrativas.

Volvemos a encontrarnos con la ausencia de correlación con la variable "?".

Podemos ver en la Tabla 40 que la mayor incidencia media la obtiene el grupo de mala imagen $(47,045)$, muy por encima de cualquier otro grupo presentando diferencias estadísticamente significativas $(<, 0001)$ con cualquiera de los grupos aquí estudiados, como puede verse en la Tabla 41.

Cuando contemplamos los análisis realizados tanto por sexos diferenciados en cada uno de los grupos como cuando los tomamos conjuntamente los sexos (Gráficas 22, 23 y Tabla 42), podemos observar la existencia de diferencias estadísticamente significativas entre ellos (intergrupos e intersexos). Estamos, pues, ante una variable importante y fundamental en el análisis de la validez y fiabilidad del MMPI-2. 
Tabla 41: Variable "F". $\mathcal{A} \mathcal{N} O \mathcal{V A}$. Diferencias significativas entre grupos.

\begin{tabular}{|c|c|c|c|c|}
\hline Grupos & Dif.Med. & Dif. Crit. & p & Signf. (5\%) \\
\hline Normal vs. Clínico & $-5,983$ &, 624 & $<, 0001$ & SI \\
\hline Normal vs. B. Imagen & 2,813 &, 824 & $<, 0001$ & SI \\
\hline Normal vs. M. Imagen & $-39,919$ &, 841 & $<, 0001$ & SI \\
\hline Normal vs. Rtas. Inc. & $-22,555$ &, 959 & $<, 0001$ & SI \\
\hline Clínico vs. B. Imagen & 8,797 &, 937 & $<, 0001$ & SI \\
\hline Clínico vs. M. Imagen & $-33,936$ &, 952 & $<, 0001$ & SI \\
\hline Clínico vs. Rtas. Inc. & $-16,571$ & 1,057 & $<, 0001$ & SI \\
\hline B. Imagen vs. M. Imagen & $-42,733$ & 1,094 & $<, 0001$ & SI \\
\hline B. Imagen vs. Rtas. Inc. & $-25,368$ & 1,186 & $<, 0001$ & SI \\
\hline M. Imagen vs. Rtas. Inc. & 17,365 & 1,198 & $<, 0001$ & SI \\
\hline
\end{tabular}

$$
\text { Gráfica 22: Variable "F". } \mathcal{A N O V \mathcal { A }}
$$

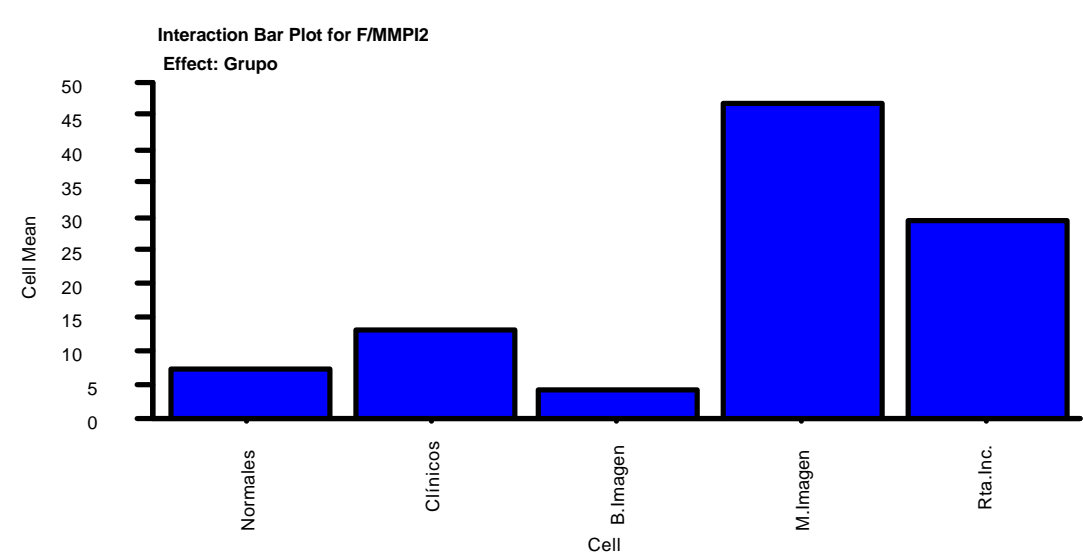

Gráfica 23: Variable "F". Análisis intersexos/intergrupos.

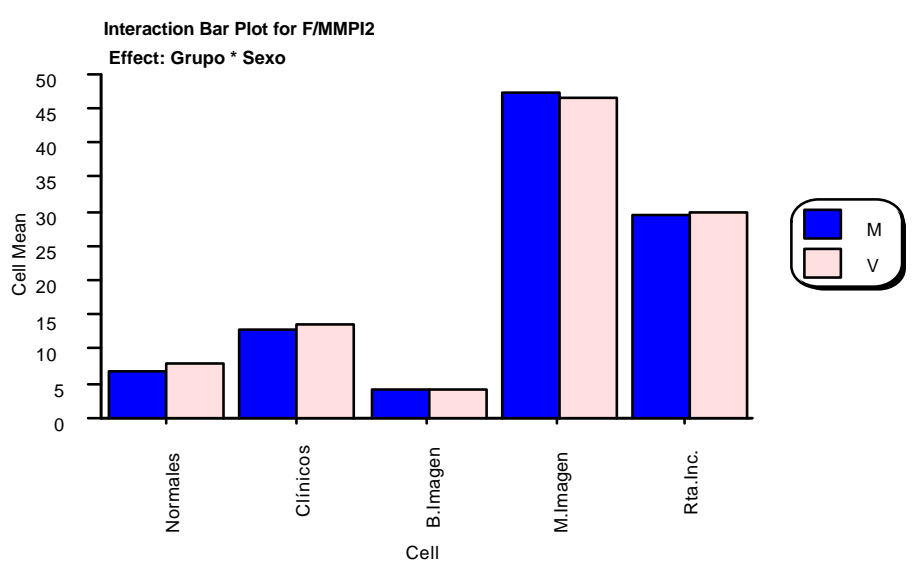


Tabla 42: Variable "F". Diferencias intergrupos e intersexos *.

\begin{tabular}{|c|c|c|c|c|}
\hline \multirow{2}{*}{\multicolumn{5}{|c|}{$\begin{array}{l}\text { Fisher's PLSD for F } \\
\text { Effect: Grupos } \\
\text { Significance Level: } 5 \% \\
\text { Split By: Género } \\
\text { Cell: M }\end{array}$}} \\
\hline & & & & \\
\hline \multirow[b]{2}{*}{ B.Imagen, Clínicos } & \multirow{2}{*}{$\begin{array}{r}\text { Mean Diff. } \\
-8,540\end{array}$} & \multirow{2}{*}{$\begin{array}{r}\text { Crit. Diff } \\
1,175\end{array}$} & \multirow{2}{*}{\begin{tabular}{|c|} 
P-Value \\
$<, 0001$ \\
\end{tabular}} & \\
\hline & & & & \\
\hline B.Imagen, M.Imagen & $-43,008$ & 1,327 & $<, 0001$ & $\mathrm{~s}$ \\
\hline B.Imagen, Normales & $-2,304$ & 1,023 & $<, 0001$ & s \\
\hline B.Imagen, Rta.Inc. & $-25,436$ & 1,542 & $<, 0001$ & S \\
\hline Clínicos, M.Imagen & $-34,467$ & 1,155 & $<<, 0001$ & \\
\hline Clínicos, Normales & 6,237 & ,787 & $<, 0001$ & \\
\hline Clínicos, Rta.Inc. & $-16,895$ & 1,397 & $<<, 0001$ & \\
\hline M.Imagen, Normales & 40,704 & ,999 & $<, 0001$ & \\
\hline M.Imagen, Rta.Inc. & 17,572 & 1,527 & $<<, 0001$ & \\
\hline Normales, Rta.Inc. & $-23,132$ & 1,271 & $<<, 0001$ & \\
\hline
\end{tabular}

\begin{tabular}{|c|c|c|c|}
\hline \multicolumn{4}{|c|}{$\begin{array}{l}\text { Fisher's PLSD for F } \\
\text { Effect: Grupos } \\
\text { Significance Level: } 5 \%\end{array}$} \\
\hline \multicolumn{4}{|l|}{ Split By: Género } \\
\hline \multicolumn{4}{|l|}{ Cell: $v$} \\
\hline & Mean Diff. & Crit. Diff & P-Value \\
\hline \multirow{2}{*}{$\begin{array}{l}\text { B.Imagen, Clínicos } \\
\text { B.Imagen, M.Imagen }\end{array}$} & $-9,108$ & 1,524 & $<, 0001$ \\
\hline & $-42,251$ & 1,874 & $<, 0001$ \\
\hline \multirow{2}{*}{$\begin{array}{l}\text { B.Imagen, Normales } \\
\text { B.Imagen, Rta.Inc. }\end{array}$} & $-3,588$ & 1,361 & $<, 0001$ \\
\hline & $-25,294$ & 1,859 & $<, 0001$ \\
\hline \multirow{2}{*}{$\begin{array}{l}\text { Clínicos, M.Imagen } \\
\text { Clínicos, Normales }\end{array}$} & $-33,143$ & 1,637 & $<, 0001$ \\
\hline & 5,520 & 1,009 & $<, 0001$ \\
\hline \multirow{2}{*}{$\begin{array}{l}\text { Clínicos, Rta.Inc. } \\
\text { M.Imagen, Normales }\end{array}$} & $-16,186$ & 1,619 & $<, 0001$ \\
\hline & 38,664 & 1,486 & $<, 0001$ \\
\hline \multirow{2}{*}{$\begin{array}{l}\text { M.Imagen, Rta.Inc. } \\
\text { Normales, Rta.Inc. }\end{array}$} & 16,958 & 1,953 & $<, 0001$ \\
\hline & $-21,706$ & 1,467 & $<, 0001$ \\
\hline
\end{tabular}

* $\mathrm{M}=$ mujeres; $\mathrm{V}=$ Varones. $\mathrm{S}=$ significativo.

Podemos llegar a concluir, por nuestros resultados, que esta variable nos puede ayudar a detectar a los sujetos que:

- - Intentan ofrecer una imagen distorsionada de sí mismos, bien exagerando sus síntomas o presentando una mala imagen de sí mismo.

- - Con sus bajas puntuaciones, en esta escala, pueden ofrecer una buena imagen.

- En definitiva, puede ser considerada como una escala de falsificación o fingimiento.

- - En una administración con sujetos normales, hemos de tener en cuenta que los varones presentan una mayor incidencia que las mujeres. Cuando se trata de otros grupos, tanto los varones como las mujeres, se comportan de manera semejante ante esta variable.

- - Para una adecuada precisión de su interpretación se debe acompañar de las puntuaciones obtenidas en las variables: Fb, F-K, FBS, Ds-r y F(p).

\section{V.2.3. - Variable "K":}

Recordemos que la escala "K", compuesta por 30 ítems en sus versiones original y reestructurada (MMPI-2, Anexo 0-4), fue elaborada inicialmente (Meehl y Hathaway, 1946; McKinley \& Hathaway, 1948) con la intención de poder detectar los intentos del sujeto de distorsionar sus respuestas, bien negando síntomas psicopatológicos, presentándose como una persona equilibrada, ajustada psicológicamente o, en sentido opuesto, exagerar su patología e intentar aparecer de un modo desfavorable.

De esta manera, las puntuaciones elevadas de $\mathrm{K}$ pueden considerarse como una forma de defensividad, una apariencia de suficiencia, control y eficacia (Graham, 1990).

Cuando estas puntuaciones elevadas se encuentran acompañadas con puntuaciones elevadas en los grupos de escalas Clínicas, es probable que la persona presente serios trastornos psicopatológicos y no tenga conciencia de ello (Graham, 1990).

Nuestros resultados confirman los datos aportados por Graham (1990) sobre las puntuaciones elevadas. Los sujetos a los que se les instruyó, al contestar los ítems del MMPI-2, para que presentaran una imagen favorable de sí mismos son los que 
presentan la puntuación media más elevada $(19,677)$ de entre todos los grupos aquí investigados, siendo estadísticamente significativa $(p<, 0001)$ en sus análisis comparativos.

Los datos aportados por Greene (2000) sobre los diferentes niveles de puntuaciones directas de esta escala $\mathrm{K}$ en la población normal, los muestra de la manera siguiente (Tabla 3.32, pg. 98):

- $\mathrm{PD}=0$-10. Considerado como una puntuación "baja".

- $\mathrm{PD}=11-17$. Considerada como una puntuación "normal"

- $\mathrm{PD}=18-22$. Considerada como una puntuación "moderada"

- $\mathrm{PD} \geq 23$. Considerada como una puntuación "elevada".

Si contemplamos nuestros resultados en la puntuación percentilada de la Tabla 43, podemos apreciar que los valores son muy semejantes, en el grupo de sujetos normales, a los encontrados por Greene (2000). Considerando la normalidad entre los percentiles 25 y 75 se observan las puntuaciones directas entre 11 y 18 (11 y 17 para Greene, 2000).

Tabla 43: Variable "K": Percentiles. Análisis comparativo entre grupos.

\begin{tabular}{|c|c|c|c|c|c|}
\hline Percentiles & Normal & Clínico & Buena Imagen & Mala Imagen & Rta. Inc. \\
\hline $\mathbf{1 0}$ & 9 & 6 & 14 & 6 & 11 \\
\hline $\mathbf{2 5}$ & 11 & 9 & 18 & 8 & 13 \\
\hline $\mathbf{5 0}$ & 15 & 12 & 20 & 10 & 15 \\
\hline $\mathbf{7 5}$ & 18 & 15 & 22 & 12 & 17 \\
\hline $\mathbf{9 0}$ & 21 & 19 & 25 & 16 & 19 \\
\hline
\end{tabular}

En su análisis comparativo percentilar entre los diferentes grupos (Tabla 43), podemos apreciar que el $90 \%$ de los sujetos que intentan mostrarse favorablemente ofrecen más de la mitad de las respuestas en esta escala.

Si comparamos nuestros resultados percentilados de la población normal con los obtenidos por Butcher el al., 1989 (citado por Greene 1997) confirmamos que coinciden exactamente las puntuaciones directas en sus respectivos percentiles.

Contemplando la Tabla 44, con respecto a las correlaciones de la variable $\mathrm{K}$ con las demás variables y en los distintos grupos, apreciamos que, esta variable presenta las correlaciones positivas más elevadas con S, L y ODecp. Siendo el grupo de sujetos de "buena imagen" el que cuenta con las correlaciones más elevadas.

Curiosamente podemos apreciar, por nuestros resultados, que también correlaciona, de forma negativa, con una gran parte de las variables aquí analizadas: $\mathrm{F}, \mathrm{Fb}, / \mathrm{F}-\mathrm{Fb} /, \mathrm{F}-$ $\mathrm{K}$, IR, Ds y Ds-r.

Los resultados obtenidos por los investigadores de la Universidad de Minnesota Butcher et al., 1989 (citado por Greene, 1997), con una población que contestó de forma honesta y sincera, son unos valores correlacionales muy semejantes a los obtenidos por nuestro estudio. Con la población normal, las correlaciones con la variable "L" fue de ,32 (nuestros resultados: ,395), con la variable " $S$ " fue de ,82 (nuestros resultados: ,813), con ODecp de ,32 (nuestros resultados: ,373) y con Wsd de ,03 (nuestros resultados: ,086). Como podemos ver los resultados son notablemente semejantes. 
Reiteradamente se nos muestra la "?" con ausencia de correlación significativa en los distintos grupos.

Tabla 44: Variable "K". Correlaciones ${ }^{*}$.

\begin{tabular}{|c|c|c|c|c|c|}
\hline Variables & Normal & Clínico & Buena Imagen & Mala Imagen & Rta. Inc. \\
\hline $\mathbf{L}$ & .395 & .373 & .648 & .683 & .413 \\
\hline $\mathbf{F}$ & -.449 & -.496 & -.520 & -.201 & -.316 \\
\hline $\mathbf{K}$ & 1.00 & 1.00 & 1.00 & 1.00 & 1.00 \\
\hline $\mathbf{F b}$ & $\begin{array}{l}-.461 \\
\end{array}$ &.- .537 & -.473 & -.248 &.- .510 \\
\hline VRIN & -.211 & .047 & -.489 & .516 & .035 \\
\hline TRIN & -.251 &.- .348 & -.171 & -.179 & -.399 \\
\hline $\mathbf{F p}$ & -.221 & -.278 & -.188 & -.065 & -.161 \\
\hline $\mathbf{S}$ & .813 & .809 & .845 & .844 & .549 \\
\hline Ds & -.677 & -.673 & $\begin{array}{l}-.628 \\
\end{array}$ & -.413 &.- .443 \\
\hline Ds-r & -.678 & -.662 & -.668 & -.430 & -.395 \\
\hline FBS & $\begin{array}{l}-.169 \\
\end{array}$ &.- .320 & .105 & -.125 & .078 \\
\hline ODecp & .373 & .325 & .540 & .483 & -.075 \\
\hline IR & -.198 & -.332 & -.116 & -.062 & -.428 \\
\hline Wsd & .086 & .018 & .355 & .307 & -.222 \\
\hline F-K & -.826 & -.786 & -.837 & -.484 & -.761 \\
\hline$i$ & -.005 & .053 & -.029 & .092 & .000 \\
\hline$/ \mathbf{F - F b /}$ & $\begin{array}{l}-.169 \\
\end{array}$ & -.077 & -.453 & -.038 & .113 \\
\hline
\end{tabular}

* Los valores en negrita, resultaron ser estadísticamente significativos al $\mathrm{p}<.001$

Tabla 45; Variable "K". Puntuaciones Medias y $\mathcal{S}$ t.D. Análisis comparativo entre grupos

\begin{tabular}{|c|c|c|c|c|c|c|c|c|c|}
\hline \multicolumn{2}{|c|}{ Normal } & \multicolumn{2}{c|}{ Clínico } & \multicolumn{2}{c|}{ Buena Imagen } & \multicolumn{2}{c|}{ Mala Imagen } & \multicolumn{2}{c|}{ Rta. Inc. } \\
\hline Media & St.D & Media & St.D & Media & St.D & Media & St.D & Media & St.D \\
\hline 14,526 & 4,532 & 12,045 & 4,582 & 19,677 & 4,141 & 10,346 & 4,093 & 15,165 & 3,603 \\
\hline
\end{tabular}

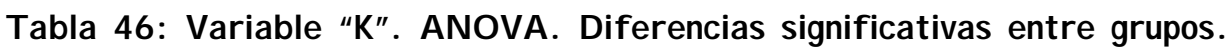

\begin{tabular}{|c|c|c|c|c|}
\hline Grupos & Dif.Med. & Dif. Crit. & p & Signf. (5\%) \\
\hline Normal vs. Clínico & 2,481 &, 421 & $<, 0001$ & SI \\
\hline Normal vs. B. Imagen & $-5,151$ &, 556 & $<, 0001$ & SI \\
\hline Normal vs. M. Imagen & 4,180 &, 567 & $<, 0001$ & SI \\
\hline Normal vs. Rtas. Inc. &,- 639 &, 646 &, 0526 & NO \\
\hline Clínico vs. B. Imagen & $-7,633$ &, 632 & $<, 0001$ & SI \\
\hline Clínico vs. M. Imagen & 1,699 &, 642 & $<, 0001$ & SI \\
\hline Clínico vs. Rtas. Inc. & $-3,120$ &, 713 & $<, 0001$ & SI \\
\hline B. Imagen vs. M. Imagen &,- 332 &, 738 & $<, 0001$ & SI \\
\hline B. Imagen vs. Rtas. Inc. & 4,512 &, 800 & $<, 0001$ & SI \\
\hline M. Imagen vs. Rtas. Inc. & $-4,819$ &, 808 & $<, 0001$ & SI \\
\hline
\end{tabular}

$\mathrm{Si}$ contemplamos las diferencias entre los diversos grupos, podemos apreciar que solamente entre los sujetos normales y los que contestan de forma inconsistentes (Rta. Inc.) no muestran diferencia alguna significativa entre sus puntuaciones (Tabla 46), por lo cual, en un caso real, nos resultaría difícil discriminar si el sujeto está contestando sin tener en cuenta el contenido de los ítems o por el contrario es un sujeto "normal". Es preciso apoyarnos en otras variables para poder salir de esta duda.

$\mathrm{Si}$ analizamos los resultados teniendo en cuenta la diferencia de sexos, solamente el grupo de sujetos normales son los que muestran una diferencia estadísticamente significativa entre varones y mujeres, siendo superior en sus puntuaciones aquellos. Solamente cuando analizamos el comportamiento de los varones normales y de Rta. Inc., podemos apreciar que no existen diferencias estadísticamente significativas (Tabla 47). 
Podemos determinar, por nuestros resultados, que esta variable $\mathrm{K}$ no discrimina entre sujetos que contestan de manera inconsistente al cuestionario del MMPI-2 de los que lo hacen de una forma consistente y sincera.

Gráfica 24: Variable "K". $\mathcal{A} \mathcal{N} O \mathcal{V} \mathcal{A}$.

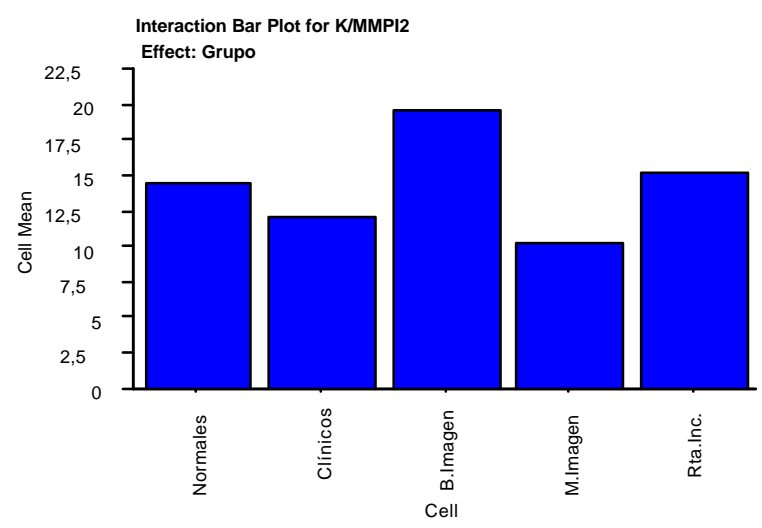

Gráfica 25: Variable "K". Análisis intersexos/interupos.

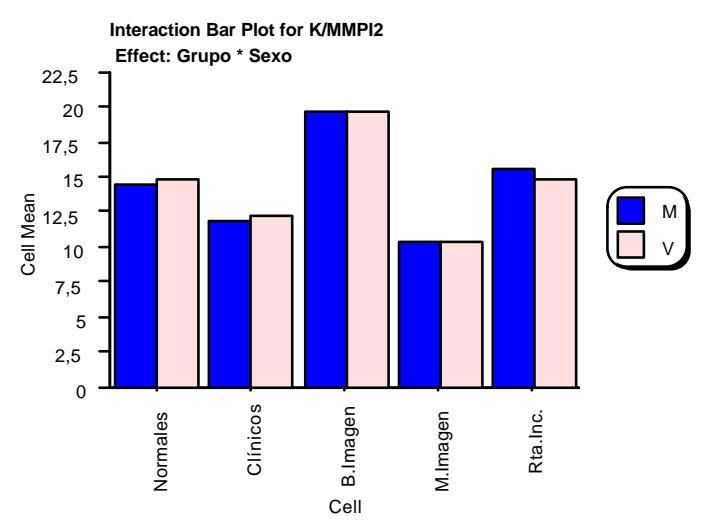

Tabla 47: Variable " $\mathcal{K}$ ". Diferencias intergrupos e intersexos ${ }^{*}$.

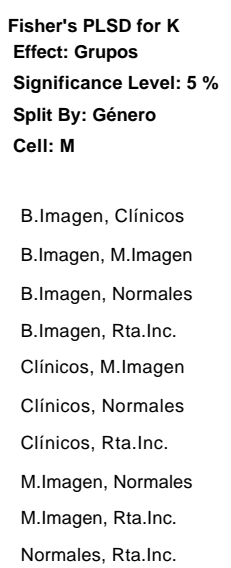

\begin{tabular}{|c|c|c|}
\hline Mean Diff. & Crit. Diff & P-Value \\
\hline 7,730 & ,818 & $<, 0001$ \\
\hline 9,343 & ,924 & $<, 0001$ \\
\hline 5,320 & ,712 & $<, 0001$ \\
\hline 4,279 & 1,074 & $<, 0001$ \\
\hline 1,613 & ,804 & $<, 0001$ \\
\hline$-2,410$ &, 548 & $<, 0001$ \\
\hline$-3,451$ & ,972 & $<, 0001$ \\
\hline$-4,023$ & ,696 & $<, 0001$ \\
\hline$-5,064$ & 1,063 & $<, 0001$ \\
\hline$-1,041$ & ,885 & ,0211 \\
\hline
\end{tabular}

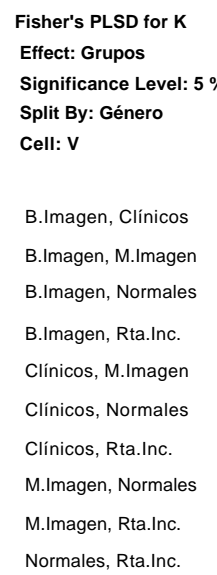

\begin{tabular}{l|r|r|r|} 
Mean Diff. & \multicolumn{1}{c}{ Crit. Diff } & \multicolumn{1}{c|}{ P-Value } \\
\hline 7,514 &, 995 & $<, 0001$ & $\mathrm{~S}$ \\
\hline 9,308 & 1,223 & $<, 0001$ & $\mathrm{~S}$ \\
\hline 4,895 &, 888 & $<, 0001$ & $\mathrm{~S}$ \\
\hline 4,749 & 1,213 & $<, 0001$ & $\mathrm{~S}$ \\
\hline 1,793 & 1,068 &, 0010 & $\mathrm{~S}$ \\
\hline$-2,620$ &, 659 & $<, 0001$ & $\mathrm{~S}$ \\
\hline$-2,765$ & 1,057 & $<, 0001$ & $\mathrm{~S}$ \\
\hline$-4,413$ &, 970 & $<, 0001$ \\
\hline$-4,559$ & 1,274 & $<$ \\
\hline,- 146 &, 957 &, 76001 & $\mathrm{~S}$ \\
\hline
\end{tabular}

$* \mathrm{M}=$ mujeres; $\mathrm{V}=$ Varones. $\mathrm{S}=$ significativo. 
En todos los demás grupos las diferencias medias de sus puntuaciones se muestran altamente significativas.

Resumiendo, la variable $\mathrm{K}$, la podemos considerar, y siempre según nuestros resultados, como:

- - Una variable que detecta la defensividad del sujeto que intenta presentar una buena imagen de sí mismo.

- - No discrimina, adecuadamente, entre grupos que contestan de forma inconsistente al cuestionario de aquellos sujetos varones normales que contestan honesta y sinceramente. Las mujeres normales si presentan diferencias estadísticamente significativas.

- - Que debe ser interpretada, para su adecuada y mejor precisión, conjuntamente con otras variables como son la L, S, ODecp y Wsd.

\section{V.2.4. - Variable "VRIN":}

Entre los indicadores adicionales de validez que llevaron a cabo Butcher, J.; Dahlstrom, W.; Graham, J.; Tellegen, A. \& Kaemer, B. (1989) en la reestructuración del MMPI, se encuentran, entre otras, esta variable elaborada a través de la estrategia de "pares de ítems " para poder apreciar la incoherencia o inconsistencia de respuestas. Esta variable no intenta detectar un determinado contenido o información del ítem, por lo tanto es independiente de lo que el ítem contenga conceptualmente.

Esta escala se encuentra compuesta por 49 pares de ítems (ver Anexo 0-5) con contenido similar u opuesto. Cada vez que un sujeto responde a los ítems de un par de forma incoherente o inconsistente, se anotará un punto en la escala VRIN.

Analizando las puntuaciones percentiladas de los diferentes grupos expuestos en la Tabla 48, podemos verificar que son los sujetos que contestan de forma inconsistente los que presentan las puntuaciones más elevadas. El 90\% de los sujetos que contestan de forma inconsistente (Rta. Inc.) presentan una puntuación directa PD >12 (equivalente a $64 \mathrm{~T}$ en mujeres y $63 \mathrm{~T}$ en varones) semejante al $10 \%$ del resto de los grupos.

A través de los resultados mostrados en la Tabla 49, podemos notar que las correlaciones más elevadas, de signo positivo, las hemos encontrado en el grupo de buena imagen, no presentando ninguna correlación estadísticamente significativa el grupo que ha contestado de forma inconsistente (Rta. Inc.) con el resto de las variables mostrada por los distintos grupos. Ni siquiera con aquellas variables tradicionalmente como de "incoherencia" o "inconsistencia" como las de IR y la de /F-Fb/.

Tabla 48: Variable "VRIN". Percentiles. Análisis comparativo entre grupos.
\begin{tabular}{|c|c|c|c|c|c|}
\hline Percentiles & Normal & Clínico & Buena Imagen & Mala Imagen & Rta. Inc. \\
\hline $\mathbf{1 0}$ & 4 & 5 & 2 & 4 & 12 \\
\hline $\mathbf{2 5}$ & 6 & 6 & 4 & 6 & 14 \\
\hline $\mathbf{5 0}$ & 8 & 8 & 5 & 8 & 16 \\
\hline $\mathbf{7 5}$ & 10 & 10 & 7 & 10,25 & 19 \\
\hline $\mathbf{9 0}$ & 12 & 13 & 10 & 13 & 21 \\
\hline
\end{tabular}


Tabla 49: Variable "VRIN $\mathcal{N}$ ". Correlaciones *.

\begin{tabular}{|c|c|c|c|c|c|}
\hline Variables & Normal & Clínico & Buena Imagen & Mala Imagen & Rta. Inc. \\
\hline $\mathbf{L}$ & -.041 & .010 & $\mathbf{- . 3 8 0}$ & $\mathbf{. 5 2 1}$ & -.029 \\
\hline F & $\mathbf{. 3 7 1}$ & .134 & $\mathbf{. 6 7 3}$ & $\mathbf{- . 2 7 5}$ & .025 \\
\hline K & $\mathbf{- . 2 1 1}$ & .047 & $\mathbf{- . 4 8 9}$ & $\mathbf{. 5 1 6}$ & .035 \\
\hline Fb & $\mathbf{. 3 5 9}$ & .080 & $\mathbf{. 6 3 5}$ & $\mathbf{- . 2 7 3}$ & .012 \\
\hline VRIN & $\mathbf{1 . 0 0}$ & $\mathbf{1 . 0 0}$ & $\mathbf{1 . 0 0}$ & $\mathbf{1 . 0 0}$ & $\mathbf{1 . 0 0}$ \\
\hline TRIN & -.008 & .058 & $\mathbf{. 0 0 0}$ & .082 & -.205 \\
\hline Fp & $\mathbf{. 3 0 2}$ & $\mathbf{. 1 7 7}$ & $\mathbf{. 4 7 7}$ & -.167 & -.013 \\
\hline S & $\mathbf{. . 1 6 3}$ & .090 & $\mathbf{- . 5 4 8}$ & $\mathbf{. 5 9 1}$ & .134 \\
\hline Ds & $\mathbf{. 3 2 9}$ & .067 & $\mathbf{. 6 6 3}$ & $\mathbf{- . 4 0 8}$ & .002 \\
\hline Ds-r & $\mathbf{. 2 7 7}$ & .047 & $\mathbf{. 6 4 9}$ & $\mathbf{- . 4 2 0}$ & -.014 \\
\hline FBS & $\mathbf{. 2 2 3}$ & .033 & .153 & $\mathbf{- . 2 3 8}$ & .080 \\
\hline ODecp & $\mathbf{. . 1 2 6}$ & $\mathbf{. 1 6 7}$ & $\mathbf{- . 3 7 3}$ & $\mathbf{. 5 6 1}$ & -.049 \\
\hline IR & $\mathbf{. 2 7 3}$ & .152 & $\mathbf{. 3 8 9}$ & -.131 & .026 \\
\hline Wsd & -.043 & .111 & $\mathbf{. . 2 6 6}$ & $\mathbf{. 5 0 3}$ & -.091 \\
\hline F-K & $\mathbf{. 3 4 8}$ & .075 & $\mathbf{. 6 7 8}$ & $\mathbf{- . 4 0 3}$ & -002 \\
\hline$\dot{\alpha}$ & -.055 & -.107 & .000 & .027 & .036 \\
\hline F-Fb/ & $\mathbf{. 1 6 1}$ & .131 & $\mathbf{. 4 5 0}$ & -.151 & -.016 \\
\hline
\end{tabular}

* Los valores en negrita, resultaron ser estadísticamente significativos al $\mathrm{p}<.001$

Advertimos de la curiosidad de que el grupo de clínicos solamente correlaciona de forma negativa con la variable "No sé/no puedo contestar" ("?" = -,107).

Las correlaciones más altas, de cualquier signo, las presentan los grupos de buena y mala imagen, siendo los demás grupos, bastantes más bajas.

- Altamente positivos con las variables L, K, ODecp, S y Wsd, en los sujetos que muestran mala imagen, y que, al mismo tiempo se corresponden con correlaciones negativas en los sujetos que ofrecen una buena imagen de sí mismos.

- Altamente positivos con las variables F, Fb, F-K, FBS, Ds-r y F(p) en los sujetos que nos ofrecen una buena imagen de sí mismos y que, al mismo tiempo, se corresponden con correlaciones altamente negativas en los sujetos que nos presentan una imagen negativa.

Observamos que el grupo clínico solamente tres variables correlacionan con bajas puntuaciones aunque todas ellas de forma significativa.

Tabla 50: Variable "VRILN". Puntuaciones Medias y $\mathcal{S}$ t. D. Anális is comparativo entre grupos.

\begin{tabular}{|c|c|c|c|c|c|c|c|c|c|}
\hline \multicolumn{2}{|c|}{ Normal } & \multicolumn{2}{c|}{ Clínico } & \multicolumn{2}{c|}{ Buena Imagen } & \multicolumn{2}{c|}{ Mala Imagen } & \multicolumn{2}{c|}{ Rta. Inc. } \\
\hline Media & St.D & Media & St.D & Media & St.D & Media & St.D & Media & St.D \\
\hline 7,882 & 3,074 & 8,565 & 3,122 & 5,723 & 3,317 & 8,346 & 3,956 & 16,445 & 3,551 \\
\hline
\end{tabular}

Según los resultados de las puntuaciones medias expuestos en la Tabla 50 y sus diferencias significativas de la Tabla 51, podemos apreciar que los datos aportados por el grupo de Respuestas inconsistentes (Rta. Inc.) son muy elevados y significativos estadísticamente del resto de los grupos.

Por otra parte, podemos señalar que esta variable no discrimina adecuadamente, por los resultados obtenidos, los sujetos clínicos de aquellos que contestan al cuestionaron intentando dar una mala imagen de sí mismo (Tabla 51).

Nuestros resultados son muy semejantes con los aportados en las investigaciones de Butcher, J.; Dahlstrom, W.; Graham, J.; Tellegen, A. \& Kaemer, B. (1989) con 2.600 sujetos considerados como normales y de Greene (1997) con 3.475 sujetos que presentan graves trastornos mentales. La puntuación media de los sujetos normales 
establecida en los resultados de Butcher et al. (1989) es de 5,05 y St.D. de 2,56 (nuestros resultados: 7,82 y St.D. de 3,074). Más coincidente son las puntuaciones con los 2.500 sujetos que contestaron aleatoriamente en el trabajo de Greene (1997) al ser comparados con los 200 sujetos nuestros (Greene: media=16,80, St.D.=3,24; nuestros resultados: Media $=16,445$ y St.D. 3,551).

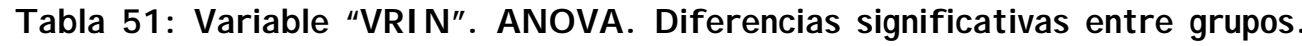

\begin{tabular}{|c|c|c|c|c|}
\hline \multicolumn{1}{|c|}{ Grupos } & Dif.Med. & Dif. Crit. & $\mathbf{p}$ & Signf. (5\%) \\
\hline Normal vs. Clínico &,- 683 &, 307 & $<, 0001$ & SI \\
\hline Normal vs. B. Imagen & 2,158 &, 406 & $<, 0001$ & SI \\
\hline Normal vs. M. Imagen &,- 464 &, 415 &, 0283 & SI \\
\hline Normal vs. Rtas. Inc. & $-8,563$ &, 472 & $<, 0001$ & SI \\
\hline Clínico vs. B. Imagen & 2,842 &, 462 & $<, 0001$ & SI \\
\hline Clínico vs. M. Imagen &, 219 &, 469 &, 3593 & NO \\
\hline Clínico vs. Rtas. Inc. & $-7,880$ &, 521 & $<, 0001$ & SI \\
\hline B. Imagen vs. M. Imagen & $-2,622$ &, 539 & $<, 0001$ & SI \\
\hline B. Imagen vs. Rtas. Inc. & $-10,722$ &, 585 & $<, 0001$ & SI \\
\hline M. Imagen vs. Rtas. Inc. & $-8,099$ &, 591 & $<, 0001$ & SI \\
\hline
\end{tabular}

Hemos de recordar que según los resultados presentados por Greene (1997, pg. 176) la variable VRIN no parece encontrarse afectada por la presencia de psicopatología, al comparar las puntuaciones medias y las desviaciones estándar similares en el MMPI-2 para el grupo normativo y los pacientes con trastornos mentales. Si analizamos el comportamiento de nuestra población clínica (no estrictamente psiquiátrica) y lo comparamos con la población considerada como "normal", podemos apreciar que las diferencias son estadísticamente significativa (a distintos niveles tanto si los analizamos por sexos o conjuntamente, pero siempre superior al 5\%. Véanse Tablas 50 y 52).

Cuando efectuamos un análisis de la población que intencionadamente quiere mostrarse de forma negativa (mala imagen) podremos apreciar que sus resultados no se diferencian estadísticamente de la población que ha contestado de forma sincera $\mathrm{y}$ honesta (normales y clínicos), por lo que esta variable VRIN se ha de servir de las aportaciones de otras para poder discriminar a los grupos adecuadamente.

Es así como VRIN podría convertirse en una variable detectora de perfiles aparentemente coherentes (al menos con la población de mala imagen), pero que en realidad no lo son, y sus puntuaciones deben ser contrastadas con las de otras variables. Sin embargo, si nos fijamos en el grupo de buena imagen, podemos observar que sus diferencias son estadísticamente significativas $(\mathrm{p}<, 0001)$ al ser comparadas con los grupos normales y también clínicos, tanto si su análisis se realiza separadamente o conjuntando ambos sexos (Tablas 50 y 52).

De todas formas podemos apreciar que la VRIN con los sujetos de mala imagen no parecen presentar muchas diferencias desde el punto de vista estadístico.

Las puntuaciones de VRIN solamente nos indican si una persona ha contestado de forma coherente pero no necesariamente honesta ya que puede, de forma coherente, mostrar su fingimiento o defensividad. Como podemos apreciar, en los perfiles correspondientes a "normal/buena imagen" y "normal/mala imagen", las puntuaciones medias de VRIN se encuentran dentro de la normalidad. 


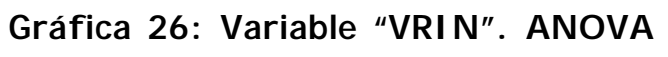

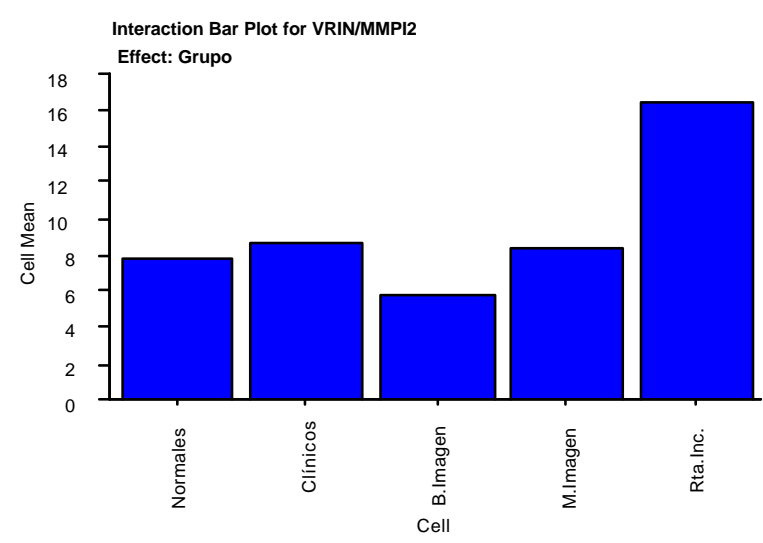

Gráfica 27: Variable "VRILN". Anális is intersexos/intergrupos.

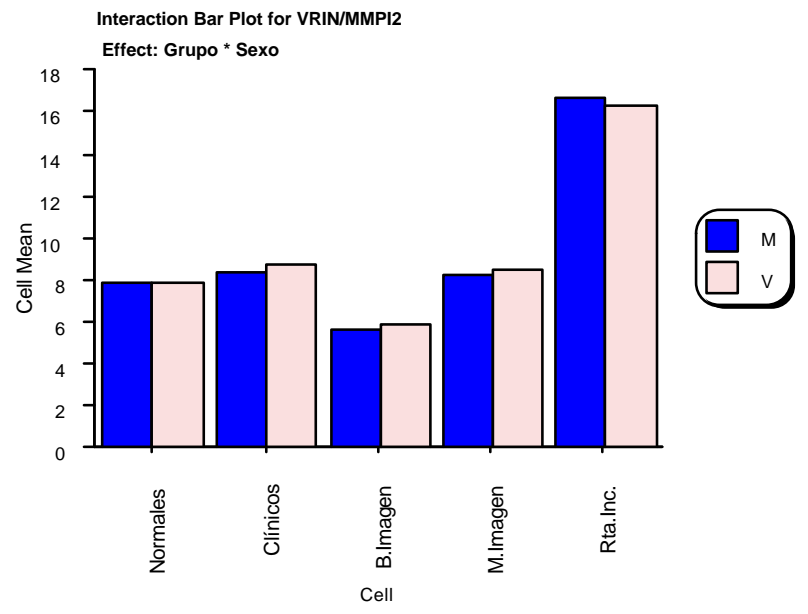

Tabla 52: Variable "VRILN". Diferencias intergrupos e intersexos *.

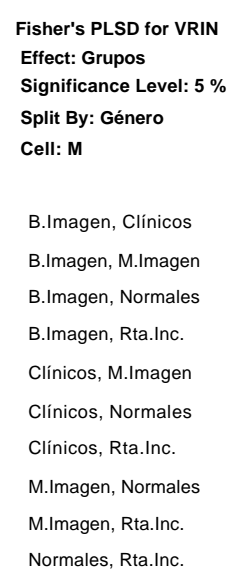

\begin{tabular}{|c|c|c|}
\hline Mean Diff. & Crit. Diff & P-Value \\
\hline$-2,795$ &, 596 & $<, 0001$ \\
\hline$-2,612$ & ,673 & $<, 0001$ \\
\hline$-2,281$ & .519 & $<, 0001$ \\
\hline$-11,028$ & ,783 & $<, 0001$ \\
\hline ,183 &, 586 & ,5404 \\
\hline, 514 & ,399 & ,0117 \\
\hline$-8,233$ & ,709 & $<, 0001$ \\
\hline .331 & .507 & 2009 \\
\hline$-8,416$ & ,775 & $<, 0001$ \\
\hline$-8,747$ & ,645 & $<, 0001$ \\
\hline
\end{tabular}

Fisher's PLSD for VRIN Effect: Grupos

Significance Level: $5 \%$

Split By: Género

Cell: $v$

B.Imagen, Clínicos

B.Imagen, M.Imagen

B.Imagen, Normales

B.Imagen, Rta.Inc.

Clínicos, M.Imagen

Clínicos, Normales

Clínicos, Rta.Inc.

M.Imagen, Normales

M.Imagen, Rta.Inc.

Normales, Rta.Inc.

\begin{tabular}{|c|c|c|}
\hline Mean Diff. & Crit. Diff & P-Value \\
\hline$-2,885$ & ,730 & $<, 0001$ \\
\hline$-2,677$ & ,897 & $<, 0001$ \\
\hline$-1,985$ & ,652 & $<, 0001$ \\
\hline$-10,381$ & ,890 & $<, 0001$ \\
\hline ,208 & ,784 & ,6022 \\
\hline 901 & ,483 & ,0003 \\
\hline$-7,496$ & ,775 & $<, 0001$ \\
\hline 692 & ,712 & ,0566 \\
\hline$-7,704$ & ,935 & $<, 0001$ \\
\hline$-8,396$ & ,702 & $<, 0001$ \\
\hline
\end{tabular}

* $\mathrm{M}=$ mujeres; $\mathrm{V}=$ Varones. $\mathrm{S}=$ significativo. 
Igualmente, en el Anexo B, en los perfiles de las personas que contestan "todo verdad" o "todo falso", se muestra que las puntuaciones de la variable VRIN no detectan esta forma de contestar. Sin embargo, cuando el sujeto contesta "Verdadero/Falso (alternativamente)" o "Falso/Verdadero (alternativamente), esta variable detecta perfectamente dicha irregularidad.

Haciendo un breve resumen de las aportaciones de esta variable, podemos decir que:

- De forma general, nos ayuda a detectar a los sujetos que contestan sin tener en cuenta el contenido de los ítems .

- Pero, de forma excepcional, no detecta adecuadamente a los sujetos que contestan al cuestionario de la forma "todo verdad" o "todo falso".

- Pero sí aquellos que alternativamente contestan "verdadero/falso" o "falso/verdadero".

- Los sujetos que intencionadamente expresan su mala imagen no se muestran estadísticamente diferentes (5\%) de los sujetos clínicos ni de los normales cuando el análisis se hace separadamente por sexos, y solamente se muestra diferente con los normales cuando se conjuntan los sexos (pero no llega al 1\%).

- Para su correcta interpretación de que esta variable VRIN pueda mostrar una mala imagen, sus puntuaciones deben ser contrastadas con las (elevadas) puntuaciones en: F, Fb, F-K, Ds-r, Ds y F(p)..

- Para su correcta interpretación de mostrar una buena imagen, las puntuaciones de esta variable deben ser contrastadas con las (elevadas) puntuaciones en: L, K, ODecp, S y Wsd

\section{V.2.5. - Variable "TRRIN":}

Esta escala de Inconsistencia de Respuestas Verdadero (TRIN), compuesta por 23 pares de ítems (véase Anexo 0-6) fue desarrollada en la nueva reestructuración del MMPI, con la intención de poder identificar a los sujetos que responden de forma incoherente o inconsistente cuando contestan "verdadero" a los diferentes ítems del cuestionario.

No debemos olvidar que su objetivo es identificar a los que responden sin tener en cuenta el contenido de los ítems, y que al igual que la variable VRIN trata de evaluar si su forma de responder guardan cierta coherencia o incoherencia en sus respuestas "verdadero" o "falso". Por ello no discrimina de los sujetos que responden con intención de falsificar los protocolos, bien intentando ofrecer una buena o mala imagen de sí mismos.

Para los investigadores Butcher et al. (1989) las puntuaciones elevadas nos pueden estar indicando una tendencia del sujeto (aquiescencia) a dar respuestas "verdadero" de forma indiscriminada, mientras que para puntuaciones bajas el sujeto puede presentar una tendencia (aquiescencia) a dar respuestas "falso", igualmente de forma indiscriminada. Nuestros resultados corroboran igualmente estos datos de Butcher, J.; Dahlstrom, W.; Graham, J.; Tellegen, A. \& Kaemer, B. (1989).

Solamente los protocolos que muestran una alta tendencia a contestar "verdadero" o "falso" presentan unas puntuaciones elevadas. Podemos indicar (véase Anexo-B: 
perfiles "todo verdadero" y "todo falso") que los perfiles se encuentran altamente distorsionados presentando la mayor puntuación en TRIN. El perfil "verdadero/falso (alternativamente)" presentan una alta inconsistencia (75T), mientras que cuando el sujeto contesta "falso/verdadero (alternativamente)", la puntuación de TRIN es perfectamente normal (53T).

Por tanto, esta variable puede detectar, solamente, la tendencia a contestar "verdadero" o "falso" y las consecuencias de las puntuaciones que puedan encontrarse en las demás Escalas Clínicas, Suplementarias o de Contenido.

Tabla 53: Variable "TRIN". Percentiles. Análisis por grupos.
\begin{tabular}{|c|c|c|c|c|c|}
\hline Percentiles & Normal & Clínico & Buena Imagen & Mala Imagen & Rta. Inc. \\
\hline $\mathbf{1 0}$ & 8 & 8 & 8 & 7 & 6 \\
\hline $\mathbf{2 5}$ & 9 & 9 & 9 & 8 & 8 \\
\hline $\mathbf{5 0}$ & 10 & 10 & 10 & 9 & 10 \\
\hline $\mathbf{7 5}$ & 11 & 11 & 11 & 10 & 12 \\
\hline $\mathbf{9 0}$ & 12 & 13 & 12 & 12 & 14 \\
\hline
\end{tabular}

A través del análisis comparativo percentual (Tabla 53) de los grupos analizados en este trabajo con respecto a esta variable TRIN, podemos señalar que no discrimina en absoluto a ninguno de los grupos. El 90\% de los sujetos suelen dar más de 6 respuestas y el $10 \%$ de los mismos presentan más de 12 respuestas a esta variable. No discrimina, por tanto a un sujeto normal de otro que presenta un problema clínico, ni tampoco sabremos ciertamente si falsifica la prueba intentando ofrecer una buena o mala imagen.

Tabla 54: Variable "TRIN". Correlaciones *

\begin{tabular}{|c|c|c|c|c|c|}
\hline Variables & Normal & Clínico & Buena Imagen & Mala Imagen & Rta. Inc. \\
\hline $\mathbf{L}$ & -.016 & -.052 & -.066 & -.092 & -.408 \\
\hline $\mathbf{F}$ & .136 & .263 & .014 & -.100 & .316 \\
\hline $\mathbf{K}$ & -.251 & -.348 & -.171 & -.179 & $\begin{array}{l}-.399 \\
-. .39\end{array}$ \\
\hline $\mathbf{F b}$ & .220 & .310 & .073 & -.040 & .398 \\
\hline VRIN & -.008 & .058 & .000 & .082 & -.205 \\
\hline TRIN & 1.00 & 1.00 & 1.00 & 1.00 & 1.00 \\
\hline $\mathbf{F p}$ & .158 & .250 & .058 & -.059 & .211 \\
\hline $\mathbf{S}$ & -.203 & -.275 & -.121 & -.102 &.- .449 \\
\hline Ds & .227 & .307 & .113 & .008 & .380 \\
\hline Ds-r & .193 & .252 & .046 & .001 & .273 \\
\hline FBS & .016 & .116 & -.081 & -.049 & -.137 \\
\hline ODecp & .160 & .174 & .066 & .164 & .137 \\
\hline IR & .166 & .294 & .064 & -.035 & .274 \\
\hline Wsd & .283 & .333 & .239 & .288 & .312 \\
\hline F-K & .222 & .338 & .095 & -.035 & .433 \\
\hline$i$ & -.076 & -.114 & -.085 & .063 & .049 \\
\hline (F $\mathrm{Fl}$ & -.045 & .025 & .038 & -.171 & -.046 \\
\hline
\end{tabular}

Al contemplar la Tabla 54, podemos apreciar el hecho de no encontrar tan elevadas correlaciones como se nos ha mostrado en otras tablas con otras variables. Podemos ver también cómo los grupos que de una forma coherente intentan ofrecer tanto una mala o buena imagen, esta variable TRIN, no parece tener nada que ver excepto con la variable de Deseabilidad social (Wsd) que correlaciona de forma estadísticamente positiva, auqnue con valores ciertamente bajos.

Constatamos que con las variables VRIN, FBS, /F-Fb/ e ?, sus correlaciones no se encuentran significación estadística alguna e igualmente, con las poblaciones que intencionadamente han intentado expresar de sí misma su buena o mala imagen, observamos la ausencia casi total de correlaciones significativas (Tabla 54). 
Los datos aportados por Greene (2000, Tabla 3.14, pg. 57) con población normal, referentes a las correlaciones de esta escala con sus respectivas infrecuentes $(\mathrm{F} \mathrm{y} \mathrm{Fb})$, muestran unos valores escasos, aunque positivos. Así TRIN tiene una correlación con F de ,193 (nuestros resultados: ,136) y con Fb muestra un valor de ,214 (nuestros resultados: ,220). Incluso nuestra correlación con el índice /F-Fb/ se muestra fuertemente escasa y negativa $(-, 045)$.

Tabla 55: Variable "TRRIN". Puntuaciones Medias y $\mathcal{S}$ t. D. Anális is comparativo entre

grupos

\begin{tabular}{|c|c|c|c|c|c|c|c|c|c|}
\hline \multicolumn{2}{|c|}{ Normal } & \multicolumn{2}{c|}{ Clínico } & \multicolumn{2}{c|}{ Buena Imagen } & \multicolumn{2}{c|}{ Mala Imagen } & \multicolumn{2}{c|}{ Rta. Inc. } \\
\hline Media & St.D & Media & St.D & Media & St.D & Media & St.D & Media & St.D \\
\hline 9,654 & 1,732 & 10,100 & 2,137 & 10,174 & 1,535 & 9,059 & 1,911 & 10,005 & 2,970 \\
\hline
\end{tabular}

Como podemos apreciar en esta Tabla 55, las puntuaciones medias son muy semejantes en todos los grupos analizados, no destacando ninguna de ellas de forma notable. Posteriormente al llevar a cabo el análisis de la varianza (ANOVA) observamos que sus resultados no discriminan adecuadamente los que responden de forma inconsistente (Rta. Inc.) de los clínicos ni de los que intentan exponer su buena imagen (Tabla 56). Esta variable TRIN tampoco diferencia adecuadamente a los sujetos dínicos de los de buena imagen. Y esto ocurre tanto si analizamos los sexos por separado como si los tomamos conjuntamente (Tabla 57).

Tabla 56: Variable "TRIN". ANOVA. Diferencias significativas entre grupos.

\begin{tabular}{|c|c|c|c|c|}
\hline \multicolumn{1}{|c|}{ Grupos } & Dif.Med. & Dif. Crit. & p & Signf. (5\%) \\
\hline Normal vs. Clínico &,- 446 &, 183 & $<, 0001$ & SI \\
\hline Normal vs. B. Imagen &,- 520 &, 241 & $<, 0001$ & SI \\
\hline Normal vs. M. Imagen &, 595 &, 246 & $<, 0001$ & SI \\
\hline Normal vs. Rtas. Inc. &,- 351 &, 281 &, 0142 & SI \\
\hline Clínico vs. B. Imagen &,- 074 &, 274 &, 5970 & NO \\
\hline Clínico vs. M. Imagen & 1,040 &, 279 & $<, 0001$ & SI \\
\hline Clínico vs. Rtas. Inc. &, 095 &, 309 &, 5478 & NO \\
\hline B. Imagen vs. M. Imagen & 1,114 &, 320 & $<, 0001$ & SI \\
\hline B. Imagen vs. Rtas. Inc. &, 169 &, 347 &, 3406 & NO \\
\hline M. Imagen vs. Rtas. Inc. &,- 946 &, 351 & $<, 0001$ & SI \\
\hline
\end{tabular}

Gráfica 28: Variable "TRRIN". $\mathcal{A N} O \mathcal{V A}$

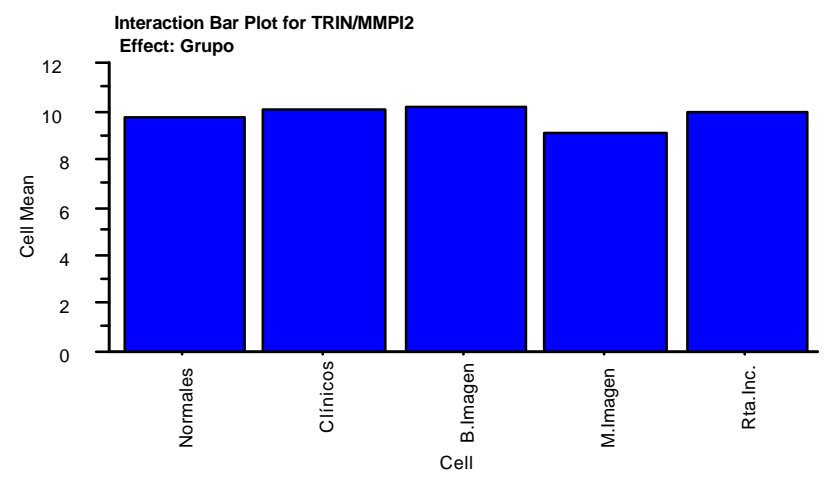


Gráfica 29: Variable "TRIN". Anális is intersexos/intergrupos.

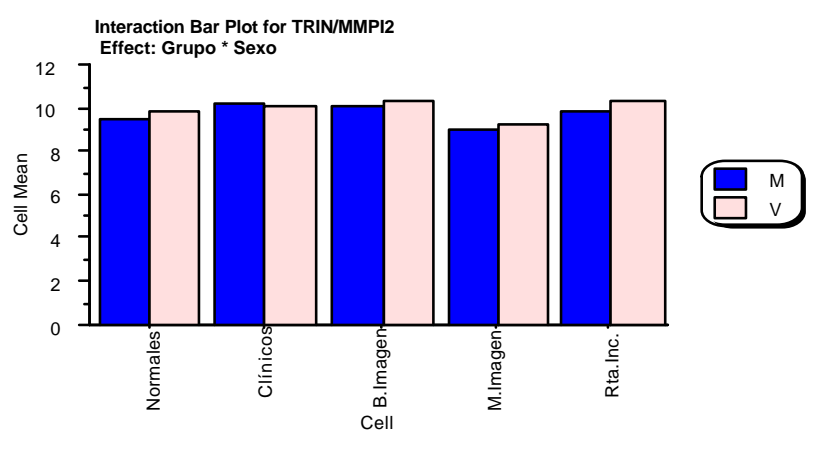

Tabla 57: Variable "TRIIN". Diferencias intergrupos e intersexos

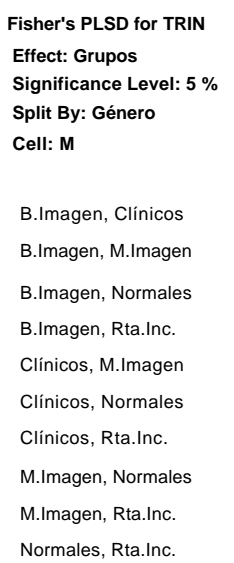

\begin{tabular}{|c|c|c|}
\hline Mean Diff. & Crit. Diff & P-Value \\
\hline - & 349 & 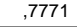 \\
\hline 1,121 & 394 & $<, 0001$ \\
\hline ,557 & ,304 & ,0003 \\
\hline ,342 & , 458 & , 1430 \\
\hline 1,171 & ,343 & $<, 0001$ \\
\hline ,608 & ,234 & $<, 0001$ \\
\hline ,392 & ,415 & , 0636 \\
\hline -, 564 & 297 & ,0002 \\
\hline - & ,453 & , 0008 \\
\hline -215 & 377 & ,2632 \\
\hline
\end{tabular}

Fisher's PLSD for TRIN
Effect: Grupos
Significance Level: $5 \%$
Split By: Género
Cell: V
B.Imagen, Clínicos
B.Imagen, M.Imagen
B.Imagen, Normales
B.Imagen, Rta.Inc.
Clínicos, M.Imagen
Clínicos, Normales
Clínicos, Rta.Inc.
M.Imagen, Normales
M.Imagen, Rta.Inc.
Normales, Rta.Inc.

\begin{tabular}{|c|c|c|} 
Mean Diff. & \multicolumn{1}{c}{ Crit. Diff } & \multicolumn{1}{c}{ P-Value } \\
\hline, 238 &, 439 &, 2879 \\
\hline 1,069 &, 540 &, 0001 \\
\hline, 451 &, 392 &, 0244 \\
\hline, 026 &, 536 &, 9250 \\
\hline, 831 &, 472 &, 0006 \\
\hline, 213 &, 291 &, 1521 \\
\hline,- 212 &, 467 &, 3723 \\
\hline,- 619 &, 429 &, 0047 \\
\hline$-1,044$ &, 563 &, 0003 \\
\hline,- 425 &, 423 &, 0489 \\
S S \\
\hline
\end{tabular}

$\mathrm{M}=$ mujeres; $\mathrm{V}=$ Varones. $\mathrm{S}=$ significativo.

De forma más evidente, podemos apreciar por la Gráfica 28, que las puntuaciones medias de los diferentes grupos en esta variable, se muestran muy parejas. La Tabla 57 nos muestran las diferencias entre sexos entre los diferentes grupos, pudiendo apreciar quesólo los varones no se muestran diferentes entre los grupos normales y clínicos.

Podemos resumir que esta variable TRIN:

- - No atiende al contenido, ni a la información del ítem, detectando solamente la tendencia a responder como "verdadero" o "falso". Esto nos permite poder detectar, por una parte, la aquiescencia de las respuestas y, por otra, identificar adecuadamente aquellos protocolos contestados como "todo verdadero" o como "todo falso".

- - No parece discriminar adecuadamente los sujetos que intentan falsificar, fingir o mostrar algún tipo de defensividad en los protocolos.

Es una variable que podemos considerar "extraña" y que aporta escasos resultados a nuestra investigación.

\section{V.2.6. - Variable "Ffb":}

Esta escala $\mathrm{Fb}$ ("F back scale") se encuentra dentro del grupo de las "adicionales" que se originaron con la reestructuración del MMPI (Butcher, et al., 1989) con el 
objetivo de poder detectar la posible desviación de las respuestas motivadas por la extensión de la prueba. La versión definitiva, para el MMPI-2, redujo la escala a 40 ítems de los 64 originales, ocupándose esencialmente de la segunda parte de la prueba y afectando, fundamentalmente, a las variables contenidas en las escalas Suplementarias y de Contenido del MMPI-2.

Tabla 58: Variable "Fb". Percentiles. Análisis por grupos.

\begin{tabular}{|c|c|c|c|c|c|}
\hline Percentiles & Normal & Clínico & Buena Imagen & Mala Imagen & Rta. Inc. \\
\hline $\mathbf{1 0}$ & 0 & 2 & 0 & 18 & 14 \\
\hline $\mathbf{2 5}$ & 1 & 4 & 0 & 27 & 17 \\
\hline $\mathbf{5 0}$ & 3 & 9 & 1 & 35 & 20 \\
\hline $\mathbf{7 5}$ & 5 & 15 & 2 & 38 & 22 \\
\hline $\mathbf{9 0}$ & 9 & 21 & 5 & 40 & 24 \\
\hline
\end{tabular}

Tabla 59: "Ff". Correlaciones".

\begin{tabular}{|c|c|c|c|c|c|}
\hline Variables & Normal & Clínico & Buena Imagen & Mala Imagen & Rta. Inc. \\
\hline $\mathbf{L}$ & $\begin{array}{l}.059 \\
\end{array}$ & -.180 & -.392 & $\begin{array}{l}-.190 \\
\end{array}$ & -.478 \\
\hline $\mathbf{F}$ & .737 & .792 & .854 & .913 & .316 \\
\hline $\mathbf{K}$ & -.461 &.- .537 & -.473 & -.248 & -.510 \\
\hline $\mathbf{F b}$ & 1.00 & 1.00 & 1.00 & 1.00 & 1.00 \\
\hline VRIN & .359 & .080 & .635 & -.273 & .012 \\
\hline TRIN & .220 & .310 & .073 & -.040 & .398 \\
\hline $\mathbf{F p}$ & .711 & .651 & .764 & .889 & .417 \\
\hline $\mathbf{S}$ & -.461 &.- .574 & -.507 & -.414 & -.447 \\
\hline Ds & .757 & .817 & .834 & .877 & .413 \\
\hline Ds-r & .676 & .777 & .771 & .827 & .361 \\
\hline FBS & .450 & .573 & .403 & .763 & -.038 \\
\hline ODecp & -.109 & -.219 & -.411 & -.467 & -.047 \\
\hline IR & .671 & .719 & .694 & .885 & .462 \\
\hline Wsd & .071 & .005 & -.287 &.- .418 & .134 \\
\hline F-K & .715 & .796 & .785 & .891 & .494 \\
\hline$i$ & -.034 & -.066 & -.004 & .003 & .011 \\
\hline /F-Fb/ & .076 & .025 & .349 & .351 & -.538 \\
\hline
\end{tabular}

* Los valores en negrita, resultaron ser estadísticamente significativos al $\mathrm{p}<.001$

Como ya hemos abordado anteriormente, la interpretación de sus puntuaciones, bajas o elevadas, se encuentran paralelamente semejantes a las puntuaciones de la variable "F", anteriormente comentadas.

Nuestros resultados ofrecen, igualmente y como podemos ver en las Tablas siguientes (58 a 61), un paralelismo semejante con la variable " $F$ ". Las puntuaciones obtenidas presentan la mayor incidencia en el grupo al que se le ha indicado que intente elaborar una mala imagen de sí mismo al contestar a la prueba. Igualmente los sujetos clínicos son los que les siguen en puntuaciones elevadas.

A través de los resultados expresados en la Tabla 58, referente a las puntuaciones percentiladas, podemos verificar que las puntuaciones más elevadas las presenta el grupo de mala imagen.en el que un $10 \%$ de éstos presentan la puntuación máxima (Percentil $90=40$ ) en esta escala, mientras que el mismo $10 \%$ de los sujetos normales obtienen una puntuación mínima de 9 (percentil $90=9$ ).

Al igual que con la variable $\mathrm{F}$, nos encontramos los resultados (Tabla 59) de las correlaciones elevadas y positivas con las variables F, F(p), Ds, Ds-r, FBS, IR, F-K, pero sobre todo en el grupo de mala imagen, mientras que las correlaciones elevadas y negativas de esta escala $\mathrm{Fb}$ las encontramos con: L, K y S. 
Tabla 60: Variable "Ffb": Puntuaciones Medias y $\mathcal{S}$ t.D. Anális is comparativo entre grupos.

\begin{tabular}{|c|c|c|c|c|c|c|c|c|c|}
\hline \multicolumn{2}{|c|}{ Normal } & \multicolumn{2}{c|}{ Clínico } & \multicolumn{2}{c|}{ Buena Imagen } & \multicolumn{2}{c|}{ Mala Imagen } & \multicolumn{2}{c|}{ Rta. Inc. } \\
\hline Media & St.D & Media & St.D & Media & St.D & Media & St.D & Media & St.D \\
\hline 3,968 & 4,360 & 10,176 & 7,240 & 2,223 & 4,525 & 31,599 & 9,090 & 19,560 & 4,314 \\
\hline
\end{tabular}

Contemplando los resultados obtenidos en la Tabla 60 y la Gráfica 30, podemos apreciar, nuevamente, el notable paralelismo con la variable F. Las puntuaciones medias más elevadas son expresadas, en primer lugar, por el grupo de mala imagen, seguido por los que contestan de forma inconsistente (Rta. Inc.), las personas con problemas clínicos, los sujetos normales que contestan honestamente a la prueba y en último lugar las personas que intentan aparentar una buena imagen de sí mismos.

Esto nos muestra que es una variable importante a la hora de distinguir los sujetos que, intentando contestar a los ítems de forma coherente, intentan mostrar su buena o mala imagen de sí mismos.

Igualmente observamos (Tablas 61 y 62) que, al realizar el análisis de la varianza (ANOVA) bien por sexos o conjuntamente, todas su puntuaciones medias han resultado ser altamente significativas cuando se contrastan sus diferencias entre sí y entre grupos diferentes.

Tabla 61: Variable "F́F". ANNOVA. Diferencia significativas entre grupos.

\begin{tabular}{|c|c|c|c|c|}
\hline Grupos & Dif.Med. & Dif. Crit. & p & Signf. (5\%) \\
\hline Normal vs. Clínico & $-6,208$ &, 531 & $<, 0001$ & SI \\
\hline Normal vs. B. Imagen & 1,745 &, 702 & $<, 0001$ & SI \\
\hline Normal vs. M. Imagen & $-27,630$ &, 716 & $<, 0001$ & SI \\
\hline Normal vs. Rtas. Inc. & $-15,592$ &, 816 & $<, 0001$ & SI \\
\hline Clínico vs. B. Imagen & 7,953 &, 797 & $<, 0001$ & SI \\
\hline Clínico vs. M. Imagen & $-21,422$ & 8,10 & $<, 0001$ & SI \\
\hline Clínico vs. Rtas. Inc. & $-9,384$ &, 899 & $<, 0001$ & SI \\
\hline B. Imagen vs. M. Imagen & $-29,375$ &, 931 & $<, 0001$ & SI \\
\hline B. Imagen vs. Rtas. Inc. & $-17,337$ & 1,010 & $<, 0001$ & SI \\
\hline M. Imagen vs. Rtas. Inc. & 12,039 & 1,020 & $<, 0001$ & SI \\
\hline
\end{tabular}

$$
\text { Gráfica 30: Variable "F́F". } \mathcal{A} \mathcal{N} O \mathcal{V} \mathcal{A}
$$

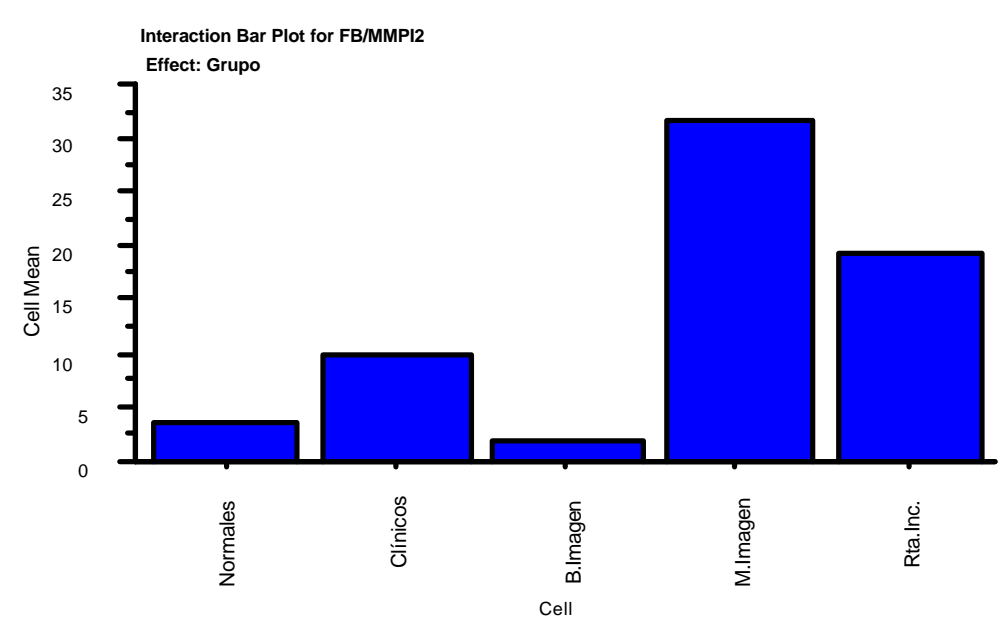


Gráfica 31: Variable "FF". Análisis intersexos/intergrupos.

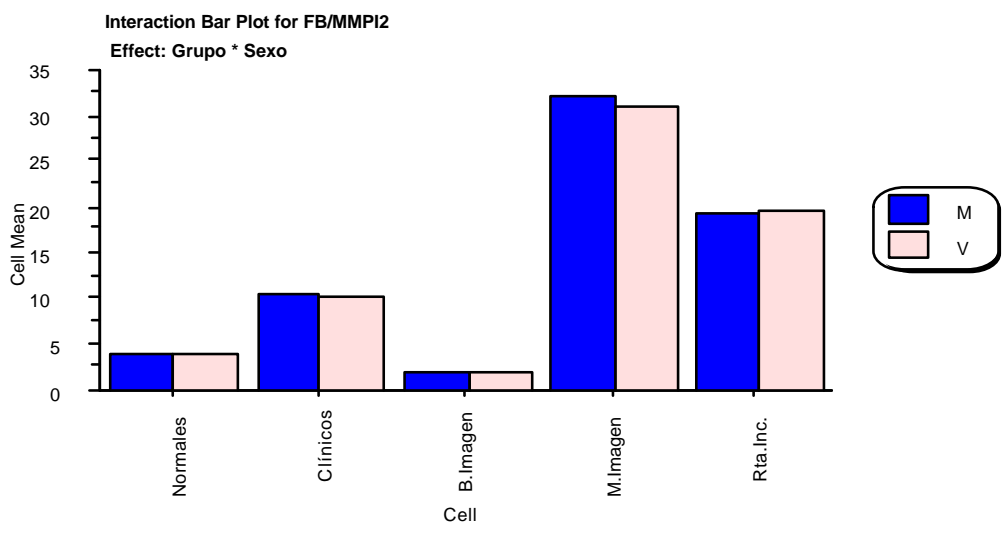

Tabla 62: Variable "Ff". Diferencias intergrupos e intersexos

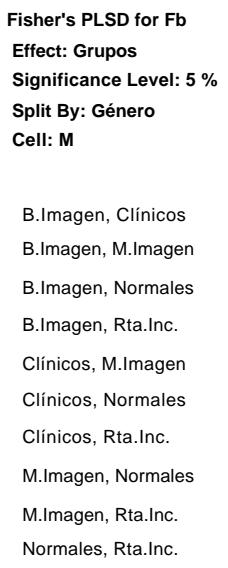

\begin{tabular}{|c|c|c|}
\hline Mean Diff. & Crit. Diff & P-Value \\
\hline$-8,097$ & ,999 & $<, 0001$ \\
\hline$-29,543$ & 1,129 & $<, 0001$ \\
\hline$-1,688$ & ,870 &, 0001 \\
\hline$-17,266$ & 1,311 & $<, 0001$ \\
\hline$-21,446$ & ,982 & $<, 0001$ \\
\hline 6,409 & ,669 & $<, 0001$ \\
\hline$-9,168$ & 1,188 & $<, 0001$ \\
\hline 27,855 & ,850 & $<, 0001$ \\
\hline 12,277 & 1,298 & $<, 0001$ \\
\hline$-15,577$ & 1,081 & $<, 0001$ \\
\hline
\end{tabular}

Fisher's PLSD for Fb
Effect: Grupos
Significance Level: $5 \%$
Split By: Género
Cell: $\mathbf{~}$
B.Imagen, Clínicos
B.Imagen, M.Imagen
B.Imagen, Normales
B.Imagen, Rta.Inc.
Clínicos, M.Imagen
Clínicos, Normales
Clínicos, Rta.Inc.
M.Imagen, Normales
M.Imagen, Rta.Inc.
Normales, Rta.Inc.

\begin{tabular}{|c|c|c|}
\hline Mean Diff. & Crit. Diff & P-Value \\
\hline$-7,787$ & 1,306 & $<, 0001$ \\
\hline$-29,049$ & 1,606 & $<, 0001$ \\
\hline$-1,820$ & 1,166 & ,0022 \\
\hline$-17,434$ & 1,593 & $<, 0001$ \\
\hline$-21,263$ & 1,403 & $<, 0001$ \\
\hline 5,967 & ,865 & $<, 0001$ \\
\hline$-9,647$ & 1,388 & $<, 0001$ \\
\hline 27,229 & 1,274 & $<, 0001$ \\
\hline 11,615 & 1,673 & $<, 0001$ \\
\hline$-15,614$ & 1,257 & $<, 0001$ \\
\hline
\end{tabular}

$\mathrm{M}=$ mujeres; $\mathrm{V}=$ Varones. $\mathrm{S}=$ significativo

En resumen, no podemos decir nada diferente que no hayamos dicho ya con la variable $\mathrm{F}$. Unicamente referir que las conclusiones sobre esta variable $\mathrm{Fb}$ se encuentran referidas a la segunda parte de la prueba haciendo referencia especialmente a los grupos de escalas Suplementarias y de Contenido.

\section{V.2.7. - Variable "F. K" (Índice de Simulación de Gough, 1947, 1950):}

Gough $(1947,1950)$ se dio cuenta que restando las puntuaciones obtenidas en la escala $\mathrm{K}$ de las obtenidas por la F, era posible obtener un "Índice de simulación" F-K. A través de sus resultados Gough pudo apreciar que este índice era útil para desechar y poder detectar protocolos que no son válidos, siendo a veces utilizado como una medida de respuesta disimulada o de exageración de síntomas psicopatológicos.

Gough propuso utilizar la diferencia entre las puntuaciones directas $\mathrm{F}$ y $\mathrm{K}$ de forma que, si el resultado es positivo y mayor de 9 (> 9) indicaría fingimiento en el sentido de ofrecer "mala imagen", mientras que si es negativo y menor de $9(<-9)$ indicaría una tendencia a ofrecer una "buena imagen" de sí mismo como estrategia de defensividad 
del sujeto. Si la puntuación se encontraba entre estos valores (0-9), el perfil del sujeto podría considerarse como válido.

Investigaciones posteriores han corroborado estos mismos resultados aunque discrepan en el establecimiento del "punto de corte" para detectar un perfil válido de otro falseado.

Tabla 63: Variable "F-K.'. Percentiles. Análisis por grupos

\begin{tabular}{|c|c|c|c|c|c|}
\hline Percentiles & Normal & Clínico & Buena Imagen & Mala Imagen & Rta. Inc. \\
\hline $\mathbf{1 0}$ & -17 & -13 & -23 & 16,4 & 6,5 \\
\hline $\mathbf{2 5}$ & $-13,5$ & -7 & -20 & 30 & 10,5 \\
\hline $\mathbf{5 0}$ & -8 & 1 & -17 & 41 & 14,5 \\
\hline $\mathbf{7 5}$ & -3 & 8 & -13 & 47 & 18 \\
\hline $\mathbf{9 0}$ & 4 & 15 & $-6,7$ & 50 & 23 \\
\hline
\end{tabular}

Nuestros resultados de la Tabla 63, en donde se presentan las puntuaciones obtenidas en los diversos grupos aquí investigados a través de diferentes percentiles, nos muestran, en una apreciación global, al grupo que intenta expresar su buena imagen con las puntuaciones más elevadas y negativas (e incluso en sus puntuacines medias: 15,365). Otro grupo que presenta puntuaciones negativas en sus percentiles es el normal (e incluso su punt. media: -7,4), mientras que es el grupo clínico el que, a partir del percentil 50 presenta sus puntuaciones positivas (P50: 1), mostrando su valor medio con 1,064 .

Continuando con esta visión globalizadora de las puntuaciones percentiladas, observamos que son los grupos de mala imagen y los que contestan de forma incoherente (Rta. Inc.) los que muestran sus valores positivos (e incluso sus puntuaciones medias, 36,699 y 14,515 respectivamente).

Los resultados obtenidos muestran de forma manifiestamente sensible cómo este Índice de simulación de Gough nos puede diferenciar los sujetos que intentan ofrecer una buena o mala imagen de sí mismos a través de sus valores positivos o negativos. Otro tanto está ocurriendo con el grupo que contesta de forma inconsistente (Rta. Inc.) cuando muestra sus valores positivos.

Tabla 64: Variable "F-K. $\mathcal{K}^{\text {". Correlaciones }}$ *.

\begin{tabular}{|c|c|c|c|c|c|}
\hline Variables & Normal & Clínico & Buena Imagen & Mala Imagen & Rta. Inc. \\
\hline $\mathbf{L}$ & -.312 &.- .312 & -.604 & -.347 & -.450 \\
\hline $\mathbf{F}$ & .874 & .927 & .902 & .954 & .856 \\
\hline $\mathbf{K}$ & -.826 & -.786 & -.837 &.- .484 & -.761 \\
\hline $\mathbf{F b}$ & .715 & .796 & .785 & .891 & .494 \\
\hline VRIN & .348 & .075 & .678 & -.403 & -.002 \\
\hline TRIN & .222 & .338 & .095 & -.035 & .433 \\
\hline $\mathbf{F p}$ & .564 & .668 & .568 & .850 & .398 \\
\hline $\mathbf{S}$ & -.742 & -.753 & -.784 & -.591 & $\begin{array}{l}-.528 \\
\end{array}$ \\
\hline Ds & .838 & .868 & .883 & .917 & .532 \\
\hline Ds-r & .789 & .813 & .860 & .876 & .414 \\
\hline FBS & .313 & .450 & .172 & .756 & -.072 \\
\hline ODecp &.- .307 & -.262 & -.568 &.- .538 & .027 \\
\hline IR & .503 & .691 & .424 & .799 & .458 \\
\hline Wsd & -.072 & .013 & -.407 & -.478 & .191 \\
\hline F-K & 1.00 & .100 & .100 & .100 & 1.00 \\
\hline$i$ & -.026 & -.065 & .018 & -.040 & .026 \\
\hline$/ \mathbf{F - F b} /$ & .479 & .350 & .679 & .638 & .351 \\
\hline
\end{tabular}


Los sujetos normales presentan un percentil medio (P50) de -8 para el grupo normal que ha contestado honestamente a la prueba y de +1 (P50) para el grupo clínico que igualmente ha contestado de forma honesta al MMPI-2. Estos resultados contrastan con los de Greene (1997) que, con una muestra de 2.600 sujetos normales (esta muestra, en realidad, es del grupo de investigadores de Butcher et als., 1989) y de 3.475 sujetos con graves trastornos mentales obtuvo un percentil 50, para los normales de -12 , y para los pacientes psiquiátricos de -4 , los resultados parecen ser "algo" más semejantes.

La Tabla 64, que muestra las correlaciones entre las distintas variables y los distintos grupos de la variable F-K, resulta interesante. Por una parte podemos apreciar las elevadas correlaciones (de ambos signos) que presenta el grupo de "mala imagen" con el resto de las variables. Por otra observamos que, en general, existen unas correlaciones sumamente elevadas y positivas especialmente con las variables F, Ds y Ds-r, F(p), Fb, IR y /F-Fb/. Las variables que correlacionan negativamente son la $\mathrm{L}, \mathrm{K}, \mathrm{S}$, y ODecp, siendo justamente el grupo de "buena imagen" el que, entre éstas últimas, presentan las negativas más elevadas.

Tabla 65: Variable "F- $\mathcal{K}$ ": Puntuaciones Medias y $\mathcal{S}$ t. D. Análisis comparativo entre grupos.

\begin{tabular}{|c|c|c|c|c|c|c|c|c|c|}
\hline \multicolumn{2}{|c|}{ Normal } & \multicolumn{2}{c|}{ Clínico } & \multicolumn{2}{c|}{ Buena Imagen } & \multicolumn{2}{c|}{ Mala Imagen } & \multicolumn{2}{c|}{ Rta. Inc. } \\
\hline Media & St.D & Media & St.D & Media & St.D & Media & St.D & Media & St.D \\
\hline$-7,400$ & 8,337 & 1,064 & 10,580 & $-15,365$ & 8,209 & 36,699 & 13,443 & 14,515 & 6,603 \\
\hline
\end{tabular}

Esta Tabla 65 Nos muestra las puntuaciones medias de los diferentes grupos de sujetos. Nos interesa resaltar especialmente su elevados valores medios positivos (mala imagen: +36,699 y Rta. Inc.: +14,515) y los negativos (buena imagen: -15,365; y normal: $-7,4)$.

Los sujetos clínicos, pacientes que solicitan ayuda psicológica en un Centro de Salud $\mathrm{y}$ que han contestado honesta y sinceramente, son los que presentan una puntuación media más baja y positiva $(+1,064)$, aspecto que contrasta de forma estadísticamente significativa con los sujetos de "mala imagen" $(36,699)$.

Podemos apreciar, por los resultados mostrados en las Tabla 66 y 67, que todos los grupos son estadísticamente significativos en sus diferencias de medias, tanto si se analizan separadamente por sexos como si su análisis se lleva a cabo conjuntamente. Esto nos confirma que esta variable $\mathrm{F}-\mathrm{K}$ se muestra indiferente cuando contesta al cuestionario un varón o una mujer.

Tabla 66: Variable "F. $\mathcal{K}$ ". ANNOVA. Diferencia significativas entre grupos.

\begin{tabular}{|c|c|c|c|c|}
\hline \multicolumn{1}{|c|}{ Grupos } & Dif.Med. & Dif. Crit. & p & Signf. (5\%) \\
\hline Normal vs. Clínico & $-8,465$ &, 880 & $<, 0001$ & SI \\
\hline Normal vs. B. Imagen & 7,965 & 1,163 & $<, 0001$ & SI \\
\hline Normal vs. M. Imagen & $-44,099$ & 1,187 & $<, 0001$ & SI \\
\hline Normal vs. Rtas. Inc. & $-21,915$ & 1,353 & $<, 0001$ & SI \\
\hline Clínico vs. B. Imagen & 16,429 & 1,322 & $<, 0001$ & SI \\
\hline Clínico vs. M. Imagen & $-35,635$ & 1,343 & $<, 0001$ & SI \\
\hline Clínico vs. Rtas. Inc. & $-13,451$ & 1,491 & $<, 0001$ & SI \\
\hline B. Imagen vs. M. Imagen & $-52,064$ & 1,543 & $<, 0001$ & SI \\
\hline B. Imagen vs. Rtas. Inc. & $-29,880$ & 1,674 & $<, 0001$ & SI \\
\hline M. Imagen vs. Rtas. Inc. & 22,184 & 1,691 & $<, 0001$ & SI \\
\hline
\end{tabular}




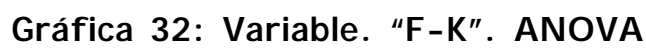

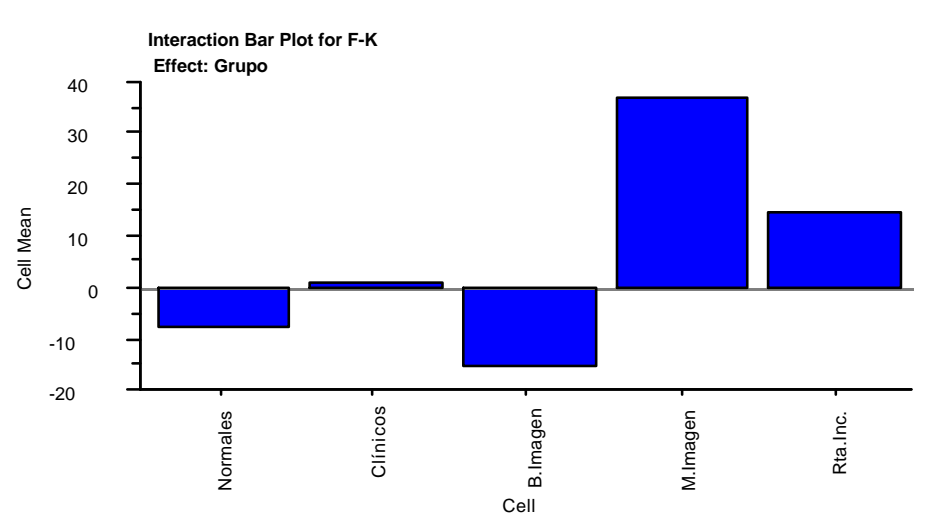

Gráfica 33: Variable "F-K $\mathcal{K}$ ". Anális is intersexos/intergrupos.

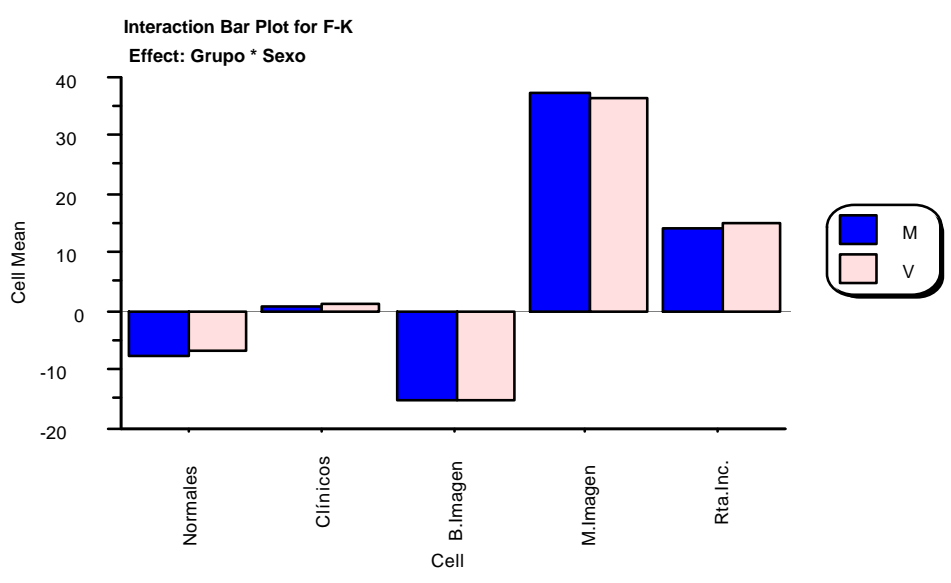

Tabla 67: Variable "F-K. $\mathcal{K}$. Diferencias intergrupos e intersexos.

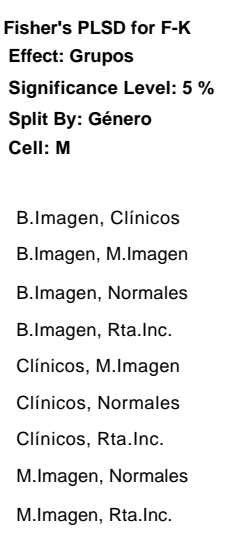

M.Imagen, Rta.Inc. Normales, Rta.Inc.

\begin{tabular}{|c|c|c|}
\hline Mean Diff. & \multicolumn{1}{|c|}{ Crit. Diff } & \multicolumn{1}{|c|}{ P-Value } \\
\hline$-16,271$ & 1,686 & $<, 0001$ \\
\hline$-52,351$ & 1,904 & $<$ \\
\hline$-7,0001$ & S \\
\hline$-7,624$ & 1,467 & $<, 0001$ \\
\hline$-29,714$ & 2,212 & $<$ \\
\hline$-36,080$ & 1,657 & $<, 0001$ \\
\hline 8,0001 & S \\
\hline 8 & 1,129 & $<, 0001$ \\
\hline$-13,444$ & 2,004 & $<$ \\
\hline 44,727 & 1,434 & $<, 0001$ \\
\hline 22,637 & 2,190 & $<$ \\
\hline$-22,090$ & 1,824 & $<, 0001$ \\
\hline
\end{tabular}

$\mathrm{M}=$ mujeres; $\mathrm{V}=$ Varones. $\mathrm{S}=$ significativo
Fisher's PLSD for F-K

Effect: Grupos

Significance Level: $5 \%$

Split By: Género

Cell: $v$

B.Imagen, Clínicos B.Imagen, M.Imagen B.Imagen, Normales B.Imagen, Rta.Inc. Clínicos, M.Imagen Clínicos, Normales Clínicos, Rta.Inc. M.Imagen, Normales M.Imagen, Rta.Inc. Normales, Rta.Inc.

\begin{tabular}{|c|c|c|}
\hline Mean Diff. & Crit. Diff & P-Value \\
\hline$-16,623$ & 2,121 & $<, 0001$ \\
\hline$-51,559$ & 2,609 & $<, 0001$ \\
\hline$-8,483$ & 1,894 & $<, 0001$ \\
\hline$-30,043$ & 2,587 & $<, 0001$ \\
\hline$-34,936$ & 2,279 & $<, 0001$ \\
\hline 8,140 & 1,405 & $<, 0001$ \\
\hline$-13,420$ & 2,254 & $<, 0001$ \\
\hline 43,076 & 2,069 & $<, 0001$ \\
\hline 21,516 & 2,718 & $<, 0001$ \\
\hline$-21,560$ & 2,041 & $<, 0001$ \\
\hline
\end{tabular}


Haciendo un breve resumen de lo que hemos hallado en nuestros resultados, podemos decir que:

- Esta variable, a través de sus valores positivos y elevados, detecta a sujetos que están intentando mostrar su aspecto más desfavorable de sí mismos.

- Contrariamente, mostrando puntuaciones elevadas y negativas, esta variable va a detectar a los sujetos que intentan mostrar una imagen favorable de sí mismos.

- Podremos detectar a los sujetos clínicos a través de sus valores sumamente bajos (próximos a 0 ).

- Los sujetos considerados como normales van a presentar siempre una valor negativo (próximo a -7,4).

- Para una mejor interpretación de esta variable, en casos necesarios, puede ayudarse de las variables $\mathrm{F}, \mathrm{F}(\mathrm{p}), \mathrm{Fb}$, IR y /F-Fb/ con las que correlaciona de forma altamente positiva. En contraste, con las variables que correlacionan negativamente son la L, K, S, y ODecp.

- Hemos podido mostrar que el Índice de simulación de Gough F-K presenta unas elevadísimas correlaciones positivas (además de las anteriormente mencionadas) con otras escalas del mismo autor y que pueden ir en la misma dirección diagnóstica, como son las variables Ds (Escala de disimulación) y la Ds-r (Escala revisada de Disimulación).

- De todos los grupos analizados solamente el de mala imagen con la variable VRIN presenta una correlación negativa elevada y significativa estadísticamente.

\section{V.2.8. - Variable "F $(p)$ " (Escala Psiquiátrica de Arbisi \& Ben-Porath, $1995,1998)$.}

Arbisi y Ben-Porath $(1995,1998)$ elaboraron esta escala, compuesta por 27 ítems (ver Anexo 0-14), con la intención de detectar a los simuladores. En realidad, ni siquiera los pacientes con trastornos mentales graves presentaban puntuaciones elevadas. Por supuesto, los sujetos normales que contestaban de una forma coherente y honesta obtenían las puntuaciones más bajas. Es fundamentalmente, una escala para detectar a los sujetos, incluso pacientes psiquiátricos, que exageran sus sintomnas. Las puntuaciones elevadas en esta escala no deben encontrarse dentro de una psicopatología severa.

Tabla 68: Variable "F $(p)$ ". Percentiles. Análisis por grupos.
\begin{tabular}{|c|c|c|c|c|c|}
\hline Percentiles & Normal & Clínico & Buena Imagen & Mala Imagen & Rta. Inc. \\
\hline $\mathbf{1 0}$ & 0 & 1 & 2 & 11,4 & 10 \\
\hline $\mathbf{2 5}$ & 1 & 1 & 3 & 16 & 12 \\
\hline $\mathbf{5 0}$ & 2 & 3 & 4 & 21 & 13 \\
\hline $\mathbf{7 5}$ & 3 & 5 & 5 & 22 & 15 \\
\hline $\mathbf{9 0}$ & 5 & 7 & 6 & 23 & 16 \\
\hline
\end{tabular}

Contemplando los resultados mostrados en la Tabla 68, podemos apreciar, de un "golpe de vista" que los sujetos que intentan expresar la faceta más desfavorable de sí mismos son los que presentan las puntuaciones más elevadas y que la mitad de éstos (P50) que muestran una puntuación $\geq 21$, mientras que el resto de los grupos, en su 
mismo percentil $(\mathrm{P} 50) \geq 2-4$. Solamente el grupo que ha respondido de forma inconsistente (Rta. Inc.) le sigue en puntuaciones elevadas $(\geq 13)$.

Si recordamos esto mismo ya lo hemos apreciado en la variable de Gough (F-K) con la que presenta una correlación altamente positiva.

Tabla 69: Variable "F(p)". Correlaciones *.

\begin{tabular}{|c|c|c|c|c|c|}
\hline Variables & Normal & Clínico & Buena Imagen & Mala Imagen & Rta. Inc. \\
\hline L & .178 & - & - & - & - \\
\hline F & .704 & .769 & .738 & .929 & .454 \\
\hline K & -.221 & -.278 & - & - & - \\
\hline Fb & .711 & .651 & .764 & .889 & .417 \\
\hline VRIN & .302 & .177 & .477 & - & - \\
\hline TRIN & .158 & .250 & - & - & - \\
\hline F(p) & 1 & 1 & 1 & 1 & 1 \\
\hline S & -.214 & -.295 & -.194 & - & - \\
\hline Ds & .506 & .572 & .609 & .790 & - \\
\hline Ds-r & .403 & .507 & .484 & .721 & - \\
\hline FBS & .302 & .321 & .352 & .757 & - \\
\hline ODecp & .133 & - & - & -.275 & - \\
\hline IR & .798 & .795 & .835 & .907 & .460 \\
\hline Wsd & .221 & .180 & - & -.272 & - \\
\hline F-K & .564 & .668 & .568 & .850 & .398 \\
\hline $\boldsymbol{?}$ & - & - & - & - & - \\
\hline /F-Fb/ & .279 & .338 & .330 & .577 & - \\
\hline
\end{tabular}

* Se exponen solamente las que resultaron ser significativas al $\mathrm{p}<, 001$

Una de las indicaciones de los autores Arbisi y Ben-Porath $(1995,1998)$ es que para detectar mejor al simulador se debe acompañar la interpretación con los resultados ofrecidos en la variable $\mathrm{F}$ cuando ésta se muestra elevada. Nuestros resultados confirman (Tabla 69) que las correlaciones más elevadas y positivas se obtienen, precisamente, con las F $(, 929)$ y $\mathrm{Fb}(, 889)$, especialmente con el grupo de mala imagen. Pero también podemos apreciar, en esta misma Tabla 69, otras elevadísimas correlaciones positivas con otras variables aquí analizadas, como por ejemplo con IR, Ds, Ds-r y F-K.

Al mismo tiempo es interesante hacer notar cómo todos los grupos presentan una correlación negativa de esta variable con $\mathrm{K}$ y S.

Esto nos puede estar indicando que, posiblemente, las interpretaciones de la escala Psiquiátrica podrían acompañarse, además de la $\mathrm{F}$, con los resultados mostrados por la escala IR (de la cual obtiene el $50 \%$ de sus ítems ) y las escalas de Disimulación de Gough (Ds y Ds-r).

Tabla 70: Variable "F(p)": Puntuaciones Medias y $\mathcal{S} t . \mathcal{D}$. Anális is comparativo entre grupos

\begin{tabular}{|c|c|c|c|c|c|c|c|c|c|}
\hline \multicolumn{2}{|c|}{ Normal } & \multicolumn{2}{c|}{ Clínico } & \multicolumn{2}{c|}{ Buena Imagen } & \multicolumn{2}{c|}{ Mala Imagen } & \multicolumn{2}{c|}{ Rta. Inc. } \\
\hline Media & St.D & Media & St.D & Media & St.D & Media & St.D & Media & St.D \\
\hline 2,220 & 2,259 & 3,661 & 3,126 & 4,156 & 2,381 & 18,550 & 5,246 & 13,270 & 2,545 \\
\hline
\end{tabular}

Nuestros resultados (Tabla 70) muestran, una vez más, que los sujetos que intencionadamente intentan presentarse de forma desfavorable, son los que obtienen los valores medios más elevados de todos los grupos.

A través de la Gráfica 34 y la Tabla 71 podemos reconocer las notables diferencias, estadísticamente significativas, existentes entre los diversos grupos. Sólo al analizar los grupos clínicos y normales no se obtuvieron la misma y elevada significación del resto 
de los grupos. Cuando este análisis se ha realizado diferenciando los sexos, podemos apreciar que son los varones los que no se muestran estadísticamente significativos al nivel de confianza mínimamente exigido en esta investigación (5\%) (Tabla 72).

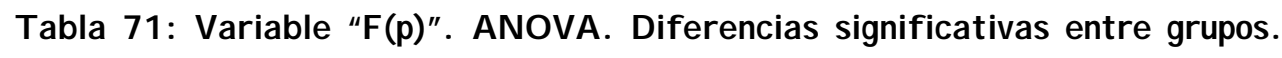

\begin{tabular}{|c|c|c|c|c|}
\hline Grupos & Dif.Med. & Dif. Crit. & p & Signf. (5\%) \\
\hline Normal vs. Clínico & $-1,441$ &, 271 & $<, 0001$ & SI \\
\hline Normal vs. B. Imagen & $-1,936$ &, 358 & $<, 0001$ & SI \\
\hline Normal vs. M. Imagen & $-16,330$ &, 366 & $<, 0001$ & SI \\
\hline Normal vs. Rtas. Inc. & $-11,050$ &, 417 & $<, 0001$ & SI \\
\hline Clínico vs. B. Imagen & -495 &, 407 &, 0173 & SI \\
\hline Clínico vs. M. Imagen & $-14,889$ &, 414 & $<, 0001$ & SI \\
\hline Clínico vs. Rtas. Inc. & $-9,609$ &, 459 & $<, 0001$ & SI \\
\hline B. Imagen vs. M. Imagen & $-14,394$ &, 475 & $<, 0001$ & SI \\
\hline B. Imagen vs. Rtas. Inc. & $-9,114$ &, 516 & $<, 0001$ & SI \\
\hline M. Imagen vs. Rtas. Inc. & 5,280 &, 521 & $<, 0001$ & SI \\
\hline
\end{tabular}

Gráfica 34: Variable "F(p)". $\mathcal{A} \mathcal{N} O \mathcal{V} \mathcal{A}$.

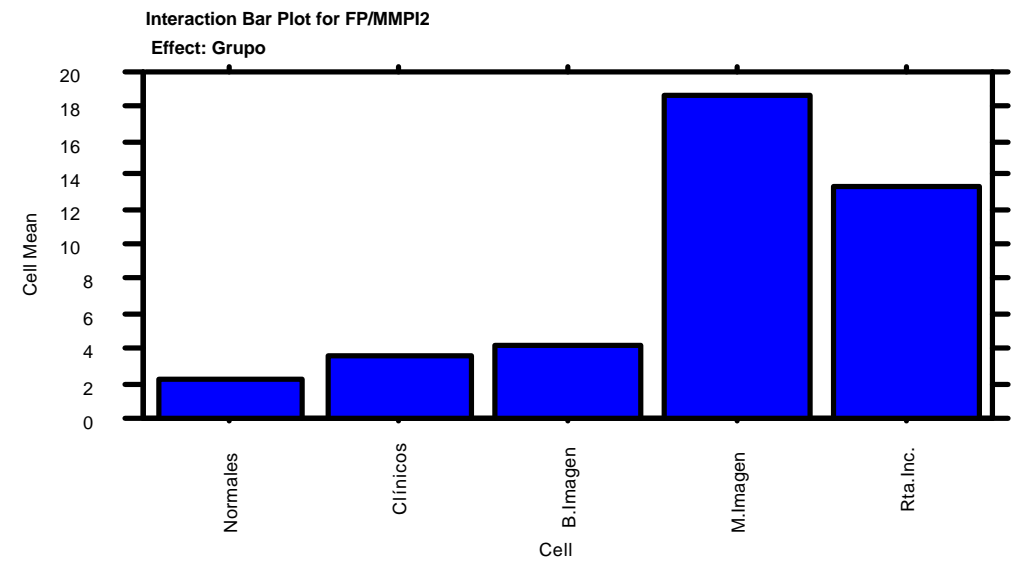

Gráfica 35: Variable "F(p)". Análisis intersexos/intergrupos.

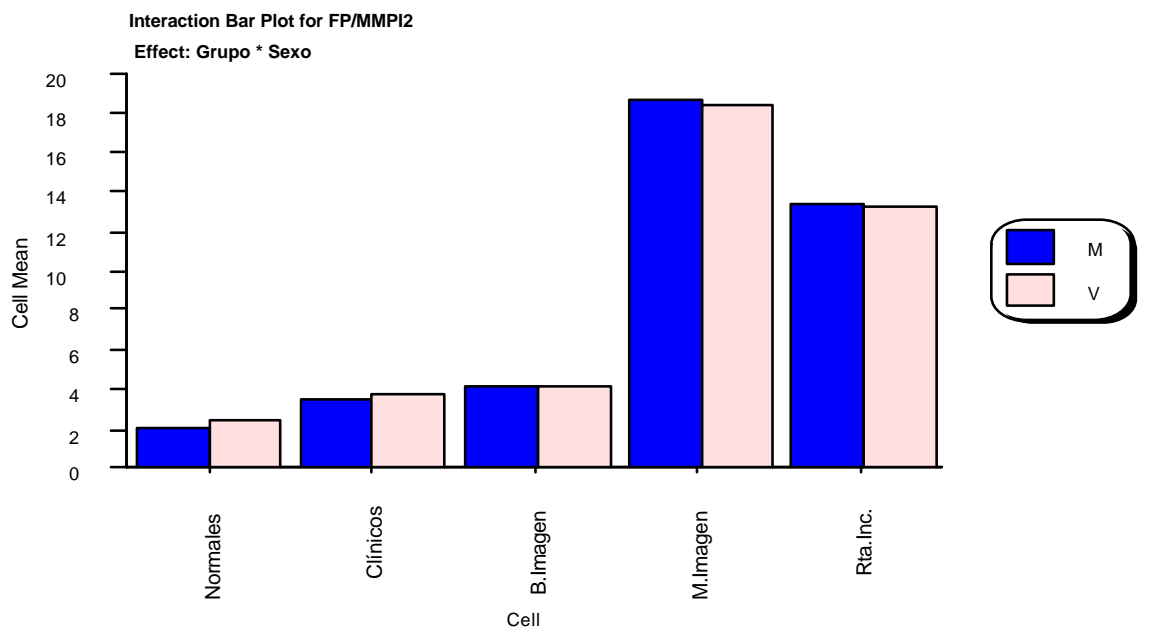


Tabla 72: Variable "F(p)". Diferencias intergrupos e intersexos.
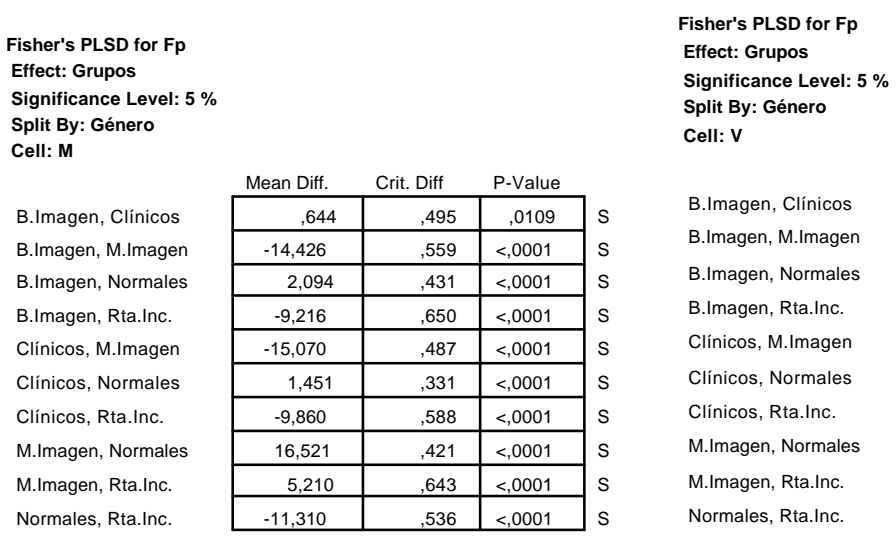

\begin{tabular}{|c|c|c|}
\hline Mean Diff. & Crit. Diff & P-Value \\
\hline ,308 & ,687 & ,3793 \\
\hline$-14,326$ & 845 & $<, 0001$ \\
\hline 1,700 & 614 & $<, 0001$ \\
\hline$-9,022$ & ,838 & $<, 0001$ \\
\hline$-14,634$ & ,738 & $<, 0001$ \\
\hline 1,392 & ,455 & $<, 0001$ \\
\hline$-9,330$ & ,730 & $<, 0001$ \\
\hline 16,026 & 670 & $<, 0001$ \\
\hline 5,303 & 881 & $<, 0001$ \\
\hline$-10,722$ & 661 & $<, 0001$ \\
\hline
\end{tabular}

$\mathrm{M}=$ mujeres; $\mathrm{V}=$ Varones. $\mathrm{S}=$ significativo.

Resumiendo, podemos determinar a través de nuestros resultados, que la Escala Psiquiátrica F(p) de Arbisi y Ben-Porath (1995, 1998):

- Parece poder detectar a los sujetos que de forma voluntaria y coherente falsean sus respuestas intentando presentar su imagen más desfavorable.

- No podría discriminar suficientemente a los sujetos que intentan presentar una buena imagen de sí mismos de aquellos otros que presentan problemas clínicos, al menos entre los varones.

- Para ayudarnos a mejor interpretar el falseamiento o disimulación, los resultados de esta variable pueden acompañarse de los resultados de las variables como $\mathrm{F}, \mathrm{Fb}$, Ds ó Ds-r y F-K.

- Los sujetos clínicos aquí analizados (pacientes necesitados de ayuda psicológica y tratamiento ambulatorio), que han contestado honesta y sinceramente al Cuestionario, presentan puntuaciones bajas.

- Esta Escala Psiquiátrica $\mathrm{F}(\mathrm{p})$ contiene la mitad de los ítems compuestos por la Escala de Inconsistencia de Respuestas (IR) de Sewell y Rogers (1994) de ahí que los resultados, globalmente considerados, sean muy semejantes a los de la Escala de Inconsistencia de Respuestas (IR) de Sewell y Rogers (1994). En nuestra última exposición de la hoja de perfil debemos elegir solamente una de ellas.

\section{V.2.9. - Variable "S" (Escala S uperlativa de Butcher y Han, 1995):}

Butcher \& Han (1995) elaboraron esta escala (ver Anexo 0-13) para evaluar la tendencia de algunas personas de mostrarse, a través del MMPI-2, extremadamente virtuosos, equilibrados y ajustados psicológicamente. Esta forma de presentarse a sí mismo podemos encontrarla en sujetos ante situaciones generales en las que se necesite ensalzar la figura personal como en los casos de selección de personal o atribución de guarda y custodia de los hijos.

Butcher \& Han (1995) sugieren la existencia de cinco dimensiones principales en los ítems de esta escala: creencia en las virtudes humanas, serenidad, satisfación con la 
vida, paciencia y negación de ira e irritabilidad, y negación de defectos morales (citado por Graham, 2000, pg.36).

Baer, Wetter \& Berry (1995) encontraron que la escala S resultó ser efectiva para identificar a los estudiantes que contestaban intentando ofrecer una buena imagen. Para estos autores,el 92\% de los sujetos de "buena imagen" presentaban una puntuación directa $\geq 29$. En nuestros resultados (Tabla 73) podemos apreciar cómo el $90 \%$ de estos mismos sujetos (aunque no son estudiantes), que igualmente intentan mostrar una buena imagen, presentan una puntuación directa $\geq 25$. Los resultados no parecen ser muy dispares.

Tabla 73: Variable "S". Percentiles. Análisis por grupos.

\begin{tabular}{|c|c|c|c|c|c|}
\hline Percentiles & Normal & Clínico & Buena Imagen & Mala Imagen & Rta. Inc. \\
\hline $\mathbf{1 0}$ & 14 & 10 & 25 & 5 & 20 \\
\hline $\mathbf{2 5}$ & 18 & 14 & 32 & 8 & 22 \\
\hline $\mathbf{5 0}$ & 24 & 19 & 38 & 11 & 26 \\
\hline $\mathbf{7 5}$ & 29 & 24 & 42 & 16 & 28 \\
\hline $\mathbf{9 0}$ & 34 & 30 & 45 & 23 & 31 \\
\hline
\end{tabular}

El $90 \%$ de los 2.600 sujetos normales presentados por Butcher et als., (1989) mostraron una puntuación directa $\geq 13$ (nuestros resultados: $\geq 14$ ). Cuando se trata de sujestos con graves trastornos, presentados por Greene (1997), el 90\% de los sujetos mostraron una puntuación directa $\geq 8$ (nuestros clínicos, que no presentan una grave patología, $\geq 10$ ).

Butcher \& Han (1995) encontraron elevadas correlaciones (citado por Graham, 2000, pg.36) con la escala K del MMPI-2 con muestras normales (,81 para varones; ,92 para mujeres), y algo más bajas con la escala L (,46, para varones y ,64 para mujeres). Si contemplamos la Tabla 74, podemos ver que nuestros resultados son coincidentes, en todos los grupos analizados, con los de Butcher \& Han (1995) con respecto a las variable $\mathrm{K}$ y L, siendo más elevada en la primera.

Tabla 74: Variable "S". Correlaciones *.

\begin{tabular}{|c|c|c|c|c|c|}
\hline Variables & Normal & Clínico & Buena Imagen & Mala Imagen & Rta. Inc. \\
\hline $\mathbf{L}$ & .451 & .450 & .732 & .739 & .440 \\
\hline $\mathbf{F}$ & -.476 & -.565 & -.559 & -.374 & -.334 \\
\hline $\mathbf{K}$ & .813 & .809 & .845 & .844 & .549 \\
\hline Fb & -.461 & -.574 & -.507 & -.414 & -.447 \\
\hline VRIN & -.163 & .090 & -.548 & .591 & .134 \\
\hline TRIN & -.203 & -.275 & -.121 & -.102 & -.449 \\
\hline Fp & -.214 & -.295 & -.194 & -.204 & -.194 \\
\hline $\mathbf{S}$ & 1.00 & 1.00 & 1.00 & 1.00 & 1.00 \\
\hline Ds & -.716 & -.731 & -.697 & -.579 & -.444 \\
\hline Ds-r & -.731 & -.717 & -.751 & -.597 & -.345 \\
\hline FBS & -.110 & -.295 & .127 & -.255 & .177 \\
\hline ODecp & .431 & .398 & .695 & .675 & .053 \\
\hline IR & -.197 & -.359 & -.108 & -.185 & -.343 \\
\hline Wsd & .115 & .072 & .523 & .522 & -.244 \\
\hline F-K & -.742 & -.753 & -.784 & -.591 & -.528 \\
\hline$i$ & -.030 & .019 & -.080 & .114 & .045 \\
\hline /F-Fb/ & -.206 & -.129 & -.458 & -.140 & .066 \\
\hline
\end{tabular}

* Los valores en negrita, resultaron ser estadísticamente significativos al $\mathrm{p}<.001$

Semejantes resultados obtuvieron los investigadores Baer, Wetter, Nichols, Greene \& Berry (1995) al llegar a la conclusión que los datos aportados por la escala $\mathrm{S}$ añadidos a los de las escalas L y K pueden discriminar entre personas que contestan a la 
prueba de forma honesta y sincera de aquellas que contestan de una forma pretendidamente perfecta y bien ajustadas psicológicamente.

Podemos reflejar, por nuestros datos, las correlaciones positivas existentes con todos los grupos con respecto a la variable ODecp y la Wsd exclusivamente con los grupos de buena y mala imagen.

Igualmente hemos podido apreciar en nuestra Tabla 74, donde se exponen las diversas correlaciones entre los grupos y con las distintas variables, que existe un nutrido grupo de variables con las que se mantiene una correlación negativa: $\mathrm{F}, \mathrm{Fb}$, Ds, Ds-r, IR, F-K y /F-Fb/. Lo cual nos lleva a poder apreciar la sensibilidad hacia el fingimiento positivo y de intentar ofrecer buena imagen más que el ofrecer el aspecto desfavorable de sí mismo.

Butcher \& Han (1995) concluyen que las puntuaciones elevadas obtenidas en la escala $\mathrm{S}$ son ofrecidas por personas no realistas, que informan positivamente de sí mismo, muy bien equilibardos psicológicamente $\mathrm{y}$ sin problemas. Pero estos investigadores no aportan dato alguno acerca de si esta variable puede detectar perfiles defensivos o perfiles de buena imagen (Graham, 2000).

Tabla 75: Variable "S": Puntuaciones Medias y St.D. Análisis comparativo entre grupos

\begin{tabular}{|c|c|c|c|c|c|c|c|c|c|}
\hline \multicolumn{2}{|c|}{ Normal } & \multicolumn{2}{c|}{ Clínico } & \multicolumn{2}{c|}{ Buena Imagen } & \multicolumn{2}{c|}{ Mala Imagen } & \multicolumn{2}{c|}{ Rta. Inc. } \\
\hline Media & St.D & Media & St.D & Media & St.D & Media & St.D & Media & St.D \\
\hline 23,893 & 7,657 & 19,316 & 7,377 & 36,333 & 8,250 & 12,613 & 7,330 & 25,430 & 4,868 \\
\hline
\end{tabular}

Consultando las Tablas 75 y 76 confirmamos que es el grupo de buena imagen el que presenta las puntuaciones más elevadas, siendo estadísticamente significativa su diferencia de puntuaciones medias con el resto de los grupos.

Tabla 76: Variable "S". $\mathcal{A} \mathcal{N} O \mathcal{V A}$. Diferencias significativas entre grupos.

\begin{tabular}{|c|c|c|c|c|}
\hline \multicolumn{1}{|c|}{ Grupos } & Dif.Med. & Dif. Crit. & $\mathbf{p}$ & Signf. (5\%) \\
\hline Normal vs. Clínico & 4,578 &, 713 & $<, 0001$ & SI \\
\hline Normal vs. B. Imagen & $-12,440$ &, 943 & $<, 0001$ & SI \\
\hline Normal vs. M. Imagen & 11,280 &, 962 & $<, 0001$ & SI \\
\hline Normal vs. Rtas. Inc. & $-1,537$ & 1,096 &, 0060 & SI \\
\hline Clínico vs. B. Imagen & $-17,018$ & 1,071 & $<, 0001$ & SI \\
\hline Clínico vs. M. Imagen & 6,702 & 1,088 & $<, 0001$ & SI \\
\hline Clínico vs. Rtas. Inc. & $-6,114$ & 1,208 & $<, 0001$ & SI \\
\hline B. Imagen vs. M. Imagen & 23,720 & 1,250 & $<, 0001$ & SI \\
\hline B. Imagen vs. Rtas. Inc. & 10,903 & 1,356 & $<, 0001$ & SI \\
\hline M. Imagen vs. Rtas. Inc. & $-12,817$ & 1,370 & $<, 0001$ & SI \\
\hline
\end{tabular}

Si nos fijamos atentamente en la Tabla 76 podemos apreciar que entre los grupos normales y los que contestan de forma inconsistente a los ítems del cuestionario (Rta. Inc.) fueron estadísticamente significativos cuando los sexos se analizaron conjuntamente, pero cuando realizamos el análisis separando los sexos (Tabla 77) podemos apreciar que existen diferencias signficativas entre estos dos grupos. Por esto mismo, a la hora de interpretar adecuadamente las variables y disponer de un criterio plenamente fiable, deberíamos acompañarnos de todas aquellas otras variables que correlacionan con ella de forma positiva y/o eventualmente negativa. 
Gráfica 36: Variable "S". ANNOVA.

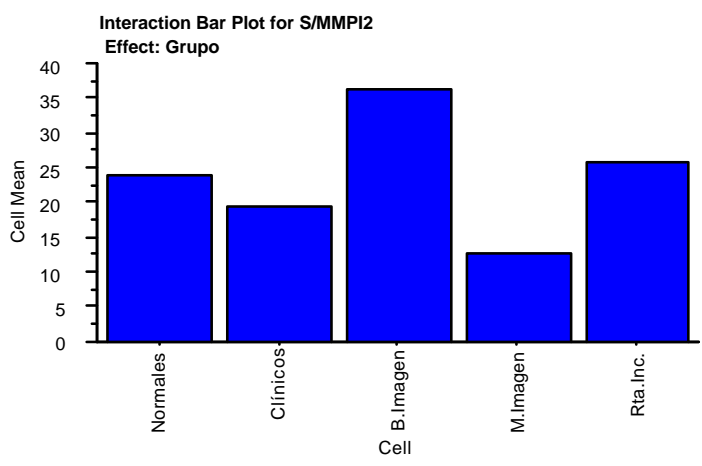

Gráfica 37: Variable "S". Anális is intersexos/intergrupos.

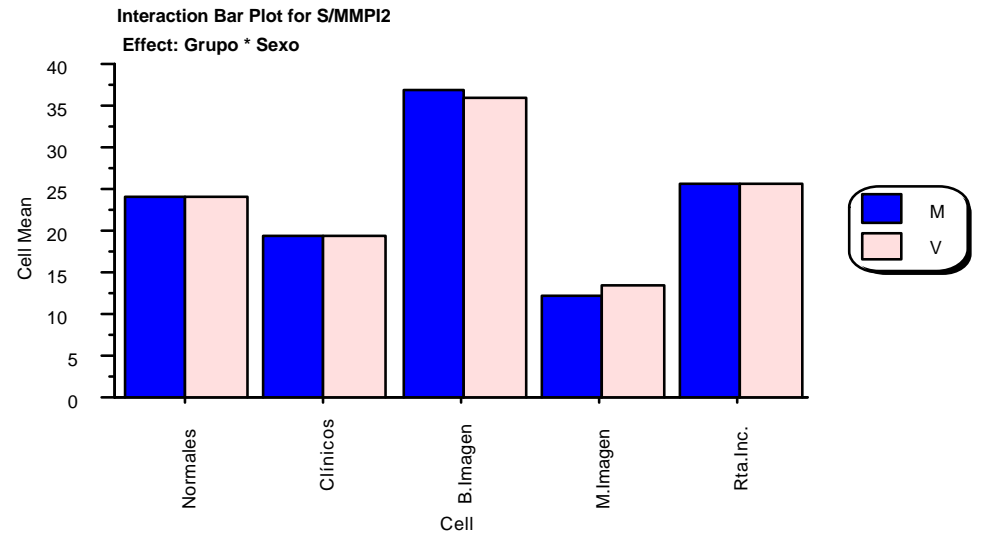

Tabla 77: Variable "S". Diferencias intergrupos/intersexos *.

Fisher's PLSD for S

Effect: Grupos

Significance Level: $5 \%$

Split By: Género

Cell: $M$

B.Imagen, Clínicos

B.Imagen, M.Imagen

B.Imagen, Normales

B.Imagen, Rta.Inc.

Clínicos, M.Imagen

Clínicos, Normales

Clínicos, Rta.Inc

M.Imagen, Normales

M.Imagen, Rta.Inc.

Normales, Rta.Inc

\begin{tabular}{|c|c|c|}
\hline Mean Diff. & Crit. Diff & P-Value \\
\hline 17,460 & 1,387 & $<, 0001$ \\
\hline 24,479 & 1,566 & $<, 0001$ \\
\hline 12,847 & 1,207 & $<, 0001$ \\
\hline 11,356 & 1,820 & $<, 0001$ \\
\hline 7,019 & 1,363 & $<, 0001$ \\
\hline$-4,612$ & ,928 & $<, 0001$ \\
\hline$-6,104$ & 1,648 & $<, 0001$ \\
\hline$-11,632$ & 1,179 & $<, 0001$ \\
\hline$-13,123$ & 1,802 & $<, 0001$ \\
\hline$-1,492$ & 1,500 & ,0513 \\
\hline
\end{tabular}

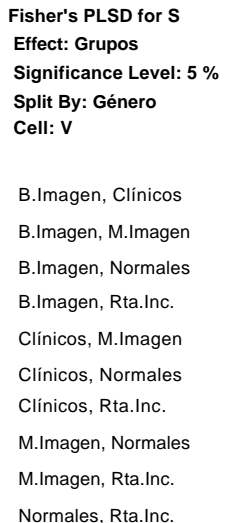

Fisher's PLSD for

Significance Level: $5 \%$

B.Imagen, Clínicos

B.Imagen, M.Imagen

B.Imagen, Normales

Clínicos, Normales

Clínicos, Rta.Inc.

M.Imagen, Rta.Inc

Normales, Rta.Inc.

* $\mathrm{M}=$ mujeres; $\mathrm{V}=$ Varones. $\mathrm{S}=$ significativ $\mathrm{o}$.

Resumiendo, a tenor de nuestros resultados, podemos decir que:

- Es una variable que detecta a los sujetos que intentan presentarse con su imagen más favorable. 
- No discrimina adecuadamente los sujetos normales que contestan honesta y sinceramente al cuestionario de aquellos otros que lo realizan sin tener en cuenta el contenido de los ítems .

- Para ayudarnos de una mejor interpretación diagnóstica, podemos acompañarnos de los resultados elevados de las variables K, L y ODecp y, de forma contraria, de las puntuaciones más bajas ofrecidas por F, las escalas de Disimulación de Gough (Ds y Ds-r) y la F-K que correlaciona de forma altamente negativa.

\section{V.2.10. - Variable "Ds-r" (Escala revisada de Disimulación de Gough,} $1957)$.

Esta escala se quedó reducida a un total de 32 ítems (véase Anexo 0-12) de los 58 que componía su anterior Escala de Disimulación (Ds).

Las altímsimas correlaciones mantenidas por todos los grupos de esta Escala revisada con su homónima nos ha obligado a tomar una de las dos después de nuestro análisis. Hemos optado por la más actual y revisada que, al mismo tiempo tiene una notable reducción de ítems (casi la mitad).

Una primera visión de nuestros resultados nos permite apreciar que esta escala es muy utilizada por aquellas personas que intentan ofrecer una mala imagen de sí mismos.

Tabla 78: Variable "Ds-r". Percentiles. Análisis por grupos.

\begin{tabular}{|c|c|c|c|c|c|}
\hline Percentiles & Normal & Clínico & Buena Imagen & Mala Imagen & Rta. Inc. \\
\hline $\mathbf{1 0}$ & 3 & 5 & 0 & 16 & 12 \\
\hline $\mathbf{2 5}$ & 5 & 8 & 1 & 21 & 14 \\
\hline $\mathbf{5 0}$ & 8 & 13 & 2 & 27 & 16 \\
\hline $\mathbf{7 5}$ & 11 & 17 & 4 & 30 & 18 \\
\hline $\mathbf{9 0}$ & 15 & 21 & 8 & 31 & 20 \\
\hline
\end{tabular}

Contemplando los resultados percentilados de la Tabla 78 podemos señalar que el $90 \%$ de las personas que intentan parecer peor de lo que son, o dar una imagen negativa de sí mismos, presentan una puntuación directa de $\geq 16$ (sobre una puntuación máxima de 32); sin embargo, esta misma puntuación apenas si la presentan las personas que responden honesta y sinceramente a la prueba, solamente un $10 \%$ de éstas.

Podemos contemplar, por los resultados expuestos en la Tabla 79 de las correlaciones de esta variable Ds-r con las demás según los diferentes grupos, que con quien correlaciona de una forma altamente positiva, en primer lugar y con todos los grupos, es con la variable Ds no revisada. Por ello, de aquí en adelante, hemos tomado la revisada (Ds-r), dejando a un lado la no revisada (Ds).

Otras correlaciones elevadas y positivas que han mantenido esta variable se encuentran especificadas por: F, Fb, F(p), FBS, F-K y también con IR.

De distinto signo, negativas, se encuentran las correlaciones mantenidas con las variables: S, K, L ODecp y también con Wsd.

Esta dirección en su correlación se va a ver expresadas en las distintas gráficas de los diversos tipos de perfiles que más adelante expondremos.

Como ya pudimos ver con la Tabla 78 de los Percentiles, aquí se muestran las puntuaciones medias más elevadas en el mismo grupo que intentó presentar los aspectos 
más negativos de sí mismos, el grupo de mala imagen (24,903). A continuación le sigue, en la puntuación más elevada, el grupo que ha respondido de forma inconsistente (Rta. Inc.: 15,860), el grupo clínico $(12,965)$, los normales $(12,963)$ y en último lugar las sujetos que intentaron dar buena imagen $(3,255)$. Todos ellos entre sí guardan tales diferencias entre sus puntuaciones medias se muestran estadísticamente significativas a un nivel muy alto (<,0001: véase Tabla 81$)$.

Tabla 79: Variable "Ds $-r$ ". Correlaciones ${ }^{*}$

\begin{tabular}{|c|c|c|c|c|c|}
\hline Variables & Normal & Clínico & Buena Imagen & Mala Imagen & Rta. Inc. \\
\hline $\mathbf{L}$ & -.348 &.- .318 & -.614 & -.382 &.- .304 \\
\hline $\mathbf{F}$ & .668 & .739 & .818 & .834 & .290 \\
\hline $\mathbf{K}$ & -.678 & -.662 & -.668 & -.430 & -.395 \\
\hline $\mathbf{F b}$ & .676 & .777 & .771 & .827 & .361 \\
\hline VRIN & .277 & .047 & .649 & -.420 & -.014 \\
\hline TRIN & .193 & .252 & .046 & .001 & .273 \\
\hline $\mathbf{F p}$ & .403 & .507 & .484 & .721 & .172 \\
\hline $\mathbf{S}$ & -.731 & -.717 & -.751 & -.597 & -.345 \\
\hline Ds & .944 & .955 & .950 & .968 & .836 \\
\hline Ds-r & 1.00 & 1.00 & 1.00 & 1.00 & 1.00 \\
\hline FBS & .420 & .635 & .217 & .834 & .152 \\
\hline ODecp & -.379 & -.330 & -.634 & -.620 & .019 \\
\hline IR & .369 & .543 & .397 & .684 & .340 \\
\hline Wsd &.- .111 & -.054 & -.487 & -.526 & .074 \\
\hline F-K & .789 & .813 & .860 & .876 & .414 \\
\hline$i$ & -.031 & -.077 & .040 & -.022 & .043 \\
\hline$/ \mathrm{F}-\mathrm{Fb} /$ & .249 & .177 & .544 & .475 & -.031 \\
\hline
\end{tabular}

* Los valores en negrita, resultaron ser estadísticamente significativos al $\mathrm{p}<.001$

Tabla 80: Variable "Ds- $r$ ": Puntuaciones Medias y $\mathcal{S}$ t.D. Análisis comparativo entre grupos.

\begin{tabular}{|c|c|c|c|c|c|c|c|c|c|}
\hline \multicolumn{2}{|c|}{ Normal } & \multicolumn{2}{c|}{ Clínico } & \multicolumn{2}{c|}{ Buena Imagen } & \multicolumn{2}{c|}{ Mala Imagen } & \multicolumn{2}{c|}{ Rta. Inc. } \\
\hline Media & St.D & Media & St.D & Media & St.D & Media & St.D & Media & St.D \\
\hline 8,334 & 4,515 & 12,963 & 5,865 & 3,255 & 3,767 & 24,903 & 5,998 & 15,860 & 3,293 \\
\hline
\end{tabular}

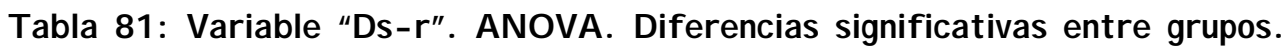

\begin{tabular}{|c|c|c|c|c|}
\hline Grupos & Dif.Med. & Dif. Crit. & p & Signf. (5\%) \\
\hline Normal vs. Clínico & $-4,629$ &, 459 & $<, 0001$ & SI \\
\hline Normal vs. B. Imagen & 5,078 &, 606 & $<, 0001$ & SI \\
\hline Normal vs. M. Imagen & $-16,570$ &, 619 & $<, 0001$ & SI \\
\hline Normal vs. Rtas. Inc. & $-7,526$ &, 705 & $<, 0001$ & SI \\
\hline Clínico vs. B. Imagen & 9,707 &, 689 & $<, 0001$ & SI \\
\hline Clínico vs. M. Imagen & $-11,941$ &, 700 & $<, 0001$ & SI \\
\hline Clínico vs. Rtas. Inc. & $-2,897$ &, 777 & $<, 0001$ & SI \\
\hline B. Imagen vs. M. Imagen & $-21,648$ &, 804 & $<, 0001$ & SI \\
\hline B. Imagen vs. Rtas. Inc. & $-12,605$ &, 872 & $<, 0001$ & SI \\
\hline M. Imagen vs. Rtas. Inc. & 9,043 &, 881 & $<, 0001$ & SI \\
\hline
\end{tabular}


Gráfica 38: Variable "Ds - r". $\mathcal{A} \mathcal{N} O \mathcal{V} \mathcal{A}$.

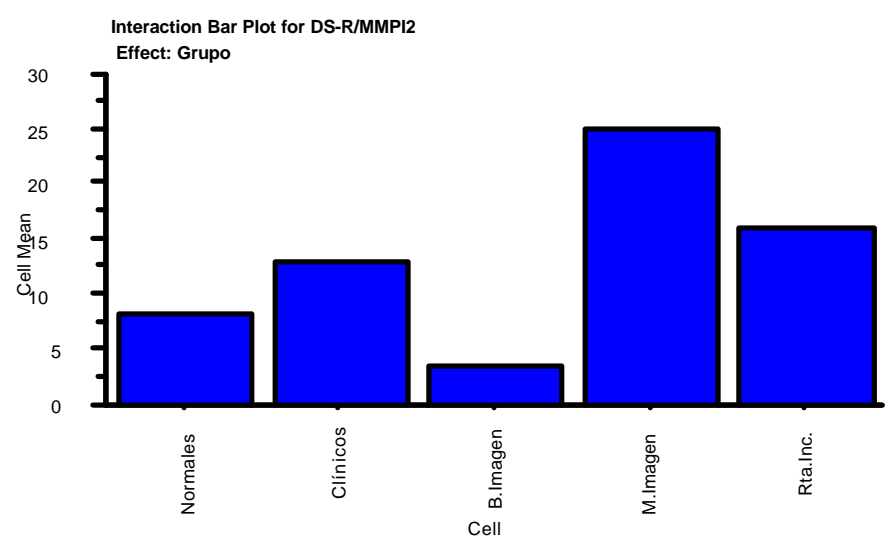

Gráfica 39: Variable "Ds-r". Análisis intersexos/intergrupos.

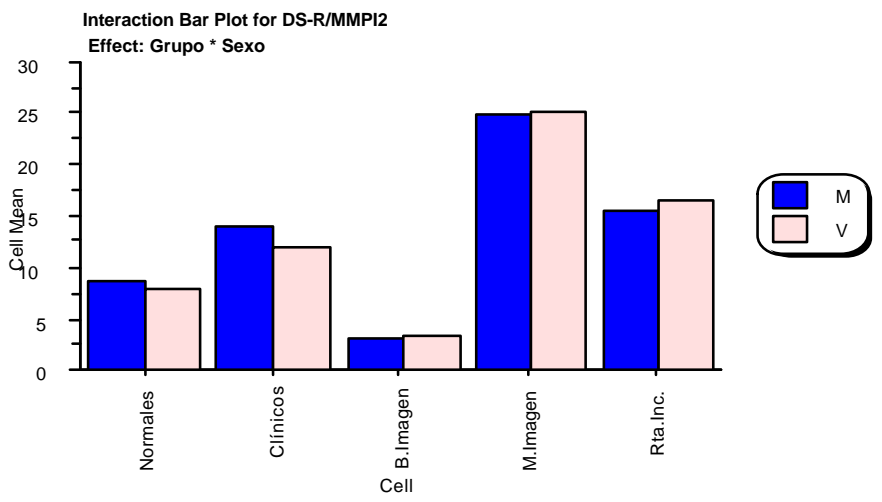

Tabla 82: Variable "Ds- $r$ ". Diferencias intergrupos e intersexos*

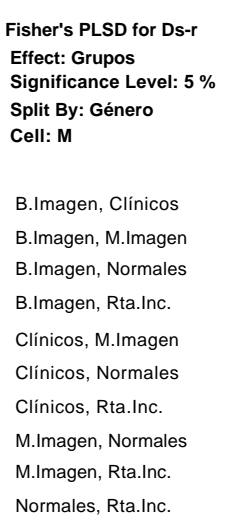

\begin{tabular}{|c|c|c|}
\hline Mean Diff. & Crit. Diff & P-Value \\
\hline$-10,690$ & ,913 & $<, 0001$ \\
\hline$-21,623$ & 1,031 & $<, 0001$ \\
\hline$-5,481$ & ,795 & $<, 0001$ \\
\hline$-12,184$ & 1,198 & $<, 0001$ \\
\hline$-10,933$ & ,897 & $<, 0001$ \\
\hline 5,209 & ,611 & $<, 0001$ \\
\hline$-1,493$ & 1,085 & ,0070 \\
\hline 16,143 & ,776 & $<, 0001$ \\
\hline 9,440 & 1,186 & $<, 0001$ \\
\hline$-6,703$ & ,987 & $<, 0001$ \\
\hline
\end{tabular}

Fisher's PLSD for Ds-r

Effect: Grupos

Significance Level: $5 \%$

Split By: Género

Cell: $\mathrm{V}$

B.Imagen, Clínicos

B.Imagen, M.Imagen

B.Imagen, Normales

B.Imagen, Rta.Inc.

Clínicos, M.Imagen

Clínicos, Normales

Clínicos, Rta.Inc.

M.Imagen, Normales

M.Imagen, Rta.Inc.

Normales, Rta.Inc.

\begin{tabular}{|c|c|c|}
\hline Mean Diff. & Crit. Diff & P-Value \\
\hline$-8,493$ & 1,036 & $<, 0001$ \\
\hline$-21,715$ & 1,274 & $<, 0001$ \\
\hline$-4,477$ & ,925 & $<, 0001$ \\
\hline$-13,004$ & 1,263 & $<, 0001$ \\
\hline$-13,222$ & 1,113 & $<, 0001$ \\
\hline 4,016 & ,686 & $<, 0001$ \\
\hline$-4,511$ & 1,101 & $<, 0001$ \\
\hline 17,238 & 1,010 & $<, 0001$ \\
\hline 8,712 & 1,327 & $<, 0001$ \\
\hline$-8,527$ & ,997 & $<, 0001$ \\
\hline
\end{tabular}

* $\mathrm{M}=$ mujeres; $\mathrm{V}=$ Varones. $\mathrm{S}=$ significativo.

Cuando hemos realizado el análisis intersexos para los diferentes grupos, hemos podido apreciar que esta variable se ha mostrado estadísticamente significativa tanto en los varones como en las muejres, como puede apreciarse en la Tabla 82. 
De los resultados obtenidos podemos resumir las conclusiones más importantes de la forma siguiente :

- Dado que de esta variable se ha hecho una revisión sobre la anterior del mismo autor (Ds) y teniendo en cuenta la casi igualdad de resultados aportados por ambas, hemos decidido trabajar sólo con la Revisada (Ds-r).

- Esta variable muestra su alta sensibilidad en aquellas personas que, intencionadamente, intentan mostrar una imagen desfavorable de sí misma..

- Para una mejor interpretación pueden acompañarse de los resultados obtenidos por otras variables como son la F, Fb, F-K, FBS y F(p), cuyos valores se han mostrado positiva y altamente correlacionados.

- Igualmente podemos apreciar la interpretación observando sus elevados valores negativos con las variables L, K, S. ODecp y Wsd con quienes ha correlacionado de forma negativa.

\section{V.2.11. Variable "FBS". Escala de "Hacerse el enfermo" de Lees. Haley, English of Gle nn, (1991):}

Esta escala de "hacerse el enfermo" o el "malo" ("Fake-bad") está compuesta por un total de 43 ítems (véase Anexo 0-10) con la intención de identificar a las personas que intentan expresar una imagen negativa de sí mismos, o que, intencionadamente, tratan de dar una imagen desfavorable.

Tabla 83: Variable "FBS". Pe rcentiles. Análisis por grupos.
\begin{tabular}{|c|c|c|c|c|c|}
\hline Percentiles & Normal & Clínico & Buena Imagen & Mala Imagen & Rta. Inc. \\
\hline $\mathbf{1 0}$ & 7 & 11 & 8 & 13 & 16,5 \\
\hline $\mathbf{2 5}$ & 10 & 14 & 11 & 19 & 19 \\
\hline $\mathbf{5 0}$ & 12 & 18 & 13 & 27 & 21 \\
\hline $\mathbf{7 5}$ & 16 & 23 & 14 & 29 & 24 \\
\hline $\mathbf{9 0}$ & 19 & 27 & 15 & 31 & 26 \\
\hline
\end{tabular}

Por los resultados expuestos en las Tabla 83 y 85, podemos apreciar que los sujetos, a los que se les instruyó para que dieran mala imagen de sí mismos, son los que alcanzaronn mayor puntuación en sus diversos percentiles y puntuaciones medias.

Vemos que el $75 \%$ de los sujetos que expresan "mala imagen" consiguen una puntuación directa de $\geq 19$, igual que el $10 \%$ de los sujetos normales que han contestado honesta y sinceramente a la prueba.

Igualmente podemos observar que los sujetos que contestan sin tener en cuenta el contenido de los ítems y el grupo de clínicos consiguen también puntuaciones elevadas.

A través de los resultados mostrados en la Tabla 84, podemos ver las elevadas correlaciones (de distinto signo) del grupo "mala imagen": hemos de resaltar, en este grupo, las elevadas correlaciones positivas con las escalas de disimulación de Gough (Ds y Ds-r), F, Fb, F(p) y F-K.

Se puede apreciar en nuestros resultados la ausencia de correlación significativa de las distintas variables con la escala de hacerse el enfermo (FBS) en el grupo que ha contestado sin tener en cuenta el contenido de los ítems (Rta. Inc.). 
Tabla 84: Variable "FBS". Correlaciones ${ }^{*}$.

\begin{tabular}{|c|c|c|c|c|c|}
\hline Variables & Normal & Clínico & Buena Imagen & Mala Imagen & Rta. Inc. \\
\hline $\mathbf{L}$ & .118 & .055 & .016 & -.046 & .179 \\
\hline $\mathbf{F}$ & .351 & .438 & .351 & .804 & -.043 \\
\hline $\mathbf{K}$ & -.169 & -.320 & .105 & -.125 & .078 \\
\hline $\mathbf{F b}$ & .450 & .573 & .403 & .763 & -.038 \\
\hline VRIN & .223 & .033 & .153 & -.238 & .080 \\
\hline TRIN & .016 & .116 & .081 & -.049 & -.137 \\
\hline Fp & .302 & .321 & .352 & .757 & .094 \\
\hline $\mathbf{S}$ & .110 & -.295 & .127 & -.255 & .177 \\
\hline Ds & .418 & .582 & .291 & .827 & .076 \\
\hline Ds-r & .420 & .635 & .217 & .834 & .152 \\
\hline FBS & 1.00 & 1.00 & 1.00 & 1.00 & 1.00 \\
\hline ODecp & -.164 & -.224 & -.126 & -.412 & .038 \\
\hline IR & .282 & .342 & .313 & .712 & .045 \\
\hline Wsd & -.078 & -.072 & -.092 & -.361 & -.141 \\
\hline F-K & .313 & .450 & .172 & .756 & -.072 \\
\hline$i$ & .024 & .020 & -.028 & .051 & .066 \\
\hline /F-Fb/ & .049 & .035 & .087 & .518 & -.017 \\
\hline
\end{tabular}

* Los valores en negrita, resultaron ser estadísticamente significativos al $\mathrm{p}<.001$

Las variables TRIN y la ? no correlacionan de forma significativa con esta variable FBS (Tabla 84).

Existen pocos estudios realizados con estas variables. Butcher et al, (1989) con 2.600 normales, que contestaron honesta y sinceramente a los ítems, encontraron correlaciones positivas de esta escala FBS con Fb $(, 26), \mathrm{F}(\mathrm{p})(, 08), \operatorname{IR}(, 01)$, VRIN $(, 16)$ y TRIN (-,02). Hemos podido comprobar que nuestros resultados, con 1.723 sujetos también honestos y sinceros al contestar, tienen unas correlaciones ligeramente más elevadas que las mostradas por el equipo de Butcher: $\mathrm{Fb}(, 450)$; $\mathrm{F}(\mathrm{p})(, 302)$, IR (,282), VRIN (,223); y TRIN (,016).

Tabla 85: Variable "FBBS": Puntuaciones Medias y $\mathcal{S}$ t. $\mathcal{D}$. Análisis comparativo entre grupos

\begin{tabular}{|c|c|c|c|c|c|c|c|c|c|}
\hline \multicolumn{2}{|c|}{ Normal } & \multicolumn{2}{c|}{ Clínico } & \multicolumn{2}{c|}{ Buena Imagen } & \multicolumn{2}{c|}{ Mala Imagen } & \multicolumn{2}{c|}{ Rta. Inc. } \\
\hline Media & St.D & Media & St.D & Media & St.D & Media & St.D & Media & St.D \\
\hline 12,955 & 4,750 & 18,651 & 6,189 & 12,461 & 3,106 & 23,933 & 6,871 & 21,295 & 3,682 \\
\hline
\end{tabular}

Podemos observar, con los resultados expuestos en la Tabla 85, que los sujetos con mala imagen son los que presentan la puntuación media más elevada, siendo estadísticamente significativa con el resto de los grupos (ver Tabla 86).

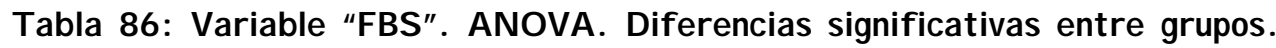

\begin{tabular}{|c|c|c|c|c|}
\hline \multicolumn{1}{|c|}{ Grupos } & Dif.Med. & Dif. Crit. & p & Signf. (5\%) \\
\hline Normal vs. Clínico & $-5,696$ &, 485 & $<, 0001$ & SI \\
\hline Normal vs. B. Imagen &, 494 &, 641 &, 1308 & NO \\
\hline Normal vs. M. Imagen & $-10,978$ &, 654 & $<, 0001$ & SI \\
\hline Normal vs. Rtas. Inc. & $-8,340$ &, 745 & $<, 0001$ & SI \\
\hline Clínico vs. B. Imagen & 6,190 &, 728 & $<, 0001$ & SI \\
\hline Clínico vs. M. Imagen & $-5,282$ &, 739 & $<, 0001$ & SI \\
\hline Clínico vs. Rtas. Inc. & $-2,644$ &, 821 & $<, 0001$ & SI \\
\hline B. Imagen vs. M. Imagen & $-11,472$ &, 850 & $<, 0001$ & SI \\
\hline B. Imagen vs. Rtas. Inc. & $-8,834$ &, 922 & $<, 0001$ & SI \\
\hline M. Imagen vs. Rtas. Inc. & 2,638 &, 931 & $<, 0001$ & SI \\
\hline
\end{tabular}




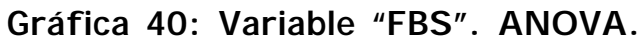

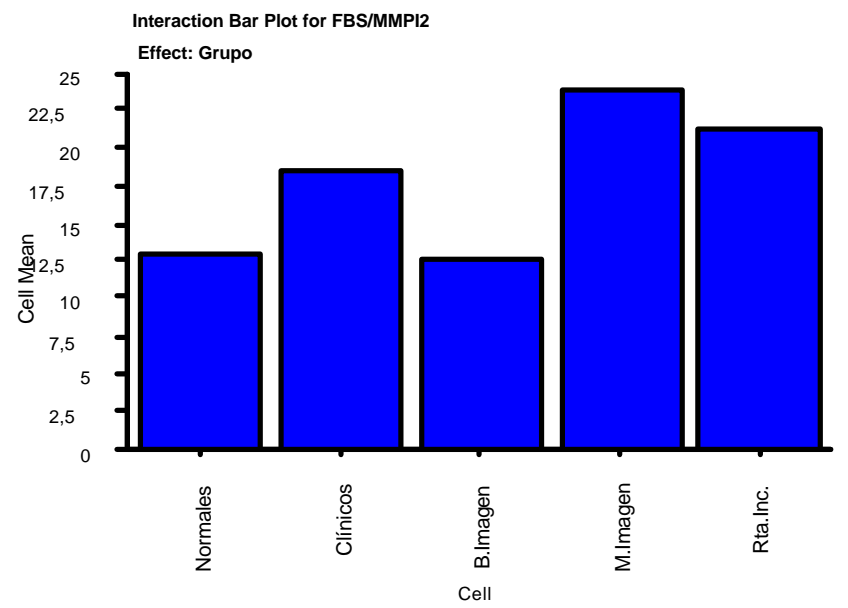

Gráfica 41: Variable "FBBS". Anális is intersexos/intergrupos.

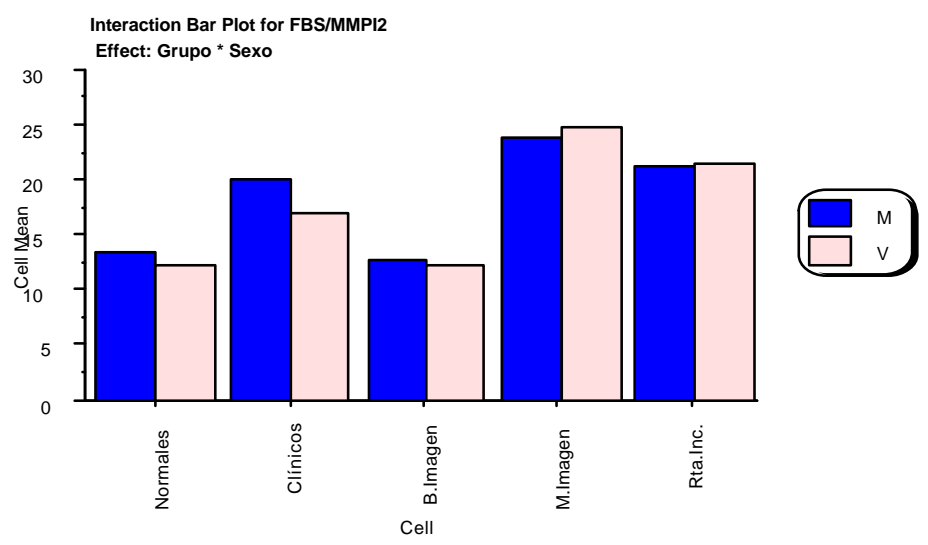

Tabla 87: Variable "FBS". Diferencias intergrupos e intersexos *.

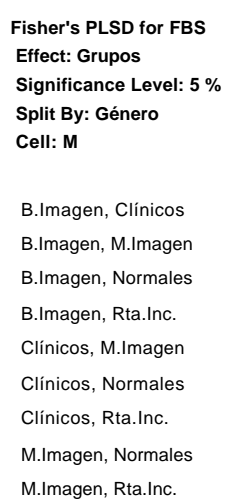

M.Imagen, Rta.Inc.

Normales, Rta.Inc.

\begin{tabular}{|c|c|c|}
\hline Mean Diff. & Crit. Diff & P-Value \\
\hline$-7,335$ & ,969 & $<, 0001$ \\
\hline$-10,834$ & 1,094 & $<, 0001$ \\
\hline,- 760 & ,843 & , 0773 \\
\hline$-8,384$ & 1,271 & $<, 0001$ \\
\hline$-3,499$ & ,952 & $<, 0001$ \\
\hline 6,575 & ,649 & $<, 0001$ \\
\hline$-1,049$ & 1,151 & ,0742 \\
\hline 10,074 & ,824 & $<, 0001$ \\
\hline 2,450 & 1,259 & ,0001 \\
\hline$-7,624$ & 1,048 & $<, 0001$ \\
\hline
\end{tabular}

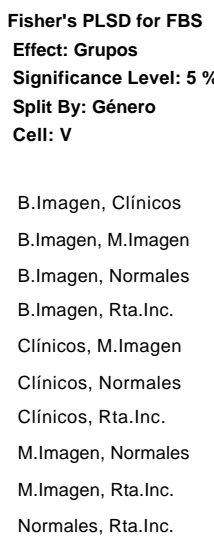

Effect: Grupos

Significance Level: $5 \%$

Cell: $v$

B.Imagen, Clínicos

B.Imagen, M.Imagen

Clínicos, M.Imagen

Clínicos, Normales

M.Imagen, Normales

Normales, Rta.Inc.

* $\mathrm{M}=$ mujeres; $\mathrm{V}=$ Varones. $\mathrm{S}=$ significativo.

Esta escala no discrimina adecuadamente los sujetos clínicos, que contestan sinceramente, de aquellos otros que, intencionadamente, muestran una imagen favorable 
de sí mismos tanto si el análisis se realiza separadamente por sexos como conjuntamente (Tablas 86 y 87). Sus resultados son tan parejos que no ofrecen diferencias estadísticamente significativas.

Haciendo un breve resumen, podemos decir que esta variable:

- Puede identificar a los sujetos que intenten presentar una imagen desfavorable de sí mismos.

- No discrimina, adecuadamente, aquellos sujetos normales que contestan honesta y sinceramente a la prueba de aquellos otros que contestan intentando evidenciar una imagen positiva y favorable de sí mismos.

- Para una mayor precisión diagnóstica, los resultados de esta variable se verían posiblemente reforzados en su interpretación por los alcanzados en las variables $\mathrm{F}$, $\mathrm{Fb}$, F-K, Ds, Ds-r, IR, F(p) y /F-Fb/ con las que muestra una correlación positiva bastante elevada.

\section{V.2.12. - Variable "ODecp" (Escala de Fingimiento Positivo o de Otro Engaño, de Nichols er Greene, 1991):}

Esta escala fue elaborada inicialmente por Cofer, Chance \& Hudson (1949) y denominada "Escala de Fingimiento Positivo" (Mp) para identificar a los sujetos que quisieran presentarse de una forma defensiva, como demasiado equilibrados y ajustados psicológicamente cuando contestaban al Cuestionario del MMPI-2. Posteriormente, la revisión y readaptación realizada por Nichols y Greene (1991) la renombraron como "Escala de Otro Engaño" (ODecp) con un total de 32 ítems (véase Anexo 0-9). Nosotros, en nuestra investigación, hemos adoptado esta readaptación de Nichols y Greene (1991) con su nombre y siglas respectivas.

Tabla 88: Variable "ODecp". Percentiles. Análisis por grupos.

\begin{tabular}{|c|c|c|c|c|c|}
\hline Percentiles & Normal & Clínico & Buena Imagen & Mala Imagen & Rta. Inc. \\
\hline $\mathbf{1 0}$ & 8 & 7 & 17 & 4 & 13 \\
\hline $\mathbf{2 5}$ & 10 & 9 & 22 & 6 & 15 \\
\hline $\mathbf{5 0}$ & 13 & 12 & 25 & 9 & 16 \\
\hline $\mathbf{7 5}$ & 16 & 15 & 27 & 12 & 18 \\
\hline $\mathbf{9 0}$ & 19 & 18 & 29 & 16 & 20 \\
\hline
\end{tabular}

Podemos confirmar, a través de los resultados mostrados en la Tabla 88 de los percentiles, que tanto los sujetos que contestan honesta y sinceramente (normales y clínicos) no presentan mayores diferencias entre ellos, pero cuando observamos a los grupos que contestan intentando falsificar (buena y mala imagen), las diferencias son notables, incluso entre ellos mismos.

Nuestros resultados se diferencian escasamente de los aportados por Butcher, J.; Dahlstrom, W.; Graham, J.; Tellegen, A. \& Kaemer, B. (1989) en una investigación con 2.600 sujetos considerados como de población normal. El percentil 50, para Butcher y su equipo (1989), se refleja en 11 puntuaciones directas (nuestros resultados: 13); el percentil 90, 17 (nosotros, 19) y el percentil 10, para Butcher y su equipo (1989), muestra una puntuación directa de 6 (nosotros: 8).

Las correlaciones obtenidas en la Tabla 89 se muestran muy elevadas y positivas con las variables: Wsd, L, K y S (y áun más elevadas en el grupo de "buena imagen"). Por el 
contrario, las correlaciones negativas se muestran con las variables: F, Fb, Ds, Ds-r, FBS y F-K (y aún más elevadas en el grupo de "buena imagen"). Podemos observar la práctica ausencia de significación estadística del grupo que contestó a los ítems de forma inconsistente (Rta. Inc.), excepto con la Deseabilidad Social (Wsd).

Tabla 89. Variable "ODecp". Correlaciones *.

\begin{tabular}{|c|c|c|c|c|c|}
\hline Variables & Normal & Clínico & Buena Imagen & Mala Imagen & Rta. Inc. \\
\hline L & $\mathbf{. 5 7 8}$ & $\mathbf{. 5 0 6}$ & $\mathbf{. 7 7 2}$ & $\mathbf{. 6 4 6}$ & .211 \\
\hline F & $\mathbf{- . 1 6 6}$ & $\mathbf{- . 1 7 0}$ & $\mathbf{- . 4 6 2}$ & $\mathbf{- . 4 3 7}$ & .027 \\
\hline K & $\mathbf{. 3 7 3}$ & $\mathbf{. 3 2 5}$ & $\mathbf{. 5 4 0}$ & $\mathbf{. 4 8 3}$ & -.015 \\
\hline Fb & $\mathbf{- . 1 0 9}$ & $\mathbf{- . 2 1 9}$ & $\mathbf{- . 4 1 1}$ & $\mathbf{- . 4 6 7}$ & -.047 \\
\hline VRIN & $\mathbf{- . 1 2 6}$ & $\mathbf{. 1 6 7}$ & $\mathbf{- . 3 7 3}$ & $\mathbf{. 5 6 1}$ & -.049 \\
\hline TRIN & $\mathbf{. 1 6 0}$ & $\mathbf{. 1 7 4}$ & .066 & .164 & .137 \\
\hline Fp & $\mathbf{. 1 3 3}$ & .095 & $\mathbf{- . 0 7 7}$ & $\mathbf{- . 2 7 5}$ & .041 \\
\hline S & $\mathbf{. 4 3 1}$ & $\mathbf{. 3 9 8}$ & $\mathbf{. 6 9 5}$ & $\mathbf{. 6 7 5}$ & .053 \\
\hline Ds & $\mathbf{- . 3 3 4}$ & $\mathbf{- . 2 8 5}$ & $\mathbf{- . 5 3 9}$ & $\mathbf{- . 5 6 1}$ & .039 \\
\hline Ds-r & $\mathbf{- . 3 7 9}$ & $\mathbf{- . 3 3 0}$ & $\mathbf{- . 6 3 4}$ & $\mathbf{- . 6 2 0}$ & .019 \\
\hline FBS & $\mathbf{- . 1 6 4}$ & $\mathbf{- . 2 2 4}$ & -.126 & $\mathbf{- . 4 1 2}$ & .038 \\
\hline ODecp & $\mathbf{1 . 0 0}$ & $\mathbf{1 . 0 0}$ & $\mathbf{1 . 0 0}$ & $\mathbf{1 . 0 0}$ & $\mathbf{1 . 0 0}$ \\
\hline IR & $\mathbf{. 1 6 2}$ & .078 & $\mathbf{. 0 2 0}$ & $\mathbf{- . 2 5 1}$ & .115 \\
\hline Wsd & $\mathbf{. 7 9 9}$ & $\mathbf{. 8 1 3}$ & $\mathbf{. 8 9 7}$ & $\mathbf{. 9 0 2}$ & $\mathbf{. 6 7 9}$ \\
\hline F-K & $\mathbf{- . 3 0 7}$ & $\mathbf{- . 2 6 2}$ & $\mathbf{- . 5 6 8}$ & $\mathbf{- . 5 3 8}$ & .027 \\
\hline$\dot{d}$ & $\mathbf{- . 1 1 9}$ & -.084 & -.104 & .057 & .048 \\
\hline F-Fb/ & $\mathbf{- . 1 2 7}$ & -.050 & $\mathbf{- . 3 4 7}$ & -.198 & .075 \\
\hline
\end{tabular}

* Los valores en negrita, resultaron ser estadísticamente significativos al $\mathrm{p}<.001$

Si comparamos nuestros resultados con los obtenidos por Butcher, J.; Dahlstrom, W.; Graham, J.; Tellegen, A. \& Kaemer, B. (1989), podemos apreciar que con el grupo de población normal, que contestan sinceramente a la prueba, los resultados son notablemente semejantes: con la variable L (Butcher: ,55; nosotros: ,578), con la variable K (Butcher: ,32; nosotros: ,373), con la variable S (Butcher: ,40; nosotros: ,431), y con la variable Wsd (Butcher: ,80; nosotros: ,799).

Tabla 90: Variable "ODecp": Puntuaciones Medias y $\mathcal{S} t . \mathcal{D}$. Análisis comparativo entre grupos

\begin{tabular}{|c|c|c|c|c|c|c|c|c|c|}
\hline \multicolumn{2}{|c|}{ Normal } & \multicolumn{2}{c|}{ Clínico } & \multicolumn{2}{c|}{ Buena Imagen } & \multicolumn{2}{c|}{ Mala Imagen } & \multicolumn{2}{c|}{ Rta. Inc. } \\
\hline Media & St.D & Media & St.D & Media & St.D & Media & St.D & Media & St.D \\
\hline 13,483 & 4,301 & 12,241 & 4,319 & 23,826 & 4,516 & 9,305 & 4,902 & 16,430 & 2,685 \\
\hline
\end{tabular}

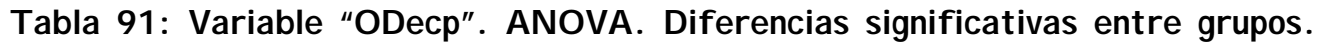

\begin{tabular}{|c|c|c|c|c|}
\hline \multicolumn{1}{|c|}{ Grupos } & Dif.Med. & Dif. Crit. & $\mathbf{p}$ & Signf. (5\%) \\
\hline Normal vs. Clínico & 1,242 &, 409 & $<, 0001$ & SI \\
\hline Normal vs. B. Imagen & $-10,343$ &, 541 & $<, 0001$ & SI \\
\hline Normal vs. M. Imagen & 4,178 &, 552 & $<, 0001$ & SI \\
\hline Normal vs. Rtas. Inc. & $-2,947$ &, 629 & $<, 0001$ & SI \\
\hline Clínico vs. B. Imagen & $-11,586$ &, 615 & $<, 0001$ & SI \\
\hline Clínico vs. M. Imagen & 2,936 &, 625 & $<, 0001$ & SI \\
\hline Clínico vs. Rtas. Inc. & $-4,189$ &, 694 & $<, 0001$ & SI \\
\hline B. Imagen vs. M. Imagen & 14,521 &, 718 & $<, 0001$ & SI \\
\hline B. Imagen vs. Rtas. Inc. & 7,396 &, 779 & $<, 0001$ & SI \\
\hline M. Imagen vs. Rtas. Inc. & $-7,125$ &, 786 & $<, 0001$ & SI \\
\hline
\end{tabular}


Gráfica 42: Variable "ODecp". $\mathcal{A N} O \mathcal{V} \mathcal{A}$.

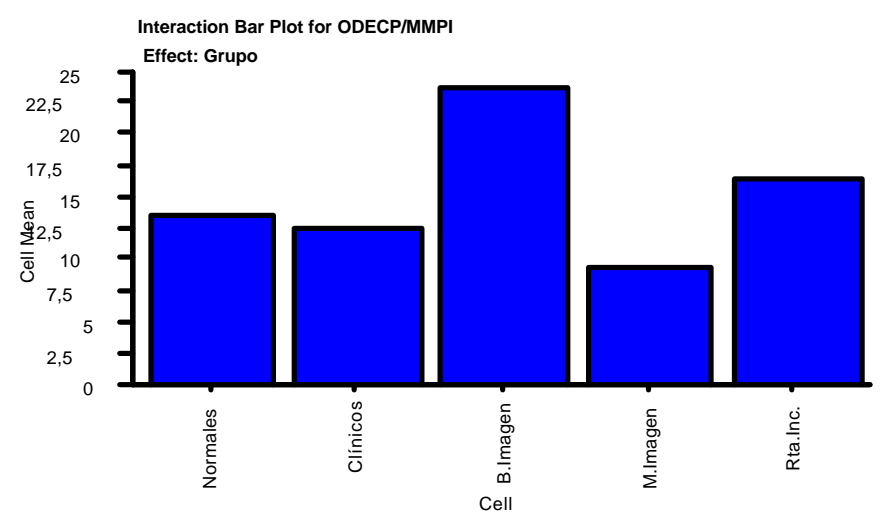

El grupo de sujetos con buena imagen son los que presentan las puntuaciones medias más elevadas (Tabla 90), siendo sus diferencias,con todos los demás grupos (y éstos entre sî), estadísticamente significativas (Tabla 91) al p<,0001.

Gráfica 43: Variable "ODecp". Análisis intersexos/intergrupos.

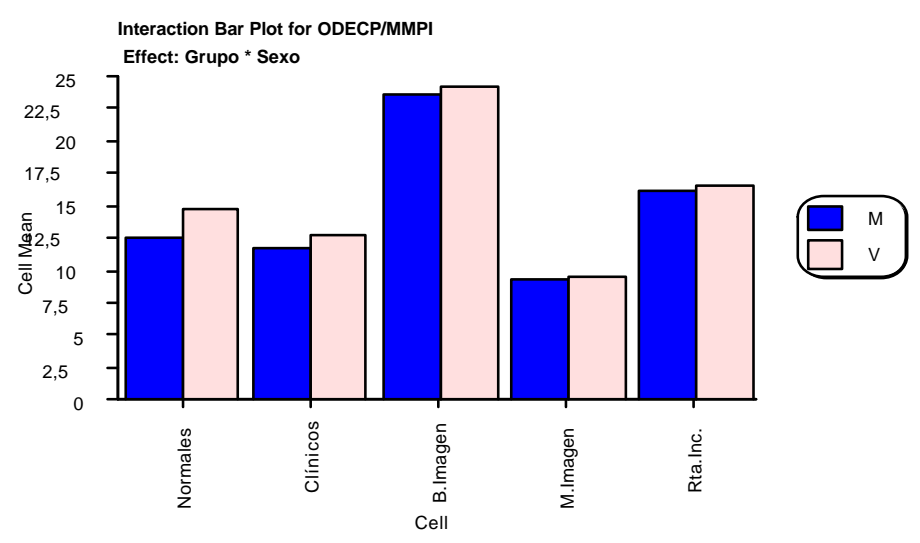

Tabla 92: Variable "ODecp". Diferencias intergrupos/intersexos *.

Fisher's PLSD for ODecp

Effect: Grupos

Significance Level: $5 \%$

Split By: Género

Cell: $M$

B.Imagen, Clínicos

B.Imagen, M.Imagen

B.Imagen, Normales

B.Imagen, Rta.Inc.

Clínicos, M.Imagen

Clínicos, Normales

Clínicos, Rta.Inc.

M.Imagen, Normales

M.Imagen, Rta.Inc.

Normales, Rta.Inc.
Fisher's PLSD for ODecp

Effect: Grupos

Significance Level: $5 \%$

Split By: Género

Cell: $\mathrm{V}$

\begin{tabular}{|c|c|c|}
\hline Mean Diff. & Crit. Diff & P-Value \\
\hline 11,968 & ,784 & $<, 0001$ \\
\hline 14,501 & ,886 & $<, 0001$ \\
\hline 11,013 & ,683 & $<, 0001$ \\
\hline 7,483 & 1,029 & $<, 0001$ \\
\hline 2,533 & ,771 & $<, 0001$ \\
\hline 年, & ,525 & ,0004 \\
\hline$-4,485$ & ,932 & $<, 0001$ \\
\hline$-3,488$ & ,667 & $<, 0001$ \\
\hline$-7,018$ & 1,019 & $<, 0001$ \\
\hline$-3,530$ & ,848 & $<, 0001$ \\
\hline
\end{tabular}

B.Imagen, Clínicos

B.Imagen, M.Imagen

B.Imagen, Normales

B.Imagen, Rta.Inc.

Clínicos, M.Imagen

Clínicos, Normales

Clínicos, Rta.Inc.

M.Imagen, Normales

M.Imagen, Rta.Inc.

Normales, Rta.Inc.

\begin{tabular}{|c|c|c|}
\hline Mean Diff. & Crit. Diff & P-Value \\
\hline 11,135 & ,951 & $<, 0001$ \\
\hline 14,503 & 1,170 & $<, 0001$ \\
\hline 9,309 & ,849 & $<, 0001$ \\
\hline 7,358 & 1,160 & $<, 0001$ \\
\hline 3,368 & 1,022 & $<, 0001$ \\
\hline$-1,826$ &, 630 & $<, 0001$ \\
\hline$-3,777$ & 1,011 & $<, 0001$ \\
\hline$-5,194$ & ,928 & $<, 0001$ \\
\hline$-7,145$ & 1,218 & $<, 0001$ \\
\hline$-1,951$ & ,915 & $<, 0001$ \\
\hline
\end{tabular}

$* \mathrm{M}=$ mujeres; $\mathrm{V}=$ Varones. $\mathrm{S}=$ significativo. 
Realizando un breve resumen podemos decir que:

- Puede detectar a los sujetos que contestan a la prueba fingiendo de forma defensiva, intentando ofrecer una buena imagen de sí mismo.

- Para una mayor precisión diagnóstica podemos ayudarnos de los resultados en las escalas Wsd, L y S en las que se verán corroboradas por la misma dirección y valor semejante de sus puntuaciones.

- Igualmente, pero en sentido contrario, podemos apreciar la misma precisión diagnóstica contemplando las puntuaciones en las escalas Ds, Ds-r, F, Fb y F-K en las que encontraremos, probablemente, valores negativos y bajos.

\section{V.2.13. - Variable "IR". Escala de Inconsistencia de Respuestas de Sewell of Rogers, (1994):}

Los 16 ítems que componen esta escala intentan identificar los perfiles simulados o que intentan exagerar su sintomatología (véase Anexo 0-8). Esta escala contiene un $50 \%$ de los mismos ítems que los de la Escala Psiquiátrica $\mathrm{F}(\mathrm{p})$ de Arbisi y Ben-Porath $(1995,1998)$, de aquí que las correlaciones sean extremadamente altas. A través de la semejanza de resultados observados en nuestra investigación, en los diferentes tratamientos estadísticos, pensamos que ambas escalas evalúan lo mismo.

Tabla 93: Variable "IR". Percentiles. Análisis por grupos.

\begin{tabular}{|c|c|c|c|c|c|}
\hline Percentiles & Normal & Clínico & Buena Imagen & Mala Imagen & Rta. Inc. \\
\hline $\mathbf{1 0}$ & 0 & 0 & 1 & 6 & 5 \\
\hline $\mathbf{2 5}$ & 0 & 1 & 2 & 10 & 6 \\
\hline $\mathbf{5 0}$ & 1 & 2 & 3 & 12 & 8 \\
\hline $\mathbf{7 5}$ & 2 & 4 & 3 & 13 & 9 \\
\hline $\mathbf{9 0}$ & 3 & 6 & 4 & 13 & 11 \\
\hline
\end{tabular}

Si observamos los resultados mostrados en la Tabla 93 sobre los diferentes percentiles podemos observar que los grupos de "mala imagen" y de "Respuestas inconsistentes" (Rta. Inc.) son los que presentan mayor incidencia en sus puntuaciones. De tal forma que el 90\% de los sujetos que, intencionadamente presentan una imagen negativa de sí mismos, obtienen una puntuación tan alta $(\geq 6)$ como el $10 \%$ de los sujetos clínicos. En el grupo de sujetos considerados como normales, solamente el $10 \%$ presentan una puntuación $\geq 3$ en esta escala.

Resultados semejantes fueron observados en la Tabla 68 con la Escala Psiquiátrica de Arbisi y Ben-Porath, F(p).

De la Tabla 94, donde podemos apreciar las diferentes correlaciones de IR obtenidas con el resto de las variables y entre los distintos grupos, destacaremos las puntuaciones elevadas positivas que ha obtenido el grupo de "mala imagen" con las variables, F (,873), Fb (,885), FBS (,712), F-K(,799) Ds-r $(, 684)$ y F(p) $(, 907)$.

Este mismo grupo presentó unas correlaciones negativas, bastante mas bajas, con las variables: Wsd $(-, 238)$ y ODecp $(-, 255)$.

Haciendo un análisis comparativo con los datos aportados por Butcher, J.; Dahlstrom, W.; Graham, J.; Tellegen, A. \& Kaemer, B. (1989) con 2.600 sujetos normales, las correlaciones de esta variable fueron: $\mathrm{F}=, 41$; (nuestros resultados: ,628); $\mathrm{FBS}=, 01$ (nosotros: ,282); $\mathrm{Fb}=, 49$ (nosotros: ,671); $\mathrm{F}(\mathrm{p})=, 58$ (nosotros: ,798). Como 
vemos coinciden en el signo positivo, pero nuestras correlaciones fueron sensiblemente más elevadas que las presentados por Butcher, J.; Dahlstrom, W.; Graham, J.; Tellegen, A. \& Kaemer, B. (1989).

Tabla 94: Variable "IR". Correlaciones *.

\begin{tabular}{|c|c|c|c|c|c|}
\hline Variables & Normal & Clínico & Buena Imagen & Mala Imagen & Rta. Inc. \\
\hline $\mathbf{L}$ & .196 & .013 & .116 & .048 & -.142 \\
\hline $\mathbf{F}$ & .628 & .769 & .572 & .873 & .329 \\
\hline $\mathbf{K}$ & $\begin{array}{l}.198 \\
-.198\end{array}$ & -.332 & -.116 & -.062 & -.428 \\
\hline $\mathbf{F b}$ & .671 & .719 & .694 & .885 & .462 \\
\hline VRIN & .273 & .152 & .389 & -.131 & .026 \\
\hline TRIN & .166 & .294 & .064 & -.035 & .274 \\
\hline $\mathbf{F p}$ & .798 & .795 & .835 & .907 & .460 \\
\hline $\mathbf{S}$ & -.197 & -.359 & -.108 & -.185 & -.343 \\
\hline Ds & .463 & .611 & .495 & .743 & .344 \\
\hline Ds-r & .369 & .543 & .397 & .684 & .340 \\
\hline FBS & .282 & .342 & 313 & .712 & .045 \\
\hline ODecp & .162 & .078 & .020 & -.255 & .115 \\
\hline IR & 1.00 & 1.00 & 1.00 & 1.00 & 1.00 \\
\hline Wsd & .250 & .210 & .104 & -.238 & .253 \\
\hline F-K & .503 & .691 & .424 & .799 & .458 \\
\hline$i$ & -.041 & -.065 & .002 & .067 & .028 \\
\hline$/ \mathrm{F}-\mathrm{Fb} /$ & .206 & .275 & .154 & .456 & -.070 \\
\hline
\end{tabular}

* Los valores en negrita, resultaron ser estadísticamente significativos al $\mathrm{p}<.001$

Podemos observar, también, que el grupo de clínicos presentan unas correlaciones positivas más elevadas que el grupo de sujetos normales.

Igualmente hemos de destacar la nula correspondencia que presenta IR con la variable L, en donde solamente con el grupo de normales presenta una correlación muy baja, aunque significativa sobre los valores aquí especificados.

Destacamos la variable ODecp que correlaciona de forma negativa únicamente con el grupo de mala imagen $(-, 255)$.

Tabla 95: Variable "IR": Puntuaciones Medias y $\mathcal{S}$ t. $\mathcal{D}$. Análisis comparativo entre

$$
\text { grupos. }
$$

\begin{tabular}{|c|c|c|c|c|c|c|c|c|c|}
\hline \multicolumn{2}{|c|}{ Normal } & \multicolumn{2}{c|}{ Clínico } & \multicolumn{2}{c|}{ Buena Imagen } & \multicolumn{2}{c|}{ Mala Imagen } & \multicolumn{2}{c|}{ Rta. Inc. } \\
\hline Media & St.D & Media & St.D & Media & St.D & Media & St.D & Media & St.D \\
\hline 1,379 & 1,566 & 2,790 & 2,379 & 3,028 & 1,463 & 10,673 & 3,184 & 7,805 & 2,279 \\
\hline
\end{tabular}

Contemplando los resultados de la Tabla 95 sobre las puntuaciones medias, podemos señalar que es el grupo de "mala imagen" el que se destaca ostensiblemente de los demás. Solamente el grupo que ha contestado de forma inconsistente (Rta. Inc.) le sigue. Los sujetos que han contestado de una forma coherente y sincera (normal y clínico) presentan unas puntuaciones medias muy escasas.

Semejantes resultados fueron obtenidos también con la Escala Psiquiátrica $\mathrm{F}(\mathrm{p})$ de Arbisi y Ben-Porath $(1995,1998)$.

Podemos determinar a través de los resultados mostrados en la Tabla 96 que esta variable puede discriminar adecuadamente a todos los grupos excepto cuando se contrastan al grupo clínico con los sujetos queintentan mostrar una imagen favorable de sí mismos.

Si contemplamos la Tabla 97, en donde se han efectuado el ANOVA intersexos e intergrupos, podemos apreciar que son los varones los que no presentan diferencias 
estadísticamente significativas entre clínicos y aquellos que han intentado ofrecer una imagen favorable de sí mismos.

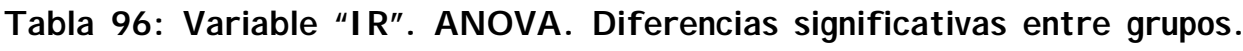

\begin{tabular}{|c|c|c|c|c|}
\hline Grupos & Dif.Med. & Dif. Crit. & p & Signf. (55) \\
\hline Normal vs. Clínico & $-1,141$ &, 188 & $<, 0001$ & SI \\
\hline Normal vs. B. Imagen & $-1,649$ &, 248 & $<, 0001$ & SI \\
\hline Normal vs. M. Imagen & $-9,294$ &, 253 & $<, 0001$ & SI \\
\hline Normal vs. Rtas. Inc. & $-6,426$ &, 288 & $<, 0001$ & SI \\
\hline Clínico vs. B. Imagen &,- 239 &, 282 & $<, 0001$ & SI \\
\hline Clínico vs. M. Imagen & $-7,883$ &, 286 &, 0969 & NO \\
\hline Clínico vs. Rtas. Inc. & $-5,015$ &, 318 & $<, 0001$ & SI \\
\hline B. Imagen vs. M. Imagen & $-7,644$ &, 329 & $<, 0001$ & SI \\
\hline B. Imagen vs. Rtas. Inc. & $-4,777$ &, 357 & $<, 0001$ & SI \\
\hline M. Imagen vs. Rtas. Inc. & 2,868 &, 360 & $<, 0001$ & SI \\
\hline
\end{tabular}

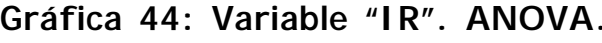

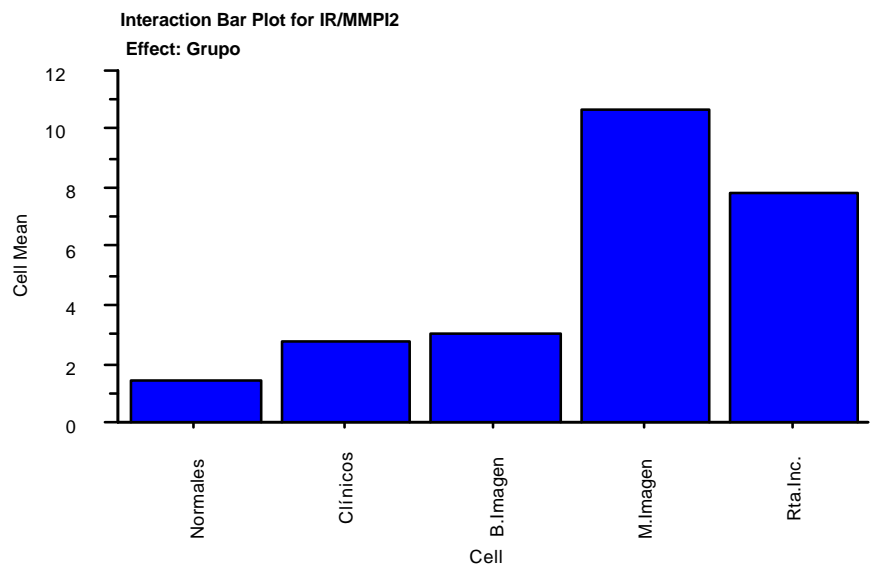

Gráfica 45: Variable "IR". Anális is intersexos/intergrupos.

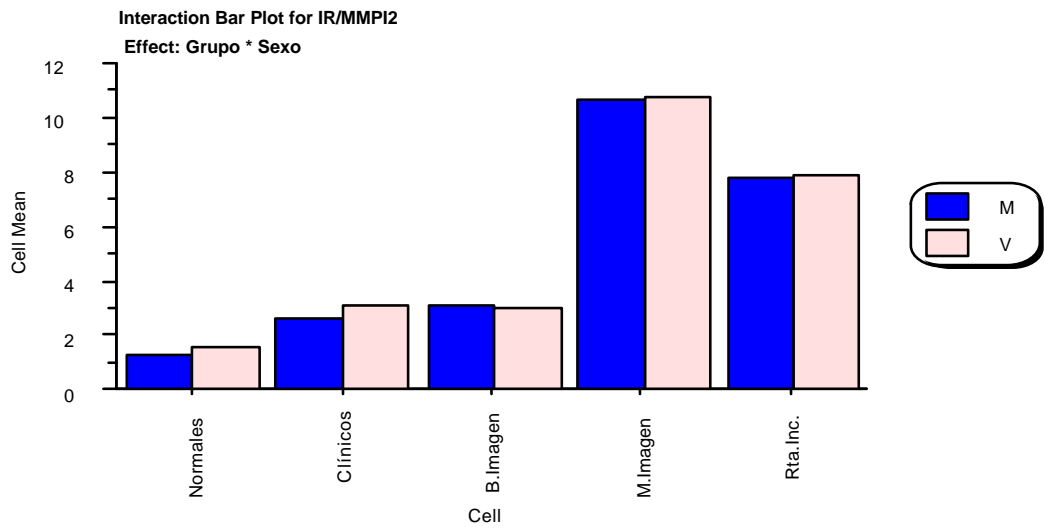


Tabla 97: Variable "IR". Diferencias intergrupos/intersexos *.
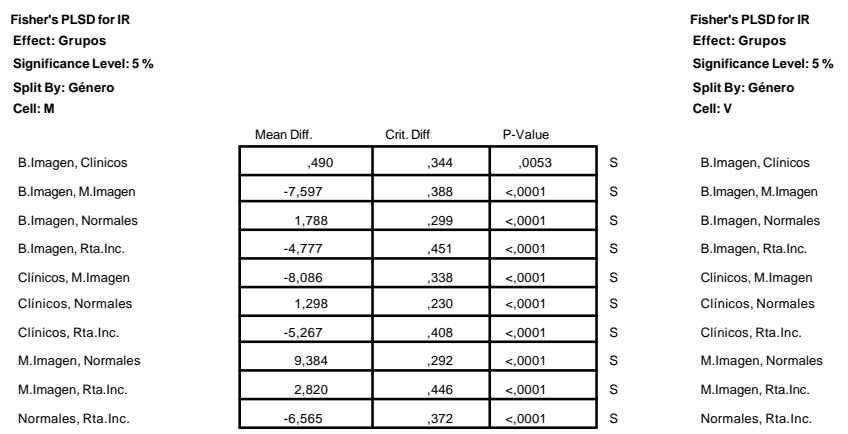

Normales, Rta.Inc.

* $\mathrm{M}=$ mujeres; $\mathrm{V}=$ Varones. $\mathrm{S}=$ significativo.

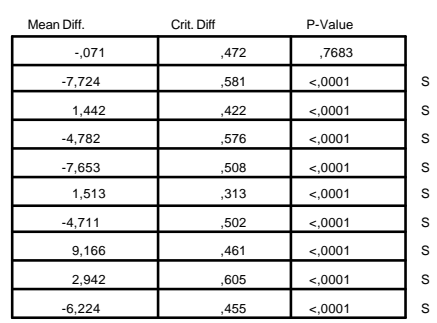

Con los resultados expresados por la Gráfica 45 podemos observar que son los varones los que muestran sus puntuaciones superiores a las mujeres, excepto en el grupo de clínicos.

Resumiendo, podemos decir que:

- Es una variable que identifica a los sujetos que intentan fingir de forma negativa; es decir, intentando mostrar de sí mismo una imagen desfavorable.

- Si comparamos los diferentes resultados obtenidos con esta variable y la Escala psiquiátrica $\mathrm{F}(\mathrm{p})$ de Arbisi y Ben-Porath (1995, 1998), podemos concluir que son extremadamente semejantes debido, fundamentalmente a que la mitad de los ítems son comunes a ambas escalas. Por consiguiente, es una variable que no aporta, en nuestra investigación, nada diferente a la Escala psiquiátrica $\mathrm{F}(\mathrm{p})$ de Arbisi y BenPorath (1995, 1998). Por tanto, una vez demostrado este solapamiento, a partir de este momento será sustituida, en nuestras referencias, por la Escala psiquiátrica $F(p)$ de Arbisi y Ben-Porath $(1995,1998)$, más actual.

\section{V.2.14.- Variable "Wsd" (Escala de Desabilidad Social de Wiggings,}

\section{9):}

El objetivo de Wiggins (1959) fue identificar a los que contestaban el MMPI de una forma socialmente deseable en un grupo de estudiantes y así poderlos diferenciar de aquellos que respondían honesta y sinceramente. Los 33 ítems que componen esta escala pueden verse en el Anexo 0-7.

Tabla 98: Variable "Wsd". Percentiles. Análisis por grupos.

\begin{tabular}{|c|c|c|c|c|c|}
\hline Percentiles & Normal & Clínico & Buena Imagen & Mala Imagen & Rta. Inc. \\
\hline $\mathbf{1 0}$ & 10 & 10 & 16,7 & 4 & 13 \\
\hline $\mathbf{2 5}$ & 12 & 11 & 20 & 6 & 15 \\
\hline $\mathbf{5 0}$ & 14 & 14 & 23 & 8 & 16 \\
\hline $\mathbf{7 5}$ & 16 & 17 & 26 & 12 & 18 \\
\hline $\mathbf{9 0}$ & 19 & 19 & 28 & 16 & 20 \\
\hline
\end{tabular}

Consultando los resultados percentilados, expuestos en la Tabla 98, dados por los diferentes grupos de sujetos aquí analizados, podemos apreciar que las personas que contestaron intentando ofrecer una imagen favorable de sí mismo son los que presentan sus puntuaciones más elevadas, de tal manera que el $75 \%$ de estas personas puntuan tan 
alto como el $10 \%$ de las personas que contestan de forma inconsistente (Rta. Inc.), o los otros dos grupos de personas que contentan honestamente (normal y clínico).

Igualmente podemos apreciar que los resultados de las personas que contestan honesta y sinceramente, normal y clínicos, son, prácticamente los mismos. Por tanto, podemos suponer que esta variable Wsd no parece discriminar entre estos dos grupos.

La Tabla 99 nos muestra las correlaciones de Wsd con el resto de las variables ofrecidos por los diferentes grupos. Podemos apreciar que los valores más elevados y positivos son manifestados por las variables del grupo "buena imagen": L (,683), ODecp $($,897) y $\mathrm{S}(, 523)$. De forma negativa, las correlaciones más altas del grupo "buena imagen" se mostraron con Ds-r $(-, 487)$, F-K $(-, 407)$.

Tabla 99. Variable "Wsd". Correlaciones *.

\begin{tabular}{|c|c|c|c|c|c|}
\hline Variables & Normal & Clínico & Buena Imagen & Mala Imagen & Rta. Inc. \\
\hline $\mathbf{L}$ & .482 & .332 & .683 & .565 & .005 \\
\hline $\mathbf{F}$ & -.040 & .030 & -356 & .431 & .103 \\
\hline $\bar{K}$ & .086 & .018 & .355 & .307 & -.222 \\
\hline Fb & .071 & .005 & -.287 & -.418 & .134 \\
\hline VRIN & -.043 & .111 & -.266 & .503 & -.091 \\
\hline TRIN & .283 & .333 & .239 & .288 & .312 \\
\hline $\mathbf{F p}$ & .221 & .180 & .010 & -.272 & .131 \\
\hline $\mathbf{S}$ & .115 & .072 & .523 & .522 & -.244 \\
\hline Ds & -.068 & .003 & -.391 & -.472 & .179 \\
\hline Ds-r & -.111 & -.054 & -.487 & -.526 & .074 \\
\hline FBS & -.078 & -.072 & -.092 &.- .361 & $\begin{array}{ll}-.141 \\
\end{array}$ \\
\hline ODecp & .799 & .813 & .897 & .902 & .679 \\
\hline IR & .250 & .210 & .104 & -.233 & .253 \\
\hline Wsd & 1.00 & 1.00 & 1.00 & 1.00 & 1.00 \\
\hline F-K & -.072 & .013 & -.407 & -.478 & .191 \\
\hline$i$ & -.132 & -.109 & -.144 & .077 & -.024 \\
\hline$/ \mathbf{F - F b /}$ & -.122 & .061 & -.285 & -.262 & -.018 \\
\hline
\end{tabular}

* Los valores en negrita, resultaron ser estadísticamente significativos al $\mathrm{p}<.001$

Otro tanto sucede con las correlaciones del grupo de mala imagen en las que podemos observar que cambian de signo con respecto a las de buena imagen en $\mathrm{F}$ (buena imagen: -.356; mala imagen: .431), VRIN (buena imagen: -.266: mala imagen: .503), IR (buena imagen: .104; mala imagen: -.233) y que en general resultaron ser las correlaciones sensiblemente más elevadas que en el grupo de buena imagen.

El grupo que contestó de forma inconsistente (Rta. Inc.) fue el que menos variables (4) resultaron significativas sus correlaciones juntamente con el clínico (6)

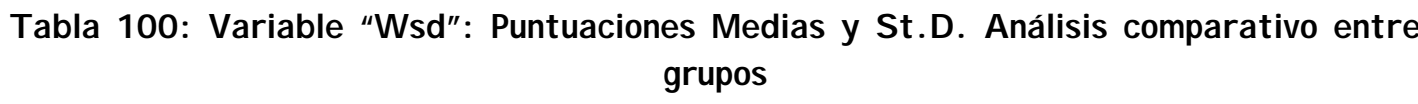

\begin{tabular}{|c|c|c|c|c|c|c|c|c|c|}
\hline \multicolumn{2}{|c|}{ Normal } & \multicolumn{2}{c|}{ Clínico } & \multicolumn{2}{c|}{ Buena Imagen } & \multicolumn{2}{c|}{ Mala Imagen } & \multicolumn{2}{c|}{ Rta. Inc. } \\
\hline Media & St.D & Media & St.D & Media & St.D & Media & St.D & Media & St.D \\
\hline 14,043 & 3,498 & 14,237 & 3,789 & 22,826 & 4,395 & 9,178 & 4,573 & 16,385 & 2,860 \\
\hline
\end{tabular}

La Tabla 100, referente a las puntuaciones medias, nos ofrece interpretaciones semejantes a las ya formuladas cuando comentamos los resultados percentilados de la Tabla 98. Las personas que intentaron dar una buena imagen de sí mismo son las que obtienen las puntuaciones más elevadas en esta escala. Los grupos que contestaron de forma honesta y sincera, como son el normal y el clínico, no manifiestan diferencias estadísticamente significativas en sus puntuaciones. 


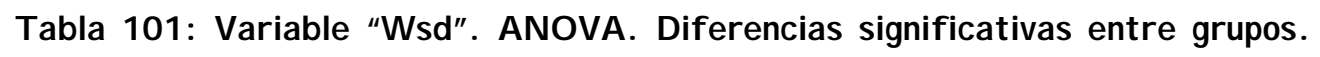

\begin{tabular}{|c|c|c|c|c|}
\hline Grupos & Dif.Med. & Dif. Crit. & $\mathbf{p}$ & Signf. (5\%) \\
\hline Normal vs. Clínico &,- 194 &, 354 &, 2822 & NO \\
\hline Normal vs. B. Imagen & $-8,783$ &, 468 & $<, 0001$ & SI \\
\hline Normal vs. M. Imagen & 4,865 &, 477 & $<, 0001$ & SI \\
\hline Normal vs. Rtas. Inc. & $-2,342$ &, 544 & $<, 0001$ & SI \\
\hline Clínico vs. B. Imagen & $-8,589$ &, 531 & $<, 0001$ & SI \\
\hline Clínico vs. M. Imagen & 5,059 &, 540 & $<, 0001$ & SI \\
\hline Clínico vs. Rtas. Inc. & $-2,148$ &, 600 & $<, 0001$ & SI \\
\hline B. Imagen vs. M. Imagen & 13,648 &, 620 & $<, 0001$ & SI \\
\hline B. Imagen vs. Rtas. Inc. & 6,441 &, 673 & $<, 0001$ & SI \\
\hline M. Imagen vs. Rtas. Inc. & $-7,207$ &, 680 & $<, 0001$ & SI \\
\hline
\end{tabular}

Gráfica 46: Variable "Wsd". $\mathcal{A} \mathcal{N} O \mathcal{V} \mathcal{A}$.

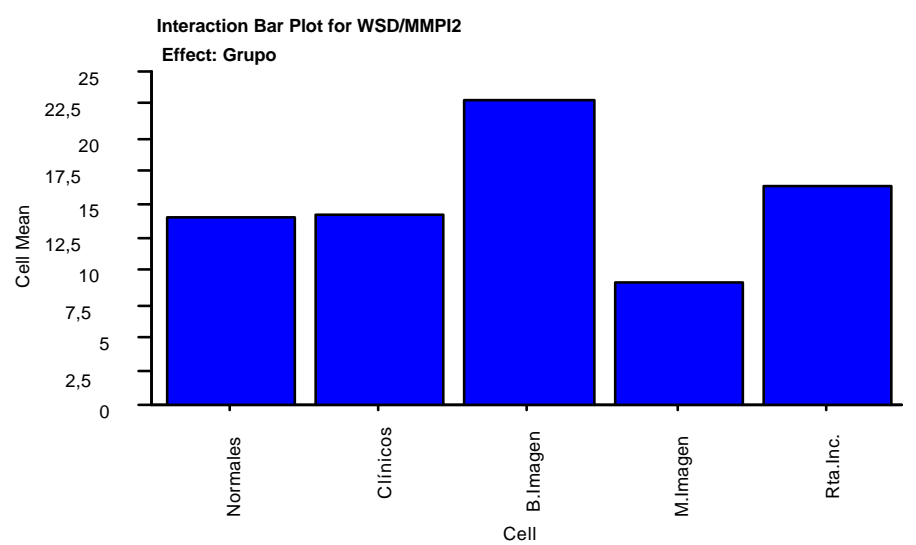

Las Tablas 101 y 102 nos muestran más explícitamente sus resultados en el análisis de sus diferencias, tanto si se toman los grupos diferenciados por sexos $\mathrm{o}$ conjuntamente. Esta variable no discrimina adecuadamente en sus puntuaciones a los sujetos normales de los clínicos, teniéndonos que ayudar de otra, u otras, variables para una mejor precisión en su interpretación.

Gráfica 47: Variable "Wsd". Análisis intersexos/intergrupos.

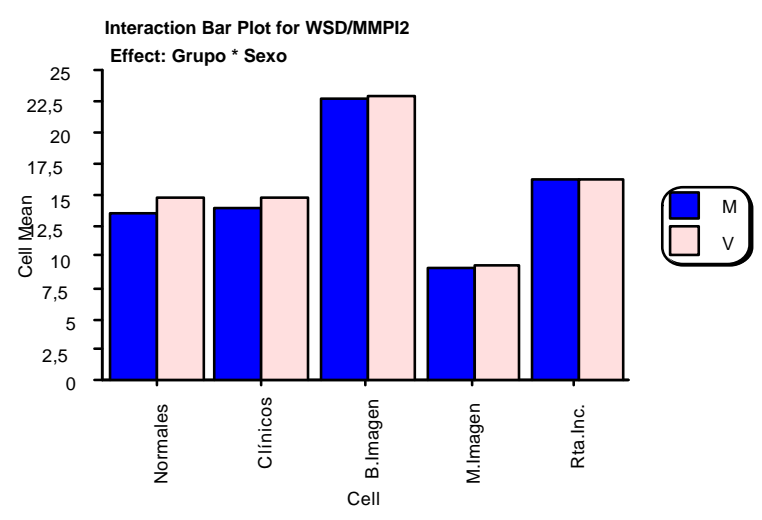


Tabla 102: Variable "Wsd". Diferencias intergrupos/intersexos *.

\begin{tabular}{|c|c|c|c|}
\hline $\begin{array}{l}\text { Fisher's PLSD for Wsd } \\
\text { Effect: Grupos } \\
\text { Significance Level: } 5 \% \\
\text { Split By: Género } \\
\text { Cell: M }\end{array}$ & & & \\
\hline B.Imagen, Clínicos & $\begin{array}{r}\text { Mean Diff. } \\
8,846\end{array}$ & Crit. Diff & P-Value \\
\hline B.Imagen, M.Imagen & 13,708 & ,775 & $<, 0001$ \\
\hline B.Imagen, Normales & 9,164 & ,597 & $<, 0001$ \\
\hline B.Imagen, Rta.Inc. & 6,338 & ,900 & $<, 0001$ \\
\hline Clínicos, M.Imagen & 4,862 & ,674 & $<, 0001$ \\
\hline Clínicos, Normales & ,318 &, 459 &, 1744 \\
\hline Clínicos, Rta.Inc. & $-2,507$ & ,815 & $<, 0001$ \\
\hline M.Imagen, Normales & $-4,544$ &, 583 & $<, 0001$ \\
\hline M.Imagen, Rta.Inc. & $-7,369$ & ,891 & $<, 0001$ \\
\hline Normales, Rta.Inc. & $-2,825$ & ,742 & $<, 0001$ \\
\hline
\end{tabular}

* $\mathrm{M}=$ mujeres; $\mathrm{V}=$ Varones. $\mathrm{S}=$ significativo.

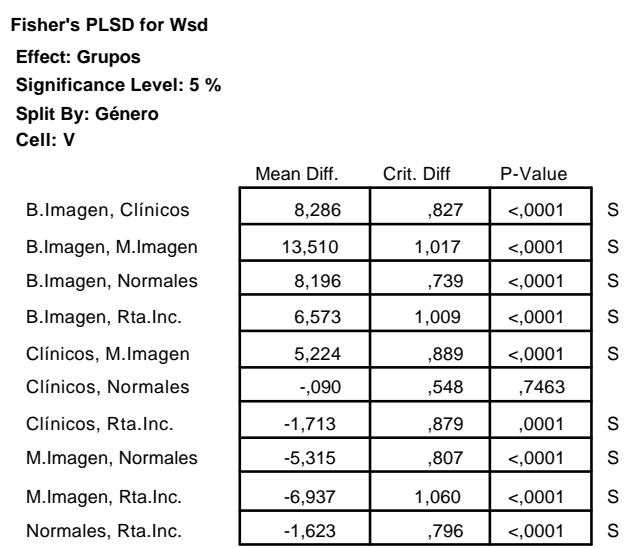

En forma breve, podemos resumir lo más importante que esta variable ha aportado a nuestra investigación a través de nuestros resultados:

- Constatamos que es una variable defensiva o de fingimiento positivo que identifica a los sujetos que se valoran de forma positiva.

- No discrimina adecuadamente el grupo de sujetos normales de los clínicos.

- Para una mayor precisión en su interpretación sus valores elevados pueden ser apoyados, ratificados o complementados por los valores, también elevados, de las escalas L, ODecp y S.

- De igual manera, tendríamos como referencia que los valores de las variables Ds, Ds-r y F-K, puntuarían en sentido contrario.

\section{V.2.15. - Variable "/F. F $6 /$ ":}

Cierto es que ya hemos analizado estas dos variables $(\mathrm{F} \mathrm{y} \mathrm{Fb})$ en distintos momentos, pero ahora las analizamos bajo el valor de su diferencia absoluta $(/ \mathrm{F}-\mathrm{Fb} /)$ en sus puntuaciones. Dada la importancia de estas variables en el MMPI-2, nos interesa saber su aportación a nuestro estudio. Sus puntuaciones se encuentran referidas por sus valores absolutos $^{4}$ y tradicionalmente esta variable ha sido considerada como "infrecuentemente" contestada por una población normal (recordemos que la $\mathrm{Fb}$ se encuentra referida esencialmente por la segunda parte de la prueba, mientras que la $\mathrm{F}$ se refiere a la primera parte).

Butcher, J.; Dahlstrom, W.; Graham, J.; Tellegen, A. \& Kaemer, B. (1989) y Greene (1997, 2000) contemplan esta variable $/ \mathrm{F}-\mathrm{Fb} / \mathrm{con}$ un indicador de la inconsistencia y/o infrecuencia de las respuestas dadas por el sujeto (Greene, 1997, pgs. 203-204, Tablas 9.16 y 9.17). Podemos admitir la inconsistencia cuando sus puntuaciones se muestran elevadas, ya que no parece habitual encontrar un protocolo que, en su primera mitad

\footnotetext{
${ }^{4}$ El valor "absoluto" cuando el valor total resultante de la diferencia entre las variables se presenta sin signo alguno. Su representación está especificada por barras.
} 
presente una puntuación elevada y nula o insignificante en su segunda parte, cuando estamos hablando de una variable "infrecuente" (que la contestan menos del 10\% de los sujetos normales la muestran).

Tabla 103 Variable "/F-F $\mathcal{F} b /$ ". Percentiles. Análisis por grupos.

\begin{tabular}{|c|c|c|c|c|c|}
\hline Percentiles & Normal & Clínico & Buena Imagen & Mala Imagen & Rta. Inc. \\
\hline $\mathbf{1 0}$ & 1 & 1 & 0 & 7,4 & 4 \\
\hline $\mathbf{2 5}$ & 2 & 2 & 1 & 13 & 6 \\
\hline $\mathbf{5 0}$ & 3 & 4 & 2 & 17 & 10 \\
\hline $\mathbf{7 5}$ & 5 & 6 & 4 & 19 & 13,5 \\
\hline $\mathbf{9 0}$ & 8 & 9 & 5,3 & 21 & 16,5 \\
\hline
\end{tabular}

Los datos aportados por Greene (1997, pg.179, Tabla 9.5), el 76,7\% de sujetos (en la revisión de 2000, pg. 53, Tabla 3.11; se encuentra referido por el 75\%) que contestan a la prueba de forma inconsistente, presentan una puntuación $\geq 6$, mientras que en nuestros datos aportados en la Tabla 103, es el 75\% de estos mismos sujetos los que presentan esa misma puntuación.

Cuando establecemos el análisis comparativo percentilado de nuestros resultados con los datos aportados por Greene (1997) sobre los sujetos considerados como normales y que han contestado de forma honesta y sincera, podemos hablar de una mayor diferencia. Mientras que para Greene (1997) el 44,2\% de los sujetos presentan una puntuación de $\geq 2$, para nosotros esta misma puntuación la obtienen el $75 \%$ de los sujetos.

Podemos observar, de forma general, que los resultados ofrecidos por esta variable /F-Fb/ no aportan sugerencia o interpretaciones importantes y diferentes a las ya ofrecidas por sus variables componentes $(\mathrm{F} \mathrm{y} \mathrm{Fb})$ cuando ya se analizaron por separado.

Greene (2000) interpreta sus puntuaciones directas como:

- "PD = 0-1: Puntuación considerada como "baja". Estas puntuaciones indican que los sujetos han contestado a los ítems de una forma más consistente de lo esperado en la mayoría de los individuos. Debería pensarse en la posibilidad de minimizar sintomatología psicopatológica.

- PD = 2-5: Considerado como "normal". El sujeto ha contestado a los ítems de forma consistente y coherente.

- $\mathrm{PD}=$ 6-9: Considerado como "dudoso". El sujetos puede haber contestado de forma incoherente o inconsistente a la prueba, pero esto debe ser contrastado con otras variables.

- $\mathrm{PD} \geq 10$ : Considerado como "acusado". El sujeto ha contestado a los ítems de forma inconsistente. Deben contrastarse las diversas razones potenciales que ha tenido el sujeto para contestar de esta forma". (pg. 64, Tabla 3.18).

Las correlaciones, mostradas en la Tabla 104, se presentan con valorees elevados para el grupo de "mala imagen" y no parecen tan altas como las aportadas por la F.

Volvemos a encontrarnos ligeras diferencias con respecto a los resultados de las correlaciones, tanto con signo positivo como negativo, de las variables $\mathrm{F}$ y Fb. 
Podemos observar, en esta misma Tabla 104, que la variable TRIN no presenta correlación significativa alguna con los valores absolutos de $/ \mathrm{F}-\mathrm{Fb} /$ en ninguno de los grupos. El comportamiento es semejante al de la variable?.

Igualmente podemos constatar en nuestros resultados que nuestra variable presenta una alta correlación positiva, y siendo la única, con la escala de "Hacerse el enfermo" (FBS: ,518) dada por el grupo de mala imagen.

El grupo que responde de forma inconsistente (Rta. Inc.) las únicas correlaciones que muestra se refieren a las variables en donde $\mathrm{F}$ actúa. Juntamente con el grupo clínico, son los dos grupos que menos variables significativas estadísticamente muestran en su resultados.

Tabla 104: Variable "/F. Fb/". Correlaciones *.

\begin{tabular}{|c|c|c|c|c|c|}
\hline Variables & Normal & Clínico & Buena Imagen & Mala Imagen & Rta. Inc. \\
\hline $\mathbf{L}$ & -.135 & -.030 & -.346 & -.023 & .109 \\
\hline $\mathbf{F}$ & .614 & .444 & .704 & .701 & .604 \\
\hline $\bar{K}$ & -.169 & -.077 & -.453 & -.038 & .113 \\
\hline $\mathbf{F b}$ & .076 & .025 & .349 & .351 &.- .538 \\
\hline VRIN & .161 & .131 & .450 & -.151 & -.016 \\
\hline TRIN & -.045 & .025 & .038 & -.171 & -.046 \\
\hline $\mathbf{F p}$ & .279 & .338 & .330 & .577 & .056 \\
\hline $\mathbf{S}$ & -.206 & -.129 & -.458 & -.140 & .066 \\
\hline Ds & .278 & .201 & .581 & .504 & .040 \\
\hline Ds-r & .249 & .177 & .544 & .475 & -.031 \\
\hline FBS & .049 & .035 & .087 & .518 & -.017 \\
\hline ODecp &.- .127 & .050 &.- .347 & -.198 & .075 \\
\hline IR & .206 & .275 & .154 & .456 & -.070 \\
\hline Wsd & -.122 & .061 & -.285 & -.262 & -.018 \\
\hline F-K & .479 & .350 & .679 & .638 & .351 \\
\hline$i$ & -.036 & .009 & .024 & .030 & .021 \\
\hline$/ \mathrm{F}-\mathrm{Fb} /$ & 1.00 & 100 & 100 & 100 & 1.00 \\
\hline
\end{tabular}

Tabla 105: Variable "/F-F Fb/": Puntuaciones Medias y St.D. Anális is comparativo entre grupos

\begin{tabular}{|c|c|c|c|c|c|c|c|c|c|}
\hline \multicolumn{2}{|c|}{ Normal } & \multicolumn{2}{c|}{ Clínico } & \multicolumn{2}{c|}{ Buena Imagen } & \multicolumn{2}{c|}{ Mala Imagen } & \multicolumn{2}{c|}{ Rta. Inc. } \\
\hline Media & St.D & Media & St.D & Media & St.D & Media & St.D & Media & St.D \\
\hline 3,753 & 2,954 & 4,476 & 3,357 & 2,550 & 2,310 & 15,483 & 5,137 & 10,240 & 4,920 \\
\hline
\end{tabular}

Siguiendo los resultados mostrados en la Tabla 105, vemos que la puntuación media más elevada la presenta el grupo de "mala imagen", con una diferencia estadísticamente significativa e importante con respecto a todos los demás grupos. El siguiente grupo que presenta la puntuación mayor es el grupo que contesta h prueba de forma inconsistente (Rta. Inc.), y también sus diferencias resultan estadísticamente significativas $(<, 0001)$.

Si contemplamos la Gráfica 48, correspondiente a la variable $/ \mathrm{F}-\mathrm{Fb} /$, así como las gráficas de las variables $\mathrm{F}$ (Gráfica 22) y $\mathrm{Fb}$ (Gráfica 30), podemos apreciar el gran paralelismo existente entre ellas: en primer lugar aparecen las puntuaciones elevadas correspondientes al grupo de "mala imagen", le siguen las del grupo "Respuestas inconsistentes" (Rta. Inc.), posteriormente el de "clínicos", "normales" y termina con los de "buena imagen".

Por la Tabla 106, donde se analizan las diferencias estadísticamente significativas entre las puntuaciones medias aportadas por los diferentes grupos, podemos ver que sus resultados muestran que todos los grupos son estadísticamente significativos a pesar de que entre el grupo clínico y normal existan escasas diferencias. Cuando contemplamos 
la Tabla 107 y su correspondiente Gráfica 49, podemos contemplar que, en este análisis intersexos e intergrupos, son los varones los que resultaron ser significativas sus diferencias entre normales y clínicos.

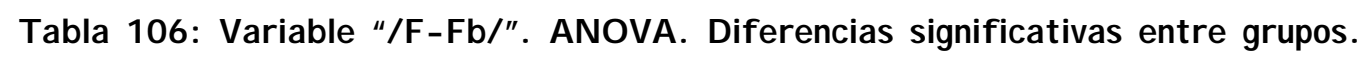

\begin{tabular}{|c|c|c|c|c|}
\hline Grupos & Dif.Med. & Dif. Crit. & p & Signf. (5\%) \\
\hline Normal vs. Clínico &,- 723 &, 323 & $<, 0001$ & SI \\
\hline Normal vs. B. Imagen & 1,203 &, 426 & $<, 0001$ & SI \\
\hline Normal vs. M. Imagen & $-11,731$ &, 435 & $<, 0001$ & SI \\
\hline Normal vs. Rtas. Inc. & $-6,487$ &, 496 & $<, 0001$ & SI \\
\hline Clínico vs. B. Imagen & 1,926 &, 485 & $<, 0001$ & SI \\
\hline Clínico vs. M. Imagen & $-11,007$ &, 492 & $<, 0001$ & SI \\
\hline Clínico vs. Rtas. Inc. & $-5,764$ &, 547 & $<, 0001$ & SI \\
\hline B. Imagen vs. M. Imagen & $-12,934$ &, 566 & $<, 0001$ & SI \\
\hline B. Imagen vs. Rtas. Inc. & $-7,690$ &, 614 & $<, 0001$ & SI \\
\hline M. Imagen vs. Rtas. Inc. & 5,243 &, 620 & $<, 0001$ & SI \\
\hline
\end{tabular}

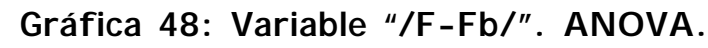

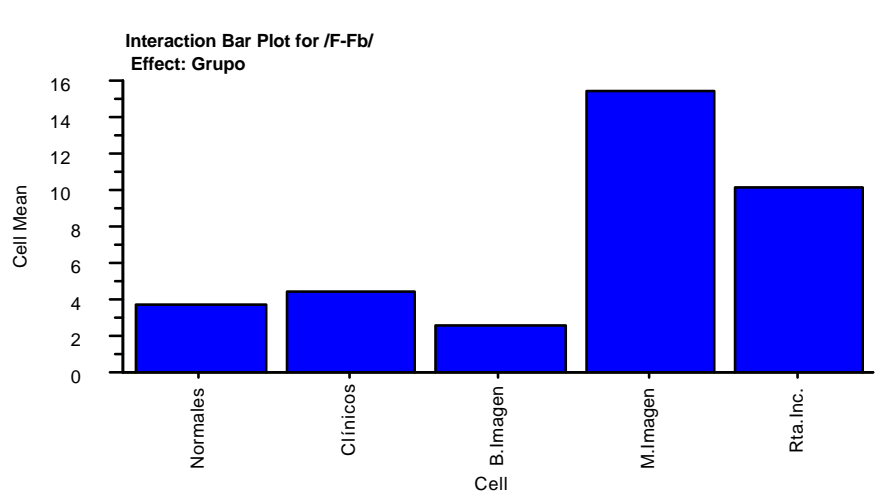

Gráfica 49: Variable "/F-F F b/". Análisis intersexos/intergrupos.

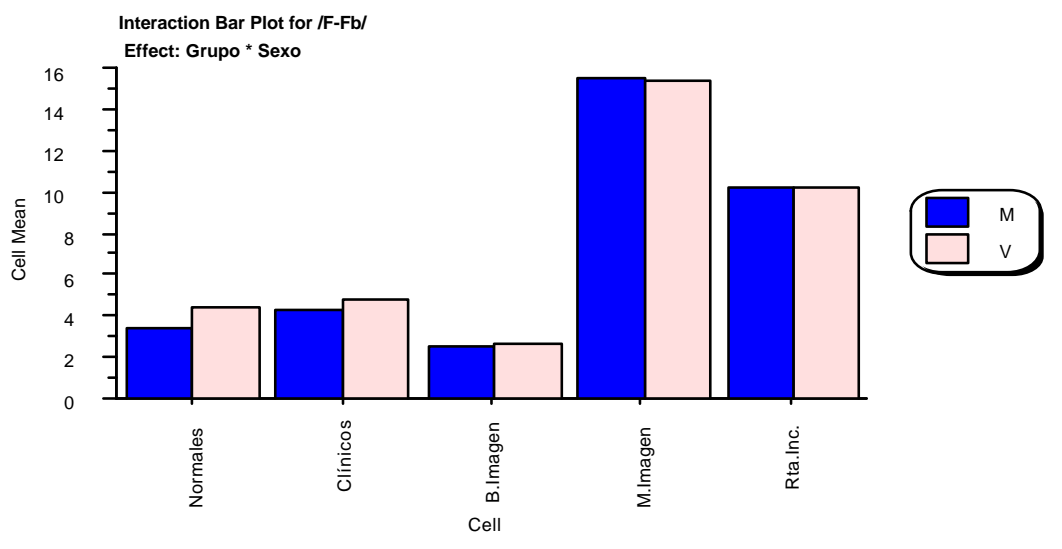


Tabla $107:$ Variable "/F-F $\mathcal{F} b /$ ". Diferencias intergrupos/intersexos *.

\begin{tabular}{|c|c|c|c|c|}
\hline \multicolumn{5}{|c|}{$\begin{array}{l}\text { Fisher's PLSD for /F-FB/ } \\
\text { Effect: Grupos } \\
\text { Significance Level: } 5 \% \\
\text { Split By: Género } \\
\text { Cell: M }\end{array}$} \\
\hline \multirow[b]{2}{*}{ B.Imagen, Clínicos } & Mean Diff. & Crit. Diff & P-Value & \\
\hline & $-1,833$ & ,621 & $<, 0001$ & S \\
\hline \multirow{2}{*}{$\begin{array}{l}\text { B.Imagen, M.Imagen } \\
\text { B.Imagen, Normales }\end{array}$} & $-13,094$ & ,701 & $<, 0001$ & $\mathrm{~S}$ \\
\hline &,- 924 &, 540 &, 0008 & $\mathrm{~S}$ \\
\hline \multirow{2}{*}{$\begin{array}{l}\text { B.Imagen, Rta.Inc. } \\
\text { Clínicos, M.Imagen }\end{array}$} & $-7,861$ & 814 & $<, 0001$ & S \\
\hline & $-11,261$ &, 610 & $<, 0001$ & S \\
\hline Clínicos, Normales & ,909 & ,415 & $<, 0001$ & S \\
\hline \multirow{2}{*}{$\begin{array}{l}\text { Clínicos, Rta.Inc. } \\
\text { M.Imagen, Normales }\end{array}$} & $-6,028$ & ,737 & $<, 0001$ & $\mathrm{~s}$ \\
\hline & 12,170 &, 528 & $<, 0001$ & $S$ \\
\hline \multirow{2}{*}{$\begin{array}{l}\text { M.Imagen, Rta.Inc. } \\
\text { Normales, Rta.Inc. }\end{array}$} & 5,233 & 806 & $<, 0001$ & S \\
\hline & $-6,936$ &, 671 & $<, 0001$ & \\
\hline
\end{tabular}

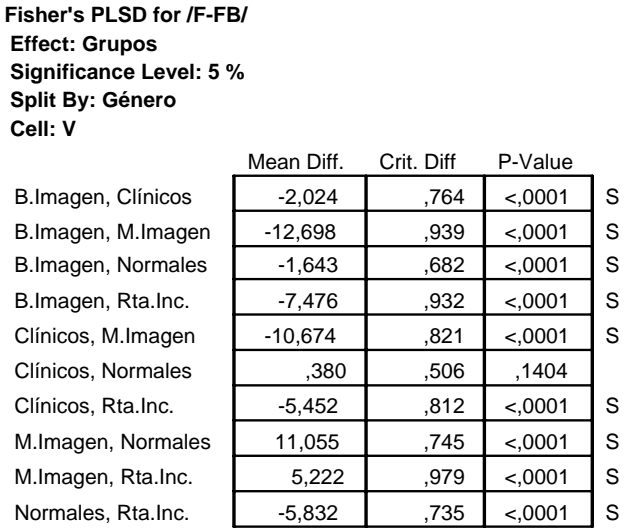

* $\mathrm{M}=$ mujeres; $\mathrm{V}=$ Varones. $\mathrm{S}=$ significativo.

Haciendo un breve resumen de las principales aportaciones de esta variable, podemos decir que:

- Es una variable que nos puede ayudar a detectar a los sujetos que intentan expresar una imagen desfavorable de sí mismos.

- Para una mayor precisión diagnóstica podemos apoyarnos de los resultados mostrados por las variables $\mathrm{F}(\mathrm{p}), \mathrm{F}$, FBS y $\mathrm{F}-\mathrm{K}$, con los que correlaciona positivamente.

- No parece aportar datos diferentes a los ya suministrados por las variables $\mathrm{F} \mathrm{y} \mathrm{Fb}$ que, individualmente, han mostrados sus propios resultados.

- En aras de la brevedad en la exposición del perfil de las variables de Validez (hoja de perfil del MMPI-2), es una de las variables de las que se podría prescindir, ya que sus aportaciones parecen ser suficientes con las expresadas por $\mathrm{F} \mathrm{y} \mathrm{Fb.}$

\section{V.2.16. - Variable "?":}

Hemos de tener en cuenta que todos los protocolos, de cualquier grupo de los aquí investigados, que han presentado en esta variable una puntuación directa $\geq 30$, han sido anulados. Por consiguiente, la variable "No sé / No puedo contestar", bien porque hayan dejado en blanco o porque hayan marcado al mismo tiempo verdadero y falso su respuesta, ha sido identificada por el interrogante (“?”), y no puede mostrarse con una puntuación $>29$.

Tabla 108 Variable "?". Percentiles. Análisis por grupos.

\begin{tabular}{|c|c|c|c|c|c|}
\hline Percentiles & Normal & Clínico & Buena Imagen & Mala Imagen & Rta. Inc. \\
\hline $\mathbf{1 0}$ & 0 & 0 & 0 & 0 & 0 \\
\hline $\mathbf{2 5}$ & 0 & 0 & 0 & 0 & 0 \\
\hline $\mathbf{5 0}$ & 1 & 1 & 0 & 0 & 0 \\
\hline $\mathbf{7 5}$ & 3 & 5 & 1 & 1 & 0 \\
\hline $\mathbf{9 0}$ & 9 & 11 & 3 & 2 & 0 \\
\hline
\end{tabular}

Podemos ver, por los resultados mostrados en la Tabla 108, que los sujetos que presentan la puntuación más elevada en esta variable se correponde con el grupo de clínicos, y también apreciamos que un $50 \%$ de sujetos, tanto de la población normal como clínica, presentan una puntuación directa de $\geq 1$. 
Los protocolos cumplimentados sin tener en cuenta el contenido de los ítems (Rta. Inc.) fueron completados en su totalidad, y los que decidieron cumplimentarlos con su buena o mala imagen, solamente el $10 \%$ dejaron $\geq 2$ ítems sin contestar o los contestaron al mismo tiempo falso y verdadero.

Tabla 109: Variable "?": Puntuaciones Medias y $\mathcal{S} t . \mathcal{D}$. Análisis comparativo entre

$$
\text { grupos }
$$

\begin{tabular}{|c|c|c|c|c|c|c|c|c|c|}
\hline \multicolumn{2}{|c|}{ Normal } & \multicolumn{2}{c|}{ Clínico } & \multicolumn{2}{c|}{ Buena Imagen } & \multicolumn{2}{c|}{ Mala Imagen } & \multicolumn{2}{c|}{ Rta. Inc. } \\
\hline Media & St.D & Media & St.D & Media & St.D & Media & St.D & Media & St.D \\
\hline 2,878 & 5,029 & 3,540 & 5,514 & 1,106 & 2,848 & 1,230 & 3,599 & 0,030 & 0,171 \\
\hline
\end{tabular}

El hecho de que el grupo clínico pueda presentar más respuestas en blanco y/o dobles marcas que el grupo de sujetos normales, puede obedecer a su propia y diferente patología y a sus problemas consecuentes como la escasa motivación, falta de atención continuada, cansancio o, simplemente distracción.

De todas maneras, aún sabiendo que esta "variable", no podría aportar elementos diferenciativos y consistentes en nuestra investigación, hemos querido exponer sus resultados como si fuera una "variable" más.

Tabla 110: Variable "?". ANOVA. Diferencias significativas entre grupos.

\begin{tabular}{|c|c|c|c|c|}
\hline Grupos & Dif.Med. & Dif. Crit. & $\mathbf{p}$ & Signf. (5\%) \\
\hline Normal vs. Clínico &,- 633 &, 446 &, 0036 & SI \\
\hline Normal vs. B. Imagen & 1,171 &, 589 & $<, 0001$ & SI \\
\hline Normal vs. M. Imagen & 1,647 &, 601 & $<, 0001$ & SI \\
\hline Normal vs. Rtas. Inc. & 2,848 &, 685 & $<, 0001$ & SI \\
\hline Clínico vs. B. Imagen & 2,434 &, 670 & $<, 0001$ & SI \\
\hline Clínico vs. M. Imagen & 2,310 &, 680 & $<, 0001$ & SI \\
\hline Clínico vs. Rtas. Inc. & 3,510 &, 756 & $<, 0001$ & SI \\
\hline B. Imagen vs. M. Imagen &,- 124 &, 782 &, 0756 & NO \\
\hline B. Imagen vs. Rtas. Inc. & 1,076 &, 848 &, 0129 & SI \\
\hline M. Imagen vs. Rtas. Inc. & 1,200 &, 857 &, 0060 & SI \\
\hline
\end{tabular}

Contemplando los resultados de la la Tabla 109, podemos apreciar que el grupo clínico es el que presenta sus valores más elevados mostrando sus diferencias estadísticamente significativas con el resto de los grupos (Tabla 110). Sin embargo, entre los grupos de buena imagen y mala imagen no hemos encontrado diferencias estadísticas, por lo que podemos interpretar que esta variable no discrimina a los sujetos que dan buena o mala imagen.

Las correlaciones, expuestas en la Tabla 111, son todas tan bajas (borradas de la tabla) que no superan la significación estadística señalada $(\mathrm{p}<, 001)$, excepto en las dos variables ODecp y Wsd que lo muestran de forma negativa con el grupo de sujetos normales. 
Tabla 111: Variable "?". Correlaciones *.

\begin{tabular}{|c|c|c|c|c|c|}
\hline Variables & Normal & Clínico & Buena Imagen & Mala Imagen & Rta. Inc. \\
\hline $\mathbf{L}$ & -.006 & .059 & -.020 & .173 & -.016 \\
\hline $\mathbf{F}$ & -.046 & -.059 & .004 & .016 & .039 \\
\hline $\mathbf{K}$ & -.005 & .053 & -.029 & .092 & .000 \\
\hline Fb & -.034 & -.066 & -.004 & .003 & .011 \\
\hline VRIN & -.055 & -.107 & .000 & .027 & .036 \\
\hline TRIN & -.076 & -.114 & -.085 & .063 & .049 \\
\hline Fp & -.011 & -.035 & -.030 & .064 & .027 \\
\hline S & -.030 & .019 & -.080 & .114 & .045 \\
\hline Ds & -.044 & -.083 & .016 & -.029 & .035 \\
\hline Ds-r & -.031 & -.077 & .040 & -.022 & .043 \\
\hline FBS & .024 & .020 & -.028 & .051 & .066 \\
\hline ODecp & -.119 & -.084 & -.104 & .057 & .048 \\
\hline IR & -.041 & -.065 & .002 & .067 & .028 \\
\hline Wsd & $\mathbf{- . 1 3 2}$ & -.109 & -.144 & .077 & -.024 \\
\hline F-K & -.026 & -.065 & .018 & -.014 & .026 \\
\hline $\mathbf{i}$ & $\mathbf{1 . 0 0}$ & $\mathbf{1 . 0 0}$ & $\mathbf{1 . 0 0}$ & $\mathbf{1 . 0 0}$ & $\mathbf{1 . 0 0}$ \\
\hline F-Fb/ & -.036 & .009 & .024 & .030 & .021 \\
\hline
\end{tabular}

* Los valores en negrita, resultaron ser estadísticamente significativos al $\mathrm{p}<.001$

Gráfica 50: Variable "?". $\mathcal{A N} O \mathcal{V} \mathcal{A}$.

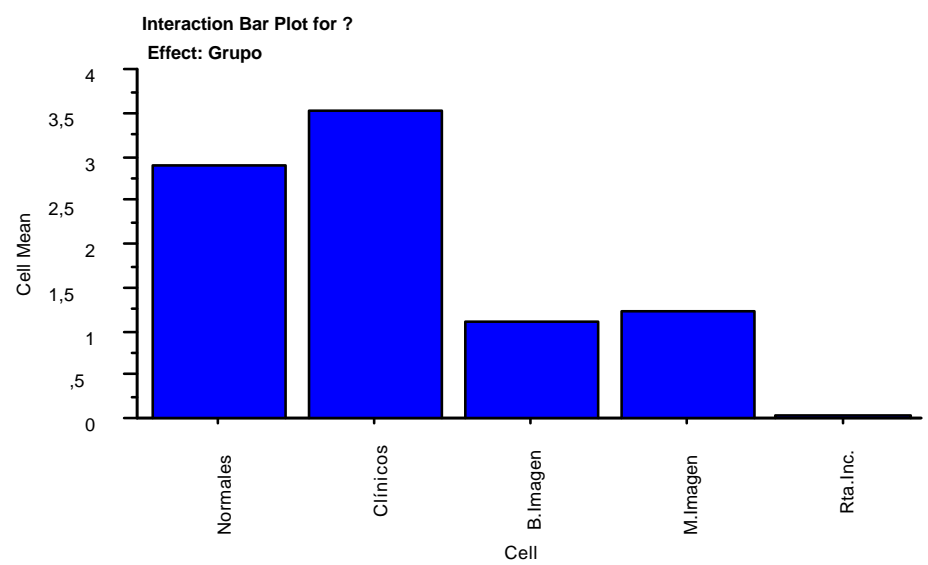

Gráfica 51: Variable "?". Análisis intersexos/intergrupos.

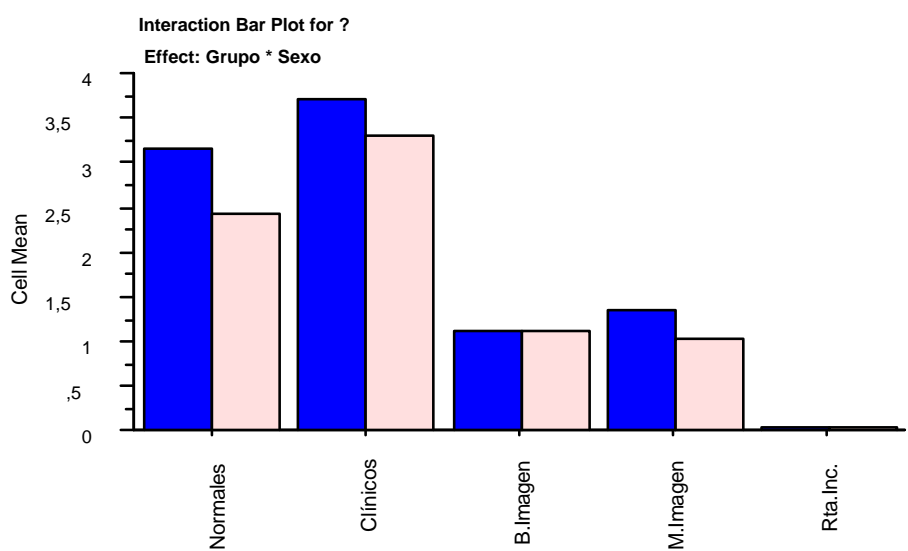


Tabla 112: Variable "?". Diferencias intergrupos/intersexos *.

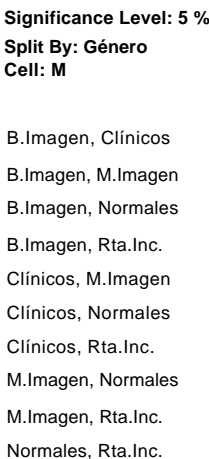

B.Imagen, Clínicos

B.Imagen, M.Imagen

B.Imagen, Normales

B.Imagen, Rta.Inc.

M.Imagen, Normales

Normales, $R$

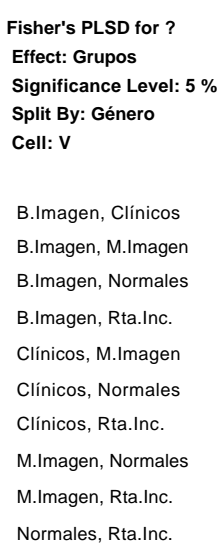

\begin{tabular}{|c|c|c|}
\hline Mean Diff. & Crit. Diff & P-Value \\
\hline$-2,205$ & ,972 & $<, 0001$ \\
\hline ,080 & 1,195 & ,8953 \\
\hline$-1,327$ & ,868 & ,0028 \\
\hline 1,061 & 1,185 & ,0794 \\
\hline 2,285 & 1,044 & $<, 0001$ \\
\hline ,878 & ,644 & ,0076 \\
\hline 3,266 & 1,033 & $<, 0001$ \\
\hline$-1,407$ & ,948 & ,0037 \\
\hline ,981 & 1,245 & 1227 \\
\hline 2,388 & ,935 & $<, 0001$ \\
\hline
\end{tabular}

* $\mathrm{M}=$ mujeres; $\mathrm{V}=$ Varones. $\mathrm{S}=$ significativo.

Resumiendo brevemente, los resultados nos muestran, que:

- Podemos apreciar que su mayor incidencia es aportada por el grupo clínico con diferencias estadísticas significativas con el grupo de sujetos normales

- La "variable" ? no discrimina suficientemente si el sujeto nos intenta mostrar una buena o mala imagen de sí mismo.

- Esta "variable" no presenta correlación alguna con ninguna otra variable, posiblemente por su escaso número de incidencia.

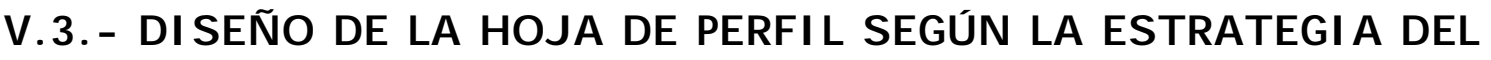
$\mathcal{M M P I}-2$.

\section{V.3.1. - El diseño tradicional del $\mathcal{M M P I}$.}

Tradicionalmente, la estrategia adoptada por la técnica del MMPI para mostrar el perfil de un determinado tipo de personalidad, reflejada en la "hoja de perfil", ha sido a través de las puntuaciones directas y su equivalencia con las "típicas" T, cuya puntuación media es de 50 y su desviación estándar de 10.

Cuando contemplamos el diseño del perfil del MMPI (y también del MMPI-2), podemos apreciar que se configura teniendo en cuenta que las puntuaciones directas aparezcan en el interior del cuadro y tengan su correspondencia en puntuaciones típicas $\mathrm{T}$ en ambos laterales de la hoja de perfil. Esta configuración es idéntica para cualquiera de los distintos grupos de Escalas (Básicas, Suplementarias o de Contenido). El punto de corte de las distintas variables pasó de 70T, en el MMPI, a 65T, en el MMPI-2.

Igualmente, el diseño tradicional muestra los valorees de las puntuaciones directas de todas y cada una de las variables (expuestas en el interior de la Tabla), en el mismo sentido que las expresadas por las puntuaciones $\mathrm{T}$; es decir, incrementando la puntuación de abajo-arriba. Pero este mismo diseño muestra, referente a este aspecto y solamente en los varones, una excepción a través de la variable MasculinidadFeminidad (Mf). 
Esta Hoja de perfil, en su correspondiente apartado de las Escalas de Validez y Escalas Cínicas (existen otras hojas referentes a las Escalas Suplementarias y de Contenido) se muestran siempre en el mismo orden (de izquierda a derecha), incluso para su preferencia de nterpretación: primero las Escalas de Validez (L, F y K) y en segundolugar las 10 Escalas Clínicas.

\section{V.3.2. - Nuestra propuesta de diseño, en la Hoja de Perfil, para algunas de las Escalas e Índices de Validez.}

En nuestra baremación de las distintas variables y Escalas indicadoras de Validez investigadas hemos mantenido escrupulosamente el mismo diseño referente a las puntuaciones directas, típicas y los mismos puntos de corte del MMPI-2. Nada se va a cambiar en la Hoja de perfil, excepto el sentido en sus puntuaciones directas de algunas variables (igual que en el perfil tradicional del MMPI de la variable Mf en los varones) en donde las puntuaciones directas inferiores se muestran a partir de la parte superior de la Hoja de perfil. Es decir, las puntuaciones directas más bajas se corresponden con las puntuaciones más elevadas en sus puntuaciones típicas $\mathrm{T}$, y viceversa.

En nuestra investigación, hemos seguido los criterios expuestos por Butcher, J.; Dahlstrom, W.; Graham, J.; Tellegen, A. \& Kaemer, B. (1989) y Greene (1997, 2000) en sus trabajos al estudiar y analizar las distintas variables de validez indicadoras de "defensividad" o "fingimiento positivo", de tal forma que la indicación de este "fingimiento positivo" siempre se reflejase en la parte inferior de la Hoja de perfil (puntuaciones significativas [1,5 desviación estandar] por debajo de 35T), mientras que la indicación de "fingimiento negativo" se reflejara en la parte superior de la Hoja (puntuaciones significativas[1,5 desviación estandar] superiores a 65T). Que el fingimiento positivo se muestre en las puntuaciones inferiores de la Hoja de perfil, o el fingimiento negativo se aprecie en la parte superior de la hoja, se debe a las investigaciones de Greene (1997, Notas de las pgs. 203 y 204), en donde se muestran invertido los valores en las variables: L, K, ODecp, S y Wsd; es decir sus valores crecientes se especifican de arriba-abajo y no de abajo-arriba como en la mayoría de las variables en el diseño tradicional del MMPI (excepto Mf).

Con esto intentamos conseguir los objetivos siguientes:

- Que, de una simple mirada a la Hoja de Perfil, pudiéramos apreciar que todas las puntuaciones de la parte superior del perfil $(>65 \mathrm{~T})$ fueran indicadoras de "fingimiento negativo"y/o inconsistencia en sus respuestas, por el que el sujeto ha intentado mostrarse de una forma negativa (mala imagen, exagerando su sintomatología, hacerse el enfermo, etc.).

- Igualmente, todas las puntuaciones de la parte inferior del perfil $(<40 \mathrm{~T})$ fueran indicadoras de "fingimiento positivo" y/o consistencia en sus respuestas, (buena imagen, ajustado y equilibrado psicológicamente, minimizando su sintomatología, defensividad, etc.).

- Todas aquellas puntuaciones que se encontraran entre estos dos "puntos de corte", pudiéramos considerar como de "normalidad" en la que el sujeto ha contestado de una forma coherente, honesta y fiable.

La propuesta de esta "hoja de perfil" tiene una finalidad eminentemente práctica para que pudieran quedar reflejadas, de una forma contrastada, las numerosas escalas analizadas y cómo se presentan para cada uno de los grupos de la muestra. 
V.3.2.1.- Cambio de sentido de las variables tradicionales del MMPI: $\mathcal{L}$ y $\mathcal{K}$

¿Por qué cambiamos el sentido a estas variables?. Toda las investigaciones demuestran que las puntuaciones elevadas de estas dos variables se corresponden con un perfil de fingimiento positivo, en donde el sujeto intenta mostrar lo mejor de sí mismo, dando una buena imagen y expresando los aspectos favorables de su personalidad. Cuando nos encontramos con puntuaciones bajas, las implicaciones psicológicas de estas variables, efectivamente, cambian de sentido; el sujeto intenta mostrar su lado negativo, exagerando su sintomatología, intentando presentar el lado más negativo y desfavorable de sí mismo fingiéndose de una forma negativa.

Tabla 113: Equivalencias de las puntuaciones típicas de las Escalas $L$ y Kal cambiar el sentido de sus puntuaciones directas.

\begin{tabular}{|c|c|c|c|c|c|c|c|}
\hline \multicolumn{9}{|c|}{ MUJERES } & \multicolumn{5}{c|}{ VARONES } \\
\hline Típ/L & PD/L & Típ/K & PD/K & Típ/L & PD/L & Típ/K & PD/K \\
\hline 70 & 0 & 83 & 0 & 70 & 0 & 81 & 0 \\
\hline 66 & 1 & 80 & 1 & 66 & 1 & 79 & 1 \\
\hline 62 & 2 & 78 & 2 & 61 & 2 & 77 & 2 \\
\hline 57 & 3 & 76 & 3 & 57 & 3 & 75 & 3 \\
\hline 53 & 4 & 74 & 4 & 53 & 4 & 73 & 4 \\
\hline 49 & 5 & 71 & 5 & 49 & 5 & 71 & 5 \\
\hline 44 & 6 & 69 & 6 & 45 & 6 & 69 & 6 \\
\hline 40 & 7 & 67 & 7 & 41 & 7 & 67 & 7 \\
\hline 36 & 8 & 64 & 8 & 37 & 8 & 64 & 8 \\
\hline 32 & 9 & 62 & 9 & 33 & 9 & 62 & 9 \\
\hline 27 & 10 & 60 & 10 & 29 & 10 & 60 & 10 \\
\hline 23 & 11 & 58 & 11 & 25 & 11 & 58 & 11 \\
\hline 19 & 12 & 55 & 12 & 21 & 12 & 56 & 12 \\
\hline 14 & 13 & 53 & 13 & 17 & 13 & 54 & 13 \\
\hline 10 & 14 & 51 & 14 & 13 & 14 & 52 & 14 \\
\hline 6 & 15 & 49 & 15 & 9 & 15 & 50 & 15 \\
\hline & & 46 & 16 & & & 47 & 16 \\
\hline & & 44 & 17 & & & 45 & 17 \\
\hline & & 42 & 18 & & & 43 & 18 \\
\hline & & 39 & 19 & & & 41 & 19 \\
\hline & & 37 & 20 & & & 39 & 20 \\
\hline & & 35 & 21 & & & 37 & 21 \\
\hline & & 33 & 22 & & & 35 & 22 \\
\hline & & 30 & 23 & & & 33 & 23 \\
\hline & & 28 & 24 & & & 30 & 24 \\
\hline & & 26 & 25 & & & 28 & 25 \\
\hline & & 23 & 26 & & & 26 & 26 \\
\hline & & 21 & 27 & & & 24 & 27 \\
\hline & & 19 & 28 & & & 22 & 28 \\
\hline & & 17 & 29 & & & 20 & 29 \\
\hline & & 14 & 30 & & & 18 & 30 \\
\hline
\end{tabular}

Cuando hemos realizado el cambio de sentido, hemos seguido la misma pauta seguida para la Escala Clínica Masculinidad-Feminidad del MMPI en su baremo con los varones (véase cómo se ha hecho en la Tabla 113).

Pero, ¿qué implicaciones tiene esto para la interpretación tradicional de estas Escalas (L y K) en el MMPI?:

Cuando las interpretaciones se hacen a través de ls puntuaciones directas, esto no implica cambio alguno. Es decir, una puntuación directa en cualquiera de estas dos escalas ( $\mathrm{L}$ y $\mathrm{K}$ ) siempre indicarán lo mismo, tanto en el MMPI (ó MMMPI-2) tradicional como en nuestro diseño. 
Cuando las interpretaciones se realizan a través de las puntuaciones típicas $\mathrm{T}$, es necesario tener cuidado, ya que un cambio de sentido en las puntuaciones directas (de nuestro diseño), implica un cambio en la dirección de sus puntuaciones típicas T. Es decir, en el MMPI (ó MMPI-2) una puntuación típica de 65T (= 1,5 desv. St.), ahora se corresponde con una puntuación de $35 \mathrm{~T}$ (= 1,5 desv. St. pero por abajo), y su interpretación debe ser idéntica.

\section{V.3.2.2. - Respecto a otras variables investigadas: "ODecp", "S" $y$ "Wsd".}

Tradicionalmente, en la Hoja de perfil del MMPI/MMPI-2, las puntuaciones directas, insertas en el interior de la hoja y exceptuando la variable clínica Mf en las Mujeres, se han expresado en el sentido de "menor a mayor" coincidiendo con el mismo sentido de las puntuaciones T. Es decir, las puntuaciones directas menores, o más bajas, se correspondían con las puntuaciones menores en las puntuaciones $\mathrm{T}$, e igualmente, las puntuaciones directas elevadas se correspondían con las puntuaciones T elevadas.

En nuestro diseño, pretendiendo exponer en la Hoja de perfil del MMPI-2 las puntuaciones significativas de "fingimiento positivo" en la parte inferior, y el "fingimiento negativo" en la parte superior, hemos tenido que acomodar el sentido de las puntuaciones directas, en las escalas ODecp, S y Wsd, al sentido dado por el autor: una mayor puntuación directa se corresponde con un mayor "fingimiento positivo", y viceversa, una puntuación menor se corresponde con una ausencia de tal fingimiento.

Por ello, las escalas ODecp, S y Wsd, van a presentarse con sus puntuaciones directas más elevadas en la zona inferior de la Hoja de perfil del MMPI-2, al modo como se encuentran, en el perfil tradicional del MMPI-2, la variable Mf para las mujeres (cambiando el sentido de las puntuaciones directas).

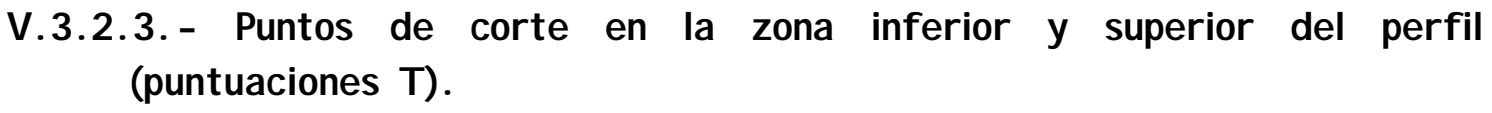

Tradicionalmente, en la Hoja de perfil del MMPI-2, se considera como zona de "normalidad" entre 1,00 desviación estándar por encima y por debajo de la puntuación media $(M=50)$ ya que por condicionamientos puramente estadísticos las puntuaciones típicas presentan una puntuación media de 50 y una desviación estandar de 10. La significación siempre se planteará, en puntuaciones típicas $\mathrm{T}$, con 1,00 desviación estándar por encima y/o por debajo de la media (50 \pm 1 desv.Std.), convirtiéndose en 60T y/o 40T respectivamente.

El MMPI tradicional mantenía como punto de corte, significativo de presencia del factor en cuestión, en 70T, esto significaba dos desviaciones estándar a partir de la puntuación media. En la reestandarización, MMPI-2, se ha rebajado en 0,5 desv.Std. el punto de corte significativo de incidencia del factor, quedando en 65T. En nuestro diseño seguimos manteniendo estos mismos parámetros de puntos de corte del MMPI-2 en las puntuaciones superiores; es decir, 65T para la significatividad para cualquier tipo de índice o Escala.

No obstante, nuestro diseño para las Escalas e Índices de Validez, propone, siguiendo la misma filosofía estadística, la existencia de un punto de corte por debajo de la media, especificado en $35 \mathrm{~T}$ correspondientes a 1,5 desv. Std. por debajo de la media (Tabla 114). 
Con todo ello, y siempre teniendo la perspectiva de poder apreciar de un "golpe de vista" la existencia de fingimiento, pretendemos exponer tres zonas fundamentales en la Hoja de Perfil del MMPI-2:

Zona de inconsistencia y/o fingimiento negativo significativo: puntuaciones $\geq 65 \mathrm{~T}$

Zona de normalidad: puntuaciones entre 35T - 65T.

Zona de fingimiento positivo:significativo: Puntuaciones $\leq 35 \mathrm{~T}$.

Tabla 114: Puntos de corte de las Escalas e Indices de Validez. Varones

\begin{tabular}{|c|c|c|c|c|c|c|}
\hline Escalas/Punt.T & 20T & 35T & 50T & 65T & 80T & 100T \\
\hline VRIN & - & 3 & 8 & 13 & 17 & 24 \\
\hline TRIN-F & - & - & - & 7 & 5 & 1 \\
\hline TRIN-V & - & - & 10 & - & 15 & 18 \\
\hline L & 12 & 7 & 5 & 1 & - & - \\
\hline F & - & 2 & 8 & 17 & 26 & 38 \\
\hline Fb & - & - & 4 & 12 & 19 & 29 \\
\hline K & 29 & 20 & 15 & 7 & 1 & - \\
\hline F-K & - & -16 & -6 & 8 & 20 & 39 \\
\hline FBS & - & 7 & 12 & 19 & 26 & 35 \\
\hline Ds-r & - & 3 & 8 & 15 & 21 & 30 \\
\hline ODecp & 28 & 19 & 15 & 7 & 2 & - \\
\hline S & 48 & 35 & 24 & 11 & 0 & - \\
\hline Wsd & 26 & 18 & 15 & 9 & 4 & - \\
\hline F(p) & - & 0 & 2 & 7 & 10 & 16 \\
\hline
\end{tabular}

Tabla 115: Puntos de corte de las Escalas e Indices de Validez. Mujeres.

\begin{tabular}{|c|c|c|c|c|c|c|}
\hline Escalas/Punt.T & 20T & 35T & 50T & 65T & 80T & 100T \\
\hline VRIN & - & 3 & 8 & 12 & & 23 \\
\hline TRIN-F & - & - & - & 7 & & 1 \\
\hline TRIN-V & - & - & - & 12 & & 16 \\
\hline L & 12 & 9 & 5 & 1 & & - \\
\hline F & - & 2 & 6 & 19 & & 46 \\
\hline Fb & - & - & 4 & 10 & & 23 \\
\hline K & 28 & 21 & 15 & 7 & & - \\
\hline F-K & - & -20 & -8 & 5 & & 30 \\
\hline FBS & - & 6 & 13 & 21 & & 37 \\
\hline Ds-r & - & 1 & 8 & 16 & & 31 \\
\hline ODecp & 25 & 19 & 13 & 6 & & - \\
\hline S & 47 & 36 & 24 & 12 & & - \\
\hline Wsd & 24 & 19 & 14 & 8 & & - \\
\hline F(p) & - & - & 2 & 5 & & 12 \\
\hline \multicolumn{7}{|r}{}
\end{tabular}


CAPITULO VI. - DIS CUL ION.

En este apartado intentamos confrontar nuestros resultados con los obtenidos por otras investigaciones más recientes. Para ello hemos seguido las directrices derivadas de las diversas hipótesis planteadas en nuestra investigación.

VI.1. Escalas e Índices de Validez que permiten diferenciar suje tos
que responden de forma inconsistente/consistente (Hipótesis $1^{a}$ ).

Cuando intentamos identificar un protocolo cumplimentado de forma inconsistente, nuestros resultados han mostrado una serie de Escalas e Índices de Validez identificadoras y otro grupo que no reconocen este tipo de protocolos.

Los datos aportados por Wetter, Baer, Berry, Smith, y otros (1992) para la investigación de los efectos de la respuesta aleatoria (random response) y las respuestas de fingimiento intencionado (malingering) con el MMPI-2, con cuatro grupos de estudiantes, mostraron puntuaciones elevadas en $\mathrm{F} \mathrm{y} \mathrm{Fb}$, y VRIN. Estos resultados, plenamente coincidentes con los nuestros, indican que una puntuación elevada en la Escala F puede ser clarificada al relacionarla con VRIN.

Rogers, Dolmesch, \& Cavanaugh (1983), compararon las muestras de 40 perfiles de pacientes con otros 40 generados aleatoriamente por ordenador, analizándose las Escalas de Validez, las Clínicas y otras escalas diseñadas para detectar aleatoriedad (índice de Test-Retest y Escala de Descuido). Los resultados denotan que la Escala F > 80 y el índice Test-Retest $>4$ son de mayor utilidad clínica para identificar correctamente a los que responden aleatoriamente. Los autores concluyen que es necesario identificar adecuadamente a los fingidores (malingeres) de los severamente trastornados y de aquellos que responden de una forma inconsistente. 
En el trabajo llevado a cabo por Greene $(1997,2000)$ comparando una muestra de población normal de 2.600 sujetos (Butcher et al., 1989) con 3.475 pacientes con trastornos mentales graves y 2.500 sujetos que contestan aleatoriamente a los ítems (Greene, 1995), se pudo comprobar que con una PD $=13(80 \mathrm{~T})$ en la escala VRIN era contestado por $0,2 \%$ de los sujetos de la población normativa, por el $2,4 \%$ de los pacientes con trastornos y por el $84,4 \%$ de los sujetos que contestaban de forma inconsistente. Nuestros datos muestran una puntuación PD $\geq 13$ (75T), para ambos sexos, en la Escala VRIN, como una puntuación claramente significativa de incoherencia o inconsistencia.

En la investigación de Berry, Wetter, Baer, Widiger, et als (1991) con una muestra de 180 estudiantes universitarios a los que se les pidió que contestaran un número de respuestas del Cuestionario del MMPI-2 de forma honesta y sincera y el resto de forma inconsistente. Los resultados mostraron que los tres índices (F, Fb y VRIN) fueron sensibles a las respuestas dadas al azar. Nuestros datos aportan que los sujetos que han contestado de forma inconsistente, su perfil medio (de las multiples forma de responder) ha mostrado una puntuación $\mathrm{PD} \geq 30$ (86T), para varones, y de $\mathrm{PD} \geq 32$ (82T) para mujeres en la escala F. Para la escala Fb resulta ser PD $\geq 20$ (82T) para los varones, PD $\geq 30$ (91T) para las mujeres. Un año después, Barry, Wetter, Baer, Larse,. et al. (1992) vuelven a corroborar los resultados con una muestra de sujetos normales. Los autores concluyeron que los índices de F, Fb y VRIN son buenos indicadores para detectar las respuestas aleatorias. Los resultados sugieren que las respuestas aleatorias son más frecuentes en la parte final del test aunque un número significativo de sujetos ha distribuido sus respuestas aleatorias a lo largo de todo el test.

Paolo y Ryan (1992) no hacen más que corroborar los resultados obtenidos por el grupo de investigadores Barry, Wetter, Baer, Larse,. et al. (1992).

Escala de Inconsistencia de Respuestas Variable (VRIN):

La mayoría de las investigaciones que se han llevado a cabo coinciden en afirmar que esta variable se muestra muy sensible para identificar la consistencia/inconsistencia de las respuestas que han dado los sujetos a los 67 pares de ítems propuestos para su detección. Aunque es útil para identificar patrones inconsistentes de respuestas, no obstante hemos de tener en cuenta que, una puntuación aceptable solamente indica que la persona ha respondido de forma coherente, pero no necesariamente con precisión o exactitud (honestidad) ya que los sujetos pueden, de forma perfectamente coherente, mostrar su fingimiento positivo o negativo. Por esto mismo los grupos de personas a los que hemos instruido para que finjan una "mala imagen" o una "buena imagen", en esta variable VRIN se han mostrado adecuadamente coherentes.

En estos casos es necesario acompañarse de otras Escalas e Índices para poder identificar adecuadamente a los sujetos que "coherentemente" intentan falsear sus protocolos ya que, como ha podido observar y apreciar (Greene, 1997, 2000) esta variable no se encuentra afectada por la presencia de psicopatología, aunque nosotros solamente no hemos visto esta diferencia entre los sujetos clínicos y aquellos que intencionadamente pretenden mostrarnos una imagen de sí mismos desfavorable. Las elevaciones de las escalas F, Fb, F-K, FBS, Ds-r y F(p) nos estarán indicando la defensividad del sujeto especificada en el falseamiento positivo o la presentanción favorable de su propia imagen. Cuando las elevaciones se muestran en las L, K, ODecp, 
S y Wsd, podemos apreciar otro tipo de defensividad, en este caso intentando aparentar su "mala imagen".

También hemos podido constatar, siendo plenamente coincidentes con Greene (1997, 2000), que VRIN, por ella misma, no identifica los patrones de respuestas "todo verdadero" ni "todo falso", pero lo hace claramente para patrones de respuestas "Falso/verdadero (alternativamente)", "verdadero/falso (alternativamente)" así como para aquellos sujetos que de forma totalmente aleatoria han contestado a los ítems del MMPI-2. Para dilucidar estas aparentes incongruencias hemos podido comprobar, coincidentemente con otros autores (Graham, 1990; Evans \& Dinning, 1983; Galluci, 1985; Maloney, Duvall \& Friesen, 1980; Wetter, Baer, Berry, Smith \& Larsen, 1992), que VRIN se muestra más eficaz cuando es acompañada en su interpretación con los valores de $\mathrm{F}$ y $\mathrm{Fb}$. Una puntuación elevada en $\mathrm{F}$ y $\mathrm{Fb}$, juntamente con la elevación de VRIN, nos está indicando una forma de responder inconsistente o confusa. Nuestros datos confirman, además, que también pueden acompañarse de puntuaciones elevadas en F-K, Ds-r y F(p).

Diferencias, aunque no importantes, las hemos encontrado en las diversas investigaciones en el momento de concretar los "puntos de corte" establecidos para ser significativas. Así Greene (1991) sugiere la puntuación de 10; Butcher, J.; Dahlstrom, W.; Graham, J.; Tellegen, A. \& Kaemer, B. (1989), en 13 y para Berry, Baer y Harris (1991) la propuesta se ha concretado en 14. No obstante la última revisión de Greene (2000, pg. 64; Tabla 3.18) propone la puntuación de PD $\geq 11$ como un valor "acusadamente inconsistente". En nuestra investigación, hemos establecido el "punto de corte" en 13 para ambos sexos. Como podemos apreciar estas puntuaciones de corte no se diferencian mucho de las establecidas en las investigaciones iniciales de Butcher, Dahlstrom, Graham, Tellegen y Kaemmer (1989). No obstante, esta pequeña variabilidad, creemos que va a estar condicionada a los diferentes ambientes en los que la prueba del MMPI-2 puede ser aplicada.

Inconsistencia de Respuestas Verdadero (TRIN):

Esta variable tampoco atiende al contenido ni a la información del ítem, detectando solamente la tendencia a responder como "verdadero" o como "falso" (aquiescencia en sus respuestas). Las escasas investigaciones realizadas con esta variable, considerandola como una variable "experimental", necesitada de investigaciones futuras por diversos autores (Butcher, Dahlstrom, Graham, Tellegen y Kaemmer, 1989), hace que no podamos contrastar suficientemente nuestros hallazgos.

Esta variable TRIN puede identificar, perfectamente (sus puntuaciones son máximas), aquellos perfiles de los protocolos contestados como "todo verdadero" así como aquellos patrones de contestación como "todo falso", e igualmente los protocolos que han sido contestados, de forma alternativa, "verdadero/falso", señalando el primer ítem como "verdadero" y el siguiente como "falso" y así sucesivamente.

Por el contrario, si el sujeto contesta al primer ítem del cuestionario como "falso" y al siguiente como "verdadero" y así sucesivamente (es decir: "falso/verdadero" alternativamente), la variable TRIN no lo detecta adecuadamente y debe servirse de las puntuaciones aportadas por otras Escalas para su correcta interpretación. 
Tampoco discrimina adecuadamente esta variable TRIN a los protocolos contestados de forma inconsistente o confusa. El perfil medio que hemos encontrado en nuestras investigaciones nos muestra una variable con una puntuación $\mathrm{PD}=10$ (50T), perfectamente dentro de la normalidad estadística.

TRIN, al igual que sucede con VRIN, por sí sola, no identifica adecuadamente aquellos protocolos que son falsificados de forma intencionada al presentar tanto una imagen favorable como desfavorable de sí mismo. Por consiguiente para una correcta identificación de estos individuos, debemos apoyarnos en los valores obtenidos por las restantes Escalas e Índices de Validez investigados en este trabajo.

Igualmente no parece ser sensible a la identificación de protocolos contestados por el grupo de sujetos clínicos de aquellos que intencionadamente muestran una imagen favorable o desfavorable de sí mismos.

Los datos aportados por Greene (1997, 2000: Tabla 3.14, pg.57) con población normal, referente a las correlaciones de esta variable con sus respectivas "infrecuentes" ( $\mathrm{F}$ y $\mathrm{Fb}$ ), son coincidentes con nuestros halazgos en cuanto al bajo valor. Para Greene la correlación mostrada con $\mathrm{F}=.193$ (.136, nuestros resultados) y con $\mathrm{Fb}=.124$ (.220, nuestros resultados).

$\mathcal{F} y / o \mathcal{F} b$.

Nuestros resultados han podido aportar, con cualquiera de estas dos variables, un elemento importante en el análisis de la inconsistencia de las respuestas dadas al cuestionario. Sus puntuaciones elevadas han sido mostradas sistemáticamente por el grupo de sujetos que han contestado el protocolo sin tener en cuenta el contenido ni la información de los ítems en sus diversas variedades y modalidades.

Si contrastamos nuestros resultados con los realizados por otros investigadores, (Butcher, 1990; Graham, 1990; Butcher y Williams, 1992) habían detectado de forma general esta peculiaridad de las variables $\mathrm{F}$ y $\mathrm{Fb}$, incluso cuando, acompañada con puntuaciones elevadas en VRIN, podrían ayudarnos a detectar la inconsistencia de las respuestas dadas al protocolo. Más específicamente Butcher y Williams (1992, pg. 47) nos señalan que cuando las puntuaciones de $\mathrm{F}$ se encuentran en el intervalo $\mathrm{T}=80$ - 109 y se acompañan con las puntuaciones de VRIN $\geq 79$, nos están indicando, como posible hipótesis, la inconsistencia del perfil.

Una de las tres razones a las que alude Greene $(1997,2000)$ cuando las puntuaciones en la Escala $\mathrm{F}$ y/o Fb se muestran elevadas es la referida por la inconsistencia de las respuestas, además de la presencia de psicopatología y del fingimiento.

Una de los orígenes de la elevación de las puntuaciones $\mathrm{F}(\mathrm{T}>100)$, para Avila y Jiménez (1999), es la posibilidad de contestar al azar al protocolo del MMPI-2 en su versión castellana, pero no lo considera cuando el valor es de $\mathrm{T} \leq 100$.

$$
\mid \mathcal{F} \cdot \mathcal{F} b / \text {. }
$$

Greene $(1997,2000)$ se plantea si la diferencia, en valores absolutos, entre $\mathrm{F} \mathrm{y} \mathrm{Fb}$ puede contemplarse como una variable sensible a la imprecisión de las respuestas. Sus últimos resultados confrontados (Greene, 2000, pg.53, Tabla 3.11) el 75\% de los sujetos 
que contestan a la prueba de forma inconsistente, presentan una puntuación $\mathrm{PD} \geq 6$, que resulta ser plenamente coincidente con nuestros resultados. Aunque si establecemos el análisis comparativo de los percentiles de nuestros hallazgos con los encontrados por Greene (1997) en aquellos sujetos que han contestado de forma sincera y honesta, podemos apreciar que existen una notable diferencia. Mientras que para Greene (1997), el $44,2 \%$ de los sujetos presentan una puntuación $\mathrm{PD} \geq 2$, para nosotros, esta misma puntuación, la obtienen el $25 \%$ de los mismos sujetos.

Nuestros datos muestran que el $90 \%$ de los sujetos que intentan presentar una imagen negativa de sí mismos van a obtener una puntuación $\mathrm{PD} \geq 7,4$, (puntuación media $=$ 15,483 ) mientras que solamente el $10 \%$ de los sujetos normales van a presentar una puntuación $\mathrm{PD} \geq 8$ (puntuación media $=3,753$ ).

Greene (2000, pg. 64, Tabla 3.18) ha establecido como puntuación de referencia el valor de $\mathrm{PD} \geq 10$ para diagnosticar el protocolo como "inconsistencia acusada", mientras que nuestros resultados comienzan a ser significativos cuando esta puntuación $\mathrm{PD} \geq 8$ (67T) para las mujeres y de $\mathrm{PD} \geq 10$ (68T) para los varones.

Hemos podido constatar que esta variable no aporta datos relevantes diferentes a los ya suministrados por las variables $\mathrm{F}$ y $\mathrm{Fb}$ que, individualmente, hemos investigado. Por ello, como hemos dicho anteriormente, en aras a la claridad en la exposición de nuestro diseño de la Hoja de perfil del MMPI-2, y evitar el solapamiento de los datos, hemos prescindido de ella en la elaboración definitiva de la Hoja de perfil del MMPI-2 en el apartado correspondiente de las Escalas e índices de Validez.

Escala de Inconsistencia de Respuestas (IR) de Sewell er Rogers, (1994):

Sabiendo que esta variable identifica a los sujetos que intentan fingirse de forma negativa, exagerarando su sintomatología y tratando de mostrar una imagen desfavorable de sí mismo, podemos decir que nuestros hallazgos son ligeramente coincidentes (superiores) a los encontrados por Butcher, J.; Dahlstrom, W.; Graham, J.; Tellegen, A. \& Kaemer, B. (1989) en una muestra de 2.600 sujetos normales, cuando se trataba de verificar las correlaciones de esta variable IR con las escalas $\mathrm{F}(.41 ; .628)$, FBS (.01; .282) Fb (.49; .671); F(p) (.58; .798).

Si comparamos los resultados obtenidos con esta variable IR y la Escala psiquiátrica F(p) de Arbisi y Ben-Porath $(1995,1998)$, podemos apreciar que son extremadamente semejantes debido, fundamentalmente, a que el 50\% de los ítems son comunes a ambas escalas y sus correlaciones positivas son muy elevadas. Recordemos que, debido a este solapamiento de los datos, en nuestra hoja de perfil del MMPI-2, en su apartado de Escalas e índices de Validez, hemos prescindido de ella intentando con ello no reiterar la información ya obtenida y simplificando al máximo el grupo de escalas que detectan la validez de los protocolos. 
Perfiles de "Todo Verdadero"/"Todo Falso":

Graham (2000, pgs.44-45) presenta la Gráfica característica de "todo verdadero" (fig. $3.2 \mathrm{~A} \mathrm{y} 3.2 \mathrm{~B}^{5}$ ) en la que se puede apreciar una puntuación extremadamente elevada en la Escala F (generalmente > que 100T), las escalas L y K suelen estar por debajo de 70T y una exagerada elevación de las puntuaciones en las Escalas Clínicas, sobre todo en las $\mathrm{Pa}$ (paranoia) y Sc (esquizofrenia). La escala $\mathrm{Fb}$ se encontrará igualmente muy elevada, muy próxima a los niveles de la escala F. Las escalas TRIN igualmente elevada ( $>$ 120T), aunque la escala VRIN se puede encontrar cerca de las 50T. Evidentemente, este perfil no debe ser objeto de interpretación en ninguno de los casos. Estos datos son plenamente coincidentes, escala por escala, con los nuestros.

Igualmente el caso de responder "todo falso" como indica la gráfica de Graham, (2000, fig. 3.3A y 3.3B). podemos apreciar elevaciones exageradas en las escalas L, F y $\mathrm{K}$ y las puntuaciones más elevadas de las escalas clínicas. Las puntuaciones $\mathrm{T}$ de $\mathrm{Fb}$ y VRIN se encuentran cerca de la puntuación 50T, pero la puntuación $\mathrm{T}$ de TRIN se encuentra excesivamente elevada $(>110)$. Estas puntuaciones son coincidentes, de forma general ${ }^{6}$, con nuestros resultados.

Hemos presentado en los diversos Anexos de los perfiles, como aporte evidenciable y constatable gráfico, una serie de perfiles con algunas variedades de contestación en donde no se tiene en cuenta el contenido ni la información de los ítems, como: todo verdadero, todo falso, verdadero/falso (alternativamente), falso/verdadero (alternativamente) y al azar. Incluso un perfil "total azar" que considera todas las modalidades de responder apuntadas al describir la muestra.

A través de las "Escalas e Índices identificadores" y "Escalas e Índices no identificadores" vamos a mostrar nuestros resultados sobre las Escalas e Índices que se muestran implicadas en los diferentes perfiles ${ }^{7}$ obtenidos cuando los sujetos contestan al Cuestionario del MMPI-2 de una forma inconsistente, en sus diferentes modos:

Perfiles de "todo Verdadero":

$\checkmark \quad$ Escalas e Índices identificadores:

- TRIN-V: puntuación máxima (120T).

- L : puntuación directa 0 (70T)

- F : puntuaciones directas elevadas (93T)

- $\mathrm{Fb}$ : puntuaciones directas extremadamente elevadas (120T)

- $\mathrm{K}$ : puntuaciones directas elevadas (80T)

- F-K : puntuación directa 0 (113T)

- Ds-r : puntuaciones directas elevadas (89T)

- $\mathrm{S}$ : puntuaciones directas bajas (74T)

- Wds : puntuaciones directas elevadas (19T)

- $\mathrm{F}(\mathrm{p})$ : puntuaciones directas extremadamente elevadas (120T).

\footnotetext{
${ }^{5}$ Podemos apreciar que Graham, en esta $3^{\text {a }}$ edición, integra en la gráfica también las escalas F(p) y S.

${ }^{6}$ Porque no coinciden nuestros datos con la variable F que se encuentra en el límite con la normalidad (66T).

${ }^{7}$ Según nuestro diseño de la Hoja de Perfil del MMPI-2 en las Escalas e ïndices de Validez.
} 
$\checkmark \quad$ Escalas e Índices no identificadores:

- VRIN : puntuaciones directas dentro de la normalidad (40T).

- FBS : puntuaciones directas dentro de la normalidad (60T)

- ODecp : puntuaciones directas dentro de la normalidad (44T)

Perfiles de "todo Falso".

$\checkmark \quad$ Escalas e Índices identificadores:

- TRIN-f : Puntuación directa = 0 (106T)

- L : puntuación directa máxima (0T)

- F : puntuación directa en el límite de la normalidad (66T)

- $\mathrm{K}$ : puntuaciones directas elevadas (17T)

- FBS : puntuaciones directas elevadas (74T)

- $\mathrm{S}$ : puntuaciones directas elevadas (23T)

- $\mathrm{F}(\mathrm{p})$ : puntuaciones directas elevadas 85T)

$\checkmark \quad$ Escalas e Índices no identificadores:

- VRIN : puntuaciones directas dentro de la normalidad (40T)

- $\mathrm{Fb}$. puntuaciones directas dentro de la normalidad (47T)

- F-K : puntuaciones directas dentro de la normalidad (44T)

- ODecp : puntuaciones directas dentro de la normalidad (44T)

- Wsd: puntuaciones directas dentro de la normalidad (64T)

Perfiles de "Verdadero/Falso (alternativamente)".

$\checkmark \quad$ Escalas e Índices identificadores:

- VRIN: puntuaciones directas moderadamente elevadas (69T)

- TRIN-V: tendencia a contestar verdadero (74T)

- F: puntuaciones directas moderadamente elevadas (72T)

- Fb: puntuaciones directas elevadas (82T)

- FBS: puntuaciones directas moderadamente elevadas (72T)

- Ds-r: puntuaciones directas moderadamente elevadas (68T)

- $\mathrm{F}(\mathrm{p})$ : puntuaciones directas elevadas (82T)

$\checkmark \quad$ Escalas e Índices no identificadores:

- L: puntuaciones directas dentro de la normalidad (53T)

- $\mathrm{K}$ : puntuaciones directas dentro de la normalidad (42T)

- F-K: puntuaciones directas dentro de la normalidad (61T)

- ODecp: puntuaciones directas dentro de la normalidad (46T)

- S: puntuaciones directas dentro de la normalidad (51T)

- Wsd: puntuaciones directas dentro de la normalidad (49T) 
Perfiles de "Falso/Verdadero (alternativamente)".

$\checkmark \quad$ Escalas e Índices identificadores:

- VRIN: puntuaciones directas elevadas (87)

- L: puntuaciones directas elevadas (22T)

- F: puntuaciones directas elevadas (91T)

- Fb: puntuaciones directas elevadas (91T)

- F-K: puntuaciones directas elevadas (95T)

- $\mathrm{F}(\mathrm{p})$ : puntuaciones directas extremadamente elevadas (120T)

- Ds-r: puntuaciones directas en el límite (66T)

$\checkmark \quad$ Escalas e Índices no identificadores:

- TRIN-F: puntuaciones directas dentro de la normalidad (53T)

- K: puntuaciones directas dentro de la normalidad (54T)

- FBS: puntuaciones directas dentro de la normalidad (63T)

- ODecp: puntuaciones directas dentro de la normalidad (39T)

- S: puntuaciones directas dentro de la normalidad (45T)

- Wsd: puntuaciones directas dentro de la normalidad (36T)

Perfiles de respuesta inconsistente (perfil medio).

$\checkmark \quad$ Escalas e Índices identificadores:

- VRIN: puntuaciones directas moderadamente elevadas (75T)

- F : puntuaciones directas elevadas (85T)

- Fb: puntuaciones directas elevadas (82T)

- F-K: puntuaciones directas moderadamente elevadas (74T)

- FBS: puntuaciones directas moderadamente elevadas (69T)

- Ds-r: puntuaciones directas moderadamente elevadas (68T)

- $\mathrm{F}(\mathrm{p})$ : puntuaciones directas elevadas (89T)

$\checkmark \quad$ Escalas e Índices no identificadores:

- TRIN-V: puntuaciones directas dentro de la normalidad (51T)

- K: puntuaciones directas dentro de la normalidad (50T)

- ODecp: puntuaciones directas dentro de la normalidad (47T)

- S: puntuaciones directas dentro de la normalidad (49T)

- Wsd: puntuaciones directas dentro de la normalidad (46T)

- Todas las Escalas Clínicas se encuentran dentro de la normalidad. 


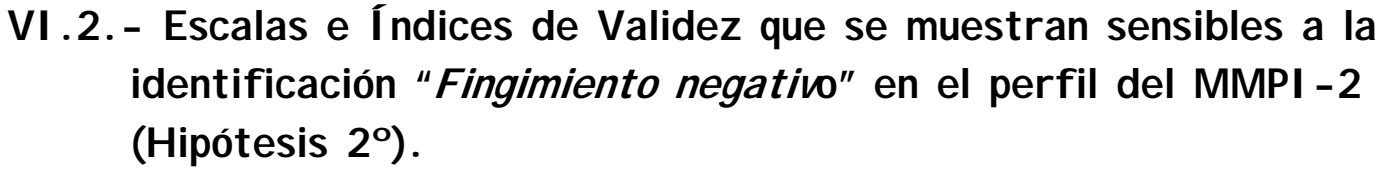

La literatura científica ha denominado de varias formas el hecho de que un simulador intente presentar una imagen negativa de sí mismo. Los términos "fake-bad", "malingering", "defensividad negativa", "hacerse el malo", "hacerse el enfermo", "mala imagen", son los más ususales. En toda esta terminología nos vamos a apoyar para poder comprobar que el sujeto, en definitiva, le va a interesar ofrecer una imagen desfavorable de sí mismo al contestar al cuestionario del MMPI-2. A continuación exponemos las Escalas de Índices de Validez que intervienen en la identificación de este tipo de simulación.

Escala $\mathcal{F}$ (infrecuencia):

A lo largo de las investigaciones realizadas con las Escalas de Validez del MMPI, esta escala F, al ser considerada como "tradicional" conjuntamente con la L y la K, ha sido una variable extensa y ampliamente investigada.

Esta variable F fue elaborada originariamente (Meehl \& Hathaway, 1946; Mckinley, Hathaway \& Mehl, 1948) para detectar formas anómalas o atípicas de contestar al cuestionario, como una medida de evidenciar la tendencia a reconocer o admitir una extensa gama de problemas psicológicos. Estos mismos resultados fueron confirmados posteriormente por diferentes investigadores (Butcher, 1990, Graham, 1990; Butcher \& Williams, 1992), estableciendo que una elevada puntuación en esta Escala refleja una tendencia a exagerar los problemas.

Nuestros resultados han confirmado los resultados obtenidos por las investigaciones anteriores, encontrando una elevada puntuación en el grupo de simuladores cuando intentan presentar una imagen desfavorable de sí mismos.

El $90 \%$ de los nuestros sujetos que ofrecen una mala imagen presentan una puntuación $\mathrm{PD} \geq 30$, (puntuación media $=47,045$ ), mientras que solamente el $10 \%$ de los sujetos que contestan de forma sincera y honesta (normales) presentan una puntuación $\mathrm{PD} \geq 13$ (puntuación media $=7,125$ ) y el mismo porcentaje de sujetos clínicos presentan una puntuación de $\mathrm{PD} \geq 23,4$.

Nuestro "punto de corte" queda establecido, para los varones, en $\mathrm{PD} \geq 18$ (67T), y para las mujeres $P D \geq 19$ (66T). Todas las puntuaciones superiores a éstas, pueden estar indicando que el sujeto está falsificando el protocolo intentando presentar una imagen negativa de sí mismo o exagerando su problemática psicológica. Los diferentes investigadores (Butcher, 1990; Greene, 1997, 2000; Graham, 1992; Butcher \& Williams, 1992) muestran diversos "puntos de corte" para delimitar el fingimiento de enfermedad, de sintomas o la validez o invalidez del protocolo, pero las diferencias son mínimas en todas y cada una de las investigaciones, va a depender sustancialmente del tipo de sujeto (paciente psiquiátrico, clinico ambulatorio, normal, homicida, etc.) al que se le esté administrando la prueba.

Para Greene (1997) la puntuación óptima de corte para la Escala F con las que se pueden identificar a personas que son fingidores, dentro de los ejemplos clínicos, tienen un rango variable que va desde 17 (Bagby, Rogers, Buis, \& Kalemba, 1994), 23 
(Graham et al., 1991) y 28 (Rogers, Bagby, \& Chakraborty, 1993). En los resultados obtenido por Greene (1997), una puntuación de corte de 17 podría clasificar aproximadamente al $20 \%$ de los pacientes fingidores, mientras que una puntuación de 28 clasificaría apenas al 5\%.

Es clara la coincidencia para todos los investigadores que a partir de una puntuación $65 \mathrm{~T}$ toman con precaución las interpretaciones diagnósticas.

Nuestros resultados son coincidentes plenamente con los de Butcher, (1990), Graham, (1990), Butcher \& Williams (1992) cuando tratamos de apreciar que los sujetos que contestan de forma inadecuada a los diversos ítems del cuestionario obtienen puntuaciones elevadas. Berry y su equipo de investigación (Berry et al., 1991; Berry, Wetter, Baer, Larsen, Clark, \& Monroe, 1992) ha examinado la utilidad de las medidas de consistencia de los ítems respondidos para detectar a las personas que fueron instruidas para responder aleatoriamente después de completar 100, 200, 300, 400 ó 500 ítems de forma coherente. Sus resultados muestran que F, Fb y VRIN fueron efectivas al detectar este tipo de personas que respondieron de forma inconsistente y que fueron más efectivas tanto en cuanto los ítems respondidos aleatoriamente se aumentaban.

Sin embargo, encontramos que solamente los sujetos que contestan a todos los ítems del cuestionario como "verdadero" ("todo verdadero") presentan puntuaciones elevadas, pero no aquellos sujetos que contestan todos los ítems como "falso" ("todo falso") presentando solamente una ligera elevación (68T) en sus respuestas. Graham (1990) muestra que también los sujetos que contestan así ("todo falso") presentan una puntuación elevada.

Hemos podido confirmar que nuestros sujetos clínicos presentan un ligero aumento de sus puntuaciones medias $(10,176)$ sobre los sujetos considerados como normales $(3,968)$, dejando constancia que ambos grupos contestan de forma sincera y honesta. Este mismo aspecto ha sido verificado por el trabajo de Greene (1997) tomando diferentes tipos de muestra (normales, con trastornos mentales graves y sujetos que responden aleatoriamente) y analizando diferentes tipos de Escalas (F, Ds, Obvio-Sutil, F-K...) que pudo comprobar que los pacientes con desórdenes mentales respondían aproximadamente 3 veces más a los ítems de la escala $\mathrm{F}$ que los sujetos normales. Resulta interesante apreciar cómo el $50 \%$ de los pacientes con trastornos mentales responden 8 o menos ítems de la Escala $\mathrm{F}$. Este relativo y pequeño número de respuestas en la Escala F, podría reflejar que estos ítems actualmente son infrecuentes en una cierta situación clínica $\mathrm{y} / \mathrm{o}$ que un porcentaje bastante alto de pacientes psiquiátricos son defensivos.

Escala $\mathcal{F b}$ (infrecuencia. $2^{a}$ P.):

Hemos de recordar que esta variable ("Fback scale") es considerada como un índice adicional con el objetivo de identificar la posible desviación de las respuestas motivadas por la larga extensión del cuestionario (Butcher et al., 1989), elaborada de forma similar a la F. Al referirse a la segunda parte del test MMPI-2, sustancialmente, llegamos a las mismas conclusiones que su homónima de la primera parte, $\mathrm{F}$.

Una puntuación elevada, y distinta de la F, puede sugerir que el sujeto dejó de prestar atención a los ítems, bien por cansancio, fatigabilidad o falta de interés. Esta es la 
aportación de la variable $/ \mathrm{F}-\mathrm{Fb} /$ ya comentada anteriormente. No debemos olvidar que los valores de esta variable afecta, sobre todo, a las interpretaciones de las Escalas de Contenido y Suplementarias del MMPI-2. La suposición de los clínicos, por otra parte habitual, de que los sujetos van a realizar los 567 ítems siguiendo siempre y continuamente el mismo patrón de motivación, no siempre es apropiada, ya que las habilidades y el poder de concentración de los sujetos, a veces pacientes psiquiátricos con diversos grados de severidad, no es siempre la más adecuada. Por ello esta escala se puede mostrar sensible para identificar estas peculiaridades del sujeto.

Para Butcher, J.; Dahlstrom, W.; Graham, J.; Tellegen, A. \& Kaemer, B. (1989) una puntuación de $\mathrm{Fb} \mathrm{T} \geq 120$ invalidarían totalmente el protocolo; sin embargo, cuando las puntuaciones se muestran $\mathrm{T} \geq 80$ sugieren estos autores la existencia de algún tipo de respuesta desviada de los ítems y sería indicativo de un cuidado extremo en la interpretación del grupo de Escalas Suplementarias y de Contenido. Para nuestros resultados el "punto de corte" queda establecido en una $\mathrm{PD} \geq 12$ (66T), para varones, $\mathrm{y}$ de $P D \geq 11$ (68T) para mujeres.

\section{Índice de Simulación de Gough (F.K. K).}

Hemos de tener en cuenta que es la única variable en nuestra investigación que puede presentar tanto puntuaciones positivas como negativas.

Nuestros resultados son plenamente coincidentes con la mayoría de las investigaciones sobre este Índice de Simulación de Gough F-K al mostrarse muy sensible para identificar a las personas que intentan falsificar un determinado protocolo pretendiendo simular el padecimiento de cualquier tipo de trastorno o exagerando su sintomatología.

No podemos estar de acuerdo con el trabajo llevado a cabo por los investigadores de la Universidad del Estado de Luisiana, McAnulty, Rappaport, y McAnulty (1985) con las variables de Validez del MMPI en una muestra de 156 estudiantes universitarios no licenciados, a los que se le pidió que fingieran una buena imagen de sí mismos, concluyen que las escalas de Validez (L, F y K) y, en concreto el índice F-K no discrimina a los sujetos que fingen una buena imagen de los que no lo hacen.

Para poder apreciar si las escalas F y F-K podrían discriminar el fingimiento de un trastorno mental, Johnson, Klingler y Williams (1977) investigadores del Hospital VA de la ciudad de Salt Lake, llevaron a cabo una investigación con un grupo de 228 veteranos que requieren tratamiento psicoterapéutico, a los que se les aplicaron el MMPI, el Examen del estado Mental y una entrevista estructurada. Los resultados obtenidos manifestaron una relación, estadísticamente significativa, entre las F y F-K conjuntamente con los clasificados como "hacerse el enfermo" ("fake bad").

Esta relación con otras escalas del mismo autor, y que pueden ir en la misma dirección diagnóstica, específicamente elaboradas para detectar "mala imagen", se ve corroborada por las elevadísimas correlaciones positivas, que hemos apreciado en nuestros resultados, con las variables Ds (Escala de disimulación: $r=.917$ con el grupo "mala imagen"; $r=.838$ con el grupo de "normales") y la Ds-r (Escala de Disimulación revisada: $\mathrm{r}=.876$ con el grupo de "mala imagen"; $\mathrm{r}=.789$, con el grupo de "normales"). 
Para Gough (1947, 1950), las puntuaciones F-K muy elevadas indicarían también casos psicóticos graves, y las muy bajas (negativas) podrían indicar tendencias acusadamente rígidas y defensivas en los sujetos. Podemos igualmente acompañarnos para la interpretación del mismo perfil para efectuar ciertas discriminaciones. En la tendencia a ofrecer una "buena imagen", destacan las elevaciones L y K, con bajo F, y las bajas puntuaciones en todas las Escalas Clínicas. En cambio, cuando se intenta ofrecer una "mala imagen", destacan el alto F y los bajos L y K, con elevaciones típicas en Sc y Pa. Todas estas afirmaciones de Gough son plenamente coincidentes con nuestros resultados como pueden apreciarse en los perfiles mostrados en el Anexo B.

El problema de los "puntos de corte" ha sido especialmente contrastado en casi todas las investigaciones. Desde la propuesta inicial de $\mathrm{PD} \geq+9$ (indicaría fingimiento negativo en el sentido de ofrecer una "mala imagen") y $\mathrm{PD} \leq-9$ (indicaría fingimiento positivo, en el sentido de ofrecer una "buena imagen") se han reestructurado los diferentes puntos de corte. Carson (1969) ha modificado esta puntuación a once (11), mientras que Butcher y Williams (1992), para el MMPI-2 concretan la puntuación en quince (15). El trabajo de Wetzler \& Marlowe (1990) va en esta misma dirección intentando detectar la exageración de los síntomas. El estudio realizado por Osborne, Colligan. \& Offord (1986) con una población normal, establece dos puntuaciones medias diferentes según sexos. Para los hombres: $\mathrm{F}-\mathrm{K}=-9,77$ y para las mujeres: $\mathrm{F}-\mathrm{K}=$ $-11,22$.

Nuestros resultados (Tabla 63), en donde se presentan las puntuaciones obtenidas en los diversos grupos aquí investigados a través de diferentes percentiles, podemos ver que los sujetos normales presentan un percentil medio (P50) de -8 para el grupo normal que ha contestado honestamente a la prueba y de +1 (P50) para el grupo clínico que igualmente ha contestado de forma honesta al MMPI-2. Estos resultados contrastan con los de Butcher et als., 1989, (citado por Greene, 1997) que, con una muestra de 2.600 sujetos normales y de 3.475 sujetos con graves trastornos mentales obtuvo un percentil 50 , para los normales de -12 , y para los pacientes psiquiátricos de -4 , los resultados parecen ser "algo" más semejantes.

No obstante, podemos apreciar, en nuestros resultados (Tabla 63) que, tanto el grupo de "mala imagen" como el de "buena imagen", instruidos para ello, muestran una notable diferencia en su percentil medio (P50), para los primeros es de -17 y para los segundos es de +41 . Comprobamos que el $90 \%$ de los sujetos que ofrecen una imagen deteriorada de sí mismo, presentan una puntuación $\mathrm{PD} \geq 16,4$ (puntuación media $=$ 36,699 ), mientras que el $10 \%$ de los sujetos, considerados como normales, presentan una puntuación $\mathrm{PD} \geq 4$. (puntuación media $=-7,400$ )

No obstante existe una pregunta en el aire acerca de la sensibilidad de esta escala de Gough para diferenciar a los pacientes psiquiátricos de los normales que fingen negativamente. Por los resultados obtenidos en nuestra investigación no podemos afirmar la existencia de esta sensibilidad por parte de la escala F-K de Gough. Nuestros pacientes clínicos son pacientes ambulatorios, no internos, y por ello con una sintomatología patológica, generalmente, no severa. Es así que el perfil medio de nuestro grupo clínico, tanto en mujeres como en varones, no sobrepasa la puntuación de $65 \mathrm{~T}$ (tanto en varones como en mujeres: $\mathrm{PD}=1$ [59T]), sin embargo el perfil medio de los sujetos que, intencionadamente, muestran una imagen desfavorable de sí mismos presentan una elavada puntuación directa de $\mathrm{PD}=37$ (mujeres $=108 \mathrm{~T}$; varones 97T). 
Según nuestros resultados, solamente, podemos evidenciar la sensibilidad de este Índice F-K para identificar a los sujetos que intentan presentar una mala imagen de sí mismos.

Graham (1990) afirma, de forma general que, siempre que la puntuación directa de la Escala $\mathrm{F}$ es mayor que la puntuación directa de la escala $\mathrm{K}$, debe considerarse la posibilidad de "hacerse el enfermo" y cuanto mayor es la diferencia tanto mayor es la probabilidad de fingir una mala imagen. A primera vista el perfil "fake bad" podría parecer similar al perfil que uno debería esperar que obtenga una persona que está realmente trastornado psicológicamente, pero, sin embargo existe, a juicio de Graham (1990) una diferencia sumamente importante: la puntuación de la escala F, generalmente es más elevada para el perfil "fake bad". El rango, comúnmente aceptado, de la puntuación $\mathrm{T}$ de la Escala $\mathrm{F}$ para personas diagnosticadas como psicóticos se encuentra entre 71 y 90, mientras que el perfil "fake bad" para la Escala F se encuentra por encima de 100T. Es decir, en un perfil "fake bad" las puntuaciones de las escalas Clínicas tienden a ser mucho más altas que en un perfil válido para una persona con un trastorno grave.

Escala de "Fake-6ad" (FBS) de Lees-Haley, English o Gle nn (1991).

Esta escala compuesta por 43 ítems muestra una notable sensibilidad para detectar adecuadamente a los sujetos que intentan ofrecer una imagen desfavorable de sí mismo, haciéndose el enfermo, exagerando o inventando cualquier tipo de sintomatología patológica.

En nuestra investigación hemos encontrado que el $90 \%$ de los sujetos que ofrecen una imagen negativa de sí mismo presentan una puntuación $\mathrm{PD} \geq 13$ (puntuación media $=23,933$ ), mientras que el $50 \%$ de los sujetos considerados como normales presentan una puntuación $\mathrm{PD} \geq 12$ (puntuación media $=12,955$ ).

El "punto de corte" establecido en nuestros resultados, para los varones, es PD $\geq 20$ (67T); y para las mujeres $\mathrm{PD} \geq 21$ (66T) a partir de las cuales podemos interpretar que el sujeto presenta un perfil con fingimiento negativo.

Existen pocos estudios realizados con esta variable, pero hemos podido apreciar que las investigaciones de Butcher et al, (1989) con 2.600 normales, que contestaron honesta y sinceramente a los ítems, encontró correlaciones positivas de esta escala FBS con $\mathrm{Fb}(, 26), \mathrm{F}(\mathrm{p})(, 08)$, IR $(, 01)$, VRIN $(, 16)$ y TRIN $(-, 02)$. Mientras que nuestros resultados, con 1.723 sujetos también honestos y sinceros al contestar, tienen unas correlaciones algo más elevadas: $\mathrm{Fb}(, 450) ; \mathrm{F}(\mathrm{p})(, 302)$, IR $(, 282)$, VRIN $(, 223)$; y TRIN $(, 016)$.

A través de esta escala FBS, no hemos podido encontrar diferencias entre los sujetos normales, que contestan de forma sincera y honesta, de aquellos que fingen intentando dar una buena imagen de sí mismos. Ello nos puede estar diciendo que con esta escala no podemos diferenciar adecuadamente si el protocolo es falso o no; es decir, más concretamente, si el sujeto ha falsificado su protocolo contestando a las respuestas de forma favorable o por el contrario no ha sido así.

La explicación que podemos encontrar a estos resultados, es que la mayoría de los ítems se están refiriendo a dolencias de tipo psicosomáticas, por lo cual los sujetos normales no suelen tenerlas y cuando un sujeto intenta dar una imagen favorable de sí mismo, normalmente estas dolencias no se padecen. Probablemente, esta escala puede 
presentar mucha más utilidad en sujetos con lesiones cerebrales en los que resultaría mucho más fácil exagerar este tipo de dolencias psicosomáticas como lo demuestra la investigación llevada a cabo por Larrabee (1998) intentando detectar a las personas que exageran y/o prolongan su malestar corporal cuando se encuentran inmersas en procesos de reclamación jurídica. El objetivo es evaluar la sensibilidad del MMPI/MMPI-2 para exagerar su sintomatología en sujetos con sospecha de "hacerse el enfermo". Para eso, a cada uno de los 12 sujetos con daño cerebral que reclaman una indemnización por encontrarse enfermos, se le administró una entrevista clínica, una batería neuropsicológica, unas pruebas que detecten los síntomas de validez para poderles aplicar las pruebas y el MMPI-2. Los resultados demuestran que 3 de los 12 sujetos presentaron puntuaciones elevadas en las escalas de Validez F y en las Escalas Clínicas Hs y Hy. Igualmente, pudo mostrar que 11 de los 12 sujetos presentaron elevaciones en la Escala FBS de Lees-Haley. La conclusión a que llega Larrabee es que debe ser diagnosticado como "Fake-bad" cuando existan, en las Escalas Clínicas, puntuaciones Hs y Hy $>80 \mathrm{~T}$ y la Escala de Validez FBS se encuentre significativamente elevada.

\section{Escala Revisada de Disimulación (Ds-r) de Gough, (1957).}

En nuestra investigación hemos operado con las dos escalas de Disimulación de Goug, la original (Ds) y la revisada (Ds-r). Para los investigadores no parece haber consenso si se debe utilizar al versión original o la revisada de la escala Ds (Bagby, Rogers, \& Buis, 1994; Bagby, Rogers, \& Kalemba, 1994; Bagby, Rogers, \& Chakraborty, 1993) o si es necesario llevar a cabo más investigaciones sobre esta escala (Berry, Baer \& Harris, 1991).

Recordemos que hemos prescindido de la Escala original (Ds) y adopado la "revisada" (Ds-r) del mismo autor por las siguientes razones:

- Todos y cada uno de los ítems (34) que componen la escala revisada se encuentran en la Escala Ds.

- Ambas evalúan el fingimiento negativo o el intento de ofrecer una mala imagen.

- Las correlaciones entre estas dos escalas de Gough, son muy elevadas y positivas entre los diversos grupos: normal $=.944$; clínico $=.955$; Buena imagen $=.950$; mala imagen $=.968 ; \mathrm{y}$ Respuestas inconsistentes $=.836$.

Al igual que la mayor parte de las investigaciones, hemos encontrado que esta variable se muestra especialmente sensible para identificar a los sujetos que intentan mostrar una imagen desfavorable y negativa de sí mismo.

El $90 \%$ de nuestros sujetos que contestan al test intentando dar "mala imagen" obtienen una puntuación, en esta escala, de PD $\geq 16$ (puntuación media $=24,903$ ), mientras que los sujetos sinceros, considerados como normales solamente el $10 \%$ presentan una puntuación $\mathrm{PD} \geq 15$ (puntuación media $=8,334$ ).

El $10 \%$ de nuestros sujetos clínicos presentan una puntuación $\mathrm{PD} \geq 21$ (puntuación media $=12,965)$, siendo esta misma puntuación para el $75 \%$ de los sujetos que ofrecen una imagen deteriorada de sí mismos. 
Escala psiquiátrica $\mathcal{F}(p)$ de Arbisi y Ben-Porath (1995, 1998).

Esta escala ha demostrado ser especialmente sensible para detectar a los sujetos que intencionadamente exageran su sintomatología de tal manera que, ni siquiera los pacientes psiquiátricos ofrecen puntuaciones elevadas.

Nuestros resultados coinciden plenamente con la indicación de los autores Arbisi y Ben-Porath $(1995,1998)$ de que para una mejor identificación del protocolo simulador, podamos contrastar las puntuaciones elevadas de esta escala con las elevaciones de F. Según los resultados de nuestra investigación, además, podemos confrontar las elevaciones de otras dos escalas más: Fb e IR7, cuyas correlaciones se han mostrado positivamente elevadas.

El 90\% de los sujetos que contestan intentando ofrecer los aspectos negativos de sí mismo, muestran una puntuación $\mathrm{PD} \geq 11,4$ (puntuación media $=18,550$ ), mientras que solamente el $10 \%$ de los sujetos normales muestran una puntuación $\mathrm{PD} \geq 5$ (puntuación media $=2,2$ ).

El "punto de corte" establecido en nuestra investigación es de $\mathrm{PD} \geq 7$ (67T) para los varones, y de $\mathrm{PD} \geq 6$ (70T) para las mujeres. Todas las puntuaciones superiores a éstas pueden ser indicativas de un protocolo falsificado de forma negativa, intentando presentar una imagen muy desfavorable de sí mismo al exagerar su psicopatología.

El hecho de que hayamos encontrado en nuestro estudio una escasa diferencia estadística $(p=, 0173)$ entre los sujetos clínicos que han contestado de forma sincera, y los que intentan presentar una imagen favorable de sí mismos, (dentro de sus bajas puntuaciones) puede venir explicada por el contenido de los mismos ítems .

La escala Fp ha sido como una nueva medida de validez en la renovada hoja de perfil para las escalas de Validez y Clínicas del MMPI-2 elaborada por la Universidad de Minnesota. En esta revisión del material, Fp aparece conjuntamente con las escalas $\mathrm{F}$ y $\mathrm{Fb}$ como una medida de la infrecuencia de respuestas (NCS Assessments, february, 2001).

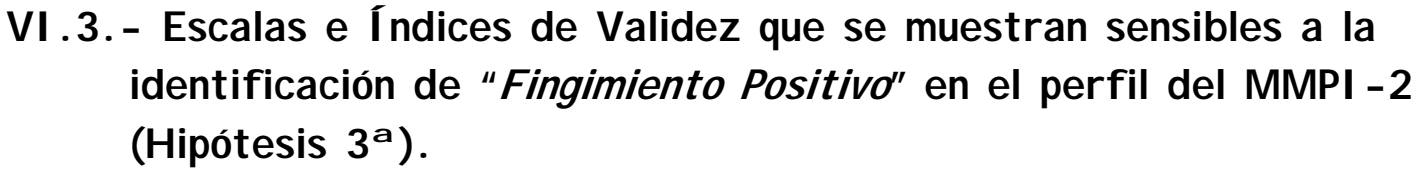

Ya hemos comentado, en páginas anteriores, que generalmente los autores que refieren el término de "defensividad" para explicar que el sujeto se manifieste con una imagen favorable, es el equivalente a nuestro "fingimiento positivo", e incluso Greene (2000, pg.97) refiere "overreporting" como "fingimiento positivo" y "underreporting" como "fingimiento negativo". Igualmente, existe en la literatura científica un término para explicar este tipo de fingimiento: "faking good" o "fake-good".

Los perfiles típicos de la actitud de "fingirse bueno" ("faking good") los muestra Graham (1990, pgs. 47 y 48) como una forma de "uve" en la configuración tradicional del perfil del MMPI-2 en las escalas de validez, con elevaciones en las escalas L y K y una puntuación, en la escala $\mathrm{F}$, en el rango entre 40 y $50 \mathrm{~T}$.

Posteriormente los trabajos de Graham, Watts, y Timbrook (1991) para detectar los perfiles "fake bad" y "fake good" en sujetos normales y clínicos mostraron en los 
resultados que la media de los perfiles y la puntuación óptima de corte se parecían a las establecidas previamente en el MMPI original.

A continuación vamos a comentar y contrastar nuestros hallazgos con los obtenidos por otros investigadores en el apartado correspondiente a lo que hemos consensuado en denominar "fingimiento positivo". Las Escalas e Índices de Validez que vamos a comentar son las siguientes:

\section{L. (me ntira).}

Recordemos que esta escala se basa en la idea de que los individuos que intentan reclamar un excelente ajuste psicológico se atribuirán ítems que indican elevadas características morales, éticas y de responsabilidad.

Nuestros resultados son plenamente coincidentes con los obtenidos por la mayor parte de los investigadores (Butcher et al., 1989; Butcher, 1990; Butcher y Williams, 1992; Graham, 1990; Burish \& Houston, 1976; Bagby, Rogers, Buis \& Kalemba, 1994; Graham et al.,1991; Rogers, Bagby \& Chakraborty, 1993; Greene, 1997, 2000) cuando refieren que el significado de las puntuaciones elevadas en esta escala están refiriendo al tipo de sujetos descritos en el párrafo anterior.

En nuestro estudio esta escala se ha mostrado como la variable con mayor incidencia de los sujetos que fingen ofrecer una imagen positiva de sí mismos (puntuación media: $10,858)$ siendo ésta, estadísticamente significativa con el resto de los demás grupos.

El 90\% de nuestros sujetos que intentan presentar una imagen favorable de sí mismo muestran una puntuación PD $\geq 7$ (puntuación media $=10,858$ ), mientras que el $10 \%$ de los sujetos normales, e igual que los clínicos, presentan una puntuación $\mathrm{PD} \geq 8$ (puntuación media $=4,71$ ), (puntuación media de los sujetos clínicos $=4,889$ ).

Sin embargo, esta escala no diferencia adecuadamente a los sujetos normales de los clínicos, sabiendo que tanto un grupo como otro contesta de forma honesta y sincera.

En la interpretación diagnóstica de "fingimiento positivo", es aconsejable que esta escala se acompañe de las puntuaciones obtenidas por $\mathrm{K}$, ODecp, S y Wsd fundamentalmente, ya que parecen presentarse en la misma dirección diagnóstica cuando muestran puntuaciones elevadas.

\section{$\mathcal{K}(\operatorname{corrección})$}

Recordemos que la escala $\mathrm{K}$ fue elaborada como un índice más sutil y efectivo ante los intentos del sujeto de negar o simular síntomas psicopatológicos queriendo con ello presentarse de forma más favorable e incluso poder, en un sentido opuesto, exagerar su patología para evidenciar una mala imagen de sí mismo (Meehl y Hathaway, 1946; Mckinley \& Hathaway, 1948). De esta manera las puntuaciones elevadas dadas en la escala $\mathrm{K}$ fueron consideradas como una forma de defensividad ante el abordaje del test, mientras que las puntuaciones bajas fueron pensadas para poder apreciar una inusual franqueza y autocrítica.

Nuestros resultados concuerdan con los datos aportados por Graham (1990) sobre las puntuaciones elevadas. Los sujetos a los que se les instruyó, al contestar los ítems del MMPI-2, para que presentaran una imagen favorable de sí mismos son los que 
presentan la puntuación media más elevada $(19,677)$ de entre todos los grupos aquí investigados, siendo estadísticamente significativa $(\mathrm{p}<, 0001)$ en sus diferentes análisis comparativos.

Los resultados obtenidos por los investigadores de la Universidad de Minnesota Butcher et al., (1989, citado por Greene, 1997), con una población que contestó de forma honesta y sincera, ofrecen unos valores correlacionales muy semejantes a los obtenidos por nuestro estudio. Con esta población normal, las correlaciones con la variable $L$ fue de ,32 (nuestros resultados: ,395), con la variable $\mathrm{S}$ fue de ,82 (nuestros resultados: ,813), con ODecp de ,32 (nuestros resultados: ,373) y con Wsd de ,03 (nuestros resultados: ,086). Como podemos apreciar los resultados son notablemente semejantes.

Queda claro y evidente que esta variable posee unas características especiales y distintas a las demás. Ya hemos comentado, en apartados anteriores, que esta variable no se muestra, en nuestros resultados, ni lo suficientemente elevada ni lo suficientemene disminuida como para que sobrepase los límites establecidos de nuestras líneas de corte ("media \pm 1,5 Desv. St.").

Son estas puntuaciones, que podemos considerar como "moderadamente elevadas" o como "moderadamente bajas" las que nos pueden estar indicando un "fingimiento positivo o negativo" mucho más sutil, sibilino, disimulado y elaborado de forma más crítica $^{8}$. A los sujetos que, intencionadamente se les intruyó para que dieran una imagen favorable o desfavorable de sí mismos, éstos no obtuvieron una puntuación claramente significativa ni identificadora de esta postura.

Los resultados encontrados muestran que esta escala $\mathrm{K}$ no diferencia adecuadamente un protocolo realizado por una persona normal, que ha respondido de forma honesta y sincera, de otra que ha contestado de forma inconsistente. Para poder diferenciar apropiadamente estos perfiles mediante esta escala $\mathrm{K}$ sería necesario apoyarse en otras escalas, como por ejemplo en la VRIN, F, Fb, F-K y F(p) cuyas puntuaciones se muestran elevadas en los tipos de respuesta inconsistentes, auqnue también podría apoyarse en aquellas otras Escalas e Indices que sus puntuaciones elevadas se correlacionan positivamente con L, S y ODecp fundamentalmente.

Debido a que es bastante obvia la naturaleza de los ítems de la escala L, individuos brillantes intelectualmente, bien educados y psicológicamente ajustados, pueden detectar la intención de los ítems y obtendrían, de esta manera, bajas puntuaciones en L. Sin embargo, en los ítems de la escala K, siendo tan obvios como los de la escala L, el mismo tipo de personas podrían producir puntuaciones muy elevadas en la escala $\mathrm{K}$, si adoptan hacia el test una actitud de "buena imagen". De todas formas, antes de concluir que una puntuación alta en $\mathrm{K}$ indica una estrategia defensiva, sería necesario tener en cuenta las características apuntadas por Graham (1990) y Butcher (1990) respecto a que esta escala correlaciona con variables como la clase social y nivel educativo, ya que los sujetos con estas particularidades tienden a puntuar más alto en $\mathrm{K}$ que los que carecen de ellos.

\footnotetext{
${ }^{8}$ No olvidemos que las personas con un buen nivel cultural, educativo, ajustadas y con un buen nivel de equilibrio psicológico y suficientemente críticas como para poder asumir abiertamente sus propios defectos, son personas que presentan puntuaciones elevadas en esta escala K.
} 
Escala de Fingimiento Positivo o de Otro engaño (ODecp) de Nichols é Greene (1991).

Es otra escala que ha mostrado ser sensible para identificar a los sujetos que intentan presentarse, de una forma defensiva, como demasiado equilibrados, honestos, sinceros, éticos, responsables y ajustados psicológicamente.

Nuestros resultados se diferencian escasamente de los aportados por Butcher, J.; Dahlstrom, W.; Graham, J.; Tellegen, A. \& Kaemer, B. (1989) en una investigación con 2.600 sujetos considerados como población normal. El percentil 50, para Butcher et al. (1989), se refleja en 11 puntuaciones directas (nuestros resultados: 13); el percentil 90, 17 (nosotros, 19) y el percentil 10, para Butcher et al.(1989), muestra una P.D. de 6 (nosotros: 8).

Las investigaciones realizadas por Greene $(1997,2000)$ con diferentes tipos de muestra (normal y con trastornos psiquiátrico) resumen el rango de puntuaciones que se obtuvieron en la escala ODecp con sujetos normales y con trastornos mentales. Las PD $\geq 19$ se encontraron en, aproximadamente, el 5\% de los sujetos tanto normales como de los pacientes con trastornos y las distribuciones de las puntuaciones tienden a ser semejantes en los dos grupos. Nuestros resultados muestran datos semejantes con respecto a los sujetos normales y clínicos. Para los primeros el $10 \%$ presentan una puntuación $\mathrm{PD} \geq 19 \mathrm{y}$ de $\mathrm{PD} \geq 18$ para el mismo porcentaje de los pacientes clínicos. Sin embargo, el $90 \%$ de los individuos que se les había instruido para que dieran una imagen positiva de sí mismos, presentaron una $\mathrm{PD} \geq 17$.

Si comparamos nuestros resultados con los obtenidos por Butcher, J.; Dahlstrom, W.; Graham, J.; Tellegen, A. \& Kaemer, B. (1989), podemos apreciar que las correlaciones de esta escala, obtenidas con el grupo de población normal que contestan honesta y sinceramente a la prueba, son notablemente semejantes: con la escala L (Butcher: ,55; nosotros: ,578), con la escala K (Butcher: ,32; nosotros: ,373), con la escala S (Butcher: ,40; nosotros: ,431), y con la escala Wsd (Butcher: ,80; nosotros: ,799).

Para una mejor interpretación diagnóstica, sería aconsejable que las elevaciones de esta escala se pudieran confrontar con los resultados de las variables L, S y Wsd para poder apreciar la posibilidad de fingimiento positivo en sus respuestas al MMPI-2.

Escala Superlativa (S) de Butcher of Han (1995).

Esta escala fue elaborada por Butcher \& Han (1995) para identificar la tendencia de algunas personas de mostrarse como extremadamente virtuosos, equilibrados y ajustados psicológicamente. El dar esta imagen favorable de sí mismo no es raro encontrarla en sujetos ante situaciones de selección de personal o en ambientes jurídicos en los que, del hecho de resaltar y/o atribuirse virtudes y excelencias, pueden obtenerse notables beneficios.

Butcher \& Han (1995) sugieren la existencia de cinco dimensiones principales en los ítems de esta escala: creencia en las virtudes humanas, serenidad, satisfación con la vida, paciencia y negación de ira e irritabilidad, y negación de defectos morales (citado por Graham, 2000, pg.36). 
Para Baer, Wetter \& Berry (1995) encontraron que la escala S resultó ser efectiva para identificar a los estudiantes que contestaban intentando ofrecer una buena imagen. Para estos autores, el 92\% de los sujetos de "buena imagen" presentaban una puntuación directa $\geq 29$. En nuestros resultados (Tabla 73) comprobamos que el $90 \%$ de estos mismos sujetos (aunque no son estudiantes), que también intentan ofrecer una buena imagen, presentan una puntuación directa $\geq 25$. Los resultados no parecen ser muy dispares.

Butcher \& Han (1995; citado por Graham, 2000, pg.36) encontraron elevadas correlaciones con la escala K del MMPI-2 con muestras normales (,81 para varones; ,92 para mujeres), y algo más bajas con la escala L (,46, para varones y ,64 para mujeres). Si contemplamos la Tabla 66, podemos confirmar que nuestros resultados son coincidentes en todos los grupos analizados con los de Butcher \& Han (1995), con respecto a las variable $\mathrm{K}$ y L, siendo más elevadas en las primeras.

Semejantes resultados obtuvieron los investigadores Baer, Wetter, Nichols, Greene \& Berry (1995) al llegar a la conclusión que los datos aportados por la escala $\mathrm{S}$ añadidos a los de las escalas L y K pueden discriminar entre personas que contestan a la prueba de forma honesta y sincera de aquellas que contestan de una forma pretendidamente perfecta y bien ajustadas psicológicamente.

Podemos demostrar, por nuestros datos, las correlaciones positivas existentes con todos los grupos respecto a las variables ODecp y Wsd exclusivamente con los grupos de Buena y mala imagen.

Igualmente hemos podido apreciar en nuestra Tabla 74, donde se exponen las diversas correlaciones entre los grupos y con las distintas variables, que existe un nutrido grupo de variables con las que mantiene una correlación negativa: $\mathrm{F}, \mathrm{Fb}$, Ds, Ds-r, IR, F-K y /F-Fb/.

Butcher \& Han (1995) concluyen que las puntuaciones elevadas obtenidas en la escala S son ofrecidas por personas no realistas, que informan positivamente de sí mismo, apareciendo bien equilibrados psicológicamente y sin problemas. Pero estos investigadores no aportan dato alguno acerca de si esta variable puede detectar perfiles defensivos o perfiles de buena imagen (Graham, 2000).

Nuestros resultados mostraron que el $90 \%$ de los sujetos que presentaron esta imagen favorable de sí mismos contestaron, a la mitad de los ítems correspondientes a esta escala, de forma poco honesta y sincera, obteniendo una puntuación PD $\geq 25$ (puntuación media $=36,333$ ), semejante al $50 \%$ de los sujetos normales que se mostraron sinceros y honestos en sus respuestas $\mathrm{PD} \geq 24$ (puntuación media $=23,893$ ) o al $25 \%$ de sujetos clínicos, también sinceros, que mostraron una puntuación de $\mathrm{PD} \geq 24$ (puntuación media $=19,316$ ).

Como sucediera con la escala Fp, también la escala $\mathrm{S}$ ha pasado a formar parte del nuevo perfil de las escalas de Validez y Clínicas del MMPI-2 que ha presentado a principios del año 2001 la Universidad de Minnesota a través de su página web de la National Computer System. En el nuevo material S aparece conjuntamente con las escalas L y K como una medida de respuesta defensiva (NCS Assessments, February, 2001). 
Escala de Deseabilidad Social (Wsd) de Wiggings (1959)

Wiggins (1959), con sus 33 ítems que componen su Escala de Deseabilidad Social, pretendía diferenciar estudiantes que contestaban al MMPI original de una manera socialmente deseable, de aquellos otros que contestaban al mismo test de forma honesta y sincera.

Nuestros resultados muestran a esta escala como una variable capaz de identificar a los sujetos que intentan presentar una imagen favorable de sí mismos, desde el punto de vista social. Pudimos ver que el $90 \%$ de nuestros sujetos que contestan de esta forma mostraron una puntuación $\mathrm{PD} \geq 16,7$ (puntuación media $=22,826$ ), casi la misma que el $25 \%$ de los sujetos normales ( $\mathrm{PD} \geq 16$; puntuación media $=14,043)$ y clínicos $(\mathrm{PD} \geq 17$; puntuación media $=14,237)$ que contestaron de forma honesta y sincera.

Nuestros datos sobre esta escala de Wiggins (1959) sobre la "deseabilidad social" son plenamente coincidentes con los hallazgos encontrados por Butcher, J.; Dahlstrom, W.; Graham, J.; Tellegen, A. \& Kaemer, B. (1989) y Greene, (1997, 2000), a la hora de constatar que parece ser una variable independiente de la patología que muestre el sujeto, como lo corrobora el análisis comparativo de sus puntuaciones medias, que no pudo discriminar estadísticamente entre los sujetos normales y clínicos que contestaban al cuestionario del MMPI-2. Para poder ofrecer luz a la resolución de este dilema se aconseja poder contrastar la información con la aportada por el grupo de Escalas Clínicas. 
CAPITULO VII. - CONCLUS IONES .

Seguidamente expondremos las principales conclusiones a las que hemos llegado, teniendo como objetivo esencial y fundamental la confrontación y contrastación de las diferentes hipótesis y subhipótesis planteadas en nuestra investigación.

VII.1. - CONCLUS IÓN GENERAL $1^{a}$ :

"En la adaptación castellana del MMPI-2, las escalas e índices de validez que nos permiten diferenciar sujetos que responden de forma inconsistente, a través de sus puntuaciones elevadas, son: VRIN, TRIN, F y Fb, /F-Fb/. IR. (Hipótesis 1ª).

Conclusión 1.1: Las puntuaciones elevadas obtenidas en la variable Inconsistencia de Respuestas Variables /VRID identifica, de forma significativa, los protocolos que son respondidos sin tener en cuenta la información contenida en los items del cuestionario del MMPI-2. (Subfipótesis 1.1: parcialmente confirmada).

- Las puntuaciones más elevadas en esta variable VRIN han sido encontradas en los sujetos que han contestado a una amplia variedad de formas que no tienen en cuenta la información contenida en los ítems del cuestionario (Rta. Inc.).

- Las puntuaciones elevadas VRIN solamente nos indican si se ha contestado de forma incoherente o inconsistente al cuestionario pero no necesariamente de forma 
honesta y sincera. Por ello las personas que han respondido intencionada y coherentemente mostrando una imagen favorable (buena imagen) o desfavorable (mala imagen) de sí mismo no son detectables por esta variable.

- No hemos encontrado diferencias estadísticamente significativas entre el grupo clínico y los sujetos que intentan presentar una imagen negativa de sí mismos, por lo que podemos considerar que esta variable VRIN no discrimina adecuadamente a estos grupos de sujetos cuando han contestado de forma coherente al cuestionario.

- La variable VRIN, por sí sola, puede invalidar un protocolo, cuando sus puntuaciones son elevadas. El "punto de corte" de nuestra baremación lo hemos establecido a partir de una $\mathrm{PD} \geq 13$ (66T), para ambos sexos. A partir de esta puntuación, podemos considerar que el protocolo puede presentar cierto grado de incoherencia entre sus respuestas.

- El $90 \%$ de los sujetos que contestan de forma inconsistente presentarán una puntuación directa $\mathrm{PD} \geq 12$ (puntuación media $=16,445$ ), mientras que esta misma puntuación la pueden presentar el 10\% de los sujetos normales (puntuación media $=$ 7,882).

- Las bajas puntuaciones obtenidas en la variable VRIN no discrimina adecuadamente los sujetos que contestan de forma coherente y consistente de aquellos otros que contestan a todo los ítems del cuestionario como "verdadero", ni tampoco a los que lo hacen como "falso".

- VRIN identifica perfectamente los protocolos contestados de forma alternativa y secuenciada como "falso/verdadero" y/o "verdadero/falso".

- También detecta adecuadamente la inconsistencia de aquellos sujetos que, utilizando diferentes estrategias, contestan sin tener en cuenta la información de los ítems del Cuestionario (Rta. Inc.).

- Para una mayor precisión diagnóstica, nos podemos ayudar de las puntuaciones elevadas en F, Fb, F-K y F(p).

Conclusión 1.2: "Las puntuaciones elevadas de la variable Inconsistencia de Respuestas Verdadero (TRIX) no identifica, de forma significativa, toda la amplia variedad de estrategias que pueden utilizar los sujetos para contestar al cuestionario del $\mathcal{M M P I - 2}$ sin tener en cuenta la información contenida en los items "(S ubfipótesis 1.2: parcialmente confirmada).

- A través de los resultados obtenidos podemos concluir que la variable TRIN se muestra sensible para identificar la tendencia a responder verdadero o falso. La hemos considerado como una variable detectora de la aquiescencia de las respuestas.

- TRIN identifica perfectamente, a través de sus puntuaciones elevadas, todos aquellos perfiles que los sujetos contestan tanto "verdadero" como "falso" a todo el Cuestionario. 
- Las puntuaciones elevadas de TRIN identifica plenamente los protocolos contestados alternando secuencial y ordenadamente sus respuestas "verdadero/falso", pero no así aquellos que lo hacen, también secuencialmente, "falso/verdadero".

- TRIN no identifica a los sujetos que intentan ofrecer, de forma intencionada y coherente, una imagen favorable o desfavorable de sí mismo.

- TRIN no se muestra sensible para discriminar adecuadamente los perfiles de los sujetos que globalmente responden de forma inconsistente (Rta. Inc.) de aquellos otros pertenecientes al grupo de clínicos.

- El "punto de corte" establecido por nuestra baremación se muestra para las puntuaciones directas PD $\leq 7$ (65T), en ambos sexos, que serán significativas de "tendencia a responder falso" (TRIN-f) por parte del individuo. Todas las puntuaciones directas $\mathrm{PD} \geq 13$ (68T), para ambos sexos, serán significativas de "tendencia a responder verdadero" (TRIN-v) por parte del sujeto.

Conclusión 1.3: "Las variables de Infrecuencia $\mathcal{F}$ y $\mathcal{F}$ de tectan, de forma significativa, todas las posibilidades estratégicas de contestar a los items MMPI-2 de forma inconsistentes (Rta. Inc.)" (Subfipótesis 1.3: parcialmente confirmada).

- Las puntuaciones elevadas de las escalas $\mathrm{F}$ y $\mathrm{Fb}$ no pueden ser consideradas específicamente como variables detectoras de inconsistencia, aunque puntualmente pueda hacerlo en algunos casos.

- Las puntuaciones elevadas de $\mathrm{F}$ y $\mathrm{Fb}$ corresponden más claramente a los protocolos que intentan mostrar una mala imagen de sí mismo.

- Las altas puntuaciones de F y Fb identifican plenamente, a través de sus puntuaciones elevadas, a los sujetos que, de diferentes formas y globalmente consideradas, contestan a los ítems sin tener en cuenta su contenido (Rta. Inc.).

- F y Fb detectan, a través de sus altas puntuaciones, los protocolos que son contestados alternativa y secuencialmente como "verdadero/falso" (mejor Fb que F) y también los protocolos, igualmente contestados, como "falso/verdadero".

- F y Fb, con sus puntuaciones elevadas, detecta los sujetos que contestan a todo el cuestionario como "verdadero", pero no cuando contestan todas sus respuestas como "falso".

Conclusión 1.4: Las puntuaciones elevadas de la variable -Indice de Infrecuencia /F-Fb/ detecta, de forma significativa, a los sujetos que contestan al Cuestionario de $\mathcal{M M P I - 2}$ sin tener en cuenta la información contenida en los items "(Subfipótesis 1.4: parcialmente confirmada).

- Las altas puntuaciones de la variables $/ \mathrm{F}-\mathrm{Fb} /$ detectan a los sujetos que utilizan diferentes estrategias de responder, conjuntamente consideradas (Rta. Inc.), que tienen en cuenta la información contenida en los ítems del Cuestionario. 
- Esta variable no aporta datos relevantes diferentes a los ya suministrados por las variables $\mathrm{F}$ y $\mathrm{Fb}$ que, individualmente, hemos investigado. Por ello, y en aras a la claridad en la exposición de nuestro diseño de Hoja de perfil del MMPI-2, y evitar el solapamiento de los datos, hemos prescindido de ella en la elaboración definitiva en el apartado correspondiente de las Escalas e índices de Validez.

- No se puede considerar como una variable específica para detectar protocolos inconsistentes.

- Las puntuaciones elevadas de /F-Fb/ se muestran sensibles y apropiadas para detectar sujetos que intentan ofrecer una imagen desfavorable de sí mismos.

- Sus puntuaciones medias han resultado ser estadísticamente significativas $(\mathrm{p}<, 0001)$ al ser analizadas comparativamente con el resto de los grupos.

- El 50\% de los sujetos que contestan sin tener en cuenta la información contenida en los ítems van a obtener una puntuación $\mathrm{PD} \geq 10$ (puntuación media $=10,24$ ) mientras que solamente el $10 \%$ de los sujetos normales van a presentar una puntuación $\mathrm{PD} \geq 8$ (puntuación media $=3,753$ ) y del grupo clínico $\mathrm{PD} \geq 9$ (puntuación media $=4,48$ ).

Conclusión 1.5: "Las puntuaciones elevadas de la escala Inconsistencia de Respuestas IR detecta, de forma significativa, los sujetos que contestan a los items $\mathcal{M M P I - 2}$ sin tener en cuenta la información contenida en los items" (Subfipótesis 1.5: parcialmente confirmada).

- Nuestros resultados demuestran que esta Escala de Inconsistencia de Respuestas (IR) de Sewell y Rogers (1994) y la Escala Psiquiátrica F(p) de Arbisi y Ben-Porath $(1995,1998)$, son extremadamente semejantes debido, fundamentalmente, a que el $50 \%$ de los ítems son comunes a ambas escalas y sus correlaciones, tanto positivas como negativas, son muy elevadas.

- En nuestro diseño de la hoja de perfil del MMPI-2, en su apartado de Escalas e índices de Validez, hemos prescindido de ella para no reiterar información ya obtenida y simplificando al máximo el grupo de escalas que detectan la validez de los protocolos.

- Las puntuaciones elevadas de la Escala de Inconsistencia IR detectan las diversas formas de contestar a los ítems, conjuntamente consideradas (Rta. Inc.), sin tener en cuenta la información del contenido de los mismos.

- A pesar de que a través de sus altas puntuaciones se pueda detectar la inconsistencia en las respuestas de un sujeto, sin embargo IR no puede considerarse como una variable específica para detectar protocolos inconsistentes.

- IR, es mas bien una variable que identifica a sujetos que intentan fingirse de forma negativa, exagerando su sintomatología y mostrar de sí mismo una imagen desfavorable, a través de sus puntuaciones elevadas..

- El 90\% de los sujetos que contestan (de diversas formas), sin tener en cuenta el contenido de los ítems han obtenido una puntuación directa $\mathrm{PD} \geq 5$ (puntuación media $=7,805)$ mientras que los sujetos que contestan de forma sincera y honesta 
(grupo de normales y clínicos) muestran una puntuación $\mathrm{PD} \geq 0$ (punt. media normales $=1,379$; punt. media clínicos $=2,79$ ).

- El "punto de corte" en nuestra baremación, se establece en una puntuación directa $\mathrm{PD} \geq 5$ (69T), en varones, y $\mathrm{PD} \geq 4$ (71T), en mujeres. Las puntuaciones superiores puede ser consideradas como un protocolo falseado negativamente.

\section{VII.2. - CONCLUS IÓN GENERAL 2 $2^{a}$ :}

$\checkmark \quad$ "En la adaptación castellana del MMPI-2, las Escalas e Indices de Validez que nos han permitido diferenciar sujetos que fingen una imagen negativa $o$ desfavorable de sí mismos, a través de sus puntuaciones elevadas, son las siguientes: F y Fb, /F-Fb/, F-K, Ds, Ds-r, FBS y F(p).” (Hipótesis general 2).

Veamos las conclusiones aportadas por cada una de estas variables de forma más específica:

Conclusión 2.1: "Las puntuaciones elevadas de las escalas de Infrecuencia (F) y (Fb) detectan, de manera significativa, a los sujetos que contestan a los items $\mathcal{M M P I}-2$ fingiéndose de forma desfavorable o negativa" (Subfipótesis 2.1: confirmada)

- Las puntuaciones elevadas obtenidas en las escalas de Infrecuencia F y Fb detectan, de forma significativa, a sujetos que deliberadamente ha ofrecido una imagen desfavorable de sí mismo, reconociendo o admitiendo una gama extensa de problemas psicológicos, o fingirse mal.

- Las puntuaciones elevadas de estas dos escalas $\mathrm{F}$ y Fb obtenidas en los sujetos que contestan de forma inconsistente y secuencialmente "verdadero/falso" y/o "falso/verdadero" hace que estas escalas no los discriminen adecuadamente de aquellos otros que de forma coherente e intencionada contestan al Cuestionario intentando mostrar una imagen negativa de sí mismos.

- De igual manera, los sujetos que contestan a todos los ítems como "verdadero" obtienen una puntuación tan elevada en $\mathrm{F}$ y $\mathrm{Fb}$ como aquellos que intentan mostrar una imagen negativa de sí mismos, por lo que en estos casos estas variables no resultan discriminantes.

- Aunando las diversas formas de contestar a los ítems sin tener en cuenta la información contenida en ellos (Rta. Inc.), estas escalas $\mathrm{F}$ y $\mathrm{Fb}$ no discriminan adecuadamente de aquellos otros sujetos que han contestado de forma coherente pero intentando ofrecer una imagen desfavorable de sí mismos.

- En caso de dudas en la precisión diagnóstica del fingimiento negativo, nos podemos ayudar de las puntuaciones elevadas en las escalas: F-K, FBS, Ds ó Ds-r $\mathrm{IR}, / \mathrm{F}-\mathrm{Fb} / \mathrm{y} \mathrm{F}(\mathrm{p})$.

- Para F, el $90 \%$ de los sujetos que ofrecen una mala imagen presentan una puntuación $\mathrm{PD} \geq 30$, (puntuación media $=47,045$ ), mientras que solamente el $10 \%$ de los sujetos que contestan de forma sincera y honesta (normales) presentan una 
puntuación $\mathrm{PD} \geq 13$ (puntuación media $=7,125$ ) y el mismo porcentaje de sujetos clínicos presentan una puntuación de $\mathrm{PD} \geq 23,4$.

- Para $\mathrm{Fb}$ el $90 \%$ de los sujetos que intentan ofrecer una imagen deteriorada de sí mismo presentan una puntuación $\mathrm{PD} \geq 18$, (puntuación media $=31,599$ ) mientras que el $10 \%$ de los sujetos normales presentan una puntuación $\mathrm{PD} \geq 9$. (puntuación media $=3,968)$.

- Las puntuaciones medias, tanto de $\mathrm{F}$ como de $\mathrm{Fb}$, han resultado ser estadísticamente significativas con respecto de los demás grupos y especialmente de los que han contestado de forma sincera y honesta al Cuestionario.

- El "punto de corte" de nuestra baremación para la escala F queda establecido, en los varones, en $\mathrm{PD} \geq 18$ (67T), y en las mujeres $\mathrm{PD} \geq 19$ (66T). Todas las puntuaciones superiores a éstas, pueden estar indicando que el sujeto está falsificando el protocolo intentando presentar una mala imagen de sí mismo.

- Igualmente, el "punto de corte" para Fb queda establecido en una PD $\geq 12$ (66T), para varones, y de $\mathrm{PD} \geq 11$ (68T) para mujeres.

- Estas variables $\mathrm{F}$ y $\mathrm{Fb}$ son consideradas como esenciales e importantes para evaluar el fingimiento negativo de la persona.

Conclusión 2.2: "Las puntuaciones elevadas del Índice de Infrecuencia/F. $\mathcal{F b} /$ detectan, de manera significativa, a los sujetos que contestan a los items $\mathcal{M M P I - 2}$ fingiéndose de forma desfavorable o negativa" (Subfipótesis 2.2: confirmada).

- El Índice de Infrecuencia /F-Fb/, a través de sus puntuaciones elevadas, detecta significativamente a las personas que intentan falsificar su protocolo aparentando presentarse a sí mismo de una forma desfavorable y negativa.

- Los valores expresados por esta variable $/ \mathrm{F}-\mathrm{Fb} /$ no aportan resultados e interpretaciones diagnósticas diferentes a los ya expresadas por las escalas de Infrecuencia $\mathrm{F}$ y Fb individualmente. Por ello, en nuestro diseño personal de la Hoja de perfil del MMPI-2, hemos prescindido de ella por la reiteración, solapamiento y simplificación de sus valores interpretativos.

- El 90\% de los sujetos que muestran intencionadamente su mala imagen presentan una $\mathrm{PD} \geq 7,4$, mientras que solamente el $10 \%$ de los sujetos que contestan sincera y honestamente (normales y clínicos) muestran unos resultado en su PD $\geq 8$

- Sus puntuaciones medias han resultado ser estadísticamente significativas en su análisis con cada uno de los grupos referidos en esta investigación.

Conclusión 2.3: "Las puntuaciones elevadas del Indice de Simulación de Gough $\mathcal{F}$-K detectan de manera significativa a los sujetos que de liberadamente contestan a los items $\mathcal{M M P I - 2}$ fingiendo una imagen negativa de símismo" (S ubfipótesis 2.3: confirmada). 
- El Índice de Simulación de Gough F-K, a través de sus puntuaciones elevadas, detecta significativamente a los sujetos que intentan falsificar su protocolo aparentando presentarse a sí mismo de una forma desfavorable y negativa.

- Pero estas puntuaciones elevadas de F-K no discriminan adecuadamente a los sujetos que intentan coherentemente mostrar una imagen negativa de sí mismo de aquellos otros que contestan secuencialmente al cuestionario de forma "falso/verdadero" o a la totalidad de los ítems como "verdadero"..

- Tampoco discriminan estas puntuaciones elevadas a los sujetos que intentan mostrar su propia imagen de forma desfavorable de aquellos otros que responden, de diversas maneras (Rta. Inc.), sin tener en cuenta la información contenida en los ítems .

- Las puntuaciones F-K, dentro de la normalidad, no llegan a discriminar adecuadamente cuando el sujeto contesta secuencialmente "verdadero/falso" o "todo falso" de otro que contesta sincera y honestamente.

- Para poder realizar una mayor precisión diagnóstica podemos ayudarnos de las puntuaciones elevadas mostradas por los índices de Simulación de Gough (Ds y /o Ds-r).

- El 90\% de los sujetos que ofrecen una imagen de sí mismo deteriorada, presentan una puntuación $\mathrm{PD} \geq 16,4$ (puntuación media $=36,699$ ), mientras que el $10 \%$ de los sujetos, considerados como normales, presentan una puntuación $\mathrm{PD} \geq 4$. (puntuación media $=-7,400)$

- Las diferencias entre las puntuaciones medias obtenidas en los diferentes grupos, se mostraron significativas estadísticamente $(\mathrm{p}<0,001)$.

- El "punto de corte" de nuestra baremación se encuentra referido e las puntuación directa, $\mathrm{PD} \geq 8$ (66T) en varones y $\mathrm{PD} \geq 5$ (66T) en mujeres, pudiendo considerar la presencia de un protocolo que intenta presentarnos una mala imagen de sí mismo.

Conclusión 2.4: "Las puntuaciones elevadas de la Escala revisada de Disimulación de Gough, Ds-r, detectan de manera significativa a los sujetos que deliberadamente contestan a los items MMPI-2 fingiendo una imagen negativa de sí mismo" (Subfipótesis 2.4: confirmada).

- Hemos llegado a la conclusión que la Escala Ds muestra resultados extremadamente semejantes con la misma escala "revisada"del mismo autor (Ds-r):

- Todos y cada uno de los ítems (34) que componen la escala Ds se encuentran contemplados en la "revisada" (Ds-r).

- Ambas evalúan el mismo fingimiento negativo o el intento de ofrecer una mala imagen.

- Las correlaciones entre estas dos escalas de Gough, son extremadamente elevadas y positivas entre los diversos grupos: Normal $=.944$; Clínico $=.955$; Buena imagen $=$ .950 ; Mala imagen $=.968$; y Rta. Inc. $=.836$. 
- Para no solapar resultados e interpretaciones y reducir las Escalas de Validez en nuestro diseño de Hoja de perfil del MMPI-2, hemos seleccionado la Escala "revisada", por ser más completa y actualizada.

- Las puntuaciones elevadas obtenidas en la Escala revisada de Disimulación de Gough, Ds-r, identifica de forma significativa a los sujetos que intentan mostrar una imagen desfavorable y negativa de sí mismo.

- Todos los grupos muestran sus diferencias estadísticamente significativas al n.c. del $<0,001$.

- Las puntuaciones moderadamente elevadas (66T para varones; y 68T para mujeres) de esta variable Ds-r no discrimina adecuadamente a los sujetos que contestan honesta y sinceramente (normales y clínicos) de aquellos otros que contestan inconsistentemente de forma secuencial "verdadero/falso".

- Las puntuaciones dentro de la normalidad (44T para mujeres; 46T para varones) de esta variable Ds-r, tampoco discrimina adecuadamente a los sujetos que contestan honesta y sinceramente (normales y clínicos) de aquellos otros que responden de forma inconsistente a todo el protocolo como "falso".

- Las puntuaciones elevadas de Ds-r no discriminan adecuadamente a los sujetos que intencionadamente quieren mostrar una imagen negativa de sí mismo de aquellos otros que contestan a todos los ítems como "verdaderos".

- Para una mayor precisión diagnóstica podemos ayudarnos de las puntuaciones elevadas en las escalas F, Fb, F-K, FBS, IR y F(p).

- El 90\% de los sujetos que contestan al test intentando dar "mala imagen" obtienen una puntuación, en esta escala, de PD $\geq 16$ (puntuación media $=24,903$ ), mientras que los sujetos normales solamente el $10 \%$ de ellos presentan una puntuación PD $\geq$ 15 (puntuación media $=8,334$ ).

- El $10 \%$ de los sujetos clínicos, otro grupo que contesta de forma sincera y honesta, presentan una puntuación $\mathrm{PD} \geq 21$ (puntuación media $=12,965$ ), siendo esta misma puntuación para el $75 \%$ de los sujetos que ofrecen una falsa imagen negativa de sí mismos.

Conclusión 2.5: "Las puntuaciones elevadas de la Escala de hacerse el enfermo, "Fake-bad" (FBS), detectan, de manera estadísticamente significativa, a los sujetos que deliberadamente contestan a los items MMPI-2 fingiendo una mala imagen de sí mismo" (Subfipótesis 2.5: confirmada).

- La escala "Fake-bad" FBS muestra una gran sensibilidad para detectar adecuadamente a los sujetos que intentan ofrecer una imagen desfavorable de sí mismo, haciéndose el enfermo, exagerando o inventando cualquier tipo de sintomatología física y/o psicopatológica. 
- La escala de Fake-bad (FBS) no discrimina adecuadamente a los sujetos sinceros, considerados como normales, de aquellos que intentan ofrecer una buena imagen de sí mismo.

- Todos los demás grupos muestran sus puntuaciones medias estadísticamente diferentes y significativas al n.c. del $<0,001$.

- Esta Escala "Fake-bad" (FBS) discrimina adecuadamente los sujetos que muestran una imagen desfavorable de sí mismos de aquellos otros que contestan secuencial y alternativamente "verdadero/falso", pero no de los que lo hacen "falso/verdadero".

- Igualmente discrimina adecuadamente los que muestran una imagen negativa de sí mismo de los que contestan a todo el Cuestionario "falso" o como "verdadero".

- Considerando las diversas maneras de contestar sin tener en cuenta la información de los ítems que componen el Cuestionario del MMPI-2, la escala FBS no discrimina adecuadamente si quien contesta es una mujer. Sin embargo si quien contesta es un varón, esta escala FBS sí discrimina adecuadamente de aquellos otros varones que intentan mostrar una imagen desfavorable de sí mismo.

- Para una mayor precisión diagnóstica podemos ayudarnos de las puntuaciones elevadas en las escalas F, Fb, Ds ó Ds-r, F-K, IR y F(p).

- El 90\% de los sujetos que ofrecen una imagen negativa de sí mismo presentan una puntuación $\mathrm{PD} \geq 13$ (puntuación media $=23,933$ ), mientras que el 50\% de los sujetos considerados como normales presentan una puntuación $\mathrm{PD} \geq 12$ (puntuación media $=$ 12,955).

- El "punto de corte" establecido en nuestra baremación es PD $\geq 20$ (67T) para los varones; y para las mujeres $\mathrm{PD} \geq 21$ (66T), a partir de las cuales podemos interpretar que el sujeto presenta un perfil con fingimiento negativo.

Conclusión 2.6: "Las puntuaciones elevadas de la Escala Psiquiátrica $\mathcal{F}(p)$ detectan, de manera estadisticamente significativa, a los sujetos que deliberadamente contestan a los items $\mathcal{M M P I - 2}$ fingiendo una mala imagen de símismo" (S ubfipótesis 2.6: confirmada).

- Esta Escala Psiquiátrica F(p) de Arbisi y Ben-Porath $(1995,1998)$ ha demostrado ser especialmente sensible para detectar, a través de sus puntuaciones elevadas y de forma estadísticamente significativa, a los sujetos que intencionadamente desean mostrar una imagen desfavorable de sí mismo.

- Todas las puntuaciones medias de los diferentes grupos, en su análisis comparativo, han resultado ser estadísticamente significativas al $\mathrm{p}<0,0001$, excepto los grupos clínico vs. buena imagen que resultaron significativos al 5\%.

- Las puntuaciones elevadas en la escala $F(p)$ no discriminan adecuadamente a los que ofrecen una mala imagen de sí mismo de aquellos otros que contestan a todo el Cuestionario ya sea como "verdadero" o como "falso".

- Tampoco las puntuaciones elevadas en la escala $F(p)$ discriminan adecuadamente a los que ofrecen una mala imagen de sí mismo de aquellos otros que contestan el 
Cuestionario de forma inconsistente y secuencialmente "verdadero/falso" o "falso/verdadero".

- Igualmente, las altas puntuaciones de esta escala $\mathrm{F}$ (p) no discriminan a los sujetos que intencionadamente expresan una imagen negativa de sí mismo de aquellos otros que contestan de forma inconsistente diversa (Rta. Inc.) conjuntamente analizadas.

- Para una mayor precisión diagnóstica podemos ayudarnos de las puntuaciones elevadas en las escalas F, Fb, Ds ó Ds-r, F-K, IR y FBS.

- El 90\% de los sujetos que contestan intentando ofrecer los aspectos negativos de sí mismo, muestran una puntuación $\mathrm{PD} \geq 11,4$ (puntuación media $=18,550$ ), mientras que solamente un $10 \%$ de los sujetos normales muestran una puntuación $\mathrm{PD} \geq 5$ (puntuación media $=2,2$ ).

- El "punto de corte" establecido en nuestra baremación resultó ser de $\mathrm{PD} \geq 7$ (67T) para los varones, y de $\mathrm{PD} \geq 6$ (70T) para las mujeres. Todas las puntuaciones superiores a éstas pueden ser indicativas de un protocolo falsificado de forma negativa, intentando presentar una mala imagen de sí mismo.

\section{VII.3. - CONCLUS IÓN GENERAL $3^{a}:$}

$\checkmark \quad$ "En la adaptación castellana del MMPI-2, las Escalas e Indices de Validez que nos han permitido detectar significativamente a sujetos que fingen una imagen positiva o favorable de sí mismos, a través de sus puntuaciones directas elevadas, son: L, K, Odecp, Wsd y S" (Hipótesis general 3).

Veamos más específicamente las conclusiones de cada una de estas variables.

Conclusión 3.1: "Las puntuaciones directas elevadas de la Escala $L$ detectan, de forma significativa, los sujetos que contestan a los items del $\mathcal{M M P I}-2$ intentando fingir una imagen positiva y favorable de símismos "(Subfipótesis 3.1: confirmada).

- Esta variable L, a través de sus altas puntuaciones directas, se ha mostrado especialmente sensible a los intentos, por parte de los sujetos, de fingirse mejor de lo que son normalmente, presentando una imagen más equilibrada y ajustada psicológicamente.

- Las puntuaciones medias de esta variable $\mathrm{L}$ resultaron ser estadísticamente diferentes $(\mathrm{p}<, 0001)$ en su análisis comparativo con el resto de los grupos, excepto con los clínicos y normales respectivamente.

- Esta variable L no discrimina adecuadamente a los grupos de sujetos que contestan de forma honesta y sincera, los normales de los clínicos.

- Las puntuaciones elevadas de esta variable L no discrimina suficientemente a los sujetos que contestan intentando mostrar una imagen favorable de sí mismos de aquellos otros que responden a los ítems de forma secuencial y ordenadamente como "falso/verdadero", sin tener en cuenta el contenido de los ítems . 
- Igualmente, las altas puntuaciones en la variable L no llegan a discriminar significativamente a los que responden fingiéndose de forma positiva de aquellos otros que responden a todo el cuestionario como "falso".

- La variable L no puede detectar, de ninguna forma, a los que intentan ofrecer una imagen negativa de sí mismo ya que, según nuestro diseño de hoja de perfil, tendrían que responder a todos los ítems de esta variable o a todo el Cuestionario como "verdadero".

- Las puntuaciones de la variable L, con valores dentro de la normalidad, no discrimina adecuadamente a los sujetos que contestan honesta y sinceramente de aquellos otros que utilizan diversas estrategias para contestar de forma inconsistente (Rta. Inc.).

- El 90\% de los sujetos que intentan presentar una imagen favorable de sí mismo nos muestran una puntuación $\mathrm{PD} \geq 7$ (puntuación media $=10,858$ ), mientras que el $10 \%$ de los sujetos normales, e igual que los clínicos, nos presentan una puntuación $\mathrm{PD} \geq 8$ (puntuación media $=4,71$ ), (puntuación media de los sujetos clínicos $=$ $4,889)$.

- El "punto de corte" establecido en nuestra baremación se especifica en una PD $\geq 9$ $(33 \mathrm{~T})^{9}$ para los varones y de $\mathrm{PD} \geq 8$ (36T) para las mujeres. Cualquier puntuación superior a estos valores nos puede estar indicando que el sujeto intenta ofrecer una buena imagen de sí mismo.

- Para una mayor precisión en la interpretación diagnóstica, es aconsejable que esta escala contemple las puntuaciones obtenidas por K, ODecp, S y Wsd.

Conclusión 3.2: "Las puntuaciones directas elevadas de la Escala $X$ detectan, de forma significativa, los sujetos que contestan a los items del $\mathcal{M M P I - 2}$ intentando fingir una imagen positiva y favorable de sí mismos "(S ubfipótesis 3.2: confirmada).

- Las puntuaciones directas elevadas en la Escala K, identifican, de forma significativa, a los sujetos que intentan mostrar una imagen favorable de sí mismos, presentándose como más equilibrados y ajustados psicológicamente.

- Las puntuaciones de esta variable $\mathrm{K}$, con valores dentro de la normalidad, no discrimina significativamente a los sujetos que contestan sincera y honestamente (normales) de aquellos que, utilizando una gran variedad de estrategias de inconsistencia (Rta. Inc.) responden sin atender a la información del contenido de los ítems del Cuestionario.

- Las puntuaciones directas excesivamente elevadas de la escala K no discriminan significativamente los sujetos que intentan presentar una imagen favorable de sí mismos de aquellos otros que contestan a todo el Cuestionario como "falso".

\footnotetext{
${ }^{9}$ Recordemos que, en nuestro diseño del perfil del MMPI-2 para las Escalas e Índices de Validez, esta escala L (mentira) está invertida con respecto al diseño tradicional; es decir, sus valores directos más altos se corresponden con sus puntuaciones T más bajas (véase Tabla 113).
} 
- Para una mayor precisión diagnóstica de esta variable $\mathrm{K}$, podemos ayudarnos de las puntuaciones obtenidas en las escalas L, ODecp, Wsd y S fundamentalmente.

- El 90\% de los sujetos que intentan mostrarse de forma favorable presentan una puntuación en esta escala $\mathrm{K}$ tan elevada como el $50 \%$ de los sujetos correspondientes a los demás grupos (normales, clínicos, mala imagen y Rta. Inc.).

- El "punto de corte" en nuestro diseño ${ }^{10}$ de la hoja de Perfil del MMPI-2 queda establecido en PD = 20 (39T) para varones; y de PD = 20 (38T) para las mujeres, a partir de las cuales los valores superiores son indicativos de que el sujeto intenta mostrarse ante nosotros con una imagen positiva y favorable.

Conclusión 3.3: "Las puntuaciones directas elevadas de la Escala de Fingimiento Positivo, ODecp, detectan, de forma significativa, los sujetos que contestan a los items del MMPI-2 intentando fingir una imagen positiva y favorable de sí mismos " (Subfipótesis 3.3: confirmada).

- Esta escala de Fingimiento Positivo o de Otro Engaño (ODecp) de Nichols y Greene (1991) se ha mostrado muy sensible para identificar, de manera significativa, a los sujetos que intentan presentarse de una forma defensiva como honestos, sinceros, éticos, responsables, equilibrados, y ajustados psicológicamente.

- Esta variable ha presentado una alta discriminación en sus valores medios, estadísticamente significativos $(\mathrm{p}<, 0001)$, con el resto de los grupos aquí investigados.

- Para una mayor precisión en la interpretación diagnóstica, sería aconsejable que se pudiera ayudar de los resultados de las variables L, S y Wsd para poder apreciar el fingimiento positivo en sus respuestas al MMPI-2.

- El $90 \%$ de los sujetos que intentan mostrarse de esta forma positiva han contestado a más de la mitad de los ítems de esta Escala de manera fingida, mostrando una puntuación $\mathrm{PD} \geq 17$ (puntuación media $=23,826$ ), mientras que el $25 \%$ los sujetos considerados normales han contestado de esta misma forma a la mitad de los ítems de esta escala, mostrando una puntuación $\mathrm{PD} \geq 16$ (puntuación media $=13,483$ ).

- El "punto de corte" establecido en nuestra baremación se encuentra referido por las puntuaciones $\mathrm{PD}=22$ (34T) para los varones; y $\mathrm{PD}=19$ (34T), a partir de las cuales podemos precisar que el sujeto intenta ofrecer una imagen favorable de sí mismo.

\footnotetext{
${ }^{10}$ Recordemos que, en nuestro diseño del perfil del MMPI-2 para las Escalas e Índices de Validez, esta escala K está invertida con respecto al diseño tradicional; es decir, sus puntuaciones directas más elevadas se corresponden con sus puntuaciones T más bajas (véase Tabla 113).
} 
Conclusión 3.4: Las puntuaciones directas elevadas en la Escala de Deseabilidad Social, Wsd, detectan, de forma significativa, los sujetos que contestan a los items del MMPPI-2 intentando fingir una imagen positiva y favorable de sí mismos "(Subfipótesis 3.4: confirmada).

- Las puntuaciones directas elevadas de la Escala de Deseabilidad Social (Wsd) de Wiggins (1959) identifican, de forma significativa, a los sujetos que intentan mostrar la imagen positiva de sí mismos socialmente deseable.

- Las puntuaciones de esta escala Wsd no discriminan significativamente a los sujetos que contestan al Cuestionario de forma sincera y honesta; es decir, los considerados como normales (grupo normal) de aquellos otros que han presentado algún problema clínico (grupo clínico).

- En su análisis comparativo con el resto de los grupos se ha mostrado estadísticamente significativa $(\mathrm{p}<, 0001)$ en sus diferentes puntuaciones medias.

- Las puntuaciones directas excesivamente elevadas de Wsd no discriminan suficientemente a los sujetos que contestan intentando mostrar una imagen favorable de sí mismos de aquellos otros que contestan a todos los ítems como "verdadero".

- Para una mayor precisión en la interpretación diagnóstica nos podemos ayudar de las puntuaciones obtenidas en las variables L, K., ODecp y S.

- El 90\% de los sujetos que contestan de esta forma mostraron una puntuación PD $\geq$ 16,7 (puntuación media $=22,826$ ), casi la misma que el 25\% de los sujetos normales $(\mathrm{PD} \geq 16$; puntuación media $=14,043)$ y clínicos $(\mathrm{PD} \geq 17$; puntuación media $=$ $14,237)$ que contestaron de forma honesta y sincera.

- El "punto de corte" de nuestra baremación en esta variable Wsd se muestra en la $\mathrm{PD} \geq 21(32 \mathrm{~T})^{11}$ para los varones, y de $\mathrm{PD} \geq 19(34 \mathrm{~T})$ para las mujeres.

Conclusión 3.5: Las puntuaciones directas elevadas de la Escala $S$ uperlativa, $S$, detectan, de forma significativa, los sujetos que contestan a los items del MMMPI-2 intentando fingir una imagen positiva y favorable de sí mismos "(Subfipótesis 3.5: confirmada).

- Las altas puntuaciones directas de la Escala Superlativa (S) de Butcher \& Han (1995) identifican, de manera significativa, a las personas que intentan ofrecer una imagen favorable de sí mismo, mostrándose extremadamente virtuosas, equilibradas y altamente ajustadas psicológicamente.

- Esta variable $\mathrm{S}$ ha presentado una alta discriminación en sus valores medios, estadísticamente significativos $(\mathrm{p}<, 0001)$, con el resto de los grupos aquí investigados. Cuando el análisis se ha realizado separadamente por sexos, podemos apreciar que los sujetos normales, tanto varones como mujeres, no se han diferenciado estadísticamente de aquellos otros que contestan sin tener en cuenta la información contenida en los ítems (Rta. Inc.).

\footnotetext{
${ }^{11}$ Esta escala, en nuestro diseño de la Hoja de Perfil del MMPI-2, sus puntuaciones se encuentran en orden inverso al de sus puntuaciones típicas $(\mathrm{T})$.
} 
- Las puntuaciones directas elevadas de $\mathrm{S}$ no discriminan suficientemente a los sujetos que contestan intentando mostrar una imagen favorable de sí mismos de aquellos otros que contestan a todos los ítems del Cuestionario como "falso".

- Para una interpretación diagnóstica más precisa, podríamos ayudarnos de las aportaciones de L, K, ODecp y Wsd con las que se obtuvieron correlaciones altamente positivas y han demostrado evaluar el mismo concepto.

- El 90\% de los sujetos que presentaron esta imagen favorable de sí mismos contestaron a la mitad de los ítems correspondientes a esta escala de forma poco honesta y sincera, obteniendo una puntuación $\mathrm{PD} \geq 25$ (puntuación media $=36,333$ ), semejante al $50 \%$ de los sujetos normales que se mostraron sinceros y honestos en sus respuestas $\mathrm{PD} \geq 24$ (puntuación media $=23,893$ ) o al $25 \%$ de sujetos clínicos, también sinceros, que obtuvieron una puntuación $\mathrm{PD} \geq 24$ (puntuación media $=$ 19,316).

- El "punto de corte" en nuestra baremación quedó establecido en una PD $\geq 37$ $(34 \mathrm{~T})^{12}$ para los varones, y de $\mathrm{PD} \geq 36$ (34T) para las mujeres, significando con ello que a partir de estas puntuaciones podemos considerar que el sujeto intenta mostrar su imagen favorable.

- Para una mayor claridad resumimos las principales conclusiones obtenidas en los siguientes cuadros:

Tabla 116: Variables que detectan la inconsistencia en las respuestas

\begin{tabular}{|c|c|c|}
\hline Variables & Puntos de corte & $\begin{array}{c}\begin{array}{c}\text { Hipótesis interpretativas } \\
\text { (puntuaciones elevadas) }\end{array} \\
\end{array}$ \\
\hline VRIN & $\mathrm{PD} \geq 13(66 \mathrm{~T})$ & $\begin{array}{l}\text { - Contesta sin tener en cuenta la información contenida en el ítem } \\
\text { - Responde de forma incoherente o inconsistente (distración, } \\
\text { incomprensión, aleatoriamente, etc.) } \\
\text { - Identifica los protocolos respondidos alternativa y secuencialmente } \\
\text { como "falso/verdadero" o como "verdadero/falso". }\end{array}$ \\
\hline TRIN & $\begin{array}{l}\mathrm{PD} \leq 7(65 \mathrm{~T}) \\
(\mathrm{TRIN}-\mathrm{F}) \\
\mathrm{PD} \geq 13(68 \mathrm{~T}) \\
\text { (TRIN-V) } \\
\text { (ambos sexos) }\end{array}$ & $\begin{array}{l}\text { - Tendencia a responder "verdadero" o "falso" (aquiescencia). } \\
\text { - Protocolos contestados "todo verdadero" o "todo falso". } \\
\text { - No discrimina a los sujetos que intencionadamente y de forma } \\
\text { coherente, intentan ofrecer una imagen positiva o negativa de sí mismos. } \\
\text { - No discrimina a los que responden de forma incoherente de aquellos } \\
\text { otros que pertenecen a unapoblación clínica. }\end{array}$ \\
\hline $\mathbf{F b}$ & $\begin{array}{l}\mathrm{PD} \geq 18(67 T) . \text { Varones } \\
\mathrm{PD} \geq 19(66 \mathrm{t}) . \text { Mujeres }\end{array}$ & $\begin{array}{l}\text { - No son variables específicas para detectar la inconsistencia de las } \\
\text { respuestas, aunque en ocasiones contribuyan. } \\
\text { - Intento de mostrar una mala imagen de sí mismo. } \\
\text { - Detecta a los que contestan todas sus respuestas como "verdadero" pero } \\
\text { no lo detecta cuando lo hacen como "falso". } \\
\text { - Contestan alternativa y secuencialmente como "verdadero/falso" o } \\
\text { "falso/verdadero". }\end{array}$ \\
\hline
\end{tabular}

\section{- Investigaciones futuras:.}

Los profesionales de la Psicología y especialmente los evaluadores cuentan mucho con la sincera cooperación y participación de los sujetos al contestar a un cuestionario, ya que la información que aporten sobre si mismos se convierte en un componente fundamental de la evaluación.

\footnotetext{
${ }^{12}$ Recordemos que nuestro diseño, en las puntuaciones de esta escala en la Hija de Perfil del MMPI-2, se encuentra invertida; es decir, a mayor puntuación directa, menor puntuación típica $(\mathrm{T})$.
} 
Pero sabemos que esta premisa no siempre se cumple, es una realidad que las pruebas que evalúan ciertas facetas de la personalidad son susceptibles de ser falseadas y que es más fácil que eso se produzca en determinados contextos donde el sujeto puede obtener con ello algún beneficio.

Tabla 117: Variables que detectan el fingimiento negativo.

\begin{tabular}{|c|c|c|}
\hline Variables & Puntos de corte & $\begin{array}{ll}\text { Hipótesis interpretativas } \\
\text { (puntuaciones elevadas)- }\end{array}$ \\
\hline $\mathrm{Fb}$ & $\begin{array}{l}\mathrm{PD} \geq 18(67 \mathrm{~T}) . \text { Varones } \\
\mathrm{PD} \geq 19(66 \mathrm{~T}) . \text { Mujeres } \\
\mathrm{PD} \geq 12(66 \mathrm{~T}) . \text { Varones } \\
\mathrm{PD} \geq 11(68 \mathrm{~T}) . \text { Mujeres }\end{array}$ & $\begin{array}{l}\text { Deliberadamente ha intentado ofrecer una imagen desfavorable y negativa de sí } \\
\text { mismo. } \\
\text { Puede estar contestando todas sus respuestas como "verdadero". } \\
\text { Puede estar contestando al cuestionario de una forma alternativa y secuencial como } \\
\text { "verdadero/falso" o "falso/verdadero". }\end{array}$ \\
\hline F-K & $\begin{array}{l}\mathrm{PD} \geq 8(66 \mathrm{~T}) . \text { Varones } \\
\mathrm{PD} \geq 5(66 \mathrm{~T}) . \text { Mujeres }\end{array}$ & $\begin{array}{l}\text { Intencionadamente muestra una mala imagen de sí mismo. } \\
\text { Puede estar contestando al cuestionario de forma secuencial y ordenada como } \\
\text { "falso/verdadero". } \\
\text { Puede estar contestando a todos los ítems como "verdadero" } \\
\text { Puede estar contestando sin tener en cuenta la información contenida en los ítems. } \\
\text { Con puntuaciones dentro de la normalidad, puede estar contestando secuencial y } \\
\text { ordenadamente como "verdadero/falso". } \\
\text { Igualmente, con puntuaciones dentro de la normalidad puede estar contestando a } \\
\text { todo el protocolo como "falso". }\end{array}$ \\
\hline Ds-r & $\begin{array}{l}\mathrm{PD} \geq 15(66 \mathrm{~T}) . \text { Varones } \\
\mathrm{PD} \geq 16(66 \mathrm{~T}) . \text { Mujeres }\end{array}$ & $\begin{array}{l}\text { Imagen desfavorable de sí mismo, realizada de forma intencionada. } \\
\text { Con puntuaciones moderadamente elevadas (66T Var. Y 68T Muj.) no discrimina } \\
\text { adecuadamente a los sujetos que contestan honesta y sinceramente de los que lo } \\
\text { hacen contestando ordenada y secuencialmente como "verdadero/falso". } \\
\text { Puntuaciones dentro de la normalidad ( } 46 \mathrm{~T} \text { var. y } 44 \mathrm{~T} \text { muj.) no discrimina } \\
\text { adecuadamente a los sujetos que contyestan honesta y sinceramente de aquellos } \\
\text { otros que responden a todos los ítems como "falso". } \\
\text { Puede estar contestando a todo el cuestionario como "verdadero". }\end{array}$ \\
\hline FBS & $\begin{array}{l}\mathrm{PD} \geq 20(67 \mathrm{~T}) . \text { Varones } \\
\mathrm{PD} \geq 21(66 \mathrm{~T}) . \text { Mujeres }\end{array}$ & $\begin{array}{l}\text { Está fingiéndose de forma negativa y desfavorable. } \\
\text { Cabe la posibilidad de que el sujeto esté contestando ordenada y secuencialmente de } \\
\text { forma "falso/verdadero". }\end{array}$ \\
\hline $\mathrm{Fp}$ & $\begin{array}{l}\mathrm{PD} \geq 7(67 \mathrm{~T}) . \text { Varones } \\
\mathrm{PD} \geq 6(70 \mathrm{~T}) . \text { Mujeres }\end{array}$ & $\begin{array}{l}\text { Inrtencionadamente presenta una imagen desfavorable de sí mismo. } \\
\text { Puede ser que esté contestando a todo el custionario, bien como "verdadero" o bien } \\
\text { como "falso". } \\
\text { Es posible que esté contestando ordenada y secuencialmente como "verdadero/falso" } \\
\text { o también como "falso/verdadero". } \\
\text { Es posible que esté xontestando al Cuestionario sin tener en cuenta el contenido de } \\
\text { los ítems. }\end{array}$ \\
\hline
\end{tabular}

Las falsificaciones, intencionadas o no, complican sumamente el proceso de evaluación y no pueden ser ignoradas en nuestrta labor profesional.

Es necesario, pues, trabajar con técnicas de evaluación que dispongan de un sistema de detección del tipo de colaboración que nos presta el sujeto. Precisamente uno de los mayores atractivos del MMPI-2 para los psicólogos es que es una técnica que dispone de escalas de validez bien elaboradas que ayudan a detectar posibles falsificaciones en las respuestas dadas por el sujeto.

Nuestro trabajo se ha centrado justamente en el estudio de numerosas escalas que evalúan tanto fingimiento como defensividad en sujetos que respondieron al MMPI-2.

En la tarea profesional es complicado manejar un número tan grande de variables para detectar una posible falsificación, creemos que futuras investigaciones darán como resultado la reducción de dichas escalas a una cifra más manejable a nivel práctico. Con mayor motivo porque en este estudio hemos podido verificar el solapamiento de algunas de ellas.

Como ejemplo tenemos que las investigaciones realizadas por la Universidad de Minnesota (Graham, 2000, figs, 3.2A; 3.2B; 3.3A y 3.3B; N.C.S., 2001) con algunas de las escalas que hemos analizado han dado como resultado la inclusión de las escalas 
Superlativa S y Psiquiátrica Fp como nuevos índices de validez en la actual hoja de perfil del MMPI-2.

Otros estudios se están centrando en la identificación de factores moderadores, como el tipo de problema que presenta el sujeto o el contexto en el que se realiza la evaluación, los datos disponibles hasta el momento sugieren que los resultados son altamente dependientes de ambos factores, contribuyendo a la heterogeneidad de las puntuaciones de corte obtenidas por las distintas investigaciones en las diferentes escalas que hemos estudiado.

Es esperable que estos trabajos permitan establecer puntos de corte para muestras particulares que ayuden a precisar la identificación de los sujetos que falsean, de una $u$ otra manera, el protocolo del MMPI-2.

Toda esta labor permitirá a los profesionales seleccionar las escalas o índices de fingimiento y defensividad más apropiadas para los sujetos y contextos específicos donde desarrollan su labor.

Tabla 118: Variables que detectan el Fingimiento positivo.

\begin{tabular}{|c|c|c|}
\hline Variables & Puntos de corte & $\begin{array}{c}\text { Hipótesis interpretativas } \\
\text { (Puntuaciones directas elevadas }-\mathrm{T} \text { bajas)* }\end{array}$ \\
\hline $\mathbf{L}$ & $\begin{array}{l}\mathrm{PD} \geq 9(33 \mathrm{~T}) . \text { Varones } \\
\mathrm{PD} \geq 9(32 \mathrm{~T}) . \text { Mujeres }\end{array}$ & $\begin{array}{l}\text { Intencionadamente presentan una imagen positiva y favorable de sí mismo. } \\
\text { Puede estar contestando al Cuestionario de forma ordenada y secuencial como } \\
\text { "falso/verdadero". } \\
\text { Puede estar contestando todas sus respuestas como "falso". } \\
\text { Con valores normales no discrimina a los sujetos que contestan de forma honesta y sincera } \\
\text { de aquellos otros que lo hacen sibn tener en cuenta el contenido de los ítems. }\end{array}$ \\
\hline $\mathbf{K}$ & $\begin{array}{l}P D \geq 23(33 T) . \text { Varones } \\
P D \geq 22(33 T) . \text { Mujeres }\end{array}$ & $\begin{array}{l}\text { Presentación de una imagen favorable de sí mismo. } \\
\text { Con puntuaciones extremadamente bajas (T) puede ser que esté contestando todas sus } \\
\text { respuestas como "falso". }\end{array}$ \\
\hline Odecp & $\begin{array}{l}\mathrm{PD} \geq 22(34 T) . \text { Varones } \\
\mathrm{PD} \geq 19(34 \mathrm{~T}) . \text { Mujeres }\end{array}$ & Intencionadamente presenta una imagen positiva de sí mismo. \\
\hline Wsd & $\begin{array}{l}\mathrm{PD} \geq 21(32 \mathrm{~T}) . \text { Varones } \\
\mathrm{PD} \geq 19(34 \mathrm{~T}) . \text { Mujeres }\end{array}$ & $\begin{array}{l}\text { Presentación de una imagen positiva y equilibrada de sí mismos. } \\
\text { Puede estar contestando a todo el cuestionario como "verdadero". }\end{array}$ \\
\hline $\mathbf{S}$ & $\begin{array}{l}\mathrm{PD} \geq 37(34 \mathrm{~T}) . \text { Varones } \\
\mathrm{PD} \geq 36(34 \mathrm{~T}) . \text { Mujeres }\end{array}$ & $\begin{array}{l}\text { Desea mostrar una imagen equilibrara y ajustada psicológicamente sobre sí mismo. } \\
\text { Puede estar contestando a todas sus respuestas como "falso". }\end{array}$ \\
\hline
\end{tabular}

* Se han invertido el sentido de las puntuaciones directas y típicas (T), según nuestro propio diseño de la hoja de perfil.

El camino abierto con nuestra investigación ha planteado éstas y otras muchas interrogantesabriendo paso a las investigaciones ya sugeridas así como a otras nuevas como puede ser el estudio de los simuladores, hasta el momento no se conocen datos sobre variables sociodemográficas, características clínicas o antecedentes psicosociales de las personas que falsean los protocolos del MMPI-2 en uno u otro sentido.

Poco se ha investigado también en el campo jurídico-forense la problemática específica de simulación para secuelas físicas y/o psicológicas. La espera de una compensación económica es uno de los factores que puede ayudar a falsear unas secuelas psicológicas que hace tiempo dejaron de serlo.

Sería sumamente interesante poder conocer la aportación, complementariedad y/o contribución, que pudieran mostrar estas variables de Validez del MMPI-2 en casos de diferentes lesiones orgánicas o neurológicas, con técnicas de neuroimagen en los distintos déficits o disfunciones neuropsicológicas. Es un campo abierto sumamente interesante que podría aportar elementos importantes en la investigación, incluso en el marco jurídico (piensese en las secuelas psicológicas de los accidentes de tráfico y de las indemnizaciones solicitadas). 
Se podría también investigar el comportamiento de algunas de las escalas estudiadas en nuestro trabajo con muestras que contestaran al MMPI-2 bajo las instrucciones de falsear un determinado trastorno, comparadas con sujetos con un diagnóstico de dicho trastorno y con otro grupo de sujetos normales que respondieran siguiendo las direcctrices estandar del cuestionario. Posiblemente, se obtendrian algunos datos nuevos que no hemos podido apreciar debidamente en nuestro trabajo.

Finalmente mencionaremos la elaboración del diseño de hoja de perfil realizada expresamente para este trabajo en la que se ha adoptado la inversión de las puntuaciones directas para todas aquellas escalas detectoras del fingimiento positivo con el objetivo de que se mostraran en la parte inferior de la hoja y faciltar la visión del perfil de dichas escalas en contraposición con el que se forma para las escalas de fingimiento negativo. No planteamos la modificación de la tradicional Hoja de perfil del MMPI-2, nuestra pretensión no llega a tanto, los profesionales debemos trabajar siguiendo unos criterios comunes y respetando la ingente labor de investigación que tiene tras de sí una prueba de evaluación tan prestigiosa como el MMPI-2. Sin embargo, podría ser utilizada a nivel de investigación como una hoja de perfil auxiliar para detectar un posible fingimiento, un trabajo continuado con ella permitiría mejorarla en el sentido de hacerla más sencilla, reduciendo el número de las escalas, donde sólo se recogiesen aquellas que mejor evalúan el fingimiento para uno u otro sentido.

Hasta aquí algunas de las puertas que se han dejado abiertas a otras investigaciones suscitadas no solo por nuevos y distintos diseños experimentales, sino también por los diversos ámbitos de aplicación. 
$\mathcal{B I} \mathcal{B} L I O G \mathcal{R} \mathcal{A F} I \mathcal{A}$

Albert, S.; Fox, H. \& Kahn, M. (1980). Fakin psychosis on the Rorschach: Can expert judges detect malingering?. Journal of Personality Assessment, 44, 115-119.

Alexy, William D.; Webb, Patrick M.(1999). Utility of the MMPI-2 in Work-Hardening rehabilitation. Rehabilitation Psychology.44(3): 266-273.

Almagor, M. \& Nevo, B. (1996). The MMPI-2: Translation and First Steps in Its Adaptation. In J.N. Butcher, International adaptations of the MMPI-2. University Of Minnesota Press. (pp. 487505).

Allen, J.; Coyne, L. (1995). Dissociation and vulnerability to psychotic experience: The dissociative Experiences Scale and the MMPI-2. Journal of Nervous and mental Disease; vol. 183(10) 615622.

American Psychiatric Association (1994). Diagnostic and Statistical manual of mental disorders (4th ed.). Washington, DC: Author. (Traducción castellana: Manual diagnóstico y estadístico de los trastornos mentales.-DSM-IV (1995). Masson, Barcelona.).

Apfeldorf, M.; Hunley, P. (1976). Exclusion of subjects with F scores at or above 16 in MMPI research on alcoholism. Journal of Clinical Psychology; Apr Vol 32(2) 498-500

Arbisi, P.; Ben-Porath, Y. (1995). An MMPI-2 infrequent response scale for use with psychopathological populations: the infrequency-psychopathology Scale, F(p). Psychological Assessment; vol. 7(4) 424-431.

Arbisi, P.; Ben-Porath, Y. (1998). The ability of Minnesota Multiphasic Personality Inventory -2 validity scales to detect fake-bad responses in psychiatric inpatients. Psychological Assessment. Sep; Vol 10(3): 221-228

Archer, R.; Fontaine, J.\& McCrae, R. (1998). Effects of two MMPI-2 validity scales on basic scale relations to external criteria. Journal of Personality Assessment. Feb; Vol 70(1): 87-102.

Archer, R. \& Elkins, D.E. (1998). Identification of random responding on the MMPI-A. Journal of Personality Assessment, vol 73(3): 407-421.

Armayones, M. (1999). Análisis de la sensibilidad de las escalas de validez para la detección de simuladores. Tesis Doctoral. Universidad de Barcelona. Facultad de Psicología. Inédita.

Atkins, D.G. (1999). Validity of the Personality Assessment Inventory for detecting malingering of psychosis in a prison population. Dissertation Abstracts International: Section B. The Sciences and Engineering. Oct. 60(4-B): 1839.

Audubon, J.J. \& Kirvin, B.R. (1982). Defensiveness in the criminaly insane. Journal of Personality Assessment, 45, 304-311. 
Austin, J. (1994). Minnesota Multiphasic Personality Inventory (MMPI-2). Special issue: The MMPI-2. Meassurement and evaluation in Counseling and Development; vol. 27(3) 178-185.

Austin,, J.S. (1992). The detection of fake good and fake bad on the MMPI-2. Educational and Psychological Measurement, 52, 669-674.

Avila, A. y Jiménez, F. (1998). Adaptación castellana del Manual del Inventario Clínico Multiaxial de Millon-II. TEA, ediciones, Madrid .

Avila, A. y Jiménez, F. (1999). Adaptación castellana del MMPI-2. TEA Ediciones, Madrid.

Avila, A. y Tomé, M.C. (1989). Evaluación de la Deseabilidad Social y correlatos defensivos y emocionales. Adaptación castellana de la Escala de Crowne y Marlowe, en A. Echevarría y D. Paez (Eds.), Emociones: perspectivas psicosociales, Madrid, Fundamentos.

Avila, A. y Jiménez, F. (1992). Evaluación clínica de la personalidad-II. El MMPI y sus derivados. En A. Avila (ed.) Evaluación en Psicologìa Clinic-I. Proceso, Método y Estrategisa psicométricas, (pp.297-336). Salamanca. Amarú ediciones.

Avila, A. y Jiménez, F. (1994). MMPI-2 Spanish validation (spain): main clinical and Psychometric indicators. Trabajo presentado al VII Congreso Europeo de Psicología de la Personalidad. Madrid, Julio, 1994.

Avila, A. y Jiménez, F. (1996). The Castilian Version of the MMPI-2 in Spain: Development, Adaptation and Psychometric properties. In J.N. Butcher (de.) International Adaptations on the MMPI-2. University of Minnesota Pres, Minneapolis (pp.305-329).

Bachna, K; Sieggreen, M-A; Cermak, L.; Penk, W.; O'Connor, M. (1998). MMPI/MMPI-2: Comparisons of amnesic patients. Archives of Clinical Neuropsychology; 13(6): 535-542.

Baer, R.\& Sekirnjak, G (1997). Detection of underreporting on the MMPI-2 in a clinical population: Effects of information about validity scales. Journal of Personality Assessment. Dec; Vol 69(3): 555-567.

Baer, R.; Ballenger, J.; Berry, D.\& Wetter, M. (1997). Detection of random responding on the MMPI-A. Journal of Personality Assessment. Feb; Vol 68(1): 139-151.

Baer, R.; Wetter, M. \& Berry, D. (1992). Detection of underreporting of psychopathology on the MMPI: A meta-analysis. Clinical Psychology Review; Vol 12(5) 509-525.

Baer, R.; Wetter, M.\& Berry, D. (1995). Effects of information about validity scales on underreporting of symptoms on the MMPI-2: An analogue investigation. Assessment. Jun; Vol 2(2): 189-200.

Baer, R.; Wetter, M.; Nichols, D.; Greene, R. Et als. (1995). Sensitivity of MMPI-2 validity scales to underreporting of symptoms. Psychological Assessment. Dec; Vol 7(4): 419-423.

Bagby, R. M.; Nicholson, R. A.; Buis,T.; Radovanovic, H.; Fidler,B. J.(1999). Defensive responding on the MMPI-2 in family custody and access evaluations. Psychological Assessment. 11(1): 24-28.

Bagby, R.; Nicholson, R.A; Buis, T. \& Bacchiochi, J.R. (2000). Can the MMPI-2 validity scales detect depression feigned by experts?. Assessment, Mar, vol 7(1): 55-62.

Bagby, R.; Buis, T. \& Nicholson, R. (1995). Relative effectiveness of the standard validity scales in detecting fake-bad and fake-good responding: Replication and extension. Psychological Assessment. Mar; Vol 7(1): 84-92.

Bagby, R.; Pajouhandeh, P. (1997) The detection of faking good on the Personality Diagnostic Questionnaire-4. Assessment. Sep; Vol 4(3): 305-309.

Bagby, R.; Rogers, R.; Buis, T.; Nicholson, R.; Cameron, S.; Rector, N.; Schuller, D. \& Seeman, M. (1997). Detecting feigned depression and schizophrenia on the MMPI-2. Journal of Personality Assessment. Jun; Vol 68(3): 650-664.

Bagby, R.; Rogers, R.; Nicholson, R.; Buis, T.; Seeman, M.\& Rector, N. (1997). Effectiveness of the MMPI-2 validity indicators in the detection of defensive responding in clinical and nonclinical samples. Psychological Assessment. Dec; Vol 9(4): 406-413.

Bagby, R.M.; Rogers, R.; Buis, T., \& Kalemba, V. (1994). Malingered and defensive response styles on the MMPI-2: and examination of validity scales. Assessment; vol,1 (1), 31-38.

Bagby, R; Gillis, J. \& Dickens, S. (1990) Detection of dissimulation with the new generation of objective personality measures. Behavioral Sciences and the Law. Win; Vol 8(1): 93-102. 
Bagby, R; Rogers, R.\& Buis, T. (1994). Detecting malingered and defensive responding on the MMPI-2 in a forensic inpatient sample. Journal of Personality Assessment. Apr; Vol 62(2): 191-203.

Baldrachi,Ryan; Hilsenroth,Mark; Arsenault, Linda; Sloan, Patrick; Walter, Charles(1999). MMPI-2 assessment of varying levels of posttraumatic stress in Vietnam combat veterans. Journal of Psychopathology and Behavioral Assessment. 21(2): 109-116.

Ballard, R. (1992) Short forms of the Marlowe-Crowne Social Desirability Scale. Psychological Reports. Dec; Vol 71(3, Pt 2): 1155-1160.

Ballard, R.; Crino, M.; Rubenfeld, S. (1988). Social desirability response bias and the Marlowe-Crowne Social Desirability Scale. Psychological Reports. Aug; Vol 63(1): 227-237.

Bannatyne, L.A; Gacono, C.B \& Greene, R.L. (1999). Differential pattern of responding among three groups of chronic, psychotic, forensic outpatiens. Journal of Clinical Psychology, Dec. 55(12): 1553-1565.

Barbenza, C.; Montoya, O. \& Borel, M. (1978). La tétrada psicótica del MMPI en un grupo de estudiantes universitarios. Revista de Psicología General y Aplicada, 150, 79-88.

Barley, W.; Sabo, T.\& Greene, R. (1986). Minnesota Multiphasic Personality Inventory normal K + and other unelevated profiles. Journal of Consulting and Clinical Psychology; 1986 Aug Vol 54(4) 502-506.

Barthlow, Deanna L.; Graham, John R.; Ben-Porath, Yossef S.; McNulty, John L.(1999). Incremental validity of the MMPI-2 content scales in an outpatient mental health setting. Psychological Assessment.; 11(1): 39-47.

Bartol, C. (1991). Predictive validation of the MMPI for small-town police officers who fail. Professional Psychology Research and Practice; Apr Vol 22(2) 127-132.

Bash, I. \& Alper, M. (1980). The determination of malingering. Anals of the New York Academy of Sciences, 347, 86-89.

Beaber, R.; Marston, A.; Michely, J. \& Mills, M. (1985). A brief test for measuring malingering in schizofrenic individuals. American Journal of Psychiatric, 142, 1478-1481.

Beal, D. (1989). Assessment of malingering in personal injury cases. American Journal of Forensic Psychology; Vol 7(4) 59-65.

Bender, L. (1938). A visual motor Gestalt test and its clinical use. New York: Orthopsychiatric Association.

Ben-Porath, Y.; Butcher, J. (1989). The comparability of MMPI and MMPI-2 scales and profiles. Psychological Assessment; Dec Vol 1(4) 345-347.

Ben-Porath, Y.; Butcher, J.\& Graham, J. (1991). Contribution of the MMPI-2 content scales to the differential diagnosis of schizophrenia and major depression. Psychological Assessment; Dec Vol 3(4) 634-640.

Ben-Porath, Y.; Hostetler, K.; Butcher, J.; Graham, J. (1989). New subscales for the MMPI-2 Social Introversion (Si) scale. Psychological Assessment; Sep Vol 1(3) 169-174.

Ben-Porath, Y.; McCully, E. \& Almagor, M. (1993). Incremental validity of the MMPI-2 Content Scales in the assessment of personality and psychopathology by self-report. Journal of Personality Assessment; Dec Vol 61(3) 557-575.

Bernard, L. (1990). Prospects for faking beliable memory deficits on neuropsychological test and the use of incentives in simulation research. Journal of Clinical and experimental Neuropsychology, 12, $715-728$

Bernard, L.; Houston, W \& Natoli, L. (1993). Malingering on neuropsychological tests: potential objective indicators. Journal of Clinical Psychology, 49, 45-53.

Bernstein, I.\& Garbin, C. (1985). A simple set of salient weights for the major dimensions of MMPI scale variation. Educational and Psychological Measurement; Win Vol 45(4) 771-787.

Berry, D, R. \& Butcher, J.(1998). Detection of feigning of head injury symptoms on the MMPI-2. In Reynolds, Cecil R. (Ed); et al. (1998). Detection of malingering during head injury litigation. Critical issues in neuropsychology. (pp. 209-238). New York, NY, USA: Plenum Press.

Berry, D.; Baer, R. \& Harris, M. (1991). Detection of malingering on the MMPI: A meta-analysis. Clinical Psychology Review.; Vol 11(5): 585-598. 
Berry, D.; Wetter, M.; Baer, R.; Larsen, L; et als (1992). MMPI-2 random responding indices: Validation using a self-report methodology. Psychological Assessment; Sep Vol 4(3) 340-345.

Berry, D.; Wetter, M.; Baer, R.; Larsen, L. Et als., (1992). MMPI-2 random responding indices: validation using a self methodology. Psychological Assessment, 4(3), 340-345.

Berry, D.; Wetter, M.; Baer, R.; Widiger, T.; et als. (1991). Detection of random responding on the MMPI-2: Utility of F, back F, and VRIN scales. Psychological Assessment; Sep Vol 3(3) 418423.

Berry, D.T.R., Wetter, M.W.; Baer, R.A.; Youngjohn, J.R., Gass, C.S.; Lamb, D.G. Franzen, M.D.; MacInnes, W.D. \& Bucholz, W.D. (1995). Overreporting of closed-head injury symptoms on the MMPI-2. Psychological Assessment, 7, 517-523.

Binder, J; Mayman, M. \& Doehrman, S. (1974). Self-ideal-self discrepancy as a defensive style. Comprehensive Psychiatry; Jul-Aug Vol 15(4) 335-343.

Binder, L. (1993). Assessment of malingering after mild head trauma with the Portland Digit Recognition Test: erratum. Journal of clinical and experimental Neuropsychology, vol 15(6). 852-860.

Blake, D.; Penk, W.; Mori, D.; Kleespies, P.; et als. (1992). Validity and clinical scale comparisons between the MMPI and MMPI-2 with psychiatric inpatients. Psychological Reports; Feb Vol 70(1) 323-332.

Bleuler, E. (1967). Tratado de psiquiatría. Madrid: Espasa-Calpe.

Boone, D. (1994). Reliability of the MMPI-2 subtle and obvius scales with psychiatric inpatiens. Journal of Personality Assessment; Apr., vol. 62(2) 346-351.

Brems, C. \& Johnson, M.E. (1991). Subtle-Obvius scales of the MMPI: indicators of profile validity in a psychiatric population. Journal of Personality Assessment, 56, 536-544.

Brophy, A.. (1993). Cooke's disturbance index on the MMPI-2. Psychological Reports; Feb Vol 72(1) 345-346.

Brophy, A.. (1995). Educational level, occupation, and the MMPI-2 F-K index. Psychological Reports. Aug; Vol 77(1): 175-178.

Brophy, A.. (1995). Gough's F-K Dissimulation Index on the MMPI-2. Psychological Reports. Feb; Vol 76(1): 158.

Brunetti, David G.; Schlottmann, Robert S.; Scott, Anne B.; Hollrah, Joni L.(1998). Instructed faking and MMPI-2 response latencies: The potential for assessing response validity. Journal of Clinical Psychology.; 54(2): 143-153.

Buechley, R. \& Ball, H. (1952). A new test of validity for the group MMPI. Journal of Consulting Psychology, 16, 299-301.

Burish, T. \& Houston, B (1976). Construct validity of the Lie scale as a measure of defensiveness. Journal of Clinical Psychology; Apr Vol 32(2) 310-314.

Butcher, J,.\& Graham, J. (1994). The MMPI-2: a new standar for personality assessment and research in counseling setting. Measurement and evaluation in Counseling and Development, Oct. Vol.27(3). 131-150.

Butcher, J.; \& Han, K. (1995). Development of an MMPI-2 scale to assess the presentation of self in a superlative manner: The S scale. In J.N. Butcher \& C.D. Spielberger (Eds.), Advances in personality assesment (vol. 10, pp.25-50). Hillsdale, NJ: LEA Press.

Butcher, J. \& Kyunghee H. (1996). Methods of Establishing Cross-Cultural Equivalence. In J.N. Butcher, International adaptations of the MMPI-2. University Of Minnesota Press. (pp.44-67).

Butcher, J. \& Pancheri, P. (1976). A handbook of cross national MMPI research. Minneapolis: University of Minnesota Press.

Butcher, J. \& Pope, K. (1992). The research base, psychometric properties, and clinical uses of the MMPI-2 and MMPI-A. Canadian Psychology; Jan vol.33(1) 61-93.

Butcher, J. \& Tellegen, A. (1966). Objections to MMPI ítems . Journal of Consulting Psychology, 30, 527-534.

Butcher, J. \& Williams, C. (1992). Essentials of MMPI-2 and MMPI-A Interpretations". University of Minnesota Press. Minneapolis.

Butcher, J. (1969). MMPI. Research development and clinical Applications. New York. McGraw Hill. 
Butcher, J. (1972). Objective personality Assessment: changing perspectives. New York. Academic Press.

Butcher, J. (1985 a). Interpreting defensive profiles. In J.N. Butcher \& J.R. Graham (Eds.), Clinical applications of the MMPI $\left(n^{o}\right.$. 3). Minneapolis: Department of Conferences, University of Minnesota.

Butcher, J. (1989). User's guide for the MMPI-2 Minnesota Report: Adult Clinical System. Minneapolis: National Computer System.

Butcher, J. (1990). "MMPI-2 in Psychological Treatment”. Oxford University Press, New York, Oxford.

Butcher, J. (1990 a ) Wat interpretative changes do the educational differences between the original MMPI and MMPI-2 normative sample require?. MMPI-2 News and Profiles. 1(1), 2.

Butcher, J. (1990b). Educational level and MMPI-2 measured psychopatology: A case of negligible influence. MMPI-2 News and Profiles, 1(2), 2.

Butcher, J. (1991). Screening for psychopathology Industrial applications of the Minnesota Multiphasic Personality Inventory-2 (MMPI-2). In Jones, B.D., Steffey y D. Bray (Eds.): Applying psychology in business: the manager's handbook. Boston: lexington Books.

Butcher, J. (1996). Translation and Adaptation of the MMPI-2 for international Use. In J.N. Butcher, International adaptations of the MMPI-2. University Of Minnesota Press. (pp. 26-44).

Butcher, J.\& Finn, S. (1983). Objective personality Assesment in clinical settings. In Hersen, M. Kazdin, A.E. y Bellack, A.S. (Eds). The clinical Psychology Handbook. New York, Pergamon Press. (pp. 329-344).

Butcher, J.(1992). The MMPI-2: A step in the right direction. National Psychologist, 1, 12.

Butcher, J., Dahlstrom, W.; Graham, J.; Tellegen, A. \& Kaemer, B. (1989). Manual for the reestandaridized Minnesota Multiphasic Personality Inventory: MMPI-2. Minneapolis University of Minnesota Press.

Butcher, J.; Aldwin, C.; Levenson, M.; Ben-Porath, Y.; et als. (1991). Personality and aging: A study of the MMPI-2 among older men. Psychology and Aging; Sep Vol 6(3) 361-370.

Butcher, J.; Dahlstrom, W.; Graham, J.; Tellegen, A. \& Kaemmer, B. (1989). MMPI-2: Manual for administration and scoring. University of Minnesota Press. Mineapolis, Minnesota.

Butcher, J.; Graham, J.; Dahlstrom, W.\& Bowman, E. (1990). The MMPI-2 with college students. Journal of Personality Assessment; Spr Vol 54(1-2) 1-15.

Butcher, J.; Graham, J.; Williams, C. \& Ben-Porath, Y. (1989). Development and use of the MMPI-2 content scales. Minneapolis: University of Minnesota Press.

Butcher, J.; Graham, J.; Williams, C. \& Ben-Porath, Y. (1990).”Development and use of the MMPI-2 Content Scales". University of Minnesota Press, Minneapolis.

Butcher, J.; Morfitt, R.; Rouse, S.\& Holden, R. (1997). Reducing MMPI-2 defensiveness: The effect of specialized instructions on retest validity in a job applicant sample. Journal of Personality Assessment. Apr; Vol 68(2): 385-401.

Butcher, J.; Williams, C.; Graham, J.; Archer, R.; Tellegen, A.; Ben-Porath, Y. \& Kaemer, B. (1992). "MMPI-A. Manual for Administration, Scoring and Interpretation". University of Minnesota Press, Minneapolis.

Butcher, J.; Williams, C.; Graham, J.; Ben-Porath, Y. \& Kaemer, B. (1993). "MMPI-2. Manual for Administration, Scoring and Interpretation”. University of Minnesota Press, Minneapolis.

Butcher, J. N.; Lim, J.; Nezami, E. (1998). Objective study of abnormal personality in cross cultural settings: The Minnesota Multiphasic Personality Inventory (MMPI-2). Journal of Cross Cultural Psychology:; 29(1): 189-211.

Butcher, J. N. (1999). A beginner's guide to the MMPI-2. Washington, DC, USA: American Psychological Association.

Butcher, J. N. (1999). Personality assessment in personal injury litigation. In Hess, A.; Weiner, I.B. et al. (ed.). The handbook of forensic psychology (2nd ed.) (pp. 104-126). New York. NY. USA: John Wiley \& Sons, Inc.

Butcher. J. (1996 ). International adaptations of the MMPI-2. University Of Minnesota Press. 
Butcher. J. (1996b). Understandins abnormal behavior across cultures: The use of objective Personality Assessment Methods. In J.N. Butcher, International adaptations of the MMPI-2. University Of Minnesota Press. (pp. 3-26).

Caldwell, A.B. (1997ª). [MMPI-2 data research file for personnel applicants]. Unpublished raw data.

Carlin, A.S. \& Hewitt, P.L. (1990). The discrimination of patient-generated and randomly generated MMPIs. Journal of Personality Assessment, 54, 24-29.

Carp, A. \& Shavzin, A. (1950). The susceptibility to falsification of the Rorschach psychodiagnostic technique. Journal of Consulting Psychology, 14, 230-233.

Carson, R. (1969).Interpretative manual to the MMPI. In J.N. Butcher (Ed.), Research developments and clinical applications (pp.279-296). New York: Graw-Hill.

Cassisi, J.\& Workman, D. (1992). The detection of malingering and deception with a short form of the MMPI-2 based on the L, F, and K scales. Journal of Clinical Psychology; Jan Vol 48(1) 54-58.

Castilla del Pino, C. (1980). Introducción a la psiquiatría. Alianza Universidad Textos, Madrid.

Casullo, M. Y cols. (1999). Aplicaciones del MMPI-2 en los ámbitos clínico, forense y laboral. Paidós

Casullo, M. y Samartino, L. (1996). Sudies of the MMPI-2 in Argentina. In J.N. Butcher, International adaptations of the MMPI-2. University Of Minnesota Press. (pp. 252-265).

Cattell, R.; Eber, H. \& Tatsuoba, M. (1970). Handbook for the Sixteen Personality Factor Questionaire (16 PF). IPAT. Campaing.

Cellucci, Tony; Wilkerson, Amy; Mandra, Douglas(1998). The MMPI-2 Gender-role scales as measures of sex-typing. Psychological Reports.; 83(3, Pt 1): 752-754.

Clavelle, Paul-R. (1992). Clinicians' perceptions of the comparability of the MMPI and MMPI-2. Psychological Assessment; Dec Vol 4(4) 466-472.

Cloak, N.; Kirklen, L.; Strozier, A. \& Reed, J. (1997). Factor analysis of Minnesota Multiphasic Personality Inventory-1 (MMPI-1) Validity Scale items. Measurement and Evaluation in Counseling and Development. Apr; Vol 30(1): 40-49.

Cofer, C.N. Chance, J., \& Judson, A.J. (1949). A study of malingering on the MMPI. Journal of Psychology, 27, 491-499.

Colby, Flder (1989). Usefulness of the Kcorrection in MMPI profiles of patients and nonpatients. Psychological Assessment; Jun Vol 1(2) 142-145.

Coleman, A. Rand; Norstrand, Julie A.; Moberg, Paul J.; Kohler, Christian G.; Gur, Ruben C.; Gur, Raquel E.(1998). MMPI-2 characteristics of adults diagnosed with attention deficit disorder. International Journal of Neuroscience.; 96(3-4): 161-175.

Colligan, Robert C.; Morey, Leslie C.; Offord, Kenneth P.(1994) The MMPI/MMPI-2 Personality Disorder scales: Contemporary norms for adults and adolescents. Journal of Clinical Psychology. Mar; Vol 50(2): 168-200.

Comrey, A.L. $\left(1958^{\mathrm{a}}\right)$. A factor analysis of items on the F scale of the MMPI. Educational and Psychological Measurement, 18, 621-632.

Conkey, V.A. (2000). Determining the sensivity of the MMPI-A to random responding and malingering in adolescents (Minnesota Multiphasic Personality Index, validity Scales). Dissertation Abstracts International. Section B. The Sciences and Engineering, Feb. Vol 60(7-B): 3608.

Cooligan el al. (1983). The MMPI: A contemporary normative study. New York: Praeger.

Coons, Philip-M.(1991) Iatrogenesis and malingering of multiple personality disorder in the forensic evaluation of homicide defendants. Psychiatric Clinics of North America. Sep; Vol 14(3): 757768.

Corrales, Monica L.; Cabiya, Jose J.; Gomez, Francisco; Ayala, Guadalupe X.; Mendoza, Sonia; Velasquez, Roberto J.(1998). MMPI-2 and MMPI-A research with U.S. Latinos: A bibliography. Psychological Reports. 83(3, Pt 1): 1027-1033.

Costello, Raymond-M.; Schneider, Sandra-L.; Schoenfeld, Lawrence-S. (1993). Applicants' fraud in law enforcement. Psychological Reports. Aug; Vol 73(1): 179-183.

Craig, Robert J.(1999). Interpreting personality tests: A clinical manual for the MMPI-2, MCMI-III, CPIR, and 16PF. New York, NY, USA: John Wiley and Sons, Inc. 
Craig, Robert J.; Ammar, Alia; Olson, Ronald E.(1998). Psychological assessment (MMPI-2) of male African American substance abusing patients with and without histories of childhood physical abuse. Journal of Substance Abuse.; 10(1): 43-51.

Cramer, K.M. (1995). Comparing three new MMPI-2 randomness indices in a novel procedure for ramdom profile derivation. Journal of Personality Assessment, 65, 514-520.

Crowne, D.P. y Marlowe, D. (1960). A new scale of Social Desirability Independent of psychopathology. Journal of Consulting Psychology, 24, 349-354.

Chervinsky, Alexander B.; Om a, Alexander K.; deJonge, Madison; Spector, Jack; Schwab, Karen; Salazar, Andres M.(1998).Motivation for traumatic brain injury rehabilitation questionnaire (MOT-Q): Reliability, factor analysis, and relationship to MMPI-2 variables. Archives of Clinical Neuropsychology.; 13(5): 433-446.

Cheung, F.M.; Song, W. \& Zhang, J. (1996). The Chinese MMPI-2: Research and Applications in Hong Kong and the People's of China. In J.N. Butcher, International adaptations of the MMPI-2. University Of Minnesota Press. (pp. 137-162).

Chojnacki, Joseph-T.; Walsh, W.-Bruce (1992). The consistency of scores and configural patterns between the MMPI and MMPI-2. Journal of Personality Assessment; Oct Vol 59(2) 276-289.

Christensen, A.L. (1975). Luria's Neuropsychological Investigation. New York: Spectrum Publications.

Christian, William-L.; Burkhart, Barry-R.; Gynther, Malcolm-D. (1978). Subtle-obvious ratings of MMPI items: New interest in an old concept. Journal of Consulting and Clinical Psychology; Dec Vol 46(6) 1178-1186.

Dahlstrom, W \& Welsh, G. (1972). An MMPI handbook. Volume I.: Clinical interpretation. Minneapolis; University of Minnesota Press.

Dahlstrom, W.; Welsh, G. \& Dahlstrom, L.E. (1975). An MMPI handbook. Volume II.: Research developments and interpretations (Ed. Revisada). Minneapolis; University of minnesota Press.

Dahlstrom, W.G., Lachar, D. Y Dahlstrom, L.E. (1986). MMPI patterns of American minorities. Minneapolis. University of Minnesota Press.

Dalton, John-E. (1994). MMPI-168 and Marlowe-Crowne profiles of adoption applicants. Journal of Clinical Psychology. Nov; Vol 50(6): 863-866.

Dannembaum, S.E. \& Lanyon, R.I. (1993). The use of subtle items in detecting deception. Journal of Personality Assessment, , 61, 501-510.

Deardorff, William-W.; Chino, Allan; Scott, David-W. (1993). Characteristics of chronic pain patients: Factor analysis of the MMPI-2. Pain; Aug Vol 54(2) 153-158.

Dederhof, A.J. (1985). Methods of coping of social desirability bieas: a review. European Journal of Social Psychology, 15 (3), 263-280.

Deinard A.S y cols. (1996). Development of a Hmong Translation of the MMPI-2. In J.N. Butcher, International adaptations of the MMPI-2. University Of Minnesota Press. (pp. 194-205).

DeLamatre, James E.; Schuerger, James M.(2000). The MMPI-2 in counseling practice. In Watkins, C. Edward Jr. (Ed); Campbell, Vicki L. (Ed); et al. Testing and assessment in counseling practice (2nd ed.). Contemporary topics in vocational psychology. (pp. 15-44). Mahwah, NJ, US: Lawrence Erlbaum Associates, Inc., Publishers.

Deutschle, J.J. Jr. (1998). The development and use of subscales for the F and Fb scales on the MMPI-2 to aid in the comparison of response styles in depressed vs. Psychotic and informed vs. Uninformed dissimulators. Dissertation Abstracts International. Section B. The Sciences and Engineering, Apr. Vol 58(10-A): 3844.

Drake, L. E. (1946). A social I.E. scale for the MMPI. Journal of Applied Psychology, 30, 51-54.

Drake, L. E. Y Thiede, W.B. (1948). Further validation of the social I.E. scale for the MMPI. Journal of Educational Research, 41, 551-556.

DuAlba, Les; Scott, Ronald-L. (1993). Somatization and malingering for workers' compensation applicants: A cross-cultural MMPI study. Journal of Clinical Psychology. Nov; Vol 49(6): 913917. 
Dush, D.M. Simons, L.E. Platt, M. Nation,P.C.\& Ayres, S.Y. (1994). Psychological profiles distinguishing litigating and nonlitigating pain patiens: Subtle, and not so subtle. Journal of Personality Assessment, 62, 299-313.

Edwards, A. (1957). The social desirability in personality assessment and research. New York: Holt.

Edwards, A. (1990). Construct validity and social desirability. American Psychologist. Feb; Vol 45(2): 287-289.

Edwards, A.; Edwards, L. (1992). Social desirability and Wiggins's MMPI content scales. Journal of Personality and Social Psychology. Jan; Vol 62(1): 147-153.

Edwards, D.; Morrison, T.; Weissman, Herbert-N. (1993). The MMPI and MMPI-2 in an outpatient sample: Comparisons of code types, validity scales, and clinical scales. Journal of Personality Assessment; Aug Vol 61(1) 1-18.

Edwards, E. L.; Holmes, C, B.; Carvajal, H. H.(1998). Oral and booklet presentation of the MMPI-2. Journal of Clinical Psychology; 54(5): 593-596.

Edwards, L.; Edwards, A. (1991). A principal components analysis of the Minnesota Multiphasic Personality Inventory factor scales. Journal of Personality and Social Psychology. May; Vol 60(5): 766-772.

Elder, R. L.; Johnson, D. C. (1989). Varying relationships between adaptation innovation and social desirability. Psychological Reports. Dec; Vol 65(3, Pt 2): 1151-1154.

Elwood, R. W. (1993). The clinical utility of the MMPI-2 in diagnosing unipolar depression among male alcoholics. Journal of Personality Assessment; Jun Vol 60(3) 511-521.

Ellertsen, B, et. Al. (1996). The Norwegian MMPI-2. In J.N. Butcher, International adaptations of the MMPI-2. University Of Minnesota Press. (pp. 350-367).

Elliot, Sharon; Lawty-Jones, Michele; Jackson, Chris (1996) Effect of dissimulation on self-report and objective measures of personality. Personality and Individual Differences. Sep; Vol 21(3): 335343.

Evans, R.G.; Dinning, W.D (1983). Response consistency among high F scale scorers on the MMPI. Journal of Clinical Psychology; Mar Vol 39(2) 246-248.

Evans, R. G. (1984). The Test-Retest Index and high F MMPI profiles. Journal of Clinical Psychology; Mar Vol 40(2) 516-518.

Exner, J.E. (1994). El Rorschach: un sistema comprehensivo. (Vol. I y II). Rorschach, Workshops Psimática, Madrid.

Fairbank, J.A., McCaffrey, R.J. \& Keane, T.M. (1985). Psychometric detection on fabricated symptoms of postraumatic stress disorders. American Journal of Psychiatry, 142, 501-503.

Fals, S.W. (1995). The effect of defensive responding by substance-abusing patients on the Millon Clinical Multiaxial Inventory. Journal of personality Assessment, 64(3), 540-551.

Fals-Stewart, W.; Lucente, S. (1997). Identifying positive dissimulation by substance-abusing individuals on the Personality Assessment Inventory: A cross-validation study. Journal of Personality Assessment. Apr; Vol 68(2): 455-469.

Fernández-Ballesteros, R. (1992). Introducción a la evaluación psicológica. Tomos I y II. Pirámide, Madrid.

Fischer, D. G.; Fick, C. (1993) Measuring social desirability: Short forms of the Marlowe-Crowne Social Desirability Scale. Educational and Psychological Measurement. Sum; Vol 53(2): 417-424.

Forbes, D.; Creamer, M.; McHugh, T.(1999). MMPI-2 data for Australian Vietnam veterans with combat related PTSD. Journal of Traumatic Stress.; 12(2): 371-378.

Ford, Ch.V. (1983). The somatizing Disorders. Elseiver. New York.

Forsberg, I.A. (1941). An experimental study of the reliability of the Rorschach Psychodiagnostic Thecnique. Rorschach Research Exchange, 5, 72-84.

Fortova, V. (1979): Validity of indicators of simulation and dissimulation in MMPI.. Research Inst of Psychiatry,23(1), 50-60.

Fox, D.D.; Gerson, A.; Lees-Haley, P.R. (1995). Interrelationship of MMPI-2 validity scales in personal injury claims. Journal of Clinical Psychology. Jan; Vol 51(1): 42-47. 
Fraboni, M.; Cooper, D. (1989) Further validation of three short forms of the Marlowe-Crowne Scale of Social Desirability. Psychological Reports. Oct; Vol 65(2): 595-600.

Frueh, B.Ch. \& Kinder, B.N. (1994). The susceptibility pf the Rorschach Inkblot test to malingering of combat related PTSD. Journal of Personality Assessment, vol. 62(2), 280-298.

Fuller, C. G.; Malony, H. N. (1984). A comparison of English and Spanish (Núñez) translations of the MMPI. Journal of Personality Assessment; 1984 Apr Vol 48(2) 130-131.

Furnham, A. (1986). Response bias, social desirability and dissimulation. Personality and individual differences, 7, 385-400.

Furnham, A. (1990) Faking personality questionnaires: Fabricating different profiles for different purposes. Current Psychology: Research and Reviews. Spr; Vol 9(1): 46-55.

Gallucci, N.T. (1984). Prediction of dissimulation on the MMPI in a clinical field setting. Journal of Consulting and Clinical Psychology; Oct Vol 52(5) 917-918.

Gallucci, N.T. (1985). Influence of dissimulation on indexes of response consistency for the MMPI. Psychological Reports, 57, 1013-1014.

Gallucci, N.T. (1987). The influence of elevated F scales on the validity of adolescent MMPI profiles. Journal of Personality Assessment; Spr Vol 51(1) 133-139.

Garcia Merita, M.L. y cols. (1984). Problemas de validez en la escala de depresión del MMPI. Revista de Psicología General y Aplicada, 39, 2, 313-340.

García, L. y cols. (1983) Llengua del test I patologia detectada en el MMPI. III Simposi Avenços en Terapeutica Psiquiátrica. Societat Catalana de Psiquiatría, Barcelona.

Gillis, J. R.; Rogers, R.; Dickens, S. E. (1990). The detection of faking bad response styles on the MMPI. Canadian Journal of Behavioural Science; Oct Vol 22(4) 408-416.

Goebel, R. A. (1983). Detection of faking on the halstead-Reitan neuropsichological test battery. Journal of clinical Psychology, 39, 731-742.

Gomez-Maqueo, E.L. y Reyes-Lagunes, I. (1994). La nueva versión del Cuestionario Multifásico de la Personalidad de Minnesota MMPI-2 para estudiantes Universitarios Mexicanos. Revista Mexicana de Psicología; Jun Vol.11(1) 45-54.

Gonzalez del Pino, C. y cols. (1969). Estudio diferencial de la tríada neurótica y escala Pd del MMPI en universitarios españoles. Revista de Psicología General y Aplicada, 99-100, 728-733

Gough, H.C. (1954). Some common misconceptions about neuroticism. Journal of Consulting Psychology, 18, 287-292.

Gough, H.G (1947). Simulated patterns on the Minnesota Multiphasic Personality Inventory. Journal of Abnormal and Social Psychology, 42, 215-225.

Gough, H.G. (1950). The F minus K disimulation index on the Minnesota Multiphasic Personality Inventory. Journal Consulting Psychology, 14, 408-413.

Gough, H.G. (1954) Some common misconceptions about neuroticism. Journal of Consulting Psychology, 18, 287-292.

Gough, H.G. (1957). Manual for the California Psychological Inventory. Palo Alto, California Consulting Psychologists Press.

Gough, H.G. (1987). California Psychological Inventory. Administrator's guide. Consulting Psychologists Press, Berkeley, California.

Graham, J. (1987). “MMPI. Guía práctica”. El Manual Moderno, México.

Graham, J. (1990). “MMPI-2, assessing Personality and Psychopathology”. Oxford University Press, New York, Oxford.

Graham, J. (1992). Interpretation of MMPI-2. Validity and Clinical Scales. Workshop, Brujas.

Graham, J. (1993). MMPI-2: Assessing personality and psychopathology (2nd.ed.) London: Oxford University Press.

Graham, J.; Watts, D. \& Timbrook, R, (1991). Detecting fake-good and fake-bad MMPI-2 profiles. Journal of personality Assessment, 57(2), 264-277.

Granleese, J.; Trew, K.; Turner, I. (1988). Social dissimulation, perceived competence and personality. Personality and Individual Differences. Vol 9(3): 565-570. 
Gravitz, M.A. (1987) An empirical study of MMPI F scale validity. Psychological Reports, 60, 389-390.

Greenblatt, Richard L.; Davis, William E.(1999). Differential diagnosis of PTSD, schizophrenia, and depression with the MMPI-2. Journal of Clinical Psychology. 55(2): 217-223.

Greene, R. L. (1978), An empirical derived MMPI carelessness scale. Journal of Clinical Psychology, 34, 407-410.

Greene, R. L. (1988) Assessment of malingering and defensiveness by objective personality inventories. In Rogers, Richard (Ed); et al. Clinical assessment of malingering and deception. (pp. 123-158). New York, NY, USA: Guilford Press.

Greene, R. L. (1988c) The MMPI: Use with specific populations. New York: Grune \& Straton.

Greene, R. L. (1988b) The relative efficacy of F-K and the obvious and subtle scales to detect overreporting of psychopathology on the MMPI. Journal of Clinical Psychology. Mar; Vol 44(2): 152-159.

Greene, R. L. (1997). Assessment of malingering and defensiveness by multiscale inventories. In Rogers, Richard (Ed); et al. Clinical assessment of malingering and deception (2nd ed.). (pp. 169-207). New York, NY, USA: Guilford Press.

Greene, R.L. (2000). The MMPI-2. An interpretative manual (2nd. Ed.). Allyn and Bacon, Boston.

Greene, R. L.; Weed, N.C.; Butcher, J. N.; Arredondo, Rudy; et al (1992). A cross-validation of MMPI-2 substance abuse scales. Journal of Personality Assessment; Apr Vol 58(2) 405-410.

Greene, R.L. (1978). An empirical derived MMPI carelessness scale. Journal of clinical Psychology, 34, 407-410.

Greene, R.L. (1995). [MMPI-2 data research file for psychiatric inpatients and outpatients]. Unpublised rax data.

Greene, R. L.; Clopton, James R.(1999). Minnesota Multiphasic Personality Inventory-2 (MMPI-2). In Maruish, Mark E. (Ed); et al. The use of psychological testing for treatment planning and outcomes assessment (2nd ed.). (pp. 1023-1049). Mahwah, NJ, USA: Lawrence Erlbaum Associates, Inc., Publishers.

Grillo, J.; Brown, R.S.; Hilsabeck, R. et als., (1994). Raising doubs about claims of malingering: implications of relationship between MCMI-II and MMPI-2 performances. Journal of Clinical Psychology, 50(4), 651-655.

Grossman, L.S. \& Craig, R.J. (1995). Comparison of MCMI-II and 16 PF validity Scales. Journal of Personality Assessment, 64(2), 384-389.

Grow, Richard; McVaugh, William; Eno, Thomas-D. (1980). Faking and the MMPI. Journal of Clinical Psychology; Oct Vol 36(4) 910-917.

Gynther, M.D.; Alman, H., \& Warbin,.W. (1973). Interpretation of uninterpretable Minnesota Multiphasic Personality Inventory profiles. Journal of Consulting and Clinical Psychology, 40, 78-83.

Gynther, M.D.; Burkhart, B.R.; Hovanitz, C. (1979). Do face-valid items have more predictive validity than subtle items? The case of the MMPI Pd scale. Journal of Consulting and Clinical Psychology; Apr Vol 47(2) 295-300.

Gynther, M.D.; Lachar, D.; Dahlstrom, W. G. (1978). Are special norms for minorities needed? Development of an MMPI F scale for Blacks. Journal of Consulting and Clinical Psychology; Dec Vol 46(6) 1403-1408.

Hall, Gordon C. Nagayama; Bansal, Anita; López, Irene R.(1999). Ethnicity and psychopathology: A meta-analytic review of 31 years of comparative MMPI/MMPI-2 research. Psychological Assessment. 11(2): 186-197.

Han Kyunghee (1996). The Korean MMPI-2. In J.N. Butcher, International adaptations of the MMPI-2. University Of Minnesota Press. (pp.88-137).

Handel, Richard W.; Ben Porath, Yossef S.; Watt, Mimi(1999). Computerized adaptive assessment with the MMPI-2 in a clinical setting. Psychological Assessment.; 11(3): 369-380.

Harrell, Thomas-H.; Honaker, L.-Michael; Parnell, Teri (1992). Equivalence of the MMPI-2 with the MMPI in psychiatric patients. Psychological Assessment; Dec Vol 4(4) 460-465. 
Hathaway, S.R. y Meehl, P.E. (1951). An atlas for the clinical use of the MMPI. Minneapolis . University of Minnesota Press.

Hathaway, S.R. \& Mckinley, J.C. (1940). A multiphasic personality schedule (Minnesota): I. Construction of the schedule. Journal of Psychology, 10, 249-254.

Hathaway, S.R. (1947). A coding system for MMPI profiles. Journal of Consulting Psychology, 11, 334337.

Hathaway, S.R. (1956). Scales 5 (masculinity-feminity), 6 (paranoia), and 8 (schizofrenia). In G.S. Welsh y W.G. Dahlstrom (Eds.). Basic readings on the MMPI in Psychology and Medicine. Minneapolis: University of Minnesota Press.

Hathaway, S.R. y McKinley, J.C. (1940). A multiphasic personality schedule (Minnesota): I. Construction of the schedule. Journal of Psychology, 10, 249-254.

Hathaway, S.R. y McKinley, J.C. (1942). A multiphasic personality schedule (Minnesota): III. The measurement of symptomatic depression. Journal of Psychology, 14, 73-84.

Hathaway, S.R. y McKinley, J.C. (1943, 1961). Cuestionario de personalidad MMPI. Madrid, Tea Ediciones (ed., 1970, 1975).

Hawk, G. L.; Cornell, D. G. (1989). MMPI profiles of malingerers diagnosed in pretrial forensic evaluations. Journal of Clinical Psychology; Jul Vol 45(4) 673-678.

Hawk, S. S.; Peterson, R. A. (1974). Do MMPI psychopathic deviancy scores reflect psychopathic deviancy or just deviancy?. Journal of Personality Assessment; Aug Vol 38(4) 362-368.

Heaton, R.K; Smith, H.H.; Lehman, R.A \& Vogt, A.T. (1978) Prospects for faking believable deficits on neuropsychological testing. Journal of consulting and clinical Psychology, 46, 892-900.

Helmes, Edward; Reddon, John-R. (1993). A perspective on developments in assessing psychopathology: A critical review of the MMPI and MMPI-2. Psychological Bulletin; May Vol 113(3) 453-471.

Hengesch, Georges; Roesler, Michael; Bellaire, Wolfgang; Burger, Ludwig (1988). Les tests de personnalite en psychiatrie legale. / Applications of personality tests in forensic psychiatry. Acta Psychiatrica Belgica. Jan-Feb; Vol 88(1): 28-41.

Hills, H.A. (1995) Diagnosing personality disorders: An examination of the MMPI-2 and MCMI-II. Journal of personality Assessment; Aug vol.65(1) 21-34.

Hjemboe, Stephen; Butcher, James-N. (1991). Couples in marital distress: A study of personality factors as measured by the MMPI-2. Journal of Personality Assessment; Oct Vol 57(2) 216-237.

Holden, R. R.; Hibbs, N. (1995) Incremental validity of response latencies for detecting fakers on a personality test. Journal of Research in Personality. Sep; Vol 29(3): 362-372.

Holden, R.R.; Kroner, D. G.; Fekken, G..C.; Popham, S. M. (1992) A model of personality test item response dissimulation. Journal of Personality and Social Psychology. Aug; Vol 63(2): 272-279.

Hough, L. M.; Eaton, N. K.; Dunnette, M.D.; Kamp, J. D.; et al (1990) Criterion-related validities of personality constructs and the effect of response distortion on those validities. Journal of Applied Psychology. Oct; Vol 75(5): 581-595.

Hsu, L.M. (1984). MMPI T scores: linear versus normalized. Journal of Consulting and Clinical Psychology, 52, 821-823.

Hsu, L. M. (1986). Implications of differences in elevations of K-corrected and non-K-corrected MMPI T scores. Journal of Consulting and Clinical Psychology; Aug Vol 54(4) 552-557.

Huesmann, L. R.; Lefkowitz, M. M.; Eron, L. D. (1978). Sum of MMPI Scales F, 4, and 9 as a measure of aggression. Journal of Consulting and Clinical Psychology; Oct Vol 46(5) 1071-1078.

Humprey, D.H. y Dahlstrom, W.G. (1995). The impact of changing from the MMPI-2 on ptofile configurations. Journal of Personality Assessment; Jun vol. 64(3) 428-439.

Hunt, W.A. \& Older, H.J. (1943). Detection of malingering through psychometric test. Naval Medical Bulletin, 41, 1318-1323.

Hyer, Lee-A.; Woods, Marilyn; Harrison, William-R.; Boudewyns, Patrick-A.; et al (1989). MMPI F-K index among hospitalized Vietnam veterans. Journal of Clinical Psychology; Mar Vol 45(2) 250-254.

Iverson, G. \& Barton, E. (1999). Interscorer reliability of the MMPI-2: Should TRIN and VRIN be computer scored?. Journal of Clinical Psychology. Jan; Vol 55(1): 65-69. 
Iverson, G.L., Franzen, M.D., \& Hammond, J.A. (1995). Examinations of inmates' ability to malinger on the MMPI-2. Psychological Assessment, 7, 118-121.

Iverson, Grant L.; Barton, Elizabeth(1999). Interscorer reliability of the MMPI-2: Should TRIN and VRIN be computer scored? Journal of Clinical Psychology. 55(1): 65-69.

Jiménez, F.; Sánchez, G. Y Merino, V. (1997). Basic styles of aggressive implications personality in the Millon Clinical Multiaxial Inventory-II and their reference with the Minnesota Multiphasic Personality Inventory-2. 4th. European Conference on Psychological Assessment, Lisbon, Portugal, 7-10, September.

Jackson, D. (1971). The dynamics of structured personality tests: 1971. Psychological Review, 78, 229248.

Johnson, J. H.; Klingler, D. E.; Williams, T. A. (1977). An external criterion study of the MMPI validity indices. Journal of Clinical Psychology; Jan Vol 33(1) 154-156.

Kahn, M.; Fox, H. \& Rhode, R. (1988). Detecting faking on the Rorschach: Computer vs. Expert clinical judgement. Journal of Personality Assessment, 52, 516-523.

Karp, J. (1999). Prediction of MMPI-2 clinical scores from the Draw-A-Person Questionnaire. In Karp, Stephen A. (Ed); et al.. Studies of objective/projective personality tests. (pp. 52-59). Brooklandville, MD, USA: Objective/Projective Tests, Inc.

Keiller, S.W.; Graham, J. R. (1993). The meaning of low scores on MMPI-2 clinical scales of normal subjects. Journal of Personality Assessment; Oct Vol 61(2) 211-223.

Kelch, L. W.; Wagner, E. E. (1992). Maximized split-half reliabilities and distributional characteristics for Harris-Lingoes subscales with few items: A reevaluation for the MMPI-2. Perceptual and Motor Skills; Dec Vol 75(3, Pt 1) 847-850.

Kelley, C. K.; King, Glen-D. (1978). Behavioral correlates for within-normal-limit MMPI profiles with and without elevated $\mathrm{K}$ in students at a university mental health center. Journal of Clinical Psychology; Jul Vol 34(3) 695-699.

Khan, F. I.; Welch, T. L.; Zillmer, E. A. . (1993). MMPI-2 profiles of battered women in transition. Journal of Personality Assessment; Feb Vol 60(1) 100-111.

Kirton, M. J. (1991-1992) Faking personality questionnaires: A response to Furnham. Current Psychology: Research and Reviews. Win; Vol 10(4): 315-317.

Klein, S.; Cross, H. J. (1984). Correlates of the MMPI L b Scale in a college population. Journal of Clinical Psychology; Jan Vol 40(1) 185-189.

Kohutek, K. J. (1992a). The location of items on the Wiggins Content Scales on the MMPI-2. Journal of Clinical Psychology; Sep Vol 48(5) 617-620.

Kohutek, K. J. (1992b). Wiggins Content Scales and the MMPI-2. Journal of Clinical Psychology; Mar Vol 48(2) 215-218.

Kokkevi, A. (1996). The Greek MMPI-2: A progress note. In J.N. Butcher, International adaptations of the MMPI-2. University Of Minnesota Press. (pp. 416-441).

Konráos, S. (1996). The Icelandic Translation of the MMPI-2: Adaptation and Validation. In J.N. Butcher, International adaptations of the MMPI-2. University Of Minnesota Press. (pp. 368384).

Koscheyev, V.S. \& Leon, G. R. (1996). The Rusian Translation and Preliminary Adaptation of the MMPI-2. In J.N. Butcher, International adaptations of the MMPI-2. University Of Minnesota Press. (pp. 385-394).

Koss, M.P. \& Butcher, J.N. (1973). A comparison of psychiatric patients' self-report with other sources of clinical information. Journal of Research in Personality, 7, 225-236.

Koss, M.P. (1979). MMPI item content: Recurring issues. In J.N. Butcher (Ed.), New developments in the use of the MMPI (pp.3-38). Minneapolis University Press.

Koss, M.P. (1980). Assessing psychological emergencies with the MMPI. In J.N. Butcher, Dahlstrom, M. Gynther, \& W. Schofield (Eds.), (Clinical notes on the MMPI, $\left.n^{\circ} .4\right)$. Minnepolis, MN: National Computer System.

Koss, M.P., Butcher, J.N., \& Hoffman, N. (1976). The MMPI critical items: How welll do they work?. Journal of Consulting and Clinical Psychology, 44, 921-928. 
Krahe, Barbara (1989) Faking personality profiles on a standard personality inventory. Personality and Individual Differences.; Vol 10(4): 437-443.

Kurlychek, Robert-T.; Jordan, L. (1980). MMPI profiles and code types of responsible and nonresponsible criminal defendants. Journal of Clinical Psychology; Apr Vol 36(2) 590-593.

Kurman, R.G.; Hursey, K.G.; Mathew, N.T.(1992). Assessment of chronic refractory headache: The role of the MMPI-2. Headache; Oct Vol 32(9) 432-435.

Kwan, Kwong Liem Karl(1999). MMPI and MMPI-2 performance of the Chinese: Cross-cultural applicability. Professional Psychology: Research and Practice. 30(3): 260-268.

Lachar, D. \& Wrobel, T.A. (1979). Validation of clinicians' hunches: construction of a new MMPI critical items set. Journal of Consulting and Clinical Psychology, 47, 277-284.

Lachar, D. (1974). The MMPI: Clinical assessment and automated interpretation. Los Angeles: Western Psychological Services.

Ladd, J. (1998). The F(p) Infrequency-Psychopathology Scale with chemically dependent inpatients. Journal of Clinical Psychology. Aug; Vol 54(5): 665-671.

Lamb, D.; Berry, D.; Wetter, M. \& Baer, R. (1994). Effects of two tipes of information on malingering of closed-head injury on the MMPI-2: Am analog investigation. Psychological Assessment, 6, 8-13.

Langevin, R; Wright, P. \& Handy, L. (1990). Use of the MMPI and its derived scales with sex offenders: I. Reliability and validity studies. Annals of Sex Research; Vol 3(3) 245-291.

Lanyon, R. (1968). A handbook of MMPI group profiles. Minneapolis: University of Minnesota Press.

Lanyon, R. (1970). Development and validation of a Psychological Screening Inventory. Journal of Consulting and Clinical Psychology, 35, 15-25.

Lanyon, R. (1974). Technology of personality assessment: the Psychological Screening Inventory. In A.B. Maher (De.), Progres in experimental personality research. New York: Academic Press, vol. 7, pg.1-48).

Lanyon, R. (1978). Psychological Screening Inventory: Manual (2a. Ed.). Port. Huron, MI: Research Psychologist Press.

Lara-Cantu, M. (1990). Validez y confiabilidad de la Escala de Deseabilidad Social de Marlowe y Crowne en una poblacion de adultos. Salud Mental. Dec; Vol 13(4): 35-38.

Lara-Cantu, M.; Suzan-Reed, M. (1988). La Escala de Deseabilidad Social de Marlowe y Crowne: Un estudio psicometrico. Salud Mental. Sep; Vol 11(3): 25-29.

Larrabee, G. J.(1998). Somatic malingering on the MMPI and MMPI-2 in personal injury litigants. Clinical Neuropsychologist. 12(2): 179-188.

Larson, J. (1932). Lying and its detection. Chicago: University of Chicago Press.

Leckart, B. (1994) A revised dissimulation scale applicable to the MMPI-2. American Journal of Forensic Psychology.; Vol 12(3): 5-15.

Lees-Haley, P.R. (1991a). MMPI-2 F and F-K scores of personal injury malingerers in vocational neuropsychological and emotional distress claims. Americam Journal of Forensic Psychology, $9(3), 5-14$.

Lees-Haley, P. R. (1991b). Ego strength denial on the MMPI-2 as a clue to simulation of personal injury in vocational neuropsychological and emotional distress evaluations. Perceptual and Motor Skills; Jun Vol 72(3, Pt 1) 815-819.

Lees-Haley, P. R. (1992a). Efficacy of MMPI-2 validity scales and MCMI-II modifier scales for detecting spurious PTSD claims: F, F-K, Fake Bad scale, Ego Strength, Subtle-Obvious subscales, DIS, and DEB. Journal of Clinical Psychology; Sep Vol 48(5) 681-689.

Lees-Haley, P. R. (1992b). Psychodiagnostic test usage by forensic psychologists. American Journal of Forensic Psychology; Vol 10(1) 25-30.

Lees-Haley, P. R. (1997). MMPI-2 base rates for 492 personal injury plaintiffs: Implications and challenges for forensic assessment. Journal of Clinical Psychology. Nov; Vol 53(7): 745-755

Lees-Haley, P. R.; English, L. T.; Glenn, W. J. (1991). A Fake Bad Scale on the MMPI-2 for personal injury claimants. Psychological Reports; Feb Vol 68(1) 203-210. 
Lees-Haley, P. R. (1989). MMPI F and F-K scales: Questionable indices of malingering. American Journal of Forensic Psychology; Vol 7(1) 81-84.

Lees-Haley. P. R. \& Fox, D. D. (1990). MMPI subtle-Obvius scales and malingering: Clinical versus simulated scores. Psychological Reports, 66, 907-911.

Leon, I.; Lucio G M, E.(1999). Consistencia y estructura interna de las escalas de abuso de sustancias del MMPI-2. / Consistency and internal structure of the substance abuse scales of the MMPI-2. Salud Mental. 22(3): 14-19.

Levitt, E. E.; Browning, J. M.; Freeland, L. J. (1992). The effect of MMPI-2 on the scoring of special scales derived from MMPI-1. Annual Meeting of the Society for Personality Assessment (1991, New Orleans, Louisiana). Journal of Personality Assessment; Aug Vol 59(1) 22-31.

Lezak, M. (1983). Neuropsichological assessment. (2 ${ }^{\mathrm{a}}$.ed.). New York: Oxford University Press.

Lim, J. \& Butcher, J.N. (1996). Detection of faking on the MMPI-2: differentiation amomg faking-bad, denial, and claiming extreme vitue. Journal of Personality Assessment, 67, 1-25.

Lilienfeld, S. O.(1999). The relation of the MMPI-2 Pd Harris-Lingoes subscales to psychopathy, psychopathy facets, and antisocial behavior: Implications for clinical practice. Journal of Clinical Psychology. 55(2): 241-255.

Liljequist, L.; Kinder, B. N.; Schinka, J. A. (1998) An investigation of malingering posttraumatic stress disorder on the Personality Assessment Inventory. Journal of Personality Assessment. Dec; Vol 71(3): 322-336.

Lovitt, R.. (1993). A strategy for integrating a normal MMPI-2 and dysfunctional Rorschach in a severely compromised patient. Annual Meeting of the Society for Personality Assessment Symposium: Combining the Rorschach and the MMPI in clinical practice (1992, Washington, DC). Journal of Personality Assessment; Feb Vol 60(1) 141-147.

Lucio G, E. \& Reyes-Lagunes, I. (1996). The mexican Version of the MMPI-2 in Mexico and Nicaragua: translation, Adaptation amd demonstrated Equivalency. In J.N. Butcher, International adaptations of the MMPI-2. University Of Minnesota Press. (pp. 284-304).

Lucio G. M., E.; Palacios, H.; Duran, C.; Butcher, J. N. (1999). MMPI-2 with Mexican psychiatric inpatients: Basic and content scales. Journal of Clinical Psychology. 55(12): 1541-1552.

Lucio, E.; Reyes-Lagunes, I. Y Scott, R.L. (1994). MMPI-2 for Mexico: translation and adaptation. Journal of Personality Assessment; Aug vol. 63(1) 105-116.

Luty, D.; Thackrey, M. (1993). Graphomotor interpretation of the MMPI-2?. Journal of Personality Assessment; Jun Vol 60(3) 604.

Lyons, J. A.; Wheeler Cox, Trilby(1999). MMPI, MMPI-2 and PTSD: Overview of scores, scales and profiles. Journal of Traumatic Stress. 12(1): 175-183.

Maloney, M.P.; Duvall, S.W.; Friesen, J. (1980). Evaluation of response consistency on the MMPI. Psychological Reports; Feb Vol 46(1) 295-298.

Marco Ribé, J.; Martí Tusquets J.1. y Pons Bartran, R. (1990). Psiquiatría forense. Salvat. Barcelona.

Marks, P.A.; Seeman, W. \& Haller, D.L. (1974). The actuarial use of the MMPI with adolescents and adults. Baltimore, MD: Williams \& Wilkins.

McAllister, L.W. (1986). A practical guide to CPI interpretation. Palo Alto, C.A: Consulting Psychologists Press.

McAnulty, D. P.; Rappaport, N. B.; McAnulty, R. D. (1985). An a posteriori investigation of standard MMPI validity scales. Psychological Reports; Aug Vol 57(1) 95-98.

McCrae, R. R.; Costa, P. T.; Dahlstrom, W.G.; Barefoot, J. C.; et al (1989). A ction on the use of the MMPI K-correction in research on psychosomatic medicine. Psychosomatic Medicine; Jan-Feb Vol 51(1) 58-65.

McGrath, R. E.; Powis, D.; Pogge, D. L.(1998a). Code type-specific tables for interpretation of MMPI-2 Harris and Lingoes Subscales: Consideration of gender and code type definition. Journal of Clinical Psychology. 54(5): 655-664.

McGrath, R. E.; Sapareto, E.; Pogge, D. L.(1998b). A new perspective on gender orientation measurement with the MMPI-2: Development of the Masculine-Feminine Pathology Scale. Journal of Personality Assessment. 70(3): 551-563. 
McGrath, R. E.; Sweeney, M.; O'Malley, W. B.; Carlton, T. K. (1998c). Identifying psychological contributions to chronic pain complaints with the MMPI-2: The role of the K scale. Journal of Personality Assessment. 70(3): 448-459.

Mckinley, J.C. y Hathaway, S.R. (1940). A multiphasic personality schedule (Minnesota). II. A diferential study of hipocondriasis. Journal of Psychology, 10, 255-268.

Mckinley, J.C. y Hathaway, S.R. (1942). A multiphasic personality schedule (Minnesota). IV. Psychasthenia. Journal of Applied Psychology, 26, 614-624.

Mckinley, J.C. y Hathaway, S.R. (1944). A multiphasic personality schedule (Minnesota). V. Hysteria, Hypomania, and Psychopathic deviate. Journal of Applied Psychology, 28, 154-174.

Mckinley, J.C. y Hathaway, S.R. (1948). A multiphasic personality schedule (Minnesota). VI. The K scale. Journal of Consulting Psychology, 12, 20-31.

McKinley, J.C.; Hathaway, S.R. \& Meehl, P.E. (1948). The MMPI: VI. The K scale. Journal of Cinsulting Psychology, 12, 20-31.

McNulty, J. L.; Ben-Porath, Y. S.; Graham, J. R.(1998). An empirical examination of the correlates of well defined and not defined MMPI-2 code types. Journal of Personality Assessment. 71(3): 393-410.

Medoff, David (1999). MMPI-2 validity scales in child custody evaluations: Clinical versus statistical significance. Behavioral Sciences and the Law. 17(4): 409-411.

Meehl, P.E. (1946). Profile analysis of the MMPI in differential diagnosis. Journal of applied Psychology, 30, 517-524.

Meehl, P.E., \& Hathaway, S.R. (1946). The K factor as a suppresor variable i the MMPI. Journal of Applied Psychology, 30, 525-564.

Megargee, E. I.; Mercer, Sara Jill; Carbonell, Joyce L.(1999). MMPI-2 with male and female state and federal prison inmates. Psychological Assessment.; 11(2): 177-185.

Megargeee, E. I. (1972). The Psychological Inventory handbook. San Francisco: Josey-Bass.

Mersman, J. L.; Shultz, K.S.(1998) Individual differences in the ability to fake on personality measures. Personality and Individual Differences. Feb; Vol 24(2): 217-227.

Merydith, S. P.; Wallbrown, F. H.(1996) Correcting for motivational distortion on selected adolescent self-report personality tests. Journal of Psychoeducational Assessment. Dec; Vol 14(4): 349-361.

Meyer, G. J. (1993). The impact of response frequency on the Rorschach constellation indices and on their validity with diagnostic and MMPI-2 criteria. Journal of Personality Assessment; Feb Vol 60(1) 153-180.

Meyer, R. C. (1983). The clinican's handbook: the psychopathology of adulthood and late adolescence. Boston: Allyn y Bacon.

Milner, B. (1970). Memory and the medial temporal regions of the brain. In K.H. Pribam \& D.E. Broadbent (Eds.), Biology of memory (pgs. 29-50). New York: Academic Press.

Millon, Th. (1992). Millon Clinical Multiaxial Inventory: I and II. Journal of Counselling and Developement, 70(3), 421-426.

Mischel, W. (1968). Personality and Assessment. New York: Willey (Traducción castellana: Personalidad y evaluación. México, Trillas, 1973).

Mo, W.; Song, W. (1991). A brief instruction to MMPI-2. Psychological Science China; Jan-Feb No 1 59-60.

Monier, C. et al. (1996). The MMPI-2 in France. In J.N. Butcher, International adaptations of the MMPI2. University Of Minnesota Press. (pp. 395-415).

Montoya, O. A. y cols. (1977). La tríada neurótica del MMPI en un grupo de estudiantes universitarios. Revista de Psicología General y Aplicada, 149, 1077-1083.

Morel, K. R. (1998). Development and preliminary validation of a forced-choice test of a response bias for posttraumatic stress disorder. Journal of Personality Assessment. Apr; Vol 70(2): 299-314.

Morey, L. C. (1993). Defensiveness and malingering indices for the PAI. Paper presented at the 101st annual meeting of the American Psychological Association. Toronto. 
Morey, L. C (1999). Personality Assessment Inventory. In Maruish, Mark E. (Ed); et al. The use of psychological testing for treatment planning and outcomes assessment (2nd ed.). (pp. 10831121). Mahwah, NJ, USA: Lawrence Erlbaum Associates, Inc., Publishers. Xvi, 1507.

Morey, L. C.; Glutting, J.H.(1994) The Personality Assessment Inventory and the measurement of normal and abnormal personality constructs. In Strack, Stephen (Ed); Lorr, Maurice (Ed); et al. Differentiating normal and abnormal personality. (pp. 402-420). New York, NY, USA: Springer Publishing Co, Inc. Xviii, 444 pp.

Morey, L. C.; Henry, W. (1994). Personality Assessment Inventory. In Maruish, Mark Edward (Ed); et al. The use of psychological testing for treatment planning and outcome assessment. (pp. 185-216). Hillsdale, NJ, USA: Lawrence Erlbaum Associates, Inc. Xv, 637 pp.

Mori, DeAnna L.; Klein, Wayne; Gallagher, Patricia(1999). Validity of the MMPI-2 and Beck Depression Inventory for making decisions of organ allocation in renal transplantation. Psychological Reports. 84(1): 114-116.

Moskowitz, Jonina L.; Lewis, Robin J.; Ito, Michael S.; Ehrmentraut, John (1999). MMPI-2 profiles of NGRI and civil patients. Journal of Clinical Psychology. 55(5): 659-668.

Mrad, D. F.; Kabacoff, Robert-I.; Duckro, Paul (1983). Validation of the Megargee typology in a halfway house setting. Criminal Justice and Behavior; Sep Vol 10(3) 252-262.

Muir, D. E. (1992). FRAME: A computer program for simulating personality, cultural, and other consonance-seeking informational systems. Social Science Computer Review. Fal; Vol 10(3): 361-367.

Munley, P. H. (1991a). A comparison of MMPI-2 and MMPI T-scores for men and women. Journal of Clinical Psychology; 1991 Jan Vol 47(1) 87-91.

Munley, P. H. (1991b). Confidence intervals for the MMPI-2. Journal of Personality Assessment; Aug Vol 57(1) 52-60.

Navarro A., R.; Casanueva R., A. (1982). Características de personalidad y sintomatología en grupos de alcohólicos hospitalizados, segun el Inventario Multifásico de la Personalidad (MMPI). (Characteristics of personality and symptomatology of hospitalized alcoholic groups according to the MMPI.) Enseñanza e Investigación en Psicología; Jul-Dec Vol 8(2) 236-246.

NCS Assessments (National Computer System) (February, 2001). MMPI-2, Minnesota Multiphasic Personality Inventory-2. http:// assessments.ncspearson.com.

Netter, B. \& Viglione, D. (199). An empirical study of malingering schizofhrenia on the Rorschach. Journal of Personality Assessment, vol. 62(1), 45-57.

Newmark, Ch. S.; Gentry, L.; Simpson, M.; Jones, T. (1978). MMPI criteria for diagnosing schizophrenia. Journal of Personality Assessment; Aug Vol 42(4) 366-373.

Nezami, E. \& Zamani, R. (1996). The Persian MMPI-2. In J.N. Butcher, International adaptations of the MMPI-2. University Of Minnesota Press. (pp. 506-522).

Nguyen Tran, Bao-Chi (1996). Vietnamese Translation and Adaptation of the MMPI-2. In J.N. Butcher, International adaptations of the MMPI-2. University Of Minnesota Press. (pp. 175-193).

Nichols, D. S.; Greene, R. L.(1997) Dimensions of deception in personality assessment: The example of the MMPI-2. Journal of Personality Assessment. Apr; Vol 68(2): 251-266.

Nichols, D. S.; Greene, R. L.; Schmolck, P. (1989). Criteria for assessing inconsistent patterns of item endorsement on the MMPI: Rationale, development, and empirical trials. Journal of Clinical Psychology. Mar; Vol 45(2): 239-250.

Nichols, D.S. \& Greene, R.L. (1991). New measures for dissimulation on the MMPI/MMPI-2. Paper presented at the 26th Annual Symposium on Recent Development in the Use of the MMPI (MMPI-2/MMPI-A). St. Petesburg Beach, Fl.

Núñez, R. (1979). Aplicación del Inventario Multifásico de la personalidad (MMPI) a la psicopatología. El Manual Moderno. México.

O’Grady, K.E. (1988). The Marlowe-Crowne and Edwards Social Desirability scales: A psychometric perspective. Multivariate Behavioral Research. Jan; Vol 23(1): 87-101.

Ones, D. S.; Viswesvaran, Ch. (1998) The effects of social desirability and faking on personality and integrity assessment for personnel selection. Human Performance.; Vol 11(2-3): 245-269. 
Osberg, T. M.(1999). Comparative validity of the MMPI-2 Wiener-Harmon subtle-obvious scales in male prison inmates. Journal of Personality Assessment. 72(1): 36-48.

Osborne, D.; Colligan, R.; Offord, K. (1986). Normative tables for the F-K index of the MMPI based on a contemporary normal sample. Journal of Clinical Psychology; Jul Vol 42(4) 593-595.

Otto, R. K.; Lang, A. R.; Megargee, E. I.; Rosenblatt, Arthur-I. (1988). Ability of alcoholics to escape detection by the MMPI. Journal of Consulting and Clinical Psychology. Jun; Vol 56(3): 452457.

Pancheri, P. et al. (1996). Adaptation of the MMPI-2 in Italy. In J.N. Butcher, International adaptations of the MMPI-2. University Of Minnesota Press. (pp. 416-441).

Paolo, A.; \& Ryan, J.(1992). Detection of random response sets on the MMPI-2. Psychotherapy in Private Practice; Vol 11(4) 1-8.

Paolo, A.; Ryan, J. \& Smith, A. (1991). Reading difficulty of MMPI-2 subscales. Journal of Clinical Psychology; Jul Vol 47(4) 529-532.

Pasquini, M.; Biondi, M.; Picardi, A.; Gaetano, P.; Pancheri, P. (1999). MMPI-2 e dimensioni psicopatologiche dei disturbi depressivi: Uno studio di analisi fattoriale in una popolazione ambulatoriale. / Psychopathological dimensions of depression: Scale-level factor analysis of the MMPI-2 in an outpatient sample. Rivista di Psichiatria. 34(4): 200-207.

Patrick, J. (1984). The effect of sex differences and nondefensiveness on the predictive validity of Barron's Es scale. Journal of Clinical Psychology; Jan Vol 40(1) 202-204.

Peebles, J.; Moore, R. J. (1998). Detecting socially desirable responding with the Personality Assessment Inventory: The Positive Impression Management Scale and the Defensiveness Index. Journal of Clinical Psychology. Aug; Vol 54(5): 621-628.

Pinsoneault, T. B. (1996). Rationally developed fake-good and fake-bad scales for the Jesness Inventory. Journal of Psychopathology and Behavioral Assessment. Sep; Vol 18(3): 255-273

Pogge, D. L.; Stokes, John-M.; Frank, Jillian; Wong, Hazel; et al (1997). Association of MMPI validity scales and therapist ratings of psychopathology in adolescent psychiatric inpatients. Assessment. Mar; Vol 4(1): 17-27.

Pongpanich, La-Or (1996). Use of the MMPI-2 in Thailand. In J.N. Butcher, International adaptations of the MMPI-2. University Of Minnesota Press. (pp. 162-174).

Pope, K. S.; Butcher, J. N.; Seelen, J. (2000). The MMPI, MMPI-2 \& MMPI-A in court: A practical guide for expert witnesses and attorneys (2nd ed.). Washington, DC, USA: American Psychological Association.

Poreh, A.; Whitman, D. (1993). MMPI-2 schizophrenia spectrum profiles among schizotypal college students and college students who seek psychological treatment. Psychological Reports; Dec Vol 73(3, Pt 1) 987-994.

Post, R. D.; Gasparikova-Krasnec, M. (1979). MMPI validity scales and behavioral disturbance in psychiatric inpatients. Journal of Personality Assessment; April Vol 43(2) 155-159.

Putnam, S. \& Millis, S. (1994). Psychological factors in the development and maintenance of chronic somatic and functional symptoms following mild traumatic brain injury. Advances in Medical Psychotherapy, 7, 1-22.

Putzke, J. D.; Williams, M. A.; Boll, T. J. (1998). A defensive response set and the relation between cognitive and emotional functioning: A replication. Perceptual and Motor Skills. Feb; Vol 86(1): 251-257.

Putzke, J. D.; Williams, M. A.; Millsaps, Ch. L.; McCarty, H. J.; Azrin, R. L.; LaMarche, J. A.; Boll, T. J.; Bourge, R. C.; Kirklin, J. K.; McGiffin, D. C. (1997). The impact of a defensive response set on the relationship between MMPI and cognitive tests among heart transplant candidates. Assessment. Dec; Vol 4(4): 365-375.

Quereshi, M. Y.; Kleman, R. (1996). Validation of selected MMPI-2 Basic and Content Scales. Current Psychology: Developmental, Learning, Personality, Social. Fal; Vol 15(3): 249-257.

Ramanaiah, N.; Schill, T.; \& Lock-Sing-L. (1977). A test of the hypothesis about the two-dimensional nature of the Marlowe-Crowne Social Desirability Scale. Journal of Research in Personality; Jun Vol 11(2) 251-259. 
Ribé, J.M.; Martí Tusquets, J.L. y Pons Bartran, R. (1990). Psiquiatría forense. Salvat. Barcelona.

Riley, J. L.; Robinson, M E.(1998). Validity of MMPI-2 profiles in chronic back pain patients: Differences in path models of coping and somatization. Clinical Journal of Pain. 14(4): 324335.

Rissetti, F. J. y cols. (1996). Use of the MMPI-2 in Chile: Translation and Adaptation. In J.N. Butcher, International adaptations of the MMPI-2. University Of Minnesota Press. (pp. 221-251).

Ritzler, B.; Singer, M. (1998). MMPI-2 by proxy and the Rorschach: A demonstration assessment of the commandment of Auschwitz. Journal of Personality Assessment. 71(2): 212-227.

Robinette, R. (1991). The relationship between the Marlowe-Crowne Form C and the validity scales of the MMPI. Journal of Clinical Psychology. May; Vol 47(3): 396-399.

Greene, (1997). Assessment of malingering and Defensiveness by Multiscale Personality Inventories, in R. Rogers, Clinical Assessment of Malingering and Deception (2 ${ }^{\mathrm{a}}$.ed.). The Guilford Press, pgs.169-207.

Rogers, R. \& Kelly, K (1997). Denial and Misrporting of substance abuse. In R. Rogers (Ed.). Clinical Assessment of malingering and deception (2a . Ed., pgs. 108-129). Guilford Press. New York.

Rogers, R. (1984). Toward an empirical model of malingering and deception. Behavioral Sciences and the Law, 2, 93-112.

Rogers, R. (1990b) Models of feigned mental illness. Professional Psychology, 21, 182-188.

Rogers, R. (1990ª). Development of a new classificatory model of malingering. Bulletin of the American Academy of Psychiatry and the Law. Vol. 18(3), 323-333.

Rogers, R.; Bagby, R. \& Chakraborty, D. (1993). Feigning schisophrenic disorders on the MMPI-2. Detection of coached simulator. Journal of Personality Assessment, 60, 215-226.

Rogers, R.; Dion, K.; \& Lynett, E. (1992). Diagnostic validity of antisocial personality disorder. Law and human Behavior, 16, 677-689.

Rogers, R.; Dolmesch, R. Cavanaugh, J.L. (1983). "Identification of random responders on MMPI protocols" Journal of Personality Assessment, 47(4), 364-368.

Rogers, R.; Gillis, J.; Dickens, S. \& Bagby, R. (1991). Standarridzed assessment of malingering: validation of the Structure Interviews of Report Symptoms. Psychological Assessment: A journal of Consulting and clinical Psychology, 3, 89-96.

Rogers, R.; Hinds, J. \& Sewell, K. (1995). Feigning psychopathology among adolescent offenders: validation of the SIRS, MMPI-A and SIMS. Paper presented at the 103rd meeting of the American Psychological Association. New York.

Rogers, R.; Nussbaum, D. (1991). Interpreting response styles of inconsistent Minnesota Multiphasic Personality Inventory profiles. Forensic Reports. Oct-Dec; Vol 4(4): 361-366.

Rogers, R.; Sewell, K., \& Salekin, R. (1994). A meta-analysis of malingering on the MMPI-2. Assessment, I, 227-239.

Rogers, R.; Sewell, K.; Morey, L.\& Ustad, K. (1996) Detection of feigned mental disorders on the Personality Assessment Inventory: A discriminant analysis. Journal of Personality Assessment. Dec; Vol 67(3): 629-640.

Roman, D.; Tuley, M.; Villanueva, M. \& Mitchell, W. (1990). Evaluating MMPI validity in a forensic psychiatric population: distinguishing between malingering and genuine psychopathology. Criminal Justice and behaviour, 17 (2), 186-198.

Roper, B.; Ben-Porath, Y.; Butcher, J. N. (1991). Comparability of computerized adaptive and conventional testing with the MMPI-2. Journal of Personality Assessment; Oct Vol 57(2) 278290.

Rose, F. E.; Hall, S \& Szalda-Petree, D. (1995). Portland Digit Recognition Test computerized: measuring response latency improves the detection of malingering. Clinical Neuropsychologist, Vol.9(2), 124-134.

Rothke, S. E.; Friedman, A. F.; Dahlstrom, W G.; Greene, R. L.; et al (1994). MMPI-2 normative data for the F - K index: Implications for clinical, neuropsychological, and forensic practice. Assessment; Mar Vol 1(1) 1-15. 
Rouse, S. V.; Butcher, J. N.; Miller, K. B.(1999). Assessment of substance abuse in psychotherapy clients: The effectiveness of the MMPI-2 substance abuse scales. Psychological Assessment. 11(1): 101-107.

Rouse, S. V.; Finger, M. S.; Butcher, J. N.(1999). Advances in clinical personality measurement: An item response theory analysis of the MMPI-2 PSY-5 scales. Journal of Personality Assessment. 72(2): 282-307.

Ruch, F.L. (1942). A technique for detecting attempts to fake performance on the self-inventory type of personality tests. In Q. McNemar \& M.A. Merrill (Eds.), Studies in personality (pp. 229-234). New York: McGraw-Hill.

Russell, M.T. \& Karol, D.L. (1994) 16PF Fifth Edition, Administrator's Manual. IPAT. Institute for Personality and Ability Testing Champaing Illinois. (Adaptación española realizada por Nicolás Seisdedos Cubero, 1995).

Samuel, S.E.; DeGirolamo, J.; Michals, T.J.; O’Brien, J. (1994) Preliminary findings on MMPI "Cannot Say" responses with personal injury litigants. American Journal of Forensic Psychology; Vol 12(4) 5-18.

Sánchez, J. A. y otros (1970). Intercorrelaciones entre preferencias vocacionales y Tétrada psicótica del MMPI en universitarios españoles. Revista de Psicología General y Aplicada, 105-106, 979-986.

Sánchez, G.; Jiménez, F.; Avila, A. y Merino, V. (1999). Psicopatología y fiabilidad: un análisis comparativo de las escalas de validez entre el MCMI-II y el MMPI-2. Revista Iberoamericana de Diagnóstico y Evaluación Psicológica, $\mathrm{n}^{\circ}$. 1, 115-125.

Savasir, I. \& Çulha, M. (1996). Development of the MMPI-2 in Turkey. In J.N. Butcher, International adaptations of the MMPI-2. University Of Minnesota Press. (pp. 448-462).

Scafidi, F. A.; Field, T. ; Prodromidis, M. ; Abrams, S. M.(1999). Association of fake-good MMPI-2 profiles with low Beck Depression Inventory scores. Adolescence. Spr; 34(133): 61-68.

Schenkenberg, T. ; Gottfredson, D. K.; Christensen, P. (1984). Age differences in MMPI scale scores from 1,189 psychiatric patients. Journal of Clinical Psychology; Nov Vol 40(6) 1420-1426.

Schinka, J. A.; LaLone, L.; Greene, R. L.(1998). Effects of psychopathology and demographic characteristics on MMPI-2 scale scores. Journal of Personality Assessment. 70(2): 197-211.

Schofield, W. (1966). Clinical and counseling psychology: some perspectives. American Psychologist, $21,122-131$

Schretlen, D. \& Arkowitz, H. (1990). A psychological test battery to detect prison inmates who fake insanity or mental retardation. Behavioral Sciences and the Law, 75-84.

Schretlen, D. (1986). Malingering: use of a Psychological test battery to detect two kinds of mental disorder. Clinical Psychology Review,9, 320-372.

Schretlen, D. (1988). The use of psychological test to identify malingered symptoms of mental disorder. Clinical Psychology Review, 8, 451-476.

Schretlen, D. (1990). A limitation of using the Wiener and Harmon obvious and subtle scales to detect faking on the MMPI. Journal of Clinical Psychology, 46, 782-786.

Schretlen, D. Stacy Schantz, W; Wilfred, G. \& Hoida, J. (1992) Crossvalidation of a Psychological test Battery to detect faked insanity. Psychological Assessment, Vol.,4(1), 77-83.

Seisdedos, N. (1970). Adaptación del cuestionario de Personalidad MMPI: estudio de la forma R (399 elementos) en la selección profesional. Revista de Psicología General y Aplicada, 105-106, 825828 .

Seisdedos, N. (1985). 16PF, monografía técnica. TEA Ediciones, Madrid.

Seisdedos, N. (1995). Adaptación española del Manual del 16 PF-5. TEA Ediciones, Madrid.

Seisdedos, N. y Roig Fusté, J.M. (1986). MMPI. Suplemento técnico e interpretación clínica. Madrid TEA ediciones.

Sepaher, I.; Bongar, B.; Greene, R. L.(1999). Codetype base rates for the "I Mean Business" suicide items on the MMPI-2. Journal of Clinical Psychology. 55(9): 1167-1173.

Sewell K.W. \& Rogers, R. (1994). Response consistency and the MMPI-2: Development of a simplified screening scale. Assessment, 1, 293-299. 
Shaffer, T. W.; Erdberg, P.; Haroian, J. (1999). Current nonpatient data for the Rorschach, WAIS-R, and MMPI-2. Journal of Personality Assessment. 73(2): 305-316.

Shapiro, D. L. (1993). Detection of malingering and deception. In VandeCreek, Leon (Ed); Knapp, Samuel (Ed); et al. (1993). Innovations in clinical practice: A source book, Vol. 12. (pp. 5-13). Sarasota, FL, USA: Professional Resource Press/Professional Resource Exchange.

Shiota, N.K.; Krauss, S.S. \& Clark, L.A. (1996). Adaptation and validation of the Japanese MMPI-2. In J.N. Butcher, International adaptations of the MMPI-2. University Of Minnesota Press. (pp.6788).

Shores, E. A.; Carstairs, J. R.(1998). Accuracy of the MMPI-2 computerized Minnesota Report in identifying fake-good and fake-bad response sets. Clinical Neuropsychologist. 12(1): 101-106.

Siegel, J. C.; Langford, J. S.(1998). MMPI-2 validity scales and suspected parental alienation syndrome. American Journal of Forensic Psychology; 16(4): 5-14.

Silverton, L. \& Gruber, C.P. (1998). The malingering probability Scale (MPS) manual. Los Angeles: Western Psychological Services.

Sines, L. K.; Baucom, D. H.; Gruba, G. H. (1979). A validity scale sign calling for caution in the interpretation of MMPIs among psychiatric inpatients. Journal of Personality Assessment; Dec Vol 43(6) 604-607.

Sinnett, E. R. ; Holen, M. C.; Albott, W. L.(1999). Profile validity standards for MMPI and MMPI-2 F scales. Psychological Reports. 84(1): 288-290.

Sipka, P. (1998) Personality correlates of faking personality tests: A cross-cultural perspective. In Saklofske, Donald H. (Ed); Eysenck, Sybil Bianca Giuletta (Ed); et al. (1988, reprinted 1998). Individual differences in children and adolescents. (pp. 321-338). New Brunswick, NJ, USA.

Sivec, H.J., Lyns, S.J. \& Garske, J.P. (1994). The effect of somatoform disorder and paranoid psychotic disorder role-related dissimulation as a response set on the MMPI-2. Assessment, 1, 69-81.

Sivec, H.; Hilsenroth, M. \& Lynn, S. (1995) Impact of simulating borderline personality disorder on the MMPI-2: A costsbenefits model employing base rates. Journal of Personality Assessment. Apr; Vol 64(2): 295-311.

Slick, D. J.; Hopp, G.; Strauss, E.; Spellacy, F. J. (1996). Victoria Symptom Validity Test: Efficiency for detecting feigned memory impairment and relationship to neuropsychological tests and MMPI-2 validity scales. Journal of Clinical and Experimental Neuropsychology. Dec; Vol 18(6): 911922.

Sloore, H. et als. (1996). The flemidh/dutch Version of the MMPI-2: Development and Adaptation of the Inventory for Belgium and the Netherlands. In J.N. Butcher, International adaptations of the MMPI-2. University Of Minnesota Press. (pp. 329-349).

Smith, C. P.; Graham, J. R. (1981). Behavioral correlates for the MMPI standard F scale and for a modified F scale for Black and White psychiatric patients. Journal of Consulting and Clinical Psychology; Jun Vol 49(3) 455-459.

Smith, G.P. \& Burger, G.K. (1997). Detection of malingering: validation of the structured Inventory of Malingered Symtomatology (SIMS). Journal of the American Academic of Psychiatry and the Law. Vol.25(2), 183-189.

Smith, G.P. \& Burger, G.K. (1998). Detection of malingering: validation of the SIMS. Bulletin of the American Academy of Psycgiatry and Law.

Smith, G.P. (1992). Detection of malingering: A validation study of the SLAM Test. Unpublished doctoral dissertation. University of Misouri. St. Louis.

Smith, G.P. (1997). Assessment of malingering with sel-report instruments. In R. Rogers (Ed.). Clinical Assessment of Malingering and Decepction (2a. Ed.,). New York: Guilford Press, pgs. 351-370.

Smith, S. R.; Hilsenroth, M. J.; Castlebury, F. D.; Durham, T. W. (1999). The clinical utility of the MMPI-2 Antisocial Practices Content Scale. Journal of Personality Disorders; 13(4): 385-393.

Soliman, A.M. (1996). Development of an Arabic Translation of the MMPI-2. In J.N. Butcher, International adaptations of the MMPI-2. University Of Minnesota Press. (pp. 463-486).

Solomon, R. (1983). Use of the MMPI with multiple personality patients. Psychological Reports; Dec Vol 53(3, Pt 1) 1004-1006. 
Sprock, J.; Bienek, J. (1998). Barron's Ego Strength Scale and Welsh's Anxiety and Repression Scales: A comparison of the MMPI and MMPI-2. Journal of Personality Assessment. 70(3): 506-513.

Stein, L. A. R.; Graham, J. R.; Ben-Porath, Y. S.; McNulty, J. L.(1999). Using the MMPI-2 to detect substance abuse in an outpatient mental health setting. Psychological Assessment. 11(1): 94-100.

Strack, S.; Guevara, L. F.(1999). Relating PACL measures of Millon's basic personality styles and MMPI-2 scales in patient and normal samples. Journal of Clinical Psychology. 55(7): 895-906.

Strassberg, D. S. (1992). "Interpretive dilemmas created by the Minnesota Multiphasic Personality Inventory 2 (MMPI-2)": Erratum. Journal of Psychopathology and Behavioral Assessment; Mar Vol 14(1) 93-95.

Strassberg, D. S.; Clutton, S.; Korboot, P. (1991). A descriptive and validity study of the Minnesota Multiphasic Personality Inventory-2 (MMPI-2) in an elderly Australian sample. Journal of Psychopathology and Behavioral Assessment; Dec Vol 13(4) 301-311.

Strong, D. R.; Greene, R. L.; Hoppe, C.; Johnston, T.; Olesen, N. (1999). Taxometric analysis of impression management and self-deception on the MMPI-2 in child-custody litigants. Journal of Personality Assessment. 73(1): 1-18.

Sue, S. et cols. (1996). Asian American and White College Students'Performance on the MMPI. In J.N. Butcher, International adaptations of the MMPI-2. University Of Minnesota Press. (pp. 206220).

Tellegen, A. (1982). Brief manual for the Differential Personality Questionnaire. Minneapolis: University Of Minnesota Press.

Tellegen, A. (1988a). The análisis of consistency in personality assessment. Journal of Personality, 56, 621-623.

Tellegen, A. (1988b) Derivation of unifor T scores for the restandardized MMPI. In R.D. Fowler (chair), Revision and restandardization of the MMPI: Rationale normative sample, new norms, and initial validation. Symposium conducted of the American Psychological Association. Atlanta, Georgia.

Tellegen, A.; Ben-Porath, Y. S. (1992). The new uniform T-scores for the MMPI-2: Rationale, derivation, and appraisal. Psychological Assessment, 4, 145-155.

Tellegen, A.; Ben-Porath, Y. S. (1993). Code-type comparability of the MMPI and MMPI-2: Analysis of recent findings and criticisms. Journal of Personality Assessment; Dec Vol 61(3) 489-500.

Terman, L.M., \& Miles, C.C. (1936). Sex and personality: studies in masculinity and feminity. New York: Russell and Russell.

Tetrick, L. E. (1989) An exploratory investigation of response latency in computerized administrations of the Marlowe-Crowne Social Desirability Scale. Personality and Individual Differences.; Vol 10(12): 1281-1287.

Thumin, F. J.; Barclay, A. G.(1993) Faking behavior and gender differences on a new personality research instrument. Consulting Psychology Journal: Practice and Research. Fal; Vol 45(4): 1122.

Timbrook, R.E.; Graham, J.R.; Keiller, S.W.; Watts, D. (1993). Comparison of the Wiener-Harmon Subtle-Obvious scales and the standard validity scales in detecting valid and invalid MMPI-2 profiles. Psychological Assessment; Mar Vol 5(1) 53-61.

Torre R., J. et al. (1970). Estudio diferencial de la tétrada psicótica del MMPI en universitarios españoles. Revista de Psicología General y Aplicada, 105-106, 987-995.

VanDeventer, J.; Webb, J. T. (1974). Manifest hostility as modified by the K and SO-R Scales of the MMPI. Journal of Psychology; Jul Vol. 87(2) 209-211.

Velasquez, R. J.; Chavira, D. A.; Karle, H. R.; Callahan, W. J.; Garcia, J. A.; Castellanos, J. (2000) Assessing bilingual and monolingual Latino students with translations of the MMPI-2: Initial data. Cultural Diversity and Ethnic Minority Psychology. 6(1): 65-72.

Vendrig, A. A.; De Mey, H. R.; Derksen, J. J. L.; van Akkerveeken, P. F.(1998). Assessment of chronic back pain patient characteristics using factor analysis of the MMPI-2: Which dimensions are actually assessed? Pain.; 76(1-2): 179-188. 
Vendrig, A. A.; Derksen, J. J. L.; De Mey, H. R.(1999). Utility of selected MMPI-2 scales in the outcome prediction for patients with chronic back pain. Psychological Assessment. 11(3): 381-385.

Veraldi, D. M. (1992). Assessing PTSD in personal injury cases. American College of Forensic Psychology's Seventh Annual Symposium in Forensic Psychology (1991, Newport Beach, California). American Journal of Forensic Psychology; Vol 10(1) 5-13.

Viglione, D. J. \& Landis, P. (1994). The development of an objective test for malingering. Paper presented at bienial meeting of the American Psychology Law Society, Santa Fe, N.M.

Viglione, D. J. \& Landis, P. (1995). The inventory of problems. Unpublised manuscript,. California School of Professional Psychology, San Diego.

Viglione, D. J.; Fals-Stewart, W.; Moxham, E. (1995). Maximizing internal and external validity in MMPI malingering research: A study of a military population. Journal of Personality Assessment. Dec; Vol 65(3): 502-513.

Walker, C. E. (1967). The effect of eliminating offensive ítems on the reliability and validity of the MMPI. Journal of clinical Psychology, 23, 363-366.

Walters, G. (1988) Assessing dissimulation and denial on the MMPI in a sample of maximum security, male inmates. Journal of Personality Assessment. Fal; Vol 52(3): 465-474.

Walters, G.; White, T.; Greene, R. (1988). Use of the MMPI to identify malingering and exaggeration of psychiatric symptomatology in male prison inmates. Journal of Consulting and Clinical Psychology. Feb; Vol 56(1): 111-117.

Wang, E. W.; Rogers, R.; Giles, Ch. L.; Diamond, P. M.; Herrington-Wang, L. E.; Taylor, E.R. (1997). A pilot study of the Personality Assessment Inventory (PAI) in corrections: Assessment of malingering, suicide risk, and aggression in male inmates. Behavioral Sciences and the Law. Fal; Vol 15(4): 469-482.

Warchspress, M.; Berenberg, A.N \& Jacobson, A (1953). Simulación of psychosis. Psychiatric Quarterly, 27, 463-473.

Ward, L. Ch.; Kersh, B. C.; Waxmonsky, J. A.(1998). Factor structure of the Paranoia scale of the MMPI2 in relation to the Harris-Lingoes subscales and Comrey factor analysis. Psychological Assessment. 10(3): 292-296.

Ward, L. Ch.; Perry, M. S.(1998). Measurement of social introversion by the MMPI-2. Journal of Personality Assessment. 70(1): 171-182.

Ward, L Ch. (1986). MMPI item subtlety research: Current issues and directions. Journal of Personality Assessment; Spr Vol 50(1) 73-79.

Ward, L.Ch. (1991). A comparison of T scores from the MMPI and the MMPI-2. Psychological Assessment; Dec Vol 3(4) 688-690.

Wechsler, D. (1958). Measurement and appraisal of adult Intelligence. Baltimore Williams and Wilkins.

Weed, N., Ben-Porath, Y. \& Butcher, J. N. (1990). Failure of the Weiner-Harmon MMPI subtle scales as predictors of psychopathology and as validity indicators. Psychological Assessment: A journal of Consulting and Clinical Psychology, 2, 281-283.

Welzler S. \& Marlowe, D (1990). Faking-bad on the MMPI, MMPI-2, and Millon-II. Psychological Reports, 67(3), 1117-1118.

Westefeld, J. S.; Maples, M. (1998). The MMPI-2 and vocational assessment: A brief report. Journal of Career Assessment. Win; 6(1): 107113.

Wetter, M. \& Tharpe, B. (en prensa). Detection of aquiescence and counter acquiescence on the MMPI-2: the utility of the TRIN scale.

Wetter, M.; Baer, R.; Berry, D.; Robison, L.; Larsen, F. (1993). MMPI-2 profiles of motivated fakers given specific symptom information: A comparison to matched patients. Psychological Assessment; Sep Vol 5(3) 317-323.

Wetter, M.; Baer, R.; Berry, D.; Smith G. et als., (1992). Sensivity of MMPI-2 validity scales to random responding and malingering. Psychological Assessment, 4(3), 369-374.

Wetter, M.; Baer, R.A.; Berry, D.T.R.; Robinson R.H.; \& Sumpter, J. (1993). MMPI-2 profiles of motivated fakers given specific symptom information: A comparison matched patients. Psychological Assessment, 5, 317-323. 
Wetter, M.; Baer, R.A.; Berry, D.T.R.\& Reynolds, S.K. (1994). The effect of symptom information on faking on the MMÎ-2. Assessment, 1, 199-207.

Wetzler, S.; Khadivi, A.; Moser, R. K. (1998). The use of the MMPI 2 for the assessment of depressive and psychotic disorders. Assessment. 5(3): 249261.

Wetzler, S.; Marlowe, D. (1990). "Faking bad" on the MMPI, MMPI-2, and Millon-II. Psychological Reports; Dec 67(3, Pt 2) 1117-1118.

Wiener, D. N. \& Harmon, L.R. (1946): Subtle and obvious keys for the MMPI: their development. (Advisement Bulletin $N^{0}$. 16). Minneapolis: regional Veterans Administration Office.

Wiener, D. N. (1948). Subtle and obvious keys for the MMPI" Journal of Consulting Psychology, 12, 164-170.

Wiggins, J. S. (1966). Substantive dimensions of self-report in the MMPI item pool. Psychological Monographs, 80 (22, Whole $\mathrm{n}^{\mathrm{o}}$. 630).

Wiggins, J.S. (1959). Interrelationships among MMPI measures of dissimulation under standard and social desirability instructions. Journal of Consulting Psychology, 23, 419-427.

Wiggins, J. S. (1969). Content dimension in the MMPI. In J.N. Butcher (Ed). MMPI Research developments and clinical applications. New York: McGraw-Hill.

Wiggins, J.S ., Goldberg, L.R. \& Appelbaum, M. (1971). MMPI content Scales: interpretative norms and correlations with other scales. Journal of Consulting and Clinical Psychology, 37, 403-410.

Williams, C.L.; Bucher, J.N.; Ben-Porath, Y.S. \& Graham, J.R. (1992). "MMPI-A Content Scales". University of Minnesota Press, Minneapolis. London.

Wong, J. L.; Besett, T. M.(1999). Sex differences on the MMPI 2 Substance Abuse Scales in psychiatric inpatients. Psychological Reports. 84(2): 582584.

Wooten, A. J. (1984). Effectiveness of the K correction in the detection of psychopathology and its impact on profile height and configuration among young adult men. Journal of Consulting and Clinical Psychology; Jun Vol 52(3) 468-473.

Worthington D.L. \& Schlottmann, R.S. (1986). The predictive validity of subtle and obvious empirically derived psychological test items under faking condition. Journal of Personality Assessment, 50, 171-181.

Woychyshyn, C. A., McElheran W.G., \& Romney D.M. (1992). MMPI validity measures: A comparative study of original with alternative indices. Journal of Personality Assessment, 58, 138-148.

Wrobel, T. A. \& Lachar, D. (1982). Validity of the Wiener Subtle and Obvious scales for the MMPI: Another example of the importance of inventory-item content. Journal of Consulting and Clinical Psychology, 50, 469-470.

Zhang, J.; Song, W.; Zhang, M. (1999). The MMPI 2 and its standardization in China and Hong Kong. Chinese Mental Health Journal.; 13(1): 2023.

Zickar, M. J.; Drasgow, F. (1996) Detecting faking on a personality instrument using appropriateness measurement. Applied Psychological Measurement. Mar; Vol 20(1): 71-87.

Zuzul, M.; Knezovic, Z.; Vizek-Vidovic, V. (1990) Faking on personality questionnaires: The effects of situation and instruction on EPQ-responses. In Van Heck, Guus L. (Ed); Hampson, Sarah E. (Ed); et al. Personality psychology in Europe, Vol. 3: Foundations, models and inquiries. (pp. 169-178). Lisse, Netherlands: Sweets \& Zeitlinger. 
ANEXO: ÍTEMS CORRES PONDIENTES A LAS ES CALAS E INDLICES DE $V \mathcal{A} L I \mathcal{D E Z}$ 
Anexo 1: Ítems correspondientes a la Escala $\mathcal{L}(15$ items).

16- De vez en cuando pienso cosas demasiado malas para hablar de ellas.

29- A veces siento ganas de maldecir.

41- No digo siempre la verdad

51- Diariamente no leo todos los artículos editoriales del periódico.

77- De vez en cuando dejo para mañana lo que debiera hacer hoy.

93- A veces, cuando no me encuentro bien, estoy de mal humor.

102- Algunas veces me enfado

107- Mis modales en la mesa no son tan correctos en mi casa como cuando salgo a comer fuera.

123- Si pudiera entrar en un espectáculo sin pagar, y estuviera seguro de no ser visto, probablemente lo haría.

139- En un juego o partida me gusta ganar más que perder.

153- Me gusta conocer a gente importante porque esto hace sentirme importante.

183- No me agradan todas las personas que conozco.

203- A veces chismorreo un poco.

232- En las elecciones. Algunas veces voto a candidatos que conozco muy poco.

260- De vez en cuando me divierten las bromas o chistes sucios. 
Anexo 2: Ítems correspondientes a la Escala $\mathcal{F}$ (60 items)

6- Mi padre es un buen hombre o(si ya ha fallecido) mi padre fue un buen hombre.

12- Mi vida sexual es satisfactoria.

18- Sufro ataques de náuseas y vómitos

24- A veces estoy poseído por espíritus diabólicos.

30- A menudo tengo pesadillas por las noches

36- Casi siempre tengo tos

42- Si los demás no la hubieran tomado conmigo, habría tenido más éxito.

48- En muchas ocasiones me gustaría sentarme y soñar despierto antes que hacer cualquier cosa.

54- A mi familia no le gusta el trabajo que he elegido (o el trabajo que pienso elegir para mi futuro).

60- Cuando estoy con gente me molesta oir cosas muy extrañas.

66- Sería mejor si se anulasen casi todas las leyes.

72- A veces mi alma abandona mi cuerpo.

78- Le agrado a la mayor parte de la gente que me conoce.

84- Cuando joven me echaron de clase una o mas veces, por mi mal comportamiento.

90- Quiero a mi padre, o (si ya ha fallecido) quise a mi padre.

96- Veo a mi alrededor cosas, animales o personas que otros no ven.

102- Algunas veces me enfado

108- Cualquier persona que sea capaz y esté dispuesta a trabajar duro, tiene muchas probabilidades de obtener éxito.

114- A veces me siento tan atraído por las cosas personales de otro (como zapatos, guantes, etc.) que desearía cogerlos o robarlos, aunque no me sean útiles.

120- Frecuentemente encuentro necesario defender lo que es justo.

126- Creo en la obligación o exigencia de las leyes.

132- Creo que existe otra vida después de esta.

138- Creo que están tramando algo contra mí.

144- Creo que me están persiguiendo.

150- Algunas veces siento deseos de hacer daño, a mí mismo o a alguien.

156- Sólo me encuentro feliz cuando ando errante o viajo de un lado para otro.

162- Alguien ha estado intentando envenenarme.

168- He tenido épocas durante las cuales he realizado actividades que luego no recordaba haberlas hecho.

174- Me gusta leer y estudiar acerca de las cosas en las que estoy trabajando.

180- Algo no marcha bien en mi cabeza.

186- No me da miedo manejar dinero.

192- Mi madre es una buena mujer o (si ya ha fallecido) mi madre fue una buena mujer.

198- A menudo oigo voces sin saber de donde vienen.

204- Aparentemente oigo tan bien como la mayoría de la gente.

210- Me gusta visitar lugares donde nunca he estado.

216- Alguien ha estado intentando robarme.

222- A los niños se les debería enseñar lo principal acerca de la vida sexual.

228- Hay personas que están intentando apoderarse de mis pensamientos e ideas.

234- Creo que estoy condenado.

240- A veces no he podido evitar el robar algo o llevarme algo de una tienda.

246- Creo que mis pecados son imperdonables.

252- Para mí todo tiene el mismo sabor o gusto.

258- Puedo dormir de día pero no por la noche.

264- He abusado de bebidas alcohólicas.

270- Personalmente no me molesta ver sufrir a los animales.

276- Quiero a mi madre o (si ya ha fallecido) quise a mi madre.

282- Me han dicho que camino cuando estoy dormido.

288- Mis padres y familiares encuentran más defectos en mí de los que debieran.

294- Frecuentemente me salen manchas rojas en el cuello.

300- Tengo motivos para sentirme celoso de uno o más miembros de mi familia.

306- Nadie se preocupa mucho por lo que le suceda a otro. 
312- La única parte interesante de los diarios son las caricaturas de la sección cómica.

318- Normalmente espero tener éxito en las cosas que hago.

324- Fácilmente puedo atemorizar a la gente, y a veces lo hago por diversión.

330- A veces estoy lleno de energía.

336- Alguien controla mi mente.

343- Me gustan los niños.

349- Nunca soy tan feliz como cuando estoy solo.

355- Una o más veces en mi vida he sentido que alguien, hipnotizándome, me obligaba a hacer algo.

361- Alguien ha tratado de influir en mi mente. 
Anexo 3: Ítems correspondientes a la Escala $\mathcal{F b}$ (40 items)

281- No me gusta tener gente a mi alrededor.

291- Nunca he estado enamorado.

303- Muchísimas veces me gustaría estar muerto.

311- Con frecuencia siento como si las cosas no fueran reales.

317- Me pongo nervioso e inquieto cuando tengo que hacer un viaje corto.

319- Oigo cosas extrañas cuando estoy solo.

322- Me da miedo utilizar cuchillos u objetos muy afilados o puntiagudos.

323- Algunas veces disfruto hiriendo a personas que amo.

329- Casi todos los días ocurre algo que me asusta.

332- A veces he disfrutado al ser herido por una persona querida.

333- La gente dice cosas ofensivas y vulgares de mí.

334- Me siento incómodo en lugares cerrados.

383- Cuando las cosas se ponen realmente mal, sé que puedo contar con la ayuda de mi familia.

387- Solamente cuando bebo puedo expresar mis verdaderos sentimientos.

395- Me da miedo estar solo en la oscuridad.

404- No tengo dificultades al tragar.

407- Merezco un severo castigo por mis pecados.

431- En el colegio, mis calificaciones en conducta fueron generalmente malas.

450- No puedo hacer ninguna cosa bien.

454- No tengo ninguna esperanza en mi porvenir.

463- Varias veces a la semana siento como si fuera a suceder algo espantoso.

468- Me da miedo estar solo en los lugares amplios y abiertos.

476- Soy muy torpe y poco hábil.

478- Odio a toda mi familia.

484- La gente no se muestra muy amable conmigo.

489- Tengo problemas con las drogas o con el alcohol.

501- A menudo es más provechoso hablar los problemas y las preocupaciones con alguien, que tomar calmantes y medicamentos.

506- Recientemente he pensado en matarme.

516- Mi vida está vacía y no tiene sentido.

517- Tengo dificultades para seguir en el trabajo.

520- Ultimamente he estado pensando mucho en suicidarme.

524- Nadie lo sabe, pero he intentado suicidarme.

525- Todo está sucediendo demasiado rápido a mi alrededor.

526- Sé que soy una carga para los demás.

528- Muchos de los problemas que estoy teniendo se deben a la mala suerte.

530- En ocasiones me hago daño o me hiero deliberadamente sin saber por qué.

539- Ultimamente he perdido el interés en resolver mis propios problemas.

540- Estando bajo los efectos del alcohol me he enfurecido y he destrozado muebles o vajilla.

544- La gente me dice que tengo problemas con el alcohol, pero no estoy de acuerdo.

555 - No puedo entrar solo en una sala oscura, incluso en mi propio hogar. 


\section{Anexo 4: Ítems correspondientes a la Escala K(30 items)}

29- A veces siento ganas de maldecir.

37- A veces siento deseos de destrozar las cosas.

58- Pienso que una gran mayoría de la gente exagera sus desgracias para lograr la simpatía y ayuda de los demás.

76- Cuesta mucho trabajo convencer a la mayoría de la gente de la verdad.

83- Tengo muy pocos disgustos con los miembros de mi familia.

110- Para no perder un beneficio o ventaja, la mayoría de la gente utilizaría medios algo injustos.

116- Frecuentemente no puedo comprender por qué he estado tan irritable y malhumorado.

122- A veces mis pensamientos han ido más rápido y por delante de mis palabras.

127- Las críticas y las reprensiones me hieren profundamente.

130- Ciertamente a veces siento que soy un/a inútil.

136- Me molesta que la gente me pida consejo o que me interrumpan cuando estoy trabajando en algo importante.

148- Nunca en mi vida me he sentido mejor que ahora.

157- No me preocupa lo que los demás piensen de mí.

158- Me siento incómodo cuando tengo que hacer una payasada en una fiesta, incluso aunque otros la estén haciendo.

167- Me es difícil entablar una conversación cuando conozco a alguien por primera vez.

171- Estoy en contra de dar dinero a los mendigos.

196- Frecuentemente me encuentro preocupado por algo.

213- Me enfado fácilmente pero se me pasa pronto.

243- Cuando estoy con un grupo de gente, tengo dificultades para pensar en temas adecuados de conversación.

267- Tengo épocas en las que me siento más animado que de costumbre sin que exista una razón especial.

284- Pienso que casi todo el mundo mentiría para evitarse problemas.

290- Me preocupan el dinero y los negocios.

330 - A veces estoy lleno de energía.

338- La gente me decepciona con mucha frecuencia.

339- A veces he sentido que las dificultades me abrumaban hasta tal punto que no podía superarlas.

341- En ocasiones mi mente parece funcionar más lenta que de costumbre.

346- Con frecuencia me he encontrado con personas supuestamente expertas, que no resultaron ser mejores que yo.

348- Con frecuencia pienso: "Me gustaría volver a ser niño/a".

356- Me cuesta bastante interrumpir, aunque sea por poco tiempo, una tarea que ya he iniciado.

365- Me gusta que la gente conozca mi punto de vista sobre las cosas. 
Anexo 5: Ítems correspondientes a la Escala VRIX (49 pares)

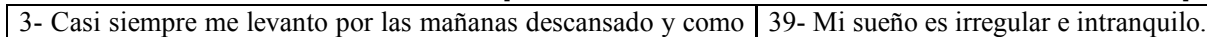
nuevo.

6-V.- Mi padre es un buen hombre, o (si ya ha fallecido) mi $90 .-$ Quiero a mi padre, o (si ya ha fallecido) quise a mi padre. padre fue un buen hombre.

6.- Mi padre es un buen hombre, o (si ya ha fallecido) mi padre 90 .- Quiero a mi padre, o (si ya ha fallecido) quise a mi padre. fue un buen hombre.

9.- En mi vida diaria hay muchas cosas que me resultan interesantes.

28 .- Me molesta el estómago varias veces a la semana.

31 .- Me cuesta bastante concentrarme en una tarea o trabajo.

32.- He tenido experiencias muy peculiares y extrañas .

40 .- La mayor parte del tiempo parece dolerme la cabeza por todas partes.

46 .- Prefiero hacerme el desentendido con amigos de colegio o personas conocidas que no veo desde hace tiempo, a menos que ellos me hablen primero.

48 - En muchas ocasiones me gustaría sentarme y soñar despierto antes que hacer cualquier cosa.

49 .- Soy una persona muy sociable.

56.- Me gustaría ser tan feliz como parecen ser los demás.

59.- Tengo molestias en la boca del estómago casi a diario.

299.- No puedo concentrarme en una sola cosa.

316 .- Tengo pensamientos extraños y raros.

176 .- Me duele la cabeza muy pocas veces.

265.- Por lo general no le hablo a la gente hasta que ellas no me hablan primero.

184 .- Muy pocas veces sueño despierto.

280.- Me parece que hago amigos tan fácilmente como los demás.

73 .- Definitivamente no tengo confianza en mí mismo.

377.- No estoy satisfecho con mi manera de ser.

81 Creo que la mayoría de la gente mentiría con tal de conseguir lo que quiere.

81.- Creo que la mayoría de la gente mentiría con tal de conseguir lo que quiere.

83 .- Tengo muy pocos disgustos con los miembros de mi familia.

84 .- Cuando joven me echaron de clase una o mas veces, por mi mal comportamiento.

86.- Me gusta asistir a reuniones o fiestas animadas y alegres.

95.- Casi siempre soy feliz.

99.- Alguien me la tiene jurada.

103.- Me divierte más el juego o una partida cuando apuesto.

110.- Para no perder un beneficio o ventaja, la mayoría de la gente utilizaría medios algo injustos.

110.- Para no perder un beneficio o ventaja, la mayoría de la gente utilizaría medios algo injustos.

116.- Frecuentemente no puedo comprender por qué he estado tan irritable y malhumorado.

125.- Creo que mi vida hogareña es tan agradable como la de la mayoría de la gente que conozco.

125.- Creo que mi vida hogareña es tan agradable como la de la mayoría de la gente que conozco.

135.- Frecuentemente pierdo o desaprovecho oportunidades por no decidirme a tiempo.

136.- Me molesta que la gente me pida consejo o que me interrumpan cuando estoy trabajando en algo importante.

136.- Me molesta que la gente me pida consejo o que me interrumpan cuando estoy trabajando en algo importante.

152.- No me canso fácilmente.

161.- Frecuentemente tengo que esforzarme para no demostrar que soy tímido.

161.- Frecuentemente tengo que esforzarme para no demostrar que soy tímido.

165.- Mi memoria parece estar en buenas condiciones.

84.- Pienso que casi todo el mundo mentiría para evitarse problemas.

284 .- Pienso que casi todo el mundo mentiría para evitarse problemas.

288 .- Mis padres y familiares encuentran más defectos en mí de los que debieran

105.- En el colegio, algunas veces, fui enviado al director/a a causa de mi mal comportamiento.

359.- Me gusta la animación de una multitud

388.- Muy rara vez tengo momentos de abatimiento.

138.- Creo que están tramando algo contra mí.

344.- Me gusta apostar cuando se trata de poco dinero.

374.- La mayoría de la gente utilizaría medios algo injustos para salir adelante en la vida.

374.- La mayoría de la gente utilizaría medios algo injustos para salir adelante en la vida.

430.- Frecuentemente me lamento por tener mal genio o ser tan gruñón.

195.- En comparación con otros hogares, en mi familia hay poco compañerismo y cariño.

195.- En comparación con otros hogares, en mi familia hay poco compañerismo y cariño.

482.- Frecuentemente me cuesta decidir qué debo hacer.

507.- Frecuentemente me irrito mucho cuando la gente interrumpe mi trabajo.

507.- Frecuentemente me irrito mucho cuando la gente interrumpe mi trabajo.

464.- Me siento cansado una buena parte del tiempo.

185.- Me gustaría no ser tan tímido.

185.- Me gustaría no ser tan tímido.

565.- Ultimamente tengo que hacer un gran esfuerzo para recordar lo que la gente me dice.

268.- Me gustaría no ser perturbado por pensamientos sexuales.

66.- Me preocupan los temas sexuales.

166.- Me preocupan los temas sexuales.

167.- Me es difícil entablar una conversación cuando conozco a alguien por primera vez.

167.- Me es difícil entablar una conversación cuando conozco a alguien por primera vez.

196.- Frecuentemente me encuentro preocupado por algo.

268.- Me gustaría no ser perturbado por pensamientos sexuales.

243.- Cuando estoy con un grupo de gente, tengo dificultades para pensar en temas adecuados de conversación.

243.- Cuando estoy con un grupo de gente, tengo dificultades para pensar en temas adecuados de conversación.

415.- Me preocupo mucho por posibles desgracias. 
199.- Me gusta la ciencia.

199.- Me gusta la ciencia.

226.- Algunas veces, sin razón alguna, o incluso cuando las cosas me van mal, me siento animadamente feliz, como "flotando entre nubes".

259.- Estoy seguro de que la gente habla de mí.

262.- Si en un grupo me pidieran que comenzara una discusión o diera mi opinión acerca de algo que conozco bien, no sentiría ninguna vergüenza.

290.- Me preocupan el dinero y los negocios.

290.- Me preocupan el dinero y los negocios.

339.- A veces he sentido que las dificultades me abrumaban hasta tal punto que no podía superarlas.

349.- Nunca soy tan feliz como cuando estoy solo.

349.- Nunca soy tan feliz como cuando estoy solo.

350.- Si me dieran la oportunidad podría ser un buen líder.

353.- Me gustan las reuniones sociales por el simple hecho de estar con gente.

353.- Me gustan las reuniones sociales por el simple hecho de estar con gente.

364.- Cuando las cosas van mal fácilmente tiendo a darme por vencido.

369.- Me inclino a dejar de hacer algo que deseo cuando los demás piensan que no vale la pena realizarlo.

372.- No me enfado fácilmente.

372.- No me enfado fácilmente.

380.- Me siento incómodo cuando la gente me halaga.

395.- Me da miedo estar solo en la oscuridad.

395.- Me da miedo estar solo en la oscuridad. comprendido cuando trataba de evitar que alguien cometiera un error.

396.- A veces me he sentido muy mal por no haber sido comprendido cuando trataba de evitar que alguien cometiera un error.

411.- A veces pienso que no valgo para nada.

411.- A veces pienso que no valgo para nada.

472.- Me molesta mucho olvidarme dónde pongo las cosas

472.- Me molesta mucho olvidarme dónde pongo las cosas.

491.- Me siento incapaz cuando tengo que tomar una decisión importante.

506.- Recientemente he pensado en matarme.

506.- Recientemente he pensado en matarme.

513.- A veces me enfado y me altero tanto que no sé lo que me pasa.
467.- Me gusta leer temas científicos.

467.- Me gusta leer temas científicos.

267.- Tengo épocas en las que me siento más animado que de costumbre sin que exista una razón especial.

333.- La gente dice cosas ofensivas y vulgares de mí.

275.- En el colegio me costaba mucho hablar delante de los demás.

556.- Me preocupa bastante el dinero.

556.- Me preocupa bastante el dinero.

394.- Frecuentemente en mis proyectos he encontrado tantas dificultades, que he tenido que abandonarlos.

515.- Nunca me siento más feliz que cuando estoy solo.

515.- Nunca me siento más feliz que cuando estoy solo.

521.- Me gusta tomar decisiones y darle trabajo a los demás.

370.- Me gustan las fiestas y reuniones sociales.

370.- Me gustan las fiestas y reuniones sociales.

554.- Cuando las cosas se me ponen difíciles me dan ganas de dejarlo todo.

421.- Tiendo a dejar algo que deseo hacer cuando los demás piensan que no es la manera correcta de hacerlo.

405.- Normalmente soy una persona tranquila y no me altero fácilmente.

405.- Normalmente soy una persona tranquila y no me altero fácilmente.

562.- Me cuesta aceptar halagos.

435.- A menudo tengo miedo de la oscuridad.

435.- A menudo tengo miedo de la oscuridad.

403.- Frecuentemente la gente ha malinterpretado mis intenciones cuando trataba de corregirles o ayudarles.

403.- Frecuentemente la gente ha malinterpretado mis intenciones cuando trataba de corregirles o ayudarles.

485.- A menudo siento que no soy tan bueno como otras personas.

485.- A menudo siento que no soy tan bueno como otras personas.

533.- Olvido dónde dejo las cosas.

533.- Olvido dónde dejo las cosas.

509.- Me pone nervioso el tener que tomar decisiones importantes.

520.- Ultimamente he estado pensando mucho en suicidarme.

520.- Ultimamente he estado pensando mucho en suicidarme.

542.- Me he enfadado tanto con alguien que he estado a punto de explotar. 
Anexo 6: Ítems correspondientes a la Escala $\mathcal{T} I \mathcal{N}(23$ pares)

3.- Casi siempre me levanto por las mañanas descansado y como 39 .- Mi sueño es irregular e intranquilo.

nuevo.

12.- Mi vida sexual es satisfactoria.

166.- Me preocupan los temas sexuales.

40.- La mayor parte del tiempo parece dolerme la cabeza por $176 .-$ Me duele la cabeza muy pocas veces. todas partes.

48.- En muchas ocasiones me gustaría sentarme y soñar $184 .-$ Muy pocas veces sueño despierto.

despierto antes que hacer cualquier cosa.

63.- Mis sentimientos no son heridos fácilmente.

65.- La mayor parte del tiempo me siento triste.

73.- Definitivamente no tengo confianza en mí mismo.

83.- Tengo muy pocos disgustos con los miembros de mi familia.

127.- Las críticas y las reprensiones me hieren profundamente.

95.- Casi siempre soy feliz.

\begin{tabular}{|l|}
\hline 94.- Muchas veces siento haber hecho algo malo o erróneo. \\
\hline 125.- Creo que mi vida hogareña es tan agradable como la de la
\end{tabular}

239.- Soy una persona plenamente seguro de mí mismo.

mayoría de la gente que conozco.

209.- Me gusta hablar sobre temas sexuales. los que debieran.

314.- No tengo enemigos que deseen realmente hacerme daño.

359.- Me gusta la animación de una multitud.

195.- En comparación con otros hogares, en mi familia hay poco

377.- No estoy satisfecho con mi manera de ser.

556.- Me preocupa bastante el dinero.

compañerismo y cariño.

9.- En mi vida diaria hay muchas cosas que me resultan interesantes.

\begin{tabular}{l|l} 
65.- La mayor parte del tiempo me siento triste. & 95.- Casi siempre soy feliz.
\end{tabular}

351.- Me siento incómodo con los chistes groseros.

367.- Siempre que puedo, evito encontrarme entre mucha gente.

534.- Si pudiera comenzar mi vida de nuevo, no la cambiaría mucho.

560.- Estoy satisfecho con la cantidad de dinero que gano.

125.- Creo que mi vida hogareña es tan agradable como la de la $195 .-$ En comparación con otros hogares, en mi familia hay poco mayoría de la gente que conozco.

140.- Casi todas las noches me duermo sin ideas o pensamientos preocupantes.

152.- No me canso fácilmente.

165.- Mi memoria parece estar en buenas condiciones. compañerismo y cariño.

196.- Frecuentemente me encuentro preocupado por algo.

262.- Si en un grupo me pidieran que comenzara una discusión o 464.- Me siento cansado una buena parte del tiempo.

diera mi opinión acerca de algo que conozco bien, no sentiría ninguna vergüenza.

265.- Por lo general no le hablo a la gente hasta que ellas no me hablan primero.

359.- Me gusta la animación de una multitud.

565.- Ultimamente tengo que hacer un gran esfuerzo para recordar lo que la gente me dice.

275.- En el colegio me costaba mucho hablar delante de los demás.

360.- No me importa conocer personas extrañas.

367.- Siempre que puedo, evito encontrarme entre mucha gente. 
Anexo 7: Escala de Deseabilidad Social (Wsd) de Wiggins (1959)

25- Me gustaría ser cantante.

29- A veces siento ganas de maldecir.

41- No digo siempre la verdad.

49- Soy una persona muy sociable.

77- De vez en cuando dejo para mañana lo que debiera hacer hoy.

80- Me gustaría ser enfermero.

93- A veces, cuando no me encuentro bien, estoy de mal humor.

100- Nunca he hecho algo peligroso sólo por la emoción de hacerlo.

131- Cuando era un muchacho pertenecía a una pandilla que intentaba mantenerse unida ante cualquier adversidad.

133- Me gustaría ser militar.

183- No me agradan todas las personas que conozco.

184- Muy pocas veces sueño despierto.

194- Nunca he tenido erupciones en la piel que me hayan preocupado.

201- Me gusta mucho cazar.

203- A veces chismorreo un poco.

206- A veces me siento capaz de tomar decisiones con extraordinaria facilidad.

207- Me gustaría pertenecer a varios clubes o asociaciones.

211- Me han sugerido un programa de vida basado en el deber y desde entonces lo he seguido cuidadosamente.

220- Nunca me preocupo por mi apariencia física.

232- En las elecciones, algunas veces voto candidatos que conozco muy poco.

249- Mi vista es ahora tan buena como lo ha sido durante años.

257- Si fuera periodista me gustaría mucho hacer reportajes sobre deportes.

263- Siento siempre rechazo por la justicia cuando un criminal sale libre gracias a la habilidad de un abogado astuto.

326- En varias ocasiones he dejado de hacer algo porque he dudado de mi habilidad.

341- En ocasiones mi mente parece funcionar más lenta que de costumbre.

345- Si me dieran la oportunidad podría hacer algunas cosas que beneficiarían mucho a la humanidad.

351- Me siento incómodo con los chistes groseros.

354- Intento recordar anécdotas interesantes para contárselas a otros.

356- Me cuesta bastante interrumpir, aunque sea por poco tiempo, una tarea que ya he iniciado.

366- He tenido épocas en las que me sentía tan animado que me parecía que, durante días, no necesitaría dormir.

402- A menudo tengo que "consultar con la almohada" antes de tomar una decisión.

416- Tengo opiniones políticas muy definidas.

439- Rápidamente me convenzo por completo de una buena idea. 
Anexo 8: Inconsistencia de Respuestas(IR) de Sewell er Rogers (1994). 51- No leo diariamente todos los artículos editoriales del periódico.

77- De vez en cuando dejo para mañana lo que debiera hacer hoy.

93- A veces, cuando no me encuentro bien, estoy de mal humor.

114- A veces me siento tan atraído por las cosas personales de otro (como zapatos, guantes, etc.) que desearía cogerlos o robarlos, aunque no me sean útiles.

182- He tenido ataques en los que perdía el control de mis movimientos o de la palabra, pero sabía lo que pasaba a mi alrededor.

228- Hay personas que están intentando apoderarse de mis pensamientos e ideas.

234- Creo que estoy condenado.

322- Me da miedo utilizar cuchillos u objetos muy afilados o puntiagudos.

332- A veces he disfrutado al ser herido por una persona querida.

336- Alguien controla mi mente.

355- Una o más veces en mi vida he sentido que alguien, hipnotizándome, me obligaba a hacer algo.

407- Merezco un severo castigo por mis pecados.

478- Odio a toda mi familia.

511- Una vez por semana, o con más frecuencia, me suelo emborrachar o drogar.

527- Después de un mal día, generalmente necesito tomar un poco de alcohol para relajarme.

530- En ocasiones me hago daño o me hiero deliberadamente sin saber por qué. 


\section{Anexo 9: Escala de Finfimiento positivo o de Otro Engaño (ODecp) de \\ Nichols of Greene (1991)}

21- A veces he deseado muchísimo abandonar el hogar.

29- A veces siento ganas de maldecir.

41- No digo siempre la verdad.

49- Soy una persona muy sociable.

77- De vez en cuando dejo para mañana lo que debiera hacer hoy.

89- Los conflictos más graves que tengo son conmigo mismo.

93- A veces, cuando no me encuentro bien, estoy de mal humor.

100- Nunca he hecho algo peligroso sólo por la emoción de hacerlo.

133- Me gustaría ser militar.

183- No me agradan todas las personas que conozco.

184- Muy pocas veces sueño despierto.

194- Nunca he tenido erupciones en la piel que me hayan preocupado.

196- Frecuentemente me encuentro preocupado por algo.

201- Me gusta mucho cazar.

203- A veces chismorreo un poco.

206- A veces me siento capaz de tomar decisiones con extraordinaria facilidad.

207- Me gustaría pertenecer a varios clubes o asociaciones.

211- Me han sugerido un programa de vida basado en el deber y desde entonces lo he seguido cuidadosamente.

220- Nunca me preocupo por mi apariencia física.

232- En las elecciones, algunas veces voto candidatos que conozco muy poco.

239- Soy una persona plenamente seguro de mí mismo.

261- Comparado con mis amigos, tengo muy pocos miedos.

290- Me preocupan el dinero y los negocios.

326- En varias ocasiones he dejado de hacer algo porque he dudado de mi habilidad.

341- En ocasiones mi mente parece funcionar más lenta que de costumbre.

345- Si me dieran la oportunidad podría hacer algunas cosas que beneficiarían mucho a la humanidad.

350- Si me dieran la oportunidad podría ser un/a buen/a líder.

356- Me cuesta bastante interrumpir, aunque sea por poco tiempo, una tarea que ya he iniciado.

416- Tengo opiniones políticas muy definidas.

428- Varias veces he cambiado de modo de pensar con respecto a mi trabajo.

439- Rápidamente me convenzo por completo de una buena idea.

442- Debo admitir que a veces he estado demasiado preocupado por algo sin importancia. 
Ane xo 10: Escala de "Fake-Bad" (FBS) de Lees-Haley, Englis of Glenn

(1991)

11- La mayor parte del tiempo me parece tener un nudo en la garganta.

12- Mi vida sexual es satisfactoria.

18- Sufro ataques de náuseas y vómitos.

28- Me molesta el estómago varias veces a la semana.

30- A menudo tengo pesadillas por las noches.

31- Me cuesta bastante concentrarme en una tarea o trabajo.

39- Mi sueño es irregular e intranquilo.

40- La mayor parte del tiempo parece dolerme la cabeza por todas partes.

41- No digo siempre la verdad.

44- Una vez a la semana o más a menudo, siento calor por todo el cuerpo sin causa aparente.

57- Muy raras veces siento dolor en la nuca.

58- Pienso que una gran mayoría de la gente exagera sus desgracias para lograr la simpatía y ayuda de los demás.

59- Tengo molestias en la boca del estómago casi a diario.

81- Creo que la mayoría de la gente mentiría con tal de conseguir lo que quiere.

110- Para no perder un beneficio o ventaja, la mayoría de la gente utilizaría medios algo injustos.

111- Tengo muchos problemas con el estómago.

117 - Nunca he vomitado o escupido sangre.

152- No me canso fácilmente.

164- Nunca, o rara vez, tengo mareos.

176- Me duele la cabeza muy pocas veces.

224- Tengo pocos o ningún dolor.

227- No culpo a nadie por tratar de apoderarse de todo lo que pueda en este mundo.

248- No culpo a aquella persona que se aprovecha de otra que se expone a ello.

249- Mi vista es ahora tan buena como lo ha sido durante años.

250- A veces me ha divertido tanto el ingenio de un pícaro que he tenido la esperanza de que tuviera éxito.

252- Para mí todo tiene el mismo sabor o gusto.

255- Casi nunca noto que me zumben o me silben los oídos.

264- He abusado de bebidas alcohólicas.

274- Soy tan susceptible respecto a algunos temas que ni siquiera puedo hablar de ellos.

284- Pienso que casi todo el mundo mentiría para evitarse problemas.

325- Es más difícil para mi concentrarme de lo que parece ser para otras personas.

339- A veces he sentido que las dificultades me abrumaban hasta tal punto que no podía superarlas.

362- Recuerdo haberme fingido estar enfermo para evitar algo.

373- Nunca hablo de las cosas malas que he hecho.

374- La mayoría de la gente utilizaría medios algo injustos para salir adelante en la vida.

419- Me desagradan tanto algunas personas que me alegro interiormente cuando pagan las consecuencias por algo que han hecho.

433- Cuando estoy en una situación difícil sólo digo aquella parte de la verdad que probablemente no me va a perjudicar.

464- Me siento cansado una buena parte del tiempo.

469- A veces siento que estoy al borde de una crisis nerviosa.

496- En estos días no estoy sintiendo mucha presión o estrés.

505- Estoy tan harto de lo que tengo que hacer diariamente que me dan ganas de abandonarlo todo.

506- Recientemente he pensado en matarme.

561- Normalmente me encuentro con suficiente energía para realizar mi trabajo. 
Ane xo 11: Escala de Disimulación (Ds) de Gough (1954)

11- La mayor parte del tiempo me parece tener un nudo en la garganta.

17- Estoy seguro que la vida es dura para mí.

18- Sufro ataques de náuseas y vómitos.

19- Cuando acepto un nuevo empleo, me gusta que se me indique, confidencialmente, a quién debo halagar.

22- Nadie parece comprenderme.

28- Me molesta el estómago varias veces a la semana.

30- A menudo tengo pesadillas por las noches.

31- Me cuesta bastante concentrarme en una tarea o trabajo.

40- La mayor parte del tiempo parece dolerme la cabeza por todas partes.

42- Si los demás no la hubieran tomado conmigo, habría tenido más éxito.

44- Una vez a la semana o más a menudo, siento calor por todo el cuerpo sin causa aparente.

54- A mi familia no le gusta el trabajo que he elegido (o el trabajo que pienso elegir para mi futuro).

57- Muy raras veces siento dolor en la nuca.

61- Soy una persona importante.

72- A veces mi alma abandona mi cuerpo.

75- Normalmente siento que la vida vale la pena vivirla.

81- Creo que la mayoría de la gente mentiría con tal de conseguir lo que quiere.

83- Tengo muy pocos disgustos con los miembros de mi familia.

85- A veces siento fuertes deseos de hacer algo dañino o escandaloso.

92- Parece que no me importa mucho lo que me pueda suceder.

108- Cualquier persona que sea capaz y esté dispuesta a trabajar duro, tiene muchas probabilidades de obtener éxito.

111- Tengo muchos problemas con el estómago.

125- Creo que mi vida hogareña es tan agradable como la de la mayoría de la gente que conozco.

166- Me preocupan los temas sexuales.

188- Disfruto con muy diferentes clases de juegos y diversiones.

190- Mi familia me trata más como a un/a niño que como a un adulto.

195- En comparación con otros hogares, en mi familia hay poco compañerismo y cariño.

205- Alguno de mis familiares tienen costumbres que me molestan y me irritan muchísimo.

221- Frecuentemente sueño sobre cosas que es mejor mantenerlas en secreto.

252- Para mí todo tiene el mismo sabor o gusto.

258- Puedo dormir de día pero no por la noche.

268- Me gustaría no ser perturbado por pensamientos sexuales.

274- Soy tan susceptible respecto a algunos temas que ni siquiera puedo hablar de ellos.

278- Tengo toda la comprensión que debiera recibir.

287- Muchos de mis sueños se relacionan con temas sexuales.

292- Algunos de mis familiares han hecho ciertas cosas que me han asustado.

294- Frecuentemente me salen manchas rojas en el cuello.

300- Tengo motivos para sentirme celoso de uno o más miembros de mi familia.

307- A veces oigo tan bien que me llega a molestar.

310- A menudo cruzo la calle para evitar encontrarme con alguna persona.

318- Normalmente espero tener éxito en las cosas que hago.

320 - He tenido miedo de cosas o personas que sabía no podían hacerme daño.

329- Casi todos los días ocurre algo que me asusta.

362- Recuerdo haberme fingido estar enfermo para evitar algo.

395- Me da miedo estar solo en la oscuridad.

404- No tengo dificultades al tragar.

412- Cuando era un/a muchacho frecuentemente hacía "novillos" en clase.

419- Me desagradan tanto algunas personas que me alegro interiormente cuando pagan las consecuencias por algo que han hecho. 
421- Tiendo a dejar algo que deseo hacer cuando los demás piensan que no es la manera correcta de hacerlo.

425- El hombre que más se ocupó de mí cuando era niño (mi padre, mi padrastro, etc.) fue muy rígido conmigo.

429- Nunca tomo drogas o pastillas para dormir, a no ser por orden del médico.

431- En el colegio, mis calificaciones en conducta fueron generalmente malas.

433- Cuando estoy en una situación difícil sólo digo aquella parte de la verdad que probablemente no me va a perjudicar.

435- A menudo tengo miedo de la oscuridad.

436- Cuando un hombre está con una mujer, generalmente está pensando cosas relacionadas con el sexo.

451- A menudo me he sentido culpable porque he fingido mayor pesar del que realmente sentía.

458- Ciertos animales me ponen nervioso.

463- Varias veces a la semana siento como si fuera a suceder algo espantoso. 
Ane xo 12: Escala Revisada de Disimulación (Ds-r) de Gough (1957)

11- La mayor parte del tiempo me parece tener un nudo en la garganta.

18- Sufro ataques de náuseas y vómitos.

22- Nadie parece comprenderme.

28- Me molesta el estómago varias veces a la semana.

30- A menudo tengo pesadillas por las noches.

31- Me cuesta bastante concentrarme en una tarea o trabajo.

40- La mayor parte del tiempo parece dolerme la cabeza por todas partes.

44- Una vez a la semana o más a menudo, siento calor por todo el cuerpo sin causa aparente.

57- Muy raras veces siento dolor en la nuca.

75- Normalmente siento que la vida vale la pena vivirla.

81- Creo que la mayoría de la gente mentiría con tal de conseguir lo que quiere.

83- Tengo muy pocos disgustos con los miembros de mi familia.

85- A veces siento fuertes deseos de hacer algo dañino o escandaloso.

92- Parece que no me importa mucho lo que me pueda suceder.

108- Cualquier persona que sea capaz y esté dispuesta a trabajar duro, tiene muchas probabilidades de obtener éxito.

111- Tengo muchos problemas con el estómago.

205- Alguno de mis familiares tienen costumbres que me molestan y me irritan muchísimo.

221- Frecuentemente sueño sobre cosas que es mejor mantenerlas en secreto.

274- Soy tan susceptible respecto a algunos temas que ni siquiera puedo hablar de ellos.

278- Tengo toda la comprensión que debiera recibir.

292- Algunos de mis familiares han hecho ciertas cosas que me han asustado.

300- Tengo motivos para sentirme celoso de uno o más miembros de mi familia.

318- Normalmente espero tener éxito en las cosas que hago.

320 - He tenido miedo de cosas o personas que sabía no podían hacerme daño.

329- Casi todos los días ocurre algo que me asusta.

362- Recuerdo haberme fingido estar enfermo para evitar algo.

395- Me da miedo estar solo en la oscuridad.

419- Me desagradan tanto algunas personas que me alegro interiormente cuando pagan las consecuencias por algo que han hecho.

433- Cuando estoy en una situación difícil sólo digo aquella parte de la verdad que probablemente no me va a perjudicar.

435- A menudo tengo miedo de la oscuridad.

436- Cuando un hombre está con una mujer, generalmente está pensando cosas relacionadas con el sexo.

451- A menudo me he sentido culpable porque he fingido mayor pesar del que realmente sentía.

458- Ciertos animales me ponen nervioso.

463- Varias veces a la semana siento como si fuera a suceder algo espantoso. 
Anexo 13: Escala Superlativa (S) de Butcher \& Han (1995)

15- Trabajo bajo una tensión muy grande.

50- Con frecuencia he tenido que recibir órdenes de personas que sabían menos que yo.

58- Pienso que una gran mayoría de la gente exagera sus desgracias para lograr la simpatía y ayuda de los demás.

76- Cuesta mucho trabajo convencer a la mayoría de la gente de la verdad.

81- Creo que la mayoría de la gente mentiría con tal de conseguir lo que quiere.

87- Me he enfrentado a problemas con tantas opciones de solución que me ha sido imposible llegar a una decisión.

89- Los conflictos más graves que tengo son conmigo mismo.

104- La mayoría de la gente es honrada por temor a ser descubierta.

110- Para no perder un beneficio o ventaja, la mayoría de la gente utilizaría medios algo injustos.

120- Frecuentemente encuentro necesario defender lo que es justo.

121- Nunca me he entregado a prácticas sexuales fuera de lo común.

123- Si pudiera entrar en un espectáculo sin pagar y estuviera seguro de no ser visto, probablemente lo haría.

148- Nunca en mi vida me he sentido mejor que ahora.

154- Siento miedo cuando miro hacia abajo desde un lugar alto.

184- Muy pocas veces sueño despierto.

194- Nunca he tenido erupciones en la piel que me hayan preocupado.

196- Frecuentemente me encuentro preocupado por algo.

205- Alguno de mis familiares tienen costumbres que me molestan y me irritan muchísimo.

213- Me enfado fácilmente pero se me pasa pronto.

225- Mi manera de hacer las cosas tiende a ser mal interpretada por los demás.

264- He abusado de bebidas alcohólicas.

279- Me niego a participar en algunos juegos porque no soy hábil en ellos.

284- Pienso que casi todo el mundo mentiría para evitarse problemas.

290- Me preocupan el dinero y los negocios.

302- Pierdo fácilmente la paciencia con la gente.

337- En las reuniones sociales o fiestas es más probable que me siente solo o con una persona antes que reunirme con un grupo.

341- En ocasiones mi mente parece funcionar más lenta que de costumbre.

346- Con frecuencia me he encontrado con personas supuestamente expertas, que no resultaron ser mejores que yo.

352- Normalmente la gente pide para sus propios derechos más respeto que el que está dispuesto a conceder a los demás.

373- Nunca hablo de las cosas malas que he hecho.

374- La mayoría de la gente utilizaría medios algo injustos para salir adelante en la vida.

403- Frecuentemente la gente ha malinterpretado mis intenciones cuando trataba de corregirles o ayudarles.

420- Me pone nervioso tener que esperar.

423- Con frecuencia me esfuerzo para triunfar sobre alguien que se enfrenta a mí.

428- Varias veces he cambiado de modo de pensar con respecto a mi trabajo.

430- Frecuentemente me lamento por tener mal genio o ser tan grunón.

433- Cuando estoy en una situación difícil sólo digo aquella parte de la verdad que probablemente no me va a perjudicar.

442- Debo admitir que a veces he estado demasiado preocupado por algo sin importancia.

445- Frecuentemente he trabajado bajo órdenes de personas que parecen haber arreglado las cosas de tal modo, que ellas son las que reciben el reconocimiento de una buena labor y, en cambio, son capaces de atribuir los errores a sus subordinados.

449- Algunos de mis familiares tienen muy mal genio.

461- Me pone de mal humor que la gente me meta prisas.

486- Soy muy terco (tozudo/a, insistente).

487- He disfrutado tomando drogas.

523- Me molesta mucho tener que hacer colas en los cines, restaurantes o acontecimientos deportivos. 
534- Si pudiera comenzar mi vida de nuevo, no la cambiaría mucho.

538- De vez en cuando la mayoría de los maridos son infieles a sus esposas.

542- Me he enfadado tanto con alguien que he estado a punto de explotar.

545- Siempre tengo muy poco tiempo para hacer las cosas.

547- A menudo guardo y conservo cosas que probablemente nunca usaré.

560- Estoy satisfecho con la cantidad de dinero que gano. 
Ane xo 14: Escala Psiquiátrica $\mathcal{F}(p)$ de Arbisi er Ben-Porath (1995)

51- No leo diariamente todos los artículos editoriales del periódico.

66- Sería mejor si se anulasen casi todas las leyes.

77- De vez en cuando dejo para mañana lo que debiera hacer hoy.

90- Quiero a mi padre, o si ya ha fallecido, quise a mi padre.

93- A veces, cuando no me encuentro bien, estoy de mal humor.

102- Algunas veces me enfado.

114- A veces me siento tan atraído por las cosas personales de otro (como zapatos, guantes, etc.) que desearía cogerlos o robarlos, aunque no me sean útiles.

126- Creo en la obligación o exigencia de las leyes.

162- Alguien ha estado intentando envenenarme.

192- Mi madre es una buena mujer, o si ya ha fallecido, mi madre fue una buena mujer.

193- Cuando camino evito cuidadosamente pisar las rayas o grietas.

216- Alguien ha estado intentando robarme.

228- Hay personas que están intentando apoderarse de mis pensamientos e ideas.

252- Para mí todo tiene el mismo sabor o gusto.

270- Personalmente no me molesta ver sufrir a los animales.

276- Quiero a mi madre, o si ya ha fallecido, quise a mi madre.

282- Me han dicho que camino cuando estoy dormido.

291- Nunca he estado enamorado.

294- Frecuentemente me salen manchas rojas en el cuello.

322- Me da miedo utilizar cuchillos u objetos muy afilados o puntiagudos.

323- Algunas veces disfruto hiriendo a personas que amo.

336- Alguien controla mi mente.

371- A menudo he deseado pertenecer al sexo opuesto.

387- Solamente cuando bebo puedo expresar mis verdaderos sentimientos.

478- Odio a toda mi familia.

501- A menudo es más provechoso hablar los problemas y las preocupaciones con alguien, que tomar calmantes y medicamentos.

555- No puedo entrar solo en una sala oscura, incluso en mi propio hogar. 